
Digitized by the Internet Archive in 2010 with funding from University of Toronto 



THE WINGS OF INSECTS 




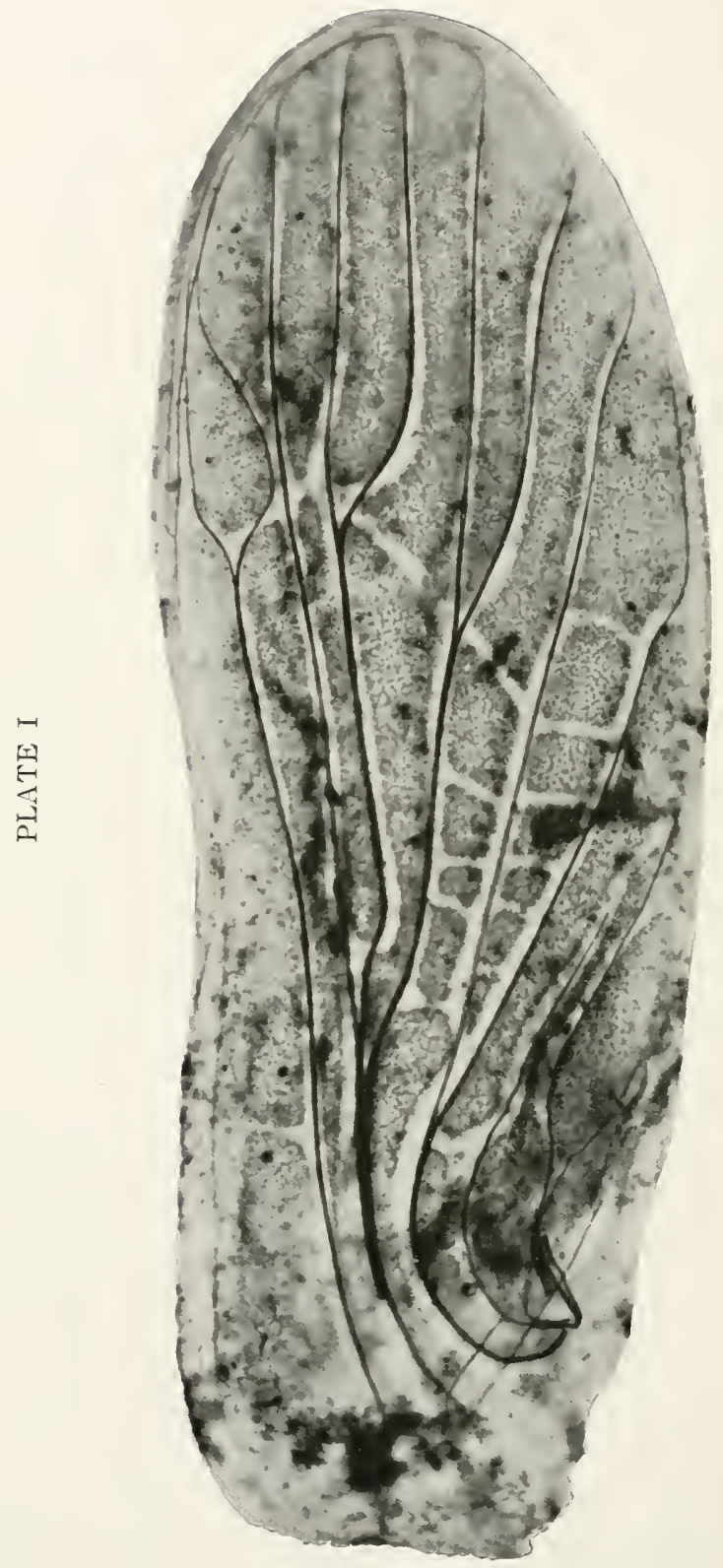

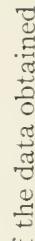

景

를

हี

这

층

. 5

.

-

¿

इ

ङ

$>$ ․․․

- 0.0

뎨 들 응

퐁요

긴

$*$

पे ढे है

.

$=$ ส

․

\&

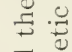

ت

สิ

$\stackrel{8}{\stackrel{5}{0}}$

突

Ð $\Xi$

总 


\section{The Wings of Insects}

An Exposition of the Uniform Terninology of the Wing-

Veins of Insects and a Discussion of the More

General Characteristics of the Wings of

the Several Orders of Insects

\section{BY JOHN HENRY COMSTOCK}

Professor of Entomology and General Invertebrate Zoology, Emeritus, in Cornell University

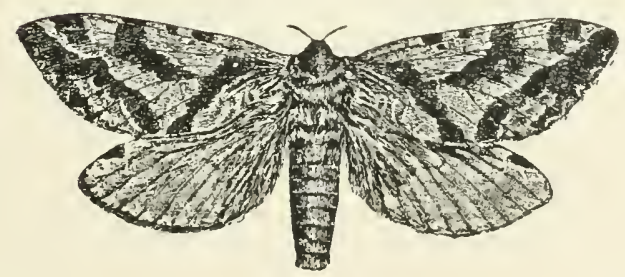

ITHACA, NEW YORK

THE COMSTOCK PUBLISIHING COMPANY

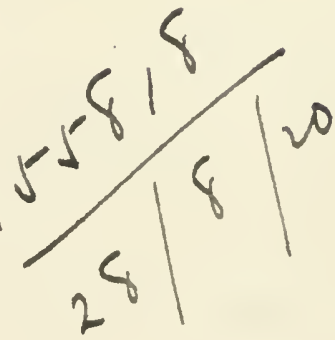


COPIRIGHT I918

BY

THE COMSTOCK PUBLISHING COMPANY 


\section{ANDREW DICKSON WHITE}

In grateful recognition of the encouragement extended to $m e$ in the beginning of my scientific work and continued to the present time, this volume is affectionately dedicated. 



\section{PREFACE}

$\mathrm{D}$

URING the last forty years, much attention has been given to the development of a terminology of the wing-veins of insects that should be available in the descriptions of insects of all orders, and that should replace the many systems that have been devised by specialists, who have restricted their studies, in each case, to a single order. There has resulted from these efforts the perfection of a uniform terminology, which is being very generally adopted, and which will doubtless supersede the many systems still in use.

Many investigators have contributed to the attainment of this result. A brief review of their more important publications on this subject is given in Chapter I of this work.

As these publications are widely scattered through various journals that are to be found only in the larger libraries, most of them are inaccessible to many who wish to obtain an understanding of the uniform terminology and of the reasons that have led to its adoption. There is, therefore, a demand for a comprehensive exposition of this terminology, and for a statement of the facts upon which it is based. It is to meet this demand that this book is offered to the public.

I undertook the preparation of this treatise upon the earnest solicitation of many co-workers in entomology, and with the feeling that the great amount of work, extending over a long period, that I have devoted to this subject made it appropriate for me to do so.

It is now more than thirty years since I began a special study of the homologies of the wing-veins of insects, a subject in which my interest had been awakened a decade before by my teacher, Dr. Hagen.

My first effort to solve the problem was undertaken in the course of the preparation of an article on the Hymenoptera published in "The Standard Natural History" in I 884 . Much time was devoted to the subject, but without the attainment of any results that seemed worthy of incorporation in that article. With our present knowledge of the subject, it is easy to see how hopeless was the attempt to solve the problem by beginning with a study of the highly specialized wings of the Hymenoptera.

A few years later I attacked the problem again; this time by a study of the wings of the Lepidoptera. This was a more fortunate starting point; and considerable progress was made. The results of these studies were published in 1892 and 1893 . The results obtained by further studies of the wings of the Lepidoptera and by a study of the wings of the Diptera and Hymenoptera were included in a text book published in I 895 .

Soon after the publication of this text book, Mr. J. G. Needham and I began the investigation of the development of the wings of representatives 
of all of the orders of insects of which we could obtain living nymphs or pupæ. The results of this investigation were published in a series of articles, entitled "The IVings of Insects," which appeared in the "American Naturalist" during the years 1898 and I 899 .

Since the appearance of this series of articles, I have watched the preparation of many theses on the wings of insects, by students in the entomological laboratory of Cornell Lniversity. The subject, therefore, has been almost constantly in my mind throughout the greater part of my scientific life.

The series of articles published jointly by Dr. Needham and myself is the most comprehensive discussion of the wings of insects in which I have taken part; and, consequently, in the writing of the following pages I have copied freely from them. I am also under obligation to Dr. Needham for continued assistance throughout the preparation of this treatise.

Acknowledgments of assistance from other colleagues and students and from published papers are given in the following chapters, where use has been made of it. In this place I will refer only to some of the more important of these contributions.

The papers that had a bearing on the development of the uniform terminology of the wing-reins that were published before the appearance of the series of articles by Comstock and Needham in ISgS and I 899 are enumerated in Chapter I, to which the reader is referred.

The most extended use that has been made of the uniform terminology of the wing-reins is that of Handlirsch in his great work on fossil insects ('o6-'os): This work was the chief source from which I drew my conclusions regarding the paleontological eridence concerning the primitive form of insect wings and the methods of their specialization that are given in Chapter IV.

Among the more important of the more special contributions to the application of the uniform terminology of the wing-veins of insects are those of Professor J. G. Needham on the Odonata, Miss Anna H. Morgan on the Ephemerida, Professor IV. D. Funkhouser on the Membracidæ, Professor Z. P. Metcalf on the Jassidæ, Fulgoridæ, and Cercopidæ, Miss Edith Patch on the Psyllidæ, Aphididæ, Aleurodidæ, and Coccidæ, Professor A. D. MacGillivray on the suborder Chalastogastra of the Hymenoptera, and Professor J. Chester Bradley on the Evaniidæ. In addition to this published paper by Professor Bradley, I have been permitted to study a very extended manuscript on the venation of the wings of the Hymenoptera written by him.

I have also made use of an unpublished thesis by Mrs. Ruby G. Smith on the "Evolution of the Venation in the Anal Area of the Wings of Insects." This thesis embodies the results of an investigation made under my direction, to test the correctness of the conclusions reached by Comstock and 
Needham regarding the venation of the anal area. In the course of this investigation the wings of more than six hundred species of insects, representing eight orders were examined.

Nearly all of the figures illustrating this work are reproductions of photographs of wings. In preparing these figures blue prints were made from the negatives and the lines in the prints were inked with waterproof India ink; then the blue was bleached from the figures by the use of a solution consisting of one ounce of potassium oxalate dissolved in six ounces of water. This results in producing figures suitable for reproduction by photo-engraving. By this method very accurate figures can be made easily, even of complicated wings like those of the Odonata.

ENTOMOLOGICAL LABORATORY,

John Henry Comstock.

Cornell University,

November, Igr 7 . 



\section{TABLE OF CONTENTS}

\section{CHAPTER I}

PAGE

The Genesis of the Uniform Terminology of the Wings by Insects

\section{CHAPTER II}

The Tracheation of the Wings of Insects

Method of study of the tracheation of wings.................. I2

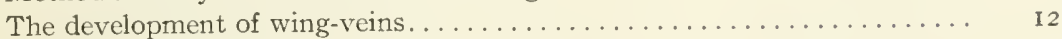

The hypothetical primitive type of insect wings................... I5

The tracheation of the wings of larvæ and pupæ............... I9

Variations in the extent of the tracheation of the wings of nymphs and

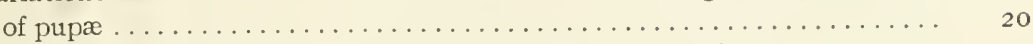

Illustrations of the simpler type of the tracheation of the wings........ 2 I

Illustrations of increased tracheation of wings.................. 2 I

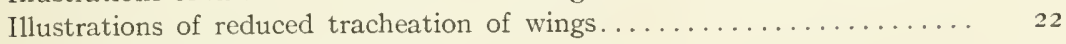

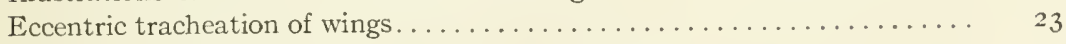

The basal connections of the tracheæ of the wings............... 25

The Basal Connections of the Trache ef the Wings of Insects. By Royal Norton Chapman......................... 27

\section{CHAPTER III}

The More General Features of the Wings of Insects

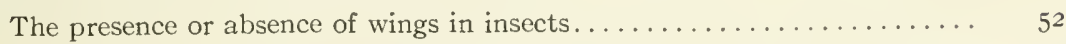

The fundamental structure of the wings of insects.............. 53

The different types of insect wings. . . . . . . . . . . . . . . 53

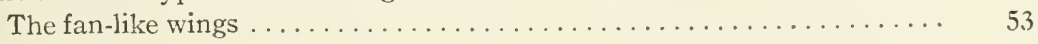

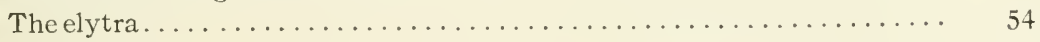

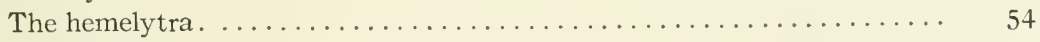

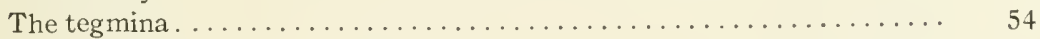

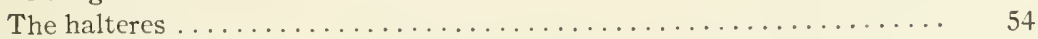

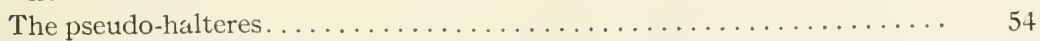

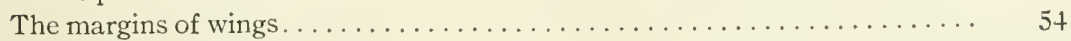

The angles of wings. . . . . . . . . .

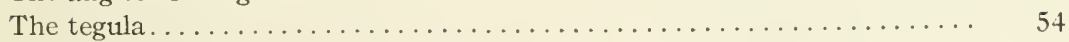

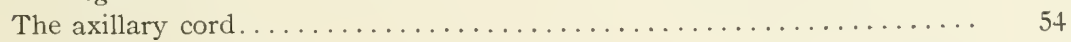

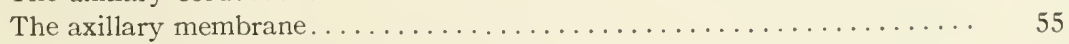

The alula......................................... 55

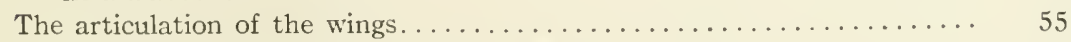

The thoracic supports of the wings.................... 55

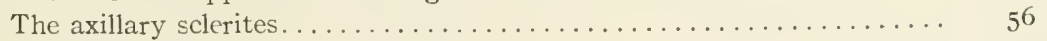

The costal sclerite. . . . . . . . . . . . . . . . . . . . . 57

The tuberosities of the base of the wing . . . . . . . . . . . . . . 57

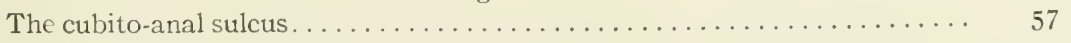

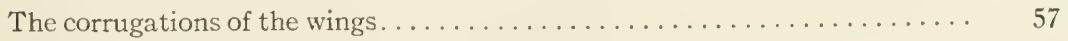

The cubito-anal fold ............................... 57 
The furrows of the wing . ........

The anal furrory

The median furrow

The nodal furrow $\ldots \ldots \ldots \ldots \ldots$

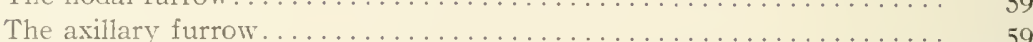

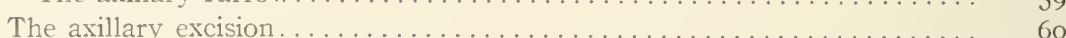

The posterior lobe. ............................. 60

The methods of uniting the two wings of each side $\ldots \ldots \ldots \ldots \ldots \ldots \ldots$

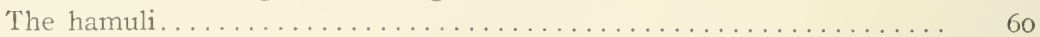

The frenulum and the frenulum hook $\ldots \ldots \ldots \ldots \ldots \ldots \ldots \ldots \ldots$ I

The jugum . . . . . . . . . . . .

The fibula............................... 6 I

An expanded humeral angle of the hind wings . . . . . . . . . . . 63

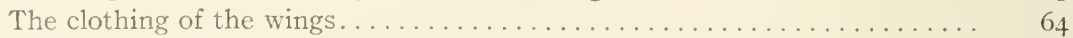

The principal wing-veins. . . . . . . . . . . . . . . . . . . . 64

The chief branches of the wing-veins of the preanal area ......... 65

The veins of the anal area . . . . . . . . . . . . . . . . . . 66

The reduction of the number of wing-veins . . . . . . . . . . . . . . . . . 67

Serial veins. . . . . . . . . . . . . . . . . . . . . . 69

The increase of the number of wing-veins . . . . . . . . . . . .

The secondary longitudinal veins. . . . . . . . . . . . . 7 I

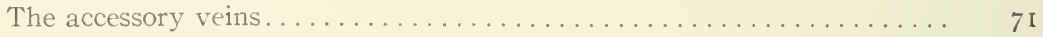

The marginal accessory veins. . . . . . . . . . . . . . . . . . . 72

The definitive accessory veins. . . . . . . . . . . . . . . . . . . . . . 72

The intercalary veins. . . . . . . .

The adventitious veins. . . . . . . . . . . . . . . $\ldots \ldots \ldots$

The anastomosis of veins. . . . . . . . . . . . . . . $6 \ldots \ldots$

The cross-veins. . . . . . . . . . . . . . . . . . . . . . . . $6 \ldots$

The humeral cross-vein . . . . . . . . . . . . . . . . . . . . .

The radial cross-vein. . . . . . . . . . . . . . . . . . . 78

The sectoral cross-vein . . . . . . . . . . . . . . . .

The radio-medial cross-rein . . . . . . . . . . . . . . . . . . . . . 78

The medial cross-vein . . . . . . . . . . . . . . . . . $7 . \ldots \ldots$

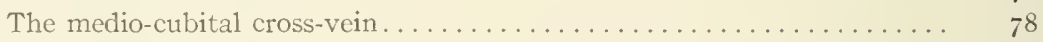

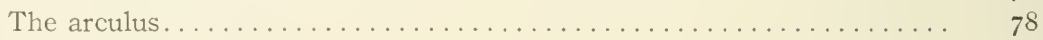

The costal cross-veins. . . . . . . . . . . . . . . . . . . . 78

Other cross-veins in many-veined wings. . . . . . . . . . . . . . 79

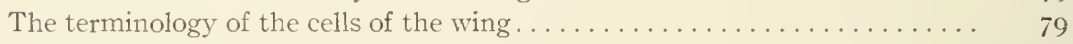

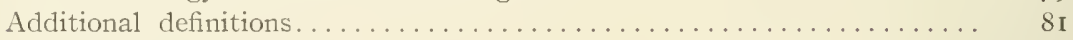

The cubito-anal excision. . . . . . . . . . . . . . . . . . . .

Convex and concave veins. . . . . . . . . . . . . . . . . .

The ambient vein $\ldots \ldots \ldots \ldots \ldots \ldots \ldots \ldots \ldots \ldots \ldots \ldots \ldots \ldots \ldots \ldots$

The humeral veins. .......................... 8 I

The pterostigma or stigma $\ldots \ldots \ldots \ldots \ldots \ldots \ldots \ldots \ldots \ldots \ldots \ldots \ldots$

The bullæ.............................. $8 \mathrm{r}$

The appendiculate cell $\ldots \ldots \ldots \ldots \ldots \ldots \ldots \ldots \ldots \ldots \ldots \ldots \ldots \ldots$.

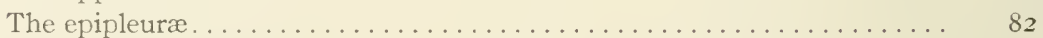

The transverse cord $\ldots \ldots \ldots \ldots \ldots \ldots \ldots \ldots \ldots \ldots \ldots \ldots \ldots \ldots \ldots$

The discal cell and the discal veins . . . . . . . . . . . . . . . . 82

Chart of Geologic Time and Formations................... $8_{+}$ 
The Paleontological Data Bearing on the Developaent and the Specialization of the Wings of Insects

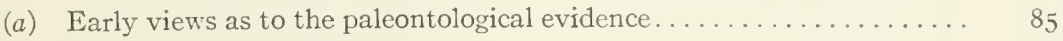

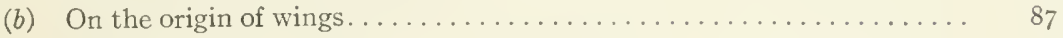

The paleontological date on the origin of wings............. 88

(c) On the course of the evolution of each of the principal wing-veins.... 9I

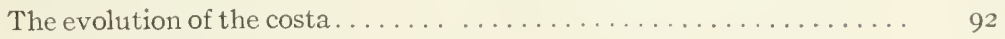

The evolution of the subcosta ...................... 92

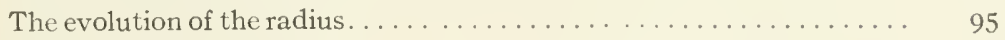

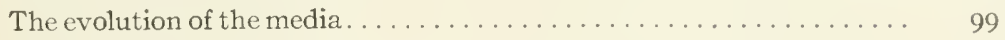

The evolution of the cubitus...................... I04

The evolution of the anal veins. . . . . . . . . . . . . . . . 07

Summary................................ I09

\section{CHAPTER V}

The Development of The Wings of Insects

(a) The development of the wings of nymphs.............. I Io

First appearance, position, and growth of the wings of nymphs ...... I I

The tracheation of the wings of nymphs.................. II 3

(b) The development of the wings of larvæ and pupæ............. I I 4

The development of the wing-buds..................... I 4

The development of the tracheation of the wings............ II5

\section{CHAPTER VI}

The Steps in the Specialization of Wings.................. I 8

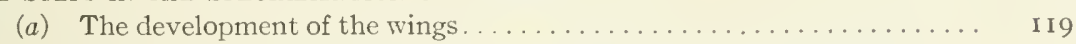

(b) The basal connections of the tracheæ that precede the wing-tracheæ.... I I9

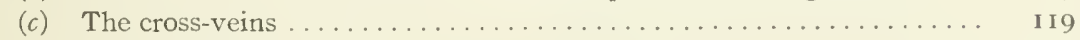

(d) The longitudinal veins......................... I20

Table of the methods of specialization of the wings characteristic of the orders

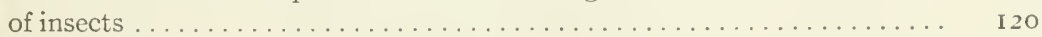

List of orders . . . . . . . . . . . 122

\section{CHAPTER VII}

The Wings OF THE ORTHOPTERA

(a) The more general features of the wings of the Orthoptera....... I23

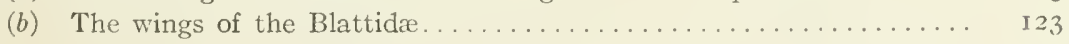

(c) The wings of the Saltatorial Orthoptera............... I27

THE WINGS OF THE ISOPTERA

\section{CHAPTER VIII}

(a) The more general features of the wings of the Isoptera ......... I32

(b) The tracheation and the venation of the wings of the Isoptera..... I 35

Résumé ................................ I43

The Wings of tile Neuroptera

\section{CHAPTER IX}

(a) The more gencral features of the wings of the Neuroptera........ I 45

(b) The special features of the wings of the Neuroptera............ I 46 
The accessory veins. . . . . . . . . . . . .

The suppression of the dichotomy of the radial sector $\ldots \ldots \ldots \ldots \ldots$ I 47

The radial cuneate area . . . . . . . . . . . . . $6 \ldots \ldots \ldots \ldots \ldots \ldots$ I

The secondary cubital fork. . . . . . . . . . . . . . $\ldots \ldots \ldots$

Gradate veins. . . . . . . . . . . . . . . . . 66

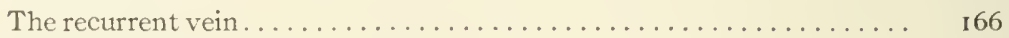

The coalescence of veins $\mathrm{Sc}$ and $\mathrm{R}_{1} \ldots \ldots \ldots \ldots \ldots \ldots \ldots \ldots$

Marginal dots or dashes. . . . . . . . . . . . . . . 67

The first radio-medial cross-vein of the hind wings . . . . . . . . . 67

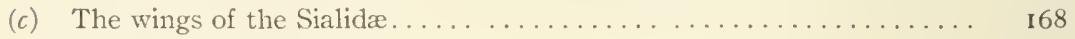

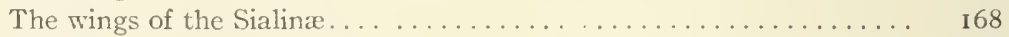

The wings of the Corydalina. . . . . . . . . . . . . .

(d) The wings of the Raphidiidæ $\ldots \ldots \ldots \ldots \ldots \ldots \ldots \ldots \ldots \ldots \ldots \ldots \ldots$ I $\mathbf{I}$

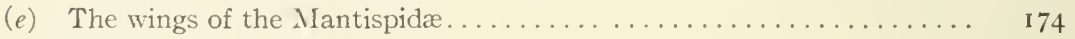

(f) The wings of the Ithonidæ....................... I75

(g) The wings of the Sisyridæ. . . . . . . . . . . . . . . $\ldots \ldots$

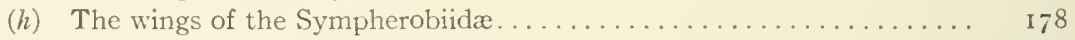

(i) The wings of the Hemerobiidæ.................... I 80

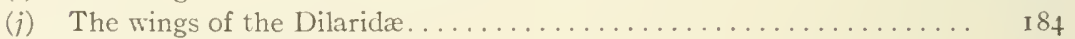

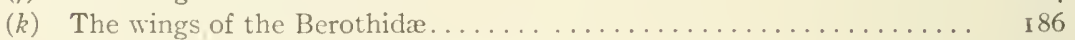

(l) The wings of the Polystrechotidz................... I 87

(m) The wings of the Psychopsida $\ldots \ldots \ldots \ldots \ldots \ldots \ldots \ldots \ldots \ldots \ldots$

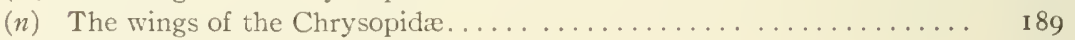

(o) The wings of the Osmylidæ. ...................... I92

(p) The wings of the Myiodactylida . . . . . . . . . . . . . . . . 193

(q) The wings of the Nymphidæ. . . . . . . . . . . . . . . . I95

(r) The wings of the Myrmeleonidæ .................... 196

(s) The wings of the Ascalaphidæ..................... 206

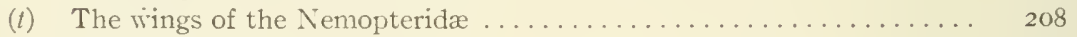

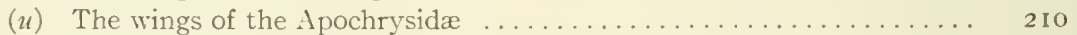

(r) The wings of the Coniopterygidæ $\ldots \ldots \ldots \ldots \ldots \ldots \ldots \ldots \ldots \ldots \ldots \ldots \ldots$

\section{CHAPTER X}

THE WINGS OF THE EPHEMERIDA

(a) The more general features of the wings of the Ephemerida ....... 2 I4

(b) The tracheation of the wings of the Ephemerida ............ 2 I4

(c) The homologies of the wing-veins of the fore wings of the Ephemerida.. 2 I 7

(d) The corrugations of the wings of the Ephemerida . . . . . . . . . 2 I9

Table of the wing-veins of the Ephemerida . . . . . . . . 220

(e) The homologies of the hind wings of the Ephemerida........... 222

THE WINgS OF THE ODONATA

\section{CHAPTER XI}

(a) The more general features of the wings of the Odonata . . . . . . . 224

Table of the wing-veins of the Odonata . . . . . . . . . . . . 228

(b) The special features of the wings of the Odonata............. 229

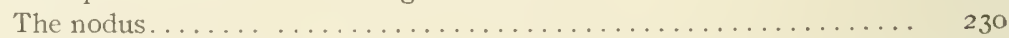

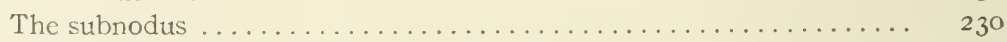

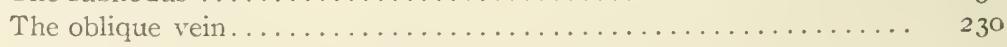

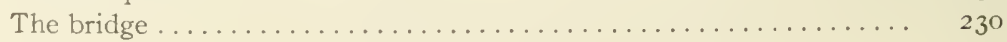




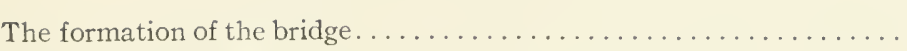

The intercalary veins. . . . . . . . . . . . . . . . . . . . . . . . . . . . . . . . . . .

The supplements. . . . . . . . . . . . . . . . . . . . . . . . . . . . . . . . .

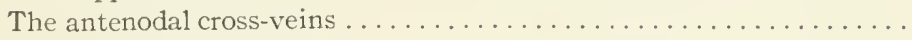

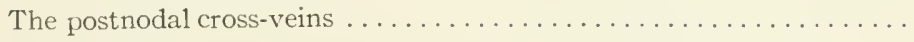

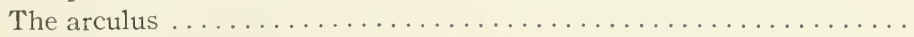

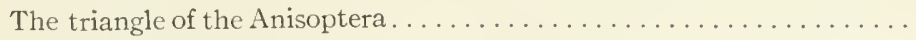

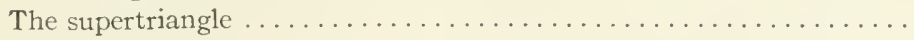

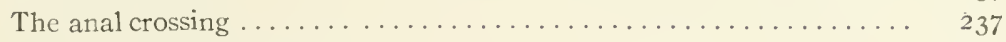

The secondary anal veins. . . . . . . . . . . . . . . . . . . . 239

The basal anal area . . . . . . . . . . . . . . . . . . . . . . 239

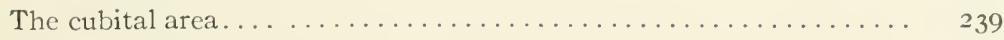

The anal triangle. . . . . . . . . . . . . . . . . . . . . . . . 239

The membranule.............................. 239

The chief cubito-anal cross-rein . . . . . . . . . . . . . . . . 239

The subtriangle. ............................... 239

The anal loop . . . . . . . . . . . . . . . . . . . . . . . . 239

The supplemental anal loop . . . . . . . . . . . . . . . . . . 240

The cubito-anal or foot-shaped loop .................. 240

The cubital supplement . . . . . . . . . . . . . . . . . . 240

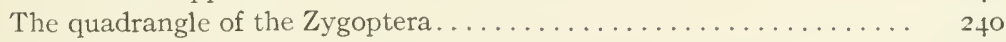

The subquadrangle of the Zygoptera................. 24 I

(c) The methods of specialization of the wings of the Odonata........ 24I

(d) Comparison of terminologies of the wing-veins of the Odonata...... 242

\section{CHAPTER XII}

\section{The Wings of the Plecoptera}

(a) The more general features of the wings of the Plecoptera....... 243

(b) The tracheation of the wings of the Plecoptera .............. 243

(c) The classification of the Plecoptera ................... 244

(d) The special features of the wings of the Plecoptera ............ 245

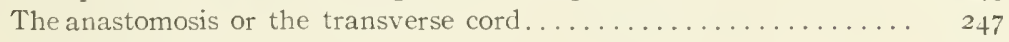

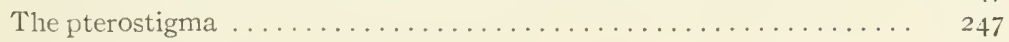

The basal anal cell. . . . . . . . . . . . . . . . . . . . . . 247

(e) The primitive plecopterous type of wings............... 248

(f) The methods of specialization of the wings of the Plecoptera...... 254 Specialization by reduction . . . . . . . . . . . . . . . . . . . 254

Specialization by addition . . . . . . . . . . . . . . . 255

\section{CHAPTER XIII}

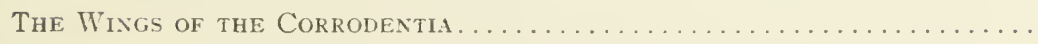

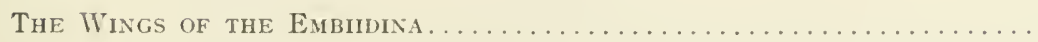

\section{CHAPTER IV}

The Wings of the Thysanoptera $\ldots \ldots \ldots \ldots \ldots \ldots \ldots \ldots \ldots \ldots \ldots$ 


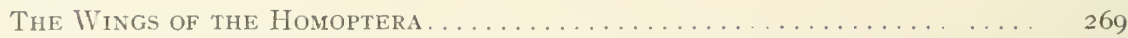

(a) The more general features of the wings of the Homoptera . . . . . . . . 269

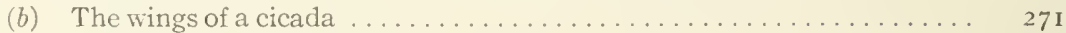

(c) The wings of the Membracida ...................... 274

(d) The wings of the Jassidæ . . . . . . . . . . . . . . . . . . 280

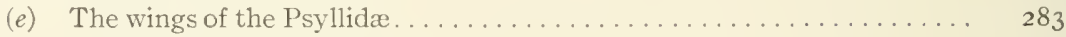

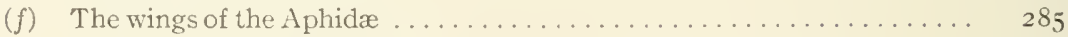

(g) The wings of the Aleurodidx ....................... 289

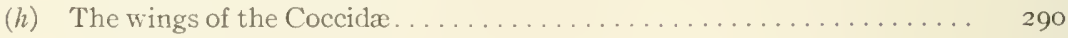

(i) Supplemental Note........................... $29 \mathrm{I}$

\section{CHAPTER XVII}

The Wings of the Heteroptera . . . . . . . . . . . . . . . . . . . . . . .

(a) The more general features of the wings of the Heteroptera . . . . . . . . 292

(b) The tracheation of the wings of the Heteroptera . . . . . . . . . . . . 292

(c) The veins and furrows of an adult wing. . . . . . . . . . . . . 294

CHAPTER XVIII

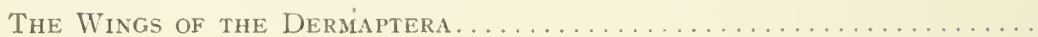

CHAPTER XIX

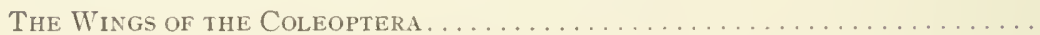

\section{CHAPTER XY}

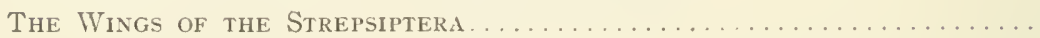

\section{CHAPTER XXI}

The Wings of the Míecoptera

(a) The more general features of the wings of the Mecoptera ........ 302

(b) The venation of the wings of the typical Mecoptera............ 302

(c) The aberrant Necoptera .......................... 303

\section{CHAPTER XXII .}

The Wings OF THE Trichoptera

SUBORDER PHRYGANEINA ............................ 307

(a) The more general features of the wings of the Phryganeina........ 307

(b) The tracheation of the wings of the Phryganeina ............. 308

(c) The phryganeid type of wing-venation. ................ 308

(d) The more general features in the specialization of the wings of the

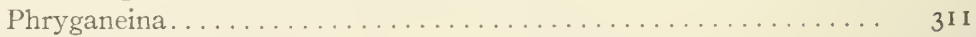

(e) The methods of uniting the two wings of each side........... $3^{12}$

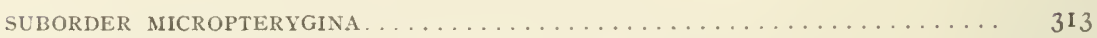

(a) The venation of the wings of the Micropterygina ............ 3 It

(b) The tracheation of the wings of the Micropterygina . . . . . . . . . 3 3.5

(c) The zoological position of the Micropterygina ............ 3 I 7 
The Wings of the Lepidoptera

(a) The more general features of the wings of the Lepidoptera ......... 319

(b) The clothing of the wings of the Lepidoptera................ $3^{19}$

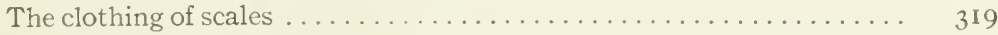

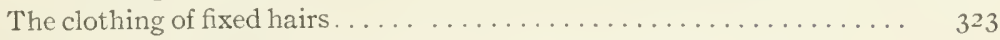

(c) Methods of specialization of the wings of the Lepidoptera .......... 324

(d) The primary divisions of the Lepidoptera indicated by the structure of

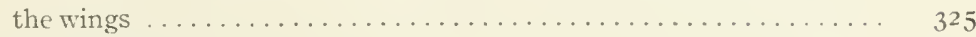

Suborder Jugatæ ............................. 325

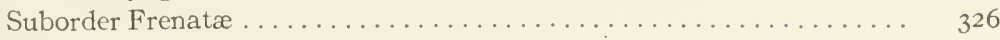

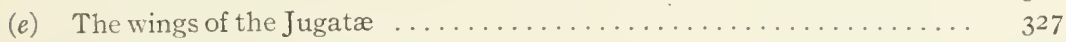

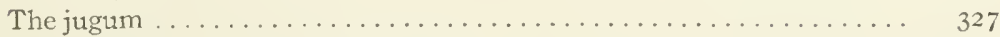

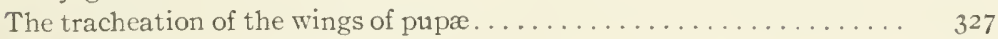

The venation of the wings of hepialids . . . . . . . . . . . . 328

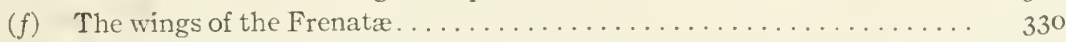

The frenulum and the frenulum hook................. 330

The loss of the frenulum in certain of the Frenatæ ............ 33 I

The reduction of the radius of the hind wings.............. 332

The reduction of media to a three-branched condition........... 334

The atrophy of the main stem of media ................ 337

The transfer of the branches of media to adjacent veins......... 338

The first anal vein and the anal furrow . . . . . . . . . . . . . 340

The reduction of the anal area . . . . . . . . . . . . . . . . 340

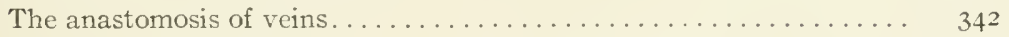

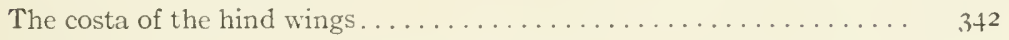

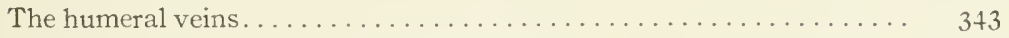

The splitting of the radial sector in butterflies ............. 343

(g) Comparison of terminologies of the wing-veins of the Lepidoptera . . . . . 345

\section{CHAPTER XXIV}

The Wings of the Diptera

(a) The more general features of the wings of the Diptera . . . . . . . 347

(b) The methods of specialization of the wings of the Diptera ........ 348

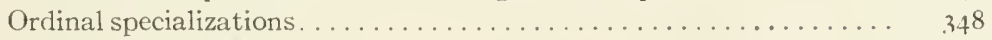

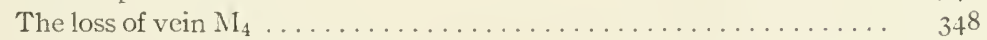

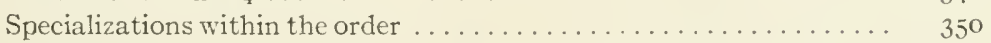

The costa . . . . . . . . . . . . . . . . . . . . . . 350

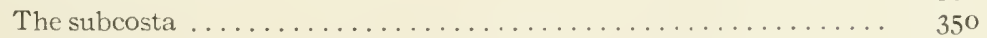

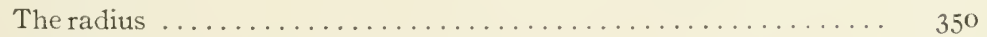

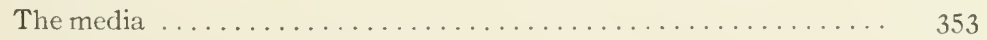

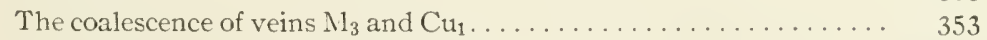

The coalescence of veins $\mathrm{Cu}_{2}$ and the second anal vein ......... 355

The reduction of the number of cells in a wing ............ 355

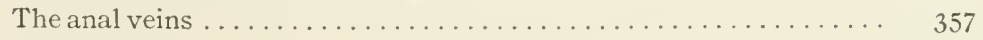

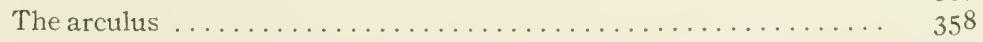

(c) Comparison of terminologies of the wing-veins of the Diptera..... 358

(d) Comparison of terminologies of the cells of the wings of Diptera..... 360 
The Wings of the HyMexoptera

(a) The general features of the wings of the Hymenoptera .......... 362

(b) The venation of the wings of the more generalized Hymenoptera .... 362

(c) The tracheation of the wings of the Hymenoptera............ 368

(d) Methods of modification of the primitive hymenopterous type of wing-

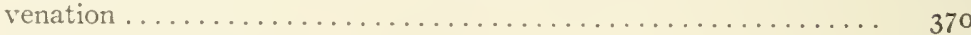

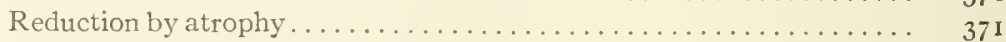

Reduction by coalescence....................... 374

Modification of the course of a vein by the coalescence at base...... 375

Modification of the course of a vein by the coalescence of its tip with an

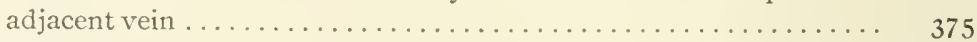

Serial veins.................................. 376

(e) An illustration of the reduction of the wing-venation in the Hymenoptera 379

\section{CHAPTER XXYI}

The Teaching of the Uniform Terminology of the Wing-Verns of Insects

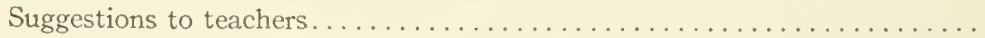

Outline of laboratory work in the study of the venation of the wings of insects $3^{82}$

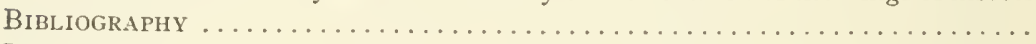


THE WINGS OF INSECTS 



\title{
THE WINGS OF INSECTS
}

\author{
CHAPTER I \\ THE GENESIS OF THE UNIFORM TERMINOLOGY OF THE \\ WING-VEINS OF INSECTS
}

Frour the earliest days of systematic entomology to the present, much use has been made of the wings in the classification of insects. The names of the Linnean orders were all suggested by the nature of the wings except one, Aptera, and that by the absence of wings; many of the established families of insects are most easily recognized by peculiarities in the form of the wings; and hundreds of genera have been distinguished by details of wing-venation.

A reason for the extensive use of characteristics of wing-structure in the classification of insects is the ease with which they can be observed. Owing to the broadly expanded form of the wings, it is more easy to see variations in their structure than it is to see variations in the form of other parts of the body. The wings are open pages upon which are to be read, with comparative ease, the results attained by the processes of evolution.

Although the wing-characters have been used in the classification of insects from a very early period, a full appreciation of their importance for this purpose is a matter of comparatively recent growth. It was not until it was demonstrated that the wings of all winged insects are modifications of a single primitive type that it was possible to fully understand the taxonomic value of these organs.

The early entomologists who worked without the aid of the modern conception of organic evolution, only vaguely attempted to recognize those homologies of the principal wing-veins that we now know to exist. The result was the establishment of many different systems of terminology, the students of each order having a system of their own, and in some cases several different systems were used by the students of a single order.

It would require too much space to explain all of these systems. The student who uses the older books will need to learn the particular system employed by the author he is studying. In later chapters, under the discussion of the venation of the wings of the separate orders, a table is given, when practicable, in which one or more of the older systems is compared with that of Redtenbacher and with the one adopted in this work. 
It seems probable that the short paper published by Dr. Hagen in I 8 70, entitled "Ueber rationelle Benennung des Geäders in den Flügeln der Insekten" was the beginning of the series of efforts to establish a system of terminology of the wing-veins of insects applicable to all orders of insects. For the author of the "Bibliotheca Entomologica" was very familiar with the literature of entomology then published, and had there been earlier efforts in that direction he would have quoted them.

It is with much pleasure that I remember that my own interest in this subject was first awakened by a lecture Dr. Hagen delivered to me, his first American student, in the summer of $8_{72}$. In this lecture he called my attention to the paper referred to above, then only two years old, and urged the importance of investigations in this field.

Dr. Hagen recognized six longitudinal veins, four principal veins and a branch of each of two of these. His paper is accompanied by a plate, which is reproduced here (Fig. I); but no explanation of the plate is given, and there is no reference to it in his text. It is evident, however, from his descriptions of the veins that he recognizes, that the significance of the lettering of the plate is that indicated below. The six longitudinal veins recognized by him are named as follows: subcosta $(a)$, mediana $(b)$, hind branch of the mediana $\left(b^{1}\right)$, front branch of the submediana $\left(c^{1}\right)$, submediana $(c)$, and postcosta $(d)$.

Dr. Hagen's view regarding the practicability of establishing a uniform terminology of the wing-reins met with little if any favor among the leaders in entomology. For example, Dr. Graber, in his "Die Insekten" published in 1877 (Vol. I, p. I96), in referring to the effort to establish a uniform terminology says that, as a matter of course, no scientific significance should be attached to such attempts.

Even as late as I 895 Professor David Sharp, in his most excellent text book of entomology (Camb. Nat. Hist. Vol. 5, p. 107-8), writes as follows:-

"Various efforts have been made to establish a system of nomenclature that shall be uniform throughout the different Orders, but at present success has not attended these efforts, and it is probable that no real homology exists between the nervures of the different Orders of Insects."

This statement by Dr. Sharp was made in spite of the fact that the classic contribution of Josef Redtenbacher, "Vergleichende Studien über das Flügelgeäder der Insecten” (I S86) had appeared nearly a decade before; in fact, it was probably this paper that suggested it; for the obscurity into which Dr. Hagen's paper had fallen would have saved it, standing alone, from comment.

It was not till the appearance of Redtenbacher's paper that any great progress was made in the establishment of a uniform terminology of the wing-veins. This paper with its numerous illustrations drawn from nearly 


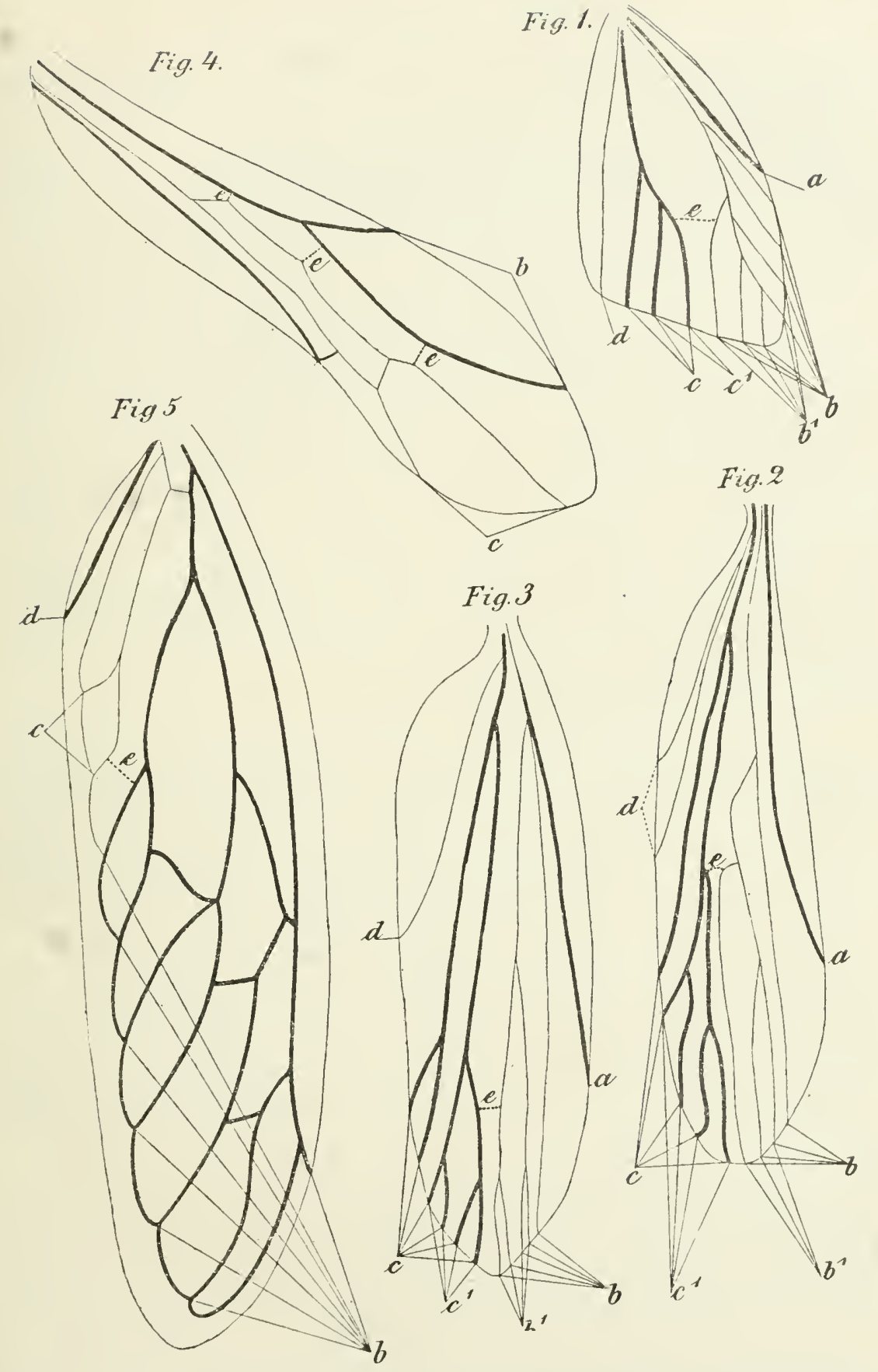

Fig. I.-The plate illustrating Dr. Hagen's paper "Ueber rationelle Benenung des Geaders in den Flügeln der Insekten." 
all orders of winged insects, is really the starting point in the actual solution of the problem.

Before referring farther to Redtenbacher's work, it is desirable to discuss briefly some publications that had a profound influence on it. These treat of the relation of the tracheation of the wings to the wing-venation and of the supposed existence of two morphologically distinct types of wing-veins, the convex and the concave.

The earliest reference that I have found to the relation of the tracheation of the wings to the wing-venation is that of Carl Semper ('57) who stated that in the development of the wing the direction and course of the wing-veins are determined by the tracheæ the principal branches of which indicate the wing-veins when of the latter no trace is to be seen.

Semper, however, did not obtain a correct understanding of the method of development of the wing-veins. He represented a cylinder of epithelial cells, which he states secrete later on their inner surface the chitin that forms the vein. It is evident that he considered the wing-vein as a separate structure from the membrane of the wing. It is an interesting fact that Semper represented a nerve within the wing-rein. Such nerves are now well-known and the connection of their branches with scales and setæ has been figured by several writers.

Landois (' $7 \mathrm{I}$ ) figures the larval wings of a Vanessa and calls attention to the now well-known fact that the larval tracheoles of the wing, the "geknäuelten Tracheen," occupy exactly the position occupied later by the wing-reins. He also describes the degeneration of these tracheoles and the development of the permanent tracher in the same position. He overlooked the fact that the permanent tracheæ are developed during the last larval stadium, observing them first in the pupal instar.

A more serious error on the part of Landois was the description of elastic cords covered with an epithelium and closely parallel with the permanent tracheæ, in the pupal wing. These he termed the "Flügelrippen" and states that they lie close upon the lower membrane of the wing. According to his view a completed wing-vein consists of one of these "Flügelrippen sensu strictiori," tracheæ, and the united upper and lower membranes of the wing enclosing these parts and a space in which the blood flows.

I can not imagine what Landois saw and described as the "Flügelrippen sensu strictiori." I have been unable to find any such structure in any of the wings that I have studied. Spuler ('92) however, gives a figure of a cross-section of a wing-vein in which he represents it, and refers to it in his text as the so-called "Rippe" of Semper, but gives no description of it.

In 1879 the "Ueber Insectenflügel" by G. Ernst Adolph appeared. The publication of this work was unfortunate; for it added little of value to our 
knowledge and did much to retard the progress of the solution of the problem of which it treated.

In this work Adolph elaborated a theory of alternating convex and concave reins. This was based on the fact, already pointed out by several writers, Selys-Longchamps, Saussure, Hagen, and others, that as a result of a corrugation of the wings some of the veins extend along raised lines and others along sunken ones. He also made use of the results of Landois concerning the relation of the tracher of the wings to the wing-veins.

According to this theory the wing tracher determine the position of the concave veins, which represent the foundation of the vein system. Only later is each tracheal tube inclosed by a mass of chitine and thereby transformed into a vein. At the same time, according to Adolph, the tracheæ force the two wing-plates apart and cause a thinning of the membrane, which shows itself, among other ways, by the fact that the wing regularly tears under pressure or strain along the concave veins. Between these primary, or concave veins appear later thickenings of the wing-membrane in the form of chitine lines with which the tracheal tubes and blood channels are finally associated, and which form the secondary, or convex veins. The two sorts of veins, accordingly, stand in direct opposition to each other; since the first is produced by a thinning, and the last by a thickening of the wing-membrane; and since, in the former, the tracheal tube, in the latter, the chitinous lines represent the primary foundation.

Subsequent investigations have shown that there is little to support this remarkable theory. There is only one method of formation of the principal wing-veins; and the differences in position of the veins, that is along raised lines or along sunken ones, is merely the result of a secondary corrugating of the wings.

Redtenbacher was profoundly influenced by the theory of alternating convex and concave veins elaborated by Adolph and made his system of terminology conform to it absolutely. He recognized five fields in the wing each traversed by a convex vein. These veins he designated by the consecutive odd Roman characters: I, III, V, VII, and IX. He also applied to these veins the names costa, radius, media, cubitus, and anal vein.

These names he selected from the many names then in use except in the case of media, which was proposed by him for the vein to which that name is now applied; and which previously had been generally regarded as belonging partly to the radius and partly to the cubitus; although it had been recognized as a principal vein by Edward Doubleday long before. See his "Remarks on the Genus Argynnis" (Trans. Linn. Soc. vol. XIX, I 845 ).

To the concave veins, which Redtenbacher, following Adolph, believed to alternate with the convex veins, be applied the consecutive even Roman 
characters: II, IV, VI, VIII, X. In the case of wings with an expanded anal area the numbers XII and XIII are also used.

The only so-called concave vein to which he applied a name is the subcosta.

In subsequent modifications of his system the six names used by him, costa, subcosta, radius, media, cubitus, and anal veins have been adopted.

The branches of the principal veins were designated by adding Arabic numerals to the Roman numeral designating the principal vein. Thus the branches of vein III are designated successively as $\mathrm{III}_{1}, \mathrm{III}_{2}, \mathrm{III}_{3}, \mathrm{III}_{4}$, and $\mathrm{III}_{5}$.

It was unfortunate that Redtenbacher was misled by the erroneous theory of alternating convex and concave veins elaborated by Adolph. The result was that, although Redtenbacher recognized the homologies of the main stems of the principal reins, he, in his efforts to apply this theory, was led into many serious errors. The result is that the terminology now adopted differs much in detail from that of Redtenbacher upon which it was based. These differences are indicated in later chapters.

Redtenbacher was also misled by the then commonly accepted view of the paleontological data bearing on the evolution of wings. Stating this view he writes (page i 55) as follows:-

The geologically older Orthoptera and Neuroptera show a much richer venation than the Coleoptera, Lepidoptera, Hymenoptera, and Diptera; likewise among the Rhyncota, the oldest forms, the Cicadidæ and the Fulgoridæ, possess much more numerous veins than the Hemiptera. There is apparently, then no doubt, that the oldest insect forms were provided to a certain extent with a superfluity of veins, and that, in the course of development, all the superfluous veins disappear by reduction, and, in this way a simple system of venation was brought about.

The acceptance of these two erroneous views, the theory of alternating concave and convex veins and the belief that the first winged insects had many wing-veins, did much to retard the progress of the efforts to establish a uniform terminology of the wing-veins.

Redtenbacher's adherence to the theory of Adolph was short lived, however; for two years after the publication of his larger paper one appeared, of which he was the junior author (Brauer und Redtenbacher, I888), in which the theory of different origins of the concave and convex veins is discredited. But there is no suggestion in this paper of a modification of the Redtenbacher system of terminology of the wing-veins.

With the appearance in I 891 , I 892 , and I 893 of papers by Dr. Erich Haase and by Dr. Arnold Spuler, there began a series of modifications of the Redtenbacher terminology.

The first of these three papers was a brief abstract by Haase ('9I) of his conclusions regarding the development of the wing-veins of Papilio 
Machaon. Then followed the more general work of Spuler ('92) entitled "Zur Phylogenie und Ontogenie des Flügelgeäders der Schmetterlinge." And last of the three was the completed work of Haase ('93), his "Untersuchungen über die Mimicry auf Grundlage eines naturlichen Systems der Papilioniden."

In this paper Haase gave excellent nigures of the tracheation of the wings of the pupa of Papilio Machaon and showed the relation of the tracheæ to the wing-veins of the adults; and he designated the wing-veins in his figures, by abbreviations of the names that he adopted for them instead of by numbers.

Like Spuler and Bauer and Redtenbacher, he regarded costa as merely the thickened margin of the wing and not a vein; and as the first anal trachea coalesces with the cubital trachea at the base in this species, he believed cubitus to be three-branched. The second and third anal veins he designated as the first and second branches of the "dorsal vein." The veins that he recognized are subcostalis, radialis with five branches, mediana with three branches, cubitalis with three branches, and dorsalis with two branches.

Spuler, in his paper which followed the brief abstract published by Haase but which appeared before the publication of the completed work by Haase, recognized two areas in the wing: an expanded area, which he termed the "Spreitentheil;" and a folded area, the "Faltentheil." The veins in the former, he numbered with Roman numerals; those in the latter, with Greek letters. He began his numbering with the subcosta, which he designated as vein I; for, as he failed to find a trachea in the costa, he did not regard it as a vein. He also omitted from his series of veins, and very correctly, the supposed concave veins IV and VI of the Redtenbacher system. The result was that he recognized five veins in the expanded area of the wing, which he designated as veins I, II, III, IV, and V respectively, and two veins in the folded area, vein $\alpha$ and vein $\beta$. The veins that he recognized in the expanded area are those now known as the subcosta, radius, media, cubitus, and Ist anal; those of the folded area are the $2 \mathrm{~d}$ and $3 \mathrm{~d}$ anal veins.

Probably the most important result of Spuler's investigations was the determination of the type of the lepidopterous wings by a study of the tracheation of the wings of many lepidopterous pupæ and of the venation of the wings of a large series of adults.

Packard ('95) published an extended review of Spuler's paper and furnished some additional matter and figures. He adopted the terminology of Spuler except that he numbered the anal veins V, VI, and VII. He followed Spuler in not regarding the costa as a vein and applied the name costa and the number I to the subcosta and the name subcosta and the 
number II to the radius, following Heinemann and other of the older writers on the Lepidoptera as regards the names of these veins.

Before the publication of Spuler's paper the writer had made an extended study of the evolution of the wings of the Lepidoptera. His more important conclusions were presented in a lecture before the California Zoological Club, Jan. 30, I892, an abstract of which was published in Zoe. vol. III, pp. $8_{4}-86$. This paper includes the suggestion that the Lepidoptera should be divided into two suborders, the Jugatæ and the Frenatæ.

Later in the same year the writer, to whom the works of Haase and of Spuler were still unknown, read a paper before the American Association for the Advancement of Science (see Proc. A. A. A. S., 4ist Meeting, Aug. I892) entitled "The Descent of the Lepidoptera. An Application of the Theory of Natural Selection to Taxonomy."

In the following year ( 1893 ) the results of the studies briefly outlined in the two preceding communications were published in a paper entitled "Evolution and Taxonomy. An Essay on the Application of the Theory of Natural Selection in the Classification of Animals and Plants, Illustrated by a Study of the Evolution of the Wings of Insects, and by a Contribution to the Classification of the Lepidoptera" (The Wilder Quarter-Century Book.)

Although no changes in the Redtenbacher system of terminology of the wing-reins of insects was suggested in these communications, they are quoted here because there is no doubt that the later consistent application of the method of study indicated in them hastened the putting of the uniform terminolog! of the wing-reins on a firm basis. The method is briefly outlined in the following quotation from the abstract published in the Proceedings of the American Association (l.c.):

\footnotetext{
"There is indicated in this paper a method of applying the theory of natural selection to taxonomy somewhat more fully than seems to have been done before.

"The method consists in beginning with the study of a single organ possessed by the group of organisms to be classified. The variations in form of this organ are observed; the function of the organ is studied; and an effort is made to trace out the phylogenetic development of the organ, keeping constantly in mind the relation of the changes in form of the organ to its function. In other words, the record of the action of natural selection upon the group of organisms is read as it is recorded in a single organ. This gives data for a provisional classification of the group. Then another organ is selected and its history worked up in the same way. Then the results obtained in the two investigations are compared; and where they differ there is indicated the need of renewed study. For if rightly understood the different records of the action of natural selection will not contradict each other. The investigation is continued by the study of other organs and a correlating of results obtained until a consistent history of the group has been worked out.

"This method differs from that commonly employed, in being a constant effort to determine the action of natural selection in the modification of the form of organisms,
} 
in order to better adapt their parts to perform their functions. By the old method a search is made for characters by which a group can be divided and subdivided with but little regard to the meaning of these characters. In fact we rarely see in purely taxonomic works any reference to the functional significance of the characters used.

"As illustrating the proposed method of study, the structure and function of the wings of the Lepidoptera are discussed and conclusions are drawn from this study regarding the phylogenetic development of the order."

The next step in advance in the development of the uniform nomenclature of the wing-veins was made by the writer, who worked out the homologies of the wing-reins of the Lepidoptera, Diptera, and Hymenoptera and published his results in "A Manual for the Study of Insects" (1895). In the preface of the book he said:

"The principal features of notation of wing-veins proposed by Josef Redtenbacher have been adopted. But as the writer's views regarding the structure of the wings of primitive insects are very different from those of Redtenbacher, the nomenclature proposed in this book is to a great extent original. The chief point of difference arises from the belief by the present writer that veins IV and VI do not exist in the Lepidoptera, Diptera, and Hymenoptera; and that, in those orders where they do exist, they are secondary developments."

I had already reached the conclusion that the few-veined wings of Hepialus represented the primitive type more closely than the fan-like wing of the Ephemerida, as was commonly believed. But as I had not made, at that time, careful studies of the wings of insects with many wingveins I was willing to admit that the reins IV and VI of the Redtenbacher system might exist as secondary developments in those orders with fan-like wings.

The investigations of the writer referred to above were based on examinations of the wings of adult insects. Soon after the publication of the volume just cited, Mr. J. G. Needham, then a graduate student in the entomological laboratory of Cornell University, and the writer began the investigation of the development of the wings of representatives of all of the orders of insects of which we could obtain living nymphs or pupæ. The results of these ontogenetic studies were published in a series of articles entitled "The Wings of Insects," which appeared in the American Naturalist during the years 1898 and 1899 . This series of articles established on a firm basis the uniform terminology of the wing-reins. The results of our investigations are given in detail in subsequent chapters.

In recording the results of our studies we found it necessary to introduce an important modification of the Redtenbacher system. As the non existence of reins IV and VI of the Redtenbacher system was demonstrated, and as it was desirable that the numbering of the principal veins should be continuous, a modification of the Redtenbacher system was obviously desirable. But we were met by another difficulty due to the fact that Spuler and others did not regard the costa as a vein and began their 
numbering of the veins with the subcosta which they designated as vein I. These facts led us to make the following statement:

"In designating the wing-veins they may be either named or numbered. The simplest method is, doubtless, to number them; and had the system which was proposed by Redtenbacher been based on a correct understanding of the primitive type, nothing better could be desired. But it was not; and, as several modifications of the Redtenbacher system are already in use, it seems doubtful if uniformity in numbering them could be soon brought about.

"From the great mass of names that had been proposed for the principal wing-veins, Redtenbacher selected a set of terms, to the acceptance of which no objection has been urged. It seems, therefore, that the surest way to bring about uniformity of nomenclature is to give up the attempt to apply a set of numbers to the wing-veins, and to use the names adopted by Redtenbacher. These names and the abbreviations of them which we shall use in our text as well as in the figures illustrating it, are as follows:

$\begin{array}{ll}\text { Costa, } C & \text { Media, } M . \\ \text { Subcosta, } S c . & \text { Cubitus, } C \text {. } \\ \text { Radius, } R . & \text { Anal veins, } A .\end{array}$

"In designating the branches of the forked veins we have adopted the principle of numbering them proposed by Redtenbacher and combine the numbers with the abbreviations of the names of the veins. Thus, the first branch of radius is designated as radius-one; and for this term the abbreviation $R_{1}$ is used."

The terminology of the wing-veins elaborated by Comstock and Needham in the series of articles referred to above is now commonly designated as the Comstock-Needham system. But it should be remembered that this system is merely a modification of that proposed by Redtenbacher; and the fundamental work of this author should not be overlooked.

Redtenbacher's system, being based upon the erroneous theory of Adolph was not available without modification. This had been shown by Brauer and Redtenbacher, Haase, and Spuler. But as each of these authors maintained that costa is not a vein, an incorrect starting point for the numbering of the veins was indicated.

Comstock and Needham demonstrated that costa is preceded by a trachea and is therefore a true vein. Previous to the publication of their articles Spuler had worked out the lepidopterous type of venation (except as regards costa), and Comstock had also worked out that of the Lepidoptera, and in addition that of the Diptera, and Hymenoptera. Taking up the work at this point, Comstock and Needham extended it by a study of the development of the wings of representatives of nearly all of the orders of winged insects, and presented a hypothetical type of primitive wingvenation from which they believe that the venation of the wings of all orders have been evolved. They also pointed out the various methods of specialization by which the primitive type has been modified. This placed the uniform terminology on a broad and firm basis. 
Although the uniform terminology adopted here is based on that of Redtenbacher, the modifications of the older system that have been found necessary have resulted in marked differences in detail between the two systems. These differences are indicated later in the discussions of the renation of the wings of the several orders.

Since the appearance of the series of articles by Comstock and Needham, the homologies of the wing-veins of several groups of insects have been studied by various authors. The more important of the contributions on this subject are referred to and utilized in later chapters; and are listed in the bibliography at the end of this essay.

The work that remains to be done to perfect the uniform terminology of the wing-veins is the application of this system in the descriptions of those highly specialized groups of insects where the homologies of the wing-veins are difficult to determine. This can be well done in each case only by a specialist who makes a thorough study of the wings of the group, family or order in question, and compares these wings with those of more generalized forms. This work will doubtless require many years for its completion; but the value of the results in determining the relationships of the groups studied will be worth the effort. 


\section{CHAPTER II}

\section{THE TRACHEATION OF THE WINGS OF INSECTS}

A STUDy of the developing wings of nymphs and of pupæ has shown that in the more generalized orders of insects the principal, longitudinal wingveins are formed about trachex, which extend into the wing early in its development and before the beginning of the formation of the wing-veins.

As these trachea are very constant in number and position, they furnish the most available data for determining the homologies of the wing-veins that are later developed about them.

An account of the earlier publications on the relation of the tracheation of the wings to the wing-venation is given in the preceding chapter. A comparative study of the tracheation of the wings of the several orders of insects for the purpose of determining the homologies of the wing-veins was first made by Comstock and Needham ('98-'99). That work of this kind had not been undertaken previously was doubtless due to difficulties that stood in its way.

The tracheæ of the wings of pupæ and of nymphs are often very delicate; and, when filled with the medium in which a wing is mounted for microscopic study, they are usually invisible. It is not strange, therefore, that the study of them was so long delayed.

Method of study of the tracheation of wings.- In the course of our investigations Dr. Needham and I devised a method of study of the wings of immature insects, which renders the observation of the tracher in them a simple matter. A description of this method, compiled from our joint account of it, with a few changes made necessary by subsequently obtained information is given in the outline of laboratory work included in Chapter XXVI of this volume.

By this method most beautiful objects can be prepared, which will show the minutest ramifications of the tracher. Plate II is a half-tone reproduction of a photograph of an object prepared in this way. This figure represents a small portion of a wing of a pupa of Corydalus cormutus.

The development of wing-veins. - "Not only can the tracheæ that precede the wing-veins be studied in this manner, but if the wing be taken at the right stage, pale bands can be seen which indicate the position of channels about which the veins are later developed; this is shown in the figure of a wing of a pupa of Sialis (Fig. 2). An examination of a crosssection of a dereloping wing (Fig. 3 ) will show the nature of these channels, or vein-cavities, as they may be termed.

"In all insect wings the two plates of the hypodermis constituting the wing fold are at first separate, $i$. $e$. not fused internally. At the time when 


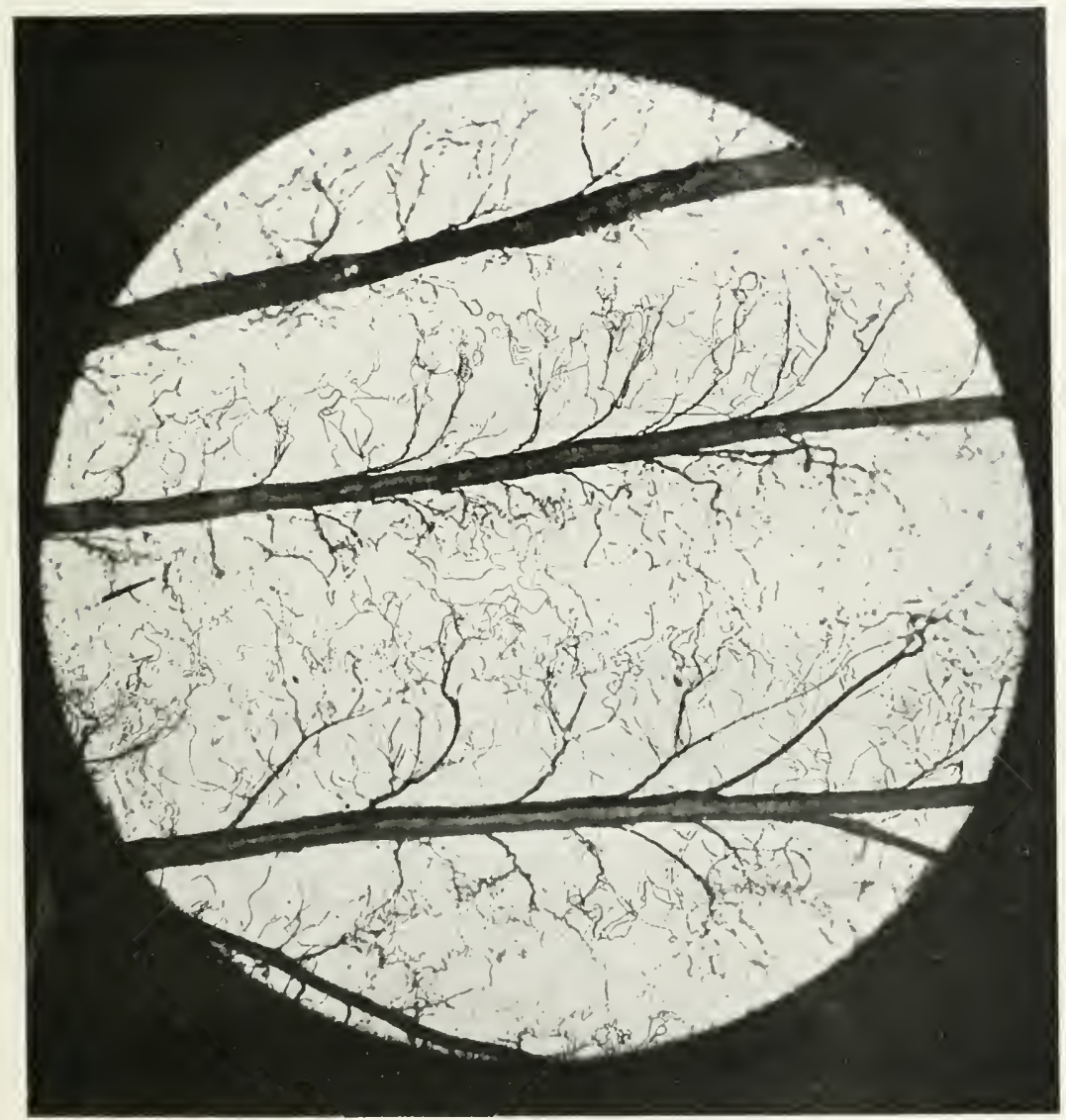

Part of a wing of a pupa of Corydulus cornutus. (From C. and N.) 

the tracheæ enter the fold the two layers become approximated along lines midway between the tracheæ, resulting in an actual fusion of the interna 1 ends of the cells. Then follows a gradual lateral extension of the areas in

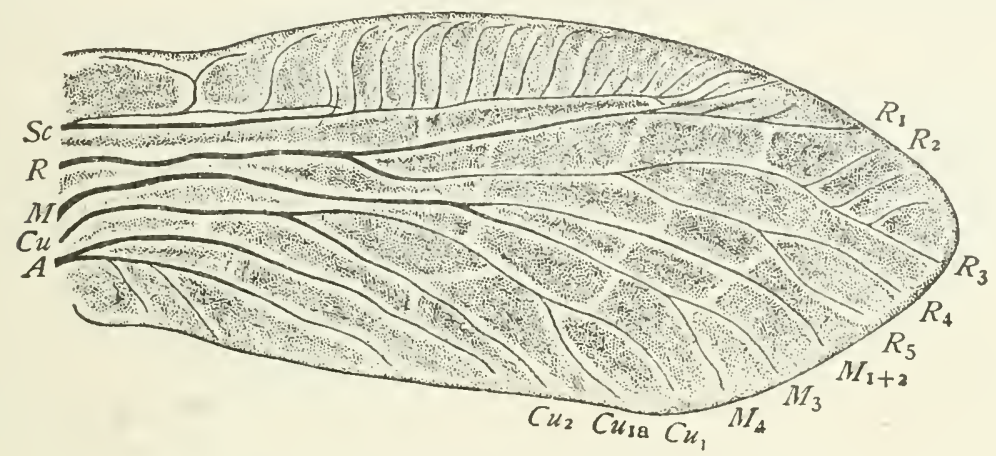

Fig. 2.-A wing of a pupa of Sialis (After C. \& N.).

which the cells are fused to delimit definitely the channels through which the tracheæ pass. This process is illustrated by the figures showing two stages in the development of the wings of Psocus (Figs. 4 and 5 ).

"The pale color of the bands, indicating the extent of the vein cavities when viewed by transmitted light, is doubtless due to the fact that the hrmolymph filling these cavities is more translucent than the hypodermal tissue, which completely fills the wing elsewhere.

"As an illustration of the nature of the data that can be obtained by the method described above, a half-tone reproduction of one of our photographs is printed here (Plate I Frontispiece). This figure represents a wing of a nearly mature nymph of a Nemoura, one of the genera of the Plecoptera. In making the preparations it was impracticable to remove all of the dirt adhering to the wing without danger of injuring it; this is often the case in preparing mounts of the wings of aquatic nymphs. The irregular blotches

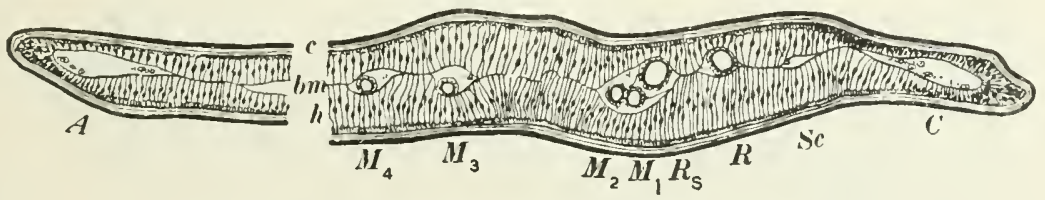

Fig. 3.-Cross section of a fore wing (in part omitted) of a nymph, two-thirds grown, and recently molted, of Anax junius (After C. \& N.).

of dark color in the figure are due to this cause. The dark lines traversing the disk of the wing represent the tracher, and the pale bands, the veincavities already described.

"It will be observed that the principal veins are formed along the courses of tracheæ, while in most cases the cross-veins have no tracheæ within them. 
It will also be observed that the tracheæ extend in straight lines or in gentle curves, while in some cases the corresponding veins are much more angular.

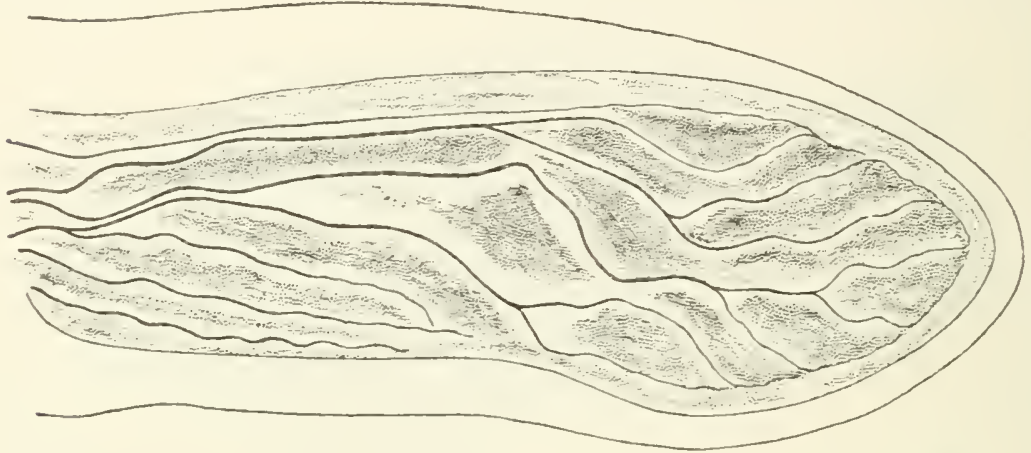

Fig. 4.-Fore wing of a partly grown nymph of Psocus (After C. \& N.).

"It is evident from this that in the perfecting of a wing as an organ of flight the position of a vein in the adult may become quite different from that of the corresponding trachea of the immature form. In other words, although there is no doubt that the courses of the principal wing-veins of primitive insects were determined by the position of the principal trachex of the wings, the wing-veins have been more or less modified to meet the needs of adult life; while at the same time the tracheæ of the immature wings serving the purpose of respiration, and lying more or less free within the wing-sac, have not been forced to follow closely the changes in the cuticular thickenings of that sac.

"The operation of this principle is shown only to a slight extent in the wing figured here. But when we study more highly specialized forms, it is

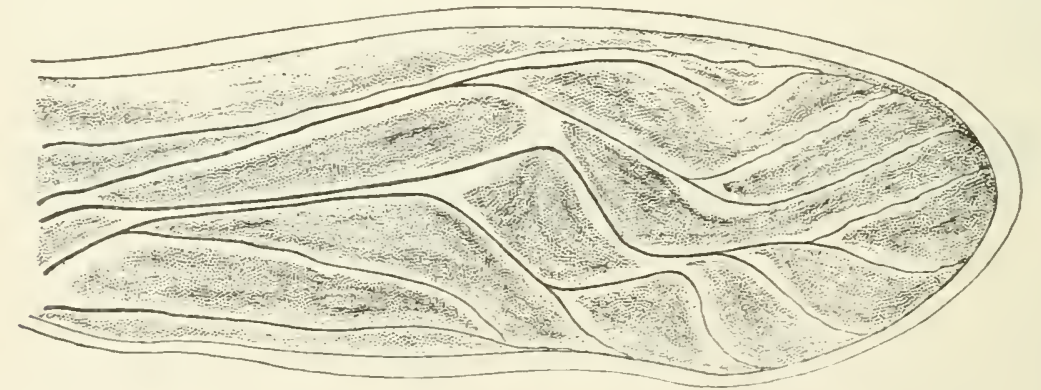

Fig. 5.-Fore wing of a full grown nymph of Psocus (After C. \& N.).

seen that the divergence of these two sets of structures is sometimes very wide, and must be taken into account in an interpretation of the characters presented by a wing. 
"While this increases the difficulty of determining the homologies of the wing-veins, it is often of great aid in taxonomic work, for it may afford an indication of the degree of divergence from a primitive type in the structure of a wing; and when a series of forms is studied the course of this divergence is often clearly indicated.

"The figure also show that in some cases what appears as a single vein is formed about two closely parallel trachex. This is shown in the case of the bases of the second and third tracher, counting from the costal margin of the wing, the radial and medial tracher. This illustrates a fact of frequent occurrence, that what appears to be a single vein may be formed by the coalescence of two primitive veins.

"In this figure the medial trachea appears not to extend to the base of the wing. This is due to the fact that in the preparation photographed the mounting medium had penetrated it for a distance, rendering the basal portions of it invisible.

"We will not go farther into the discussion of the technique of this method of study. Enough has been said to show that we have at hand a comparatively simple method of determining those questions of homologies of wing-veins that have sorely puzzled all investigators that have attempted to deal with them, and to indicate the nature of the material upon which we have based the conclusions that we purpose to offer in succeeding chapters of this paper' (Comstock and Needham '98-'99).

Following the definite delimiting of the channels through which the trachex pass, which results in the formation of the vein-cavities described above, there takes place, during the final stages in the development of the wings: first, a segregation of the hypodermis about the vein-cavities; and later, the production by this hypodermis of the thickened lines in the cuticula of the wing that constitute the walls of the wing-veins. In fact the hypodermal layers of the wing-sac are almost completely used up in the formation of the cuticula of the wing, the wing membrane and the wingveins. Almost no trace of the hypodermis is to be found in the wings of adults.

The hypothetical primitive type of insect wings. - The most important result obtained by a study of the tracheation of the wings of nymphs and of pupæ was the demonstration of the truth of the conclusion, already reached by the study of the wings of adults, that the wings of all orders of insects are modifications of a single primitive type; and that consequently it is possible to homologize the wing-veins of any of the orders with those of any other order.

Comstock and Needham made an extended comparative study of the trachcation of the wings of nymphs and of pupæ of the several orders for the purpose of determining what features were common to all; for, as it is evident that features common to all must have been inherited from a 
common ancestor, it was believed that such a study would reveal the more important features of the tracheation of the wings of the primitive winged insects, and, consequently, of the wing-venation of the same.

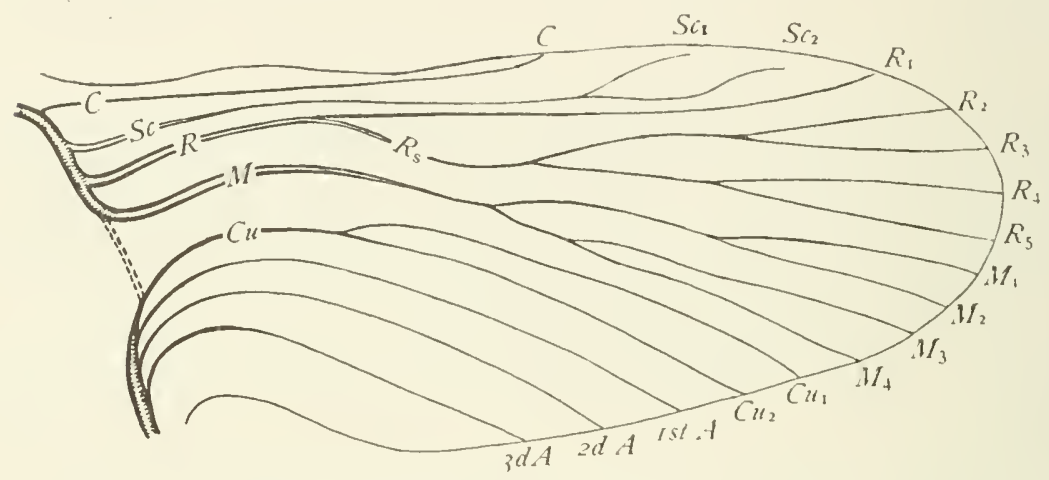

Fig. 6.-Hypothetical tracheation of a wing of the primitive nymph (After C. \& N.).

The result of our studies enabled us to construct a diagram representing the hypothetical tracheation of a wing of the primitive nymph (Fig. 6). Since there is no doubt that the trachere of the fore wings and of the hind wings are homodynamous, a single diagram serves to represent the tracheation of either the fore wing or the hind wing of the hypothetical primitive nymph.

In order to avoid unnecessary repetition the data upon which our conclusions regarding the probable primitive type of wing-venation were based are not given here. In the discussions of the wing-venation of the different orders of insects, given later, the fundamental type of the wingvenation of each order is described and its correspondence with the hypothetical type demonstrated; and in Chapter IV the correlation of the paleontological data with that drawn from the study of living insects, as regards the typical form of each of the wing-veins is indicated.

In Figure 6, and in other figures representing the tracheation of wings, the trachere are designated by the abbreviations of the names of the veins with which they correspond. In referring to tracheæ in the text they are designated in one of two ways. Thus the trachea that precedes the radius, for example, may be designated as the radial trachea or it may be termed trachea $R$. The trachea that precedes the first branch of the radius is designated as trachea $R_{1}$; and other branches of the branched tracheæ are designated in a corresponding manner.

It was found that the basal connections of the wing tracher afford characters of considerable taxonomic importance. In what we regard as the more generalized of winged insects, $i . e .$, in the Plecoptera and in certain 
members of the family Blattidæ of the Orthoptera, there are two distinct groups of tracheæ that enter the wing; these we designated as the costoradial group and the cubito-anal group respectively. In these insects the medial trachea is a member of the costo-radial group (Fig. 6).

In all other forms that we studied, except the Ephemerida, a transverse trachea connects these two groups of wing tracher; the position of this transverse basal trachea of the wing is indicated in the figure (Fig. 6) by dotted lines.* Frequently the transverse basal trachea is indistinguishable from the two main trunks which it connects, the three forming a single, continuous, transverse trachea, from which arise all of the wing tracheæ (Fig. 7). All of the stages of this development were found by us within the Orthoptera.

We also found that when a transierse basal trachea is formed, the medial trachea tends to migrate along it toward the cubito-anal group of

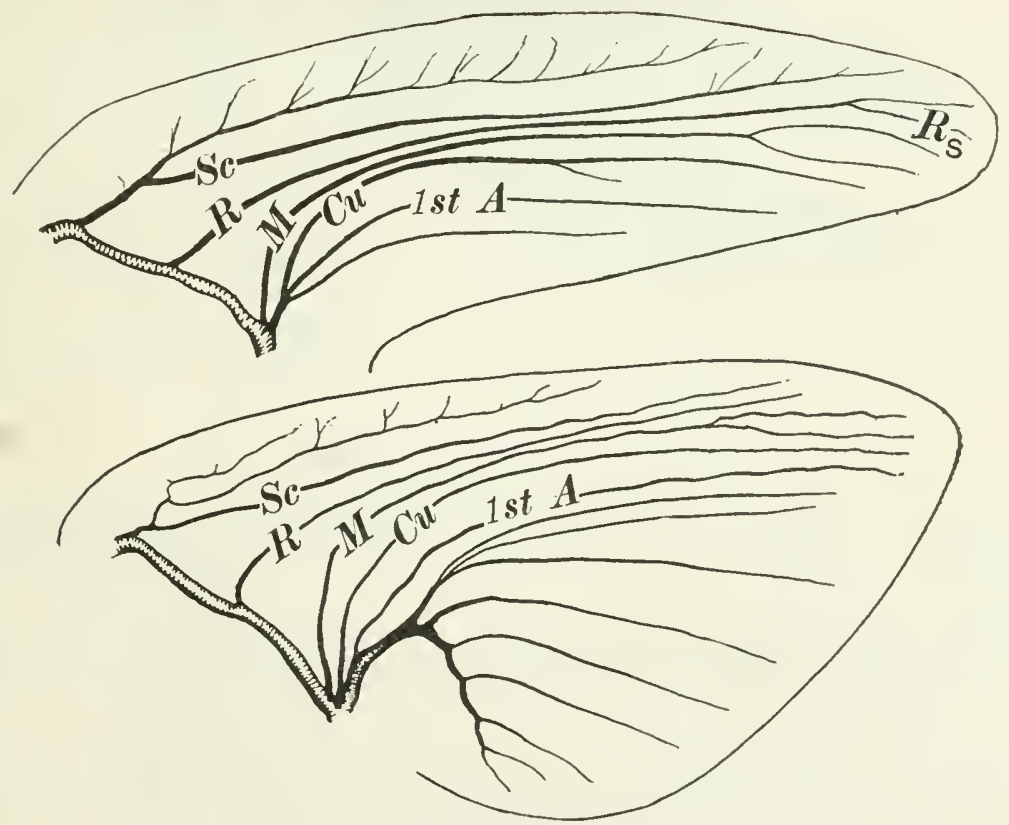

Fig. 7.-Wings of an acridid nymph (After C. \& N.).

tracheæ, and often becomes united with that group. This is well shown in certain Orthoptera and in the cicada. In some cases the base of the radial

*More recently it has been found that in certain Homoptera, the Membracidæ and the Jassidæ, the same gencralized condition of the basal connections of the wing tracheæ exists as in the Plecoptera. 
trachea tends to follow that of the medial trachea in its migration along the transverse basal trachea towards the cubito-anal group (Fig. 7).*

As the diagram representing the hypothetical type of the tracheation of the wings will serve also to represent the supposed primitive type of wingvenation, there may be indicated in it the position of a few cross-veins, which are so constant in their position, and which occur in so many widely separated groups, that they are regarded as being comparatively primitive. This is done in Figure. Io.

None of the cross-veins are primitive in the sense in which the longitudinal veins are primitive; for in the wings of the older Paleozoic insects

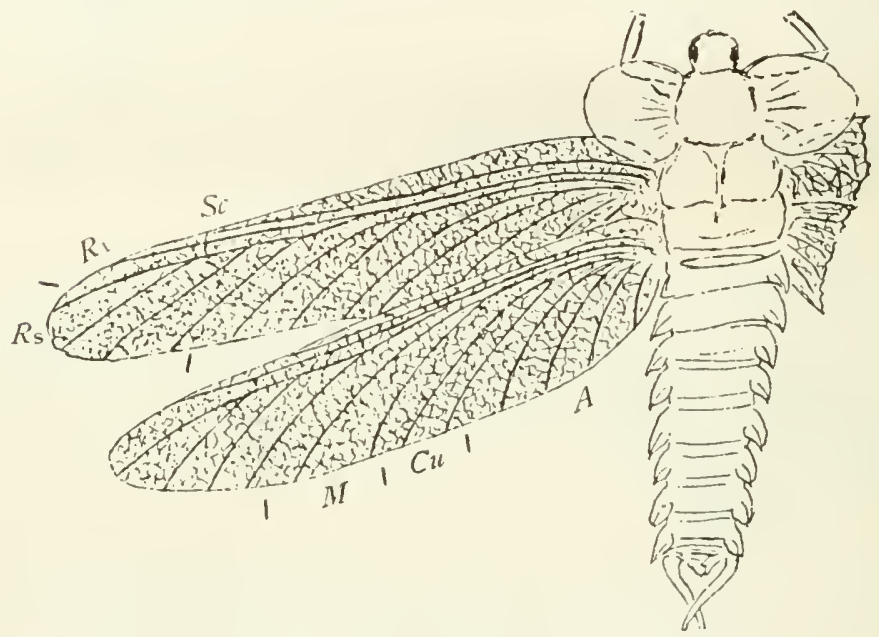

Fig. 8.-Stenodictya lobata (After Handlirsch).

there were no distinct cross-veins, but an irregular network of thickened lines; this is well-shown in the wings of Stenodictya (Fig. 8), which is described in Chapter IV.

In the older insect wings in which there are distinct cross-veins there are many of them, and the few cross-veins that are referred to above, and

*Enderlein ('O2) has worked out with great care the tracheation of the wings of Antheraea pernyi, a saturniid moth, and the connections of the tracher of the wings with the longitudinal tracheæ of the body; and his account is illustrated by most excellent figures.

In this highly specialized moth, media has completed its migration along the transverse basal trachea and become a member of the cubito-anal group of tracheæ. This fact has probably misled Enderlein, for he argues at length that the veins of each wing are separated "in zwei genetisch völlig verschiedene Systeme, das radiale und das mediane Adersystem" (l. c. p. 28). He quotes the separation of the veins of the wing, by Comstock and Needham, into the costo-radial group and the cubito-anal group, but evidently overlooked our account of the migration of media; for he proposes the division of the wing-trachex into a radial and a medial group, without any reference to the facts that led us to make the division indicated above. 
that we have named, can not be identified; one of the oldest of these wings is that of Eurythmopteryx (Fig. 9), which is also discussed in Chapter IV.

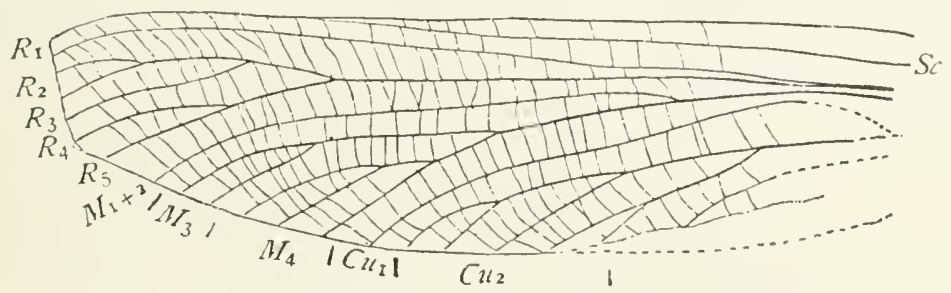

Fig. 9.-Wing of Eurythmopteryx (After Handlirsch).

In the course of the evolution of the few-veined type of wing nearly all of the cross-veins were lost; but five or six were retained and are still preserved in several orders of insects. These we have named as follows: the humeral cross-vein (Fig. Io $h$ ); the radial cross-vein (Fig. Io, $r$ ); the sectorial cross-vein (Fig. Io, $s$ ); the radio-medial cross-vein (Fig. 10, $r-m$ ); the medio-cubital cross-vein (Fig. Io, $m-c u$ ); the medial cross-vein (Fig. Io, $m$ ); and the posterior arculus (Fig. II, p. a.) The cross-veins are described more fully in the next chapter.

The tracheation of the wings of larvæ and pupæ.-The development of the tracheation of the wings in insects with a complete metamorphosis, where the wings reach an advanced stage of development within the body, differs remarkably from that of the wings of insects with a gradual or with an incomplete metamorphose. With the latter the wings of the nymphs

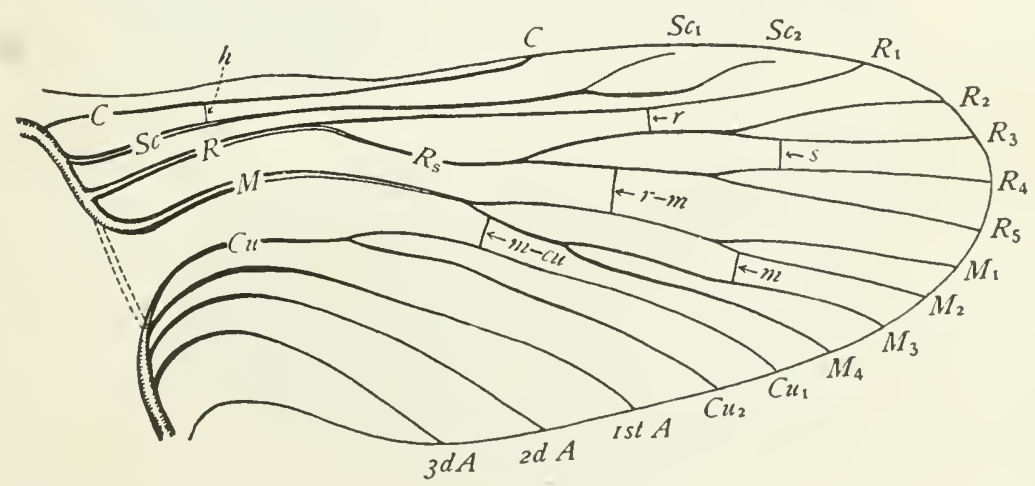

Fig. I0.-The hypothetical primitive type of wing venation with the named cross-veins added.

are developed as outward projecting appendages of the body, into which the tracheæ penetrate early; and there is a gradual, direct development of the tracheation in the successive stadia. But in insects with a complete 
metamorphosis the development of the tracheation of the wings presents some of the more remarkable features of this highly specialized mode of development.

As an understanding of the more general features of the internal development of wings is essential to an understanding of the development of the

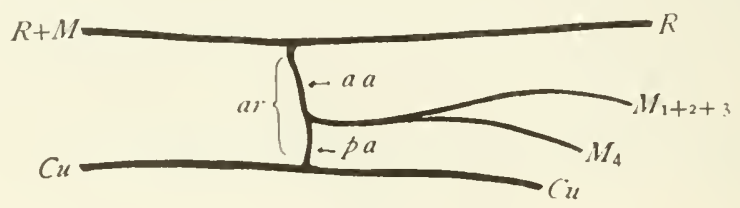

Fig. I I.-Diagram of an arculus of a dragon-fly.

tracheation of the wings of larva and pupx a discussion of this subject is omitted here, and will be taken up in Chapter $\mathrm{V}$.

Variations in the extent of the tracheation of the wings of nymphs and of pupæ.- While the study of the tracheation of the wings of nymphs and of pupæ has yielded most valuable data for determining the homologies of the wing-veins of adult insects, an extended investigation in this field has revealed remarkable differences in the extent of the tracheation of the
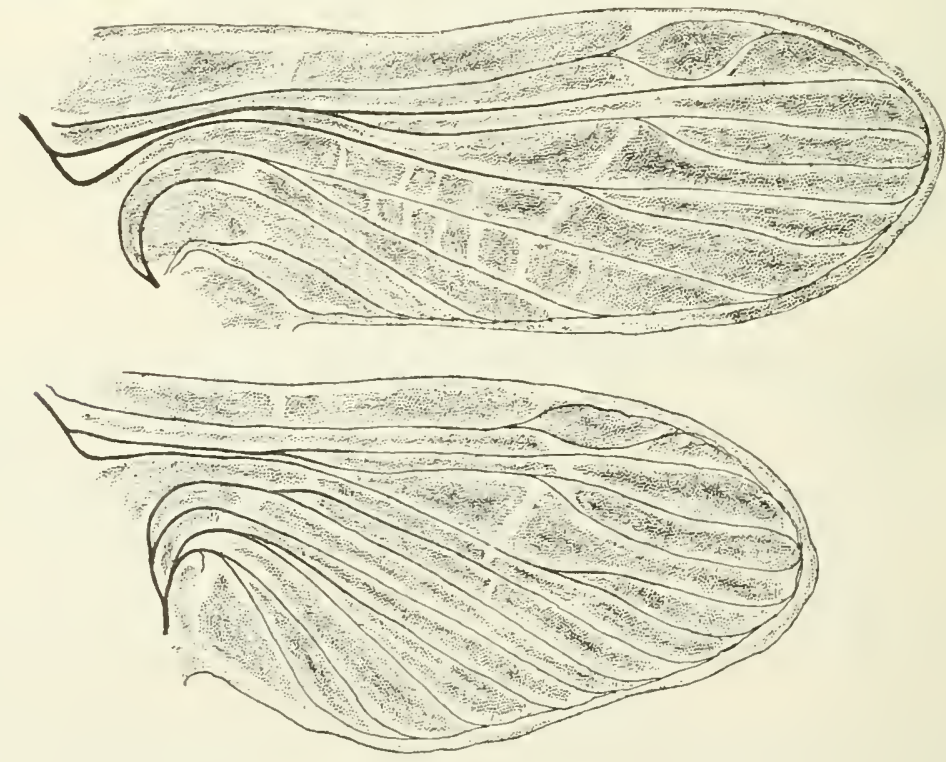

Fig. 12.-The wings of a nymph of Nemoura (After C. \& N.).

wings of immature forms and in the degree of its correspondence with the venation of the wings of adults. In some of the orders of insects, the tracheation of the developing wings is of the greatest importance in deter- 
mining the homologies of the wing-veins; in others, it is of little or no value for this purpose. And, as a rule, there is throughout each order a marked uniformity in this respect.

The variations in the extent of the tracheation of developing wings can be grouped under a few general heads: in certain orders the tracheation is comparatively simple; in others, there has been developed a greatly increased tracheation of the wings; while in still others the tracheation has been greatly reduced; and in one order at least, the tracheation is eccentric. Examples of each of these classes are given below.

Illustrations of the simpler type of the tracheation of the wings.-Excellent illustrations of the simpler type of the tracheation of the wings of nymphs are presented by members of the Plecoptera, of which Nemoura (Fig. I2) may be taken as an example. The figure represents the wings of a

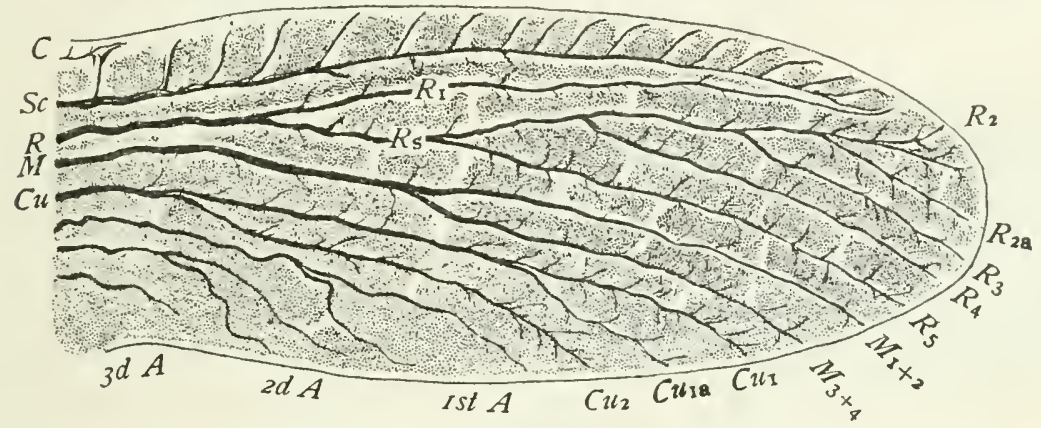

Fig. I3.-A wing of a pupa of Chauliodes (After C. \& N.).

grown nymph in which the developing veins appear as pale bands. In each of the principal veins and in the branches of these there is a prominent trachea; while the cross-veins are without tracheæ.*

Wings in which the tracheation is of this type present few if any difficulties in the determination of the homologies of the wing-veins. This is especially true as the cross-veins are sharply differentiated from the principal veins by the absence of tracher in them.

Of the other orders that exhibit a simple type of tracheation of the wings there may be cited: the Corrodentia, of which Psocus (Fig. 5) will serve as an example; the Homoptera, illustrated by a cicada, the wings of which are figured later; and the Lepidoptera, which is discussed in detail in another chapter.

Illustrations of increased tracheation of wings. - In the simpler type of tracheation of the wings only the primitive wing-veins, those represented in our hypothetical primitive type, are represented by prominent tracheæ.

*In the specimen figured the costal trachea was not observed; but this trachea was found in other, closely allicd, forms. 
What may be regarded as the first step in the direction of an increased tracheation of the wings is illustrated by the Neuroptera, of which Chauliodes (Fig. I3) will serve as an example. Here the primitive wing-veins and the secondarily developed accessory veins are preceded by tracheæ, while the cross-reins are not. Although many fine tracheæ branch from the principal tracheæ and ramify throughout the wing sac they do not follow the courses of the cross-veins.

The extreme limit of increased tracheation is reached by the Odonata, where not only the principal veins and the intercalary veins are traversed by tracheæ, but there is also a distinct segregation of small tracheæ and tracheoles in the cross-reins; this is shown in Plate $V$. In this order the study of the tracheation of the wings affords no help in distinguishing the cross-veins from other veins.

Illustrations of reduced tracheation of wings.--In several of the orders of insects a remarkable reduction of the tracheation of the wings has taken

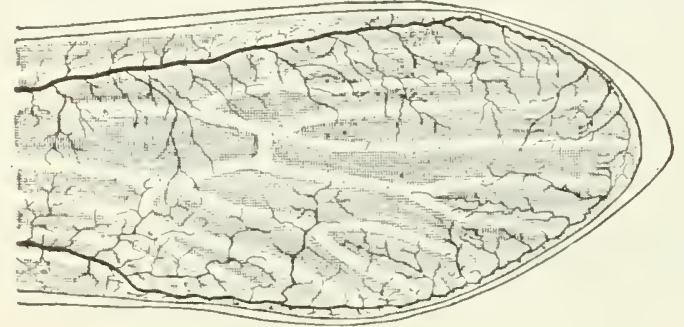

Fig. I 4.-A wing of a pupa of a caddice-fly (After C. \& N.). place; and in some cases, at least, associated with this reduction is a retardation in the development of those tracheæ that are retained.

In what is regarded as the more normal relation between the tracheation and the venation of wings, the tracheæ are developed early in the growth of the wing, before the beginning of the development of the wing-veins, which are later formed about them. Here the courses of the tracheæ determine to a great extent the courses of the wing-veins.

But in those orders where there is a reduction of the tracheation of the wings, the tracher, in those cases that we have studied, do not penetrate the wing-sac until after the vein cavities are formed, and then they follow the most available channels, which in a wing where the venation is highly specialized, as in the Hymenoptera, may be very different from the primitive course of the tracheæ.

A great reduction of the tracheation of the wings has taken place in the Trichoptera. If a wing of a pupa of a caddice-fly be examined at that stage when the forming wing-veins appear as pale bands (Fig. I 4), it will be seen that the tracheation bears but little relation to the wing-veins. Usually only two or three main trachea are present; and although these may coincide with forming veins, their branches bear no relation to veins.

In the Diptera an equally great reduction of the tracheation of the wings has taken place in most families; and even when most of the 
tracheæ are retained, as in certain asilids, they have not retained their primitive position.

A similar condition exists in the Hymenoptera. In the more generalized Hymenoptera, as in Tremex (Fig. I 5), the main stems of the principal

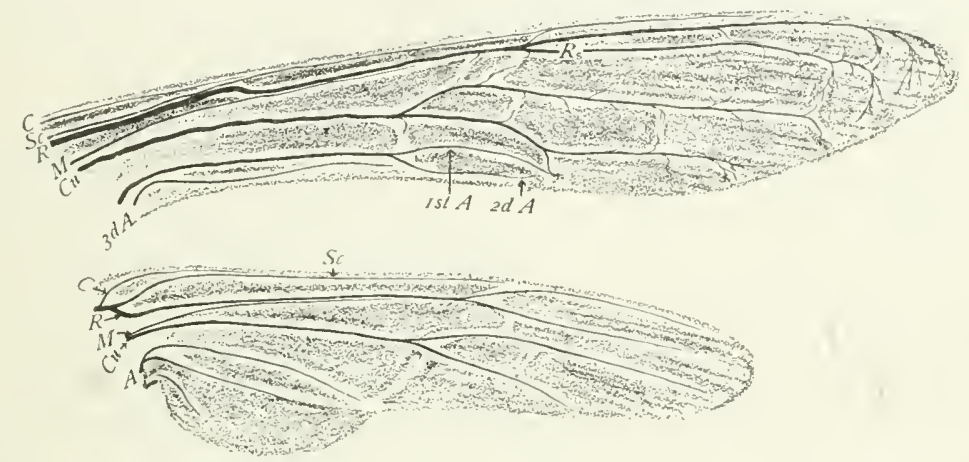

Fig. 15.-The wings of a pupa of Tremex (After C. \& N.).

tracheæ are retained, and occupy very nearly the normal positions; but the courses of the branches of these tracheæ bear little if any relation to their primitive courses. In the more specialized families, there is a greater reduction of the tracheation and a wider deviation from the primitive type in the branches of the tracher that are retained. The wings of a young pupa of Apis (Fig. I6) illustrates this. In these wings the vein-cavities are already formed and the trachex are beginning to push out into them, following the most direct courses in the already formed vein-cavities.

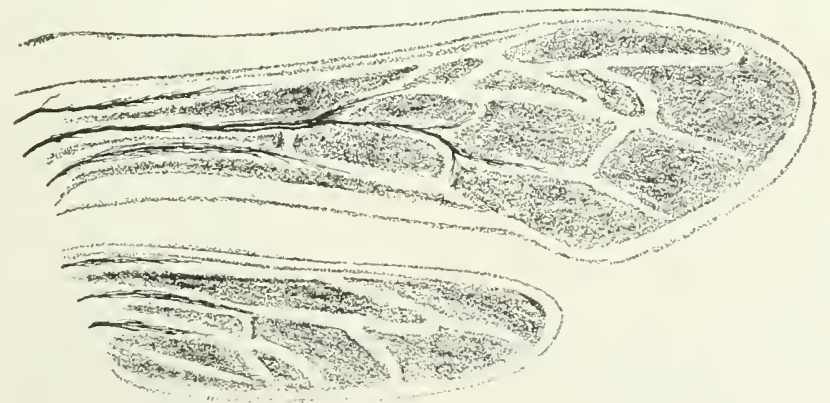

Fig. I6.-The wings of a pupa of Apis (After C. \& N.).

Eccentric tracheation of wings.-In the Ephemerida there are many modifications of the tracheation of the wings that do not appear to result from any definite course of specialization. In many cases a principal trachea is reduced in length, so that it traverses only a part of the vein with which it corresponds; frequently a trachea follows its vein for a dis- 
tance and then changes its course suddenly and enters and follows another parallel vein; and there is no regularity in these aberations. In some forms there is a great reduction of the principal tracheæ and correlated with this reduction a remarkable increase of fine tracheal twigs; so that the result is an increased tracheation of the wing. Examples of these deviations from the typical tracheation are figured in the chapter devoted to the wings of the Ephemerida.

Limitations to the value of tracheæ in determining the homologies of veins.--Much stress has been laid in the preceding pages upon the value of the tracheæ of the rings as an aid to determining the homologies of the wing-veins. In fact the most conclusive proof of the uniformity of the fundamental type of the wing-venation of all orders of insects is drawn from studies of the tracheation of the wings of representatives of those orders in which the tracheation is well preserved. Fortunately in the case of those orders where the tracheation is reduced the venation of the wings of adults so closely resembles in its more general features that of the orders in which the tracheæ are well preserved that there is no difficulty in recognizing the identity of the principal reins.

There are cases, however, in which the evidence presented by the tracheation of the wings is misleading and can not be accepted. This does not imply that we are to accept the testimony of the tracher if it suits our purpose and to reject it if it does not; but rather that we are to consider other evidence as well as that presented by the tracheation. Two illustrations will serve to make this point clear.

In the suborder Anisoptera of the order Odonata studies of the tracheation of the wings have shown that in the adult wing of Gomphus, for example, the radial sector occupies a position between veins $\mathrm{M}_{2}$ and $\mathrm{M}_{3}$. Not only does the basal connection of the radial sector trachea show this but the successive stages of the migration of the radial sector trachea from its normal position to this unusual one can be seen in the wings of a series of nymphs of different ages. Figures illustrating this are given in the chapter treating of the Odonata.

If one studies the wings of a member of the suborder Zygoptera of this order and compares the renation with that of Gomplus there will be no difficulty in identifying the reins and in recognizing the fact that the radial sector occupies the same position as in the Anisoptera. But when one studies the tracheation of the wing of a nymph of one of the Zygoptera the radial trachea is found to be unbranched and the trachea that precedes what is doubtless the radial sector is a branch of media. It is obvious that in this case the evidence presented by the tracheation is misleading and that the evidence presented by the adult venation is more reliable. The explanation of the discrepancy is that in the $Z$ ygoptera the radial sector 
trachea has become united with the medial trachea at the point where it crosses the medial trachea and has lost its earlier basal connection.

The second illustration is found in the more specialized Lepidoptera where the base of media has been lost by atrophy and the first branch of media, vein $R_{1}$, has become attached to the radial sector; correlated with this shifting of the base of vein $M_{1}$ to the radial sector trachea $R_{1}$ appears to be a branch of the radial sector trachea. In the more generalized Lepidoptera trachea $M_{1}$ has preserved its primitive connection with the other branches of the medial trachea. In the latter case the evidence presented by the tracheation is complete in itself; in the former case there is other evidence to show that the tracheation has been modified secondarily.

In general it may be said that the evidence presented by the tracheation of the wings of the more generalized insects is reliable, but in the case of the more specialized insects where extensive modifications of the venation have taken place the evidence presented by the tracheation should be carefully considered before it is accepted.

The basal connections of the tracheæ of the wings.--It has been shown on an earlier page that the trachex of the wings are branches of two large tracher, one of which enters the wing near the humeral angle of the wing, the other, in the region of the base of the anal area. In the Plecoptera and in certain other groups of insects these two large tracheæ are distinct, but in most insects they become connected by what has been termed the transverse basal trachea.

In the diagram representing the hypothetical primitive tracheation of the wings (Fig. 6) the connections of the trachex of the wings with these two large trachere are represented; and the position in which the transverse basal trachea is found when it exists is indicated by two dotted lines.

The two groups of wing-tracheæ arising from these two large tracheæ have been designated as the costo-radial group and the cubito-anal group, respectively. And it has been shown that although the medial trachea belongs to the costo-radial group of trachex in those forms in which there is no connection between the two groups of tracheæ, when the two groups are connected by a transverse basal trachea the base of the medial trachea tends to migrate along the transverse basal trachea towards the cubito-anal group of tracher, which it reaches in the more specialized forms. These facts suggested the question: what are the causes that produce this result? Regarding this Comstock and Needham wrote as follows:

"We have found no indication that the formation of a transverse basal trachea and the subsequent migration along it of the base of the medial trachea is influenced at all by the flight function of the wing, as the arrangement of the wing-veins does not appear to be modified by it. It should be remembered that the transverse basal trachea and the bases of the wing 
tracheæ are within the thorax of the adult insect, and are thus beyond the influence of the migrations of the wing-reins.

"It is probable that these changes have to do with improving the air supply of the wing; but we have not sufficient data, as yet, to warrant a definite statement on this point. The important thing for the purpose of the present discussion is that one must know of this tendency on the part of the medial trachea to migrate along the transverse basal trachea in order to be able to recognize it in its various positions.'

In taking up the subject again, in the course of the preparation of the present essay, it occurred to me that there are certain modifications of the wing venation in certain insects that may be due to the same cause as that which causes the migration of the base of the medial trachea along the transverse basal trachea. For example, if the large trachea that supplies the cubito-anal group of tracheæ with air affords a better supply of air to the wing than does the trachea that supplies the costo-radial group of trachex, this may be the factor that determines in the wings of dragon-flies the invasion of the area of the radial sector by some of the branches of the media.

It seemed worth while, therefore, to make a special study of the basal connections of the two large tracheæ that supply the wing with air. This investigation was undertaken, at my suggestion, by Mr. R. N. Chapman; and the work was done in the entomological laboratory of Cornell University, where I had the pleasure of following it step by step.

The investigation was a very difficult one, involving the making of a large number of most delicate dissections; but it was prosecuted in a most successful manner. We now know the facts regarding the basal connections of the tracheæ of the wings in most of the orders of insects.

The results of this investigation have not shown that the air supply of the cubito-anal group of tracheæ is better than that of the costo-radial group. It does not seem probable, therefore, that an improvement of the air supply to the wing is the factor that has determined the migration of the base of the medial trachea, when it occurs, or the invasion of the area of the radial sector by branches of media in the Odonata and Ephemerida.

In order that the data now at hand bearing on this problem may be kept together, I publish Mr. Chapman's account of the results of his investigation as an appendix to this chapter. 


\section{THE BASAL CONNECTIONS OF THE TRACHE EF THE IVINGS OF INSECTS}

\section{By Royal Norton Chapman, M.A.}

THrs paper is the result of an investigation undertaken at the suggestion of Prof. J. H. Comstock, under whose direction the work has been done. The purpose of the work has been to determine the generalized type of the basal connections of the tracheæ of insect wings and to ascertain what the principal lines of modification have been, with the hope that the conditions of the basal connections of the tracheæ may offer some explanation for some of the modifications of the tracher in the wings themselves.

It was found by Comstock and Needham (American Naturalist, xxxii, I 898 , p. 88-89) that the tracheæ that supply the wings with air arise from two distinct trunks, an anterior costo-radial trunk and a posterior cubitoanal trunk. In certain generalized insects these two trunks are distinct; where this condition exists the medial trunk is a member of the costo-radial group of trachex. In most insects there has been developed a transverse trachea connecting these two groups of tracheæ,. the transverse basal trachea (Fig. I $7, t b$ ).* When a transverse basal trachea is formed, the base of the medial trachea tends to migrate along it towards the cubito-anal group of tracheæ, and often becomes united with that group.

Comstock and Needham were unable to explain the cause of the formation of a transverse basal trachea and the migration along it of the base of

*Lettering of the Figures lillestrating the B.isal Connections of the TRACHEE OF THE WINGS OF INSECTS.

a. $c-r$, accessory costo-radial trachea;

a. $c u-a$, accessory cubito-anal trachea;

$a$. $d t$, accessory longitudinal trachea;

as, anterior stem of the leg trachea;

$c$, costal trachea;

$c-r$, costo-radial trachea;

$c u-a$, cubito-anal trachea:

d. li, dorsal longitudinal trachea;

$g$, tracheal gill:

gi, gill trachea;

$l_{2}$, mesothoracic leg trachea;

$l_{3}$, metathoracic leg trachea;

$l t$, longitudinal thoracic trachea;

$m t$, muscle trachea:

$p s$, posterior stem of the leg trachea;

r. $s p_{1}$, rudiment of the mesothoracic spiracle;

r. $s p_{2}$, rudiment of the metathoracic spiracle;

r. $s p_{3}$, rudiment of the first abdominal spiracle;

$s p_{1}$, mesothoracic spiracle;

$s p_{2}$, metathoracic spiracle;

$s p_{3}$, first abdominal spiracle;

$s p_{4}$, second abdominal spiracle;

tv, transverse basal trachea;

$u$, union of the costo-radial and transverse basal tracheæ;

vit, ventral longitudinal trachea:

i. $s p_{2}$, restige of the metathoracic spiracular trunk:

$i$. $s p_{3}$, vestige of the first abdominal spiracular trunk. 
the medial trachea when it is formed. Concerning this they made the following statement: "It is probable that these changes have to do with improving the air supply of the wing; but we have not sufficient data, as yet, to warrant a definite statement on this point."

A desire on the part of Professor Comstock to have ascertained the exact nature of the basal connections of the trachex of the wings in different orders of insects, in the hope that this knowledge would throw light on this problem, led him to suggest the making of the investigation the results of which are given here.

Another condition that suggested the same question is the fact that in the Odonata the branches of the medial trachea invade the region of the tracheæ of the radial sector, which becomes greatly reduced. If the medial trachea has a better air supply than has the radial trachea, this invasion can be understood.

The references to the basal connections of the wing tracher which have been found in literature are few and fragmentary. So far as can be determined no general study of the subject has been made previously. However, various authors, while working on closely related subjects, have noted and described the conditions in certain forms. These descriptions may be best referred to in the parts of the paper relating to these various forms.

However the work of Karel Sulc [Über Respiration, Tracheensystem und Schaumproduction der Schaumcikadenlarven (AphrophorinaeHomoptera) Zeitschrift für wissenschafliche Zoologie. I9 I I :99, p. I 47-188] deserves special mention. This author described and figured the tracheal system of Philaenus lineatus L. with detailed drawings of the leg and wing tracher in the various nymphal stages. The basal connections of the wing trachere are more generalized than those of the Hemiptera described and figured in this paper (Figs. 22, 23, and 24) and agree with the typical condition of the wing trachere (Figs. I 7 a and $\mathrm{z}$ b) except that the transverse basal trachea has been developed. The basal connections of the fore wing pad of a first stage nymph of A phrophora salicis are described and figured in which the transverse basal trachea is not developed and the costo-radial and cubito-anal groups of tracheæ are shown arising respectively from the anterior and posterior stems of the leg tracher.

Careful dissection was found to be the best means of studying the trachex. The use of transmitted light to distinguish the opaque tracheæ in the more or less transparent bodies, without dissection, was not satisfactory because it was not possible, in this way, to accurately determine the relationships of the tracheæ which lie one above the other. Nymphs and pupæ were dissected under water and care was taken not to break large trachex and allow the air to escape. In this way the trachere were kept filled with air and were easily studied. Sereral dissections were made of 
each species and the results were carefully checked over to make sure that no tracheæ had been broken or overlooked.

The dissections were drawn with a camera-lucida before the air had escaped from the tracheæ and while the trunks retained their normal size. It is to be noted that no pretense has been made to include all of the muscle tracheæ; only the larger muscle tracheæ connected with the wing or leg tracheæ have been shown.

THE TYPICAL ARRANGEMENT OF THE BASAL CONNECTIONS OF THE TRACHEE OF THE WINGS

Two diagrams of what seems to be the typical condition of the basal connections of the wing trachere have been constructed (Fig. I 7 ). The condition of the tracheal branches to the wings and legs, as figured in these diagrams, does not differ in any of its essentials from the condition found in the more generalized insects. It will also be noticed that none of the insects studied present conditions which cannot be looked upon as modifications of this typical condition. The construction of these diagrams is, therefore, necessary only to simplify the discussion of the modifications of the typical condition and not to represent an imaginary step in the development of any of the conditions found in any of the more specialized insects studied.

One of the diagrams (A) is a side view of the thoracic tracheæ in which
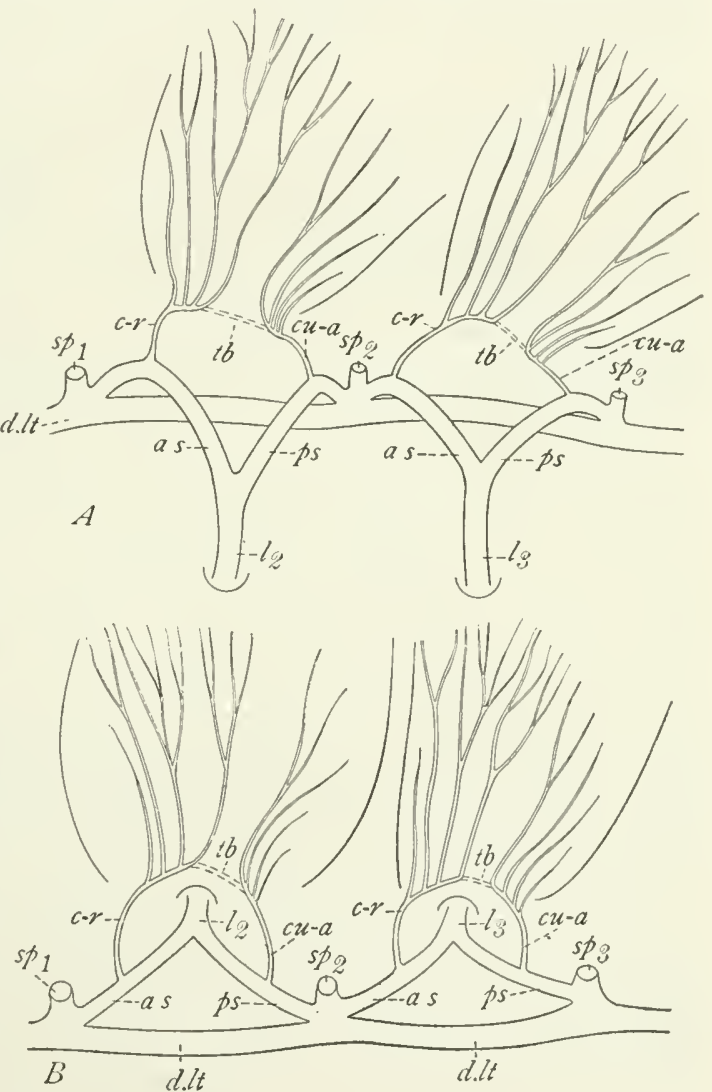

Fig. I7.-The typical condition of the basal connections of the tracheæ of the wings of insects. A. Side view. B. Dorsal view.

the wing tracheæ are represented as extending vertically above the thorax and those of the legs extending downward. The other diagram (B) is a 
dorsal view of the thoracic tracheæ and represents the tracheæ of both the wings and legs extending laterad. It must be kept in mind that when the thorax is viewed from the dorsal side the wings are directly above the legs (Fig. I 7, B). Since the conformation of some of the insects has made it necessary to draw the dissections from the side view and others from the dorsal view, the two diagrams are given to aid in the comparison of these two different aspects of the thorax.

There are three spiracles directly connected with the respiration of the wings; one in each of the last two segments of the thorax and one in the first segment of the abdomen $\left(s p_{1}, s p_{2}\right.$, and $\left.s p_{3}\right)$. The anterior and posterior of these two spiracles ( $s p_{1}$ and $s p_{3}$ ) each contributes one tracheal branch to the appendages of the mesothorax and the metathorax respectively. The middle spiracle $\left(s p_{2}\right)$ contributes two branches; one to the mesothoracic appendages and one to the metathoracic appendages. In this way each wing and each leg receives two tracheal branches; one from the spiracle anterior to it ( $c-r$ to the wing, and as to the leg) and one from the spiracle posterior to it ( $c u-a$ to the wing, and ps to the leg.) This condition is retained, in its essentials, in all the insects studied. Even tho the metathoracic spiracle is absent in many of the more specialized insects, its position is indicated by the rudimentary spiracular trunk (Fig. 2I, r. s $p_{2}$ ), from which arise branches to the thoracic appendages, very much as in the more generalized insects, where the metathoracic spiracle is well developed.

As has already been stated, these branches that arise from the trunks at the bases of the spiracles supply air to both the wings and the legs. The leg tracheæ are $\mathrm{Y}$-shaped; each leg trachea being formed by the union of two trunks. These trunks are designated as the anterior stem (as) and the posterior stem ( $p s$ ) respectively. In the more generalized insects the branches to the wings arise from the stems of the leg tracheæ, which form the arms of the Y. The figure of the nymphal cockroach (Fig. I8) shows that the tracheæ going to the legs are much larger than those leading to the wings. The relations of the leg and wing tracheæ are such that it seems very evident that the branches coming from the spiracles are primarily leg tracheæ and that the branches to the wings are secondary.

In some cases the wing and leg tracheæ arise separately from the spiracles. Such a condition may be explained as the result of a divergence of the bases of the two tracheæ which has been carried so far that their connections are entirely separate. However the more general relations between the tracheæ to the wings and those to the legs have been retained, at least to some extent, in all of the insects studied. For this reason it would seem that a consideration of the tracher to the wings cannot ignore the condition of the tracher to the legs. If there is any preference as to the air supply from the different spiracles which results in a modification of the tracheæ to the wings, some modification of the tracheæ to the legs might 
also be expected. If it is found that any factor causes changes in the tracheal branches to the wings, it may be expected that a similar factor affecting the legs will cause similar changes in the tracheæ entering the legs and the converse should also be true.

\section{EXAMPLES OF THE MORE GENERALITED ARRANGEMENT}

The basal connections of the wing trachece in a cockroach nymph (Phylodrcmia germanica), Order Orthoptera.-The condition of the tracheæ in the cockroach is very similar to that shown in the diagrams. The connections are as shown in the drawing (Fig. I8) which is a dorsal view. The cubitoanal tracheæ $(c u-a)$ originate nearer the spiracles than the costo-radial tracheæ $(c-r)$ do, but they have the typical connections with the stems of

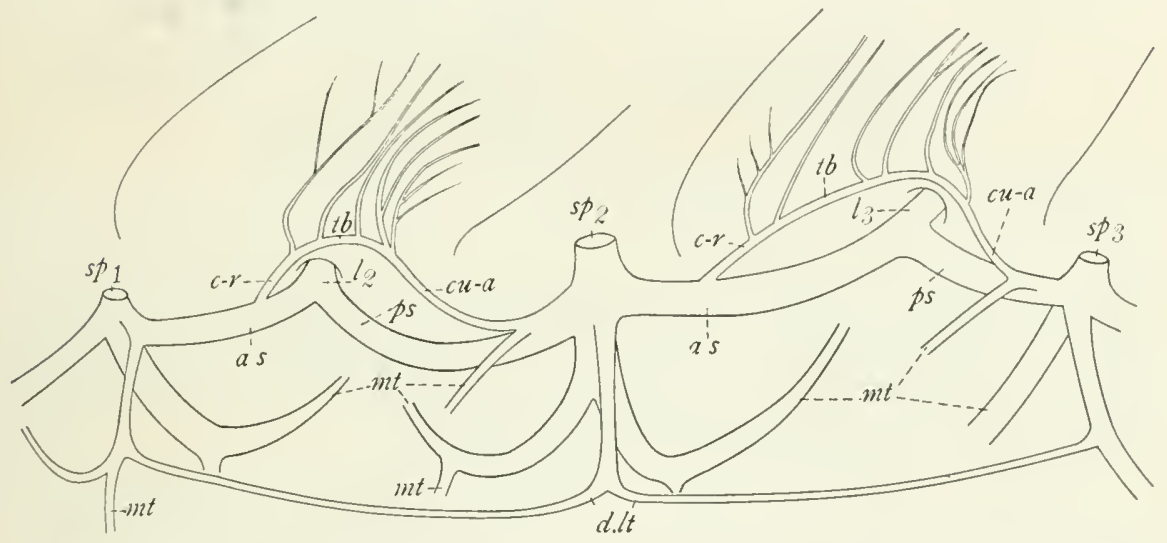

Fig. 18.-The basal connections of the wing tracheæ of a cockroach. Dorsal view.

the leg tracher (as and ps) which form the two arms of the Y-shaped leg tracheæ. There are muscle tracher $(m t)$ which go to the coxal muscles but they do not continue into the legs as do the tracher labeled $l_{2}$ and $l_{3}$.

In the nymphal cockroach there is a single slender dorsal longitudinal trachea $(d . l t)$, on each side of the thorax, lying near the digestive tract and connecting the branches from each of the three spiracles $\left(s p_{1}, s p_{2}\right.$, and $\left.s p_{3}\right)$. The size and relationships of this trachea are such as to indicate that it may be only an enlarged anastomosis of the branches from the different spiracles. In adult cockroaches the intra-segmental portions of this longitudinal trachea become enlarged to form air sacs.

The former statement that the wing tracheæ of cockroaches are connected with the longitudinal tracheæ of the thorax has not been confirmed. (Comstock and Needham, Am. Nat. xxxii, p. 88). As the drawing shows, the basal connections of the wing tracher and the dorsal longitudinal tracheæ are quite separate. 
The basal connections of the wing trachece in a nymph of Pteronarcys, Order Plecoptera.-The conditions of the wing and leg tracheæ in the stoneflies (Fig. 19) is somewhat complicated by the presence of tracheal gills

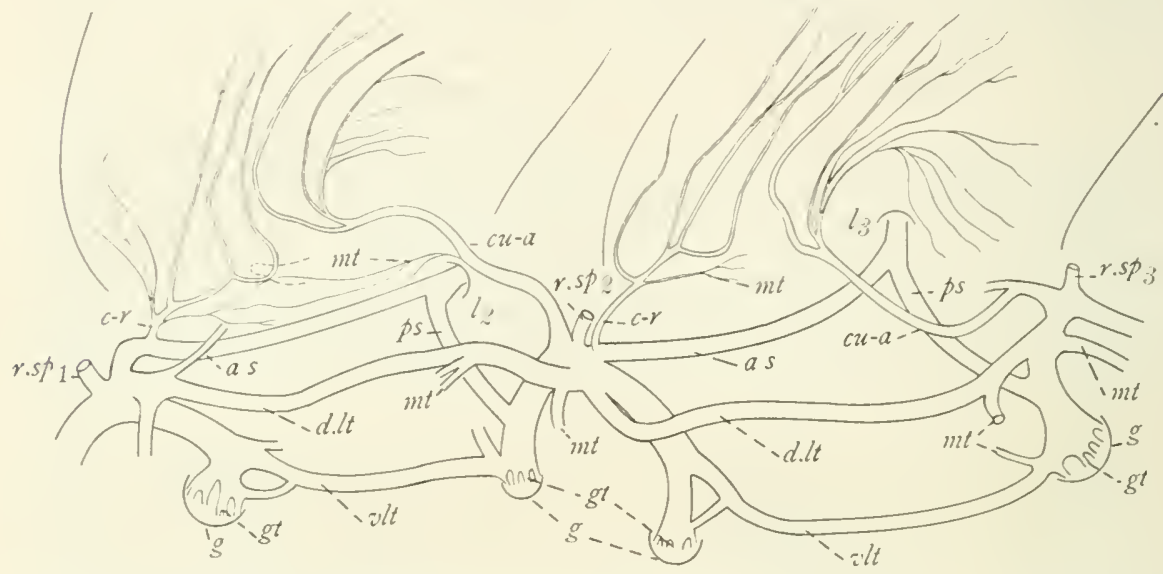

Fig. 19.-The basal connections of the wing tracheæ of Pteronarcys. Dorsal view.

but the relationships are quite generalized. The typical Y-shaped leg tracheæ are present in both cases, but in the case of both legs the posterior stem $(p s)$ is connected with a trunk leading from the spiracle to the tracheal gill $(g t)$. The cubito-anal wing tracheæ $(c u-a)$ have diverged from the leg trachea until they have attained independent origins.

The conditions of the anterior branches to the legs and wings have not been modified and the wing trachea $(c-r)$ arises in common with the anterior stem of the leg trachea (as).

The dorsal longitudinal trachea $(d . l t)$ is well developed but it will be noticed that it has no direct relationship to the wing tracheæ.

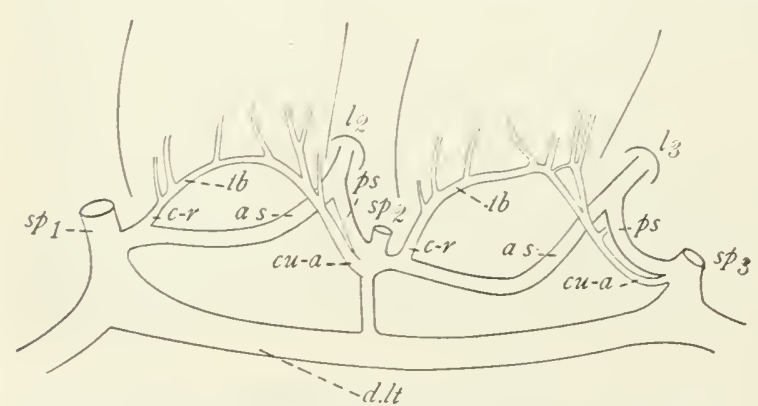

Fig. 20.-The basal connections of the wing tracheæ of Chauliodes. Dorsal view.

The basal connections of the wing trachece of Chauliodes, Order Neuroptera.-The wing tracheæ of Chauliodes (Fig. 20) represent no great deviation from the typical condition. It is interesting to note that the cubito-anal trachea $(c u-a)$ and the posterior stem of the leg trachea ( $p s)$ are separated at their bases in both cases and that the costoradial trachex $(c-r)$ and the anterior stems to the legs (as) are connected 
for only a short distance. It would seem that the tracheæ to the wings are almost at the point of being separated from those of the legs, in this form.

The longitudinal trachea $(d . l t)$ is well developed yet it does not seem to be in any way connected with the wing tracheæ.

The basal connections of the wing trachea of Antherce roylei, Order Lepidoptera.-Three pupæ of the Lepidoptera were dissected, Actias lma, Samia cecropea, and Antherce roylei. Any of the three might have been used equally well for the conditions of the tracheæ are the same in all of them. In the mesothorax (Fig. 2I) there seems to have been no modification from the typical condition, but in the metathorax the cubito-anal trachea (cu-a)

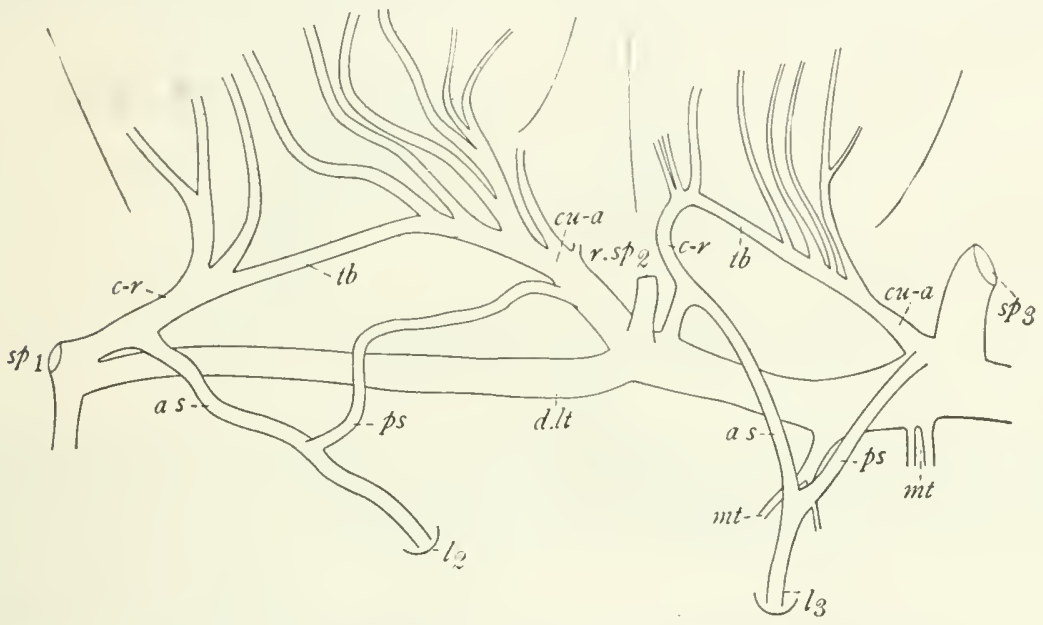

Fig. 21. - The basal connections of the wing trachex of Antherca. Side view.

and the posterior stem of the leg trachea ( $p s)$ are just separate from each other at their bases.

The dorsal longitudinal trachea $(d . l t)$ is present but has no connection with the wing tracheæ. The metathoracic spiracle is absent but is represented by the trunk of the rudimentary spiracle $\left(r . s p_{2}\right)$ with which the tracheæ have retained their typical relationships.

The thoracic tracheæ of Antherca perni have been described and figured by Enderlein (Zoologische Jahrbucher, I902; vi.).

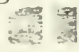

This author figures tracheæ to the mesothoracic leg as a single stem arising from the spiracular trunk of the mesothorax and the leg trachea of the metathorax as also single and arising from the costo-radial trachea of the mesothorax. The conditions of the tracheæ seem to be so constant in representatives of this order which have been studied that it would seem very improbable that there should be such a grcat difference between two members of the same genus as Enderlein's figure would indicate. 
The basal connections of the wing trachece of a notonectid nymph, Order Hemiptera.-The costo-radial trachea (Fig. $22 \mathrm{c}-r$ ) arise from the anterior

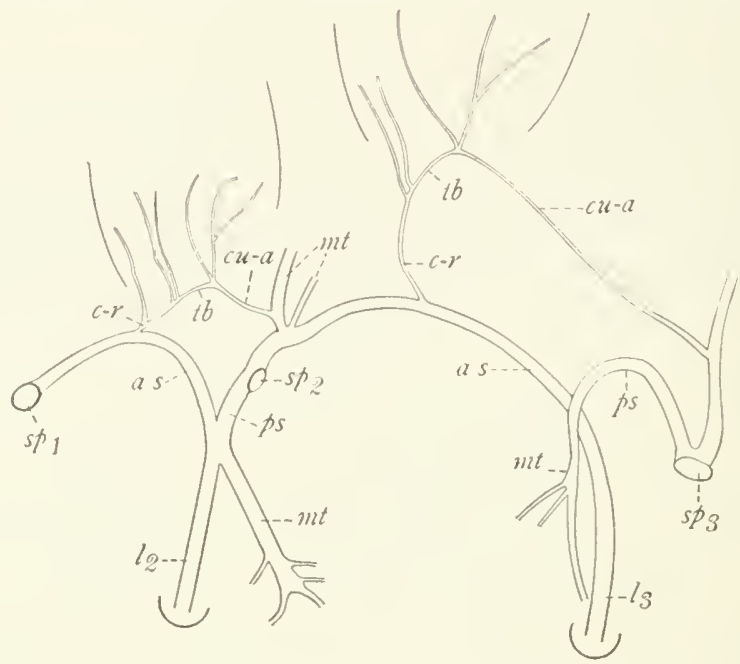

Fig. 22.-The basal connections of the wing tracheæ of a notonectid nymph. Side view.

stem of the leg trachex (as). The bases of the cubito-anal tracheæ $(c u-a)$ have diverged from the posterior stems of the leg tracheæ (ps.) and have come to arise in common with muscle tracheæ $(m t)$ which pass to the median

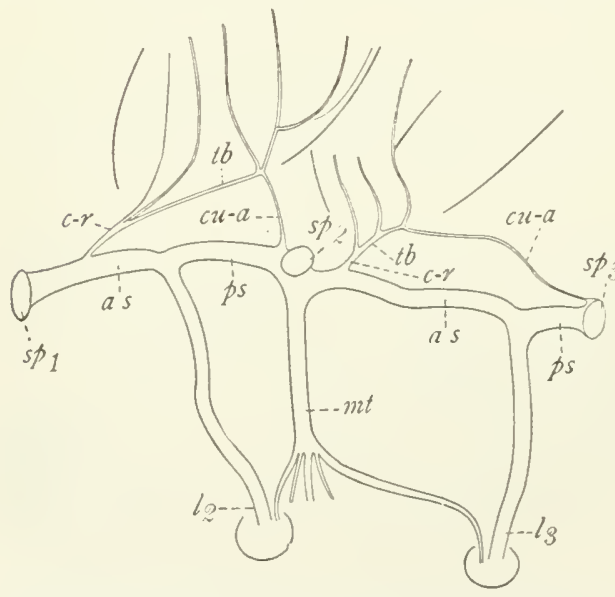

Fig. 23. - The basal connections of the wing trachea of a corisid nymph. Side view. part of the body. The conditions of the wing tracheæ are, however, so near the typical that there is no difficulty in understanding the relationships.

The leg tracheæ are modified to a greater extent. In the meso-thorax the anterior and posterior stems to the leg (as and $p s$ ) unite to form the typical Y-shaped leg trachea and at their point of union give off a large muscle trachea ( $m t$.). The posterior stem of the leg trachea in the metathorax ( $p s$,$) lies$ laterad of the anterior stem (as) at their point of union and the muscle trachea $(m t)$ appears to be a continuation of the posterior stem of the leg trachea ( $p s)$. 
The basal connections of the wing trachece of a corisid nymph, Order Hemiptera.-The two tracheal stems to the wings (Fig. 23, c-r and $\mathrm{cu}-a$ ) have retained their typical relationships in this form, but the cubito-anal trachea $(\mathrm{Cu}-a)$ to the hind wing is so small at its base that it is followed with difficulty. The anterior and posterior stems of the leg tracheæ (as and $p s$ ) have attained an almost horizontal position, giving the leg tracheæ a T-shape. However, the relationships between the wing and leg tracheæ have remained typical.

The basal connections of the wing trachea of a Lethocerus nymph, Order Hemiptera.-The trachex leading to the wings are, of themselves, rather typical save for the divergence of the costal trachea (Fig. 24, c) from the

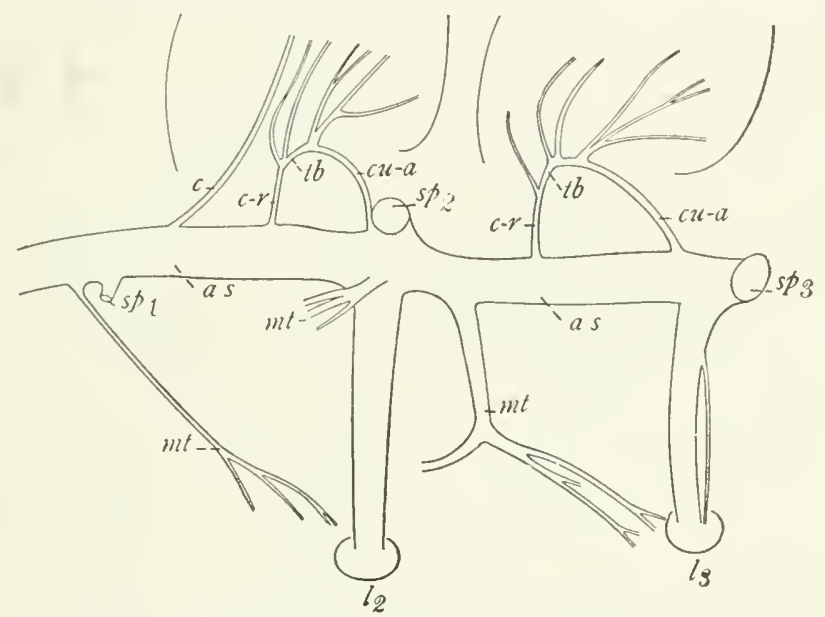

Fig. 24. -The basal connections of the wing tracheæ of Lethocerus. Side view.

costo-radial trachea $(c-r)$ of the front wing. The relationships of the leg and wing tracheæ at first seem quite puzzling but if conditions are compared with those found in notonectids and corisids the explanation seems rather simple. It is quite evident that a "T" shaped trachea similar to that found in the corisid nymph has been modified by the posterior migration of the main trunk to the leg which has resulted in the lengthening of the anterior stem (as) and shortening of the posterior stem ( $p s)$ which results in the practical obliteration of the latter.

The horizontal trunk leading from the mesothoracic spiracle $\left(s p_{1}\right)$ to the metathoracic spiracle $\left(s p_{2}\right)$ is, therefore, the anterior stem of the leg trachea (as) and the posterior stem of the leg trachea has disappeared. The costoradial trachea $(c-r)$ has its typical origin with the anterior stem of the leg trachea (as) altho it diverges from the latter some distance posterior to the typical position, and the costal trachea $(c)$ has an independent origin. The 
condition of the trachere of the metathorax is similar to that of the mesothorax except that the costal trachea $(c)$ has retained its typical position and the cubito-anal trachea $(\mathrm{cu}-\mathrm{a})$ has moved slightly forward and might almost be said to arise from the anterior stem of the leg trachea (as) in the absence of the posterior stem from which it typically arises.

The basal comnections of the wing trachea of Monohammus, Order Coleoptera.-The wing trachex of the Coleoptera have retained their original relationships to the spiracular trunks but there is a modification of the leg tracheæ. Both of the posterior stems of the leg tracheæ (Fig. 25, ps.) are split nearly to their basal connections and they are entirely independent of

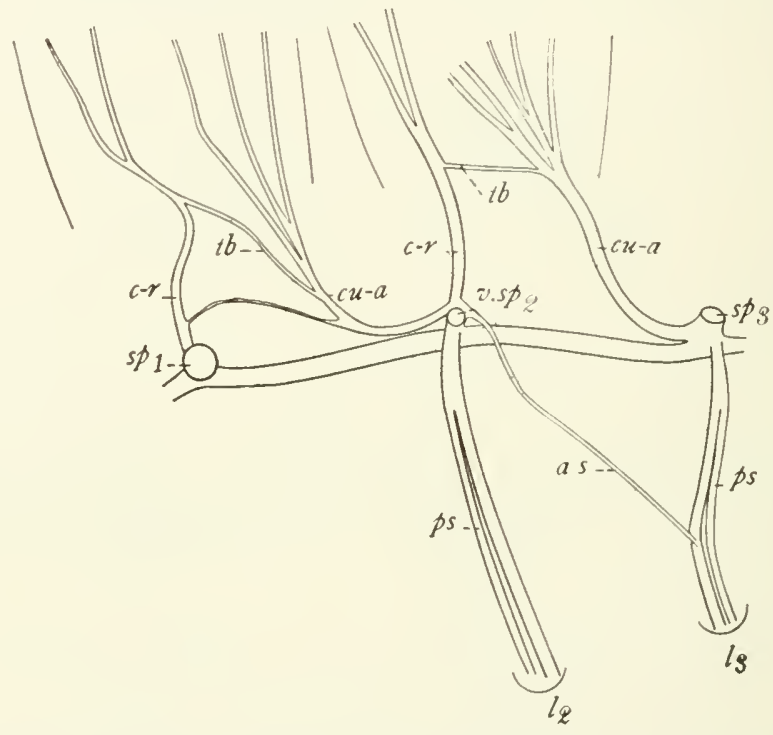

Fig. 25. - The basal connections of the tracheæ of the wings of Monohamus. Side view.

the cubito-anal tracheæ $(c u-a)$. The anterior stem of the leg tracheæ (as.) of the metathorax is very slender but it has retained its original connection with the costo-radial trachea $(c-r)$. In the mesothorax the anterior stem of the leg trachea is entirely absent.

The longitudinal trachea is well developed and the position of the metathoracic spiracle, which is absent, is indicated by the spiracular trunk (v. $s p_{2}$ ). None of these conditions seem to have modified the original relationship of the wing tracher to the spiracular trunks.

The basal comections of the wing trachece of Bittacomorpha, Order Diptera. - The connections in this form are rather generalized and even tho the hind wing is absent the halter receives tracheæ which have all the relationships that the tracheæ to the wing would have (Fig. 26). There is a tendency 
toward the reduction of the cubito-anal tracheæ which are very small and are followed with difficulty in dissection. The tracheæ to the legs are unmodified except for the shortening of the anterior stem (as) to the hind leg.

\section{EXAMPLES OF SPECIALIZATION BY REDUCTION}

The basal connections of the wing trachece of Ryacophila, Order Trichoptera.-The wing tracheæ of Ryacophila are greatly reduced and the basal connections are correspondingly specialized. The thorax is specialized in that there are marked intersegmental depressions on the sides, within which the rudimentary spiracles are found. However, the connections to the legs have retained their primitive condition.

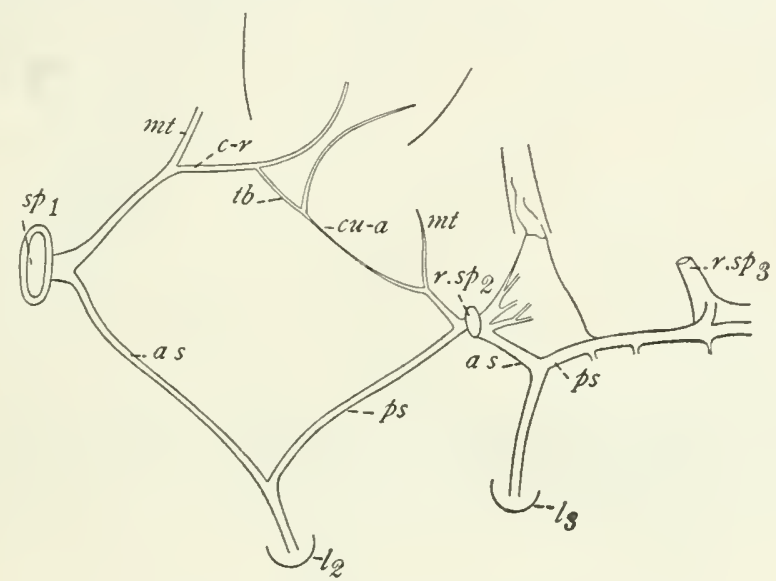

Fig. 26.-The basal connections of the tracheæ of the wings of Bittacomorpha. Side view.

The wing tracheæ of each wing appear to arise as two trunks which connect indirectly with the mesothoracic spiracular trunk (Fig. 27, s $p_{1}$ ) in the case of the front wing, and the metathoracic spiracular trunk $\left(s p_{2}\right)$ in the case of the hind wing. The anterior trunk to each wing arises in common with the anterior stem of the leg trachea and is undoubtedly the costo-radial trachea $(c-r)$.

The cubito-anal trachea of each wing $(c u-a)$ arises in its typical position near the spiracle which normally supplies it with air. But owing to a cephalization of its air supply which results in this trachea receiving the greater part of its air by the way of the transverse basal trachea $(t b)$ its course becomes greatly modified and the proximal portion of it greatly reduced. This results in that part of it beyond the point of union with the transverse basal trachea appearing to be a continuation of that trachea.

There has been developed a small accessory longitudinal trachea $(a-d t)$ which arises with the transverse basal trachea near the spiracular trunk 
and extends parallel to the dorsal longitudinal trachea $(d . l t)$. Its only connection with the wing trachea is at its point of origin.

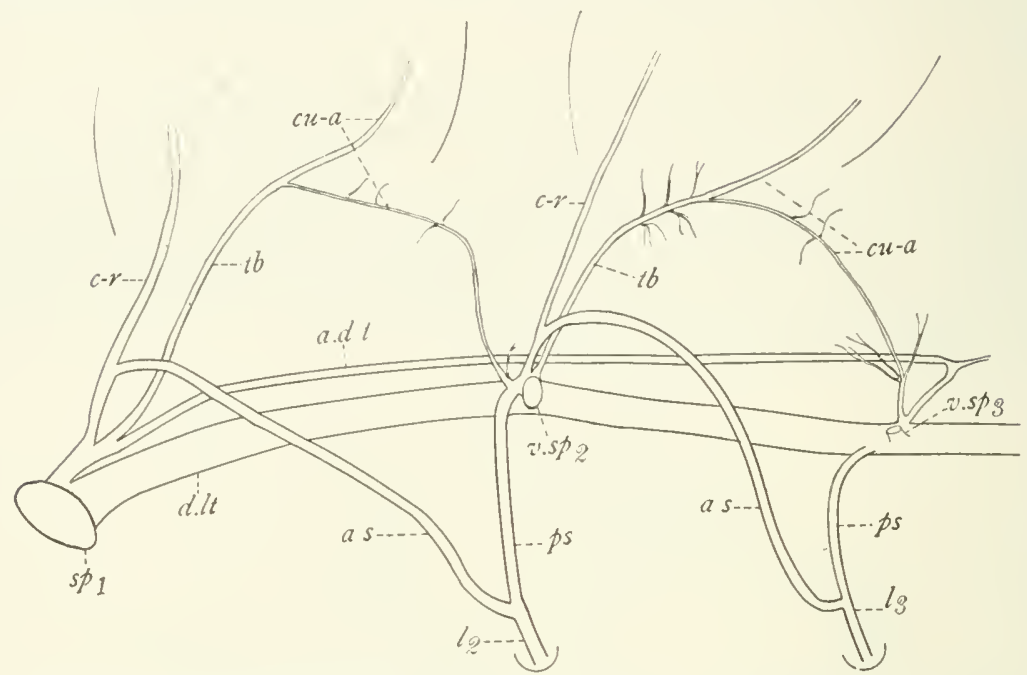

Fig. 27.-The basal connections of the tracher of the wings of Ryacophila. Side view.

The basal comnections of the wing trachece of an unknown gemus (Limnophilida), Order Trichoptera.-This form illustrates an interesting step in the reduction of the tracher to the wings. (Fig. 28 ). In the hind wing both

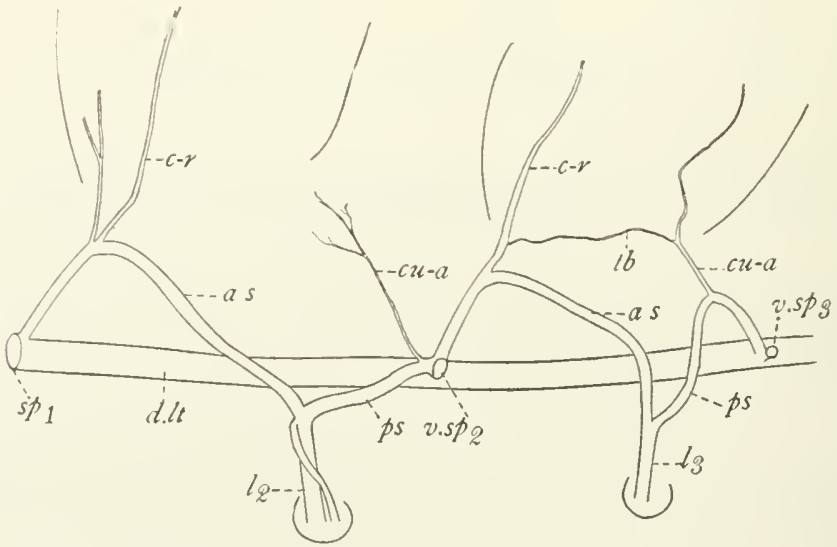

Fig. 28.-The basal connections of the tracher of the wings of unknown genus of Trichoptera. Side view.

the costo-radial $(c-r)$ and cubito-anal tracheæ $(c u-a)$ are present altho the latter is very small as is also the transverse-basal trachea $(t b)$. In the front wing the cubito-anal trachea and the transverse basal trachea are 
absent. However the reduced cubito-anal trachea $(c u-a)$ is present in the thorax with its typical connections except that it fails to reach the wing. The leg tracher have the typical connections.

The basal connections of the wing trachea of Stenophylax, Order Trichoptera.-The cubito-anal tracheæ (Fig. 29) do not reach the wing in either case in this form altho their vestiges are present in the thorax $(c u-a)$ and both have their typical connections with the posterior stems of the leg tracheæ $(p s)$. In both cases the costo-radial tracheæ $(c-r)$ have their typical connections except that the transverse basal tracheæ are entirely absent.

The basal connections of the wing trachece of a nymph of Epeorus. Order Ephemerida.-The wing tracheæ of Mayflies are highly specialized and

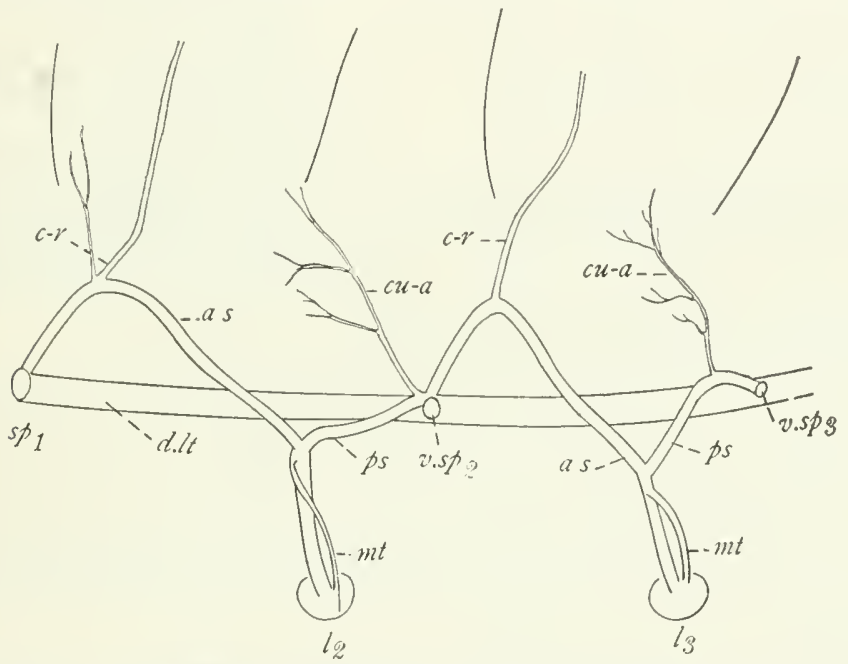

Fig. 29. - The basal connections of the tracheæ of the wings of Stenophylax. Side view.

there is a marked cephalization of the flight function in this order. Morgan in a paper on the wings of May-flies (Morgan, Anna H. Homologies of the wing veins of the May-flies, Annals, Ent. Soc. Amer. rg 2, v. 5, p. 89-105), concluded that the wing trachea of Epeorus represented one of the more generalized conditions. For this reason Epcorus has been used for the study of the basal connections of these trachere.

The anterior trachere to each leg and wing have retained their primitive conditions (Fig. 30); the anterior stem of the leg tracher (as) and the costo-radial trachea $(c-r)$ to the wing have a common origin in each case. However the posterior connections to the wings and legs have been greatly reduced. The portion of the cubito-anal trachea (cuta) proximal to its union with the transverse basal trachea $(t b)$ is absent except for a short vestige in the front wing. This short vestige extends proximally from the 
union of the transverse basal trachea $(t b)$ and the cubito-anal trachea ( $c u-a)$ and connects with a small accessory trachea which leads anteriorly to the costo-radial trachea $(c-r)$. The remainder of the cubito-anal trachea which

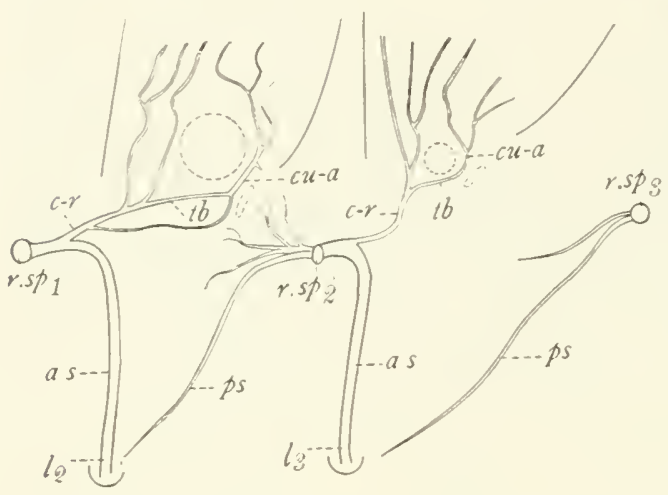

Fig. 30.-The basal connections of the tracheæ of the wings of Epeorus. Side view.

Morgan had suspected to be present, was not found in any of the specimens dissected. Even this small vestige was found to be absent in the hind wing.

The posterior stems of the leg tracher $(p s)$ are represented by slender tracheæ which enter the coxæ in the typical position for the posterior stems of the leg tracheæ but their connections with the anterior stems (as) are very slight and seem to be lacking in some cases. It is very evident that the posterior tracheæ to the legs are at the point of being lost in this form.

There is a saucer shaped disc, which has been indicated by a dotted line in the figure, between the cubito-anal and costo-radial groups of tracheæ in each wing. There is also a rrell developed apodeme, represented by a dotted line, just posterior to the union of the cubito-anal trachea (cu-a) and the transverse basal trachea $(t b)$ in each wing. The influence of these structures upon the tracher of the wings will be taken up in the latter part of this paper.

The basal connections of the wing trachece of Chirotonetes nymph, Order Ephemerida.-The conditions of the basal connections of the wing tracheæ of Chirotonetes are more easily understood after having studied the conditions in Epeorus. In Chirotonetes (Fig. 3I) the anterior tracheal connections to the legs and wings have retained their primitive condition but the posterior connections are entirely absent. Small muscle tracheæ, somewhat resembling the typical posterior connections, were found but their former

connections have been entirely lost and the Fig. 3I. - The basal connections of cephalization of the air supply to the wings is complete.

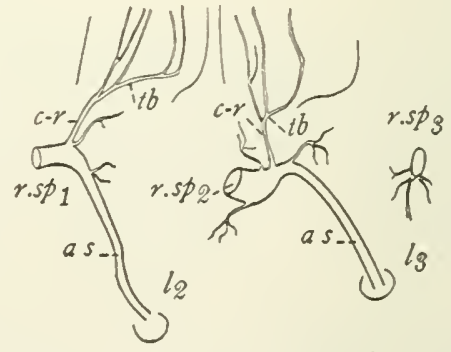
Chirotonetes. Side view.

The basal connections of the wing trachece of Apis mellifica, Order Hymenoptera.-The pupa of a drone honey bee was used for the study of the trachea 
of this form because of its large size. The highly specialized bee has specialized tracheal conditions but a study of the figure will recall the conditions in the more generalized insects. The $\mathrm{Y}$-shape of the leg tracheæ is as striking in the metathorax of the honey-bee as in the diagram of the typical condition (Fig. 32). In the mesothorax the anterior stem to the leg (as) is greatly elongated and extends dorsally to its connection with the costo-radial $(c-r)$ branch to the wing and then passes ventrally into the leg. The posterior stem (ps.) to the mesothoracic leg $\left(l_{.2}\right)$ is united with the anterior stem (as) to the metathoracic leg a short distance from the spiracular trunk. The spiracular trunk leading to the vestige of the meta-

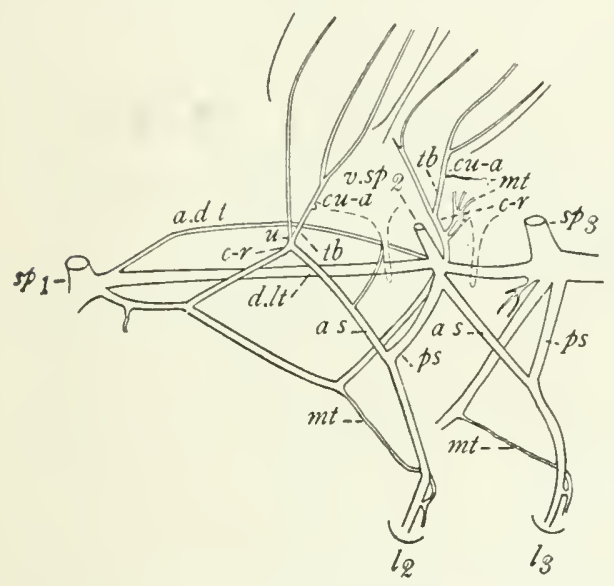

Fig. 32.-The basal connections of the tracheæ of the wings of $A$ pis. Side view. thoracic spiracle $\left(v . s p_{2}\right)$ is very long.

The trachere leading to the muscles of the coxae $(m t)$ are well developed, and as shown in the figure, are united much like the leg tracheæ with which they actually connect. But these muscle trachea lie deep within the thorax and are relatively much smaller than the true leg tracheæ.

The branches to the wings exhibit the greatest specialization. In the case of both wings the air supply comes entirely from the spiracle anterior to the wing, for there is no connection with the spiracle posterior to the wing. A short distance distad from the union of the two branches to the front wing there will be noticed a slight projection from the tracheæ. This projection is in such a position that it is highly suggestive of a vestige of the former cubito-anal trachea which extended from this point to the base of the metathoracic spiracular trunk. In a similar position on the trachea leading to the hind wing there are a few tracheal branches which may have a significance similar to that which has been ascribed to the projection on the trachea leading to the front wing. If these structures represent the vestiges of the cubito-anal tracher leading to the spiracular trunks, the part of the tracher between these structures and the union of the tracheæ $(u)$ must represent the transverse basal trachea and the remainder of the posterior branch must represent the distal part of the cubito-anal trachea $(c u-a)$. 


\section{EXAMPLES OF SPECIALIZATION BY ADDITION}

The basal connections of the wing trachece of a nymph of Melanoplus sp., Order Orthoptera.-The dissection of an acridid nymph is rather difficult because of the many tracheal branches and air sacs in the thoracic region. The minor branches and the air sacs were removed in the course of the dissection and the figure is a camera-lucida drawing of the tracher with which this paper is concerned together with the more important minor branches.

The tracheal connections are modified to a certain extent but the conditions are easily explained (Fig. 33). The point of union of the costo-radial

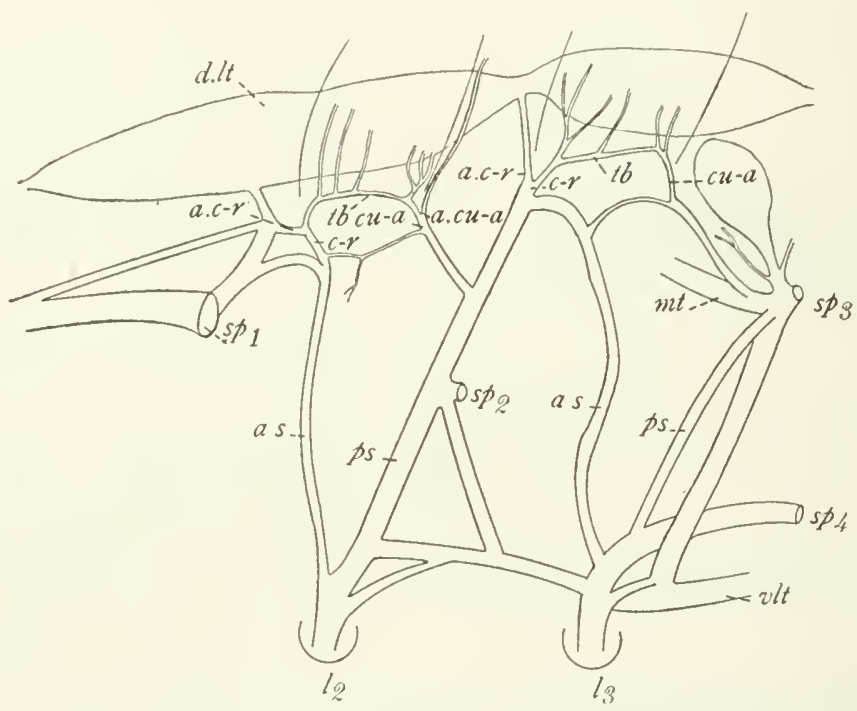

Fig. 33. - The basal connections of the trachea of the wings of Melanoplus. Side view.

trachea $(c-r)$ and the anterior stem of the leg trachea (as) has moved dorsad in both cases. In the mesothorax the anterior stem to the leg arises from the spiracular trunk $\left(s p_{1}\right)$ and goes dorsad to the point where the costoradial trunk $(c-r)$ is given off and then it passes ventrad to meet the posterior stem (ps) thus forming the usual $\mathrm{Y}$-shaped trachea to the leg. It will be noticed that the posterior stem is the larger of the two.

From the costo-radial trachea $(c-r)$ of the front wing there is an accessory trachea $(a, c-r)$ which connects with the saclike dilated dorsal longitudinal trachea $(d . l t)$. The base of the cubito-anal trachea $(c u-a)$ has fused with the anterior stem (as) to the metathoracic leg to form a common trunk extending dorsad for a short distance from the metathoracic spiracle. The cubito-anal trunk (cu-a) to the front wing has an accessory tracheal 
connection (a. c-a) which passes mesad, just dorsad of the dorsal longitudinal trachea $(d . l t)$, to anastomose with its fellow of the opposite side.

The changes in the costo-radial trachea to the hind wing have been similar to those to the front wing. The anterior tracheal stem to the leg (as) forms a common trunk with the cubito-anal trachea of the front wing, as has just been described, and then it continues dorsad, in common with the costo-radial trunk $(c-r)$ of the hind wing, until it becomes independent of the wing trachea and passes ventrad to unite with the posterior stem of the leg trachea ( $p s)$.

The costo-radial trachea of the hind wing also has an accessory connection $(a . c-r)$ with the dilated dorsal longitudinal trachea $(d . l t)$. The cubitoanal connection $(c u-a)$ is unmodified except for a small accessory connection between it and the anterior stem of the leg trachea (as), similar to a connection found in the mesothorax.

The posterior stem $(p s)$ of the trachea to the metathoracic leg $\left(l_{3}\right)$ is small and has new relationships at its point of entrance into the specialized hind leg. The descriptions of the leg trachea in the metathorax, which have given rise to these new relationships involving the second abdominal spiracle, belong more properly to the last part of this paper and their discussion will be postponed for the present.

The basal connections of the wing trachea of Anax and Lestes, Order Odonota.-The tracheation of Plathemis lydia was described and figured by G. G. Scott (Biological Bulletin $\mathrm{I} 905$, ix: 34I-354). The author described the tracher of the wing as arising from a loop, the anterior trachea of the loop arising from the dorsal longitudinal trachea and the posterior trachea, in the case of the mesothorax, arising from the short transverse connective in such a way that the two posterior tracheæ of the fore wings originate side by side. The tracheation of the hind wings is described as similar to that of the fore wings except that the anterior trachea arises from the spiracular trunk near the dorsal longitudinal trachea and the posterior trachea is described as originating directly from the dorsal longitudinal trachea.

R. J. Tillyard (Proceedings of the Linnean Society of New South IV'ales, I9I 4, xxxix, pt. I, p. I63-2 I6, pl. xi-xiii) made a study of Odonata nymphs using transmitted light to distinguish the tracheæ. His description is said to embody the results obtained from the study of both the Anisoptera and the Zygoptera and a diagram of the lateral view of the thorax is given to show the connections of the wing tracher. This author describes one tracheal branch to each leg and one trachea, arising from the dorsal longitudinal trachea, as entering each wing pad from the anal end, forming a loop from which the wing trachex arise, and passing out of the wing pad at the costal end as a fine threadlike trachea which connects with the leg trachea of the same segment. 
Tillyard's description and figure differ from those of Scott in that the former author has the anterior wing tracheæ connecting with the leg tracheæ and the posterior wing tracheæ connecting with the longitudinal

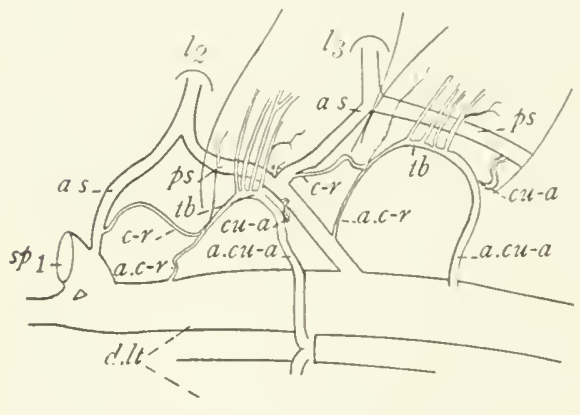

Fig. 34.-The basal connections of the trachex of the wings of Anax. Dorsal view. trachea, while the latter author has the anterior trachea of the fore wing connecting with the dorsal longitudinal trachea and that of the hind wing connecting with the spiracular trunk near the dorsal longitudinal trachea.

The posterior trachea to the wings is said by him to connect with a transverse connective, in the case of the fore wing, and with the dorsal longitudinal trachea in the case of the hind wing.

The figures accompanying this paper are the result of numerous dissections and show the conditions in a representative of each of the two suborders (Figs. 34 and 35 ). There are two trachere entering the front of each wing pad, the usual costo-radial trunk $(c-r)$ connecting with the anterior stem of the leg trachea (as) and accessory costo-radial trunk (a.c-r) connecting with the dorsal longitudinal trachea $(d . l t)$, in the case of the front wing, and with the trunk to the vestigial metathoracic spiracle, in the case of the hind wing. It is probable that Tillyard has seen the costo-radial trachea in studying the lateral view of the thorax while Scott has seen the accessory costoradial trachea in hisstudy of the dorsal view of the thorax, which he figures.

There are likewise two posterior tracheæ to each wing pad. The cubito-anal tracheæ $(c u-a)$ of both wings are vestigial and are made out with some difficulty but they have retained their original connections with the posterior stems of the leg

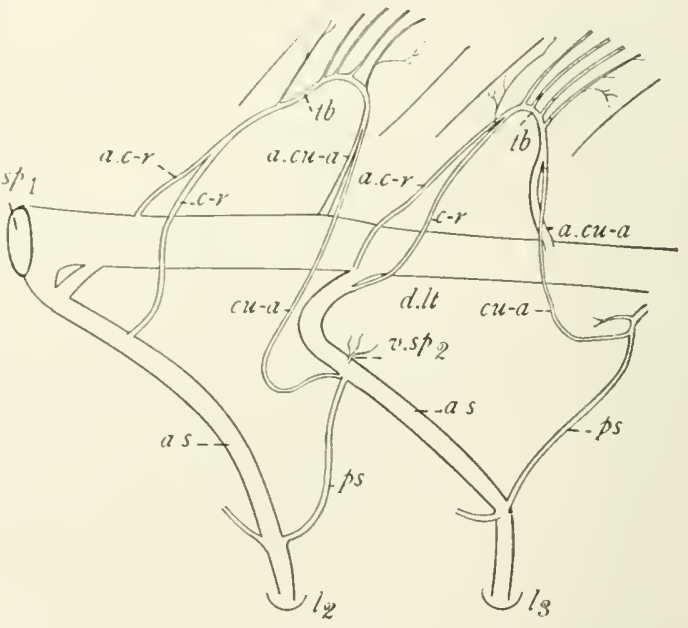

Fig. 35.-The basal connections of the tracheæ of the wings of Lestes. Side view.

tracheæ. The accessory cubito-anal tracheæ $(a . c u-a)$ are much the larger; the one to the fore wing arises from the transverse connective which lies 
between the two dorsal longitudinal tracheæ $(d . l t)$ as described by Scott (l.c.) and the one to the hind wing arises from the dorsal longitudinal trachea. It will be noticed that in the side view of Lestes (Fig. 35) the connection of the accessory cubito-anal trachea $(a$. cu-a) of the mesothorax with the transverse connective cannot be seen for it is hidden by the dorsal longitudinal trachea $(d . l t)$. The vestige of the true cubitoanal trachea $(c u-a)$ has doubtless been overlooked by both of the former authors.

THE INFIUENCE OF THORACIC STRUCTURE ON THE CONNECTIONS OF THE WING TRACHEE

The main tracheæ of insects lie in the spaces of the body allowing for the free passage of air thru their lumina. Their flexibility is a necessity for tracheæ entering the appendages of the body must bend readily when these structures are moved and it is all important that the flexible tracheæ should avoid contact with any structure which might at any time bring pressure to bear upon their walls and interfere with the free passage of air. The course of the tracheæ to the wings might be expected to be direct but at the same time the avoidance of rigid structures, such as those concerned with the movement and articulation of the wings, among which the tracheæ must pass, would seem to be an important factor in determining their course.

The material presented in this paper affords many examples of altered courses of tracheæ which seem to be due to peculiarities of thoracic structure. In the wing of the Mayfly, Epeorus, (Fig. 30) a simple example may be found. There is a saucer-shaped disc, which has already been referred to as lying between the medial, cubital, and transverse basal tracheæ, and which has been indicated in the drawing by a dotted line, around which the tracheæ pass. This disc with its two chitinous walls of such convexity would undoubtedly be a great obstacle to the passage of air if the tracheæ crossed it rather than encircled it as they do, altho the latter course of the tracheæ is the longer.

The case of the stone fly, Pteronarcys (Fig. I9), presents an example of the modification of the medial trachea $(m)$ which is very suggestive. The medial trachea $(m)$ will be noticed to arch caudad toward the cubito-anal group of tracheæ and altho there is no transverse basal trachea the medial trachea might, from its position, be considered to be midway between the costo-radial and cubito-anal groups of tracheæ. The examination of a nymph which is nearly ready to emerge will show a strong process, evidently the wing process, (indicated by a dotted line in the drawing) projecting between the radial $(r)$ and medial $(m)$ tracheæ to articulate with an over-lying articular sclerite, evidently the second axillary sclerite. Here again it seems very clear that the course of a trachea is modified from the most direct route by a mechanical obstruction. Moreover this case is very 
significant for the cause of the migration of the medial trachea along the transverse basal trachea, as stated in the introduction, was one of the problems which prompted this research.

Modifications of the thorax which would result in the posterior migration of the wing process would also result in the posterior migration of the base of the medial trachea. Likewise a cephalization of the wing would bring the cubito-anal group of trachex nearer the medial trachea, if the wing process remained in its original position and did not allow the medial trachea to move cephalad with the rest of the structures of the wing.

The consideration of the relationships of thoracic peculiarities and the modifications of the tracheæ to the wings may profitably be extended to the more general conditions. The insects considered in this paper have been divided into three groups: those with generalized connections of the wing tracheæ, those with reduced connections of the wing tracheæ, and those in which the connections of the wing tracheæ have been specialized by the addition of new connections. In the group where the conditions of the tracheal connections are generalized the thoracic structure is also generalized. The examples of the Blattidæ among the Orthoptera, the Plecoptera, the Neuroptera, the Lepidoptera, and the others are quite generalized, while the Coleoptera and Hemiptera are mentioned both for their somervhat generalized wing connections and for the reduced connections to the legs, which latter condition is accompanied by the oblique position of the lateral sclerites of the thorax.

Among the insects with reduced connections of the wing tracheæ there are many varieties of thoracic structure illustrating several lines of specialization. It is not the purpose of this discussion to enter into the details of so complex a region as the thorax or to attempt to ascribe all the modifications of the connections of the wing tracher to the pcculiarities of thoracic structure alone, but rather to call attention to the fact that reduced wing tracheæ occur in the insects that have a specialized thorax. In the drawings of the Ephemerida (Figs. 30 and $3 \mathrm{I}$ ) and the Hymenoptera (Fig. 32). apodemes are represented by dotted lines just posterior to each wing. These apodemes may be studied in insects which are about to emerge from the pupal state and from their position it seems very probable that they obstruct the course of the cubito-anal tracheæ and eventually lead to their reduction and the consequent cephalization of the air supply to the wings.

The last group of insects, those with additional tracheal connections to the wings, includes the Odonata (Figs. 34 and 35 ) and the jumping Orthoptera (Fig. 33). These two groups of insects are peculiar in that their nymphs have their wing pads flexed dorsally, approximating the mid-dorsal line. Such a position of the wingpads favors the enlargement of any median tracheal connections such as the accessory connections to the wings (a.c-r) and $(a . c u-a)$ because the wingpads are drawn so close to the dorsal longi- 
tudinal tracheæ. On the other hand, the original tracheæ (cu-a and $c-r$ ) must be greatly elongated and no doubt are obstructed by apodemes along their new path, especially in the case of Odonata.

The accessory cubito-anal trachea $(a . c u-a)$ of the Odonata is much larger than the reduced cubito-anal trachea $(c u-a)$ and is also larger than either of the anterior tracheal connections (c-r and $a . c-r$ ), each of which is about half its size. The fact that the two anterior tracher have had their courses altered by the change in form is probably the cause of their reduction.

Some of the most interesting correlations between thoracic structure and tracheal conditions are to be found in the study of the leg tracheæ and the analogy with the conditions of the wings is most instructive in the consideration of their tracheæ. In the Coleoptera (Fig. 25) where the thorax is oblique and the legs have moved caudad, the anterior stem (as) to the mesothoracic leg $\left(l_{2}\right)$ is absent and the anterior stem to the metathoracic leg $\left(l_{3}\right)$ is small while both of the posterior stems are large.

The Hemiptera (Figs. 22, 23, and 24), which have a thorax like that of the Coleoptera, also have modified conditions of the leg tracher which are most marked in the Belostomidæ (Fig. 24) where there is a single stem of the leg trachea, due to the posterior migration of the main leg trachea which results in the obliteration of the posterior stem and the elongation of the anterior stem of the trachea.

The Odonata present a thorax which is oblique in the opposite direction from the examples mentioned above, for the legs have moved cephalad. This skewness of the thorax in the Odonata was studied by Needham and Anthony (Journal of the New York Entomological Society, I903, xi: I I 7 I 25) and the angle formed between the perpendicular and the humeral angle was found to vary from 2 I degrees in some of the Aeschninæ to 7 I degrees in certain Agrioninæ. This furnishes a series of modifications in which the tracheæ may be studied and it has been found by a study of a series of nymphs that the proportionate size of the anterior stem of the leg trachea varies in direct proportion to the size of the angle of the thorax, while the size of the posterior stem of the leg trachea varies in inverse proportion to the size of the thoracic angle. The thoracic angle of Anax junims (Fig. 34) is 27 degrees and the posterior stem of the leg trachea (ps) is slightly larger than the anterior stem (as). Lestes (Fig. 35) has a thoracic angle of 66 degrees and the posterior stem of the leg tracheæ ( $p s)$ is very small while the anterior stem (as) is comparatively large.

In this connection it is interesting to note that Tillyard (1.c. p. 205) entirely overlooked the posterior stem of the leg trachea in his figure of Austrolestes. The Odonata, therefore, with their highly modified thorax and greatly altered trachere to both the wings and legs, present the best example of the correlation between thoracic structure and the tracheal connections. 
The jumping Orthoptera (Fig. 33) have the tracheation of the hind leg greatly modified in that a part of the tracheæ come from the second abdominal spiracle. This is a condition which has been met with nowhere else and is indoubtedly due to the great development of the hind leg and its intrusion into the abdominal region.

THE COMPARATIVE VALUES OF THE AIR SLPPLIES TO THE TWO PRINCIPAL TRACHEE OF THE TINGS

The value of the air supply of the wing tracheæ has been suspected of being the cause of some of the tracheal modifications of the wings. This theory has been mentioned in the introduction of this paper and it has been given some study by Tillyard (1. c. p. 207-218). This author has made a study of the Odonata where the basal connections of the tracheæ are most highly modified. The author has formulated a theory, as the result of his work, which reads as follows:

"The peculiarities shown by the wing-renation of the Odonata, as contrasted with that of other insects, are due primarily to the aquatic habits of the larræ; whereby, thru the development of rectal or caudal breathing, the oxygen-supply of the developing wing is carried from the posterior end of the body, and enters the wing-base at its anal end."

The invasion of the area of the radial sector by the medial trachea is accounted for by the fact that the medial trachea is nearer the air supply than the radial trachea. Sereral other modifications are ascribed to the same cause.

The Odonata would seem a very unfavorable order to use in the study of the comparative values of the air supplies to the wings because the conditions are so highly specialized. A better understanding of the subject may be had by returning to the typical condition of the tracheal connections and following the various lines of development.

Each wing typically receives air from two spiracles and the metathoracic spiracle (Fig. I $7, s p_{2}$ ) supplies the cubito-anal portion of the front wing and the costo-radial portion of the hind wing. It may be assumed that the three typical sources of air supply are equal. The Lepidoptera (Fig. 2 I) have the tracheal connections to the wings very generalized but the metathoracic spiracle $(r . s p)$ is rudimentary in the pupa. This would seem to make the air supply to the cubito-anal portion of the front wing and the costo-radial portion of the hind wing inferior to the others and the tracheation of the two wings should be quite different. On the other hand the tracheæ seem to have been unmodified and to have retained their typical relationships.

It is difficult to apply the air-supply theory to the case of the honey-bee for the hind wing has lost its cubito-anal connection which was with the functional first abdominal spiracle (Fig. $32 s p_{3}$ ) and has retained its costo- 
radial connection $(c-r)$ with the trunk of the vestigial metathoracic spiracle (v. $\left.s p_{2}\right)$. The posterior wing has, therefore, forsaken the best source of air supply and retained a connection with a trunk which no longer has an opening to the exterior.

In all the cases where the wing tracheation has been reduced it is the cubito-anal trachea which has been lost. If the air supply is the factor causing the one connection to be lost and the other connection to be retained it is not easy to understand how it operates in the case of the metathoracic spiracle, for here the cubito-anal trachea to the front wing is lost and the costo-radial trachea to the hind wing is retained.

To return to the case of the Odonata where the air-supply theory seems to find its best support, the posterior connection to the front wing should be considered. If the accessory cubito-anal trachea (Fig. 34, a. cu-a), which is enlarged, connected with the dorsal longitudinal connective $(d . l t)$ as Tillyard $(l . c$. ) thought, it would be favorable to the air-supply theory, but it connects with a small transverse connective between the two dorsal longitudinal tracheæ. This makes an indirect course for the air to follow in going to the wing and the condition would seem to be more easily explained as having arisen as an enlargement of a simple anastomosis of the accessory cubito-anal tracheæ of both sides, a condition found in Melanoplus (Fig. 33). The union of these tracheæ might easily have anastomosed with a transverse connective to form a course which later became enlarged because it was the least obstructed route for the air to follow to the wings.

It should be remembered that there are two anterior tracheæ leading to the wing pad ( $c-r$ and $a . c-r$ ), each of which is about half the size of the posterior trachea ( $a . c u-a)$ and the two together must supply about as much air to the wing as this posterior trachea does.

The condition of the leg tracheæ in the Odonata is very instructive in the study of the values of the air supplies in the thorax. The legs, like the wings, each have two tracheal connections which typically derive their air supply from the same sources as do the tracher to the wings. But in the Odonata the posterior stem of the leg tracheæ, which should offer the more direct course for the air to follow in passing to the legs from the gills at the posterior end of the body, is greatly reduced, when the thoracic angle is great, while the anterior stem with its less direct course is enlarged. This would indicate that the directness of the air supply has little to do with the modification of the leg tracheæ in the Odonata.

The belief that the migration of the medial trachea along the transverse basal trachea toward the cubito-anal group of tracheæ might be due to the better air supply to that group was referred to in the introduction of this paper. In view of the fact that the basal connection of the posterior group of tracher is the one to be lost in all cases where there is a reduction of the tracheal connections, it seems more reasonable to ascribe this migration of 
the medial trachea to peculiarities of thoracic structure, as has been done above.

The invasion of the area of the radial sector by the medial trachea in the Odonata was also referred to in the introduction as a condition which might be due to the better air supply of the cubito-anal trachea. In the Odonata the distance between the bases of the radial and medial tracheæ is so short that it would hardly seem that the medial trachea should be so modified as to invade the area of the radial trachea in order to save the air from passing so short a distance along the transierse basal trachea. The May-flies illustrate the same condition of the medial trachea invading the area of the radial sector, but here the connection of the cubito-anal trachea has been lost and the air supply of the wing has been completely cephalized so that the medial trachea is less favorably situated, with regard to the directness of the air supply, than is the radial trachea, the area of which it has invaded.

From all these considerations it would seem that the directness of the air supply is not an important factor in controlling the relationships of the tracheæ. However, the function of the tracheæ is to supply air and, even tho the surrounding structures may obstruct their way and cause them to become modified and adopt new and longer courses, they must still furnish an adequate supply of air to the tissues. The accessory cubito-anal tracheæ to the hind wings of the Odonata is a case where the least obstructed course for the tracheæ to follow is also the shortest course, but the majority of cases, such as the modified base of the medial trachea of the stonefly and the single trachea to the wing of the honey-bee connecting with the trunk of a vestigial spiracle, have seemed to have no regard for the distance which the air must pass in reaching the tissues, but they have all adopted the least obstructed course for the air to follow. The length of the tracheæ, therefore, does not seem to be the factor causing the modifications of structure, but rather a course for the trachex which is free from obstruction and which will allow for the passage of the air. Whether the air reaching the radial trachea comes from the costo-radial or cubito-anal trachea makes no difference to the tissues so long as the course of the radial trachea is unobstructed. The medial trachea, on the other hand, would not be expected to invade the area of the radial trachea simply because its base might be a millimeter or two nearer to the source of air supply any more than the radius should invade the area of the media in forms like the Mayflies where the cubito-anal trachea has been lost.

\section{CONCLUSIONS}

The material upon which this discussion is based does not constitute an exhaustive study of this subject, for each order of insects presents an opportunity for more detailed research. However, there are certain points with 
regard to the general subject of the basal connections of the wing tracheæ which are clearly brought out by the study of the material presented.

It has been shown that the basal connections of the tracheæ of the wings of insects may be referred to a typical condition which is found in the more generalized forms and which may be traced thru various modifications to the more specialized groups.

Very generalized conditions of the connections have been found in the Blattidæ, among the Orthoptera, the Plecoptera, Neuroptera, and the Lepidoptera. The Hemiptera, Coleoptera, and Diptera show the beginnings of specialization but have been grouped with those having generalized conditions.

The typical conditions of the connections of the wing tracheæ have been specialized by reduction in the Trichoptera, Ephemerida, and the Hymenoptera and this modification accompanies the specialized condition of the thorax.

In other groups, the jumping Orthoptera and the Odonata, the tracheal connections of the wings have been modified by the addition of accessory tracher and this condition is correlated with the position of the wing pads which are dorsally flexed in the nymphs of these two groups.

Peculiarities of thoracic structure seem to be the most important factor in governing the course and relationships of the tracheæ. Processes and apodomes have been found to lie in the typical paths of the tracheæ so obstructing them that the tracheæ could not do otherwise than go around them even tho their course was lengthened by so doing.

The directness of the air supply does not seem to be an important factor in controlling the course and relationships of the tracheæ. Both the migration of the medial trachea toward the cubito-anal group, along the transverse basal trachea, and the invasion of the area of the radial sector by the medial trachea in the wing have been found to take place without regard to the directness of the source of the air supply. 


\section{CHAPTER III}

\section{THE MORE GENERAL FEATURES OF THE WINGS OF INSECTS}

THE series of investigations briefly reviewed in the preceding chapters has led to the adoption of a uniform terminology of the wing-veins of insects. The application of this terminology to the wings of representatives of the several orders of insects is discussed in later chapters; but, in order to avoid repetition, the more general features of the wings of insects are discussed here, and the terms applied to the different types of wings and to the parts of wings are defined.

The presence or absence of wings in insects.-Excepting in that division of the Hexapoda, or insects, that is known as the Apterygogenea, and which includes the Collembola, the Campodeoidea, and the Thysanura, wings are usually present in adult insects. Regarding the absence of wings in the Apterygogenea two very different theories are held. The first was proposed by Friedrich Brauer, in his Systematisch-Zoologische Studien (I885). According to this theory, the Collembola, Campodeoidea, and Thysanura represent a branch of the insect series that separated from the main stem before wings were evolved, and which consequently is phylogenetically distinct from the series of orders of insects that decended froms the primitive winged insects, and in which the absence of wings, when such is the case, is due to their having been lost.

Brauer, therefore, separated the Hexapoda into two primary divisions: the Apterygogenea, or originally wingless insects; and Pterygogenea, or originally winged insects. The former division includes only the Collembola, Campodeoidea, and the Thysanura; the latter includes all other insects.

The second theory is that maintained by Handlirsch in his Die Fossilen Insekten (I906-I908). According to this theory all living insects have descended from the winged Palæodictyoptera of Paleozoic times; and the absence of wings in the so-called Apterygogenea is due to specialization by reduction. It does not fall within the scope of this essay to discuss these rival theories.

Even in the Pterygogenea many wingless forms are found; there being wingless representatives of nearly all of the orders of winged insects. But here the wingless condition is unquestionably an acquired one.

The loss of wings by members of the Pterygogenea is often confined to a single sex of a species; thus with the canker-worm moths, for example, the females are wingless, while the males have well-developed wings; on the other hand, with the fig-insect, Blastophaga, the female is winged and the male wingless. 
When the wings are all present, there are two pairs: one pair borne by the mesothorax; and one pair, by the metathorax; prothoracic wings are unknown among living insects.

In certain cases one pair of wings may be either wanting or so modified in form as to be not fitted for organs of flight. Thus the flies, or Diptera, have only the first pair of wings fitted for flight, the second pair being represented by a pair of knobbed threads, the halteres, which are probably organs of some special sense; and with the earwigs and the beetles, the first pair of wings are greatly thickened and serve as wing-covers or elytra, which protect the hind wings when they are not in use. In these cases the hind wings are the chief, if not the only organs of flight.

The fundamental structure of the wings of insects.- Studies of the development of wings have shown that each wing is a saclike fold of the body-wall; but in the fully developed wing, its saclike nature is not obvious; the upper and lower walls become closely applied throughout the greater part of their extent; and, since they become very thin, they present the appearance of a single delicate membrane. Along certain lines, however, the walls remain separate, and are thickened, forming the firmer framework of the wing. These thickened and hollow lines are termed the veins of the wing; and their arrangement is described as the venation of the wing. Many of the older writers termed the wing-veins nervures and their arrangement the neuration of the wing.

The thin spaces of the wings which are bounded by veins are called cells. When a cell is completely surrounded by veins it is said to be closed; but when it extends to the margin of the wing it is said to be open.

The different types of insect wings.--What may be regarded as the typical form of insect wing is a nearly flat, delicate, membranous appendage of the body, which is stiffened by the so-called wing-veins. But striking modifications of this form exist; and to certain of them distinctive names have been applied.

The fan-like wings.-While the typical form of insect wing presents a nearly flat surface, in many insects the wings are more or less corrugated, and in some the corrugating of the wings has proceded so far that a fan-like form of wing has resulted.

Among the more perfectly fan-like wings two quite distinct types can be recognized; these may be designated as the fixed fan-like type and the folding fan-like type respectively. The most perfect examples of the former are the wings of the Ephemerida; of the latter, the anal area of the hind wings of the Acrididæ.

In the fixed fan-like type the corrugating of the wing serves to strengthen it, and thus fit it to withstand better the strain brought upon it by beating the air in flight. This can be easily illustrated by first attempting to use a flat sheet of paper as a fan and then after folding the paper in plaits using 
it for that purpose. In the fixed fan-like type of wing the so-called concave and convex veins are quite evenly developed.

The folding fan-like type of wing is better fitted to function as a parachute when outspread than as an organ for beating the air; in this type the convex veins are much more prominent than the concare reins.

The elytra.- In the Coleoptera and in the Dermaptera the front wings are thickened and serve chiefly to protect the dorsal wall of the body and the membranous hind wings, which are folded beneath them when not in use. Front wings of this type are termed wing-covers or elytra.

The hemelytra.-The front wings of the Heteroptera, which are thickened at the base like elytra, are often designated the hemelytra.

The tegmina.-The thickened fore wings of Orthoptera are termed the tegmina by many writers.

The halteres.-The hind wings of the Diptera, which are knobbed threadlike organs, are termed the halteres. The hind wings of the males of the family Coccidæ are also thread-like.

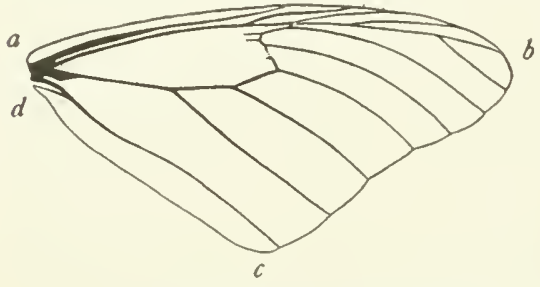

Fig. 36.-Diagram of a wing showing margins and angles.

The psendo-lialteres.-The reduced front wings of the Strepsiptera are known as the psendo-halteres.

The margins of wings.-An insect's wing is more or less triangular in outline; it, therefore, presents three margins: the costal margin or costa (Fig. $36, a-b)$; the onter margin (Fig. $36, b-c$ ), and the imer margin (Fig. 36, c-d).

The angles of wings.-The angle at the base of the costal margin of a wing is the hmmeral angle (Fig. 36,a); that between the costal margin and the outer margin is the apex of the wing (Fig. $36, b$ ); and that between the outer margin and the inner margin is the anal angle (Fig. 36,c).

The tegula.- In several orders of insects there is at the base of the costal vein a small, hairy, slightly chitinized pad; this is the tegula (Fig. $38, T g$ ). In the more specialized orders, the Lepidoptera, the Hymenoptera, and the Diptera, the tegula is largely dereloped so as to form a scale-like plate overlapping the base of the wing.

The tegulæ of the front wings of Lepidoptera are specially large and are carried by special tegular plates of the notum. These in turn, are supported by special internal tegular arms from the bases of the pleural wing processes (Snodgrass, 'og).

The axillary cord.-The posterior margin of the membrane at the base of the wing is sually thickened and corrugated; this cord-like structure is termed the axillary cord. The axillary cord normally arises, on each side, 
from the posterior lateral angle of the notum, and thus serves as a mark for determining the posterior limits of the notum.

The axillary membrane.-The membrane of the wing base is termed by Snodgrass the axillary membrane; it extends from the tegula at the base of the costal margin of the wing to the axillary cord at the base of the anal area of the wing; in it are found the axillary sclerites; it is most prominent at the base of the anal area of the wing, where it is margined by the axillary cord.

The alula.-In certain families of the Diptera and of the Coleoptera the axillary membrane is expanded so as to form a lobe or lobes which fold beneath the base of the wing when the wings are closed; this part of the wing is the alula or alulet. The alulæ are termed the squance by some writers, and the calypteres by others.

The articulation of the wings. - The wings are articulated to the lateral margins of the notum of the two wing bearing segments. In the membrane at the base of each wing, the axillary membrane, there are several axillary sclerites, which are relatively constant in position but which vary in form in different insects.

These axillary sclerites have been much studied for nearly one hundred years. They were described in the early part of the last century by Jurine (1820), Chabrier (I 820), Fig. 37-- Lateral view of a wingand Straus-Dürckheim (I828); the more important of the later papers on this subject

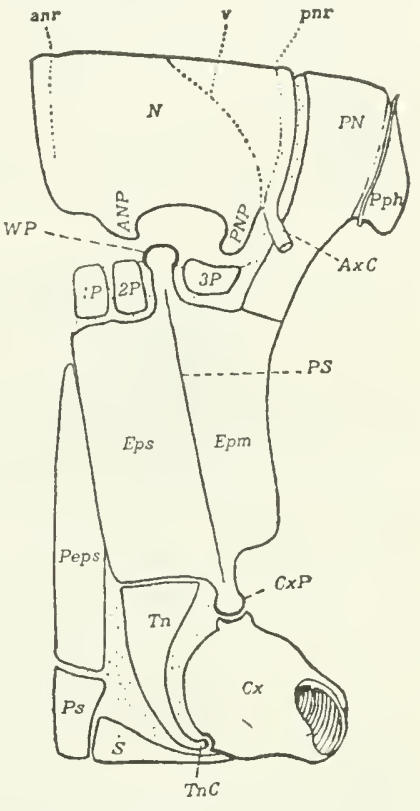
bearing segment (From Snodgrass). are those of Amans (I885), Lowne (1892), Voss (1905), Berlese (I909), and Snodgrass (igo9, ig Io a, I9 10 b.).

The accounts by Snodgrass are the most complete and logical, and as his terminology of the parts of the thorax to which the wings are attached and of the axillary sclerites is the simplest I have adopted it here. The following statement is compiled from these accounts.

The thoracic supports of the wings.--Figure 37 is a diagram, given by Snodgrass, of a lateral view of a generalized, wing bearing segment, left side. The chief supports of the wing are two processes of the notum and one of the pleurum; these are the anterior notal wing process (ANP), the posterior notal wing process (PNP), and the wing process of the pleurum (WP). Behind the posterior notal wing process is the attachment of the axillary cord $(\mathrm{AxC})$. 
The above generalization is true of all of the orders of winged insects except the Ephemerida and the Odonata. In these two orders the flexible bases of wing-veins merge into the lateral margins of the notum, and only one distinct axillary sclerite is present at the base of each wing.

The axillary sclerites.-There are typically four axillary sclerites; but occasionally some of these are subdivided and sometimes there occur small extra chitinizations in the axillary membrane.

The four principal axillary sclerites are designated as the first, second, third, and fourth axillary, respectively. Their relative positions are indicated in Figure 38 . "Two of these, the first $(I A x)$ and the fourth $(4 A x)$, form a hinge with the anterior and the posterior notal wing processes, respectively, while the second $(2 A x)$ articulates below with the wing process of the pleurum, constituting thus a sort of pivotal element. The third

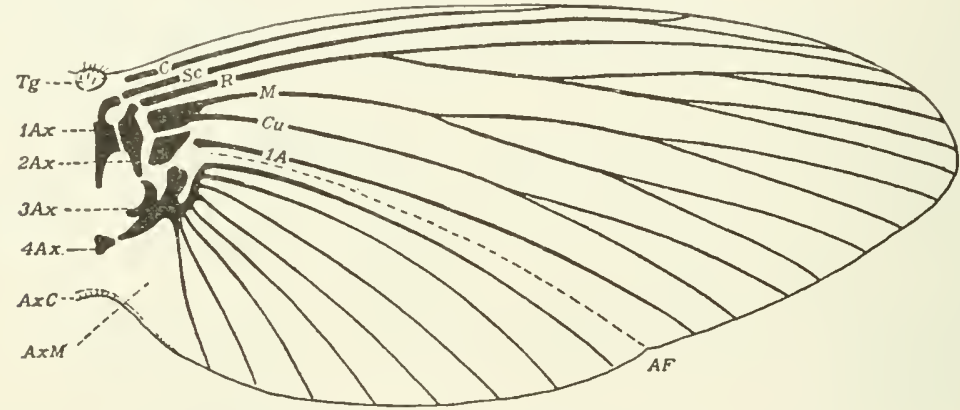

Fig. 38.-Diagram of a wing showing the axillary sclerites

(From Snodgrass).

axillary $(3 A x)$ intermediates between the bases of the anal veins and the fourth axillary-except when the latter is absent ( as it is in nearly all insects except Orthoptera and Hymenoptera), in which case it articulates directly with the posterior notal process.

"The base of the costa is not directly associated with any of the axillaries, but is specially connected by tough membrane below with the episternal paraptera. The subcosta abuts against the end of the curved neck of the first axillary. The radius is either attached to or touches upon the anterior end of the second. The media and the cubitus are usually associated with each other at their bases and also more or less closely with one or two median plates $(m)$ in the wing base. These plates, however, are not of constant shape and occurrence as are the articulating axillaries. The anals are generally attached to the outer end of the third axillary, which acts as a lever in the folding of the wing.

"A few insects have a generalized wing almost identical with the diagram (Fig. 38 ), but most of them depart from it in varying degrees." (Snodgrass, 'Io). 
The costal sclerite.-The costa does not connect with any of the axillary sclerites named above; but there is very generally at its base a more or less distinct sclerite, which may be termed the costal sclerite. This is regarded by Snodgrass as merely the base of the costa; but as it is frequently a distinct sclerite of considerable width it merits a special name.

In the hind wings of many of the Lepidoptera, the costal sclerite forms a strong support for the frenulum. This sclerite is represented, but not lettered, in the figure of the wings of Prionoxystus (Fig. 62); it is also very prominent in the hind wing of Cacocia (Fig. 353).

Figures of the bases of many insect wings showing the form and position of the axillaries are given by Snodgrass.

The tuberosities of the base of the wing.-At the base of each wing in most insects, there are two prominent, elevated, shoulder-like areas; these were designated by Amans ('85) as the antcrior tuberosity and the posterior tuberosity respectively. These tuberosities are better defined in the fore wings than they are in the hind wings.

The anterior tuberosity is at the base of the radius and the adjacent veins, and the posterior tuberosity is at the base of the anal veins. The posterior tuberosity is sometimes divided into two or three tuberosities, corresponding to the separate anal veins.

The cubito-anal sulcus.- The deep channel between the anterior and the posterior tuberosities may be termed the cubito-anal sulcus.

In most insects the cubito-anal sulcus is traversed by the basal part of a wing-vein. This vein is either the cubitus, the first anal vein, or the coalesced bases of these two veins, differing in different insects. In a few insects, as in Corydalus, there is no vein at the bottom of the sulcus, the cubitus extending along one side of it and the first anal vein along the other.

As a rule, a vein traversing this sulcus is more or less atrophied at its base.

The corrugations of the wings.- The wings of comparatively few insects present a flat surface; in most cases we find that the membrane of the wing is thrown into a series of folds or corrugations. This corrugating of the wing in some cases adds greatly to its strength; this is well-shown by the wings of dragonflies; and in most orders the costal margin of the wing is strengthened by a plication between the costa and the radius, this is the subcostal fold. In other cases, the corrugations are the result of a folding of the wing when not in use; this is well-shown in the anal area when this part is broadly expanded.

The cubito-anal fold.-There is one fold that is almost universally present in the wings of insects. This fold is a continuation of the cubito-anal sulcus, which usually extends to the margin of the wing; it may be termed the cubito-anal fold. It is in this fold that the anal furrow is developed when present. 
The anal area and the preanal area.--In descriptions of wings it is frequently necessary to refer to that part of the wing that is supported by the anal veins; this is designated as the anal area of the wing; and that part

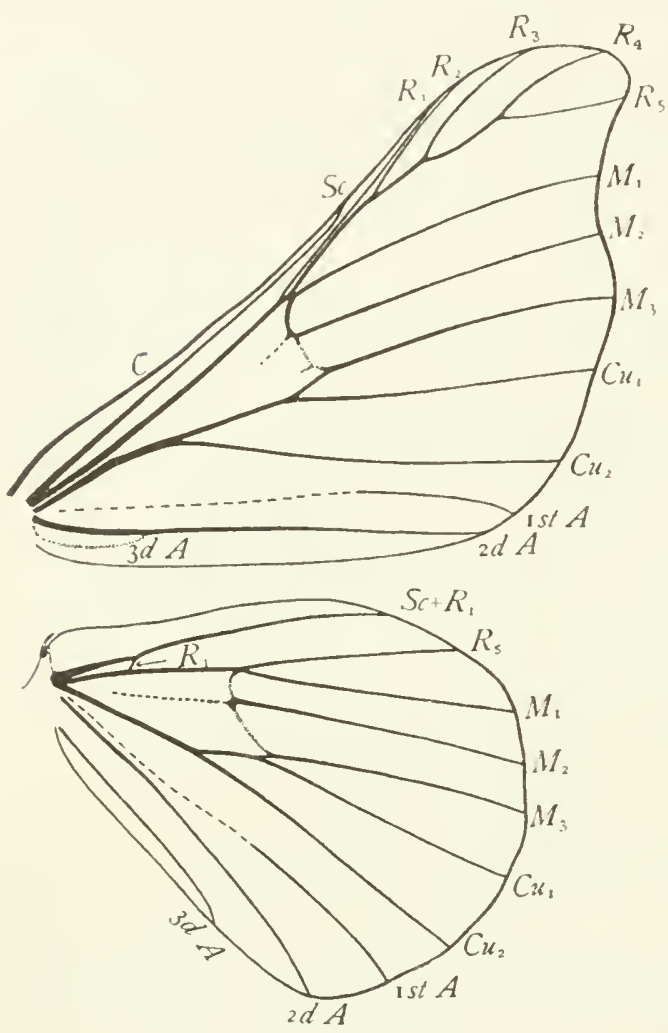

Fig. 39. - Wings of Bombyx mori. of the wing lying in front of the anal area, including all of the wing except the anal area, is termed the preanal area.

The furrows of the wing. -There are found in the wings of many insects one or more suture-like grooves in the membrane of the wing; these are termed the furrows of the wing. The following furrows have received distinctive names. They occur chiefly in the fore wings.

The anal furrow.-The anal furrow is the one of the furrows of the wing that is most often present. It is dereloped in the cubito-anal fold; but in many insects where there is a well-developed cubito-anal fold there is no definite, suture-like anal furrow.

The anal furrow is usually either between the cubitus and the first anal rein or it is coincident with the first anal vein which it may supplant in forms in which the renation of the anal area is reduced. This is the case in the Lepidoptera and the Diptera and is well-shown in the wings of Bombyx mori (Fig. 39), in which a vestige of the first anal vein is preserved near the margin of the wing.

In the Hymenoptera, where the anal furrow is developed between the cubitus and the first anal vein, it cuts through those veins, the tips of which, coalescing with the anal reins, crosses its course (Fig. 40).

In those Heteroptera in which we have been able to determine the veins in the fore wings, the anal furrow has been dereloped in front of the cubitus (Fig. 4I, af).

A study of the musical organs of adult Orthoptera throws light on the nature of the anal furrow. In the female this furrow lies in its usual posi- 
tion between the cubitus and the first anal vein; but in the males of the Locustidæ and the Gryllidæ the anal furrow crosses vein Cu2. It is evident,

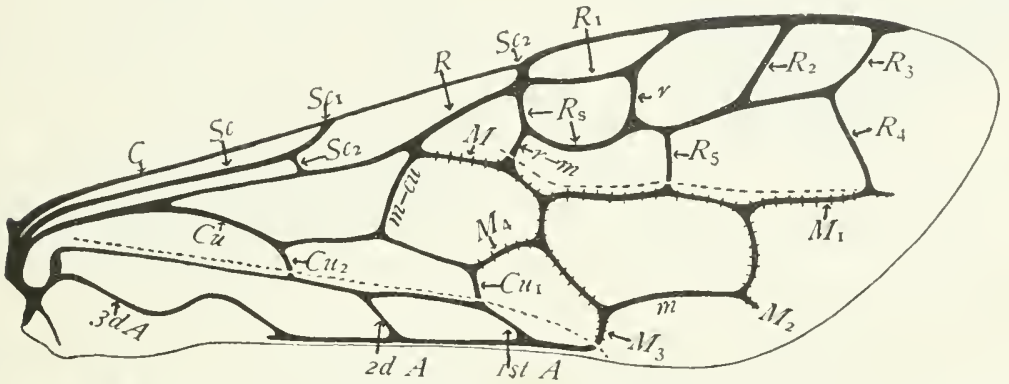

Fig. 40.- Typical hymenopterous wing. The median furrow and the anal furrow are indicated by dotted lines.

therefore, that this furrow is merely a fold in the adult wing, and that its position is variable.

The median furrow.-This is a longitudinal furrow which is usually between radius and media (Fig. $4 \mathrm{I}, \mathrm{mf}$ ). . It is well-marked in many of the Heteroptera, where it separates the embolium from the remainder of the corium (Fig. 42); and in the Hymenoptera its course is marked by a series of weak spots, the bullæ, in certain veins (Fig. 40).

The nodal furrow.-The nodal furrow is a transverse suture beginning at a point in the costal margin of the wing corresponding to the nodus of the Odonata and extending towards the inner margin of the wing. It crosses a varying number of veins in different orders of insects. It is well-shown in

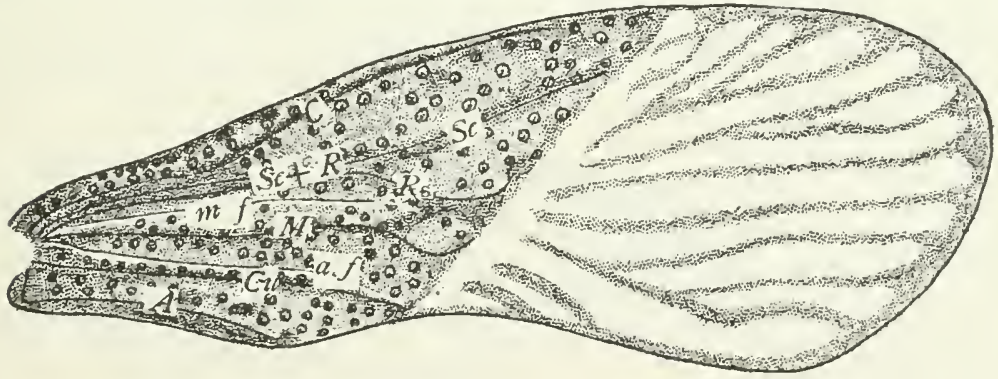

Fig. +1.-Fore wing of a bug, IIormostes reflexulus; $m f$, median furrow; uf, anal furrow (After C. \& N.).

the fore wing of the flower-bug (Fig. 42); and in the fore wing of a Cicada (Fig. 43, n f). The nodal furrow is termed the costal hinge by some writers.

The axillary furrow. - The axillary furrow is a suture-like line extending from the base of the wing to the inner margin; it ends at the axillary excision 
when this is present. This line serres as a hinge which facilitates the folding of the posterior lobe of the ring under that part of the wing in front of it.

The axillary excision.--In the

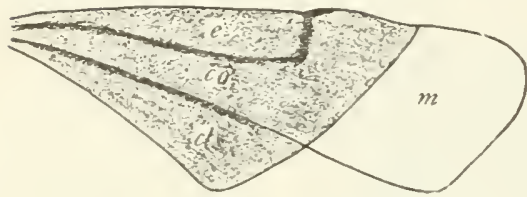

Fig. 42.-Fore wing of a filower-bug (Acanthiidæ); $e$ embolium. wings of most Diptera there is a notch in the inner margin of the wing near its base (Fig. 44, ae); this has long been known as the axillary. excision; the application of this term may be extended advantageously to the notch in a similar position that exists in the wings of many other insects.

The posterior lobe.- That part of the wing lying between the axillary excision and the axillary membrane at the base of the wing in the wings of Diptera (Fig. $4, l, l$ ) has been termed the posterior lobe. The development of a posterior lobe, however, is not limited to the Diptera, a distinct posterior lobe being found in the representatives of several of the orders.

In some cases, as in those Diptera where an alula is dereloped, the posterior lobe and the axillary membrane are distinctly differentiated; but in other cases they are not, as in the wings of Corydalus.

The posterior lobe of the fore wings of certain insects has been specialized so as to serve as an organ for uniting the fore and hind wings. Two types of such an organ are defined later.

The posterior lobe of the wing and the clarus of the Heteroptera are not homologous, the clavus including a much larger part of the wing than does the posterior lobe.

The methods of uniting the two wings of each side.-It is obvious that a provision for ensuring the synchronous action of the fore and hind wings adds to their efficiency; it is as important that the two pairs of wings should act as a unit as it is that the members of a boat's crew should pull together.

In many insects the synchronous action of the wings is ensured br the fore wing of each side overlapping the hind wing. But in other insects special structures have been developed which fasten

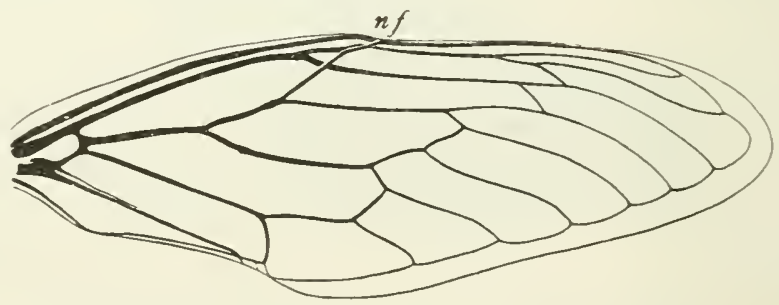

Fig. 43.-Fore wing of a Cicada; $n f$, nodal furrow. together the two wings of each side. The difierent types of these structures have received special names.

The hamuli.-With certain insects the costal margin of the hind wings bears a row of hooks, which fasten into a corresponding fold on the inner 
margin of the front wings (Fig. 45). These hooks are named the hamuli, and serve to hold the two wings of the same side toegther, thus insuring their action as a unit.

The fremulum and the fremulum hook.-In most moths there is a strong spine-like organ or a bunch of bristles borne by the hind wing at the humeral

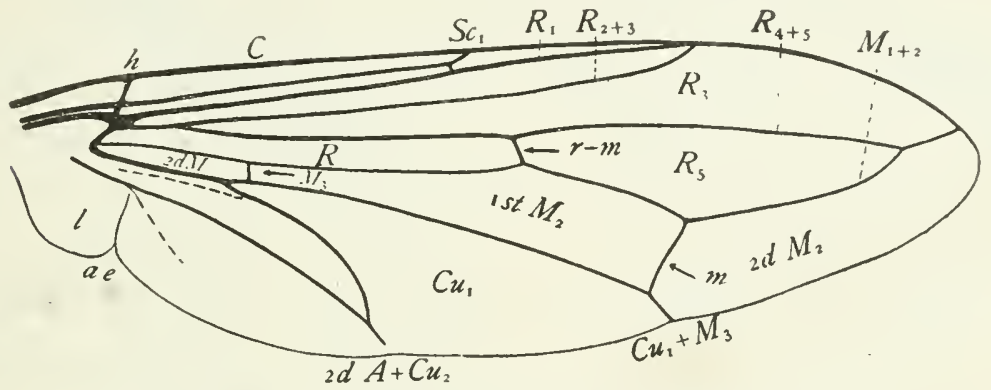

Fig. 44.-Wing of Conops; a e, axillary excision; $l$, posterior lobe of the wing.

angle (Fig. 46, $f$ ); this is the frenulum or little bridle. As a rule the frenulum of the female consists of several bristles; that of the male, of a single, strong, spine-like organ. In the males of certain moths, where the frenulum is highly developed, there is a membranous fold on the fore wing for receiving the end of the frenulum, and thus more securely fastening the two wings together: this is the fremulum hook (Fig. $46, f h$ ).

The jugzmm.-In one family of moths, the Hepialidæ, the posterior lobe of the fore wing is a slender, finger-like organ, which is stiffened by a branch of the third anal vein, and which projects beneath the costal margin of the hind wing. As the greater part of the inner margin of the fore wing overlaps the hind wing, the hind wing is held between the two. This type of posterior lobe of the fore wing is termed the jugum or yoke. Figure 47 represents the wings of a hepialid seen from below and shows the manner in which the two wings of one side are yoked together.

The jugum is behind one of the two principal branches of the third anal vein, which may be designated as vein ${ }_{3} \mathrm{dA}_{1}$, and is supported by the other of these two branches, which may be designated as vein $3 \mathrm{dA}_{2}$ (Fig. 48).

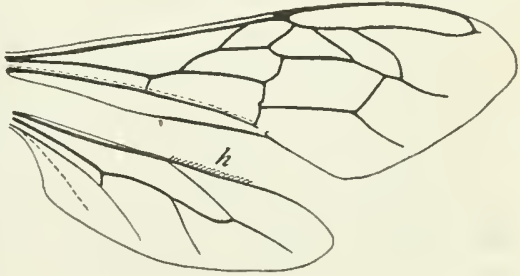

Fig. 45--Wings of a honey-bee; $h$, hamuli.

The fibula.-In several groups of insects an organ has been developed that serves to unite the fore and hind wings, but which functions in a way quite different from that of the jugum. Like the jugum it is found at the 
base of the fore wing; but unlike the jugum it extends back above the base of the hind wing and is clasped over an elevated part of the hind wing.
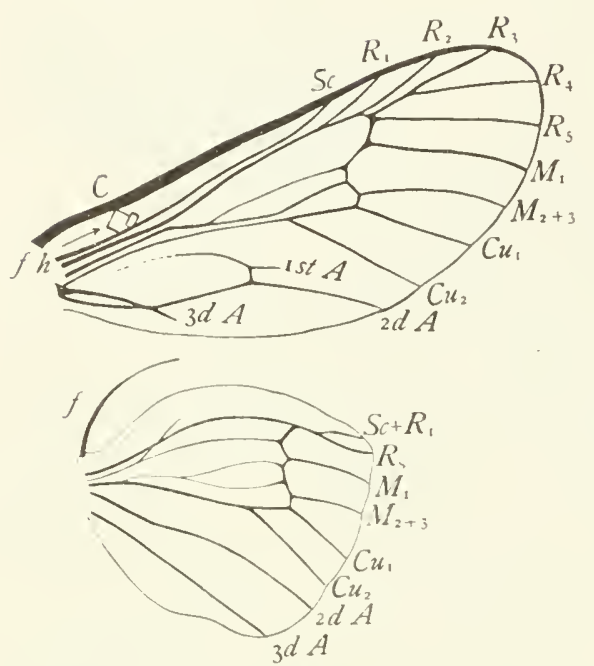

Fig. 46.-Wings of Thyridoptery'x ephemerceformis; $f$, frenulum; $f h$, frenulum hook.

This organ may be termed the fibula or clasp.

The fibula differs in different insects in respect to the part of the wing that enters into its composition. In some insects it is strietly homologots with the jugum being composed merely of the posterior lobe of the wing; in other insects it consists of the posterior lobe of the wing and a part of the axillary membrane. These two types are illustrated by the fibulæ of Rhyacophala and of Corydalus respectively.

The fibula of Rhyacophila, a generalized member of the order Trichoptera, is a hatchet-shaped lobe at the base of the wing (Fig. 49).

It is joined to that part of the anal area lying in front of it by the axillary furrow, which acts as a hinge. It is evident that the structure of the wing is such that the fibula is depressed with considerable force, for it is very difficult to mount a wing without the fibula being folded under it. As the longitudinal free margin of the fibula is curved down it seems probable that the fibula clasps the anterior tuberosity of the hind wing and thus the two wings are held together.

Although the fibula of Rhyacophila differs greatly in appearance from the jugum of the Hepialidæ and functions in a different manner, the two are formed of

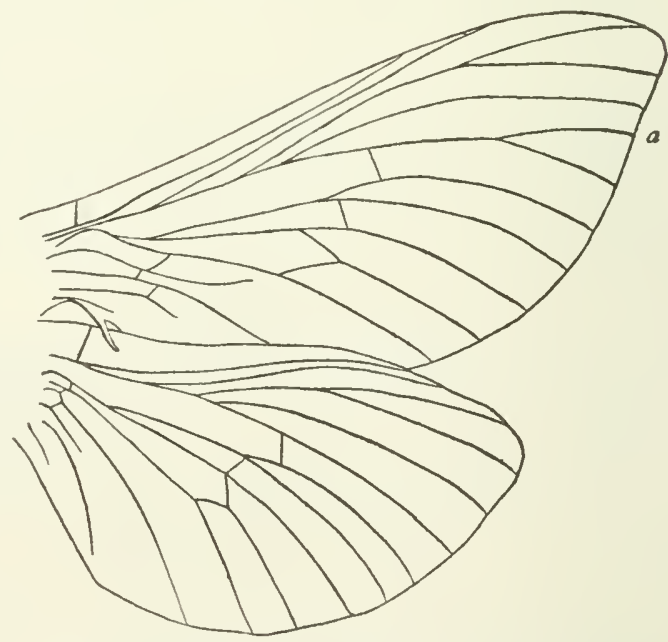

Fig. 47.- Wings of a hepialid, seen from below. homologous parts of the wing. In Rhyacophila the axillary furrow is immediately behind vein $3 \mathrm{dA}_{1}$ (Fig. 49); in the Hepialidæe there is a slit 
in the wing in this position; in both the longitudinal margin is strengthened by vein $3 \mathrm{dA}_{2}$.

The fibula of Corydalus differs in structure from that of Rhyacophila in that it is composed in part of the axillary membrane. It is a triangular,

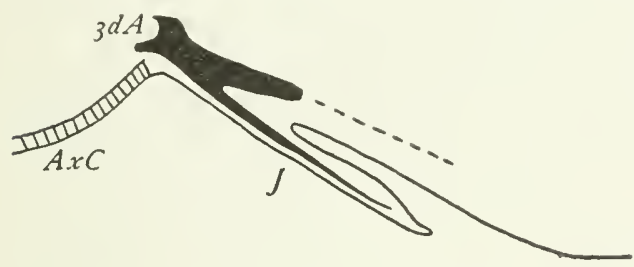

Fig. 48.-Jugum of a hepialid. backward projecting lobe of the wing, along the middle of which extends vein $3 \mathrm{dA}_{2}$ (Fig. 50). That part of this fibula that lies distad of this vein is homologous with the jugum of the Hepialidæe and the fibula of Rhyacophila; the part lying proximad of this vein is a portion of the axillary membrane; this is evident from the fact that it is margined by the axillary cord.

The apex of this fibula, which is strengthened by the tip of vein $3 \mathrm{dA}_{2}$, curves down forming a hook. In the living insect, this hook clasps a fold in the hind wing, which extends from the apex of the anterior tuberosity to the margin of the cubito-anal sulcus. In this manner the two wings are clasped together.

The relation of the fibula to the hind wing can be seen only rarely in dried insects. In the spreading of specimens the fibula is pulled out of its normal position; and in drying both the fibula and the fold of the hind wing behind which it hooks become shriveled so that their normal relations

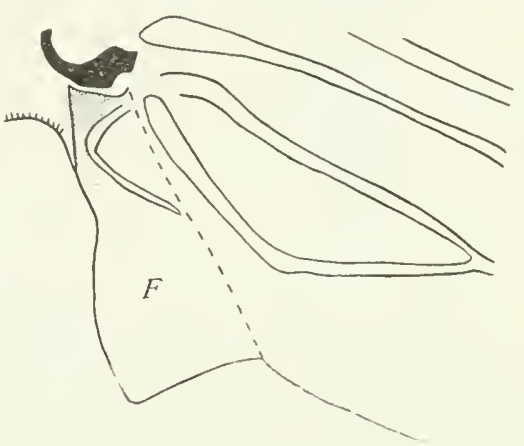

Fig. 49.-Fibula of Rhyacophila. are not obvious. The conclusions given above are based on a study of living individuals.

The two types of fibula described above will serve as a basis for more

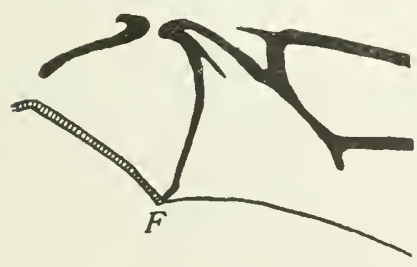

Fig. 50.-Fibula of Corydalus. extended studies of this organ. Doubtless much material of taxonomic value can be obtained from a study of this part of the wing. But such a study does not fall within the scope of this essay, the preparation of which was undertaken with special reference to the application of the uniform terminology of the wing-veins.

An expanded humeral angle of the hind wings.-In certain insects the humeral angle of the hind wings is greatly expanded so that it projects 
forward beneath the fore wing thus insuring the synchronous action of the two wings. Examples of this exist in several families of moths, in butterflies, and in the Ephemerida.

The clothing of the wings.- With the greater number of insects the wings appear to be naked; but in many cases they are only apparently so, an examination with a microscope revealing a fine covering of setæ or spines. On the other hand, the wings of certain insects are obviously clothed. Thus the wings of the aquatic Trichoptera are densely clothed with long hairs, and those of the Lepidoptera are covered with scales.

The more conspicuous clothing of wiings is composed of setæ more or less modified. In the aquatic Trichoptera the setæ are essentially typical in form, being hair-like structures attached to the membrane of the wing by a

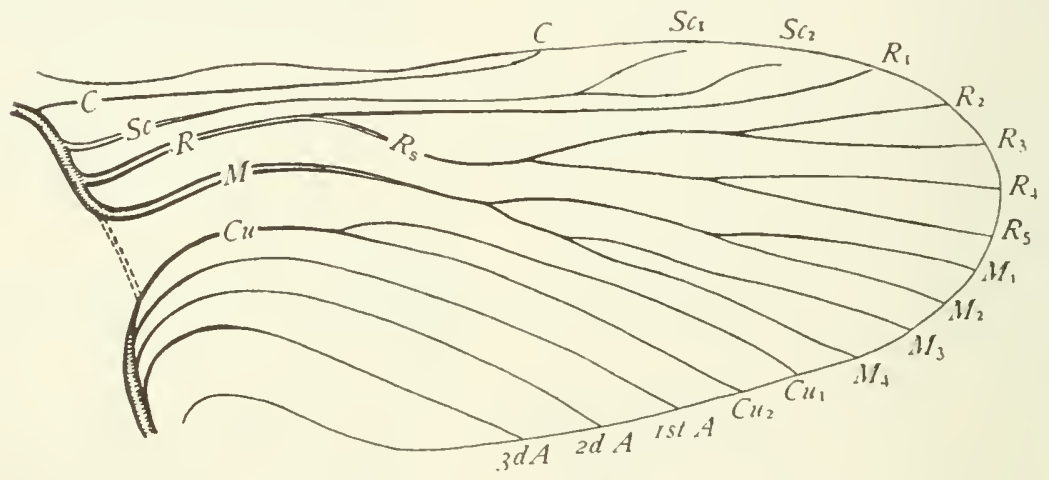

Fig. 51.-Hypothetical tracheation of a wing of the primitive nymph (After C. \& N.).

movable joint. In the Lepidoptera and in certain other insects, the setæ are modified into scales.

In addition to setæ the wings of certain insects bear hair-like structures which are morphologically different from setæ; they lack the joint at the base and are probably merely elongated cuticular nodules.

A more extended discussion of the clothing of the wings is given later in the discussion of the wings of the Lepidoptera.

The principal wing-veins.- It has been shown in the previous chapters that in the more generalized insects the principal wing-veins are developed about preexisting tracheæ; and a study of these tracheæ in the more generalized members of several orders of insects has enabled us to construct a diagram representing the hypothetical type of the primitive wing-venation.

In nymphs and pupæ the tracheæ about which the principal veins are later developed extend separate from within the thorax, and their courses are easily traced. But it frequently happens that through the narrowing 
of the base of the wing, which occurs at the change to the adult form, the bases of these tracheæ are crowded together, which results in the coalescing of the bases of two or more veins, so that they appear as a single vein. For this reason the figure of the hypothetical type (Fig. $5 \mathrm{I}$ ) is made to represent the tracheation of a nymph; and the different tracheæ are designated by the same terms as are the veins to which they correspond. By representing the wing of a nymph, we are able to represent the basal connections of the tracher that precede the wing-veins, and thus show which are principal veins and which are branches of them.

A glance at Figure 5 I will show that there are eight principal veins; and that the second, third, fourth, and fifth are branched. The names of these veins and the abbreviations by which they are designated are as follows, beginning with the one nearest the costal margin:

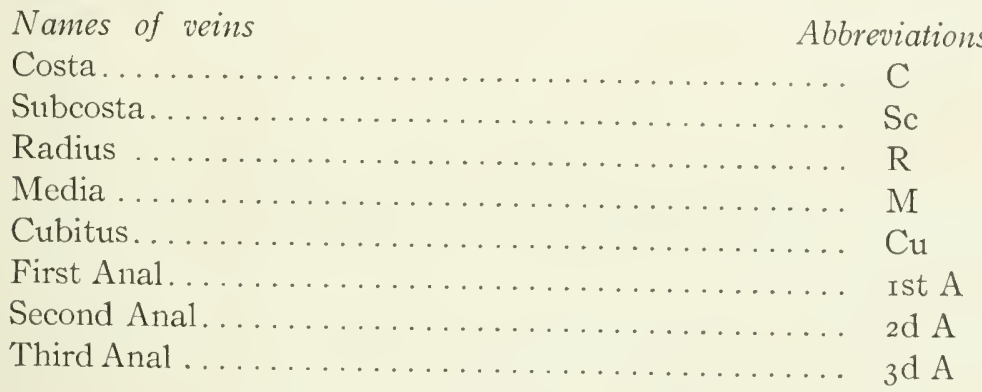

Enderlein ('o2) has revived the old name axillaris and applied it to the second and third anal veins, which he designates as $a x_{1}$, and $a x_{2}$ respectively, and applies, the term analis to the first anal vein. He states that he does this in order to better characterize the morphologically different veins grouped as anal veins ( $l, c$. p. I 5$)$. But he does not state in what respect the second and third anal veins differ morphologically from the first anal vein. I see no reason for making the change that he suggests.

The names of the wing-veins used in the uniform terminology are those adopted by Redtenbacher in his work upon which this terminology was based. The terms costa, subcosta, radius, cubitus, and anal veins were selected by this author from those already in use; the term media was proposed by him for what appears to be the middle vein, "in der That als die 'Mittelader' erscheint," that is as the vena media. The changing of this term to the masculine form, "medius," as has been done by several recent writers, is unwarranted.

The chief branches of the wing-veins of the preanal arca.-The chief branches of the principal veins are numbered, beginning with the branch nearest to the costal margin of the wing. The term used to designate a branch of a vein is formed by compounding the name of the vein with a numeral indicating the number of the branch. The names of the branches 
that are thus recognized and the abbreviations of these names that are used are the following:

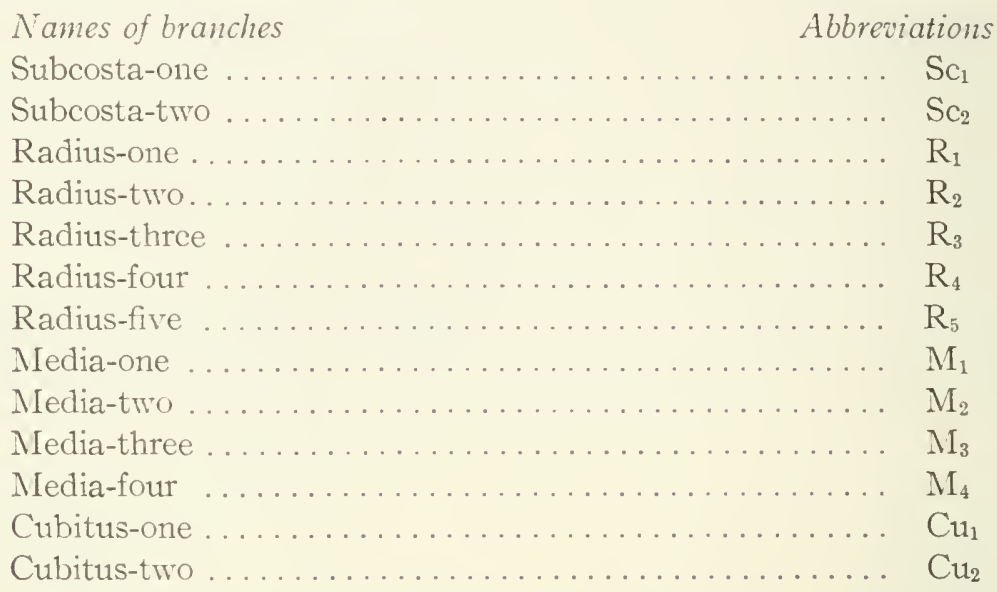

In the case of radius and of media, each of which has more than two branches, each division of the vein that bears two or more branches has received a special name. Thus after the separation of radius-one from the main stem of radius there remains a dirision which is typically fourbranched; this division is termed the radial sector or $\mathrm{R}_{\mathrm{s}}$; the first division of the radial sector, which later separates into radius-two and radius-three, is designated as radius-two-plus-three or $\mathrm{R}_{2}+_{3}$; and the second division is termed radius-four-plus-five or $R_{4+5}$. Media is typically separated into two divisions, each of which is two-branched; the first division is mediaone-plus-two or $\mathrm{M}_{1}+2$, the second, media-three-plus-four or $\mathrm{M}_{3}+_{4}$.

The veins of the anal area.-The three veins of the anal area, which are designated as the first anal ( Ist $A$ ), second anal (2d A), and third anal ( $3 d A$ ) respectively, exhibit a wide range of variation both as to their persistence and as to their form when present. In wings with a reduced anal area any or all of the anal veins may be lacking; on the other hand, in wings with an expanded anal area some or all of the anal veins may be branched.

In those cases where the anal reins are branched there is no indication that the branching has been derived from a uniform primitive type of branching, as is the case with the other branched principal veins. The principal branches of either radius, media, or cubitus can be homologized, when present, throughout the insect series; and, therefore, have been given distinctive names; but there is no reason to believe that this can be done with the branches of the anal reins. For this reason in describing a branched anal rein merely the number of branches is indicated.

In many cases where there is a reduction in the number of anal veins a study of the development of the wing will reveal the manner in which the 
reduction has taken place; it may be due either to the atrophy of one or more veins, or it may be due to the coalescence of veins. In either case if the manner of reduction be determined the homology of the remaining vein or veins can be indicated.

But in some cases, as for example, in the Odonata, there has been a specialization by reduction, which has resulted in the preservation of a single anal vein, and there is available no data showing the course of this evolution. The three anal veins may have coalesced into one: or one anal vein may have atrophied and the remaining two coalesced; or two of the veins may have been lost, leaving a single vein. Obviously, in this state of uncertainty, it is best to designate the single vein as the anal vein (A) without any predicate.

When a single anal vein is present the identity of which can not be determined and this vein is branched, we are not warranted in designating these branches to make use of the names $I s t A, 2 d A$, and $3 d A$, as this would indicate homologies that we do not know to exist. Therefore in such cases the branches of vein $\mathrm{A}$ are designated as $A_{1}, A_{2}, A_{3}$, etc.

The reduction of the number of wing-veins. - In many wings the number of the veins is less than it is in the hypothetical type. In some cases this is due to the fact that one or more veins have faded out in the course of the evolution of the insects showing this deficiency; frequently in such insects vestiges of the lacking veins remain, either as faint lines in the positions formerly occupied by the veins or as short fragments of the veins. A much more common way in which the number of veins has been reduced is by the coalescence of adjacent veins. In many wings the basal parts of two or more prinicpal veins are united so as to appear as a single vein; and the number of the branches of a vein has been reduced in very many cases by two or more branches becoming united throughout their entire length.

The evolutionary process by which the number of the veins has been reduced, whether by the fading out of veins or by the coalescence of adjacent veins, is termed specialization by reduction.

The coalescence of principal veins is usually made evident by a study of their branches, the branches of two or more veins arising from a common stem. The coalescence of the branches of a vein is often shown, by a study of a series of allied forms in which different degrees of it can be observed, the point of separation of two branches being nearer and nearer to the margin of the wing in successive forms until the margin is reached.

As the venation of the wings affords some of the most available characteristics for use in the classification of insects, it is of the utmost importance that the same name should be applied to homologous veins in the wings of different insects. For this reason when a vein consists of two or more of the primitive veins united, the name applied to the compound veins should 
indicate this fact. In the wing of Rhyphus (Fig. 52), for example, radius is only three-branched; but it would be misleading to designate these branches as $R_{1}, R_{2}, R_{3}$, for this would indicate that $R_{4}$ and $R_{5}$ larellacking.

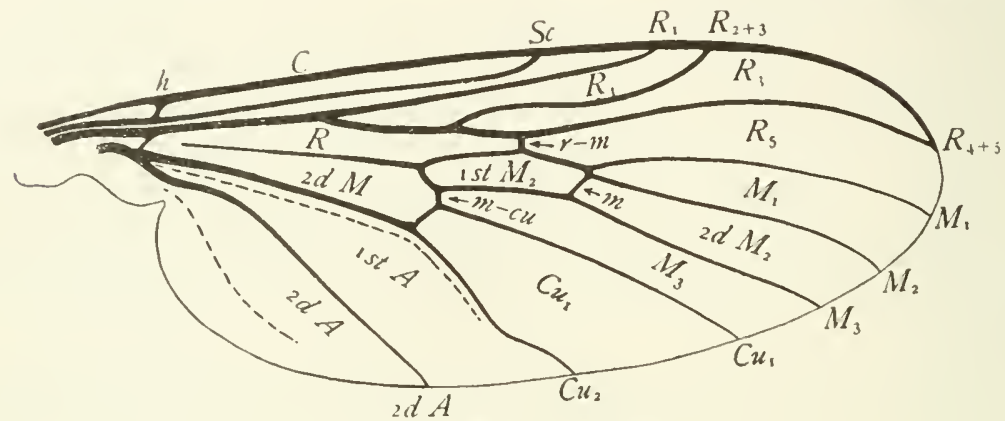

Fig. 52.-Wing of Rhyphus.

The first branch is evidently $R_{1}$; the second branch is composed of the coalesced $R_{2}$ and $R_{3}$, it is, therefore, designated as $R_{2}+_{3}$; and the third branch, which consists of the coalesced $R_{4}$ and $R_{5}$ is designated $R_{4}+_{5}$.

The wing of Rhyphus illustrates also the other method of reduction of wing-veins, as the basal part of media has faded out.

A second method of coalescence of veins is illustrated by the wing of Tabamus (Fig. 53). In this wing the tips of cubitus-two and the second anal vein are united; here the coalescence began at the margin of the wing and is progressing towards the base. The united portions of the two veins are designated as $2 \mathrm{~d} \mathrm{~A}+\mathrm{Cu}_{2}$.

In those cases where the reduction of the venation has proceeded very far, as in some of the smaller Hymenoptera for example, the logical carrying

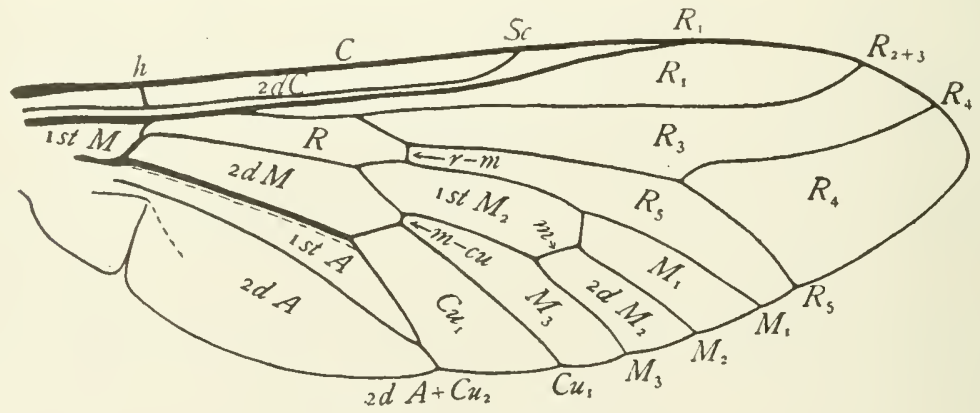

Fig. 53.-Wing of Tabanus.

out of the plan of designating a compound vein by a combination of the names of all of the veins that have entered into the composition of it would result in a very cumbersome terminology. Such a designation, however 
complex, may be desirable in detailed taxonomic work; but for the purposes of ordinary descriptions a designation indicating the most obvious element of the compound vein is sufficient. Thus in the hind wing of

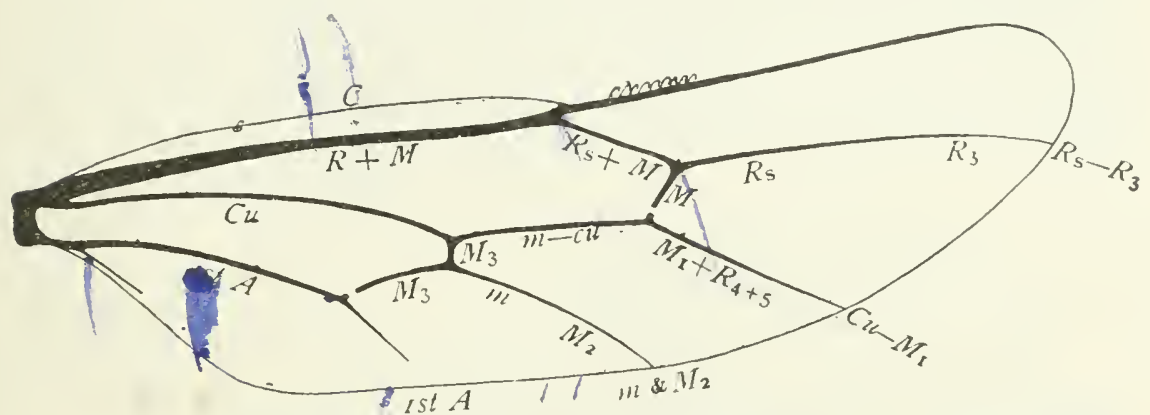

Fig. 54.- - Hind wing of an ichneumon-fly.

Exetastes (Fig- 54), where veins $\mathrm{M}_{3}, \mathrm{M}_{4}, \mathrm{Cu}_{1}, \mathrm{Cu}_{2}$ and $2 \mathrm{~d} \mathrm{~A}$ coalesce with the first anal fein the united tips of these veins is designated, by the term indicating its most obyious element, ist A.

Serial veins.-In the wings of some insects, where the wing-venation has been greatly modified, as i certain Hymenoptera, there exists what appear to be simple veins that if weality are compound veins composed of sections of two or more veins joined end to end with no indication of the point of union. For cdmpound veins formed in this manner I propose the term serial veins. The following comparatively simple example will serve as an illustration of a serial vein.

In those Hymenoptera in which the wing-venation is not greatly reduced vein $\mathrm{M}_{2}$ of the fore wings extends in a transverse direction from the point of separation from vein $\mathrm{M}_{1}$ to the point where it is joined by the medial crossvein; it then bends more or less abruptly and extends in a longitudinal direction. Thiscondition persistsin the fore wing of an ichnemonfly (Fig. 55). But in the fore wing of a braconid (Fig. 56) the transverse section of vein $\mathrm{M}_{2}$ has been lost; and the longitudinal section of this vein and the medial cross-vein for

The example just cited is pe

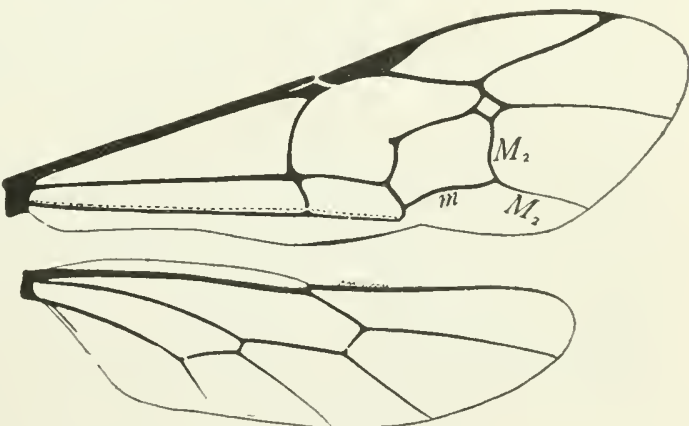

Fig. 55.-Wings of an ichneumon-fly.

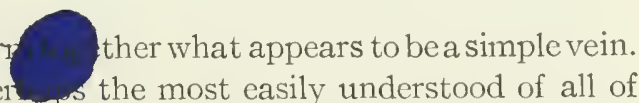
the most easily understood of all of the serial veins. But there are cases where sections of several veins enter 
into the composition of a serial vein, and where, owing to extensive modifications of the wing-renation, it is impossible to determine completely the composition of the resulting rein.

The problem of devising a method of designating serial veins now arises. In cases where the vein consists of only two elements it is a simple matter. The serial vein in the braconid wing. described above, consisting of the medial cross-vein $(m)$ and vein $\mathrm{M}_{2}$, can be designated as $m \& M_{2}$. The

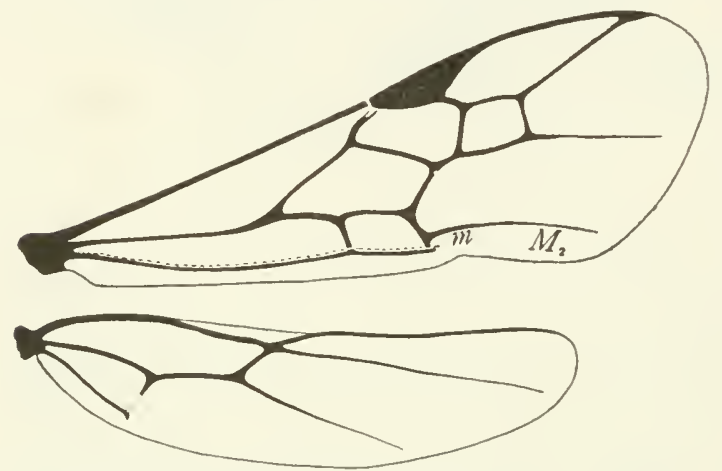

Fig. 56.-Wings of a braconid. $\operatorname{sign} \&$ is used instead of + , as the latter is used to indicate compound veins formed by the coalescence of veins side by side, as indicated on an earlier page.

In those cases where sections of several veins enter into the composition of a serial vein, it is usually possible to determine the basal element and also that forming the tip of the serial vein, even though it is impossible to determine definitely the veins that are represented by the intermediate portion of the vein. In such cases the serial vein can be designated by the abbreviation of the name of the basal element connected by a dash with the abbreviation of the name of the terminal portion. Thus a serial vein, the basal element of which is the cubitus and the terminal element vein $\mathrm{M}_{1}$ is designated as vein $\mathrm{Cu}-\mathrm{M}_{1}$. A serial vein thus formed exists in the hind wings of certain ichneumon-flies (Fig. 54). This method of designating serial veins is suggested by Professor Bradley as a substitute for that used in his monograph of the Evaniidæ (Bradley 'o8).

The increase of the number of wing-veins. - In many insects the wings are furnished with a larger number of veins than that which we believed to have been characteristic of the wings of the primitive winged insects; the evolutionary process by which this change has been brought about is termed specialization by addition.

This multiplication of veins is due either to an increase in the number of the branches of the principal veins by the addition of secondary branches, or to the development of secondary longitudinal veins between these branches. In no case is there an increase in the number of principal veins.

In some cases the specialization by addition has taken place only in the preanal area; in others it is confined to the anal area; in still others it has occurred in both areas; and in many insects a reduction in the number of 
the veins has taken place in one part of the wing while there is an increase in another part.

The secondary longitudinal veins.-Omitting certain adventitious veins, which will be discussed later, and branches of the anal veins, the secondary longitudinal veins are of two kinds, which may be designated as the accessory veins and the intercalary veins, respectively. These two kinds of veins differ fundamentally in their mode of origin. Accessory veins arise as secondary branches of the principal veins or of their branches; and their
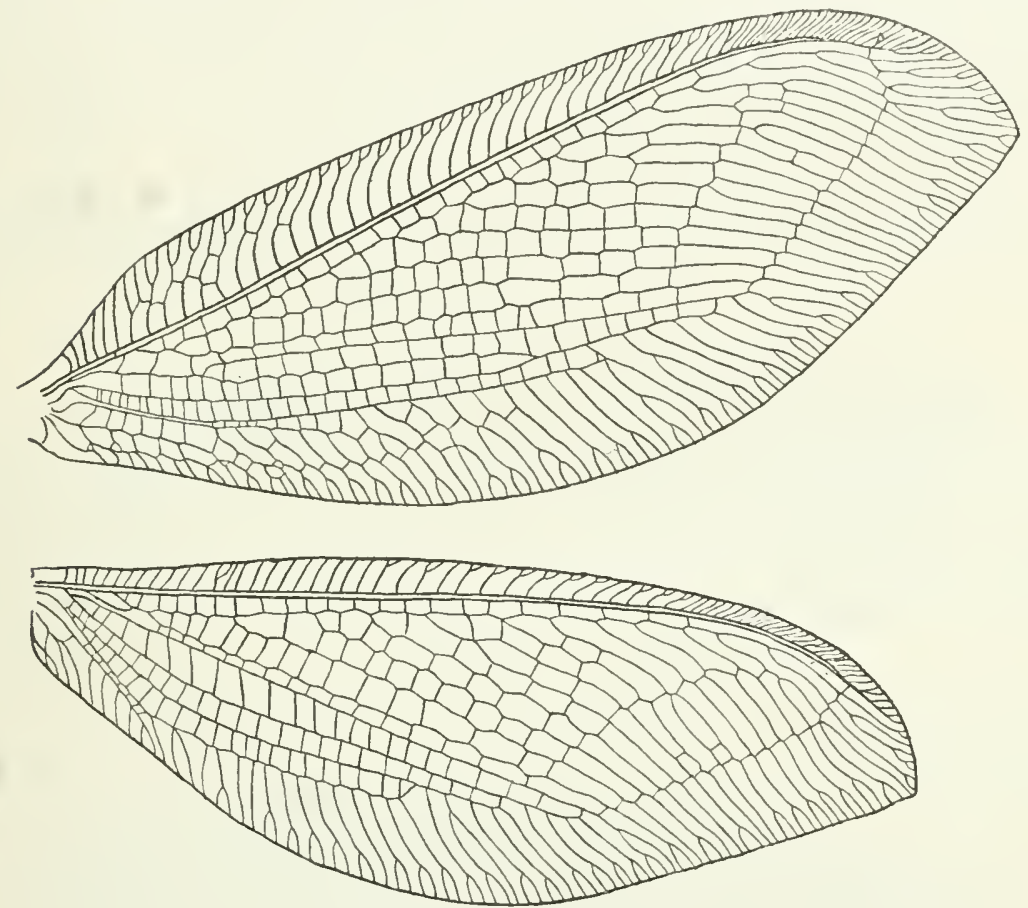

Fig. 57.-Wings of Osmylus.

presence is not correlated in any way with a corrugating of the wing. Intercalary veins, on the other hand, are thickened folds; each of which arises more or less nearly midway between two preexisting veins, with which, as a rule, it has no connection except by cross-veins, and can not, therefore, be considered accessory to either. Frequently, however, an intercalary vein becomes joined to one of the two veins between which it was developed in such a way as to appear to be a branch of it.

The accessory veins.-The secondary longitudinal veins that arise as branches of the principal veins or of their branches are termed accessory veins. Accessory veins may be borne by any of the primitive longitudinal ${ }_{\mathrm{v}}$ eins; and they may arise from either of the two sides of such a vein. 
Accessory veins are found only in the Orthoptera, Isoptera, Neuroptera, Plecoptera, Mecoptera, and, rarely in the Trichoptera and Embiidina.

Two types of accessory veins can be recognized, although in many cases it is difficult to determine with which of the two types certain accessory veins should be classed. These two types may be designated as marginal accessory veins and definitive accessory veins respectively.

The marginal accessory veins are twig-like branches that are the result of bifurcations of veins that have not extended far back from the margin of the wing. Many such short branches of veins exist in the wings of Osmylus (Fig. 57). Note especially the outer margin of the wing where the forking of the veins is quite regular and where some of the marginal accessory veins are themselves forked.

The most important characteristic of the marginal accessory veins, for the purposes of this discussion, is the fact that their number and position are not at all constant. Not only do they vary in these respects in different

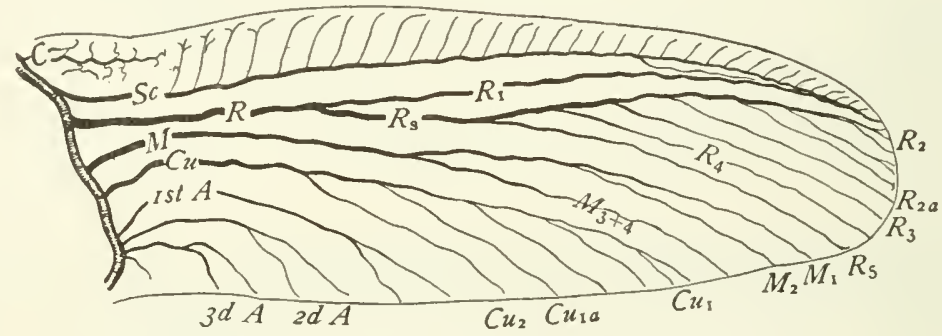

Fig. 58.-A wing of a pupa of Corydalus (After C. \& N.).

individuals of the same species but also in the wings of the two sides of the same individual. There is on this account no occasion for providing a terminology for them.

In the paleozoic insects the marginal accessory veins were very irregular in length, this is shown by the figures illustrating Chapter IV. Strongly contrasting with this condition is that seen in many recent Neuroptera, where there are one or more ranks of these veins, the members of each rank being of comparatively uniform length.

The definitive accessory veins differ from the marginal accessory veins in having attained a position that is comparable in stability to that of the primitive branches of the principal veins; for this reason it is practicable to designate them individually, either by names or by numbers, depending on the manner in which they have been added.

Comstock and Needham pointed out that accessory veins are added to the principal veins in two ways: first, in some insects they are added distally by successive splittings of the tip of a principal vein, thus forming a regular series; and second, the number of accessory veins may be increased 
in an irregular manner by interpolation, $i$. $e$. by the splitting of various members of a series of accessory veins.

Illustrations of the adding of accessory veins distally are to be seen in Corydalus and allied genera. The presence of fine twigs at the tip of

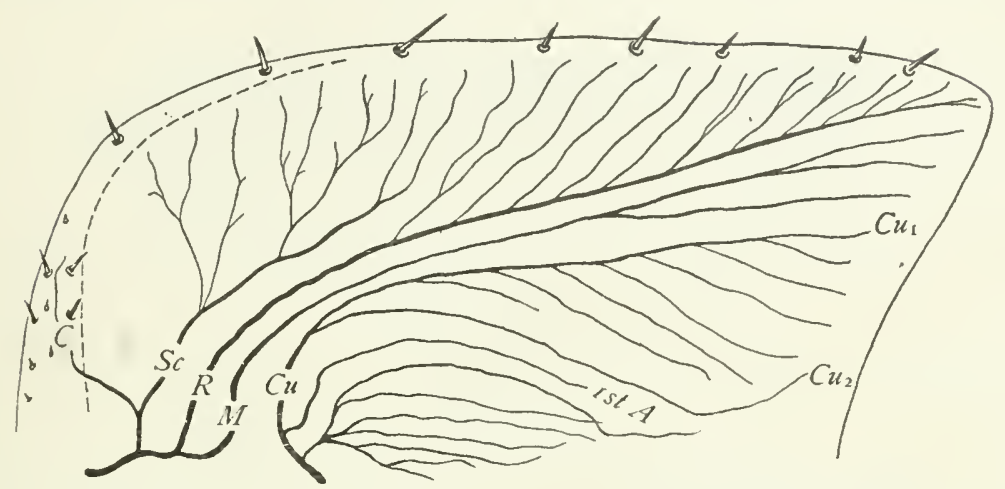

Fig. 59.-Fore wing of a nymph of a cockroach (After C. \& N.).

trachea $\mathrm{R}_{2}$ in the pupal wing of Corydalus (Fig. $5^{8}$ ) indicates the method of increase, which is doubtless as follows: the branches have been added one after another to the tip of trachea $R_{2}$, there being a migration of the base of each accessory trachea towards the base of the wing, thus making room for the addition of new branches. In this case the first accessory vein is the proximal one.

In the wing of a nymph of a cockroach represented by Figure 59 there are many accessory tracheæ branching from the front side of the radial

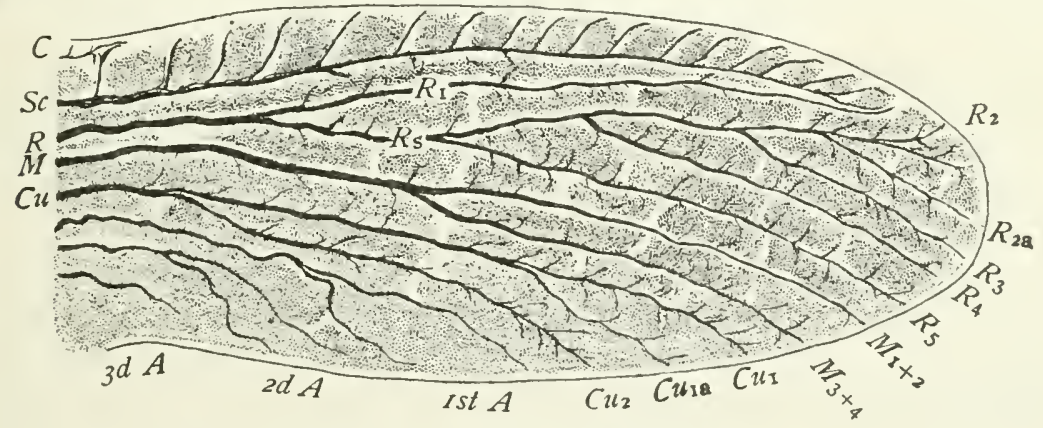

Fig. 60.-A wing of a pupa of Chauliodes (After C. \& N.).

trachea. From the presence of the fine twigs near the apex of the wing, it is evident that accessory trachex are being added distally. It is also evident that the number of accessory tracher is being increased by the splitting of some of these accessory tracheæ, $i$. e., by interpolation. 
Where the veins are added distally so as to form a regular series it is practicable to designate them individually. In this case the accessory veins arising from one side of a primitive vein are considered as a single series, and to each series a distinct set of letters is applied beginning with the

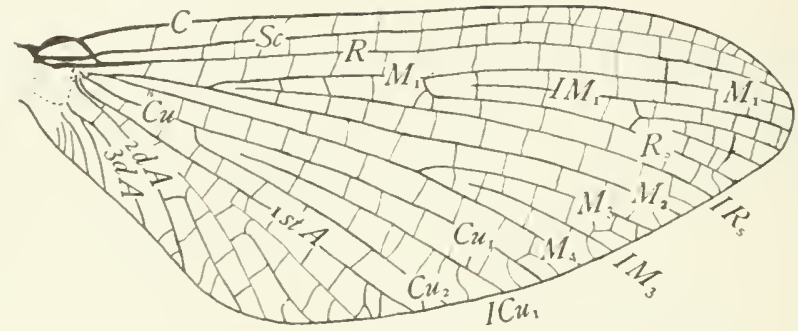

Fig. 61.- Wing of a May-fly, Epeorus humeralis (After Morgan).

first developed member of the series of accessory veins. Thus if vein $R_{2}$ bears three accessory veins they are designated as reins $R_{2_{a}}, R_{2 b}$, and $R_{2 c}$ respectively (Fig. 60).

By this method homologous reins, when a homology exists, will bear the same designation. But it should be remembered that as accessory reins have arisen independently in many different groups of insects, it often happens that accessory veins similar in position, and bearing the same designation in our system, are merely analogous and not homologous.

The discussion of the sequence of derelopment of definitive accessory veins is continued in the Chapter treating of the wings of Neuroptera; as it is in this order that this class of veins reaches its most perfect development.

The intercalary veins. - The intercalary veins are secondarily developed longitudinal veins that did not arise as branches of the primitive reins, but were developed in each case as a thickened line, in a corrugated wing, more or less nearly midway between two preexisting veins, with which primarily it was connected only by cross veins.

In many cases, however, an intercalary rein has become united to one of the two veins between which it was dereloped in such a way as to appear to be a branch of it. This resemblance to an accessory rein is greatly increased when the intercalary vein is penetrated by a branch of the trachea of the principal vein; this condition is rell-illustrated by the intercalary veins of the Odonata. Excellent illustrations of unmodified intercalary veins are common in the Ephemerida, where most of the intercalary reins remain distinct from the reins between which they were developed, being connected with them only by cross-veins, the proximal end of the intercalary vein being free (Fig. 6I). 
In the formation of an intercalary vein there is a straightening out of veins that form part of the boundaries of polygonal cells into a longitudinal line. Different stages of this development can be seen in the wings of dragon-flies; see figures in Chapter XI.

Intercalary reins did not exist in the wings of the Palæodictyoptera. Their development is correlated with the development of corrugated wings. In the preanal area of recent insects, intercalary veins are found only in the Ephemerida and in the Odonata. In the anal area they are found in these two orders and in the Orthoptera, where the convex veins are accessory and the concave veins intercalary. In paleozoic insects they were present in the Protodonata and Protoephemeroidea, and judging from some published figures, they were present in some of the Protoblattoidea.

When it is desirable to refer to a particular intercalary vein it may be done by combining the initial I, indicating intercalary, with the designation of the area of the wing in which the intercalary vein occurs. For example, in the wings of most May-flies in which the venation is not reduced, there

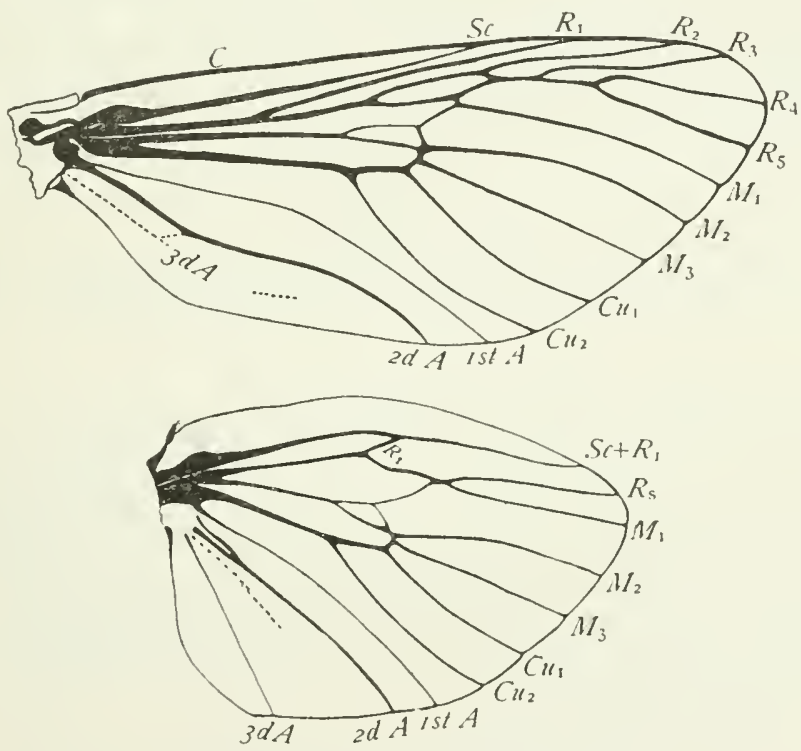

Fig. 62.-The wings of Prionoxystus.

is an intercalary vein between veins $\mathrm{Cu}_{1}$ and $\mathrm{Cu}_{2}, i$. e. in the area $\mathrm{Cu}_{1}$. This intercalary vein is designated as $\mathrm{ICu}_{1}$ (Fig. 6r).

When more than one intercalary vein exists in a single area of the wing, as in area $\mathrm{M}_{1}$ of Epeorus (Fig. 6I), and it is desired to designate them individually, it can be done by the use of appended letters. Thus, for example, the three intercalary veins in area $\mathrm{M}_{1}$ of Epeorus may be desig- 
nated as $I M_{1 a}, I M_{1 b}$, and $I M_{1 c}$, respectively, beginning with the oldest, $i . e$. the longest one. It will rarely be necessary, howerer, to resort to this somewhat cumbersome terminology; as it will be sufficient in most cases to indicate the number of distinct intercalary veins in a given area.

The Adrentitious ieins. - In certain insects there occur secondary veins that are neither accessory reins nor intercalary reins as defined above; these may be termed adientitions ceins. The more important of them are described in later chapters in the course of the descriptions of the wings in which they occur. Examples of them are the supplements of the wings of certain Odonata and the spurions rein of the Syrphidæ.

The anastomosis of veins. - The typical arrangement of the wing-veins is often modified by an anastomosis of adjacent veins; that is, two reins will come together at some point more or less remote from their extremities and merge into one for a greater or less distance, while their extremities remain separate. This is illustrated by Nemoura (Fig. I2) where tracheæ

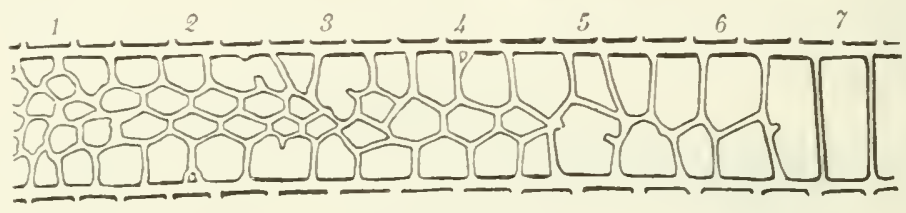

Fig. 63.-Diagram illustrating the formation of regular cross-veins (After Needham).

$\mathrm{Sc}_{2}$ and $\mathrm{R}_{1}$ extend for a short distance in the same vein carity. In the fore wing of Prionoxystus (Fig. 62) there is an anastomosis of veins $R_{3}$ and $\mathrm{R}_{4}+{ }_{5}$.

The cross-veins. - It has been shown that so far as the principal longitudinal reins are concerned the wings of all orders of insects are modifications of a single primitive type, and a diagram representing our conclusions regarding this type has been given on an earlier page (Fig. 6).

In the discussion of our hypothetical type no reference is made to crossveins; for it is evident that a homology, similar to that which exists between the longitudinal reins of the several orders of insects does not exist between the cross-reins of these orders.

It is shown in Chapter IV that in the wings of the more generalized members of the Palæodictyoptera, the order of fossil insects from which the orders of recent insects were evolved, there were no definite cross-veins, but instead an irregular netrork of reins in the spaces between the longitudinal veins (see Fig. 8). A similar network exists to-day in the fore wings of the Acrididæ, for example.

The transformation of an irregular network of reins into regular transverse cross-reins is discussed by Needham ('o3) and is illustrated by the accompanying diagram (Fig. 63). His conclusions were based on his 
studies of the wings of Odonata. But similar series of gradations between an irregular network of veins and regular transverse cross-veins can be found in the wings of several of the more specialized Palæodictyoptera, in

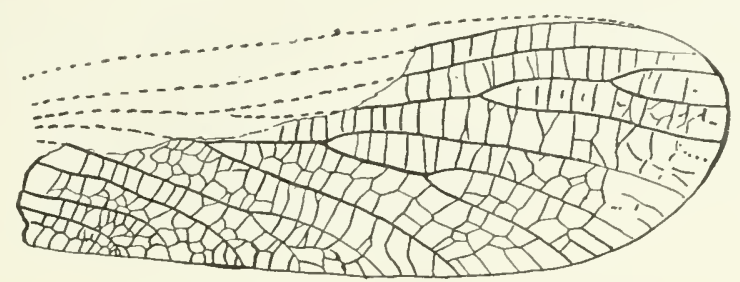

Fig. 64.-Wing of Aenigmatodes danielsi (After Handlirsch).

which order regular transverse cross-veins first appeared. The wing of Aenigmatodes danielsi (Fig. 64) will serve as an illustration of this. The wing of Eurythomopteryx antiqua (Fig. 9) is an illustration of a palæodictyopterous insect in which regular transverse cross-veins had been fully attained. It is evident, however, that the specialization of the cross-vein occurred independently in different families of this order; and obviously no homology exists between the cross-veins of two groups in each of which they have been developed independently.

While there is no reason to believe that homologous cross-veins exist throughout the insect series, in several of the orders, where the number of the cross-veins has been greatly reduced, there are several cross-veins in

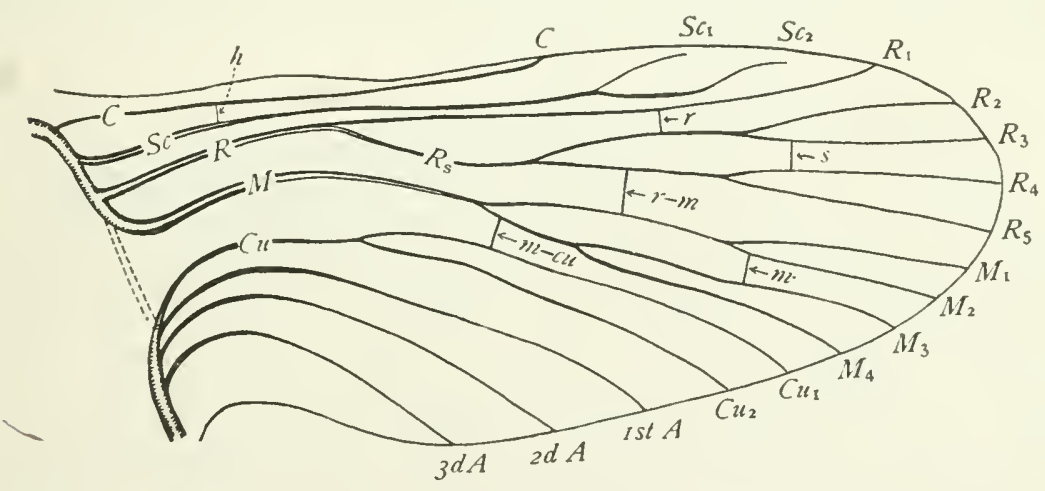

Fig. 65.-The hypothetical primitive type of wing-venation with the named cross-veins added.

each case that so closely resemble in position those found in the other orders of insects with few-veined wings, that analogies if not homologies can be traced; and it has been found desirable, in order to facilitate descriptive work, to name these cross-veins. The orders in which the named cross- 
veins can be most frequently recognized are the following: Plecoptera, Trichoptera, Lepidoptera, Diptera, Hymenoptera, Hemiptera, and Homoptera. The names applied to these cross-reins are as follows:

The Inmeral cross-iein. - This extends from subcosta to the costa near the humeral angle of the wing, and is designated by the abbreviation $h$ (Fig. 65). It is the most constant of all of the named cross-veins.

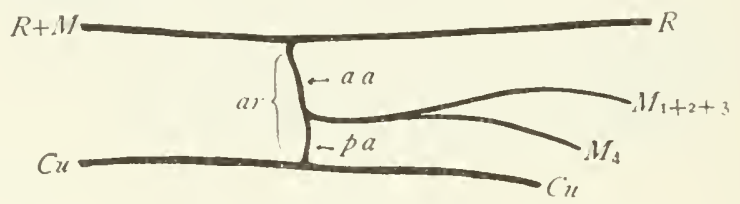

Fig. 66.--Diagram of an arculus of a dragon-fly.

The radial cross-iein.-This extends between the two principal divisions of radius, $i$. $e$. from vein $R_{1}$ to vein $R_{s}$, and is designated by the abbreviation $r$ (Fig. 65).

The sectoral cross-vein. - This extends between the principal divisions of the radial sector, $i$. $e$. from vein $R_{2+3}$ to vein $R_{4}+5$, or from vein $R_{3}$ to vein $R_{4}$, and is designated by the abbreviation $s$ (Fig. 65).

The radio-medial cross-vein.- This extends from radius to media, usually near the center of the wing, and is designated by the abbreviation $r-m$ (Fig. 65).

The medial cross-iein. - This extends from rein $\mathrm{M}_{2}$ to vein $\mathrm{M}_{3}$, dividing cell $\mathrm{M}_{2}$ into cells ist $\mathrm{M}_{2}$ and $2 \mathrm{~d}_{2}$. The presence or absence of this crossvein is often a character of considerable taxonomic importance. It is designated by the abbreviation $m$ (Fig. 65).

The medio-cubital cross-vein.- This extends from media to cubitus and is designated by the abbreviation $m$-cu (Fig. 65 ).

The arculus. - In many insects there is what appears to be a cross-vein extending from radius to cubitus near the base of the wing. This has been termed the arculus by writers on the Odonata, and we have extended the use of the term to all orders in which there is a similar arrangement of the veins in this part of the wing. The arculus is designated by the abbreviation $a r$ (Fig. 66). Usually when the arculus is present media appears to arise from it. The fact is, the arculus is compound, being composed of a section of media and a cross-vein. MacGillivray (' 12 ) has designated that part of the arculus which is a section of media the anterior arculus $(a \mathrm{a})$ and that part formed by a cross-vein, the posterior arculus $(p a)$.

The costal cross-veins.- In some cases it is desirable to refer to certain cross-veins in many reined wings. This most often occurs in the case of those cross-veins that extend between the costa and the subcosta. These are commonly designated as the costal cross-veins. This name is appropriate 
as they traverse the costal area of the wing, that area that corresponds to cell $\mathrm{C}$ in the few-veined wings, and it is well that it be retained; although, morphologically, they are marginal accessory veins, that arise as branches of the subcosta; this is the case at least in the Neuroptera, where they reach their highest development.

Other cross-veins in many-veined wings.--In other cases where it is desired to refer to the number or nature of the cross-veins in a certain area of the wing it can be donc by reference to that area of the wing. Thus, for example, the Myrmelionidxe are characterized by the absence of cross-veins in cell Sc while in the closely allied Nymphidæ the subcostal area of the wing is traversed by many cross-veins.

The terminology of the cells of the wing.--In descriptions of wings it is often desirable to refer to one or more cells. It is necessary, therefore, to have a terminology of the cells of the wing, as well as of the wing-veins.

Having named the wing-veins, the simplest possible method of designating the cells of the wing is to apply to each the abbreviation of the name of the vein that normally forms its cephalic (front) margin. It should be borne in mind, however, that by modifications of the typical arrangement of the wing-veins, a vein that normally forms the cephalic margin of a cell may apparently bear a very different relation to it; and this must be taken into account if we are to apply the same term to homologous cells throughout the insect series. Figure 67 represents a wing of Rhyphus with the veins and cells labeled.

The cells of the wing fall naturally into two groups: first, those on the basal part of the wing; and second, those nearer the distal end of the wing.

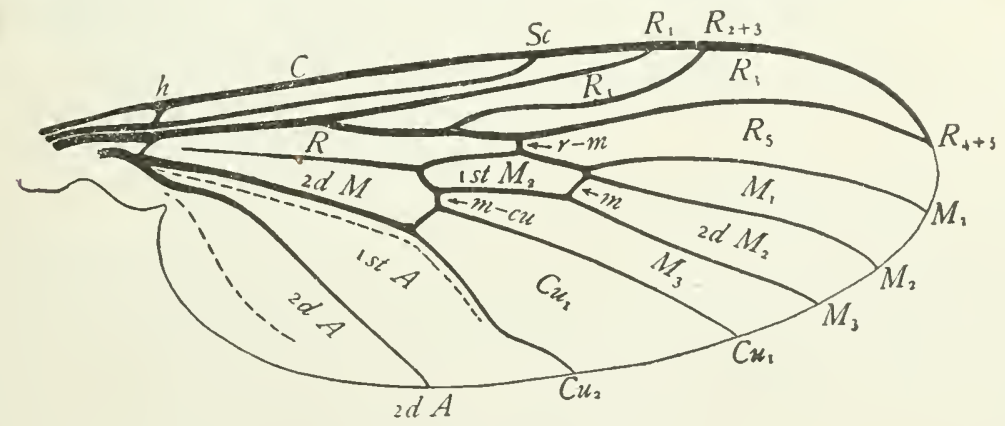

Fig. 67.-Wing of Rhyphus.

The former are bounded by the principal veins; the latter by the branches of the forked veins; a corresponding distinction is made in designating the cells. Thus the cell lying behind the main stem of radius and on the basal part of the wing is designated as cell $R$; while the cell lying behind radiusone is designated as cell $\mathrm{R}_{\mathrm{I}}$. 
It should be remembered that the coalescence of two reins results in the obliteration of the cell that was between them. Thus when veins $R_{2}$ and $R_{3}$ coalesce, as in Rhyphus (Fig. 67), the cell lying behind vein $R_{2}+_{3}$ is cell $R_{3}$ and not cell $R_{2}+3$, cell $R_{2}$ having been obliterated.

When one of these principal cells is divided into two or more parts by one or more cross-reins, the parts are numbered, beginning with the proximal one. Thus in Rhyphus (Fig. $6_{7}$ ) cell $\mathrm{M}_{2}$ is divided by the medial cross-rein into two parts, which are designated as cell ist $M_{2}$ and cell $2 \mathrm{~d} \mathrm{M}_{2}$ respectively.

The application of this system of naming the cells of the wing is an easy matter in those orders where the wings hare ferv reins; but in those
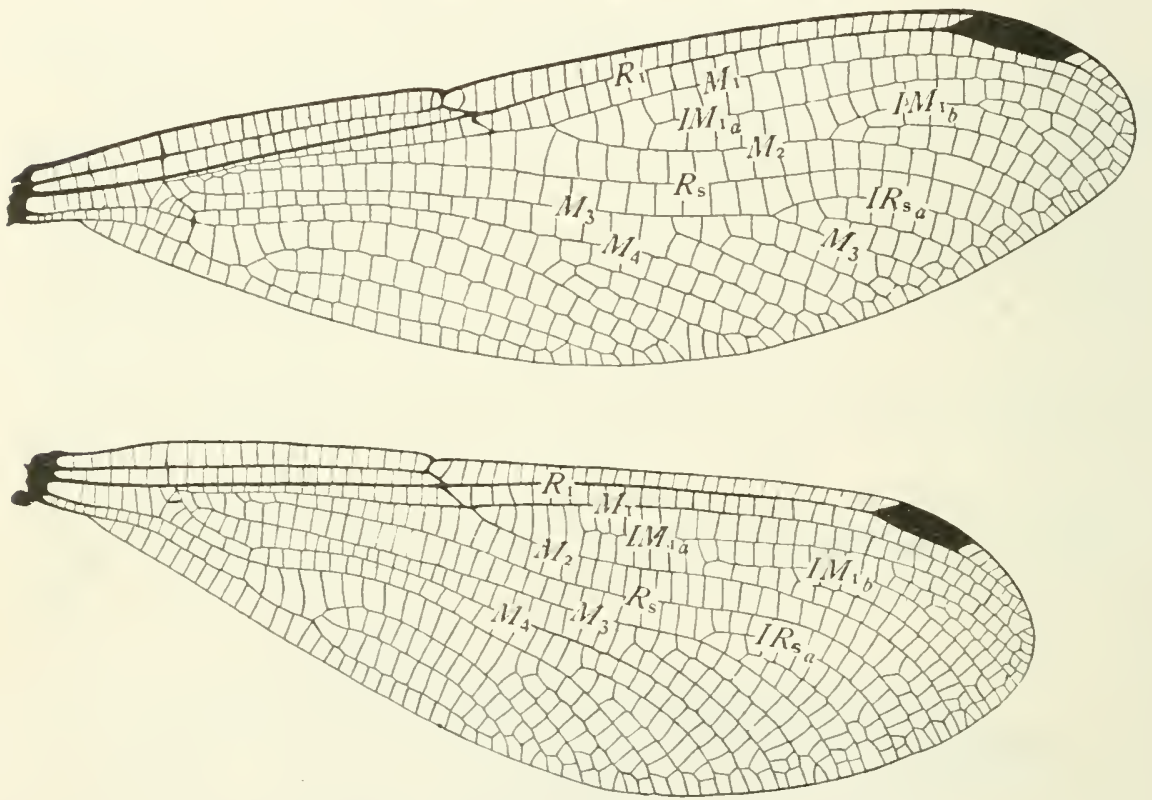

Fig. 68.-Wings of Chalcopteryx rutilans (After Needham).

orders where many secondary veins are developed it is difficult to apply it. In the latter case we have to do with areas of the wing rather than with separate cells. Thus, for example, in the Odonata (Fig. 68) that portion of the wing lying between veins $M_{1}$ and $M_{2}$, and which is traversed by one or more intercalary veins and many cross-veins, is designated as area $M_{1}$. This area is homologous with cell $\mathrm{M}_{1}$ of the Diptera (Fig. 67 ).

In applying this sytem to the Odonata, where the radial sector crosses veins $M_{1}$ and $M_{2}$ (Fig. 68) and traverses that part of the wing that really corresponds to cell $\mathrm{M}_{2}$ of the Diptera, the term area $\mathrm{I}_{2}$ is applied to that part of the wing between veins $M_{2}$ and $R_{s}$, and that part of the wing between veins $R_{s}$ and $M_{3}$ is designated as area $R_{s}$. 
Additional definitions. - In concluding this general account of the wings it is necessary to define a few terms that are not included in the preceding pages.

The cubito-anal excision.-In many insects there is a notch in the margin of the wing at the point where the preanal and anal areas join; this may be termed the cubito-anal excision.

Convex and concave veins.-In many insects the wings are corrugated like a partly open fan. In this case, the wing-veins that follow the crests of ridges are termed convex veins; and those that follow the furrows, concave veins. The corrugating of the wings is very marked in the Odonata, the Ephemerida, and in the anal area of the hind wings of the Orthoptera.

The ambient vein.-Sometimes the entire margin of the wing is stiffened by a veinlike structure; this has been designated the ambient vein by writers on the Diptera.

The humeral veins.-In certain Lepidoptera and especially in the Lasiocampidæ and the butterflies the humeral area of the hind wings is greatly expanded and in many cases is strengthened by the development of secondary veins. These are termed the humeral veins (Fig. 69, $h v$ ).

The pterostigma or stigma.-A thickened opaque spot which exists near the costal margin of the outer

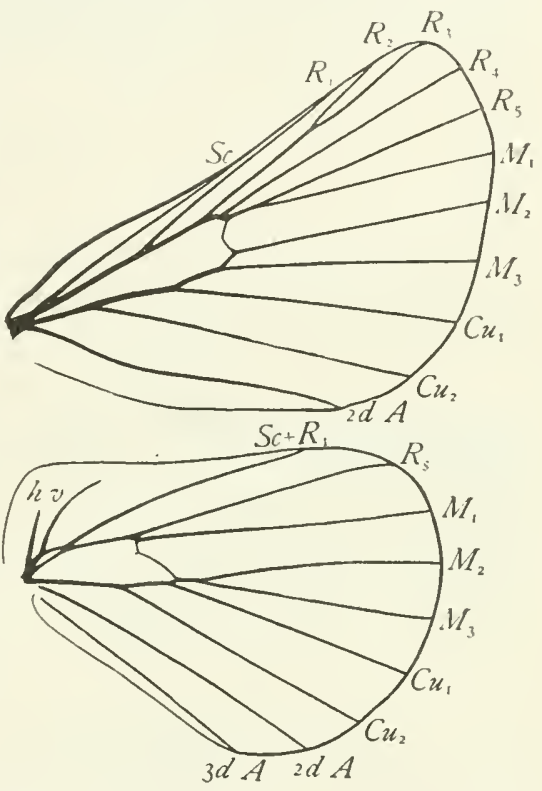

Fig. 69.-Wings of Clisiocampa americana; $h v$, humeral veins. part of the wing in many insects is known as the pterostigma or stigma. The pterostigma is present in the fore wings of most Hymenoptera, in both wings of the Odonata, and in the fore wings of the Psocidæ and Mantispidæ.

The bulla.-The bulle are weakened places in veins of the wing where they are crossed by furrows. The bullæ are usually paler in color than the other portions of the wing. They are common in wings of the Hymenoptera (Fig. 70) and of some other insects.

The bullæ are termed thyridia by some writers.

The appendiculate cell.- In the front wings of some Hymenoptera the tip of vein $R_{1}$ curves away from the margin of the wing and coalesces with the tip of vein $R_{3}$ at some distance from it. The space thus formed between the united tips of veins $R_{1}$ and $R_{3}$ and the costal margin of the wing is termed the appendiculate cell (Fig. $7 \mathrm{I}, a_{p}$ ). 
The epipleurce.-A part of the outer margin of the elytra of beetles when turned down on the side of the thorax is termed the epipleura.

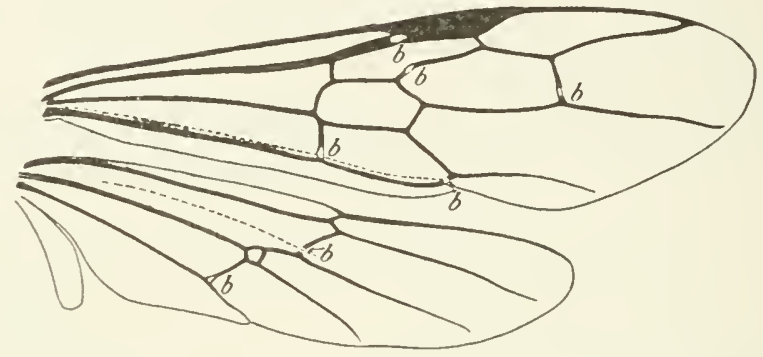

Fig. 7o.-Wings of Myrmecia; $b, b, b$, bullæ.

The transverse cord.- In many cases the wing is strengthened by a transverse series of cross-veins or of cross-veins and divaricated forks of longitudinal veins extending across the wing just beyond the middle of its

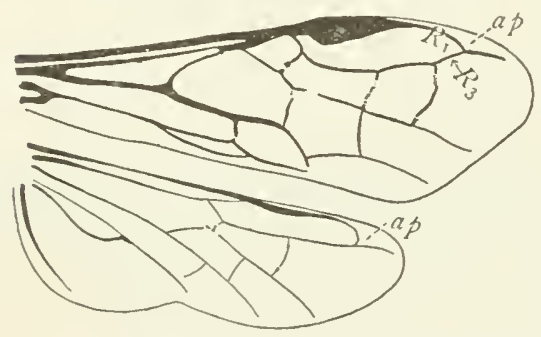

Fig. 71.-Wings of Labidarge dibapha; $a p$, appendiculate cell. length. This series may be designated as the transverse cord. In the wings of Hepialus (Fig. 72), there is a transverse cord extending between the points marked $a$ and $b$ in the figure. In this case the transverse cord does not extend to either margin of the wing; but in many insects it reaches one or both margins.

The discal cell and the discal vein.-There are two terms that, although not belonging to the uniform terminology, are frequently used as a matter of convenience by those who have adopted the uniform terminology; these are the discal cell and the discal vein.

These terms can not be made a part of the uniform terminology for they are not used in a uniform manner, being applied to different parts of the wing by the writers on different orders.

The term discal cell is applied to a large cell which

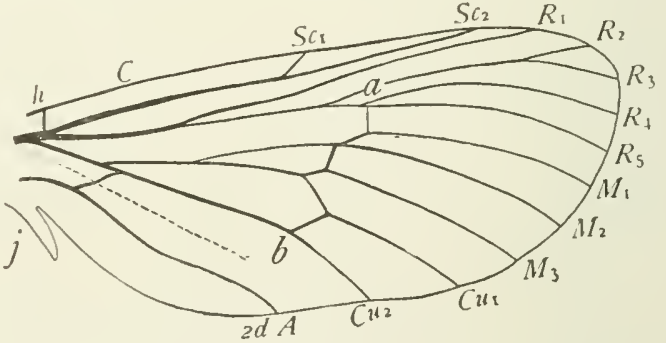

Fig. 72.-Wing of Hepialus; $a-b$, the transverse cord. is situated near the center of the wing; and the term discal vein, to the vein or series of veins that limits the outer end of the discal cell. 
In the Lepidoptera, in descriptions of which the term discal cell is most often used, it is cell $\mathrm{R}+\mathrm{M}+$ Ist $\mathrm{M}_{2}$ that is thus designated. The formation of a large discal cell is due in this case to the atrophy of the base of media, which results in the combination of the three cells named above into one.

In the Diptera it is cell rst $\mathrm{M}_{2}$ that is termed the discal cell; and in the Trichoptera it is cell $R_{2}+3$.

The hypostigmatic space.-In the Myrmeleonidæ and in some other families of the Neuroptera, there is a greatly elongated cell behind the point of fusion of veins $S c$ and $R_{1}$, this is termed by Tillyard the hypostigmatic space. 


\section{CHART OF GEOLOGIC TIME AND FORMATIONS}

The following chart will serve to indicate the geologic position of the strata from which the insect remains described in Chapter IV were obtained.

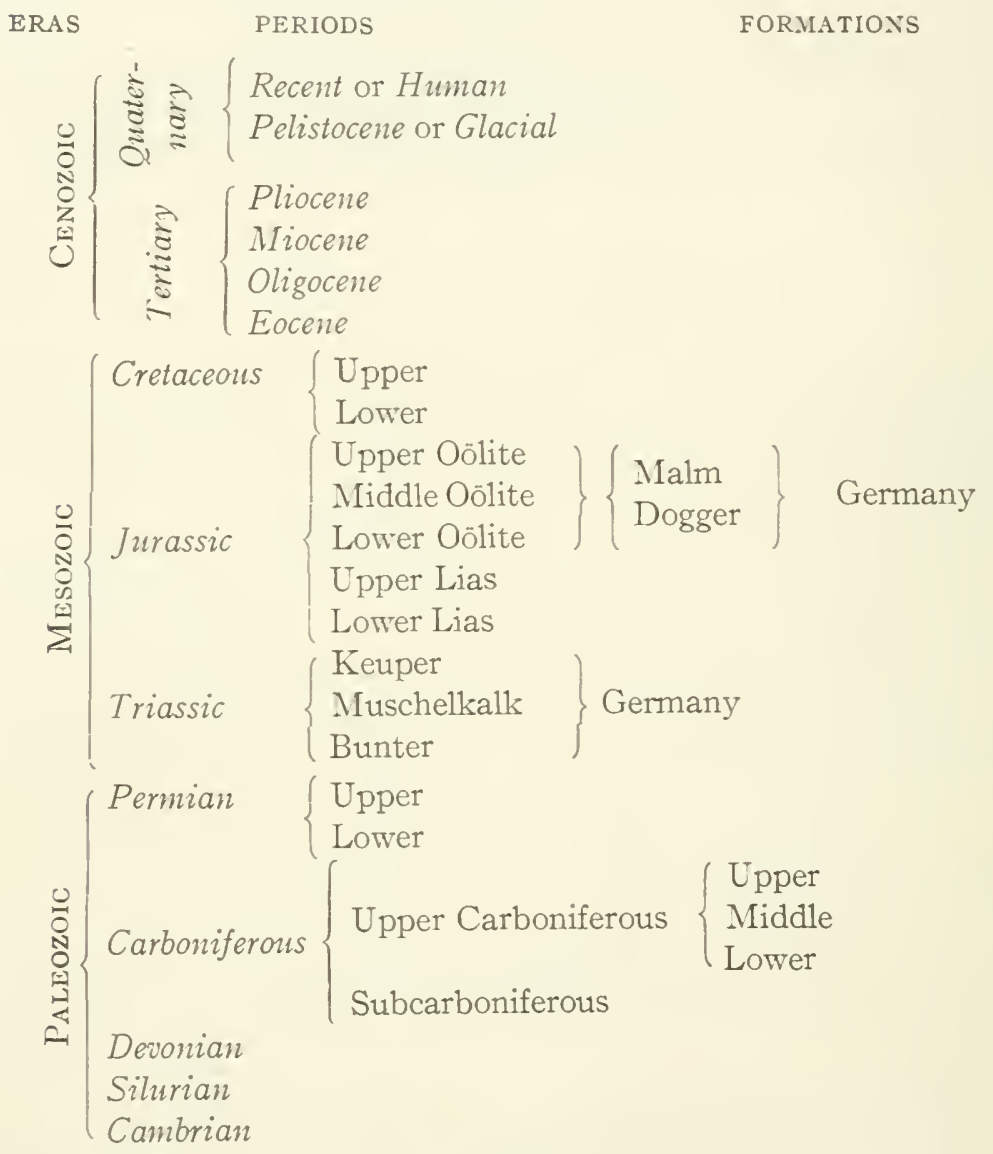

Proterozic

ARCHAOZOIC 


\section{CHAPTER IV}

\section{THE PALEONTOLOGICAL DATA BEARING ON THE DEVELOPMENT AND}

THE SPECIALIZATION OF THE WINGS OF INSECTS

\section{(a) EARly Views as to the Paleontological Evidence}

IN the development of the uniform terminology of the wing-veins almost no use was made of paleontological data. In fact the conclusions drawn from the study of fossil insects by the older writers tended to retard rather than to advance this development.

It was commonly assumed at the time Redtenbacher wrote his "Vergleichende Studien über das Flügelgeäder der Insecten" that the wings of May-flies resemble closely the wings of the primitive winged insect; and there are frequent references in the literature of that period to the supposed fact that the older insects had a "richer" wing-venation than that of most of the recent insects. Thus Redtenbacher (l.c.p. I53) makes the following statement:

"The geologically older Orthoptera and Neuroptera show a much richer venation than the Coleoptera, Lepidoptera, Hymenoptera, and Diptera; likewise among the Rhyncota the oldest forms, the Cicadas and the Fulgoridæ, possess much more numerous veins than the Hemiptera. There is apparently, then, no doubt that the oldest insect forms were provided, to a certain extent, with a superfluity of veins, and that, in the course of development, all the superflous veins disappeared by reduction, and in this way a simple system of venation was brought about."

The accuracy of this conclusion was first seriously questioned by Comstock and Needham.* At the time we wrote our "The Wings of Insects"

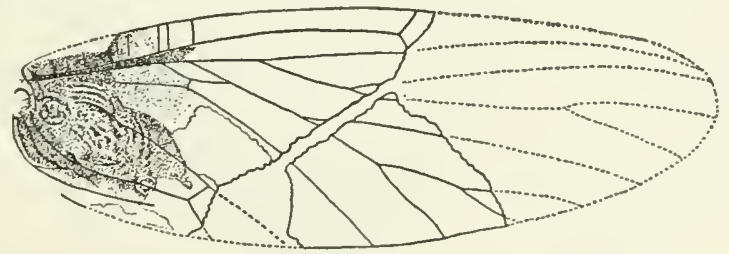

Fig. 73.-Xenoneura antiquorum (After Scudder).

the fossils described by Mr. Scudder from St. Johns, New Brunswick, were supposed to be from Devonian rocks, and consequently to be the oldest well-preserved insect remains. Regarding these we wrote as follows:

"Of the Devonian insects, the remains of several are known. Those that are best preserved are Homothetus fossilis (Fig. 74), Xenoneura antiquorum (Fig. 73), and Platephemera antiqua (Fig. 75). (The figures given

*The American Naturalist, Vol. 33, p. 125. 
here are reproduced from Plate VII of Mr. Scudder's 'Pretertiary Insects'). A glance at these figures will convince the reader that the insects of the Deronian times varied greatly in the structure of their wings. For these

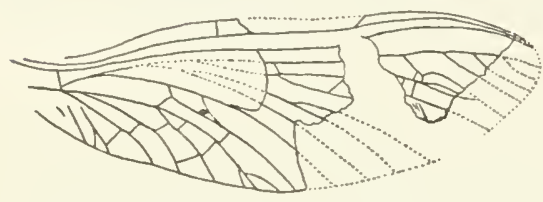

Fig. 74.- Homothetus fossilis (After Scudder).

three insects differ as much from each other as do the more generalized members of widely separated orders of living insects. Evidently, comparatively high specializations in widely different directions had been attained already at that early time. But the point to which we wish to call especial attention is that, of the three better-preserved Devonian insects, one (Xenoneura) had but few wing-veins. And when we consider the slight amount of data that we have, the numerical preponderance of the manyveined type has no significance.

"It is easy to conceive of the development of the wings of all living insects from forms allied to Xenoneura, by the different methods of specialization which we have pointed out; for it will be seen that the wing of this insect closely resembles our hypothetical type. And we can say, therefore, that the paleontological evidence does not contradict the conclusions drawn from a study of the ontogeny of living forms."

The time has now come when we can present the paleontological data bearing on this subject much more in detail than was possible at the time the above paragraphs were written; for since then the great work on fossil insects by Handlirsch ('o6-'o8) has appeared. In this work there is

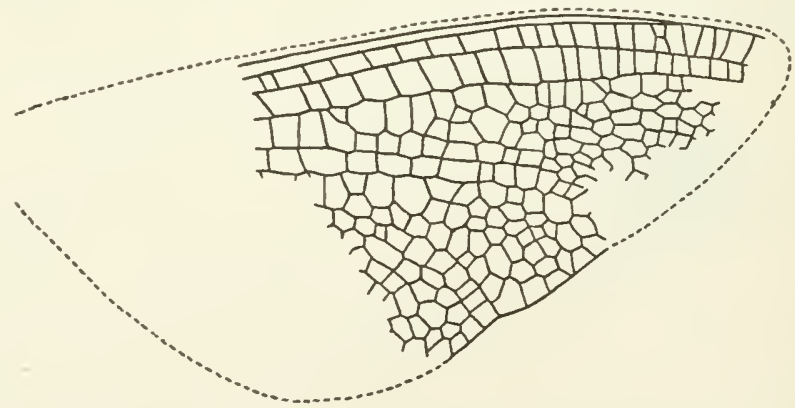

Fig. 75.-Platephemera antiqua (After Scudder).

brought together and systematized in a masterly manner what was known regarding Paleozoic insects at the time the book was written; and the most excellent figures accompanying this work enable us to see clearly what was the characteristics of the wing-venation of the oldest insects whose remains have been found. 
Before entering upon a discussion of the data bearing on the primitive type of wing-venation it may be well to examine briefly the data bearing upon the origin of wings.

\section{(b) ON THE ORIGIN OF WINGS}

The question as to the origin of the wings of insects has been discussed for nearly or quite one hundred years; and although a large number of the more eminent entomologists of this period have taken part in this discussion, the writers of to-day hold widely different opinions on this subject.

A detailed discussion of this question does not fall within the scope of this essay. The reasons that have led to the adoption of the uniform terminology of the wing-veins of insects are entirely independent of the question as to the method in which wings were originally developed. The important fact in this connection is that a study of the more generalized members of the several orders of winged insects shows that the type of venation is the same for them all, which indicates that wings have originated but once in the class Hexapoda; or, to state the same thing in other words, all of the orders of winged insects have descended from a common stock.

In discussing the origin of wings, we must assume that they were developed to a comparatively large size before they began to function as active organs of flight; for minute rudimentary wings would be useless as active organs of flight.

As to the function of the organs that were later modified into wings there are two views, each of which have been widely advocated. One school of writers believe that the wings are modified gills; that they were derived from either the dorsal gills of the annelidan ancestors of insects or from tracheal gills resembling those of the nymphs of May-flies. Another school of writers believe that the wings were evolved from lateral expansions of body-segments which at first merely functioned as parachutes.

The theory that the wings were evolved from lateral expansions of the body-segments is the one that I believe is most strongly supported by the available evidence; the nature of this evidence will be shown a little later. A review of these two theories has been published recently by Crampton ('I6); and the reader is referred to this paper for references to the literature of the subject.

The view that the wings of insects originated as dorsal backward . prolongations of the tergum is combatted by Tower ('०3) who believes "that the evidence points strongly to Verson's ('90) view that the wings of Coleoptera and Lepidoptera are derived from the rudiments of the mesothoracic and metathoracic spiracles." Verson studied the embryo of Bombyx mori and Tower that of Leptinotarsa decemilineata.

Powell ('05), however, as a result of a study of the development of the wings of two species of the Scolytide, shows that the wings do not arise 
from any part of the spiracles of the mesothorax or metathorax; and concludes "that the wings have been derived as lateral outgrowths or folds of the hypodermis of the pleurum or tergum, or both."

Some authors, as Handlirsch and also Lameere, regard the wings as homologues of the pleuræ of Trilobites; the Trilobites being regarded as the stem form from which the insect series as well as the arachnid series have been evolved. Handlirsch gives a series of diagrams illustrating this supposed homology. It seems to me, however, hardly necessary to believe that this homology means more than that in the two cases corresponding parts of the body are expanded. I do not believe that the broadly expanded plura of Triolbites were preserved by all of the forms intervening between the Trilobites and the winged insects. In fact Handlirsch describes the primitive insect, the Protentomon of Paul Mayer, as having the body moderately slender, almost cylindrical.

We can imagine that from a form like the supposed Protentomon forms were evolved in which the body became shortened and flattened; and that the subsequent course of development was as follows:

The flattened form of the body was well-fitted for running over the trunks of the carboniferous plants and for creeping between fronds of the giant ferns of that time. Lateral expansions of the pleura of most of the segments were developed which facilitated leaping from trunk to trunk in a manner analogous to that now used by our flying squirrels.

At first nearly all of the body-segments, all except those at the caudal end of the body, were furnished with the lateral expansions. Later there was an increased specialization of the lateral expansions of the mesothorax and metathorax and a reduction of those of the other segments, resulting in a form with two pairs of fixed wings.

The next step was the development of a hinge at the base of each of these four wings; but at first these wings could be moved only in a vertical direction, and were held outspread when at rest. Later the ability to fold the wings over the abdomen was attained.

The paleontological data on the origin of wings.- The account of the origin of wings just given is largely hypothetical. Let us now see what data bearing on the subject we actually have.

We naturally turn to paleontology for this data. Fortunately the paleontological data has been made very available by the magificent work of Handlirsch, in which every known paleozoic insect is figured, except some recently described.

Although nearly goo paleozoic insects are known (Handlirsch lists 884), unfortunately we have no specimens of the insects that preceded those with well-developed wings. The oldest fossil insects known to us had wings as large as those of modern insects. But although some of the connecting 
links that we should be glad to see have not been found, certain others that throw much light on the origin of wings are known.

It is now believed that the oldest known insect remains are from the lower part of the Upper Carboniferous; for it has been concluded that the two supposed insect remains from the Silurian are not of insect origin; and that the supposed Devonian insects describer by Scudder belong to the Upper Carboniferous. No insect remains have been found in the Subcarboniferous. $^{*}$

In the classification of geological formations adopted by Handlirsch, the Upper Carboniferous, in which most of the insect remains that are referred to in this Chapter were found, is divided into the Lower Upper Carboniferous, the Middle Upper Carboniferous, and the Upper Upper Carboniferous. For convenience of reference to his work I have followed him in the use of this somewhat cumbersome nomenclature.

Among the Paleozoic insects there are certain very generalized forms that differ so markedly from all of the living orders of insects that they have been placed in a separate order to which the name Palæodic-

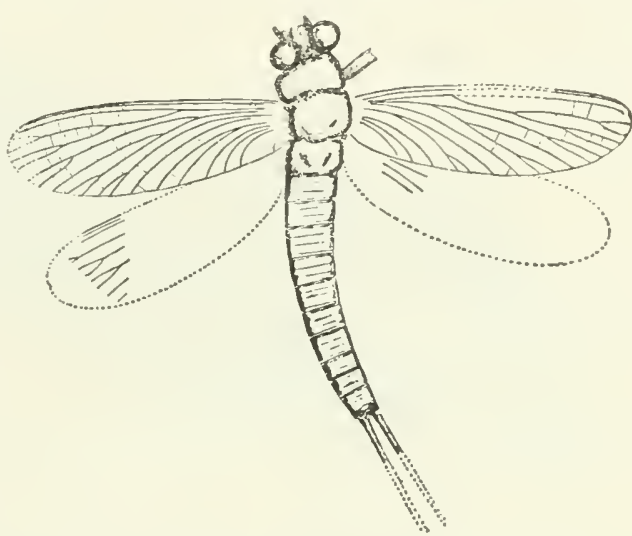

Fig, 76.-Eubleptus danielsi (After Handlirsch). tyoptera has been applied. Many representatives of this order have been found. Handlirsch describes and figures i 5 of them.

The Palæodictyoptera is believed to include the stem forms from which all other orders of insects, both fossil and recent, have been evolved. It is obvious, therefore, that the search for paleontological data bearing on the origin of wings should be made among the remains of this order. These are found in each of the divisions of the Upper Carboniferous mentioned above.

From the Lower Upper Carboniferous only eight insect remains are known; these are all wings or fragments of wings. To test either of the theories regarding the origin of wings it is necessary to study the remains of the body of a palæodictyopteron.

In the Middle Upper Carboniferous, there has been found a member of this order in which the body is well-preserved. This is Eubleptus danielsi (Fig. 76), from Mazon Creek, Illinois. While this insect furnishes important data regarding the venation of the wings of primitive insects, it throws but little if any light on the origin of wings.

*The reader is referred to page $8+$ for a chart of geologic time and formations. 
It is in the Upper Upper Carboniferous that has been found the most important evidence regarding the origin of wings. This is furnished by the remarkably well-preserved Stenodictya lobata (Fig. 77), from Commentry, France.

The most striking feature of this insect is that the prothorax bears wings of considerable size, and that there is a small wing on each side of each of the first eight abdominal segments.

The presence of these prothoracic and abdominal wings in the Palæodictyoptera is the basis for the conclusion that the wings were derived from

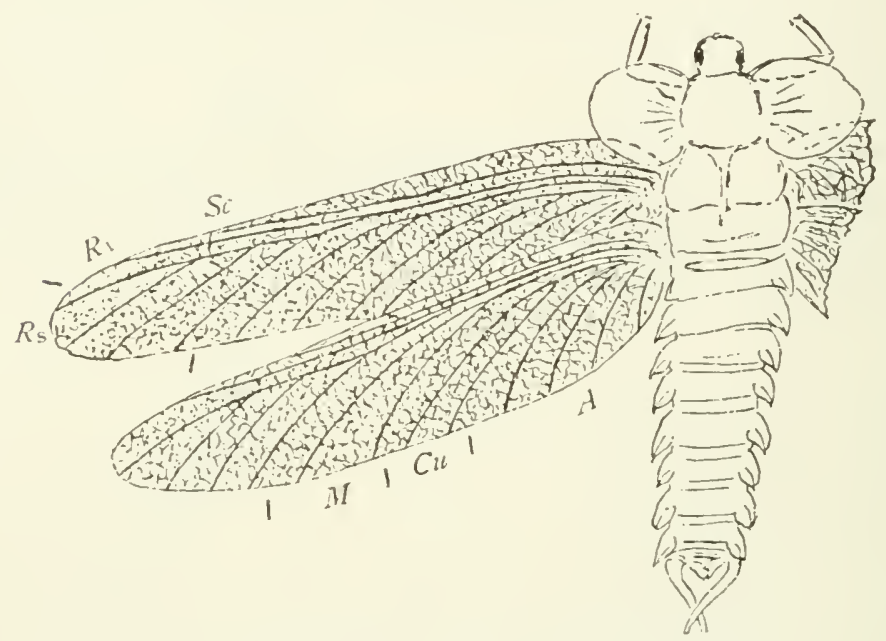

Fig. 77.-Stenodictya lobata (After Handlirsch).

lateral expansions of the plura of the body-segments, which functioned as parachutes; that nearly all of the body-segments bore these expansions; and that later there was an increase in size of the mesothoracic and metathoracic expansions and a reduction of the others.

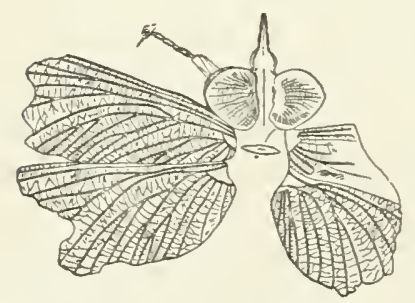

Fig.78.-Lithomantis carbonaria (After Woodward).

It is evident that when the mesothoracic and metathoracic pleural expansions became active organs of flight, by the development of a hinge at the base, they became the field of variations and of selective processes that resulted in their greatly increased size and in the development of many forms of wing-venation, while the other pleural expansions remained with little change for a long period. This is shown by the fact that, although there are comparatively fer cases among the remains of the Palæodictyoptera where any part of the prothorax is preserved, these include representatives of five 
families in which there are prothoracic wings.* One of these is represented in Figure 78.

It is probable that the prothoracic expansions were useful even after the appendages of the second and third thoracic segments became active organs of flight. That they were retained after the loss of the abdominal expansions is shown by Lycocercus Goldenbergi, (Handlirsch, P1. X, Fig. 20).

In all of the remains of the Palæodictyoptera in which both the wings and the body are preserved, the wings are extended. It seems probable, therefore, that they could be moved only vertically. The ability to fold the wings over the abdomen was acquired only by later developed orders. One of the older illustrations of this is Spaniodera ambulans (Fig. 79), a member of the Order Protorthoptera, found in Illinois and in Pennsylvania, in the Middle Upper Carboniferous.

Handlirsch believes that the Palæodictyoptera were amphibious; but it does not seem to me at all probable that this was the case. Two nymphs from the Middle Upper Carboniferous are known: one (Fig. 8o) from Sadgley, England; and one

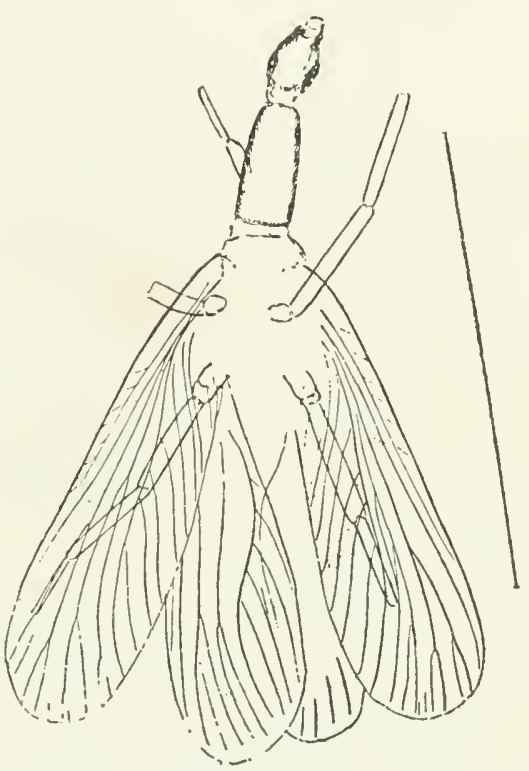

Fig. 79.-Spaniodera ambulans (After Handlirsch).

(Fig. 8I) from Hampton, West Virginia. It is difficult to imagine insects with laterally projecting wing-buds, such as these nymphs possessed, swimming through the water.

It seems to me obvious that the development of aquatic nymphs could have occurred only after the developing wings had become folded back along the sides of the body. The fact that the three recent orders with aquatic nymphs, the Odonata, the Ephemerida, and the Plecoptera, have different types of tracheal gills indicates that they could not have been evolved from a common aquatic progenitor.

\section{(c) ON the Course of the Evolution o'f EACH OF The PRincifal WING-VEINS}

In our efforts to construct a diagram representing the probable type of the wing-venation of the primitive winged insect Comstock and Needham

\footnotetext{
*These are Stenodictya, Lithomantis, Lycocercus, IIomcophlebia, and Homaloneurina.
} 
studied the tracheation of the wings of nymphs and of pupæ of the more generalized members of all of the orders of living insects of which material was available.

In the case of each of the wing-veins, a comparative study was made of the trachea that precedes it in all of the orders in which that trachea is

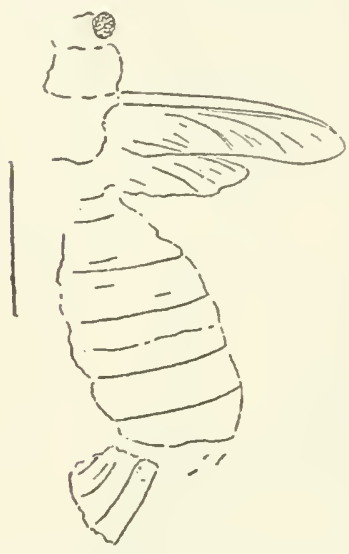
Fig. 80.-Nymph of a Paleo- vein.

dictyopteron (After Handlirsch). retained; and in those orders where the tracheation is reduced, a study was made of the wingvein in the more generalized members of the order. It was upon these studies that our conclusion regarding the probable primitive form of the wing-vein was based. It is of interest now to ascertain to what extent the validity of these conclusions is supported by the paleontological data at hand.

The evolution of the costa.-Little can be said about the evolution of the costa; for in the oldest of winged insects known to us it had reached the form characteristic of the most specialized of living insects, that of an unbranched marginal

The need of a firm support of that margin of the wing where the greatest stress falls in active flight evidently led very early to the attainment of the form of the vein that has persisted to the present.

The evolution of the subcosta.-Among recent insects three types of the subcosta exist: first, that which is well-shown in Nemoura, in which the rein is divided into two branches (Fig. $82, a)$; second, the type found in many insects, in which it is a simple unbranched vein (Fig. $82, b)$; and third the type that is well-illustrated by the subcosta of Corydalis, in which the principal vein bears many small branches Fig. $\left.S_{2}, c\right)$.

It seemed probable to Comstock and Needham that the second and third types had been derived from the first; that the second type was erolved by the loss of one of the branches existing in the first; and that the third type was the result of a specialization by

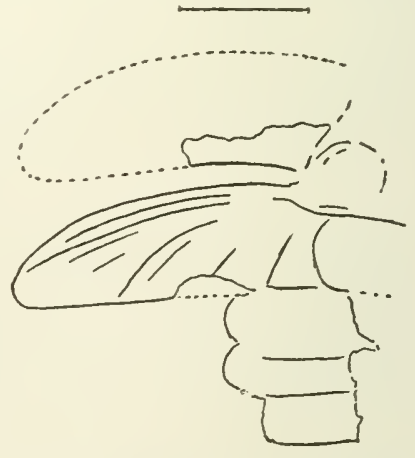

Fig. 81.-Nymph of a Paleodictyopteron (After Handlirsch). addition.

Among the facts that led to the conclusion that the two-branched type was the more primitive one are the following: In Xenoneura (Fig. 73), which at the time we wrote our series of articles was believed to be a 
Devonian insect and consequently one of the oldest insects known, the subcosta as figured by Scudder is clearly of this type. In the Plecoptera, which is a very generalized order of insects, probably more generalized than any other of the recent orders of winged insects, except perhaps the Orthoptera, the subcosta is of this type (Fig. 82,a). In very young nymphs of Odonata the subcostal trachea is two-branched (Fig. 227), and unbranched in the wing of a mature nymph (Fig. 228). In the Lepidoptera, the subcosta is two-branched in Hepialus; and MacGillivray has since shown that the subcostal trachea is two-branched.

Passing to the orders in which the tracheation is reduced, and consequently of no aid in the solution of this problem, the subcosta is twobranched in many of the Trichoptera, in the more generalized Hymenoptera, and in Protoplasa, the most generalized of the recent Diptera. It is

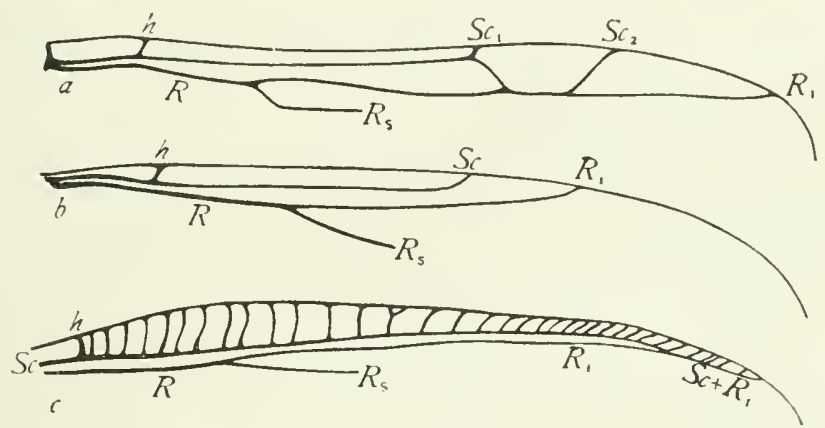

Fig. 82.-The three types of the subcosta; $a$, subcosta of Nemoura; $b$, subcosta of Rhyphus; c, subcosta of Corydalus.

unnecessary to go farther to show that we had good reason for regarding the two-branched type of the subcosta as primitive.

Let us now turn to an examination of the paleontological evidence bearing on the primitive type of the subcosta. At first sight this evidence does not support the conclusion drawn from the study of living forms; for in the Palæodictyoptera, which in most respects are the most generalized of fossil insects, the subcosta was not branched (Fig. 77).

I do not feel, however, that this evidence is conclusive. The most generalized of the Palæodictyoptera are the Dictyoneuridæ, of which Stenodictya lobata (Fig. 77) is the best preserved form known. While the members of this family have retained the prothoracic and abdominal wing-rudiments, and have not yet attained definite cross-veins in the wings, both primitive characteristics, the mesothoracic and metathoracic wings have evidently been specialized in certain ways that will be discussed later. And it is quite possible that along with these specializations there has been a loss of one branch of the subcosta. One must keep constantly in mind 
the fact that the oldest of the Dictyoneuridæ known are from the Middle Upper Carboniferous, and that at that period winged insects had existed

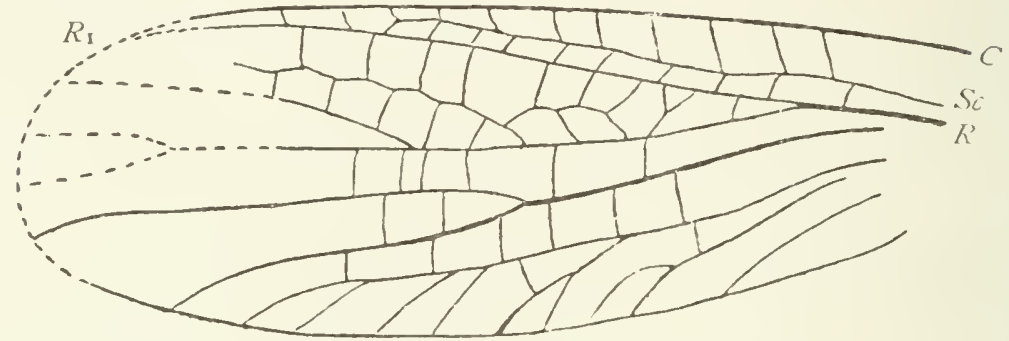

Fig. 83.-Hadentomum americanum (After Handlirsch).

for a long time. The stem form of the wing-insect series evidently existed either very early in the Lower Upper Carboniferous or, which is more probable, in the Subcarboniferous.

In the order Hadentomoidea, represented by a single species, Hadentomum americamum, from the Middle Upper Carboniferous, and consequently contemporaneous with the most generalized of the Palæodictyoptera, there is what appears to be a division of the subcosta into two branches (Fig. 83 ). In the fore wing of this insect the subcosta has two tips: one tip ends in the margin of the wing, the other extends to vein $R_{1}$. It may be, however, that the latter is merely the last of the series of cross-veins between veins $S c$ and $R_{1}$.

In the order Mixotermitoidea, which is represented by only two known genera, we find in Mixotermes lugauensis a forked subcosta (Fig. 84); and, among the "Palæodictyoptera incertæ sedis" of Handlirsch, Xenoneura antiquorum, as figured by Scudder (Fig. 73), has a

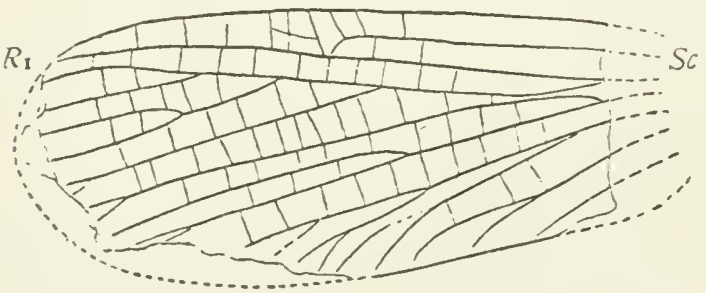

Fig. 84.-Mixotermes lugauensis (After Handlirsch). forked subcosta. Both of these species are from the Middle Upper Carboniferous and were, therefore, like Hadentomum, contemporaneous with the most generalized of the known Palæodictyoptera.

In the order Megasecoptera we find a distinctly branched subcosta in Diaphanoptera Munieri (Fig. 85). But in the closely allied Corydaloides and Aspidothorax the subcosta is simple. These are all from the Upper Upper Carboniferous. 
This condition is paralleled by the recent Diptera, among which the very generalized Protoplasa (Fig. 360) has a distinctly branched subcosta, while in most members of the order this vein is simple.

In conclusion one can say that the forking of the subcosta is a very ancient feature of this vein; whether it existed or not in the stem form of the winged insect series remains to be determined. Obviously nothing

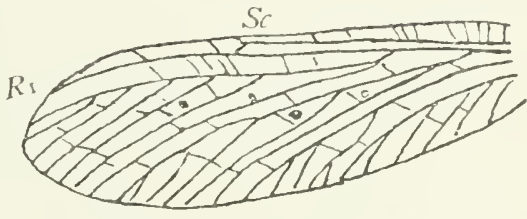

Fig. 85--Diaphanoptera Munieri (After Handlirsch). would be gained by representing it as a simple vein in our diagram of the hypothetical type of primitive wing-venation.

The evolution of the radius.-As the result of our studies of recent insects Comstock and Needham concluded that the primitive form of the radius was that represented in our hypothetical type of primitive wingvenation (Fig. 6). We were led to this conclusion by the fact that in the more generalized members of several of the orders of insects this type of radius exists. Among these are the Homoptera, Lepidoptera, Trichoptera, Diptera, and Neuroptera. Detailed discussions of examples are given in later chapters. And in each of those orders where another type of radius exists, it is easy to see how it has been derived from the hypothetical typical form by well-known methods of specialization.

Let us pass now to an examination of the paleontological data bearing on the primitive form of the radius. There can be no doubt that the first forking of the radius, by which this vein becomes divided into two parts, which are now known as veins $R_{1}$ and the radial sector, or vein $R_{s}$, respec-
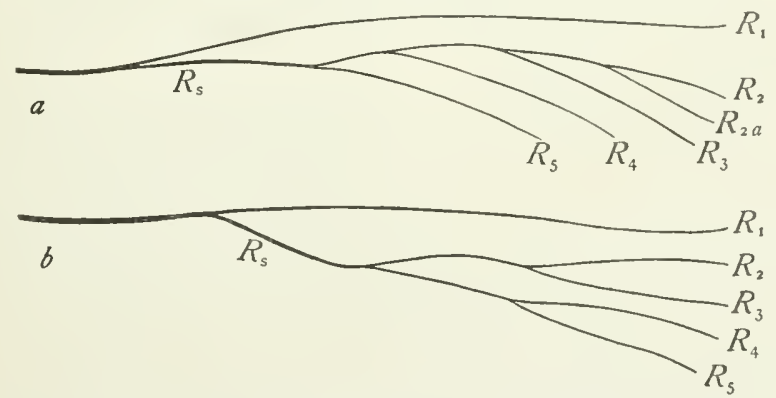

Fig. 86.-Diagram representing the two types of the radial sector; $a$, the pectinate type; $b$, the dichotomously branched type.

tively, is a very ancient characteristic of this vein. This forking is so constantly present in the fossils to be discussed later that it is unnecessary to cite examples of it here. The part of the radius that requires special study is the radial sector. 
Two types of the radial sector are found in the older insect remains, and in living insects as well. These may be defined as the pectinate radial sector and the dichotomously branched radial sector, respectively.

In the pectinate radial sector the principal branches form a single series of approximately parallel veins, resembling in their arrangement the teeth of a comb (Fig. 86, a). In the dichotomously branched radial sector, the principal branches, typically four in number, show a dichotomous arrangement; that is the sector divides into two stems and each of these in turn divides into two branches (Fig. 86, b).

A good example of the pectinate type of radial sector is that of Stenodictya (Fig. 77). The genus Stenodictya is placed by Handlirsch in what he considers the most generalized family of the Palæodictyoptera, the Dictyoneuridæ. In another genus, Polioptenus, both types occur; and in all other known genera of this family of which the wings are sufficiently

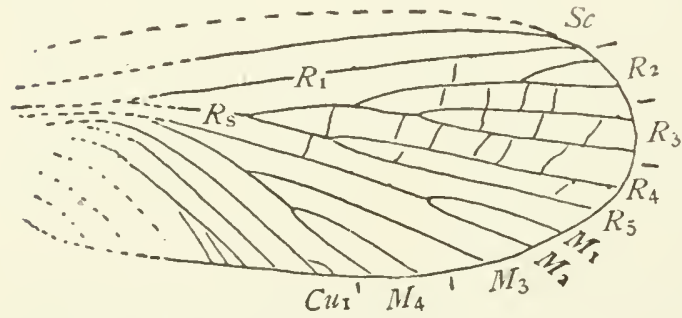

Fig. 87.-Metropator pussillus (After Handlirsch). well-preserved to show the form of the radial sector the principal branches show a dichotomous arrangement. There are ten of these genera; eight of which are from the Middle Upper Carboniferous; while all of the species of Stenodictya are from the Upper Upper Carboniferous.

In other words, all of the older Dictyoneuridæ, except Polioptemus in which both types of radial sector are found, had the radial sector dichotomously branched.

It seems evident, therefore, that in the later appearing Stenodictya from the Upper Upper Carboniferous, the radial sector has not retained its primitive form; and that the pectinate type was derived from the dichotomously branched type. In the chapter on the wings of the Neuroptera the suppression of the dichotomy of the radial sector is discussed.

A careful tabulation of the data exhibited by the Palæodictyoptera as a whole shows that the type of branching of the radial sector can be determined in representatives of twenty of the twenty-two families included in the order; and that in fourteen of these twenty families only the dichotomous type is found; in two, only the pectinate type; and in four both types existed.

Let us now study the evidence presented by the oldest insect remains that are known, those from the Lower Upper Carboniferous. Of these there are eight, six from the United States, and one each from Wales and from Germany. 
The only one from the Anthracite Region of the United States is Metropator pusillus (Fig. 87), from the Lower Lykens series, near Altamont

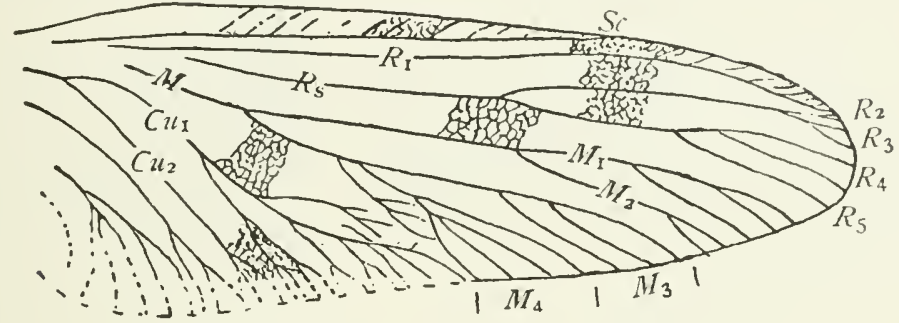

Fig. 88.-Paolia vetusta (After Handlirsch).

Colliery, Pennsylvania. In this wing, the radial sector corresponds closely with the hypothetical type except that it bears two accessory veins, one each on veins $R_{2}$ and $R_{3}$.

Of about the same age as Metropator are two fossils from Indiana and one from Alabama. The best preserved of these three is Paolia vetusta (Fig. 88), from the Mansfield formation, near French Lick, Indiana. That this is a very generalized insect is shown by the fact that the spaces between the veins were filled with an irregular network of veins; definite cross-veins had not yet been attained. In this wing the radial sector is dichotomously branched. Veins $R_{2}$ and $R_{3}$ coalesce nearly to the margin of the wing; and vein $R_{3}$ bears an accessory vein. There is also an accessory vein on vein $R_{4}$.

A second species from the same formation is Paolia Gurleyi (Fig. 89). The radial sector of this is also dichotomously branched. It differs from that of the preceding species Fig. 89.-Paolia Gurleyi (After Handlirsch). in a slightly different distribution

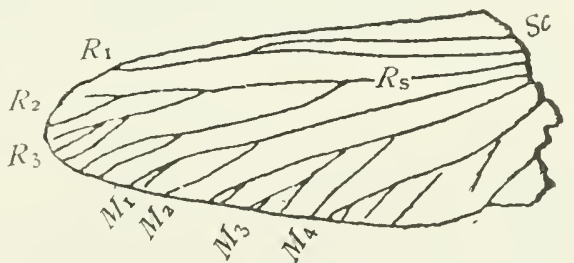
of the accessory veins, there being two on vein $R_{3}$ and none on vein $R_{4}$.

The Alabama species, which is believed to be nearly contemporaneous with the two first described, is Campteroneura reticulata (Fig. 90). This is a fragment of a wing from the Mary Lee group, Cordova, Alabama. This fragment includes only a part of the anal area and perhaps a part of the cubital area; it throws no light on the branching of the radial sector.

Another fragment of a wing from Alabama is supposed to be of a slightly more recent time; this is Bathytaptus falcipennis (Fig. 9I), of the Pratt group, Coalbury near Birmingham. This is a more specialized wing than either of those described above; definite cross-veins had been attained. In this wing the radial sector is clearly typical with the addition of two accessory yeins on vein $\mathbf{R}_{\mathbf{2}}$. 
The last of the series of American fossil insect remains from the Lower Upper Carboniferous is Eurythmopteryx antiqua (Fig. 92), from the Pratt

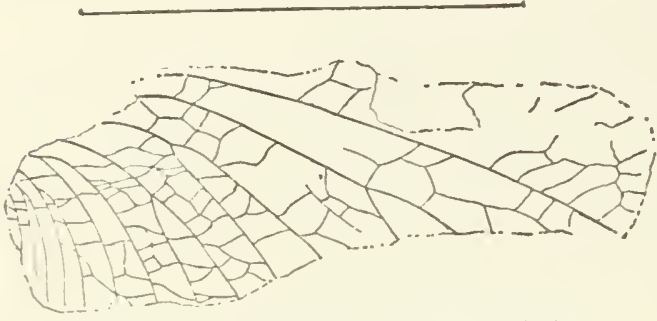

Fig. 90.-Campteroneura reticulata (After Handlirsch). Mines, near Birmingham, Alabama. As in the preceding species, this wing shows definite cross-veins. The radial sector is typical with the addition of one accessory vein on vein $R_{2}$.

The single representative of the Lower Upper Carboniferous insects found in the British Islands is

Psendofonquea cambrensis (Fig. 93), from the Lower Coal Measures, Cardiff, Wales. In this wing the radial sector is typical with the addition of an accessory vein on vein $R_{2}$.

There remains only a single Lower Upper Carboniferous insect to be mentioned. This is the German Stygne Roemeri (Fig. 94), from Laurahütte in Upper Silesia. In this species the radial sector is dichotomously branched and bears many accessory veins. A remarkable feature of this wing is the presence of a series of accessory veins extending from the radial sector into cell $\mathrm{R}_{1}$.

This series of the oldest insect remains confirms the conclusion, drawn from a study of recent insects, regarding the primitive type of branching of the radial

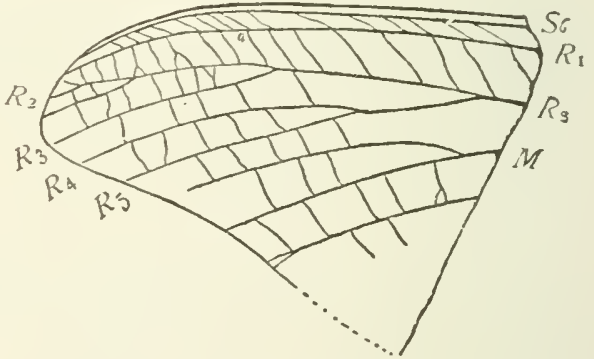

Fig. 91.-Bathytaptus falcipennis (After Handlirsch). sector. That is the sector was typically four branched and the branching was dichotomous. In addition to the four principal branches there

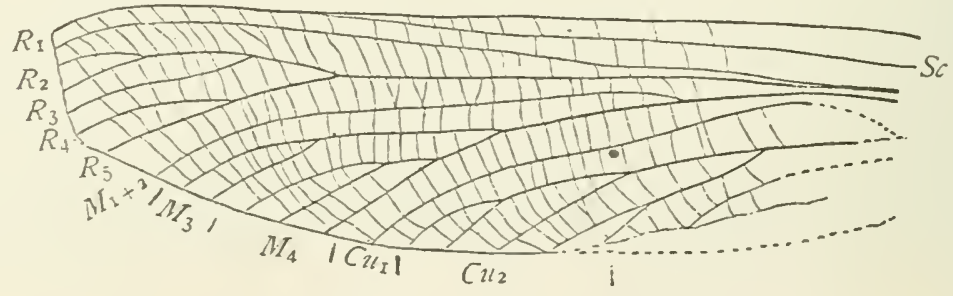

Fig. 92.-Eurythmopleryx antiqua (After Handlirsch). 
was a variable number of accessory veins. But the fact that there was no regularity in the position and number of these accessory veins indicates that they were not of fundamental importance and could not be included in a diagram representing the primitive type of branching of the wing-veins.*

The evolution of the media.-In the case of media it is much more

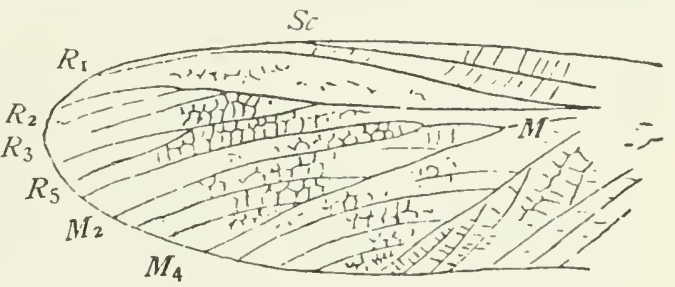

Fig. 93.-Pseudofouquea cambrensis (After Handlirsch).

difficult to determine the primitive type of branching. A study of recent forms led Comstock and Needham to conclude that the primitive media was four branched and that the branching was dichotomous. Regarding this we made the following statement:

"The vein occupying the center of the wing is the media (M). In those orders in which it retains most nearly its primitive form it is usually three-

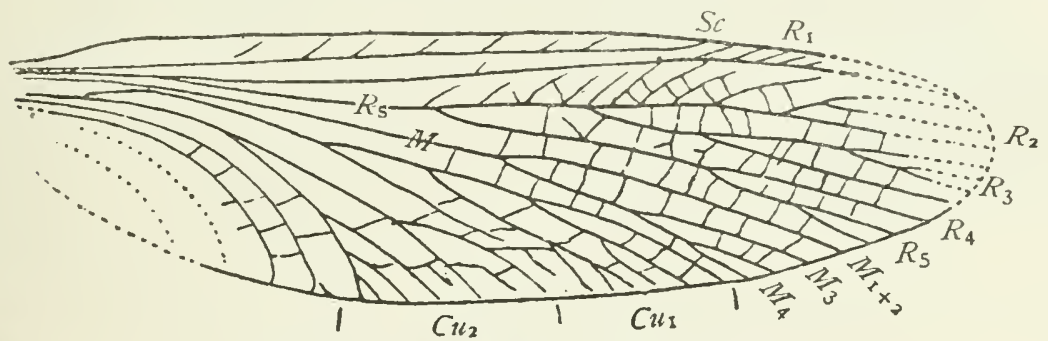

Fig. 94.-Stygne Roemeri (After Handlirsch).

branched; but the fact that in the more generalized members of several widely separated orders it is four-branched leads us to believe that it was four-branched in the stem form of winged insects. The branches are designated as media-one $\left(M_{1}\right)$, media-two $\left(M_{2}\right)$, media-three $\left(M_{3}\right)$, and mediafour $\left(M_{4}\right)$, respectively."

The following are examples of generalized forms among living insects showing a four-branched media:

*Distribution of Accessory Veins in the Lower Upper Carboniferous Insects Fig. $\mathrm{R}_{2} \mathrm{R}_{3} \mathrm{R}_{4} \mathrm{R}_{5} \mathrm{M}_{\mathrm{I}} \mathrm{M}_{2} \mathrm{M}_{3} \mathrm{M}_{4} \mathrm{Cu}_{1} \mathrm{Cu}_{2}$

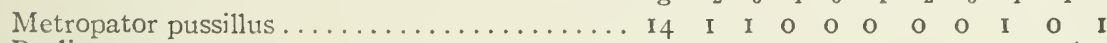

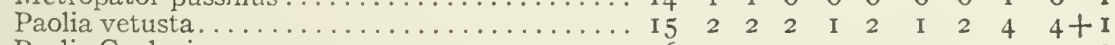

Paolia Gurleyi.......................... I6 $16 \ldots \ldots$

Camptoroneura reticulata...................... I

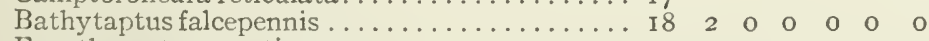

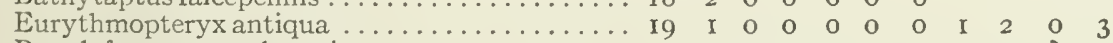

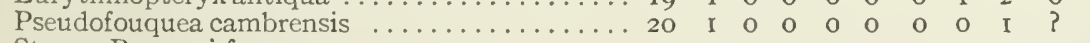

Stygne Roemeri fore $w \ldots \ldots \ldots \ldots \ldots \ldots \ldots \ldots \ldots \ldots \ldots$

hind $w \ldots \ldots \ldots \ldots \ldots \ldots \ldots \ldots$ 2I

$\begin{array}{llllllllllll}3 & 0 & 0 & 0 & I & 0 & \text { I } & \text { I } & 4 & 0\end{array}$

2I ? 00 O 
In the nymph of a Cicada (Fig. 269), the medial trachea is four-branched and about each of these branches a vein of the adult wing is formed. In the nymph of a Pentatomid (Fig. 302) the medial trachea is four-branched. In the Odonata media is four-branched (Fig. 228); this is also true of the Ephemerida (Fig. 6I), and of the more generalized of the Trichoptera (Fig. 320).

When one consults the paleontological evidences regarding the primitive form of media and examines the wings of the Palæodictyoptera one is met by a bewildering variety in the branchings of this vein. And at first sight the evidence does not seem to support the conclusion, drawn from the study of recent insects, that this vein is typically four-branched and that the branching is dichotomous.

It is natural that the attention should be focused at first on the wonderfully well-preserved specimen of Stenodictya lobata (Fig. 77), the generalized

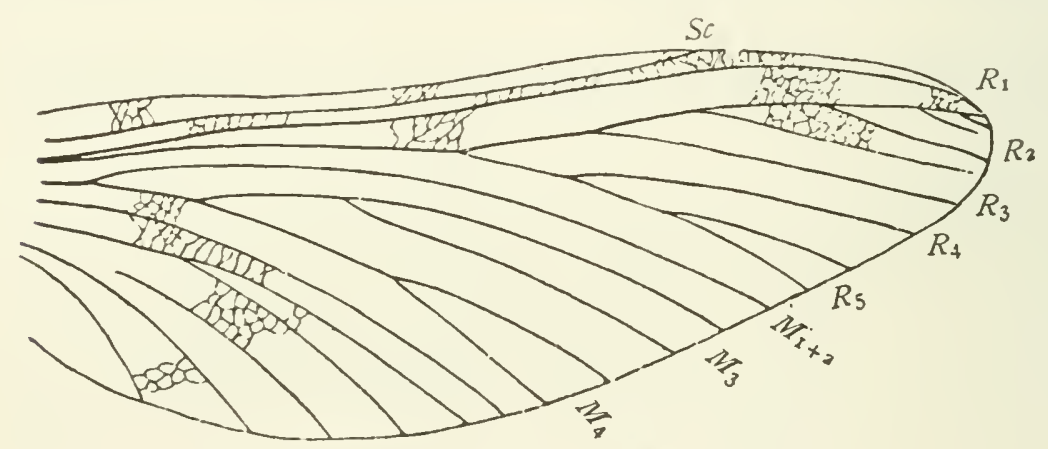

Fig. 95.-Dictyoneura libelluloides (After Handlirsch).

features of which have been already discussed. In this insect media is two-branched, and this is the case in all of the six known species of this genus. But of the fifty two genera, representing twenty-one families of the Palæodictyoptera, of which the remains are sufficiently well-preserved to enable us to determine the nature of media, this is the only genus in which this vein is two-branched. Even in the other thirteen genera of the family in which Stenodictya is placed, the Dictyoneuridæ, the media is more than two-branched. It is evident, therefore, that the two-branched condition of this vein in this genus is the result of specialization by reduction, The fact that Stenodictya is from the Upper Upper Carboniferous and that all of the insects of the Lower and Middle Upper Carboniferous have media more than two-branched confirms this conclusion.

An even more puzzling matter than the two-branched media of Stenodictya is the fact that in about one-half of the genera of the Palæodictyoptera media is of a form that may be termed the isolated front branch type, and in about one-half of these there is what resembles a four-branched 
sector, with or without accessory veins, which results in the vein resembling the typical radius in form. This is well-illustrated by Dictyoneura libelluloides (Fig. 95), which is a simple example of this type; and by Hadroneuria

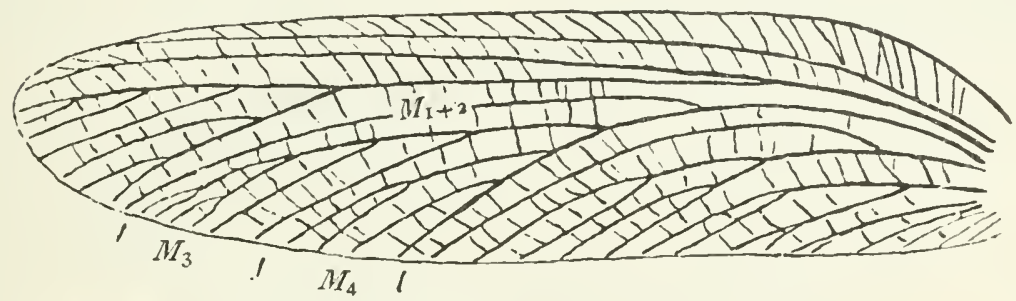

Fig. 96.--Hadroneura bohemica (After Handlirsch).

bohemica (Fig. 96), in which the type is complicated by the addition of several accessory veins, although the front branch remains isolated. In these and in other figures, I have labeled this isolated front branch as vein $\mathrm{M}_{1}+_{2}$; my reason for doing this will be given later.

Let us now determine the type of branching of media in the oldest insect remains that have been found up to the present time, that is in those of the Lower Upper Carboniferous. The exact locality in which each of these fossils was found has been indicated in the foregoing discussion of the radial sector, and need not be given here. The figures are repeated, however, for . convenience of reference.

In Metropator pussillus (Fig. 97) the media is five-branched, and the branching is dichotomous. It differs from the hypothetical type by the presence of an extra branch on vein $\mathrm{M}_{4}$. This is correlated with a similar condition in other veins. The radial sector is also typical with an accessory branch on vein $R_{2}$ and one on vein $R_{3}$. Vein $\mathrm{Cu}_{1}$ also bears a short accessory branch. Only a small part of the anal area

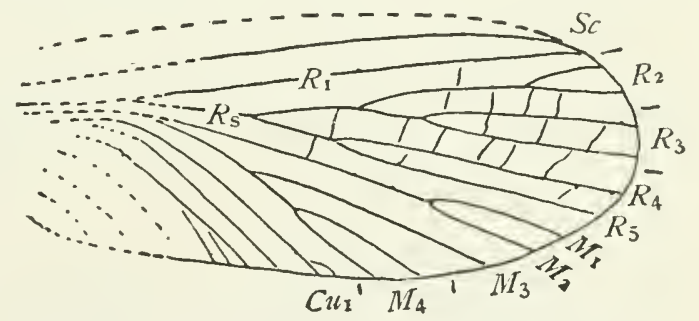

Fig. 97--Metropator pussillus (After Handlirsch). is preserved, but there is enough to show that the first anal vein was branched.

Of about the same age as the fossil just described are two from Indiana and one from Alabama. The best preserved of these three is Paolia vetusta (Fig. 98). In this wing media has many branches; but the branching is dichotomous. It is easy to recognize the typical form of media with the addition of several accessory branches. 
A second species from the same formation is Paolia Gurleyi (Fig. 99). This differs from the preceding species in the smaller number of the accessory branches of media.

A study of these three wings, the oldest of the known insect remains found in the United States, leads to the conclusion that the primitive

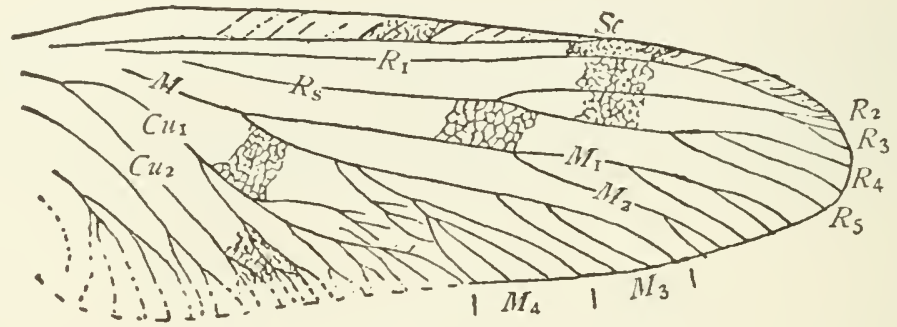

Fig. 98.-Paolia vetusta (After Handlirsch).

arrangement of the principal branches of media was that indicated in the diagram, by Comstock and Needham, of the hypothetical primitive type. It also shows that in these ancient insects the four principal branches of media bore a variable number of accessory veins, near the margin of the wing. The lack of uniformity in the number and position of these accessory veins parallels the conditions $R_{3}$ that exist in recent insects with accessory veins; where the number and position of the accessory veins is of hardly more than specific value.

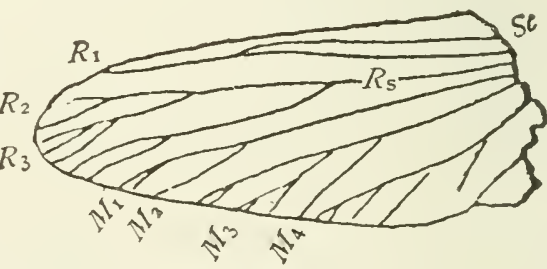

Fig. 99.-Paolia Gurleyi (After Handlirsch).

The Alabama specimen, which is believed to be nearly contemporaneous with the two just described, is Campteroneura reticulata (Fig. Ioo). It is doubtful if the fragment preserved contains any part of the media;

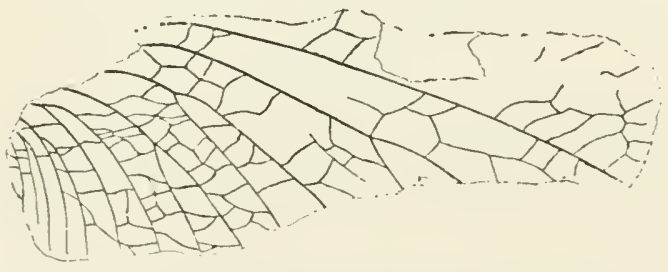

Fig. I00.-Campteroneura reticulata (After Handlirsch). but even if it does, there is not enough of this vein to enable us to determine the nature of the branching of it.

Another fragment of a wing from Alabama is supposed to be of a slightly more recent time; this is the Bathytaptus falcipennis (Fig. IOI). Only part of media is preserved, but enough to show that it was not of the isolated front branch type. 
The last of the series of American fossil insect remains from the Lower Upper Carboniferous is Eurythmopteryx antiqua (Fig. IO2). In this wing definite cross-veins had been attained; and media is of the isolated front branch type, which will be discussed a little later.

The single representative of the Lower Upper Carboniferous insects found in the British Islands is Psendofonquea cambrensis (Fig. 103). In this media is clearly dichotomouslybranched, with an accessory vein on vein $\mathrm{M}_{4}$.

There remains only a single Lower Upper Carboniferous insect

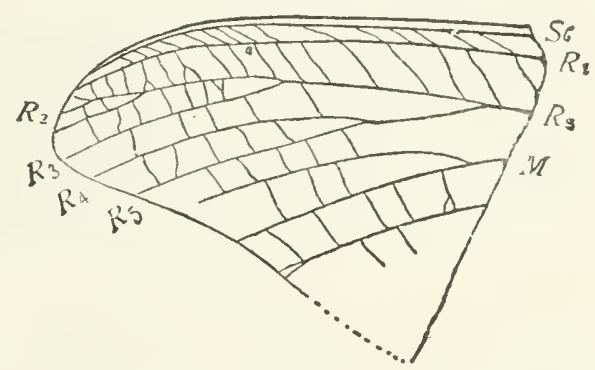

Fig. IоI.-Bathytaptus falcipennis (After Handlirsch).

to be mentioned. This is the German Stygne Roemeri (Fig. 104). In this species media was of the isolated front branch type.

I will now state my reason for believing that this isolated front branch of media is vein $M_{1+2}$. The determination of the origin of this type of

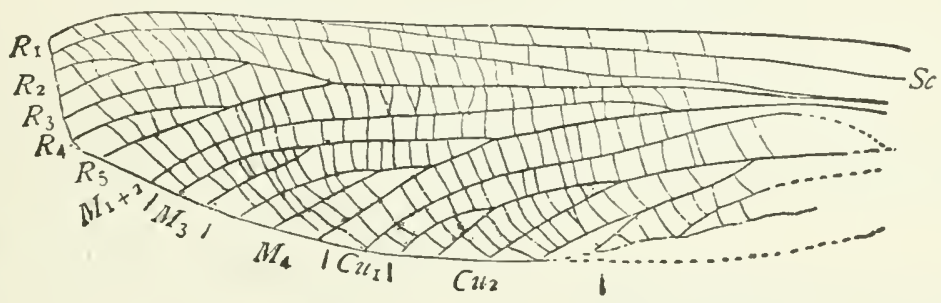

Fig. I02.-Eurythmopteryx antiqua (After Handlirsch).

media was an exceedingly puzzling problem. It was made more so by the existence of many genera in which this vein resembles the typical form of

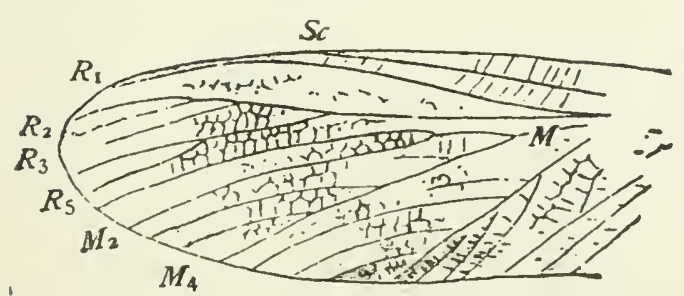

Fig. 103.-Pseudofouquea cambrensis (After Handlirsch). radius, that is with a simple front branch and a fourbranched sector (Fig. 95). This led me to think for a time that the four-branched sector represented the fourbranched media of the hypothetical type of Comstock and Needham and that the isolated front branch was a vein that had been lost in the course of the evolution of more recent insects. 
The key to the solution of the problem was found in the study of the wings of Homaloneura punctata (Fig. 105), from the Upper Upper Carboniferous, of Commentry, France. Both wings of this insect are preserved;

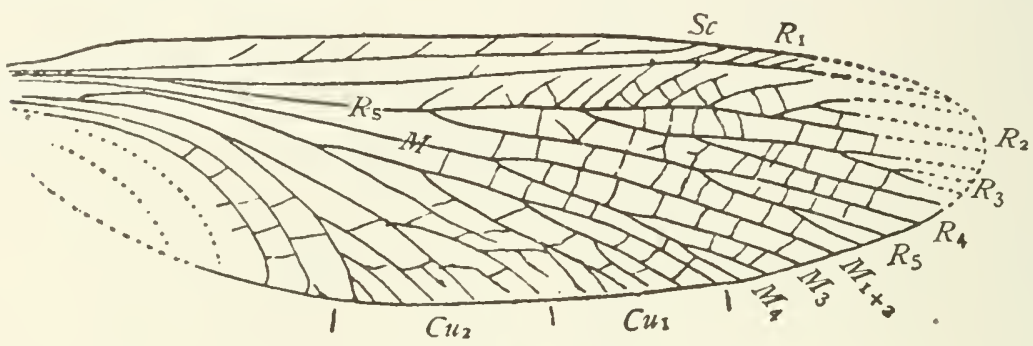

Fig. 104.-Stygne Roemeri (After Handlirsch).

in the front wing media is dichotomously branched and in the hind wing this vein is of the isolated front branch type. From a study of these wings it is evident that the isolated front branch of media of the hind wing is the result of the coalescence of veins $M_{1}$ and $M_{2}$ by which a single unbranched vein was formed.

The beginning of this reduction of vein $\mathrm{M}_{1+2}$ to an unbranched condition is shown in Metropator (Fig. 97) and in the two species of Paolia (Fig. 98 and 99). In each of these the forking of vein $\mathbf{M}_{1+2}$ is much nearer the margin of the wing than that of vein $\mathrm{M}_{3}+_{4}$.

Correlated with the reduction of vein $\mathrm{M}_{1}+_{2}$ to an unbranched condition, there has been in very many of the genera in which this condition exists a moving back of the point of separation of veins $\mathrm{M}_{1+2}$ and $\mathrm{M}_{3+4}$ towards the base of the wing, which has resulted in an accentuation of the isolation of vein $\mathrm{M}_{1+2}$. This is shown. to a certain

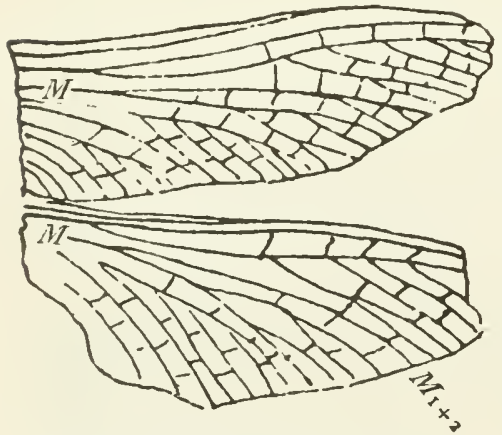

Fig. I05.-Homaloneura punctata (After Handlirsch). extent in Eurythmopteryx (Fig. I02) and more markedly in Dictyoneura Libelluloides (Fig. 95).

In conclusion, the paleontological data indicates that in the primitive insect wing the media was four-branched and the branching was dichotomous. It also indicates that in addition to the four principal branches there was a variable number of accessory veins near the margin of the wing (See foot note page 99).

The evolution of the cubitus.-A study of recent insects led Comstock and Needham to conclude that in the primitive insect wing cubitus was two-branched; and it is so represented in our diagram of the hypothetical primitive type of wing venation. 
The two-branched condition of cubitus is clearly shown in the Plecoptera (Fig. I2), Corrodentia (Fig. 4), Odonata (Fig. 228), Homoptera (Fig. 270), Trichoptera (Fig. 320), Lepidoptera (Fig. 344), Diptera (Fig. 357), and Hymenoptera (Fig. 391).

In the Orthoptera and in the Neuroptera we found that frequently there are on one or both of the two principal branches of cubitus a variable number of accessory veins; but we found no constancy in the number or in the position of these accessory veins, closely allied genera showing marked differences in these respects. We felt, therefore, that the stem form from which the recent orders of insects have been evolved had, without doubt a two-branched cubitus.

When we turn to the study of the Paleozoic insects we find a much smaller amount of data regarding the form of cubitus than we found regarding either of the veins already discussed. This is due to the fact

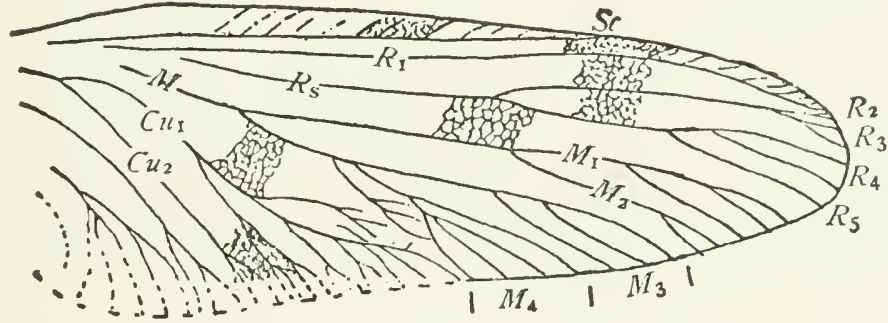

Fig. I06.-Paolia vetusta (After Handlirsch).

that frequently in otherwise well-preserved wings the cubital and anal areas are lacking entirely or in part; this is especially true of the basal parts of the cubitus and the anal veins.

In four of the eight wings found in the Lower Upper Carboniferous the cubitus is fairly well-preserved. We will begin our study of the paleontological data with these, the oldest known insect remains.

In Paolia vetusta (Fig. Io6) the cubitus has two principal branches each of which bears accessory veins near the margin of the wing. These accessory veins are branched very irregularly. So irregular is this branching, that it does not seem probable that it was even of specific value; evidently a definite arrangement of the accessory veins borne by cubitus had not yet been attained; and we can regard only the main stem and the two principal branches as being fundamental.

In Stygne Roemeri (Fig. 107) we find a more advanced stage of specialization; this is evident from the fact that definite cross-veins had been attained, which is not the case in Paolia. In Stygne each of the two principal branches of cubitus bears several branches; the cubital area being greatly widened at the margin of the wing, and well-supplied with accessory veins, most of which have attained a definite longitudinal direction. 
A somewhat more specialized species is Eurythmopteryx antiqua (Fig. I08). Here too are found definite cross-veins and the accessory veins appear to have a definite arrangement. The most striking feature of the

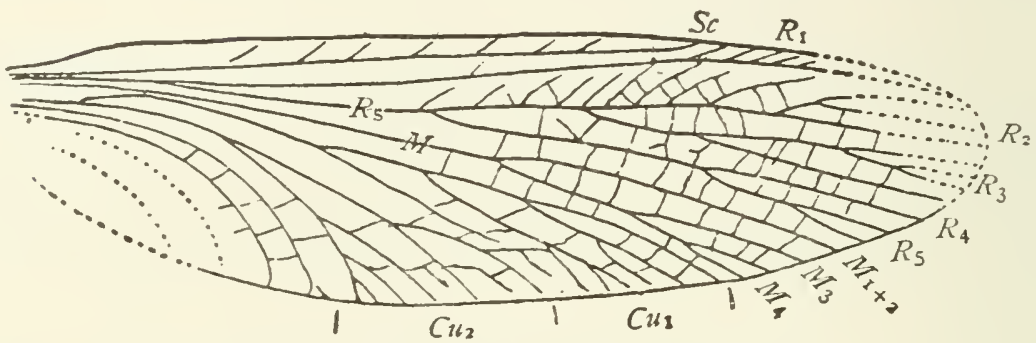

Fig. 107.-Stygne Roemeri (After Handlirsch).

cubitus in this wing is the fact that vein $\mathrm{Cu}_{1}$ is simple while vein $\mathrm{Cu}_{2}$ bears two, forked accessory veins; a curious result of this is that the three branched veins in this wing, the radius, the media, and the cubitus resemble each other to a remarkable degree; in fact each is of what I have termed the isolated front branch type in my discussion of the media. In many of the Palæodictyoptera the cubitus is of this type But in many others vein $\mathrm{Cu}_{1}$ bears as many or even more accessory veins than does vein $\mathrm{Cu}_{2}$. This is the case in the two older insects, Paolia vetusta and Stygne Roemeri, described above.

The fourth wing from the Lower Upper Carboniferous in which cubitus is preserved is Psendofouquea cambrensis (Fig. I03). If the figure correctly represents this vein it is of so unique a type that it must be regarded as a sidewise development, resembling nothing of which we know that either preceded or followed it; and consequently it throws no light on the question regarding the primitive form of the cubitus.

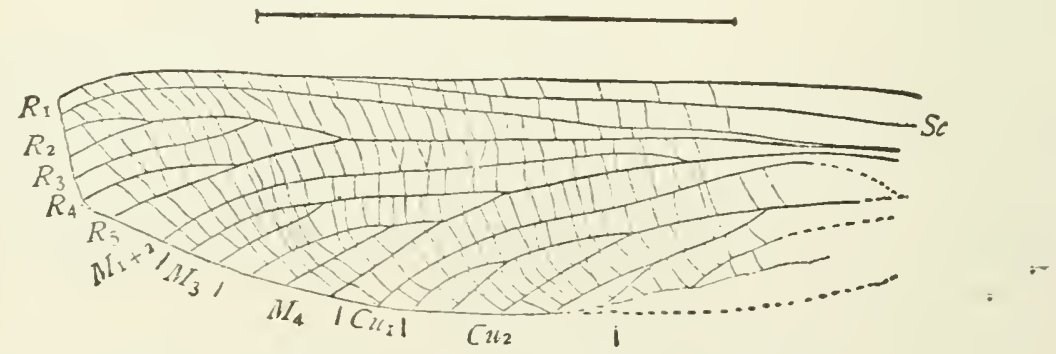

Fig. 108.-Eurythmopteryx antiqua (After Handlirsch).

In marked contrast to the isolated front branch type of cubitus is a type in which vein $\mathrm{Cu}_{2}$ is simple and vein $\mathrm{Cu}_{1}$ bears accessory veins, which might be designated as the isolated hind branch type of cubitus. An illus- 
tration of this is seen in Becquerelia Grehanti (Fig. I09), from the Upper Upper Carboniferous of France.

It is not necessary to multiply examples. It is evident from those given above that the primitive cubitus was two-branched, and that probably each of these branches bore a variable number of accessory vein, which had no definite arrangement, as illustrated by Paolia vetusta (Fig. Io6). From this primitive type there were evolved the following:

Forms in which the accessory veins of both branches of the cubitus attained a definite arrangement, as in Stygne Roemori (Fig. Io7).

Forms in which the accessory veins of vein $\mathrm{Cu}_{1}$ were lost, thus producing the isolated front branch type, as in Eurythmopteryx antiqua (Fig. I08).

Forms in which the accessory veins of vein $\mathrm{Cu}_{2}$ were lost, thus producing the isolated hind branch type, as in Becquerelia Grehanti (Fig. Io9).

And finally, forms, not mentioned in the above discussion, in which the accessory veins of both of the branches of cubitus were lost, producing a

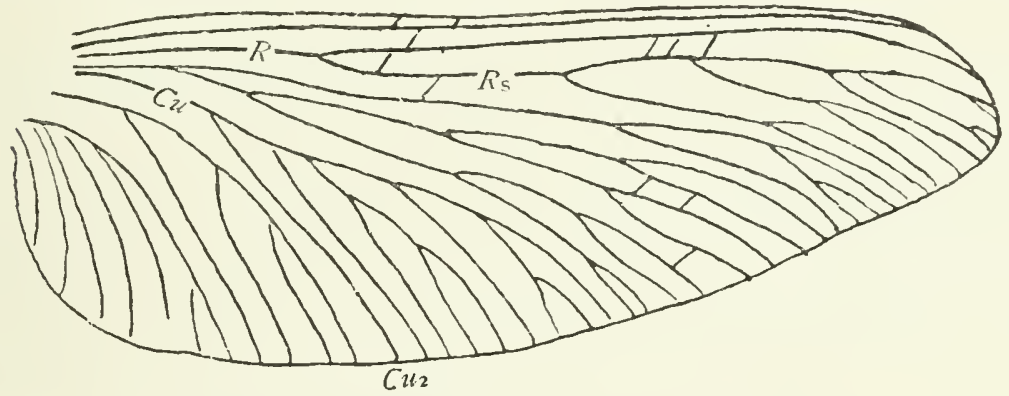

Fig. 109.-Becquerelia Grehanti (After Handlirsch).

simple two branched cubitus. This type arose comparatively early and was associated with very generalized features, as in the case in Stenodictya lobata (Fig. 77). It is this type that is most common among living insects.

The evolution of the anal veins. - The determination of the probable primitive number and form of the anal veins in the wings of insects is a more difficult matter than the determination of the probable number and forms of the other principal veins.

There can be no doubt as to the number of principal veins in the preanal area. In the case of each of these veins, the trachea that precedes it, in those orders where the tracheation is not reduced, arises separately from the thoracic trachex, and extends into the wing-bud for a considerable distance before branching; thus forming a definite, distinct entity; and in those orders where the tracheation is reduced the number and branching of the principal veins of the preanal area is easily determined in the more generalized forms. 
In the anal area, the number of the principal veins can be determined in certain cases by a study of the tracheation of the wings of the nymph. Thus in the hind wing of a nymph of Nemoura (Fig. I2, page 20) there are clearly three principal anal tracheæ, the first of which is simple, while the second and third are two-branched. But as the line along which the hinge of the wing of the adult is formed extends across the wing beyond the points of branching of these trachex; and as the wing is greatly narrowed along this line at the last transformation, thus crowding the veins together, it is impossible, by a study of the wing of the adult alone, to determine, with certainty, whether a given vein is a simple, unbranched, principal vein or merely a branch of a forked vein.

The condition is very different here from what it is in the preanal area where the branching of the principal veins takes place at a considerable distance from the base of the wing.

Another factor that often complicates the determination of the identity of the anal veins is the tendency of the bases of these veins to coalesce; this is shown in the hind wing of Nemoura (Fig. I2, page 20) where the $2 \mathrm{~d}$ and $3 \mathrm{~d}$ anal tracheæ coalesce for a short distance; and in Psocus (Fig. 5, page I4) what is doubtless the Ist anal trachea coalesces with the cubital trachea and thus appears to be a branch of it.

A comparative study of many generalized forms led Comstock and Needham to conclude that typically there are three anal veins; and subsequent studies have revealed no reason for modifying this view. Abundant data to substantiate the correctness of it is given in the discussion of the venation of the wings of the different orders of insects in the later part of this work.

When we turn to an examination of the paleontological data bearing on the number of the anal veins, we find that we have to deal with a much more difficult problem than that presented by recent insects; for here we can derive no help from ontogeny, but must confine ourselves to the study of remains of wings of adults; and these in most cases have this part of the wing poorly or not at all preserved.

The fact is that in none of the remains of the Palæodictyoptera yet found is the anal area sufficiently well-preserved to enable one to determine conclusively the number of principal veins in this area. Take for example the wonderfully well-preserved Stenodictya lobata (Fig. 77); here there are three anal veins in the fore wing and four in the hind wing. It seems probable that the first two anal veins in each case are branches of the first anal vein; for in many of the Palæodictyoptera, where the venation is less reduced than it is in Stenodictya, the first anal vein is branched; this is illustrated by Polioptenus elegans (Fig. I Io), from the Middle Upper Carboniferous, in which the branching of the first anal vein takes place near the middle of the length of this vein. But it is impossible to determine 
either in Polioptemus or in Stenodictya whether the third and fourth anal veins are simple principal veins or are merely branches of a principal vein.

We are forced to conclude from this examination of the paleontological data that so far as the anal area is concerned the study of the ontogeny of

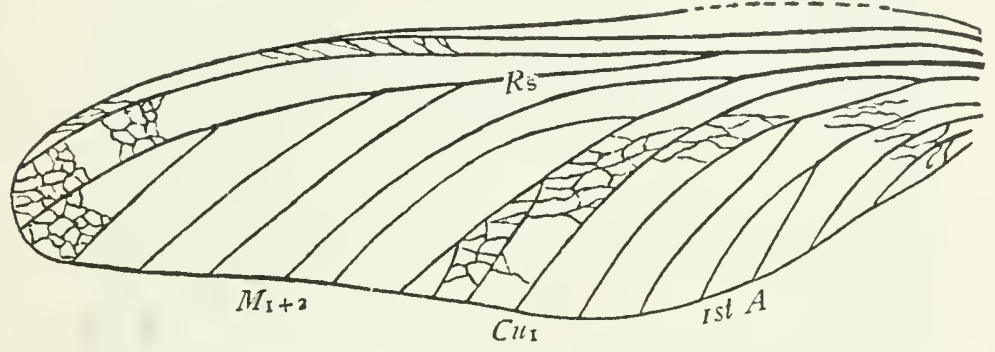

Fig. I Io.-Polioptenus elegans (After Handlirsch).

living insects is the surest guide to a knowledge of the primitive venation of this area; and that there is no reason now evident for modifying the conclusions regarding this area expressed in the diagram by Comstock and Needham of the hypothetical primitive wing-venation.

While the paleontological evidence throws little light on the venation of the anal area, we can draw some conclusions from it as to the form of this area as a whole in primitive insects. In the Palæodictyoptera the anal area is not greatly enlarged; it is never separated from the preanal area by an anal furrow; and it was never developed into a fan-like form, there being no longitudinal folds in it.

Summary.-A study of the paleontological data confirms to a remarkable degree the conclusions drawn from the study of the ontogeny of living insects as to the probable primitive type of wing-venation.

It is evident that in the wings of the primitive insects the branches of the principal longitudinal veins bore near the margin of the wing a variable number of accessory veins; but it is equally evident that the number and position of these accessory veins was not at all constant, they being of the type defined in the preceding chapter as marginal accessory veins and not definitive accessory veins. It is obvious, therefore, that it would be impractical to introduce accessory veins into our dagram of the hypothetical type, for the doing of this would indicate a definiteness in number and position that did not exist.

If the diagram of the hypothetical primitive type be regarded as representing only the principal veins and the chief branches of them, there is no change that it is certain should be made in it. The only vein regarding the primitive form of which there is doubt is the subcosta. This was not branched in any of the known Palæodictyoptera; but it was branched in very ancient insects, that existed at the same time as the Palæodictyoptera. 


\section{CHAPTER V}

\section{THE DEVELOPMENT OF THE WINGS OF INSECTS}

$I_{N}$ the discussion of the tracheation of the wings of insects and of the development of the wing-veins, in an earlier chapter, same data have been given regarding certain changes that take place in the course of the growth of wings; there are, however, other features to which reference should be made in this place.

Two quite distinct methods of development of wings exist in insects; by one method, the wings are developed as outward projecting appendages of the body; by the other, they reach an advanced stage of development within the body. The former method of development takes place with
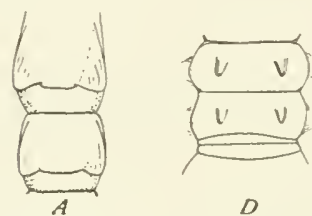

$D$

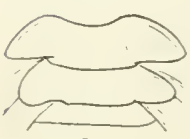

B
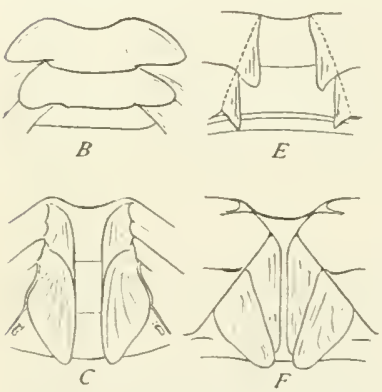

Fig. I I I.-Wings of nymphs: A, of a stone-fly (Capnia); $\mathrm{B}$ and $\mathrm{C}$, of a grasshopper; $\mathrm{D}, \mathrm{E}$, and $\mathrm{F}$, of a dragon-fly. In the four lower figures the dorsal half of the body of the nymph is represented as spread out flat. Figures B and $\mathrm{E}$ are from nymphs onethird grown; and $\mathrm{C}$ and $\mathrm{F}$ from nymphs that were threefifths grown (After C. \& N.). nymphs, the latter, with larvæ. The two methods will be discussed separately.

(a) The Development of the wings OF NYMPHS

The development of the wings of insects that undergo a gradual metamorphosis, or paurometabolous development, and of those that undergo an incomplete metamorphosis, or hemimetabolous development is comparatively simple and easily observed. With these insects the wings are sac-like outgrowths, which appear comparatively early in the life of the nymph and become larger and larger with successive molts, the expanding of the wingbud taking place immediately after the molt.

First appearance position and growth of the wings of nymphs.-The sac-like folds of the body-wall that develop into wings first appear along a line where the suture between the tergum and the pleurum later develops. In most nymphs they are so directly continuous with the tergum and become so solidly chitinized with it that they have generally been interpreted as out-growths from its caudo-lateral margin (Fig. I I I, A, B); but in the Odonata, the wings arise in an erect position upon the body-wall, at mid-way the length of their respective segments (Fig. I I I, D). In insects with a complete metamorphosis, the rudiments of the wings are concealed until the assumption of pupal instar, as is shown later. 


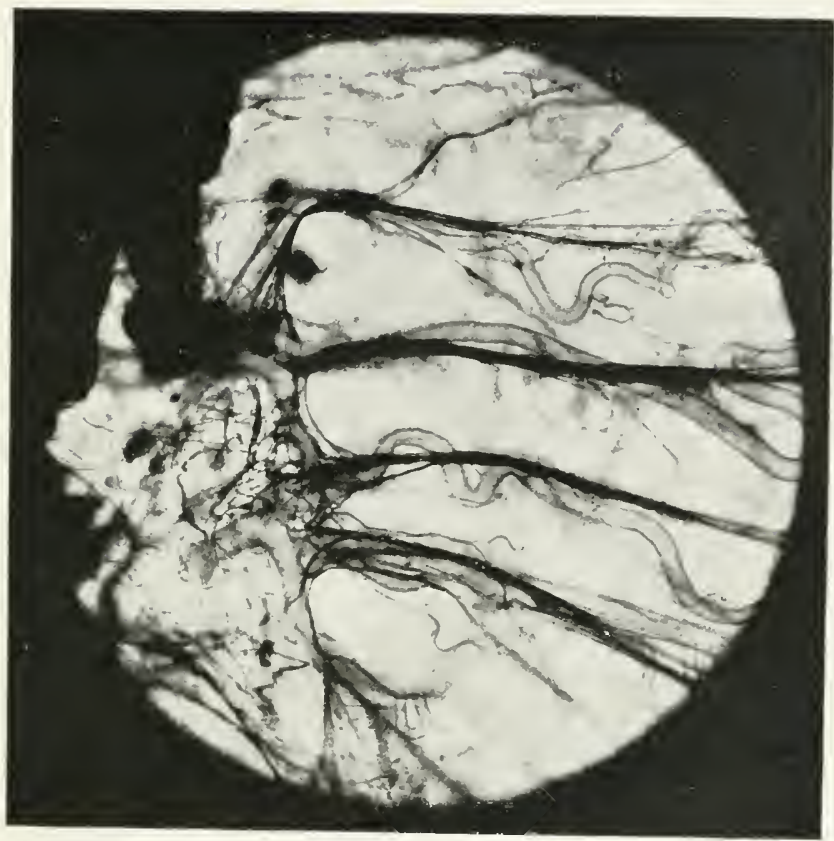

Fig. 1.-Base of a wing of a prepupa of Bombyx.

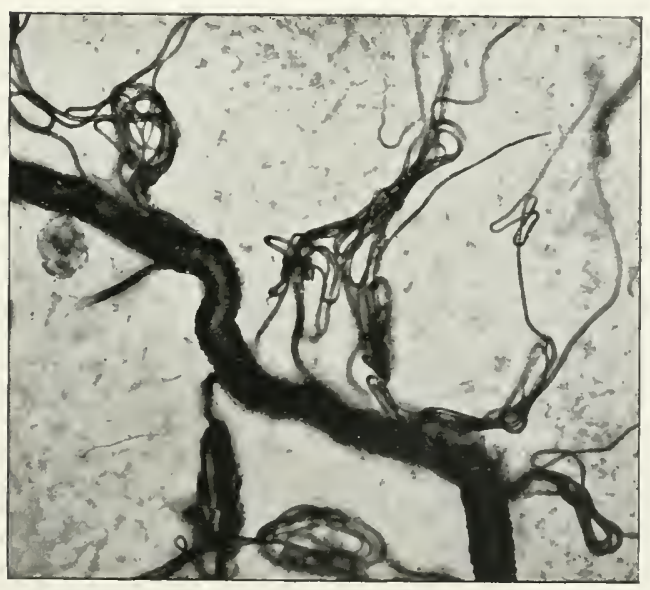

Fig. 2.-A trachea and uncoiling tracheoles in a wing of Clisiocampa. 



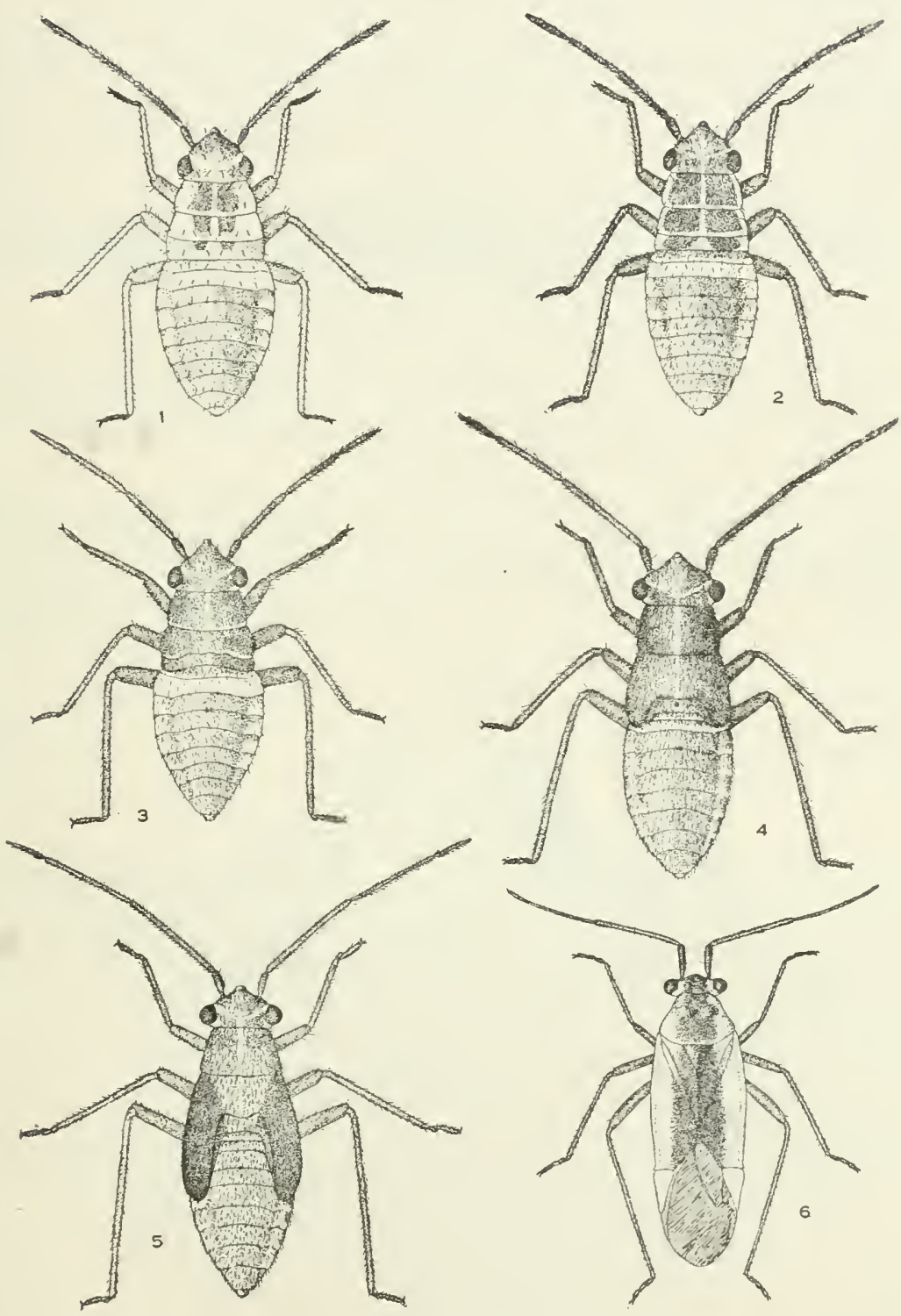

Fig. I 12.-The six postembryonic instars in the development of Lopidea robinia. In the third instar the wing-pads are just beginning to show; in the fourth, they reach back nearly to the third abdominal segment; in the fifth, they reach to the middle of the fifth abdominal segment; in the sixth or adult instar the wings extend beyond the tip of the abdomen. (After Leonard'I6). 
In insects with a gradual or with an incomplete metamorphosis the external changes during growth are comparatively slight, with each molt there is an increase in size, and at the assumption of the adult instar there takes place a great expansion of the wings, the perfection of the veins, the thinning of the spaces between the reins, and the perfection of the basal articulations.

The gradual increase in the size of the wings in the successive nymphal instars and their great increase in size at the assumption of the adult instar are well illustrated by the transformations of a capsid bug, Lopidea robinice described and figured by M. D. Leonard ('I6), (Fig. I I2).

In the change from the last nymphal instar to the adult, there occurs in the jumping Orthoptera and in the Odonata the well known reversal of the position of the wings by which that face of each wing which has been exposed becomes the lower surface of the wing.

"Figure I I 3 shows the relation of parts in a dragon-fly nymph one-third grown. It represents a partial cross-section passing through the posterior part of the basal attachments of the hind wings and through the fore wings just before the arculus. In the hind wings are seen $(a, b)$ the cut ends of

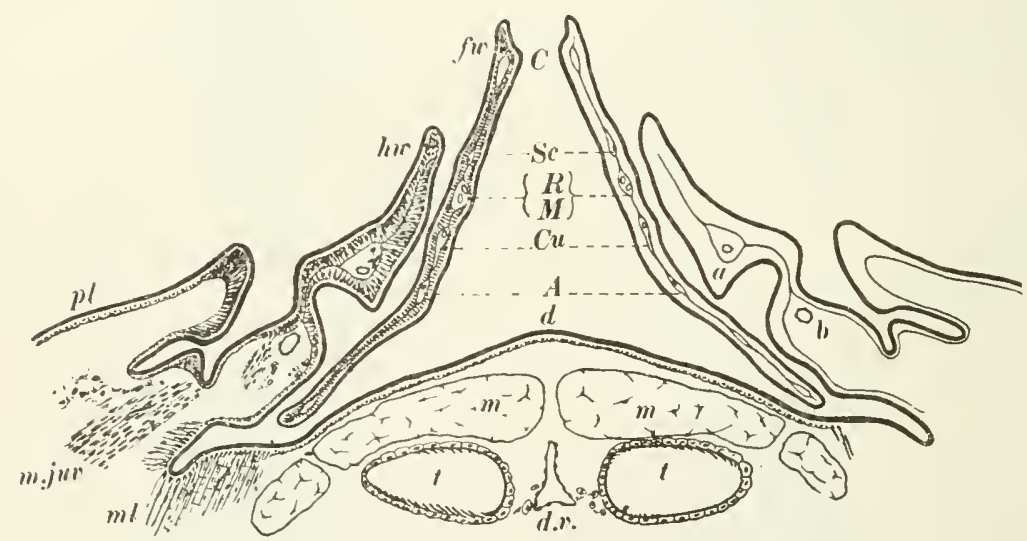

Fig. II3.-Dorsal part of a transverse section of a nymph of Celithemis elisa, one-third grown: $d$, dorsum; $p l$, pleurum; $d . v$., dorsal vessel; $t, t$, tracheæ; $m, m$, muscles in cross-section; $m l$, muscles in longitudinal section; $m$, $j u v$, developing muscles of the wing; $h w$, hind wing; $f w$, fore-

wing; $a$ and $b$, the cut ends of the basal transverse trachea of the hind wing; C, costa; Sc, subcosta; R M, the coalesced radius and media; $\mathrm{Cu}$, cubitus; $\mathrm{A}$, anal vein.

(After C. \& N.).

the transverse basal trachea. In the fore wings the tracheæ in the vein cavities are seen in section. The pleura $(p l)$ are seen overlying the bases of the wings.

"It is interesting to follow the basement membrane of the hypodermis throughout the section, noting how the hypodermal cells are elongated in 
certain parts, rounding out the sharp angles of the exterior, and completely occupying the narrower spaces in the wings.

"It is also important to note that the basement membrane of the hypodermis of the wing differs in no respect from that of the hypodermis of the body-wall, and is continuous with it. In the thinner parts of the wing

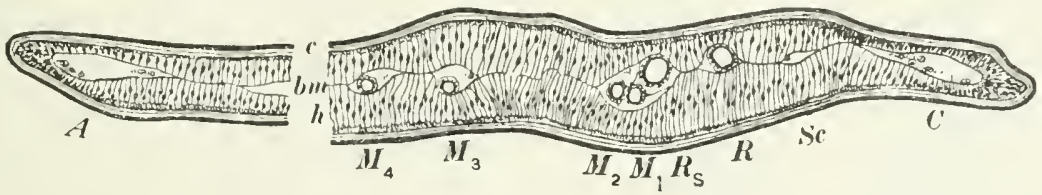

Fig. I I 4.-A cross-section of a fore-wing (in part omitted) of a nymph, twothirds grown, and recently molted, of Anax junius; c, cuticula; bm, basement membrane; $h$, hypodermis; the veins of the wing are designated by the usual lettering. (After C. \& N.).

the two basement membranes meet and fuse, thus forming what has been termed the middle membrane of the wing. Along certain lines, seen in section in the figure, the two membranes remain separate, and thus are formed the cavities of the wing-veins.

"Figure II 4 represents a partial section of a fore wing of a nymph of Anax junius two-thirds grown; the section was taken at the nodus. The general features here seen are common to the wings of all nymphs-two layers of very elongate, hypodermal cells, which meet in places and form the middle membrane, and remain separate in other places, forming the vein cavities, which usually contain tracheæ" (C. and N.).

The tracheation of the wings of nymphs.- In the course of the development of the wings of nymphs, the principal tracheæ pass out into the wingbud very early and extend as the wing grows. There larger trachea give off many small lateral and terminal branches so that all parts of the developing wing are supplied with air.

In preparations of wings made by the method commonly employed for the study of the tracheation of the wings, the tracheoles are rarely visible; but in some preparations they are very evident. In the preparation of a wing of a dragon-fly, of which Fig. I Plate VIII represents a small part, it was easy to see that the entire wing was traversed by numerous tracheoles.*

*In descriptions of the tracheation of wings, and of the other parts of the body as well, it is important that the distinction between trachea and tracheoles be kept clearly in mind.

The term tracheole has been used frequently to designate any small trachea; but this is an incorrect use of the term. The tracheoles are certain minute tubes, which are connected with the tips of tracheæ or arise from their sides, but which differ from tracheæ in their appearance, structure, and mode of origin; in other words, tracheoles are not small trachere, but structures that differ both histologically and morphologically from tracheæ.

Tracheoles are exceedingly slender, measuring less than one micron in diameter; they are of uniform diameter, not tapering as do tracheæ; they differ strikingly from 
As detailed discussions of the tracheation of the wings of nymphs are given in several of the following chapters, it is unnecessary to dwell further on this subject here.

\section{(b) THE DEVELOPMENT OF THE WINGS OF LARVE AND OF PUPAE}

Although there are differences in details in the development of the wings in different insects undergoing a complete metamorphosis, the essential features are the same in all. The most striking feature is that the rudiments of the wings, the wing-buds, arise within the body and become exposed for the first time when the last larval skin is shed. This internal development of the wings presents many remarkable phenomena that have attracted the attention of many observers, among whom were Weissmann ('64 and '66), Landois ('7 I), Ganin ('76), Dewitz ('8I), Pancritius ('84), Schäffer ('89), Mayer ('96), Gonin ('92), and Mercer ('oo).

Lack of space prevents the giving in this place of an historical account of the growth of knowledge of this subject, for this the writers named above can be consulted. The following account consists largely of a tracing of the development of the wings of a single lepidopterous insect, the cabbage butterfly (Pieris rapce), which is taken as an example. This account is based primarily on the observations of Gonin and the later studies of Mercer, which were made under my direction, to these I have added the results of some of my own studies.

The development of the wing-buds.- The first indication of a wing-bud is a thickening of the hypodermis; this can be observed by making sections of the body-wall of the wing bearing segments, of very young larvæ or even of embryos. In the first larval stadium of Pieris, this histoblast is well marked (Fig. I I,$a$ ). In the second stadium, it becomes more prominent, and is invaginated, forming a pocket-like structure (Fig. I I5, b). In the third stadium a part of this invagination becomes thickened and evaginated into the pocket formed by the thinner portions of the invagination (Fig. II $5, c)$. In the fourth stadium, the evaginated part of the histoblast becomes greatly extended (Fig. I I $5, d$ ). It is this evaginated portion of

tracheæ in the absence of tænidia; they rarely branch, but often anastonase, which give them a branched appearance (Plate II and Plate III, Fig. 2).

Each tracheole is of unicellular origin, and is at first intracellular in position; while tracheæ are of multicellular origin and the lumen of each is intercellular in position. The development of tracheoles, each coiled within a single cell of the epithelium of a trachea, and the subsequent opening of communication between the tracheoles and the lumen of the trachea, and the uncoiling and stretching out of the tracheoles, so that they reach all parts of the wing, are described later in the account of the development of the wings of Pieris

It is probable that the tracheoles are the essential organs of respiration, and that the tracheæ act merely as conduits, conveying the air from the spiracles to the tracheoles. But a discussion of this question does not fall within the scope of this essay. I wish merely to emphasize the importance of distinguishing clearly between trachex and tracheoles in descriptions of the tracheation of the wings. 
the histoblast that later becomes the wing. In the fifth stadium, the wingbud attains the form shown in Figure I $_{5}, e$, which represents it dissected out of the wing-pocket. At the close of the last larval stadium, the fifth, the wing is pushed out from the wing pocket, and lies under the old larval cuticula during the prepupal stadium. It is then of the form shown in Figure i I 5, $f$. The molt that marks the beginning of the pupal stadium exposes the wing-buds, which in the Lepidoptera become closely soldered to the sides and breast of the pupa. Immediately after the last molt, when the adult emerges, the wings expand greatly and assume their definitive form.

The development of the tracheation of the wings. In the earlier stages of its development, the wing-bud is not provided with special organs of respiration, resembling in this respect other portions of the hypodermis of which it is a part. It should be noted, however, that the histoblast is developed near a large trachea, a cross-section of which is shown in (Figure I I $5, a, b$, $c, d)$, which represents sections of these parts of the first, second, third and fourth instars respectively.

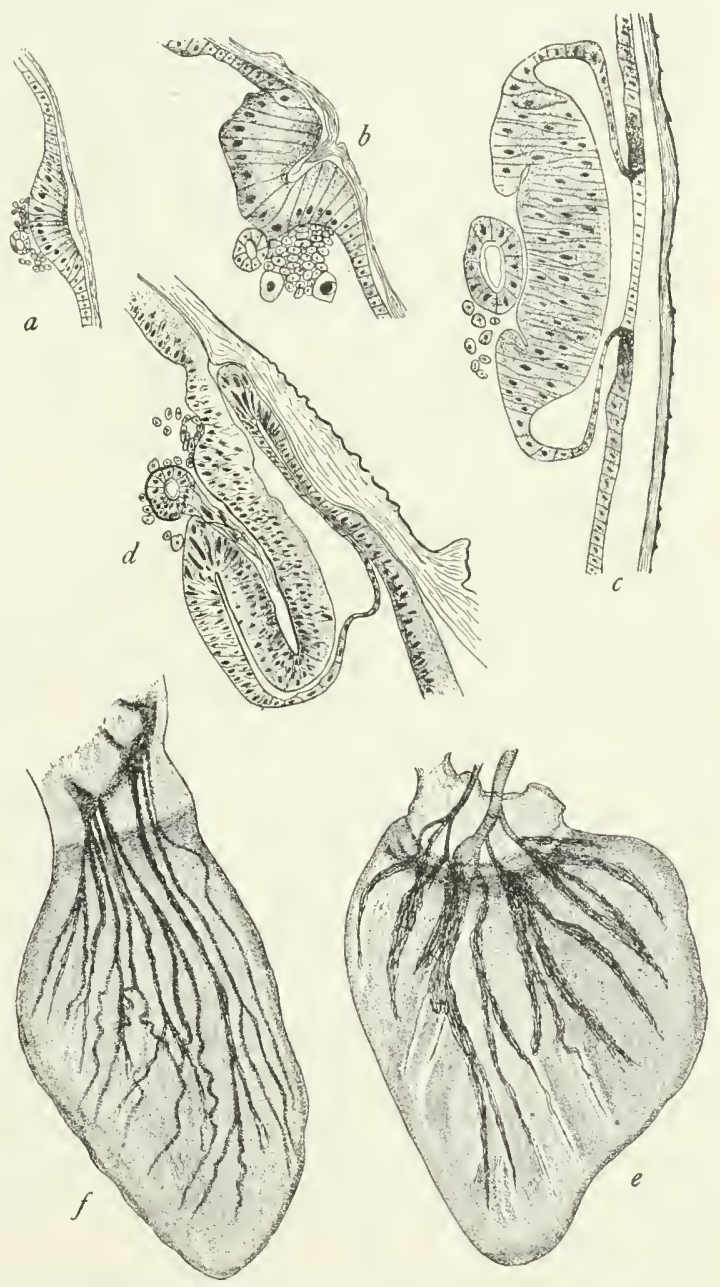

Fig. 11 5. - Several stages in the development of the wings of a cabbage butterfly (After Mercer).

During the fourth stadium, certain cells forming a part of the epithelium of this trachea become greatly enlarged and project into the cavity of the wing-bud (Fig. I I5, d). Within each of these cells there is developed a closely coiled tracheole. During this stadium the tracheoles have no communication with the lumen of the large trachea; but as the new intima of this trachea is formed it is not extended over the mouths of the tracheoles 
and when the old intima is molted at the beginning of the fifth stadium the tracheoles become connected with the trachea. At the same time the tracheoles uncoil, and extend in bundles in the forming vein-cavities of the wing-bud (Fig. II5, e). These tracheoles may be termed the larval tracheoles of the wing, as their existence is transient; they supply the developing appendage with air only during the last larval and the prepupal stadia.

At the beginning of the fifth stadium or at the end of the fourth, there begins the development of the trachex of the wing. These extend out into the developing vein-cavities along with the larval tracheoles. Each is developed as a tubular extension of the epithelium of the large trachea, the mouth of which is closed by the intima of this trachea. For this reason, during the last larval and the prepupal stadia the wing trachea are not functional; they contain no air and are apparently filled with lymph. During this period the wing-bud is supplied with air by the larval tracheoles as indicated above.

At the molt that marks the beginning of the pupal stadium, the shedding of the old intima of the trachea from which the wing-bud trachea arise, opens the mouths of the wing-trachex, and they become functional. At the same time, that is early in the pupal stadium, the larval tracheoles degenerate; their function having been assumed by the wing-tracheæ. Plate III, Fig. I represents the base of a wing of Bombyx photographed during the prepupal period; the wing-tracheæ are still filled with lymph, and the bundles of larval tracheoles have begun to degenerate.

During the pupal stadium a second series of tracheoles are developed. Each of these arises in a cell forming a part of the epithelium of a wing trachea; and they are distributed along the length of these trachex. At first each tracheole is coiled within the cell in which it originated; but later the tracheoles uncoil and become greatly extended so that the entire wing is traversed by them. Plate III, Fig. 2 is from a photograph of a small part of wing of a pupa of Clisiocampa; the photograph was taken just after the tracheoles had begun to uncoil. This series of tracheoles may be termed the pupal tracheoles of the wing; for they first appear during the pupal stadium.

As these tracheoles are developed during the pupal stadium within epithelial cells of the wing-tracheæ, they can not become functional until their mouths are opened by the shedding of the intima of the wing-trachex at the final molt. And it is evident that the period of their functioning must be limited to the short time during which the wing is expanding and the hypodermis is being used up in the formation of the cuticula of the wing. But as yet no observations have been made to demonstrate this point.

It seems probable, also, that the supplying of the developing appendage with air by means of the larval tracheoles alone, during the last larval and 
the prepupal stadia, is due to the retention of the wing within the narrow limits of its hypodermal pouch; for its small size renders possible its aeration by tracheoles alone. In an externally developing wing it is necessary that tracheæ should grow with the wing, in order to carry the tracheoles out within reach of the tissues; but when a wing develops internally its length for a long time does not exceed the length of normal tracheoles. In such a wing, tracheæ develop only when needed, at the approach of the time when rapid extension is to take place. 


\section{CHAPTER VI}

\section{THE STEPS IN THE SPECIALIZATION OF WINGS}

IN order to make use in taxonomic work of the characters presented by the wings of insects, it is necessary to gain a clear idea of what are the more generalized features of these wings and of the various ways in which the primitive type of insect wing has been modified. With this data in hand much information is available, that will be of use in determining the relationships of the subdivision of the class Insecta.

The making of a genealogical tree does not fall within the scope of this book. The writer fully appreciates that a natural classification of insects cannot be based on the study of a single set of organs. But there can be no doubt that the wings of insects present characters that will be of great value in the working out of such a classification.

While no attempt to construct a genealogical tree is to be made here, it is desirable that the data that can be obtained by a study of the wings should be presented in such a way that it shall be available for correlation with the data to be derived from the study of other parts. For this reason there is given in this chapter a brief discussion of the methods of specialization of wings and, at the close of the chapter, an analytical table of the orders of insects based on the different methods of specialization of these organs characteristic of the different orders.

The sequence in which the orders of insects are discussed in the following chapters has been determined by this table. This sequence, like all linear arrangements of groups of organisms, is more or less arbitrary. Thus while there is an effort to place first the more generalized orders and later those that are more specialized, the putting together of orders exhibiting the same type of specialization results in some cases in the placing of comparatively generalized forms after those that are obviously more highly specialized. The position of the Plecoptera is an illustration of this. The insects of this order are evidently more generalized than, for example, the Neuroptera or the Odonata, which are placed earlier in the linear series.

The comparatively high position assigned to the Plecoptera is, however, only apparent. A reference to the table will show that the orders of insects are grouped in two series, "A" and "AA". Under " $\mathrm{A}$ " are placed those orders in which the wings are specialized by addition in the preanal area and under "AA" those orders in which the wings are specialized by reduction in the preanal area. Each of these series includes some quite generalized insects and others that are highly specialized. The completion of the discussion of the first series before taking up the second series results in the 
generalized members of the second series following the highly specialized members of the first series.

The more generalized members of these two series, the Orthoptera of the first series and the Plecoptera of the second series, are probably more closely allied to each other than is either of these orders to the more specialized orders of the series in which it is placed; the two series arose from a common starting point, the Palæodictyoptera, but have widely diverged in the course of their development.

In discussing the steps in the specialization of wings several features in the development and perfecting of these organs are to be considered; these may be treated under separate heads, as follows:

\section{(a) The Development of the wings}

(I.) The development of wings externally.

This is the more primitive method of development of wings and is characteristic of the more generalized orders of insects, those in which the metamorphosis is either of the type known as gradual or of the type known as incomplete.

(2) The development of wings internally.

This is an acquired method of development of wings and is characteristic of the more highly specialized orders of insects, those in which the type of metamorphosis is that known as complete.

It is not probable that the orders in which the metamorphosis is complete constitute a monophylitic group; the indications being that this type of metamorphosis has arisen independently in different parts of the insect series.

(b) THE Basal CONNECtions of THE TRACHEÆ THAT PRECEDE THE WING-VEINS

(r.) The costo-radial and the cubito-anal groups of tracheæ distinct, i. e. with no transverse basal trachea. Correlated with this condition, the medial trachea is a member of the costo-radial group.

(2.) The costo-radial and the cubito-anal groups of tracheæ united by a transverse basal trachea. Correlated with this are the successive stages in the migration of the base of the medial trachea, along the transverse basal trachea, from the costo-radial group of tracheæ to the cubito-anal group.

\section{(c) THE CROSS-VEINS}

(I.) The areas of the wings between the longitudinal veins traversed by an irregular network of veins.

(2.) With numerous regular cross-veins.

(3.) With the cross-veins greatly reduced in number. 


\section{(d) THE LONGitudinal veins}

(r.) The number and branching of the longitudinal veins as represented in the hypothetical primitive type of Comstock and Needham, with the addition, near the margin of the wing, of accessory veins, which were inconstant in number and position.

From this primitive type of wing-venation three quite distinct lines of specialization arose, as indicated under 2, 3, and 4, below.

(2.) The number of the wing-veins increased by the addition of accessory veins.

(3.) The number of the wing-veins increased by the addition of intercalary veins.

(4.) The number of the wing-veins reduced by the coalescence of veins, and also, in many cases, by the atrophy of veins.

Note.-In some cases the method of specialization of the anal area of the wings is quite different from that of the preanal area. Thus, in the series of orders in which the characteristic method of specialization of the preanal area is by a reduction in the number of veins there are forms in which the anal area is expanded and the number of veins is increased.

TABLE OF THE METHODS OF SPECIALIZATION OF THE WINGS CHARACTERISTIC OF THE ORDERS OF INSECTS

This table is merely the result of an effort to indicate the more striking of the methods of specialization of the wings characteristic of each of the orders of insects. It is not a key for determining the orders of insects. It is not available for this purpose; because, in many cases, the wings of an insect do not show the type of specialization characteristic of the order to which the insect belongs. Thus, for example, while the most characteristic modification of the courses of the wing-veins in the Diptera and Hymenoptera is due to the coalescence of veins proceeding from the margin of the wing towards the base of the wing, there is no indication of this type of coalescence of veins in some of the nematocerous Diptera.

A. Wings specialized by the development of supernumerary veins in the preanal area.

B. Supernumerary veins of the accessory type.

C. Wings developed externally.

D. Wings retained throughout life. Wings without a striking contrast in the thickness of the veins of the anterior part of the wing and those of the middle portion.......... OrthopterA

DD. Wings deciduous, there being near the base of each wing a transverse suture along which the wing is broken off after the swarming flight. Wings with the veins of the anterior part of the 
wing greatly thickened and those of the middle portion reduced

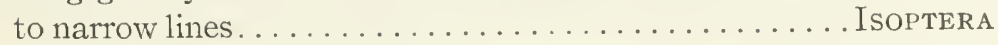

CC. Wings developed internally.............. Neuroptera

BB. Supernumerary veins of the intercalary type.

C. Flight-function cephalized; the hind wings being greatly reduced

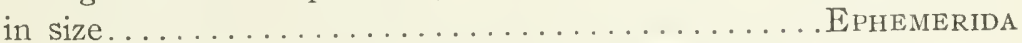

CC. Flight-function not cephalized; the hind wings as large as or

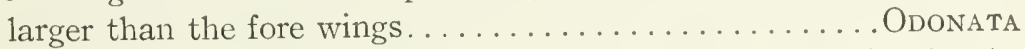

AA. Wings specialized by a reduction in the number of veins in the preanal area.

B. Wings developed externally.

C. The two pairs of wings similar in texture.

D. With the terdency to develop accessory veins retained.

Plecoptera

DD. With the tendency to develop accessory veins in the preanal area lost.

E. With the courses of some of the longitudinal veins modified so that they function as cross-veins.......... Corodentia EE. The transverse bracing of the wing attained in the usual way.

F. The veins of the wing bordered with dark bands. Embinina FF. The veins of the wing not bordered with dark bands.

G. Wings long and narrow, supplemented by a wide fringe of hairs.................. Thysanoptera

GG. Wings not greatly narrowed and not supplemented by

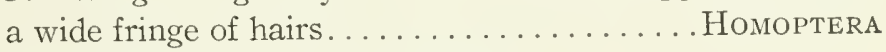

CC. The front wings more or less thickened.

D. The front wings not greatly reduced in length as compared with the hind wings.

E. The front wings thickened throughout....... HomopterA EE. The front wings thickened at the base, the terminal portion

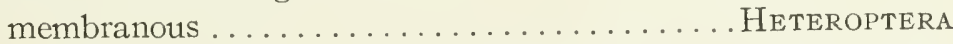

DD. The front wings greatly reduced in length.... DERMAPTERA

BB. Wings developed internally.

C. Fore wings greatly thickened.

D. Fore wings modified so as to serve as covers of the posterior wings $\ldots \ldots \ldots \ldots \ldots \ldots \ldots \ldots \ldots \ldots \ldots \ldots \ldots \ldots \ldots \ldots$ Coleoptera

DD. Fore wings reduced to slender, leathery, club-shaped appen-

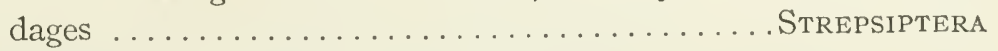

CC. The two pairs of wings similar in texture.

D. With the tendency to develop accessory veins retained.

Mecoptera

DD. With the tendency to develop accessory veins lost. 
E. The most characteristic method of reduction of the wing-veins of the preanal area being by coalescence outward.

F. Anal veins of the fore wings tending to coalesce at the tip. Wings usually clothed with hairs........ TRICHOPTERA FF. Anal veins of the fore wings not tending to coalesce at the tip. Wings clothed with scales........... LEPIDOPTERA EE. The most characteristic method of reduction of the wingveins of the preanal area being by coalescence from the margin of the wing inward.

F. With only one pair of wings........... DipterA FF. With two pairs of wings........... Hymenoptera

LIST OF ORDERS

Orthoptera

Isoptera

Neuroptera

Ephemerida

Odonata

Plecoptera

Corrodentia

Embiidina

Thysanoptera

Homoptera
Heteroptera

Dermaptera

Coleoptera

Strepsiptera

Mecoptera

Trichoptera

Lepidoptera

Diptera

Hymenoptera 


\section{CHAPTER VII}

\section{THE WINGS OF THE ORTHOPTERA}

\section{(a) THE MORE General FEATURes OF THE WINGS OF THE ORTHOPtera}

THE two pairs of wings of the Orthoptera differ in structure. The front wings are leathery or parchment-like, forming covers for the more delicate hind wings. These wing-covers have received the special name tegmina. The tegmina usually overlap, at least at the tips, when at rest. The hind wings are thinner than the tegmina and usually have a broadly expanded anal area, which is folded in plaits like a fan when at rest. Many Orthoptera have vestigial wings, and many are wingless. In the males of the saltatorial Orthoptera, the Acridiidæ, Locustidæ, and Gryllidæ, musical organs have been formed by modifications of certain parts of the wings.

Correlated with the modification of the fore wings into tegmina there are striking modifications of the shape of these organs and of the venation of the costo-subcostal area. The costal margin of the wing is usually more strongly convex than it is in insects in which the front wings are more efficient organs of flight; and the costal vein is either greatly reduced or not at all developed. In fact, the part played by the costal vein in the formation of the fore wings of the Orthoptera is problematic.

The subcostal vein, on the other hand, is usually well-developed, and usually gives off many branches that extend to the costal margin of the wing. In many cases, one of these branches is larger than the others and arises near the base of the wing. This is regarded by some writers as the costa. If this view is correct the costa in these cases is distant from the margin of the wing; and it, like the subcosta, often gives off branches which extend to the margin of the wing. For data bearing on this point see the figures illustrating the tracheation of the wings of nymphs given later.

As some recent writers place the Blattidæ and the saltatorial Orthoptera in separate orders, I discuss the venation of the wings of these two groups separately. I have not studied the development of the wings of any of the Mantidæ or of the Phasmidæ, hence a discussion of the wings of these two families is omitted. It is not probable, however, that these will present serious difficulties.

\section{(b) THE Wings of THE BLAtTid}

The tracheation of the wings. - The tracheation of the wings of nymphs of cockroaches was studied by Comstock and Needham. As but little additional data on this subject has been published, the present account is based chiefly on the facts determined by us jointly. 
The basal connections of the wing trachece.-It was found that in regard to the basal connections of the wing tracheæ two quite different conditions exist within this family. In some cockroaches (Fig. I I6) a basal transverse

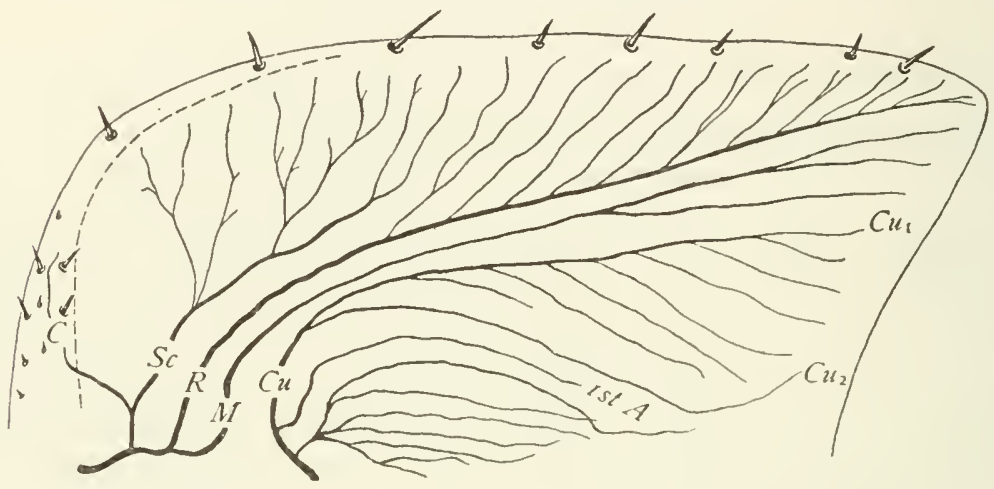

Fig. I 16.-Fore wing of a nymph of a cockroach. (After C. \& N.).

trachea has not been developed; in these the medial trachea is a member of the costo-radial group. In other cockroaches (Fig. I I 7), there is a welldeveloped basal transverse trachea and the base of the medial trachea is far advanced in its migration towards the cubito-anal group of tracheæ. As the significance of these facts is discussed in an earlier chapter (see p. I7), I will not dwell upon them here.

The costal trachea.-As yet very little data is available regarding the costal trachea of cockroaches. In the wing represented by Figure in6, there was a trachea in the humeral angle of the wing which may be the costal trachea. But, although we labeled it as such, I do not feel sure that this conclusion is correct, for this trachea may be merely a branch of the subcostal trachea. In the wings represented by Figure II 7 no costal trachea was found.

It is desirable that further studies should be made regarding the identity of the costal trachea in this family and in the Mantidæ as well. This is especially important because Handlirsch ('06-'o8) has proposed the establishment of distinct orders for these two families, the Blattoidea and the Mantoidea, and has placed these orders with several other orders of insects in a subclass of the Class Pterygogenea, the Blattæoformia, distinct from the subclass Orthopteroidea, in which the other families of the Orthoptera and certain other orders of insects are placed; and in his characterizations of the orders placed in the Blattæformia, he states that the costa is marginal, and in the characterizations of the orders placed in the Orthopteroidea, he states that the costa is distant from the costal margin of the wing. It is obviously important to determine whether this distinction exists or not. 
The subcostal trachea.-The subcostal trachea is well-developed; but it is short, extending but little if at all beyond the middle of the length of the wing. Its main stem is distant from the margin of the wing; but it usually gives off numerous branches, which are more or less forked, towards the margin of the wing.

The radial trachea.-The radial trachea is well-developed and, like the subcostal trachea, gives off numerous branches which extend towards the costal margin of the wing. The radial sector, however, is greatly reduced.

The medial trachea.-The medial trachea is not greatly branched and is sometimes reduced to an unbranched condition.

The cubital trachea.-The cubital trachea is either with or without accessory branches. In the fore wings of the forms studied, trachea $\mathrm{Cu}_{1}$ bore many branches.

The anal trachece.-Trachea ist A is simple in all Orthoptera studied; it often coalesces at the base with the cubital trachea for a greater or less

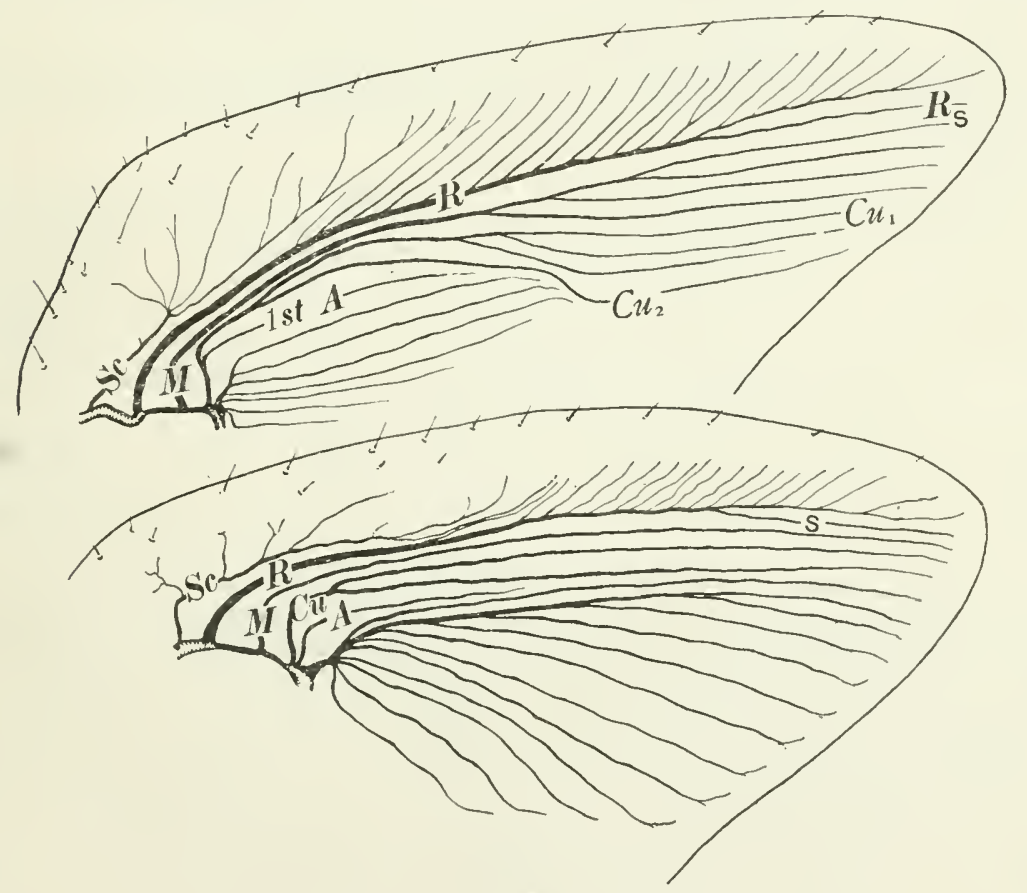

Fig. I 17.-Wings of a nymph of a cockroach (After C. \& N.).

distance. The second and third anal tracheæ are represented by a single stout stem which is divided into many branches.

The venation of the wings. - The data given above regarding the tracheation of the wings of nymphs furnish material for determining the 
homologies of the wing-veins of adults. The principal veins are easily recognized except the costa, which is either greatly reduced or is entirely lacking. But the general appearance of the wings of recent cockroaches is

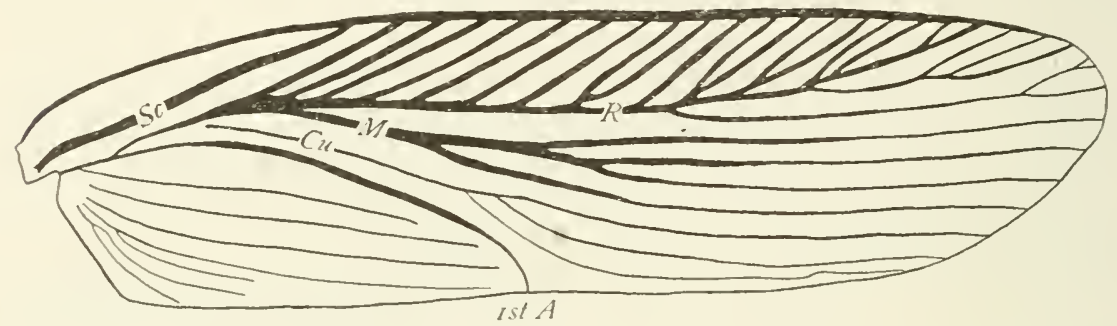

Fig. I 18.-Right fore wing of Phyllodroma germanica.

very different from that of the hypothetical primitive type. In fact, although cockroaches are in many respects very generalized insects, the structure of their wings has been greatly modified in the course of the evolution of the family. There has been an extensive development of accessory veins, a great reduction of the radial sector, and a modification of the branching of the media, or the reduction of this vein to an unbranched condition.

The venation of the wings of certain modern cockroaches does not differ so much from the hypothetical primitive type as does that of the wings figured above. For example, the fore wings of Phyllodroma germanica, commonly known in the United States as the croton bug, present a much more generalized condition. Figures II 8 and I 9 represent the venation of the two tegmina of the same individual.

The radial sector in the right tegmen of this insect (Fig. II8) is nearly typical; veins $R_{2}$ and $R_{3}$ coalesce nearly to the margin of the wing, but

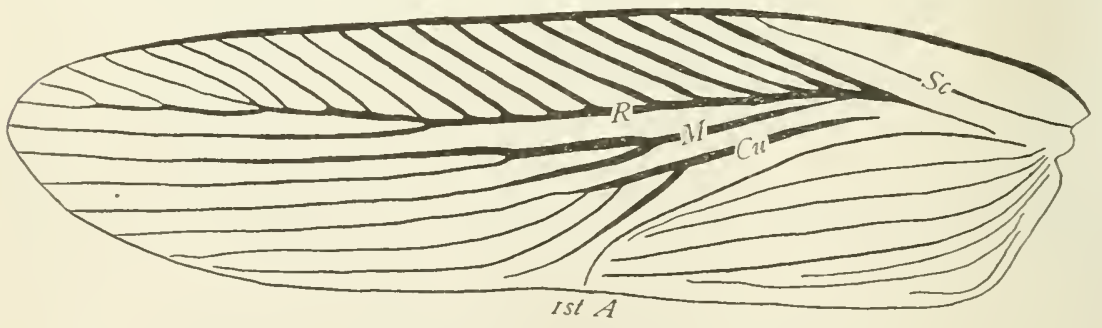

Fig. I 19.-Left fore wing of Phyllodroma germanica.

their tips are still distinct; veins $R_{4}$ and $R_{5}$ coalesce throughout. In the left tegmen (Fig. II9), the radial sector is reduced to an unbranched condition.

5. The media is four branched in the right tegmen (Fig. I I 8), but the branching is not quite typical. Spuler ('92) figures the right wings of this 
species; in the fore wing as figured by this author the media is completely typical. In the left tegmen figured here (Fig. I I9) media is three branched; it appears that veins $\mathrm{M}_{3}$ and $\mathrm{M}_{4}$ coalesce to the margin of the wing, otherwise the arrangement is typical.

The cubitus bears one accessory vein in the right tegmen (Fig. II 8 ), and two in the left (Fig. I I9).

\section{(c) THE Wings OF THE SALtatorial ORTHOPtERA}

Although the discussion of the wings of the saltatorial Orthoptera is here separated from that of the wings of the Blattidæ, for the reason given on an earlier page, I am unable to point out any distinguishing characteristic between the wings of the two groups. The only attempt that has been made to do this is the statement by Handlirsch that the costa is marginal in the Blattidæ and distant from the margin of the wing in the saltatorial

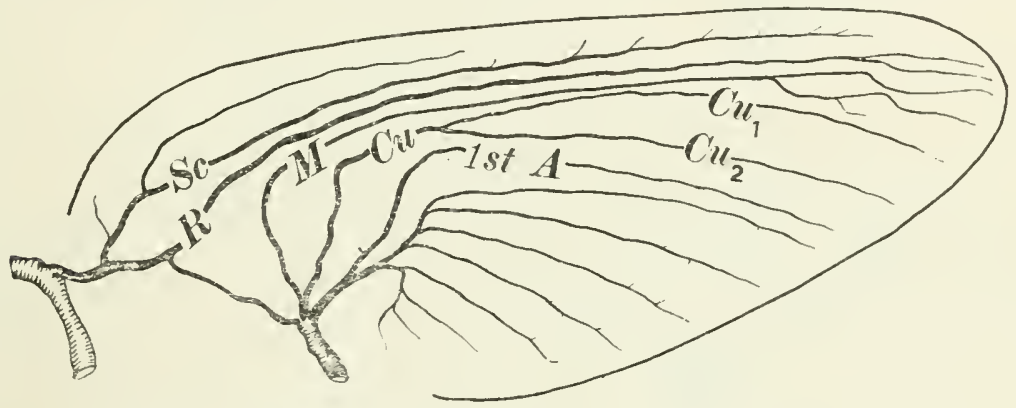

Fig. 120.-Hind wing of a nymph of Xiphidium (After C. \& N.).

Orthoptera; but I regard the evidence supporting this view as far from being conclusive.

The tracheation of the wings.- The development of wings of saltatorial Orthoptera was studied by Comstock and Needham; as very little has been published on this subject since the appearance of our paper, the following account is based on the data obtained by us jointly.*

The basal connections of the wing trachece.-In all of the saltatorial Orthoptera studied by us a transverse basal trachea was found. But in the hind wing of a nymph of Xiphidium (Fig. I 20) this trachea was greatly reduced. That this trachea is vestigial and not rudimentary is evident from the fact that the base of the medial trachea has completed its migration towards the cubito-anal group of trachea and coalesces with the cubital trachea for a short distance. The transverse basal trachea has served its purpose in making possible this migration of the base of the medial trachea, and, like an abandoned road, is disappearing from view.

*Hancock ('O2) has discussed the tracheation of the wings of the Tettigidæ and gives several figures of the wings in which the tracheæ are represented. 
The costal trachea.-The data regarding the costal trachea in the saltatorial Orthoptera is as inconclusive as is that regarding the costal trachea in the Blattidæ. In none of the Orthoptera that we examined was a distinct separate costal trachea found. Frequently, as in the acridid nymph (Fig. I 2 I) and in that of Conocephalus (Fig. I22), there is a prominent branch of the subcostal trachea of the fore wing that simulates a costal trachea; but a study of a series of forms led us to believe that this is merely an overgrown

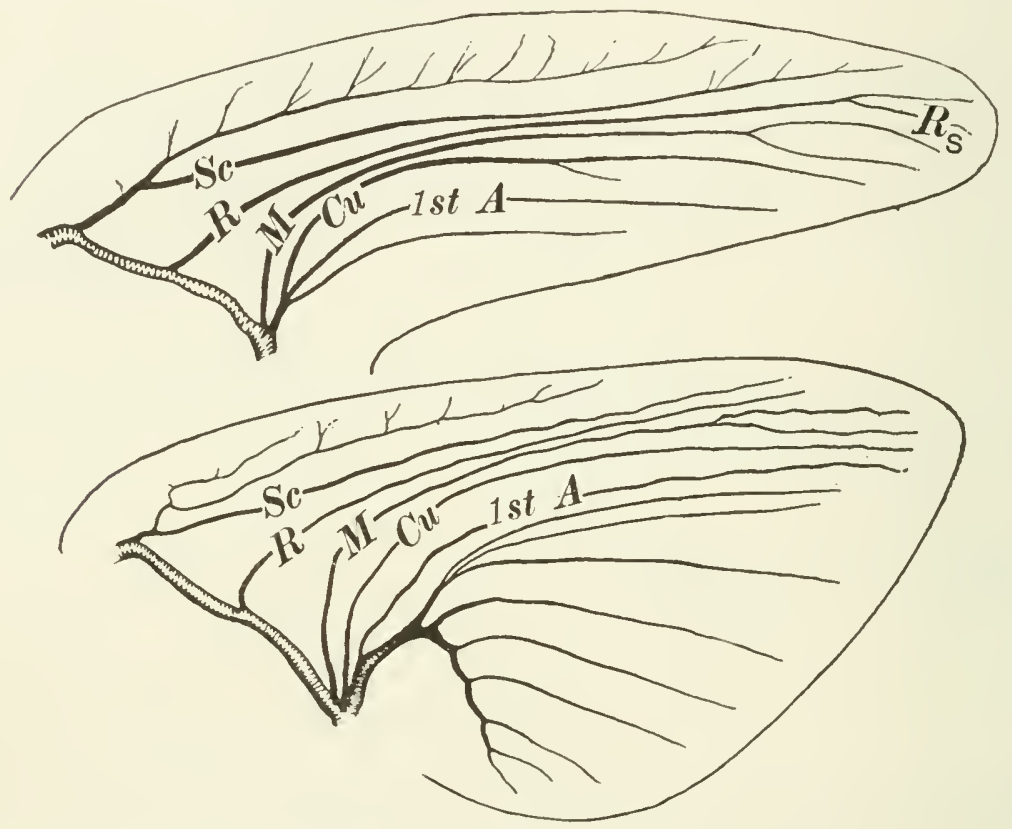

Fig. I21.-Wings of an acridid nymph (After C. \& N.).

branch of the subcostal trachea; in the hind wing of Conocephalus (Fig. I22) there are two such branches.

Handlirsch ('06-'08) copies this figure of the tracheation of the wings of Conocephalus and labels this prominent branch of the subcostal trachea in the fore wing as the costal trachea; and he labels the corresponding vein in an adult wing the costa. This is probably the basis for his conclusion that in the saltatorial Orthoptera the costa is remote from the margin of the wing.

The subcostal trachea.-In the forms studied the subcostal trachea was well-developed and in some of them extended nearly to the tip of the wing (Fig. I2 I and I22). In some cases it gives off many branches towards the margin of the wing (Fig. I22); in others it is nearly or quite simple (Fig. I 23), but in no case is there a division into two branches that clearly correspond to the $\mathrm{Sc}_{1}$ and $\mathrm{Sc}_{2}$ of the hypothetical primitive wing. 
The radial trachea.-There is a great variation in the size of the main trunk of the radial trachea; in Conocephalus (Fig. I22), it corresponds in

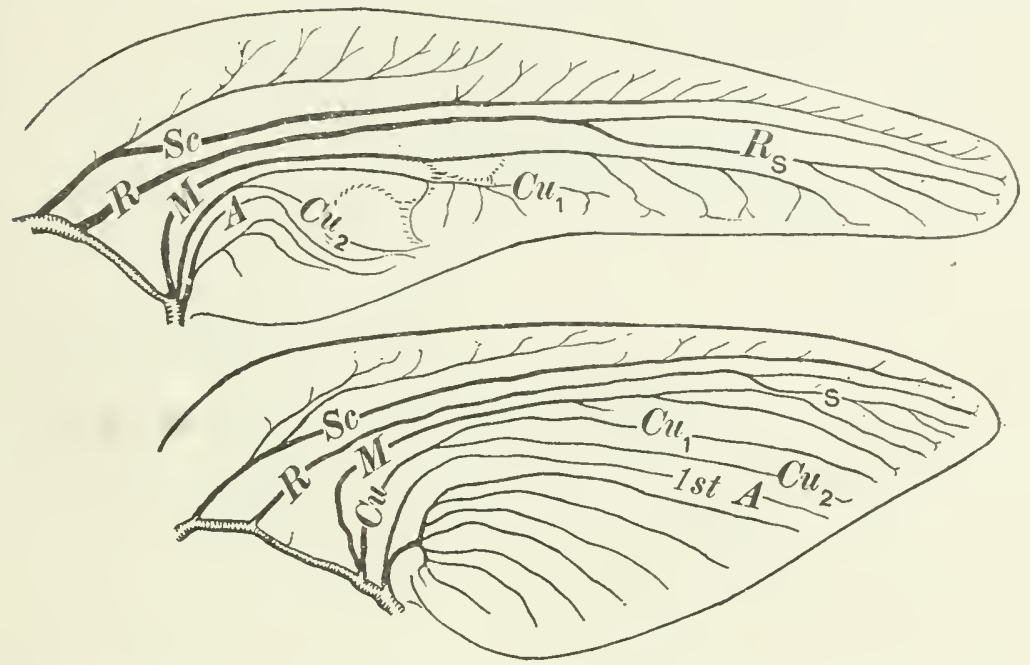

Fig. 122.-Wings of a nymph of Conocephalus (After C. \& N.).

size with the other principal tracheæ; but in the fore wing of Oecanthus (Fig. I 24) it is the least developed of the principal veins. In all cases the radial sector is greatly reduced; and in some, the radius is unbranched.

The medial trachea.-In most cases the medial trachea has become a member of the cubito-anal group of tracheæ, but in the hind wing of Oecanthus (Fig. I 24) it arises from the transverse basal trachea only a slightly nearer to the cubital trachea than to the radial. The typical branching of this trachea is not preserved in any of the forms studied.

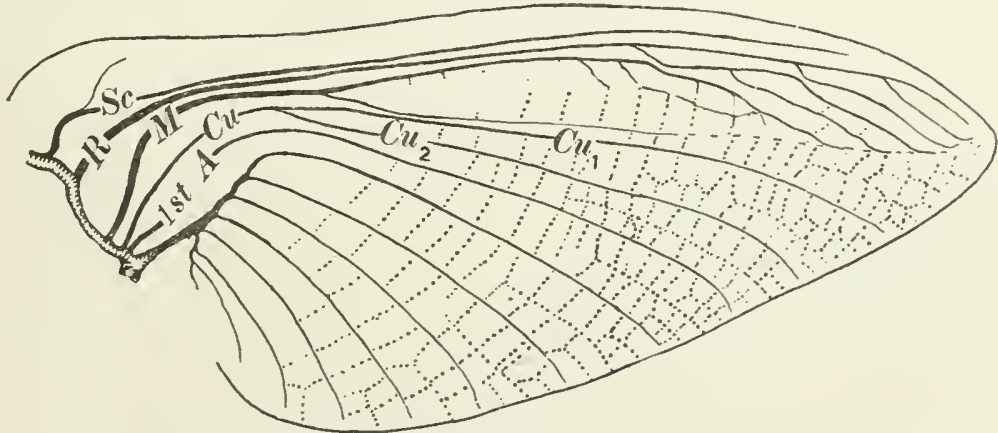

Fig. 123.-Hind wing of a nymph of Scudderia. Dotted lines indicate adult venation in part (After C. \& N.).

The cubital trachea.-Great variations exist in the development of the cubital trachea even within the limits of a single family. In the acridid 
nymph (Fig. I 2 I) it is reduced to a nearly simple condition; in the hind wings of Conocephalus (Fig. I22) and in the hind wings of Scudderia (Fig.

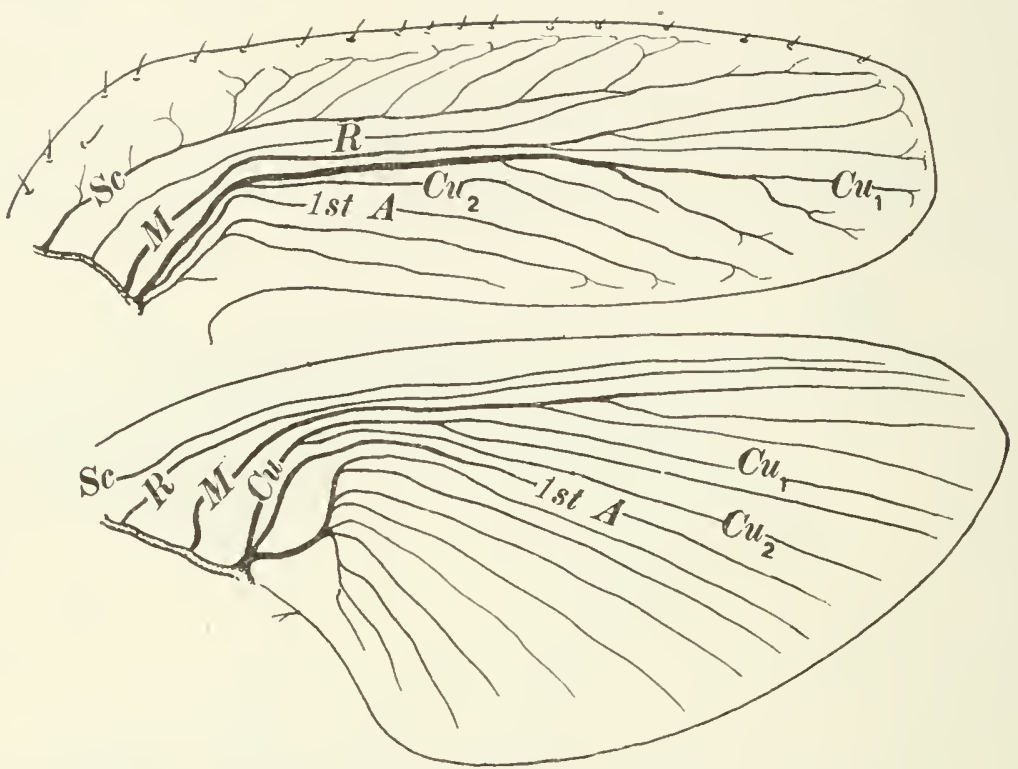

Fig. I24.-Wings of a female nymph of Oecanthus (After C. \& N.).

r23) it is typical in form; in other cases accessory tracheæ have been developed upon trachea $\mathrm{Cu}_{1}$.

The anal trachece.-Trachea Ist A is always unbranched; it often coalesces at the base with the cubital trachea. The second and third anal tracheæ are represented by a single stout stem, which is slightly branched in the fore wings, but which bears many branches in the hind wings; this

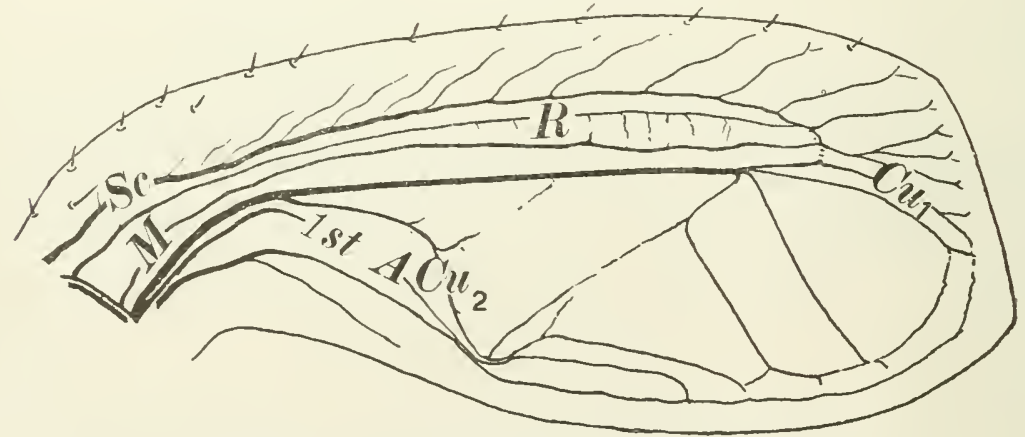

Fig. 125.-Fore wing of a male nymph of Oecanthus (After C. \& N.).

condition is correlated with the reduction of the anal area of the fore wings and the greatly expanded anal area of the hind wings. 
The tracheation of the musical organs.-In the males of the Locustidæ (Fig. I 22) and of the Gryllidæ (Fig. I 25) the formation of a musical organ has been attained by a modification of the cubital and anal areas of the front wings. An extreme case of this is furnished by the male of Oecanthus (Fig. I25). The principal vibrating area of the wing lies between the branches of the cubitus, which diverge widely in this sex.

Although the wings of the two sexes of Oecanthus present a very different appearance, there is really a very close correspondence in the tracheation, and consequently in the venation, of the two, as can be seen by comparing the lettering of Figures I24 and I25.

The anal furrow.- A study of the musical organs of adult Orthoptera throws light on the nature of the anal furrow. In the female this furrow lies between the cubitus and the first anal vein; but in the males of the Locustidæ and Gryllidæ the anal furrow crosses bein $\mathrm{Cu}_{2}$. It is evident, therefore, that this furrow is merely a fold in the adult wing, and that its position is variable. It will be shown later that in the Heteroptera, when an anal furrow is developed, it is in front of the cubitus, instead of in the more usual position between the cubitus and the first anal vein.

The venation of the wings. - It does not seem worth while to give a detailed discussion of the venation of the wings, as the data given above regarding the tracheation of the wings of nymphs furnish material for determining the homologies of the wing-veins of adults. There are, however, some features of the venation of the wings that merit attention.

The cross-veins. - Although well-developed cross-veins are present in the wings of the Orthoptera, it is an interesting fact that in a considerable part of the wings the spaces between the principal veins are traversed by an irregular network of veins resembling those of the more generalized Palæodictyoptera. In this respect the Orthoptera (including the Blattidæ) is the most generalized of the orders of recent insects.

The venation of the anal area of the hind wings. - In many of the saltatorial Orthoptera the anal area of the hind wings bears a striking resemblance to the wings of the Ephemerida, there being a regular alternation of convex and concave veins. In these cases the concave veins are evidently a later development than the convex veins. The increase in the number of the branches of the anal tracher takes place at the caudal end of the series, and about each added trachea a convex vein is developed. It is only after the space between two of the convex veins becomes wide enough to admit of a fold in the wing that a concave vein is developed, and this development takes place in the same manner as in the Ephemerida; the convex veins being of the accessory type, and the concave veins, of the intercalary type.

In some cases, as in the hind wings of Scudderia (Fig. I23), a tertiary set of anal veins is developed; these extend only a short distance from the margin of the wing, and increase the resemblance of this area to an ephemerid wing. 


\section{CHAPTER IIII}

\section{THE WINGS OF THE ISOPTERA}

\section{(a) The more general features of the Wings of the isoptera}

IN these social insects, in which each species consists of several castes, only the sexual forms are winged. These have four, long, narrow wings, which are somewhat leathery in structure, and which are furnished with numerous veins. The wings are large, extending far beyond the end of the abdomen, when folded upon it, as they are when at rest. Except in a single

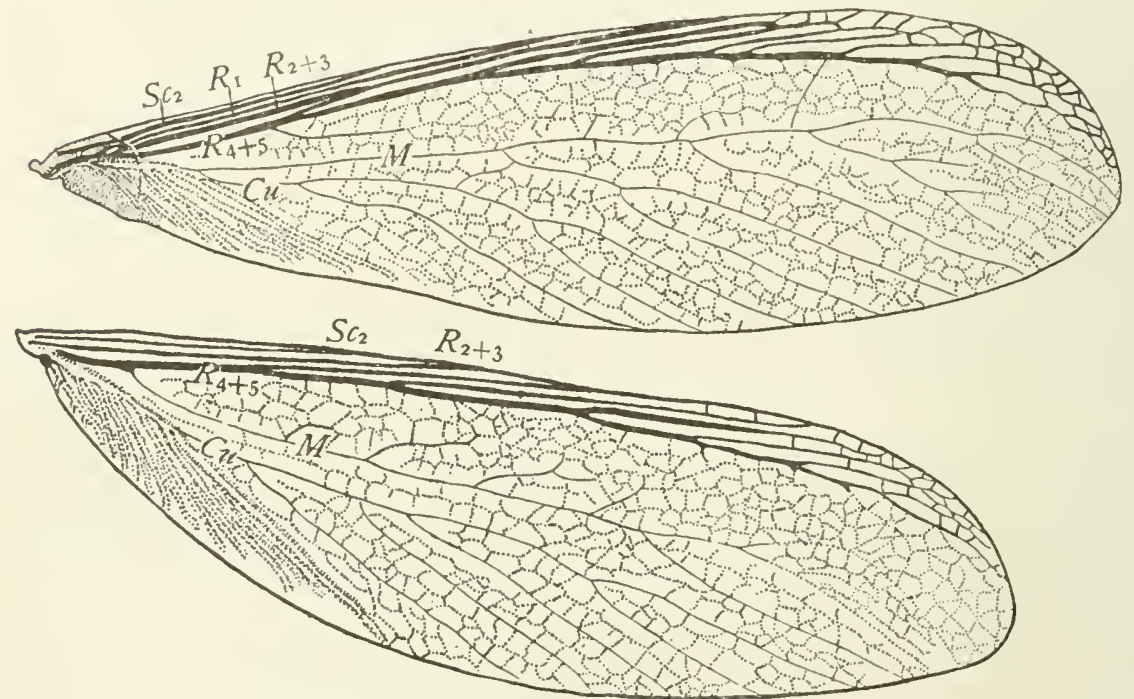

Fig. I26.-Wings of Termopsis angusticollis.

genus, the two pairs of wings are similar in form and in the more general features of their venation (Fig. I 26). In the Australian genus Mastotermes (Fig. I 27) the hind wings differ from the fore wings in having a broadly expanded anal area. The veins of the anterior part of the wing are greatly thickened and those of the middle portion reduced to indistinct bands or to narrow lines. Regular cross-veins are lacking, the membrane of the wing being strengthened by an irregular network of slightly chitinized wrinkles. Sometimes in narrow spaces, these wrinkles are transverse and resemble cross-veins more or less. This is the case in the sub-costo radial area of the wings of Mastotermes (Fig. I 29). 
The wings are deciduous, being shed after the swarming flight. The shedding of the wings is facilitated by the presence in each wing, except in the hind wings of certain genera, of a curved transverse suture near the base of the wing, which may be termed the humeral suture (Fig. 128, hs). In the more generalized members of the order, this suture is present only in the fore wings; but in the more specialized genera it exists in the hind wings as well.

That portion of the wing that is between the humeral suture and the body, and which remains attached to the body throughout life is more densely chitinized than the remainder of the wing. This part of the wing

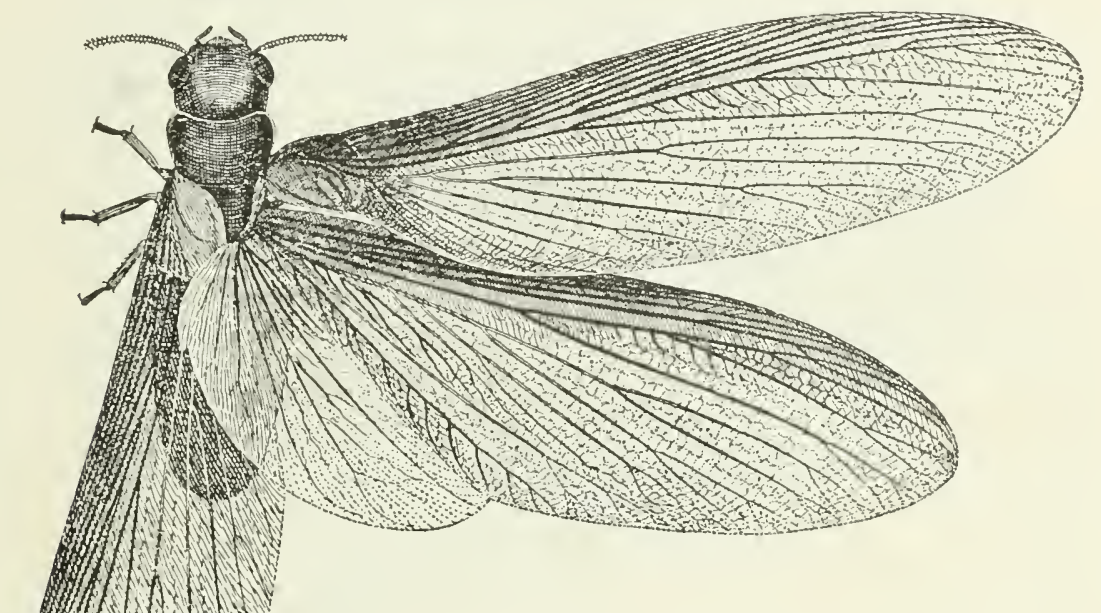

Fig. I27.-Mastotermes darwiniensis, adult male (After Froggatt 'i3).

is termed the scale by most writers on the Isoptera; Froggatt calls it the scapular shield, which is a much more distinctive term.

The scapular shield is traversed by the median furrow (Fig. I28, $m f$ ) and the anal furrow (Fig. I28, F). The position of the anal furrow indicates how greatly the anal area of the wing is reduced in the fore wings; in the hind wings the extent of the anal area varies in different genera, as is shown later.

The termite type of wing is a distinctively characteristic one and was evidently evolved very early. This is shown by the absence of regular cross-veins. It is obvious that the termites branched off from the insect stem before regular cross-veins were evolved; and it is an interesting fact that the tendency to develop regular cross-veins has not arisen in this order; instead of this there is a reduction in the chitinization of the irregular net- 
work and an increase in the wrinkling of the wing in the more specialized genera; this is well shown in the wings of Lencotermes. Other distinctive features of the termite type of wing are the provision made for the shedding of the wings after the swarming flight, a strengthening of the anterior portion of the wing, the development of a group of prominent accessory veins on cubitus near the base of the wing, the reduction of the veins in the inter-

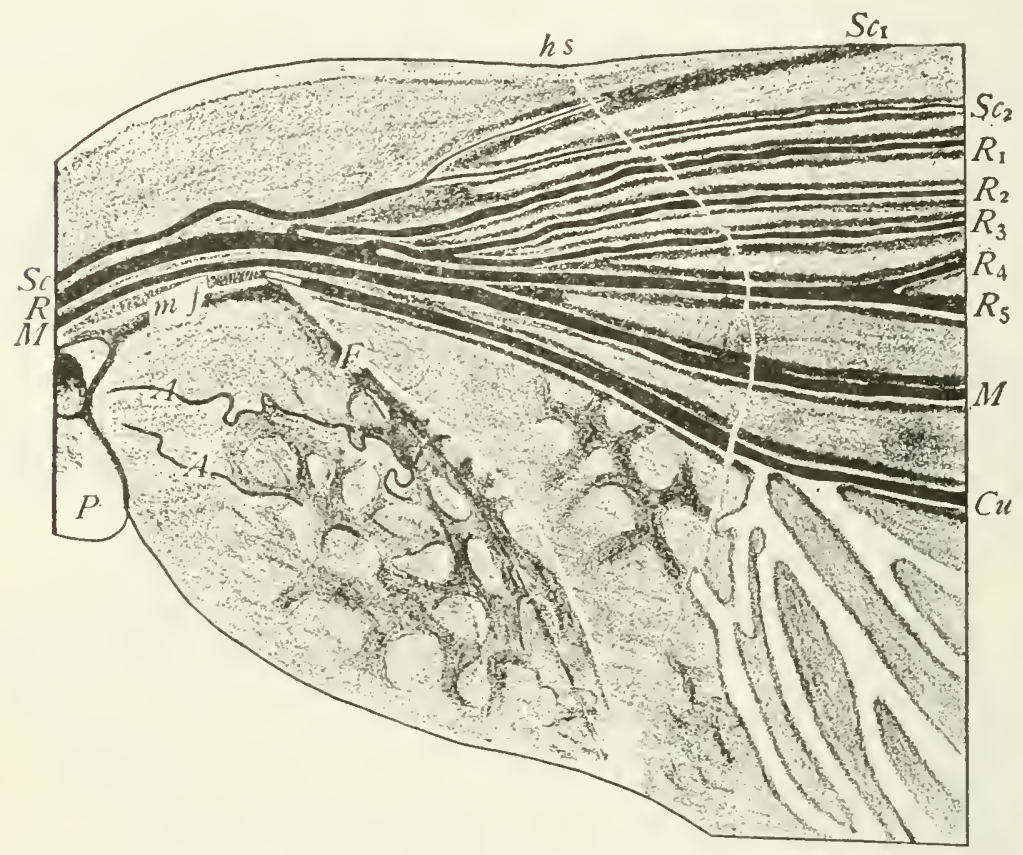

Fig. I28.-Base of a fore wing of Mastotermes darwiniensis, showing the wing-tracheæ and the following: hs, humeral suture; F, anal furrow; $m f$, median furrow; $\mathrm{P}$, posterior lobe of the wing.

mediate region to mere lines, and the position of the principal forks of radius near the base of the wing.

The evidence presented by the wings indicates that the termites constitute a highly specialized and very distinct order of insects one that was evolved early and one that has progressed far in its peculiar methods of specialization of the wings

The view that they are highly specialized insects is supported by the fact that they have attained a social mode of life, with the correlated separation of the species into numerous castes and the development of remarkable instincts. 


\section{(b) THE tRaChEation and the venation of the Wings of the ISOPTERA}

There are two very characteristic features of the venation of the wings of termites, an understanding of which facilitates the determination of the homologies of the wing-veins: first, the great reduction of the anal area, except in the hind wings of Mastotermes; second, the division of the radius into veins $R_{1}$ and $R_{s}$ and the division of the radial sector into veins $R_{2}+3$ and $R_{4}+5$ in an unusual position, that is very near the base of the wing. This is very clearly shown by the tracheation of the fore wing of Mastotermes described later.

The typical venation of the wings of the Isoptera and the chief ways in which this type is modified can be well-shown by a study of a series of representatives of the order consisting of Mastotermes, the most generalized member of the order, Termopsis, a slightly specialized form, and Lencoermes one of the more highly specialized forms.

Comparatively little attention has been given to the study of the tracheation of the wings of members of this order as an aid to the determination of the homologies of the wing-veins. Professor Needham and I secured nymphs of two of the three genera that occur in the United States and photographed the tracheation of their wings; but as this material did not enable us to determine satisfactorily the homologies of the wing-veins, no account of these wings was included in our series of articles. The figures of the tracheation of the wings of Termopsis and of Lencotermes in later paragraphs were made from photographs that we took jointly; and during the preparation of this chapter we have reviewed the subject, having obtained many living nymphs of Termopsis from California and of Lencotermes from Florida. The only published figure of the tracheation of a termite wing is that of Holmgren ('II), who sketches the tracheæ in the base of a fore wing of an adult Mastotermes darwiniensis.

The tracheation and the venation of the wings of Mastotermes darwiniensis.-Several authors, notable Desneux ('o4a and 'o4b), Silvestri ('о9), Holmgren ('ті), and Rosen ('т3), have published descriptions and figures of the wings of this insect, the most generalized of all living termites known.

There is no difficulty in recognizing the homologies of the wing-veins excepting those near the costal margin of the wing, $i . e$. those that lie in front of the media. Here there is considerable difficulty, which is due to the fact that there are variations in the venation and in the tracheation of this part of the wing. Not only do different individuals vary, but the wings of the two sides of the same individual may differ. This is true of the branching of the principal tracher, which can be seen in the adult wing with comparative ease, as well as of the venation. 
The descriptions by Desneux of this part of the wing are incomplete; that of Silvestri is obviously incorrect, as he designates a vein that lies a considerable distance from the costal margin of the wing as the costa; Holmgren, whose account is the most complete, has been misled, I believe, by an aberration in the tracheation of the wing studied by him, which led him to believe that vein $\mathrm{R}_{1}$, which he terms "radius," is represented by two veins.

Recently, through the kindness of Mr. Walter IV. Froggatt, who first described this remarkable insect, I have received a specimen of it. In the fore wings of this individual the trachex are clearly visible, and in the right wing the arrangement of the principal branches closely resembles that of the hypothetical type. Figure I 28 represents the base of this wing; the entire wing is figured later. Great care has been taken to represent accurately the courses of the tracheæ in that part of the wing figured here, the figure being based on a photomicrograph.

In the left wing of this individual the branching of the tracheæ is somewhat different. It seems to me that the tracheation of the right wing should be regarded as typical, as it corresponds closely to that of the hypothetical primitive type, and that of the left wing as aberrant.

Regarding the identity of the radial trachea (Fig. I 28, R) there can be no doubt; its position and manner of branching are typical, except that the branching takes place unusually near the base of the wing. Trachea $R_{1}$ branches off from trachea $R$ near the end of the first third of the length of the scapular shield. A short distance beyond the point where trachea $R_{1}$ separates from trachea $R$, the trachea of the radial sector divides; the branch $R_{2}+_{3}$ is much smaller than the branch $R_{4}+5$. Trachea $R_{2}+3$ divides a short distance beyond its point of origin, near the middle of the length of the scapular shield, one branch extending into vein $R_{2}$ and the other into vein $R_{3}$. Trachea $R_{4+5}$ passes into vein $R_{4}+5$, which first divides beyond the end of the scapular shield.

Immediately in front of the radial trachea is the subcostal trachea (Fig. I $28, \mathrm{Sc}$ ). This enters the wing separate from the radial trachea, but the two tracheæ extend closely parallel in the first third of the length of the scapular shield; the subcostal trachea then extends obliquely towards the costal margin of the wing; near the beginning of the last third of the length of the scapular shield, the subcostal trachea forks, trachea $\mathrm{Sc}_{2}$ enters vein $\mathrm{Sc}_{2}$, which is a well-developed vein. Vein $\mathrm{Sc}_{1}$ is very indistinct.

The costal margin of the wing is not greatly thickened and no costal trachea is visible in this specimen.

The medial trachea (Fig. I28, m) enters the wing separately; it is closely parallel with the radial trachea in the basal part of the scapular shield; it crosses the median furrow and enters the strong media near the 
beginning of the last third of the length of the scapular shield; this vein passes from the shield unbranched.

The cubital trachea (Fig. I $28, \mathrm{Cu}$ ) is first visible at the point where the anal furrow and the median furrow separate, the basal part of it being concealed by the dark color of that part of the scapular shield that it traverses; it extends nearly parallel with the medial trachea. Between the main trunk of the cubitus and the anal furrow there is a network of irregular veins, but I can not discover any tracheæ in them.

In the anal area there are no distinct veins, but merely an irregular network of cuticular thickenings. In this area, there are, in the specimen
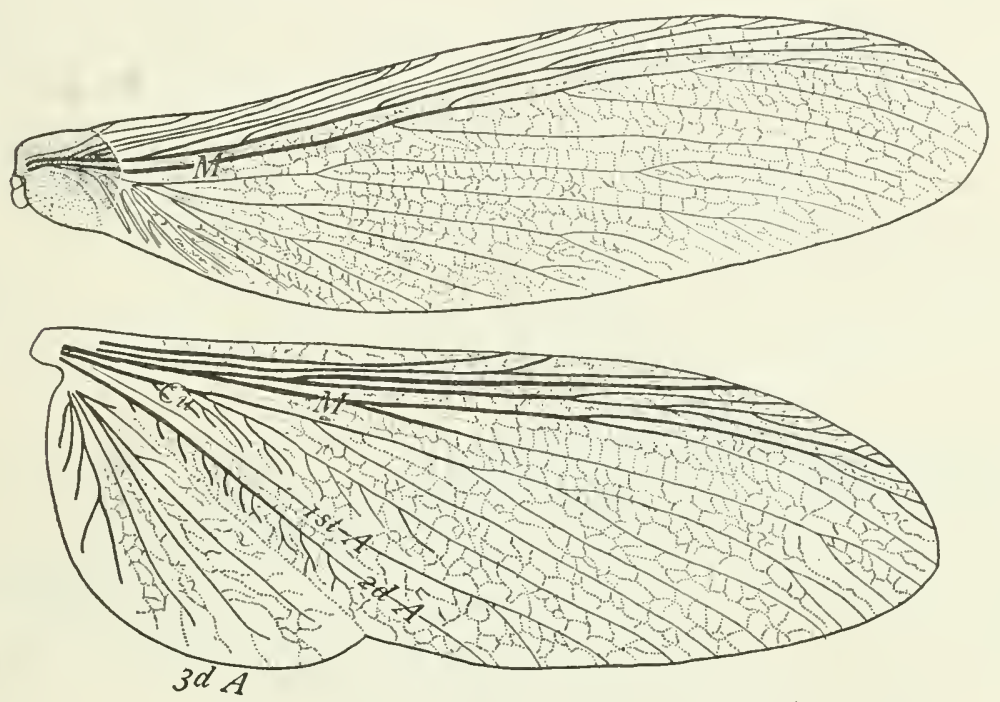

Fig. 129.-Wings of Mastotermes darwiniensis.

figured, two trachex (Fig. I $28, \mathrm{~A}, \mathrm{~A}$ ), which are visible in only a part of their extent, and which do not appear to bear any relation to the cuticular thickenings of this area of the wing.

In the left wing of the individual, the base of the right wing of which is figured and described above, trachea $\mathrm{R}_{2}+3$ is not divided, and trachea $\mathrm{Sc}_{2}$ enters the vein that appears to correspond to vein $R_{1}$ of the right side.

In the fore wings of Mastotermes there is a posterior lobe of the wing (Fig. I $28, \mathrm{P}$ ); this is termed by Holmgren the postanalfield.

Figure 129 represents the entire wings of Mastotermes darwiniensis. In the case of the fore wing, there may be noted, in addition to the features shown in Figure 128 , the marked difference in the strength of the veins of the anterior part of the wing and those of the middle portion, the presence of several strong accessory veins borne by cubitus near the base of the wing, 
and the presence of a network of irregular, slightly chitinized wrinkles, indicated by dotted lines.

In determining the homologies of the hind wings it is well to begin with the cubitus, which can be easily recognized by the group of prominent

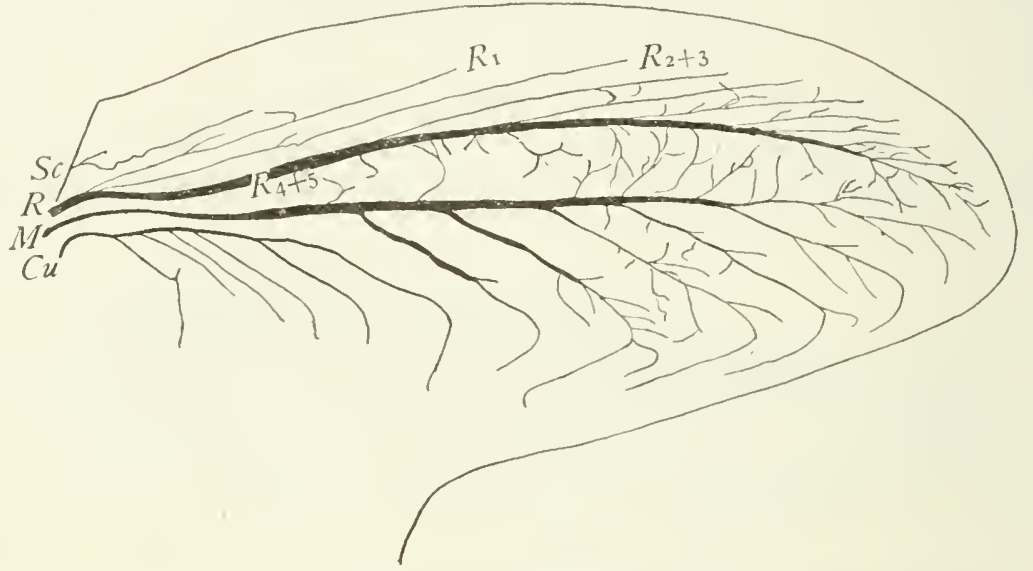

Fig. I30.--The tracheation of a fore wing of a nymph of Termopsis angusticollis.

accessory veins near its base; this group of prominent accessory veins borne by cubitus in both fore and hind wings is one of the most characteristic features of the wings of termites. Immediately in front of cubitus is the media, which coalesces with vein $R_{4+5}$ at its base. In front of vein $R_{4+5}$ are two veins; that one of these two which is nearest the costal margin of the wing I believe to be the subcosta and the other, vein $R_{2}+3$. I am led to this conclusion by the fact that the hind wing of Termopsis angusticollis closely resembles Mastotermes in this region of the wing, and by studies of the tracheation of the wings of Termopsis I have been able to determine the homologies of these veins.

Back of the cubitus lies the first anal vein. This is simple for the greater part of its length, but is forked near the margin of the wing. The basal part of the first anal vein is very weak, its place having been taken by an anal furrow. The second and third anal veins are much branched, and between them is an axillary furrow.

The tracheation and the venation of the wings of Termopsis angusticollis.-An understanding of the tracheation of the fore wings of Mastotermes, illustrated above, renders easy the interpretation of the tracheation of a fore wing of Termopsis angusticollis, which is represented by Figure I 30 .

In this wing no costal trachea was found. The subcostal trachea is short, and enters the wing distinct from the radial trachea; only a short vestige of trachea $\mathrm{Sc}_{1}$ remains. The radial trachea resembles quite closely, 
that of Mastotermes in the arrangement of its principal branches, except that trachea $R_{2}+_{3}$ is not divided. Trachea $R_{1}$ separates from trachea $R$ at the base of the wing; the first forking of the radial sector trachea takes place very close to the point where it separates from trachea $R_{1}$, as is the case in Mastotermes, and the anterior branch of this trachea, trachea $\mathrm{R}_{2}+3$ is much weaker than the posterior branch; it is not divided, and extends a little more than half the length of the wing. I have been unable to determine whether tracheæ $R_{2}$ and $R_{3}$ coalesce or whether one of them has atrophied. In either case the single trachea that remains represents the anterior division of the radial sector trachea and may be designated as trachea $R_{2+3}$ provisionally. The posterior branch of the radial sector trachea, trachea $R_{4}{ }_{5}$, is the largest trachea in the wing; it gives off seven parallel branches from its anterior side and several irregular branches from its posterior side. The medial trachea is large; it gives off several irregular branches from its anterior side and five prominent parallel branches from its posterior side. The cubital trachea is six branched.

It is evident that in Termopsis, as in Mastotermes, the most important part of the radius is vein $\mathrm{R}_{4}+5$; it is the branches of this vein that support the larger part of the radial area of the wing. All of the tracheæ in front of trachea $R_{4}+_{5}$ are comparatively weak, suggesting the approaching loss of

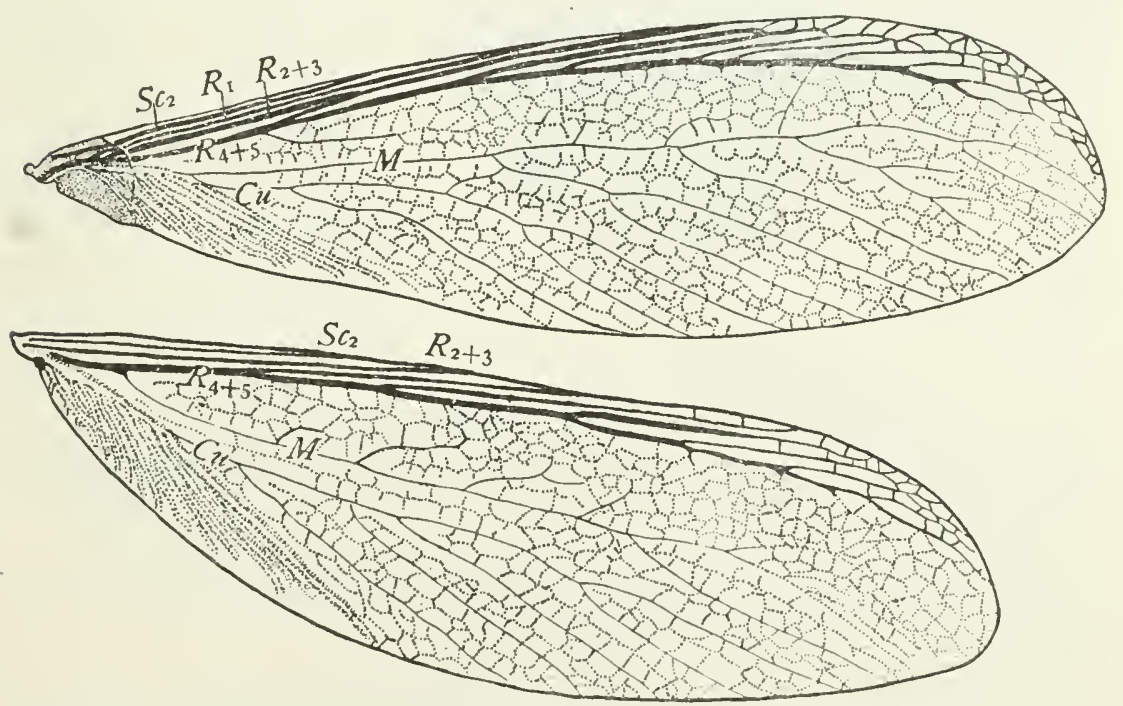

Fig. I3I.-Wings of Termopsis angusticollis.

the veins that they represent, and it is probable that where the radius is represented by a single vein, as is the case in the more specialized genera, this vein is vein $R_{4}+5$. 
The wings of different adult individuals of this species differ greatly in the number and arrangement of the veins of the subcosto-radial area of the wing. In the fore wing represented in Figure I3I, there are only three distinct veins in front of vein $R_{4+5}$. This condition corresponds with the tracheation of the wing of a nymph represented by Figure $\mathrm{r}_{30}$; and consequently these veins are designated as veins $S c_{2}, R_{1}$, and $R_{2}+3$ respectively.

In some individuals, however, there is no reduction in the number of the veins $i$ this part of the wing. Figure $\Upsilon_{32}$ represents the base of a fore wing of this species in which all of the veins of the subcosto-radial area are preserved.

Holmgren ('I I) figures the base of a fore wing of this species in which there are only four veins crossing the humeral suture in front of media.

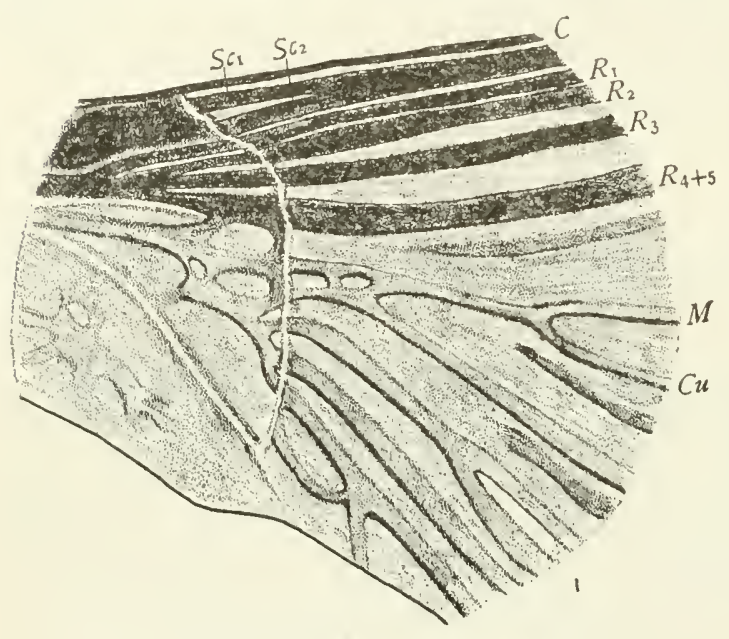

Fig. I 32.-Base of a"fore wing of Termopsis angusticollis. This condition corresponds with the tracheation of a wing of a nymph represented in Figure I30; and I believe that the veins in the individual figured by Holmgren should be identified as are the tracheæ in Figure r3o. Holmgren recognizes a subcosta, a double "radius" (i.e. $\mathrm{R}_{\mathbf{1}}$ ), and a radial sector, which is my $R_{4+5}$. The differences between our interpretations of the homologies of these veins is doubtless due to his conclusion that in Mastotermes vein $\mathrm{R}_{1}$ is represented by two distinct parallel veins, a conclusion that is based on what I regard as an instance of aberrant tracheation as stated above.

The hind wing of the Termopsis angusticollis figured here (Fig. $\mathrm{r} 3 \mathrm{I}$ ) differs from the fore wing in that there are only two distinct veins between vein $R_{1}+5$ and the thickened costal margin.

An examination of the tracheation of many hind wings of this species convinces me that these two veins are vein $\mathrm{Sc}_{2}$ and vein $\mathrm{R}_{2}+3$. The subcostal trachea is unmistakable, as it enters the wing distinct from the radial trachea; trachea $\mathrm{Sc}_{1}$ is usually merely a short branch, while trachea $\mathrm{Sc}_{2}$ is well developed. In a few specimens there is a small vestige of trachea $R_{1}$, but in all trachea $\mathrm{R}_{2}+_{3}$ is well developed. 
In the hind wing the base of media coalesces with vein $R_{4}+5$, while in the fore wing it coalesces with the cubitus.

In the hind wing much more of the anal area is preserved than in the fore wing. To understand this area of this wing the corresponding area of the hind wing of Mastotermes should be studied. In Termopsis the anal furrow is quite distinct (Fig. I33, $\mathrm{F})$, but there is no trace of the first anal vein. The second anal vein, however, is well preserved. The basal part of the anal area, that part behind the anal furrow, is considerably thickened, and the second anal vein appears to arise from this thickened part of the

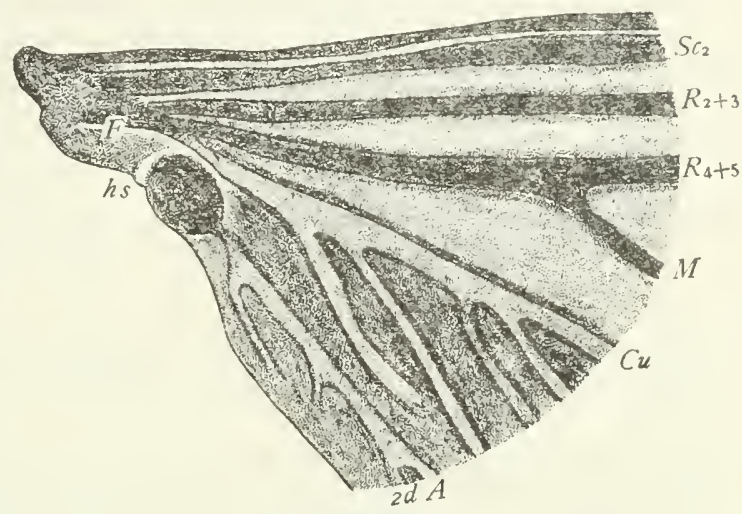

Fig. 133.-Base of a hind wing of Termopsis angusticollis.

wing. The third anal vein is wanting, and there is 110 axillary furrow. In comparing the hind wing of Termopsis with that of Mastotermes one receives the impression that in the making of the Termopsis wing that part of a primitive termite wing back of the axillary furrow was cut away.

The thickened portion of the anal area of the hind wing that lies behind the anal furrow is divided by a transverse suture which is probably the beginning of a humeral suture (Fig. I33, hs).

The tracheation and the venation of the wings of Leucotermes flavipes. -In this species the venation of the wings is greatly reduced. In the costo-radial part of the wing the reduction is in the number of the veins;

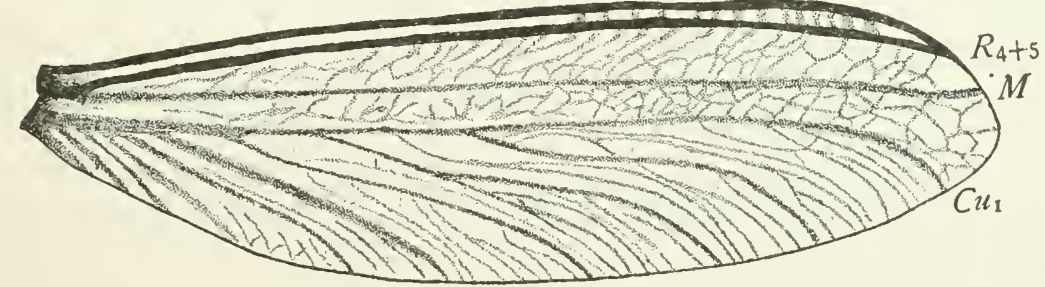

Fig. 134.-A hind wing of Leucotermes flavipes. Only the detached portion is shown.

but in other parts of the wing the reduction is in the amount of their chitinization (Fig. I34). The wing figured is a hind wing, which differs from the fore wing in that media coalesces with radius at the base, while in the fore wing media is free where it crosses the humeral suture. 
The costal margin of the wing is greatly thickened. It probably is formed by the coalesced costa and subcosta and may also include vein

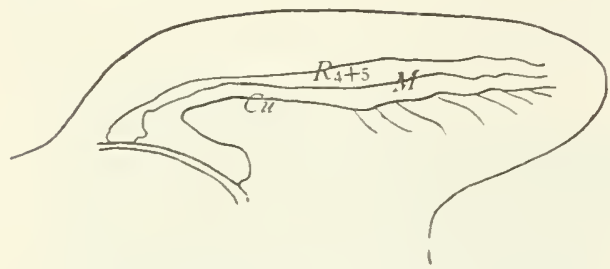
Fig. 135. - The tracheation of a wing of
Leucotermes flavipes.

$\mathrm{R}_{2+3}$; as there is avalable no means of determining its constitution, it seems better to refer to it as the costal margin of the wing than to attempt to indicate the veins of which it is composed.

The strong vein parallel with the costal margin is probably vein $R_{4+5}$, as it appears to correspond with this vein in Mastotermes and in Termopsis.

The media is unbranched. The cubitus bears several branches of which those near the base of the wing are quite prominent. The cubital area occupies about one-half of the area of the wing. There are no anal veins in the detached portion of the wing; the anal area being restricted to the scapular shield in the hind wing as well as in the fore wing.

The wrinkling of the wing characteristic of termites, is here carried to an extreme extent. Back of vein $R_{4+5}$, which is very strongly chitinized, the veins are little more than wrinkles; and between the veins there are very many smaller wrinkles.

Figure 135 represents the tracheation of a wing of a nymph of Leucotermes flavipes. Only three tracheæ are preserved in this wing; these are those that precede veins $R_{4+5}$,

$\mathrm{M}$, and $\mathrm{Cu}$.

The tracheation of the wings of a nymph of an unknown species of Leucotermes.-Among the photographs taken by Dr. Needham and myself are two, representing the tracheation of a fore wing and of a hind wingrespectively of the same individual. These wings differ from those of Leucotermes flavipes in that the medial trachea is fourbranched in the fore wing and three-branched in the

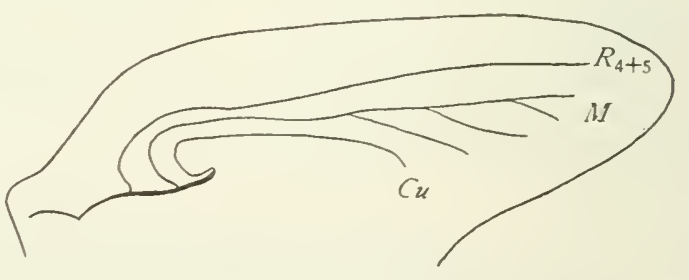
hind wing, while the cubital trachea gives off only some small tracheal twigs (Fig. I36). This termite was collected at Ithaca, and as Leucotermes flavipes is supposed to be the only termite found in the Northeastern 
States, it may be that this is merely an instance of variation; but if so it is a remarkable one.

In these wings and in those of Leucotermes flavipes the loss of tracheæ has proceeded to a greater extent than in Termopsis. In fact the three genera illustrated here form a good series showing the direction of specialization as regards the wing tracheæ in this order. In Mastotermes, the costal trachea is the only one lost in the preanal area; in Termopsis, the costal trachea is lost, the subcostal tracheæ is reduced to a nearly unbranched condition, and trachea $\mathrm{R}_{2}+3$ is represented by a single trachea; in Leucotermes both the costal and the subcostal tracheæ are lost, and the radial trachea is reduced to an unbranched condition.

\section{RESUMÍ:}

The series of wings described in this chapter show the following steps in specialization:

Common features.-In all of the wings examined there is an absence of regular cross-veins, the membrane of the wing being stiffened by an irregular network of slightly chitinized wrinkles; the veins in the anterior part of the wing are greatly thickened, those in the intermediate region are reduced to thin lines, and there is a group of wide accessory veins borne by cubitus near the base of the wing.

Humeral suture.-In Mastotermes darwiniensis, the most generalized of the living termites known, a complete humeral suture has been developed in the fore wings, but in the hind wing this suture is lacking. In Termopsis there is a complete humeral suture in the fore wing, as in Mastotermes, and in the hind wing the anal area is crossed by a suture that appears to be the beginning of a humeral suture. In Leucotermes there is a complete humeral suture in the hind wings as well as in the fore wings.

The subcosto-radial veins of the fore wings. - In Mastotermes the veins $\mathrm{Sc}_{1}, \mathrm{Sc}_{2}, \mathrm{R}_{1}, \mathrm{R}_{2}, \mathrm{R}_{3}, \mathrm{R}_{4}$, and $\mathrm{R}_{5}$ are preserved distinct. In Termopsis angusticollis all of these veins are preserved distinct in some individuals, but in other individuals there is a greater or less reduction in the number of veins in the subcosto-radial area of the wing. In Lencotermes there are only two veins in this area of the wing: first, a very much thickened costal margin of the wing, which probably was formed by the coalescence of two or more veins; and second a thick vein parallel with the costal margin, which is probably vein $R_{4}+5$.

The subcosto-radial veins of the hind wings.-In the more generalized members of the order, Mastotermes and Termopsis, there are, in addition to a more or less thickened costal margin, three distinct veins in front of the media. These are veins $\mathrm{Sc}_{2}, \mathrm{R}_{2}+_{3}$, and $\mathrm{R}_{4+5}$. In Leucotermes there is a greatly thickened costal margin and what is probably vein $R_{4}{ }_{5}$. 
The anal area.-In all living termites known the anal area of the fore wings is reduced to a small space at the base of the wing in which there are no distinct anal veins.

In the hind wings of Mastotermes the anal area is not reduced, in fact a specialization by addition appears to have taken place; the three anal veins are present, and the second and third anal veins are much branched. In the hind wings of Termopsis a marked reduction of the anal area has taken place, but it is still more prominent than that of the fore wings; the first and third anal veins are lost, and the second anal vein is greatly reduced. In the hind wings of Leucotermes the anal area is reduced to the condition of this area in the fore wings of all living termites. 


\section{CHAPTER IX}

\section{THE WINGS OF THE NEUROPTERA}

\section{(a) THE MORE General Features of the Wings of the NeUroptera}

The wings of the Neuroptera are membranous and usually furnished with many wing-veins. The two pairs of wings are similar in texture and usually in outline; in some, the fore wings are slightly larger than the hind wings, in others the two pairs of wings are of the same size. The anal area is small in both fore and hind wings; it is rarely folded, and then only slightly so. A distinct anal furrow is rarely developed. Definitive accessory veins are usually present, and, as a rule, there are many marginal accessory veins. Intercalary veins are never developed. When at rest, with few exceptions, the wings are folded roof-like over the abdomen. In some cases organs for uniting the fore and hind wings are present.

In most of the families the radial sector is pectinately branched. In nearly all cases, media is obviously not more than two branched, if accessory veins be not counted; and in those cases where it appears to be three or four branched it may be that this condition is due to a secondary splitting of one or of both of the two primitive branches. In a few members of the order the hind wings are very small and in some they are wanting in one sex. In the family Nemopteridæ the two pairs of wings differ greatly in form, the hind wings being very long and narrow; in some members of this family the hind wings are thread-like.

In the following discussion of the wings of the Neuroptera figures are given of the wings of representatives of all of the recognized families of the order. It was necessary to figure a large proportion of these in order to illustrate the various methods of specialization that are found within the order; and when this was done it seemed worth while to add figures of representatives of the remaining families, for the sake of completeness, although they presented no difficulties in the application of the uniform terminology of the wing-veins.

For convenience in making generalizations the families Sisyridæ, Sympherobiidæ, Hemerobiidæ, and Dilaridæ are referred to as the hemerobiid group of families; and the Nymphidæ, Myrmeleonidæ, Ascalaphidæ, Nemopteridæ, and Apochrysidæ, as the myrmeleonid group.

This study of the wings of the Neuroptera has been greatly facilitated by the presence in the entomological museum of Cornell University of a large collection of Neuroptera, which has been brought together by Dr. Needham. 
(b) THE SPECial FEATURES OF THE WiNgs of THE NEURoftera

In the order Neuroptera there are several very distinct types of specialization of the wings. Some of these are described in the accounts of the wings of the families in which they occur; but there are others that are characteristic of more than one family; these are described here in order to avoid repetition.

The accessory veins.--In some Neuroptera the development of accessory veins has progressed to a very limited extent; but in a much larger
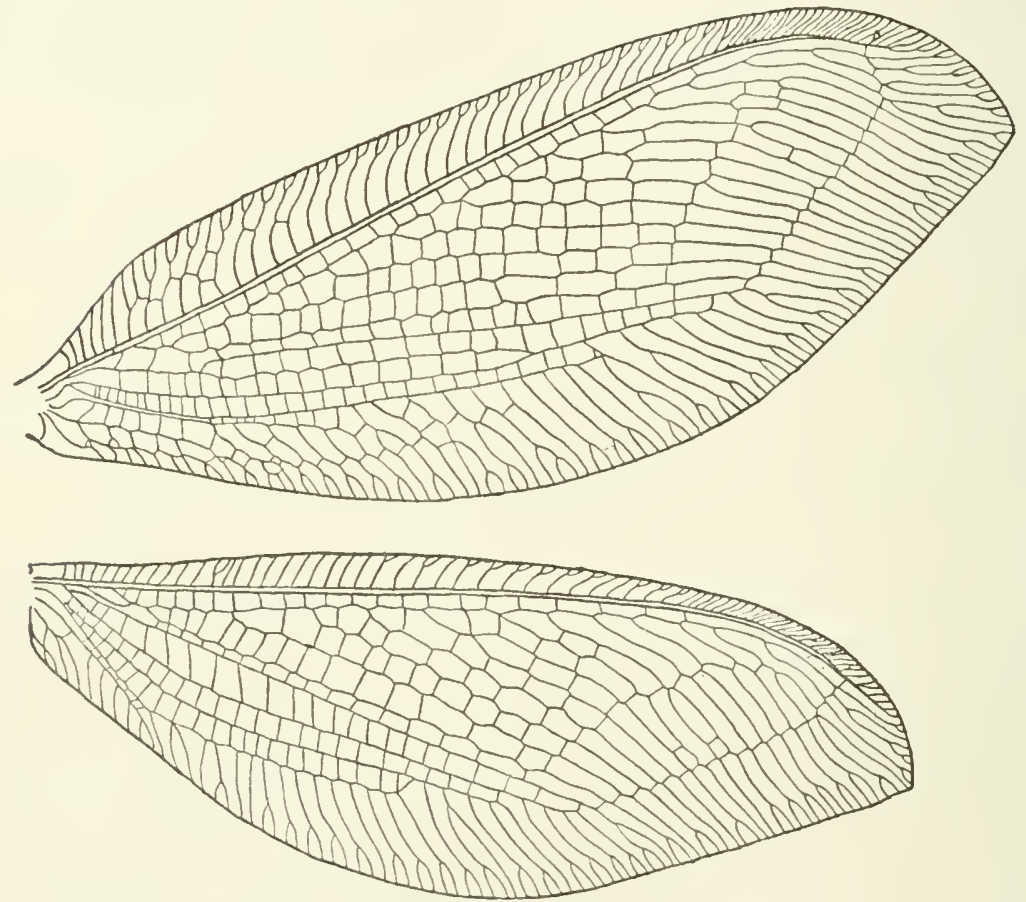

Fig. I37.- Wings of Osmylus hyalinatus.

number of representatives of this order the most striking features of the wings are produced by accessory veins. It is here that the development of accessory veins, both definitive and marginal, reaches its most perfect condition, and wings of wonderful beauty of form are the result.

The definitive accessory reins of the Neuroptera are produced in two ways; in some cases they are added distally by successive splittings of the tip of a principal vein, thus forming a regular series; in other cases, the number of accessory veins is increased in an irregular manner, by the splitting of branches of the principal veins. Wings illustrating each of these methods of increase in the number of accessory veins are figured later. 
The marginal accessory veins in many of the Neuroptera differ remarkably from those of the other orders of insects in which this type of veins is found in the fact that they form a regular border of quite uniform width. This is illustrated by the veins of the outer margin of the wings of Osmylus hyalinatus (Fig. 137 ).

In some cases there is a splitting of one or both forks of a vein that has been split, thus forming a second rank of marginal accessory veins; this is the case in the wings of Polystochotes, figured later (Fig. I4I).

The distinctive characteristic of marginal accessory veins is their instability; they vary in number and in length in different individuals of the same species, and even in the wings of the two sides of the same individual. But when the splitting of a vein has progressed sufficiently far it becomes fixed, and what at first, phylogenetically, was merely a marginal accessory vein become transformed into a definitive accessory vein.

The beautiful symmetry of the borders of marginal accessory veins in certain members of this order is due not merely to the nearly equal length of these veins but also to the fact that the two forks of each forked vein occupy bilaterally symmetrical positions. It follows that neither fork can be regarded as accessory to the other, they are sister veins, both accessory to the stem from which they were derived.

The suppression of the dichotomy of the radial sector.-Correlated with the extensive dvelopment of accessory veins in the Neuroptera, there has resulted in nearly all of the families of this order the production of a pectinately branched radial sector; that is, this vein is so modified that it consists of a supporting stem upon which are borne a greater or less number of parallel branches. This is shown in most of the figures of wings illustrating this chapter. This is a distinctive characteristic of this order; in no one of the other orders of living insects in which accessory veins occur is a welldeveloped pectinately branched radial sector found. Such a sector existed, however, in many of the Palæodictyoptera.

The typical radial sector is dichotomously branched, being divided into two chief branches, veins $R_{2}+3$, and $R_{4}+5$, and each of these in turn is divided into two branches, the former into veins $R_{2}$ and $R_{3}$ and the latter into veins $R_{4}$ and $R_{5}$.

The transformation of a dichotomously branched radial sector into one that is pectinately branched was discussed by Comstock and Needham, and the process by which this transformation is attained was termed by us the suppression of the dichotomy of the radial sector. In the course of our discussion, we pointed out that there are three ways in which this result may have been attained: first, by the splitting apart of veins $R_{4}$ and $R_{5}$ so that they arise separately from the supporting stem of the pectinate vein thus formed; second, by the switching of the base of vein $R_{4}$ to vein $R_{2}+3$, following a cross-vein, this also resulting in the two veins arising separately 
from the supporting stem of the pectinate vein; and third, by the coalescence of veins $R_{4}$ and $R_{5}$, which would obliterate the forking of these veins. The accompanying series of diagrams (Fig. ${ }^{3} 8$ ) illustrates these changes.

The first diagram (Fig. I38, I) represents the manner of branching of the typical radius in which the radial sector is dichotomously branched. The

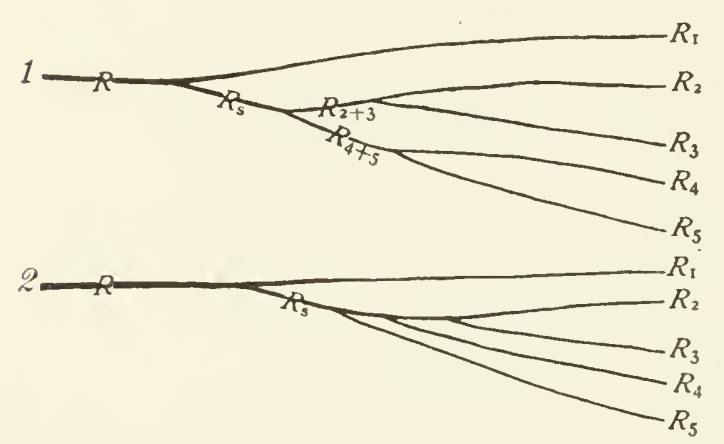
second diagram represents a radius in which the radial sector has become pectinate by the splitting apart of veins $R_{4}$ and $R_{5}$, so that they arise separately from the supporting stem of the pectinate vein thus formed. This represents the simplest type of a pectinately branched radial sector.

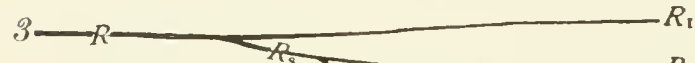
An illustration of this simplest type is afforded by the wings of Sisyra (Fig. I39).

In comparatively few cases is a pectinately

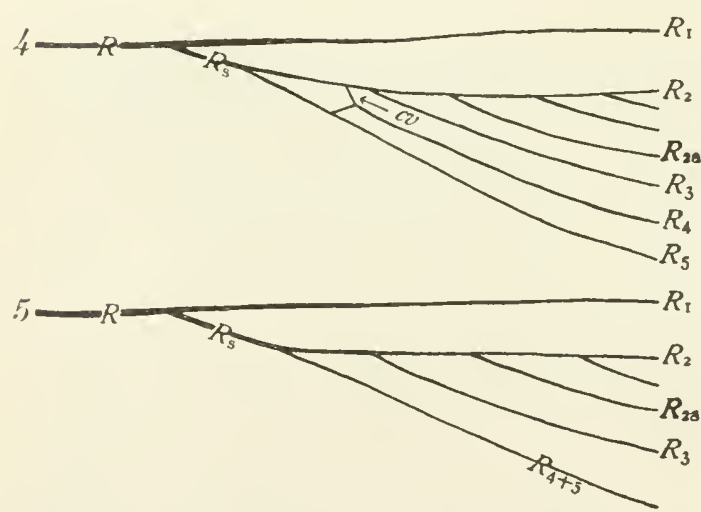

Flig. 138.-Diagrams of severa] types of radius.

branched radial sector so simple as that of Sisyra; usually a pectinate sector bears more than four branches; this is the result of the development of accessory veins on the posterior side of vein $R_{2}$. The third diagram (Fig. I3 8,3 ) represents a radial sector in which vein $R_{2}$ bears two accessory veins, labeled $\mathrm{R}_{2 \mathrm{a}}$ and $\mathrm{R}_{2 \mathrm{~b}}$; this condition exists in the wing of Chauliodes (Fig. I40); in the wings of Polystæchotes (Fig. I4I) the addition of accessory veins to vein $R_{2}$ has been carried to a much greater extent.

The second method of suppression of the dichotomy of the radial sector occurs in the wings of certain insects in which there are many crossveins. In these cases the base of vein $R_{4}$ has become connected with a cross-vein, perhaps by splitting back until the cross-vein is reached, and 
then has migrated along this cross-vein till vein $\mathrm{R}_{2}+_{3}$ is reached. The fourth diagram (Fig. 138,4 ) represents an intermediate stage in this

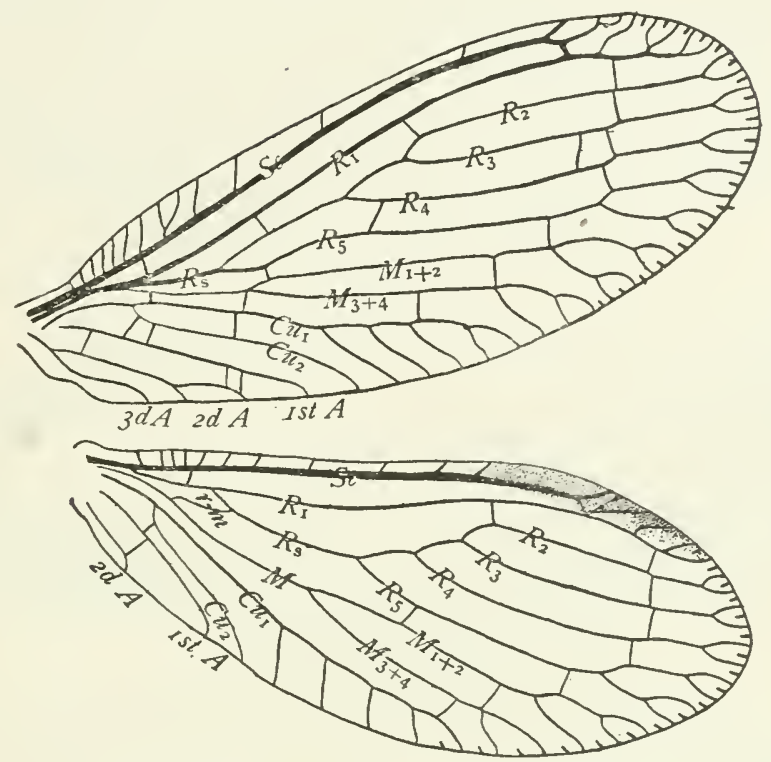

Fig. I3o-Wings of Sisyra flavicornis.

switching of the basal connection of vein $R_{4}$. Here the base of vein $R_{4}$ appears to be forked, one arm of the fork arising from vein $R_{5}$, and the other from vein $R_{2}+3$. The former is the true base of vein $R_{4}$, the latter is a cross-vein which is assuming the function of a base of this vein. An

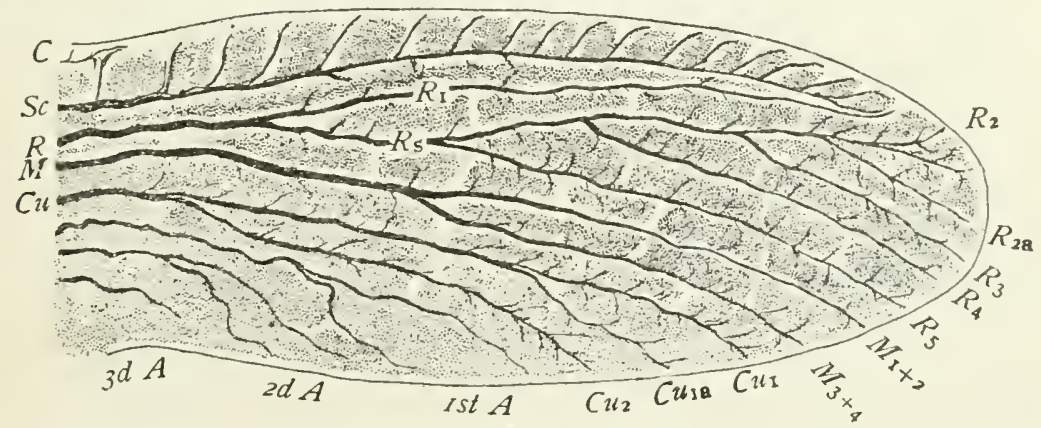

Fig. I 40.-Fore wing of a pupa of Chauliodes pecticornis (After C. \& N.).

example of this condition of the base of vein $R_{4}$ exists in the wings of Ululodes hyalina (Fig. I42).

The fact that the base of a vein can be switched from one support to another is shown by the fore wing of a specimen of Neuroptynx appendicula- 

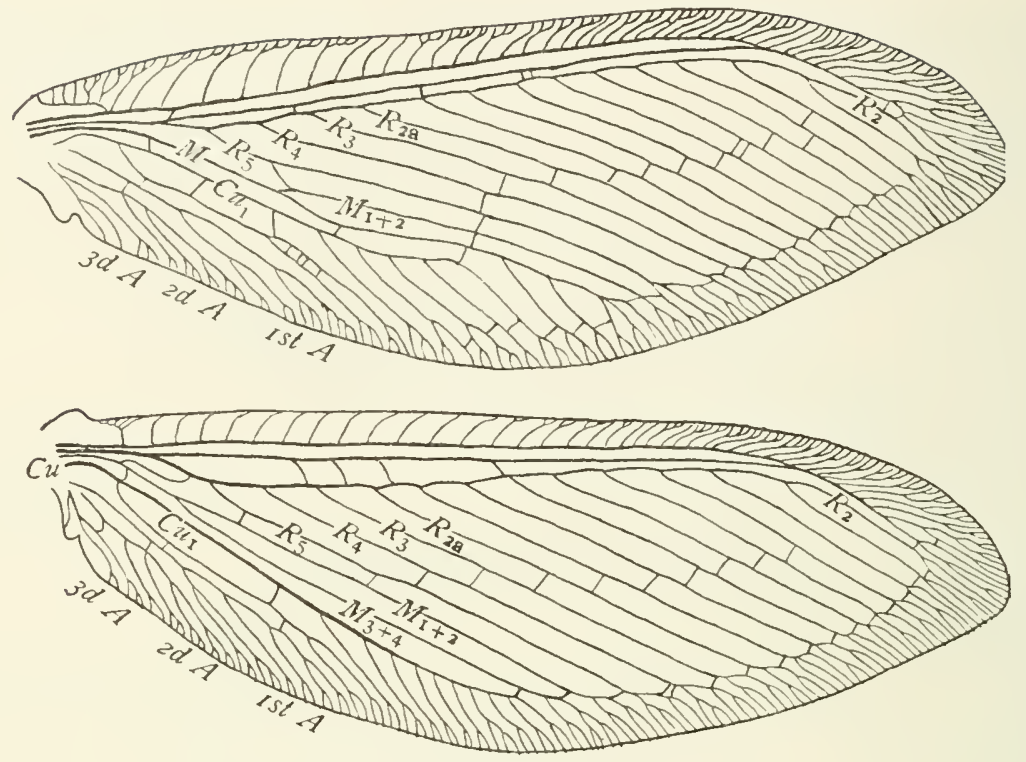

Fig. I4I.-Wings of Polystæchotes punctatus.

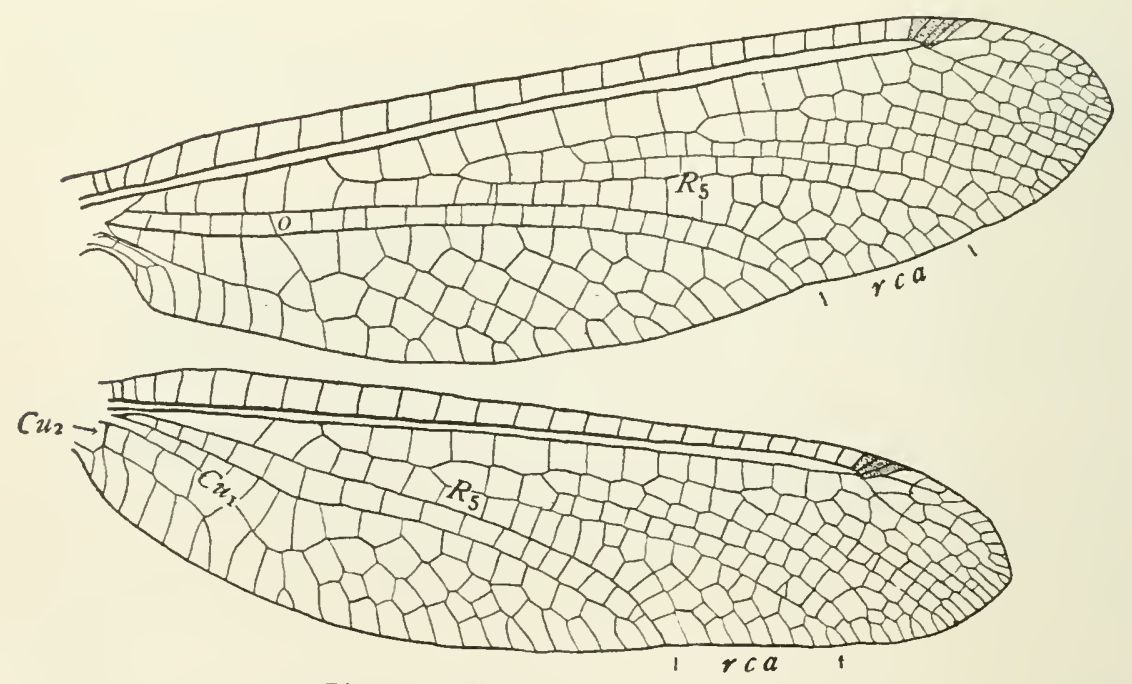

Fig. I42.-Wings of Ululodes hyalina. 
tus (Fig. I43) that I collected in Florida. In this wing the base of vein $\mathrm{R}_{2}+{ }_{3}+4$ has been switched along a cross-vein to vein $R_{1}$, so that there appear to be two radial sectors.

It was the existence of this abnormal wing that suggested the probability that in wings like those of the Myrmeleonidæ, where there are many crossveins, the suppression of the dichotomy had been attained by the switching of the base of vein $R_{4}$ to vein $R_{2}+3$ along a cross-vein; and it was thought that an examination of a larger series of wings would reveal the existence of examples of the successive stages of this switching.

Very many examples were found of wings in which the base of vein $R_{4}$ appears to be at a halfway station in its journey along a cross-vein from
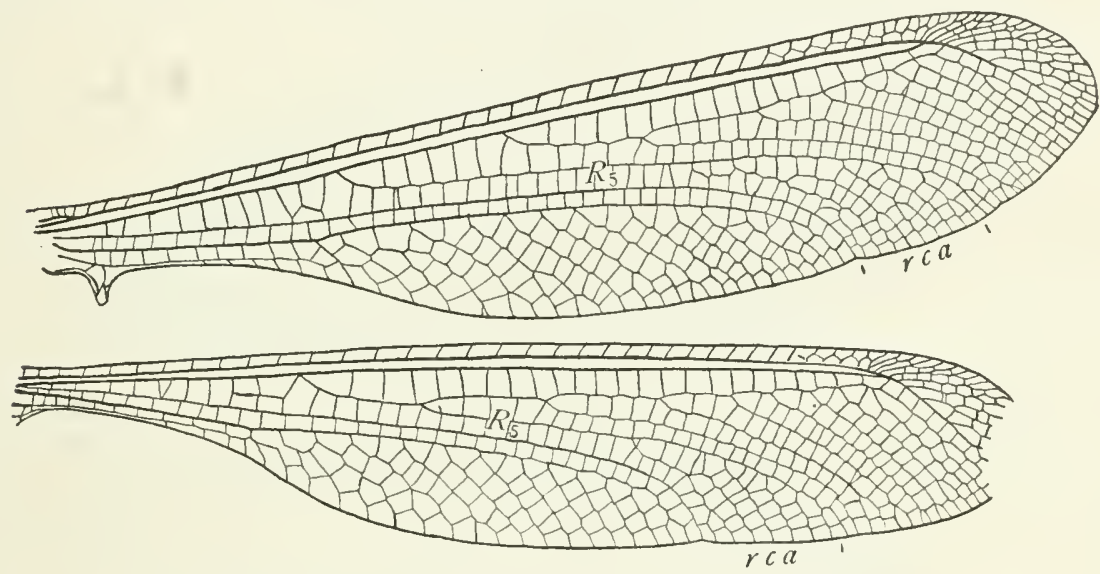

Fig. I +3.-Wings of Neuroptynx appendiculatus.

vein $R_{5}$ to vein $R_{2}+3$. This condition is very common in the Ascalaphidæ (Fig. 142).

It is only recently that $I$ have been able to find examples of the successive stages of the switching of the base of vein $R_{4}$ from vein $R_{5}$ to vein $\mathrm{R}_{2+3}$. These were found in the Osmylidæ, a family in which the dichotomy of the radial sector is normally suppressed.

Figure 144 represents the wings of an atavistic individual of Osmylus hyalinatus, in which the primitive dichotomy of the radial sector has been retained; the homologies of the wing-veins are indicated in Figure I 45.

That such cases may be common in the Osmylidæ is indicated by the fact that in the small collection of osmylids to which I now have access two individuals present this condition. In one Osmylus hyalinatus the radial sector is dichotomously branched in both fore wings and in one hind wing. In an Osmylus tessellatus the radial sector is dichotomously branched in the fore wings; but in the hind wings the dichotomy has been suppressed. 

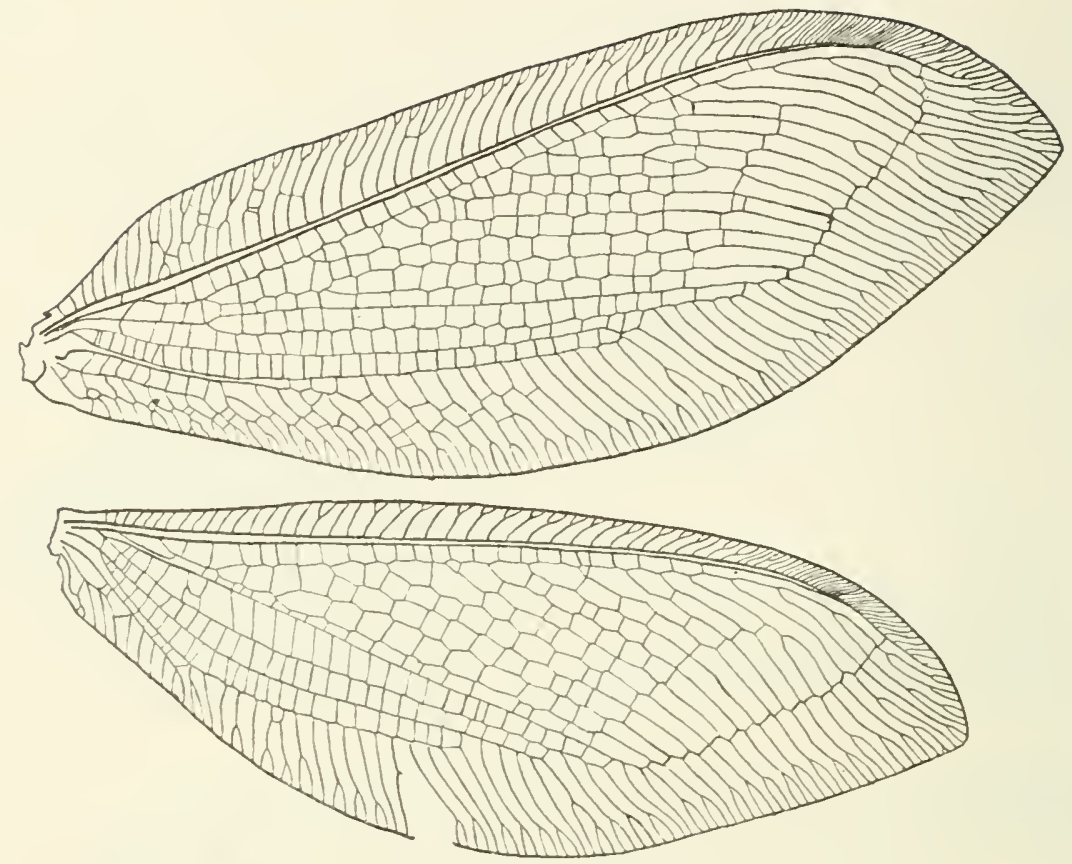

Fig. 144.-Wings of Osmylus hyalinatus in which the dichotomy of the radial sector has not been suppressed.

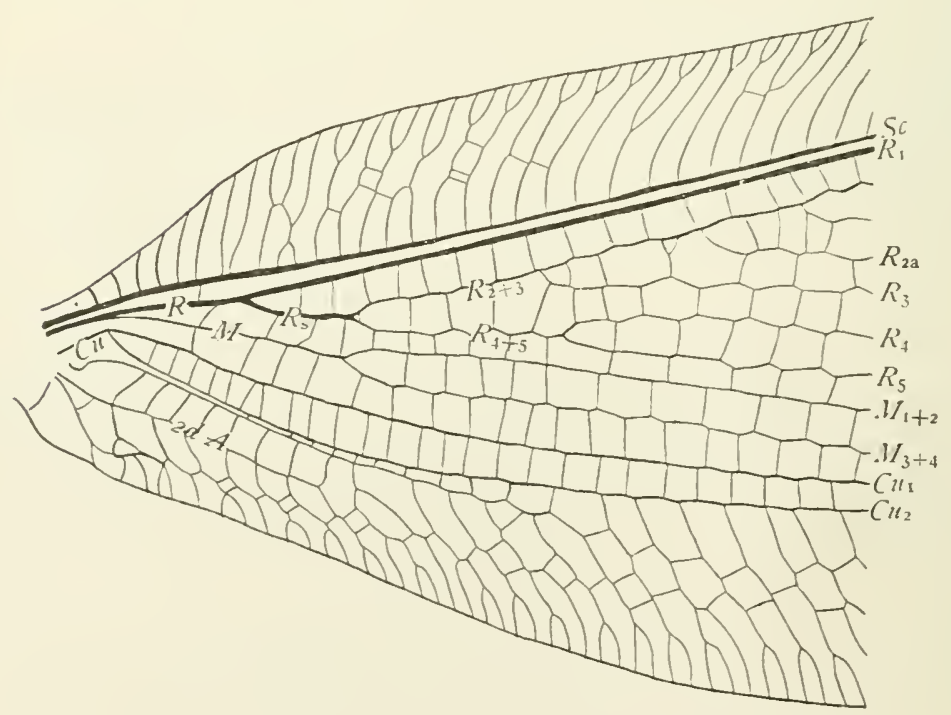

Fig. I 45.-Base of the fore wing shown in Figure I44, enlarged. 
Figures i 46 and 147 represent the wings of a normal Osmylus hyalinatus. An important fact bearing on this question of the switching of the base of a vein from one support to another is that in the family Sympherobiidx the base of vein $R_{2}{ }_{3}$ has been transferred to vein $R_{1}$.

The third possible method of suppression of the dichotomy of the radial sector would produce the result shown diagrammatically in the fifth diagram (Fig. $I_{3} 8,5$ ), where veins $R_{4}$ and $R_{5}$ are represented as coalescing completely. I know of no case where the suppression of the dichotomy has
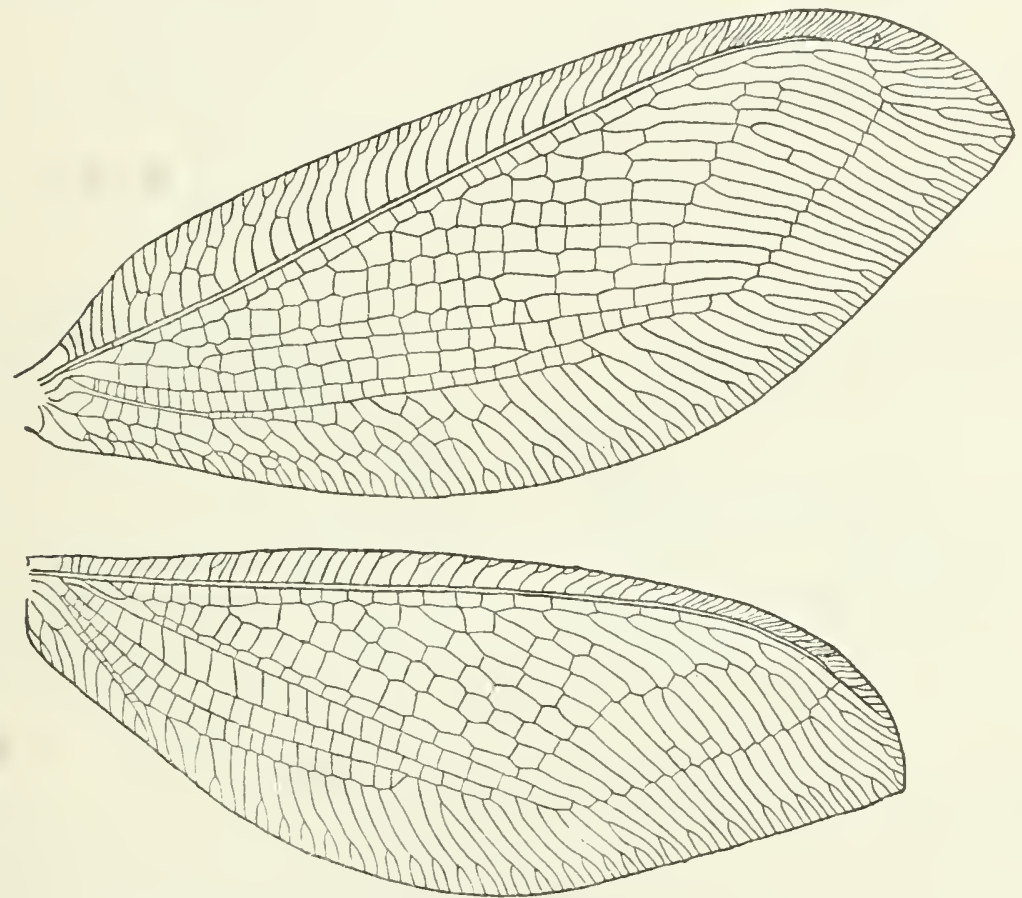

Fig. I 6.-Wings of Osmylus hyalinatus with the radial sector pectinately branched.

been attained by this method. I am now convinced that in the supposed examples of this method, cited by Comstock and Needham, that is in Corydalus and Chauliodes, the result has been attained by the splitting apart of veins $R_{4}$ and $R_{5}$, instead of by their coalescence.

The earlier conclusion was based on the fact that occasionally the first branch of the radial sector in Corydalus is forked, as is the case in the wing represented by Figure $\mathrm{I} 48$, I. The forked condition of this first branch was believed to indicate that it is a compound vein in which the coalescence of its two elements is not quite complete. My reasons for abandoning this view are the following. 
A study of a series of wings of Corydalus cornutus has shown that the forking of the first branch of the radial sector in this species is of very

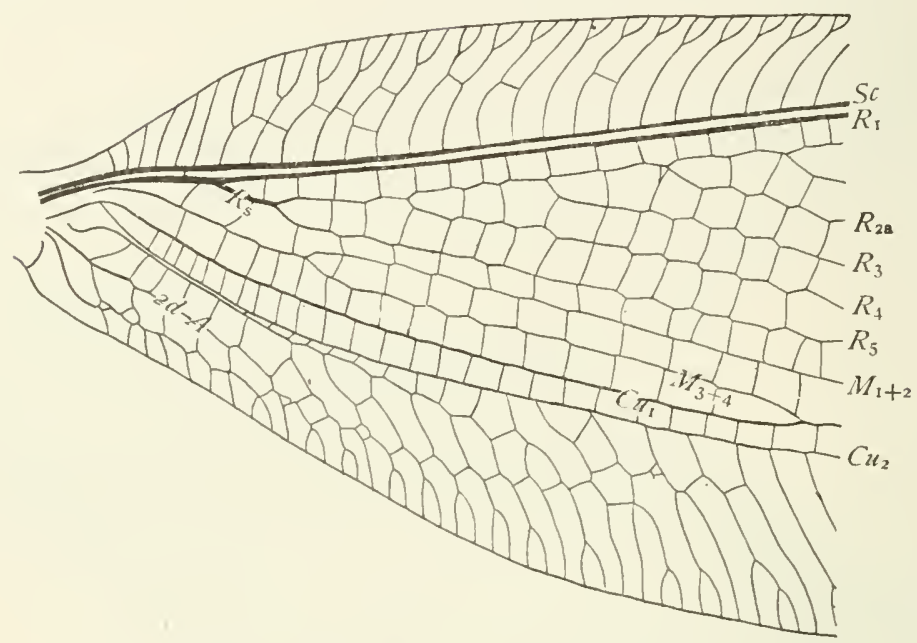

Fig. I 47.-Base of the forc wing shown in Figure I 46 , enlarged.

irregular occurrence, and that there is a similar irregular forking of other veins in this region of the wing. In the specimen represented in Figure I48 vein $M_{1}$ is forked in a similar manner, so too is the fourth branch of the sector; in the latter case one division of the forked vein is again forked.

In a collection of nineteen wings of Corydalus cormutus, that had been mounted for laboratory use and which had been taken at random, I find the first branch of the radial sector forked 'n only two specimens; the third branch, in one; the fourth branch, in one; the fifth branch, in seven; the sixth branch, in twelve; and the seventh branch in four.

The evidence presented by this species indicates that the short branches near the margin of the wing in the area of the radial sector are merely marginal accessory veins; and that the forking of the first branch of the

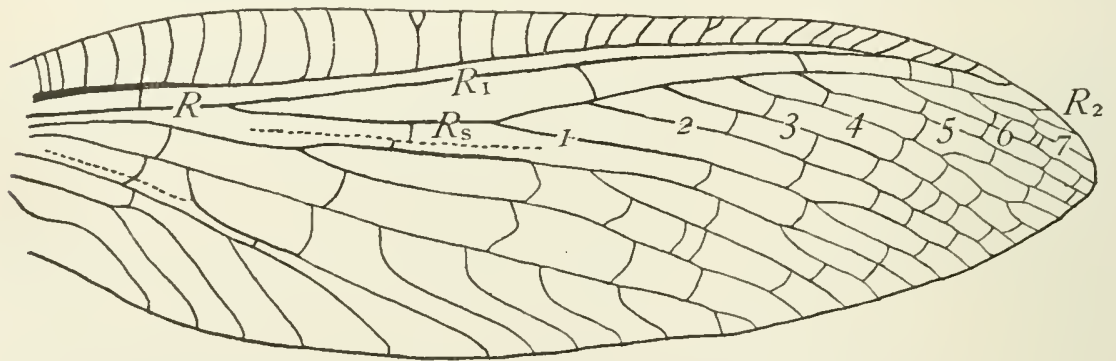

Fig. I48.-Fore wing of Corydalus cormutus in which the first branch of the radial sector is forked. 
sector does not indicate that this branch is composed of two coalesced veins; it merely shows that the first branch of the sector is occasionally split at the tip as are other veins in this region of the wing.

This evidence is confirmed by a study of the wings of representatives of nearly all of the genera of this family. Fortunately we are able to make such a study, thanks to the labors of Dr. H.W. van der Weele. This author in his Monographic Revision of the Megaloptera (Weele, I910) has given photographic illustrations of representatives of nearly all of the genera of the Sialidæ.

The most important, for the purposes of the present discussion, of the figures in this work is that of Corydalus primitivus, a species found in the Argentine Republic. The entire insect is figured, but I copy only the wings (Fig. I 49).

In this individual the dichotomy of the radial sector is not suppressed in the right hind wing; but it is in the other three wings. That the first and
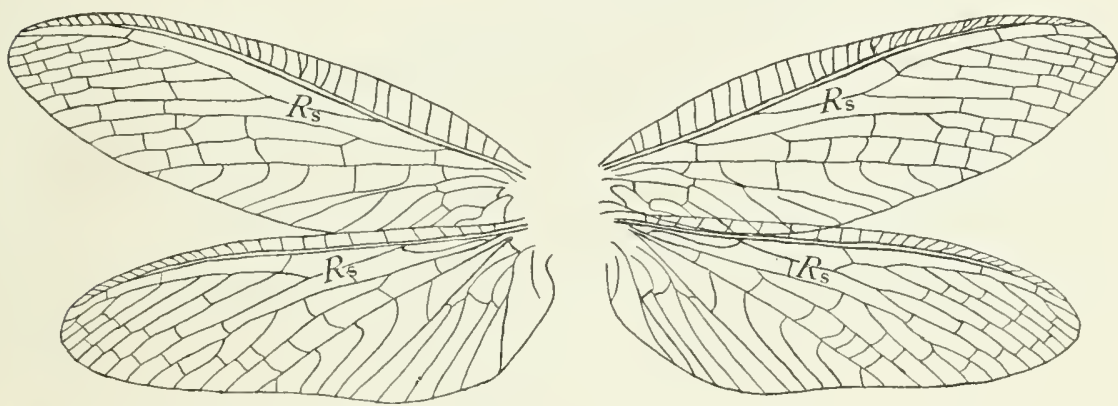

Fig. I49.-Wings of Corydalus primitizus (After van der Weele).

second branches of the sector in the left hind wing and in both fore wings correspond to the forked first branch in the right hind wing is shown by the fact that counting the forked first branch of the right hind wing as two branches, the sector is eight-branched in all wings. The splitting apart of veins $R_{4}$ and $R_{5}$ in the right hind wing so that they arise separately, would make the sector of this wing eight-branched like those of the other wings.

I regard the structure of the right hind wing of this insect as an example of atavism, similar to those found in the osmylids described above.

Another remarkable insect figured by van der Weele, in the same monograph, is Protohermes davidi from China. I copy a part of his figure somewhat enlarged (Fig. I 50), he figures the entire insect.

Excepting the right hind wing of Corydalus primitivus discussed above, the deepest forking of the first branch of the radial sector shown in the figures given by van der Weele occurs. in this insect. That this forking is due to a splitting of the tip of this rein is evident by a comparison of it 
with the tips of the branches of media in which there is a similar splitting of the tips of veins.

Finally, excepting those cases in which the development of a pectinate radial sector has not progressed very far, as in Sisyra (Fig. I39), the most

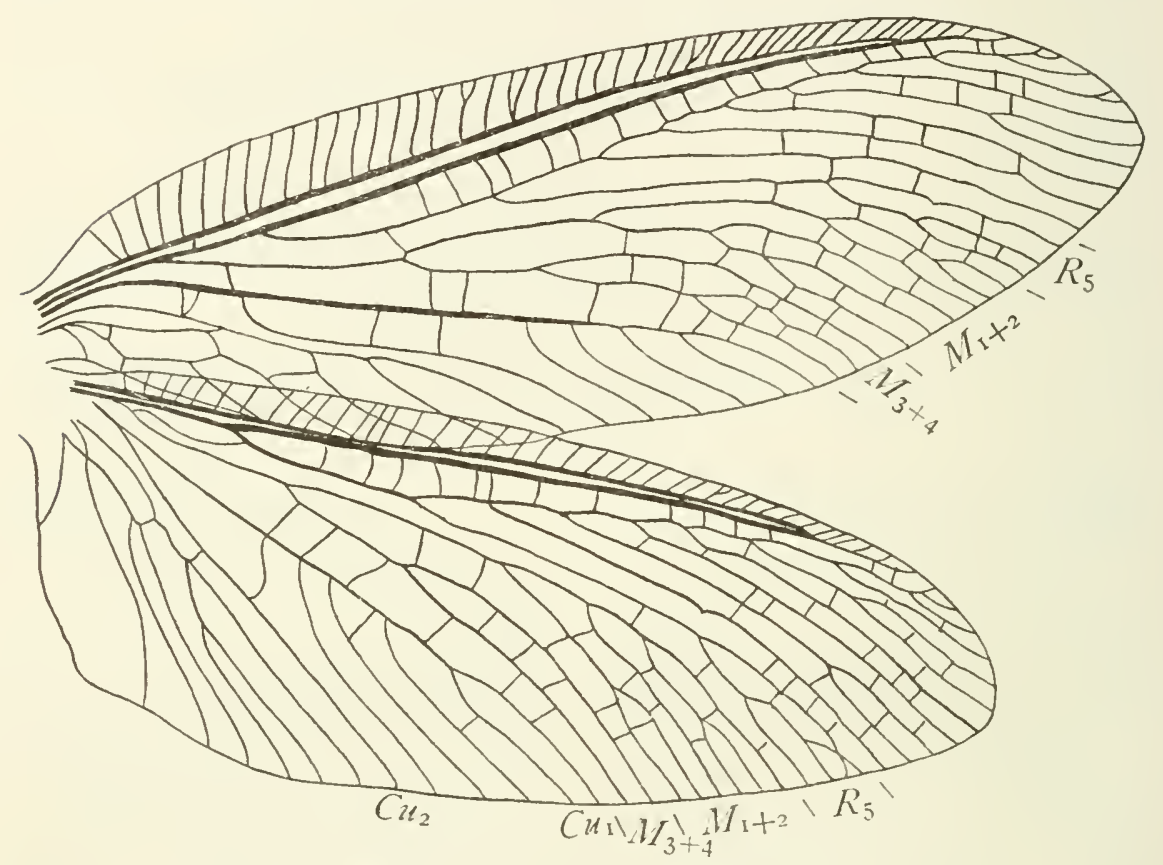

Fig. 150.- Wings of Protohermes davidi (After van der Weele).

striking feature of this rein, when its dichotomy has been suppressed and a pectinate form attained, is the presence of a greater or less number of supernumerary reins. These are accessory veins; and it has been shown that veins of this type are produced and their number increased by the splitting of veins.

It is evident, therefore, that the force that makes for the development of the pectinate type of radial sector acts by the splitting of veins; and it is not probable that this force should cause veins $R_{4}$ and $R_{5}$ to coalesce in the Sialidx, instead of splitting apart as we know they do in the Hemerobiidæ.

The numbering of the branches of the radial sector when it is pecinately branched.-In most of the Neuroptera in which the radial sector is pectinately branched, the number of the branches of this vein is more than four, the number of branches of the typical radial sector. It is evident that when this is the case, some of the branches are accessory veins. The question arises, therefore, which of the branches are the primitive ones and which are 
accessory veins? In other words, to which end of the series of branches of the radial sector are the accessory veins added?

Comstock and Needham concluded from their studies of the tracheation of the wings of pupæ of Chauliodes (Fig. 140) and Corydalus (Fig. I 5 I) that in the case of these insects the accessory veins are added to the distal end of the series. The presence of fine twigs at the tip of trachea $R_{2}$ indicated to us the method of increase, which we concluded to be as follows:

The fine tracheal twigs at the tip of trachea $R_{2}$ are the beginnings of accessory branches, which in the course of phylogenetic development become larger and, moving towards the base of the wing, make room for the addition of other branches.

From this it follows that vein $R_{2}$ forms the terminal portion of the stem of the pectinate vein and that veins $R_{5}, R_{4}$, and $R_{3}$ are the proximal branches. It also follows that of the accessory veins that have been developed on vein $\mathrm{R}_{2}$ the proximal one is the oldest, and according to our system should be labeled $\mathrm{R}_{2_{\mathrm{a}}}$, as is done in Figures $\mathrm{I}_{4} \mathrm{O}$ and $\mathrm{I}_{5} \mathrm{r}$.

My studies of the venation of the wings of insects during the twenty years that have elapsed since these conclusions were reached have only served to confirm them; and I am now convinced that what we showed to be the case in Chauliodes and Corydalus is true primarily of all of those neuropterous insects in which the radial sector is pectinately branched. In some cases, however, to be discussed later, accessory veins are interpolated in the primary series by the splitting of members of this series.

I am led to make this statement because some of the writers on the Neuroptera have not accepted these conclusions. Thus Enderlein ('Io) in his figures of the wings of Mantispidæ numbers the branches of the radial

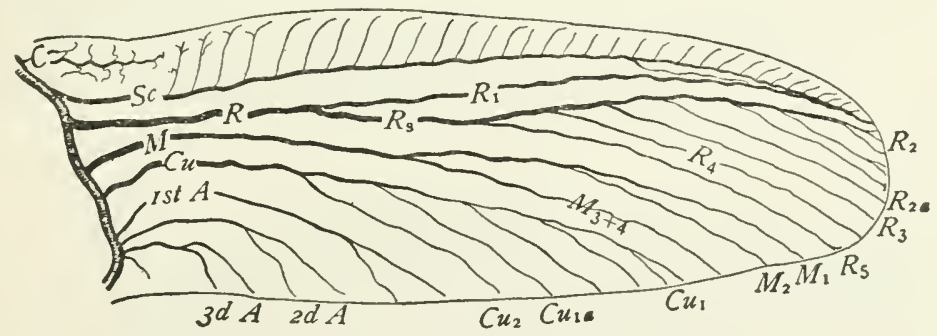

Fig. 151.-Tracheation of a wing of a pupa of Corydalus cornutus (after C. \& N.).

sector from the apex of the wing towards the base; and Tillyard (' $16, \mathrm{p}$. 277) violently attacks the view of Comstock and Needham. For this reason it seems incumbent upon me to give the additional data that have confirmed my belief in this view. 

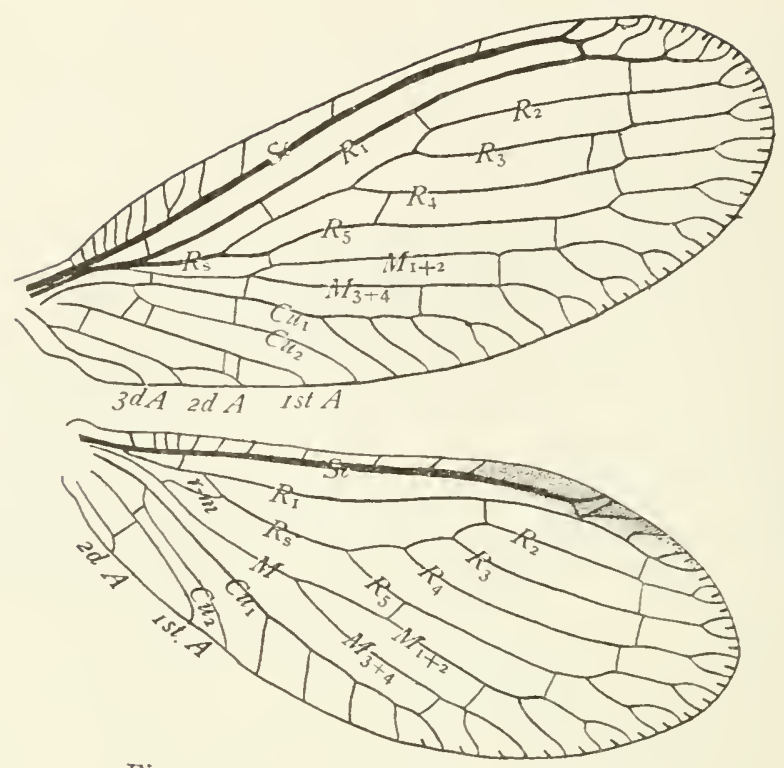

Fig. 152.- Tings of Sisyra flavicornis.
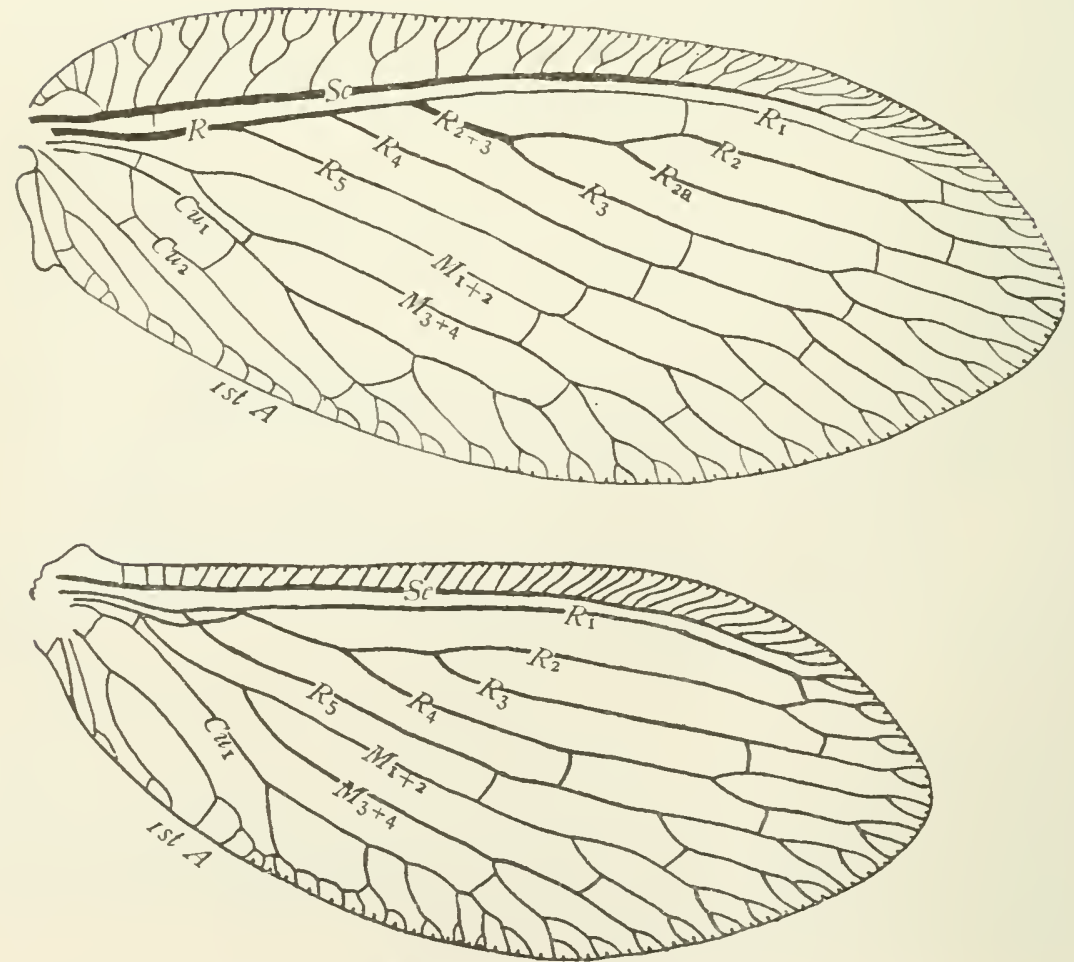

Fig. I 53.-Wings of Hemerobizes humuli. 
In Sisyra flavicornis (Fig. I 52) definitive accessory veins have not been developed upon the radial sector, although there are marginal accessory veins upon its branches. In each wing the sector is four-branched. These

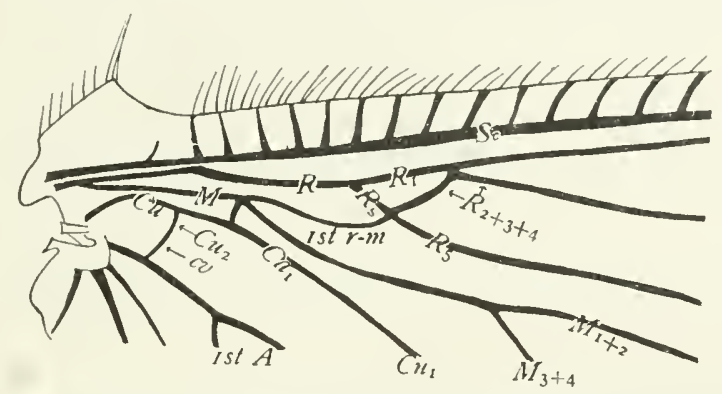

Fig. 154.-Base of a hind wing of Hemerobius humuli.

branches are doubtless veins $R_{2}, R_{3}, R_{4}$, and $R_{5}$. The dichotomy of the sector has been suppressed by the splitting back of vein $R_{5}$. Two stages in this splitting process are represented by the two wings, it having been carried much farther in the fore wing than in the hind wing. Attention is called to the wings of this insect to show that the veins that are split back in the hemerobiid group of families are primitive branches of the radial sector and not accessory veins.

In the wings of Hemerobius humuli (Fig. I53), the splitting back of branches of the radial sector is carried much farther than in Sisyra. In the
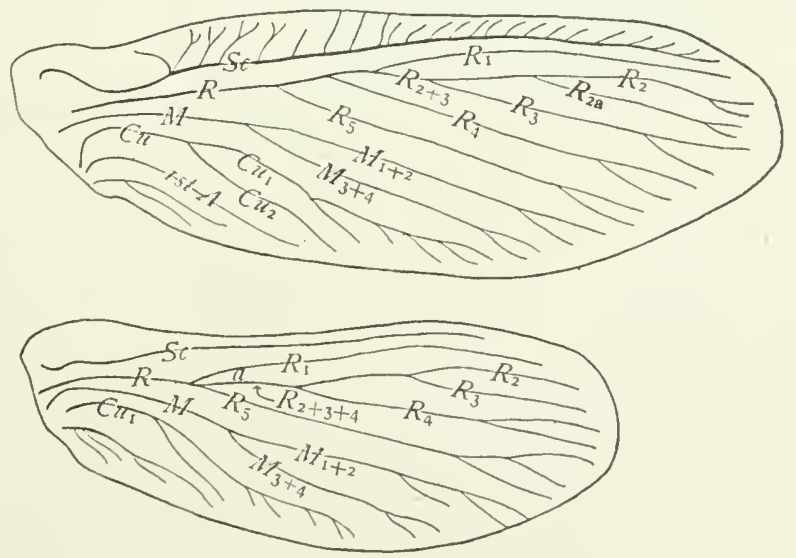

Fig. 155.-Tracheation of the wings of a pupa of Ilemerobius humuli.

hind wings of this species there are only four definitive branches of the radial sector, although there are many marginal accessory veins. The 
four definitive branches are doubtless veins $R_{2}, R_{3}, R_{4}$, and $R_{5}$, as indicated in the figure. Vein $\mathrm{R}_{5}$ is split back nearly to the base of the sector and the remainder of the sector, after the separation of vein $R_{5}$, anastomoses with vein $R_{1}$. (Figure ${ }_{54}$ represents this part of the wing greatly magnified.)

A study of the tracheation of the hind wing of a pupa of this species (Fig. I55) confirms the interpretation of the venation of this part of the wing given in Figures $\mathrm{I}_{53}$ and $\mathrm{I} 54$. The trachea of the radial sector is typical except that trachea $R_{5}$ is split back from trachea $R_{4}$; and this splitting has been carried so far that the undivided stem of the radial sector is very short; the tracheation of the pupal wing and the venation of the adult wing correspond very closely in this respect. But in the pupal wing there is no indication of the anastomosis of veins $R_{1}$ and $R_{2}+3+4$. It is evident, however, that these two tracheæ come together at the point marked $a$ in Figure $\mathrm{I}_{55}$ in the course of the later development of the wing.

This anastomosis of vein $R_{2+3}+4$ with vein $R_{1}$ is carried much farther in the fore wing, where the two reins coalesce for a considerable distance, with the result that two of the branches of the radial sector are stranded on the main stem of the radius before the separation of the remainder of the radial sector from vein $R_{1}$. The first of these two stranded branches is doubtless vein $R_{5}$, as it is obviously serially homologous with vein $R_{5}$ of the hind wing, in which there are no definitive accessory veins to cast a doubt on the determination of the homologies of the branches of radius. From this it follows that the extra branch of the radial sector in this wing has not been added to the proximal end of the series but to vein $R_{2}$, and is the one labeled $\mathrm{R}_{\mathbf{2}_{\mathrm{a}}}$ in the figure.

According to the view that the accessory veins are added to the proximal end of the series we must believe that the first fork of the radial sector has been pushed out to near the apex of the wing by the development of the accessory veins, and that the three short veins next to vein $R_{2}$ are veins $R_{3}$, $R_{4}$, and $R_{5}$. If this be true, either the size of the wing has been greatly increased or veins $R_{3}, R_{4}$, and $R_{5}$ have been greatly shortened during the specialization of the wing. Either of these alternatives may be true, but neither seems probable.

In many cases the branches at the tip of the radial sector are merely short twigs, which differ in size, number, or arrangement in the wings of the two sides of the same insect; in such cases it is obviously impracticable to begin the numbering at the apex of the sector. The fact is, these terminal branches in cases of this kind are merely marginal accessory veins, that have not attained a definitive form and position.

Finally, while there are many cases, like those of Chauliodes and Corydalus, in which there appear to be taking place the development of additional branches at the distal end of the series of branches of the radial 
sector, no instance has been observed in the Neuroptera in which there is such an appearance at the proximal end of the series. The only possible exception to this statement is that it is conceivable that in the development of a radial cuneate area vein $R_{5}$ may be split to its base and in this way an addition to the number of branches of the radial sector be made at the proximal end of the series.

As a rule, in the development of a radial cuneate area vein $R_{5}$ is not split back far enough to warrant this suggestion; but in Rapisma (Fig. I 7 I) and in Megalomus (Fig. I78) the splitting back of vein $\mathrm{R}_{5}$ has progressed nearly to the base of this vein.

I know of no near allies of Rapisma, but Megalomus can be compared with more generalized members of its family, as Hemerobius, in which there
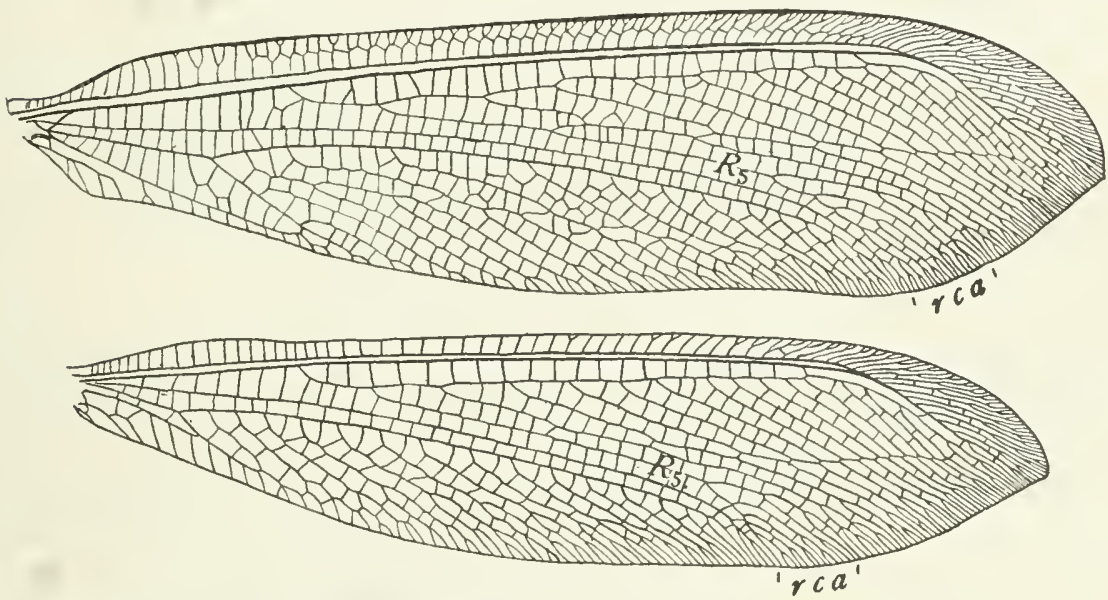

Fig. 156.-Wings of Acanthaclisis; a species from the Seychelles Islands.

is no indication of accessory veins being added to the proximal end of the series.

It seems worth while to make this extended discussion of this question, for the chief object of the uniform terminology is to apply the same term to homologous veins, in order that affinities between different groups of insects and differences in methods of specialization can be more clearly indicated. This end would be defeated, so far as the evidence presented by the radial sector is concerned, if the numbering of its branches begins at the wrong end of the series, that is at the distal end.

In those families in which the accessory veins of the radial sector are added only distally, thus forming a regular series, and this appears to be the case in most of the families, the first branch of the radial sector is vein $R_{5}$, and following this in regular order are veins $R_{4}, R_{3}, R_{2_{a}}, R_{2 b}$, and so on to the end of the series of definitive accessory veins. 
But in those cases, as in the Nemopteridæ, where accessory veins are interpolated by the splitting of veins, it is difficult, if not impossible, to determine the homologies of the branches of the radial sector; and it is
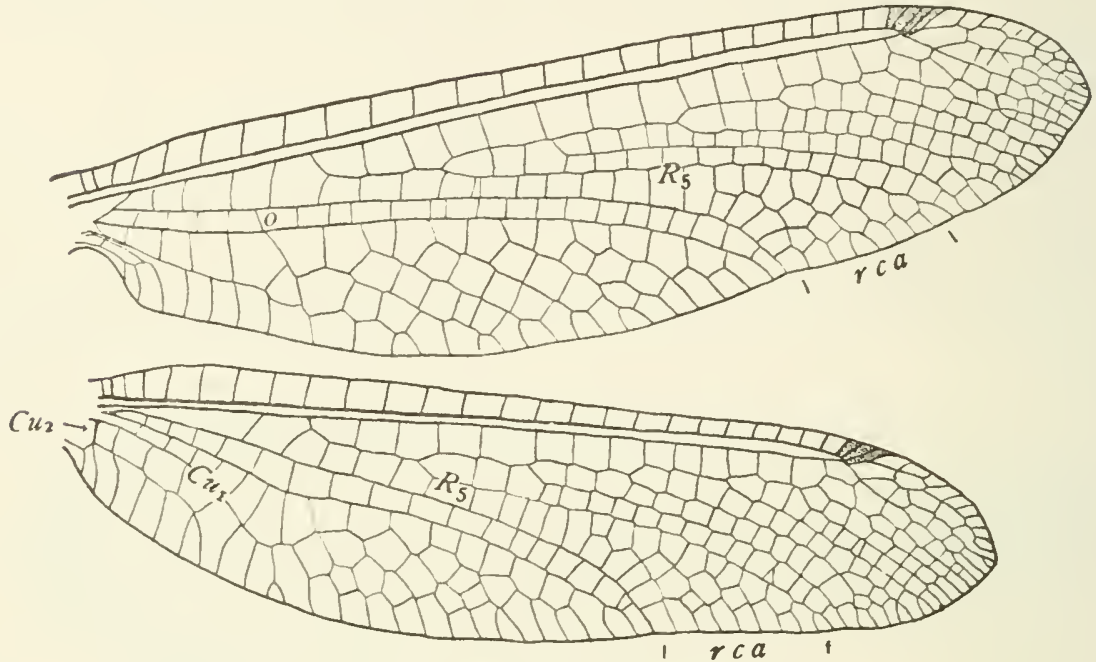

Fig. 157.- Wings of Ululodes hyalina.

doubtless best to merely number the branches, first, second, third, etc., beginning with the proximal one, without attempting to indicate the homologies of the veins.

The radial cuneate area.--In the wings of the Myrmeleonidre, the Ascalaphidx, and of some other Neuroptera there are many instances of the
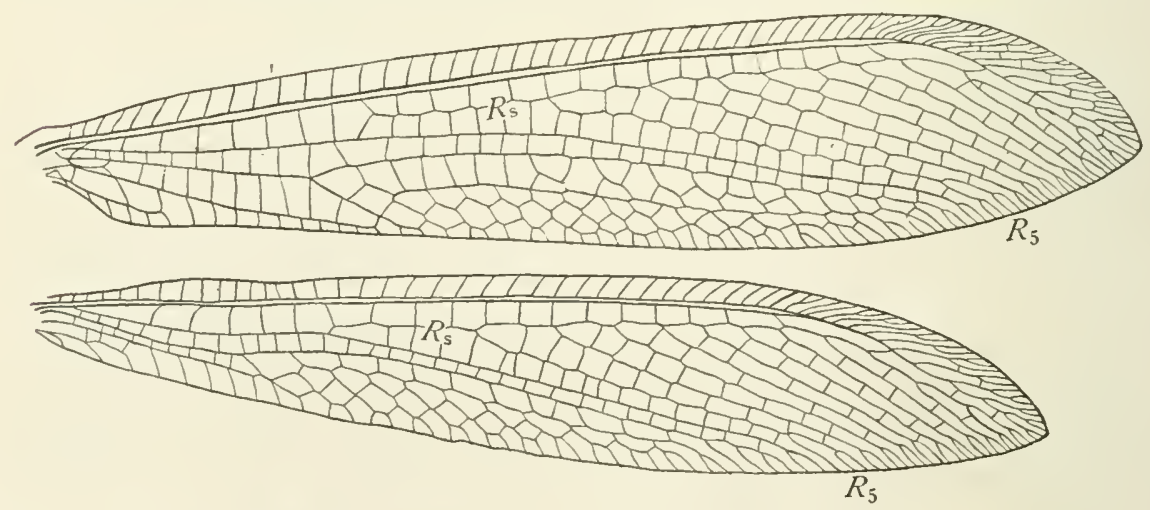

Fig. I 58.- Wings of $M_{y}$ rmeleon; a species from Katihar, British India.

expansion of the area of the wing lying between the distal portion of vein $\mathrm{R}_{5}$ and the media or between branches of vein $\mathrm{R}_{5}$, as if a gore had been set into this part of the wing. This condition is well shown in the wings of 
insects of the genus Acanthaclisis (Fig. I56, rca). This area may be termed the radial cuneate area. The size of this area and the arrangement of the veins within it afford characters of considerable taxonomic importance, which will doubtless be used in the future.

In many cases, especially in the Myrmeleonidæ, but less frequently in the Ascalaphidæ, this area is bounded by two forks of the first branch of the radial sector (Fig. I 56); in others it is irregular in form and appears to be behind the terminal portion of this branch of the radial sector (Fig. I 57).

In many of the Myrmeleonidx the only indication of the expansion of this area is a splitting back of the tip of vein $R_{5}$ to a somewhat greater distance than are split the tips of other veins in this region of the wing (Fig. I 58 ).

All intergrades between a slight splitting of the tip of vein $R_{5}$ and a broadly expanded radial cuneate area exist in the Myrmeleonidæ. When the splitting of vein $R_{5}$ has progressed to any considerable extent, accessory veins have been developed on one or on both branches of vein $R_{5}$ (Fig. I ${ }_{5} 6$ ).

Some students of the Myrmeleonidæ in our laboratory have suggested that when the first branch of the radial sector is forked the two divisions of this branch represent $R_{4}$ and $R_{5}$ respectively, thus indicating that the suppression of the dichotomy of the radial sector is by a coalescence of these two veins, which in these cases is not quite complete.

It is quite important to determine if possible, which of these two views is correct; as the terminology of the branches of the radial sector depends on the view adopted. If the suppression of the dichotomy is by the switching of the base of vein $R_{4}$ from vein $R_{5}$ to vein $R_{2}+3$, the first branch of the sector is vein $\mathrm{R}_{5}$; the second, $\mathrm{R}_{4}$; the third, $\mathrm{R}_{3}$; and the following branches are accessory veins. If the suppression of the dichotomy is by the coalescence of veins $R_{4}$ and $R_{5}$, the first branch of the sector is vein $R_{4}+5$; the second, $\mathrm{R}_{3}$; and the series of accessory veins begins with the third branch.

The most conclusive evidence that the former view is the correct one is given in the earlier section of this chapter referred to above; but there are other considerations that support this view.

All of the data so far observed on the suppression of the dichotomy of the radial sector indicate that the forces that make for this suppression act to spread apart veins $R_{4}$ and $R_{5}$ so that they become separate and parallel branches of the sector. This has been shown in the case of the Sialidæ and of the Hemerobiidæ. In the Osmylidæ we have seen that the switching of vein $R_{4}$ to vein $R_{2}+3$ is merely a modification of this process; veins $R_{4}$ and $R_{5}$ split apart for a short distance and then the base of vein $R_{1}$ takes a short cut to vein $R_{2+3}$ via a cross-vein. The suppression of the dichotomy by the coalescence of veins $R_{4}$ and $R_{5}$ would be the result of a force acting in the opposite direction, one that tends to bring veins $R_{4}$ and $R_{5}$ together instead of splitting them apart. That such a force has acted seems improbable 
when the data presented by the Sialidæ, Hemerobiidæ, and Osmylidæ are considered.

If the suppression of the dichotomy of the sector were taking place by the coalescence of veins $R_{4}$ and $R_{5}$ one would expect to find the incomplete

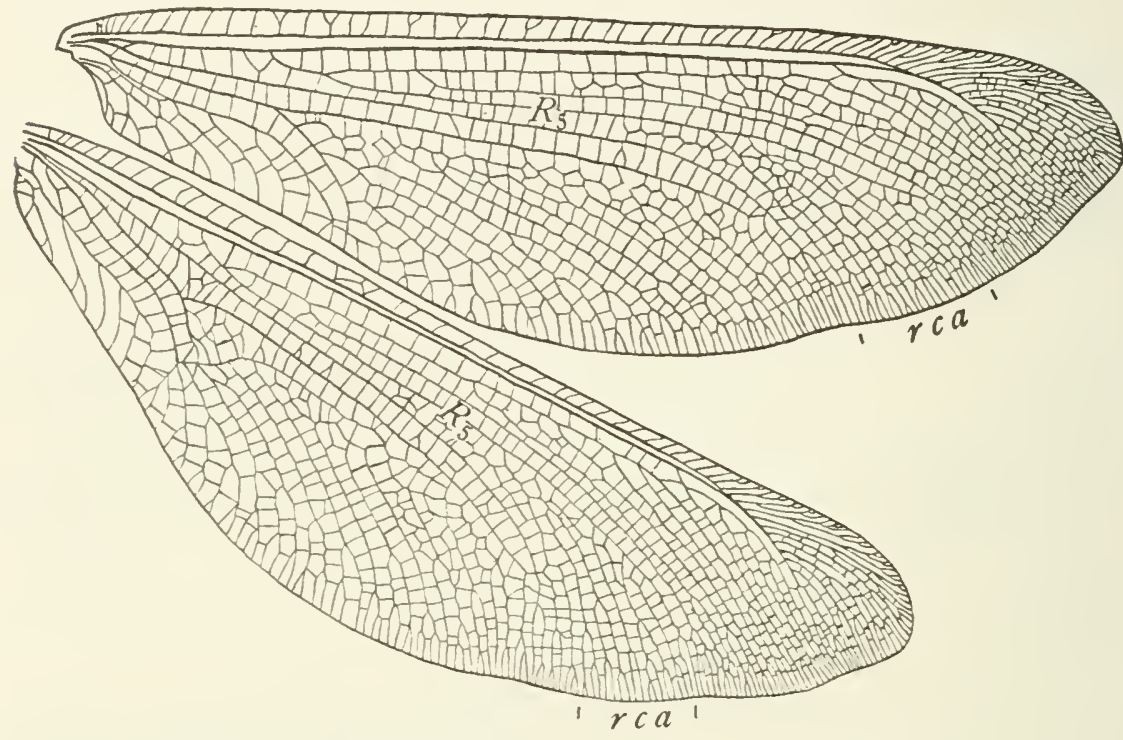

Fig. 159.- Wings of Palpares aschnoides var. libelluloides.

stages of this coalescence, if they still exist, in the more generalized wings of this family, and to find it completely attained in the most specialized wings. The fact is the radial cuneate area is largest in the more highly modified wings of the Myrmelionidæ, as in the Acanthaclisinæ (Fig. I 56) and in the Palparinæ (Fig. I 59), while it is lacking only in wings that are much less modified (Fig. I60).

That the radial cuneate area is a secondary development is indicated by the fact that in the wings where it is the largest similar areas have been developed in other parts of the wing, as in area behind the serial vein $\mathrm{Cu}_{1}$ $\& \mathrm{M}_{3}+_{4}$ of the fore wing of Palpares (Fig. I59). In this connection compare the splitting back of the tip of vein $R_{5}$ in the myrmeleonid wings represented by Figure ${ }_{5} \$ 8$ with similar splitting back of the tips of accessory reins near the apex of the same wings.

The secondary nature of the radial cuneate area is also shown in the Hemerobiidæ. In the generalized Hemerobius humuli (Fig. I75) there is little if any indication of a greater expansion of the tip of vein $R_{5}$ than there is of other branches of the radial sector; but in the highly specialized Megalomus mœstus (Fig. I $78, r c a$ ) the radial cuneate area is very prominent. 
In Megalomus the radial cuneate area is distinctly between branches of vein $\mathrm{R}_{5}$; but in most cases where this area has become large it does not appear to be between two forks of vein $R_{5}$ but to be between the tip of vein $\mathrm{R}_{\mathbf{5}}$ and the tip of media; this is especially the case in the Ascalaphidæ (Fig. I 57).

The secondary cubital fork.--In the hemerobiid and myrmeleonid groups of families, vein $\mathrm{Cu}_{1}$ is usually more or less bent at the point where its first accessory vein, vein $\mathrm{Cu}_{1}$, is given off and this accessory is quite prominent. In this way a fork is formed that frequently appears to be the chief fork of vein $\mathrm{Cu}$; and, for this reason, vein $\mathrm{Cu}_{1_{\mathrm{a}}}$ is liable to be mistaken for vein $\mathrm{Cu}_{2}$.

In those cases where a prominent fork of cubitus is formed in this way, vein $\mathrm{Cu}_{2}$ separates from the stem of cubitus near the base of the wing and in many cases is greatly reduced or even lost; but in other cases this rein is well preserved.

Tillyard, who recognized the nature of this fork and the position of vein $\mathrm{Cu}_{2}$ in the Hemerobiidæ and in some of the Myrmeleonidæ, termed the
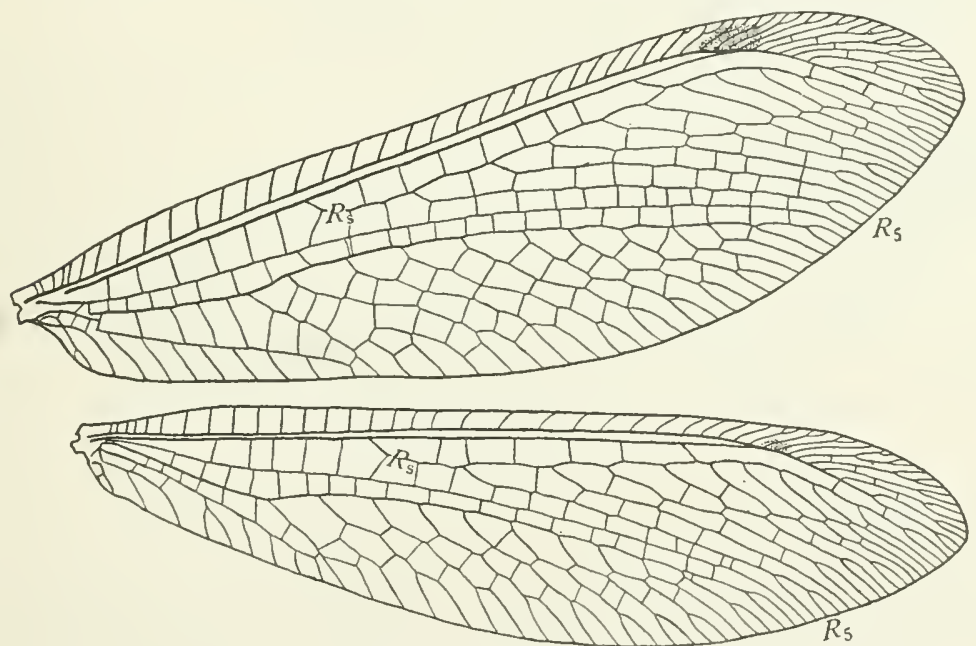

Fig. 160.-Wings of a myrmeleonid from Persia. The base of the fore wing is broken in the specimen figured.

fork between veins $\mathrm{Cu}_{1}$ and $\mathrm{Cu}_{1_{\mathrm{a}}}$ the secondary cubital fork (cuf'), and that between veins $\mathrm{Cu}_{1}$ and $\mathrm{Cu}_{2}$ the primary cubital fork (cuf) (Tillyard ' 6 , p. 29I).

The secondary cubital fork can be easily recognized in most of the figures of wings illustrating the accounts of the wings of the families named above. 
Gradate veins.- In many Neuroptera one or more series of cross-veins extend across the wing and form with sections of the longitudinal veins that they connect a very regular zigzag line; such cross-veins are termed gradate veins; there is a well-developed series of gradate veins parallel with the outer margin in each of the wings of Osmylus hyalinatus (Fig. I6I), and a second, less perfect series proximad of this one.

The recurrent vein.- In many families of the Neuroptera the humeral cross-vein curves back toward the base of the wing and bears branches,
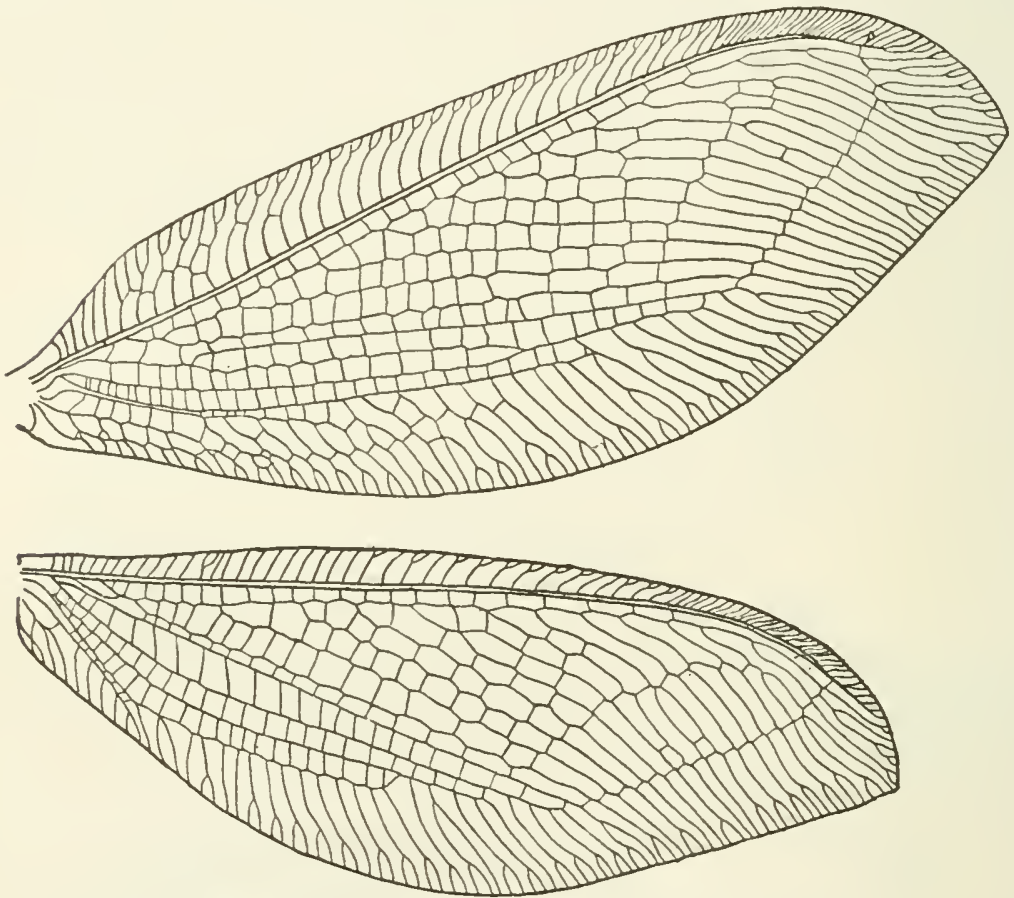

Fig. 16r.-Wings of Osmylus hyalinatus, showing gradate veins.

when of this form it is designated as the recurrent vein. The statement often made in descriptions of Neuroptera that there is no recurrent vein does not indicate the absence of the humeral cross-vein, but merely that this vein is not recurved and branched.

The coalescence of veins $S c$ and $R_{1}$. - In many families, veins $S c$ and $R_{1}$ come together in the outer part of the wing and appear to be continued as a single vein, which is designated as vein $\mathrm{Sc}+\mathrm{R}_{1}$. This apparent coalescence of these two veins, or the lack of it, is commonly considered an important characteristic, and is frequently mentioned in diagnoses of families.

I believe, however, that in some cases, where there appears to be a coalescence of these two veins, vein $S c$ ends upon vein $R_{1}$ at the point 
where the coalescence appears to begin. Examples of this condition are to be found in the Berothidæ and are discussed later. In Megalomus mestus, of the Hemerobiidæ, vein $S c$ ends upon vein $R_{1}$ in the fore wing, while the two end separately in the hind wing.

Marginal dots or dashes.-- While intercalary veins are never developed in the Neuroptera, there are present in the wings of many members of the order small thickened areas alternating with the tips of veins. The areas in some cases are small dots, in others they are slightly elongate. They are probably sense organs, as they bear one or more groups of setæ, like those borne by the veins of the wing. These thickened areas are never long enough to be termed veins; for this reason I designate them as marginal dots or dashes. In some cases they are mere dots in one part of the margin of the wing and dashlike in another part.

The marginal dots and dashes are present quite commonly in the Ithonidæ, Berothidæ, Polystœchotidæ, Psychopsidæ, the hemerobiid group of families, Osmylidæ, and Nymphidæ.

Although they are present in Nymphes, I have not observed them in any other member of the myrmeleonid group of families.

In some cases they are present throughout the entire margin of the w'ng in other cases they are limited to a portion of the margin.

The first radio-medial cross-vein of the hind wings.- One of the most characteristic features of the venation of the hind wings of several families of neuropterous insects is the form of the first radio-medial cross-vein, which extends longitudinally in a sigmoid curve instead of transversely (Fig. $162, I$ st $r-m$ ). It arises from the radial sector and extends towards the base of the wing, joining media near its base.

The fact that this peculiar feature is found in the so-called Megaloptera as well as in the "True Neuroptera" may have some bearing on the proposed separation of the Megaloptera from other Neuroptera as a distinct order.

Frequently there is a fold in the wing which causes the base of the radius to overlap the base of the media, covering the point where this crossvein joins media. A result of this is that in photographs of such wings the proximal end of the first radio-medial cross-vein appears to be attached to radius. This is the case in the wings of Osmylus hyalinatus represented by Figure 144 , which is an accurate copy of a photograph.

It was probably this condition that led Tillyard to mistake this crossvein for the base of the radial sector in the Hemerobiidx and to regard the stalk of the radial sector as a cross-vein; this is indicated by his figure of the venation of Hemerobius humuli (Tillyard 'I6, p. 285). This matter is of considerable importance as "the presence of at least one false or secondary origin for the radial sector in the hind wing" is given as a distinctive characteristic of the Hemerobiida as restricted by him. 
The first radio-medial cross-vein of the hind wings is longitudinal and sigmoid in the subfamily Corydalinæ, the genus Ithone, and in the families

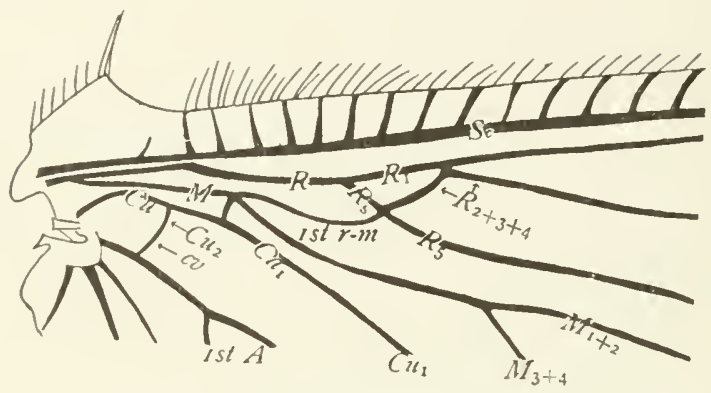

Fig. 162.-Base of hind wing of Hemerobius humuli.

Polystœchotidæ, Sisyridæ, Sympherobiidæ, Hemerobiidæ, Dilaridæ, and Osmylidæ.

(c) THE Wixgs of THE Sialide

The wings of the Sialidæe form an excellent starting point for a study of the methods of specialization of the wings that have been evolved in the order Neuroptera.

The most character stic feature of the more highiy specialized wings found in this order is the presence of a very perfectly developed pectinately branched radial sector. In one of the two subfamilies of this family the Sialinæ, the modification of the typical dichotomously branched radial sector into a pectinately branched one has not begun; in the other subfamily, the Corydalinæ, this modification has taken place; but in some members of this subfamily, as Chauliodes, the modification has not progressed far, consisting merely in the suppression of the dichotomy and the development of one or two accessory veins.

The tracheation of the wings of nymphs of three of the genera of this family was figured by Comstock and Needham and the result of our studies leaves no doubt as to the homologies of the principal veins.

The family includes two quite distinct subfamilies, the Sialinæ and the Corydalinæ, which are distinguished by different types of wing-venation.

The wings of the Sialinæ.-The subfamily Sialinæ includes only two genera, Sialis and Protosialis. These resemble each other very closely in the more general features of the venation of the wings. As we were able to study the wings of pupæ of Sialis infumata, this species is used to illustrate the type of wing venation characteristic of the subfamily.

Figure ${ }_{1} 6_{3}$ represents the tracheation of a wing of a pupa of this species which was photographed when the forming veins appeared as pale bands; and Figure ${ }^{6} 64$ represents the wings of an adult. 
It is unnecessary to describe these wings in detail, as the lettering of the figures indicates the homologies of the wing-reins. Some of the more

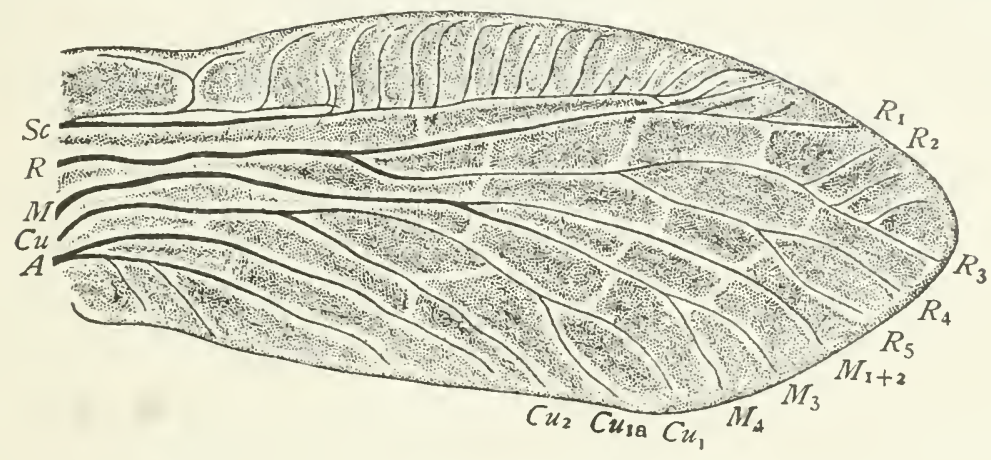

Fig. 163.-Wing of a pupa of Sialis infumata (After C. \& N.).

striking features are the following: the prominence of the accessory branches of the subcosta; the coalescence of the tips of veins $S c$ and $R_{1}$; the partial atrophy of the intermediate portion of media in the fore wing
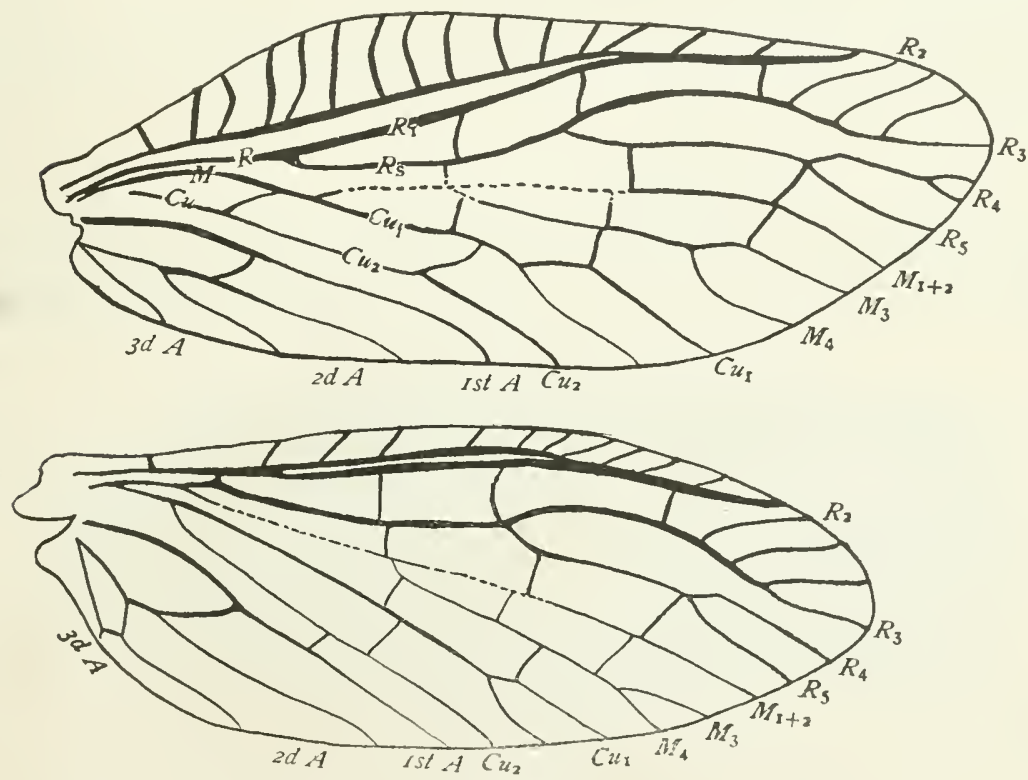

Fig. 16.4.-Wings of Sialis infumata.

and of the greater part of the stem of this vein in the hind wing; the anastomosis of veins $\mathrm{M}$ and $\mathrm{Ct}_{1}$ in the fore wing; and the manner of branching of the radial sector. 
The last mentioned feature is the one to which I wish to call especial attention. The radial sector in this genus is nearly typical in form; the only modification being the development of one or more marginal accessory reins upon it. These accessory veins, however, are in a quite different position than that occupied by the accessory veins borne by the radial sector in the Corydalinæ, where a pectinately branched radial sector has been developed.

In Sialis the accessory veins are borne by vein $R_{3}$, instead of vein $R_{2}$ as in the Corydialinæ, and they extend toward the costal margin of the wing. The method of specialization is in a quite different direction than that which produces the pectinately branched radial sector of the Corydalinæ.

The accessory veins borne by vein $\mathrm{R}_{3}$ in Sialis have not attained a permanent form; they vary in number in different individuals of the same species and in being either simple or forked; for this reason they are not numbered; they are not definitive accessory veins, but are of the type termed marginal accessory veins. Occasionally there are accessory veins on other branches of the radial sector; there is one on vein $R_{4}$ in the fore wing represented in Figure 164.

The dichotomously branched radial sector of Sialis, which closely resembles the radial sector of the hypothetical primitive type of wing venation, shows conclusively that the pectinately branched radial sector of the allied genera and of most other Neuroptera, has been derived from the dichotomously branched type.

The wings of the Corydalinæ. - The wings of the members of the subfamily Corydalinæ present a very different appearance from those of Sialis; this is due largely to the fact that in the Corydalinæ a pectinately branched

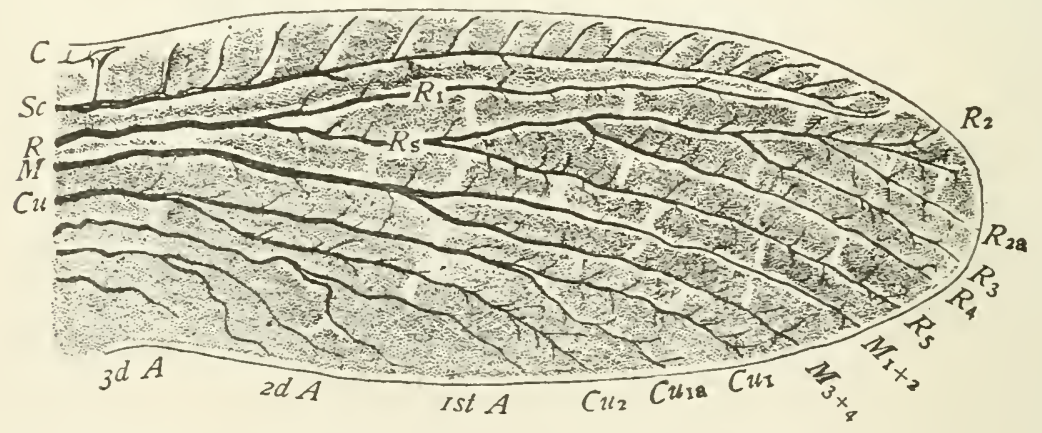

Fig. 165.- TWing of a pupa of Chauliodes pectinicornis (After C. \& N.).

radial sector has been developed, while in Sialis this vein has retained the dichotomous type of branching, modified only by the addition of a limited number of marginal accessory veins. 
Figure ${ }_{6} 6$ represents a wing of a pupa of Chauliodes pectinicornis, taken at the stage when the forming wing-veins appear as pale bands; and Figure t66 represents the tracheation of a wing of a pupa of Corydalus cormutus.

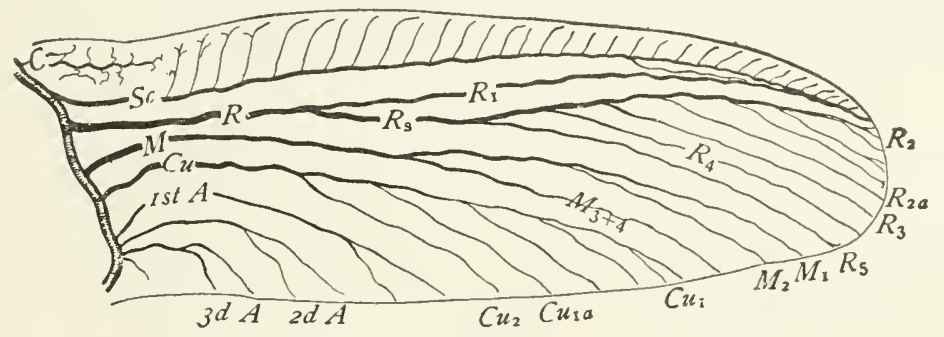

Fig. 166.-Tracheation of a wing of a pupa of Corydalus cornutus (After C. \& N.).

These figures are from Comstock and Needham, but with a change in the lettering of the branches of the radial sector. The homologies of the wingveins are indicated by the lettering of the figures and require no discussion except in the case of the branches of the radial sector, where there may be a difference of opinion, depending on the view held regarding the method by which the dichotomy of the sector has been suppressed. This has been discussed on an earlier page.

\section{(d) THE WINGS OF THE RAPHIDIIDE}

As no account of the tracheation of the wings of any pupa belonging to the Raphidiide has been published, we are forced to base our conclusions regarding the homologies of the wing-veins in this family upon a study of the wings of adults.

Of the two genera belonging to this family, Inocellia appears to be the more generalized, as regards the structure of the wings. The wings of Inocellia longicornis are figured here (Fig. 167).

In both genera, the subcosta ends in the costal margin of the wing a short distance before the pterostigma; the pterostigma is definitely limited, and conspicuous; the humeral vein is not recurrent, but sometimes it is forked; and the costal area of the wing is more or less widened in the proximal half of the wing.

In Inocellia there is no indication of a tendency to form a pectinately branched radial sector, the dichotomous branching of this vein being obvious. The forks of veins $\mathrm{R}_{2+3}$ and $\mathrm{R}_{4}+_{5}$ are nearly opposite each other; and both are quite near the margin of the wing. The tip of vein $\mathrm{R}_{1}$ and of some of the branches of the radial sector bear short marginal accessory veins; but these differ in number in the wings of the two sides of the same individual. 
Media coalesces with radius for a considerable distance at the base of the wing. It is four-branched; and reins $\mathrm{M}_{3}$ and $\mathrm{M}_{4}$ each bears an accessory rein. A similar accessory vein is borne by vein $\mathrm{Cu}_{1}$.

The fore and hind wings are very similar as regards the features mentioned above; but the course of vein $\mathrm{Cu}_{1}$ is markedly different in the two wings. In the fore wing, the basal part of rein $\mathrm{Cu}_{1}$ extends directly forward
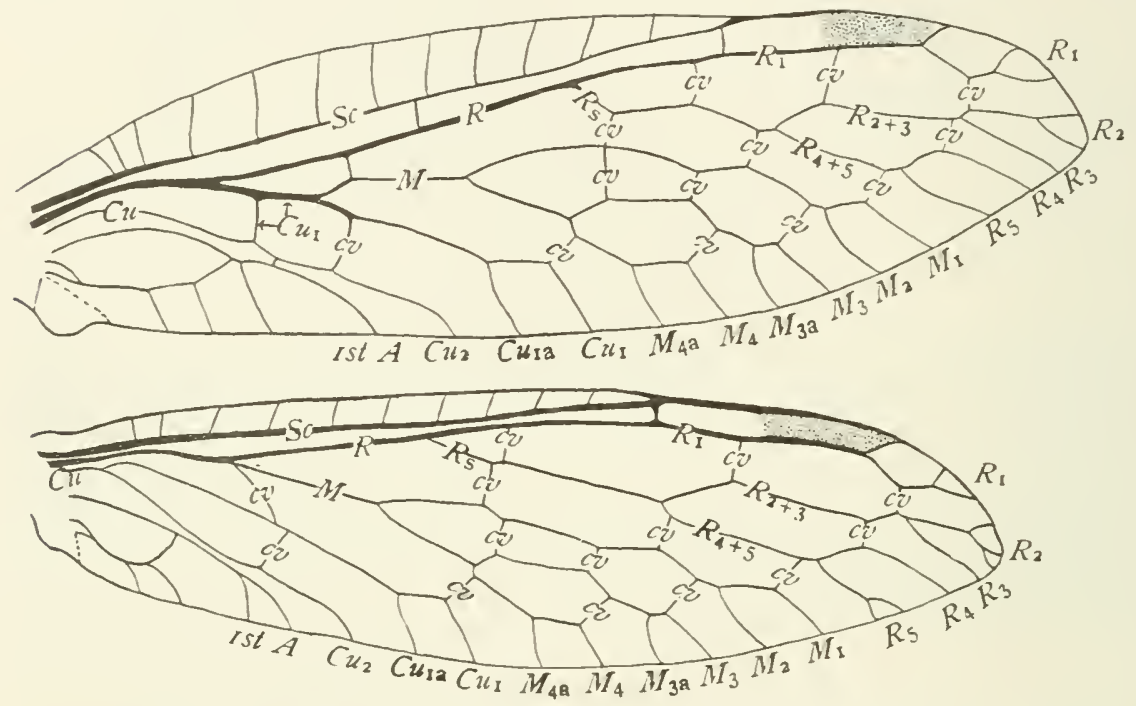

Fig. 167.-Wings of Inocellia longicornis; $c v, c v, c v$, cross-veins.

from the cubital fork until it reaches media, with which its coalesces for a short distance. In the hind wing, the cubital fork is much nearer the base of the wing than it is in the fore wing, and vein $\mathrm{Cu}_{1}$ extends directly to the margin of the wing, being connected with media only by two cross-veins, the first of which is oblique.

Vein $\mathrm{Cu}_{2}$ in the fore wing is connected with the first anal vein by a very short cross-vein; in the hind wing these two veins are closely approximate but they do not anastomose.

In Inocellia the radial sector has moved out towards the apex of the wing, which has resulted in the shortening of veins $R_{2}, R_{3}, R_{4}$, and $R_{5}$ so that they appear like the accessory veins that have been developed upon veins $\mathrm{M}_{3}, \mathrm{M}_{4}$, and $\mathrm{Cu}_{1}$.

The wings of Raphidia adnixa may be taken as illustrating the type of wing-venation characteristic of the genus Raphidia (Fig. I68). In this species, the wings present two marked differences from those of Inocellia longicornis; these are the presence of a larger number of accessory veins and the fact that the radial sector, although still dichotomously branched, shows the beginning of the development of the pectinately branched type. 
In Raphidia adnixa the forking of vein $\mathrm{R}_{4+5}$ is in about the same position as in Inocellia, but the tips of one or of both of the veins $R_{4}$ and $R_{5}$ are split; vein $\mathrm{R}_{3}$ is split back a considerable distance; and the forking of vein $\mathrm{R}_{2}$ has progressed so far that what is probably a definitive accessory vein, vein $R_{2_{2}}$, has been developed. This development of a definitive accessory vein upon vein $R_{2}$ is of considerable interest as it indicates the beginning of the development of a pectinate radial sector.

In certain other species of Raphidia, the wings of which are figured by Albarda ('9I), the forks of veins $R_{2}+3$ and $R_{4+5}$ are more nearly opposite than they are in the wings figured here.

Returning to the wings of Raphidia adnixa, we find that the tips of all of the branches of media are split and that the number of accessory veins borne by vein $\mathrm{Cu}_{1}$ is greater than in Inocellia. In fore wing of the Raphidia, vein $\mathrm{Cu}_{1}$ not only anastomoses with media at its base but there is also an anastomosis of this vein with vein $\mathrm{M}_{3}+4$. The fact of this last anastomosis is made evident by comparison with the hind wing where the two veins are connected by a short cross-vein. In the hind wing veins $\mathrm{Cu}_{2}$ and ist $\mathrm{A}$ anastomose along the region where they are closely parallel in Inocellia.
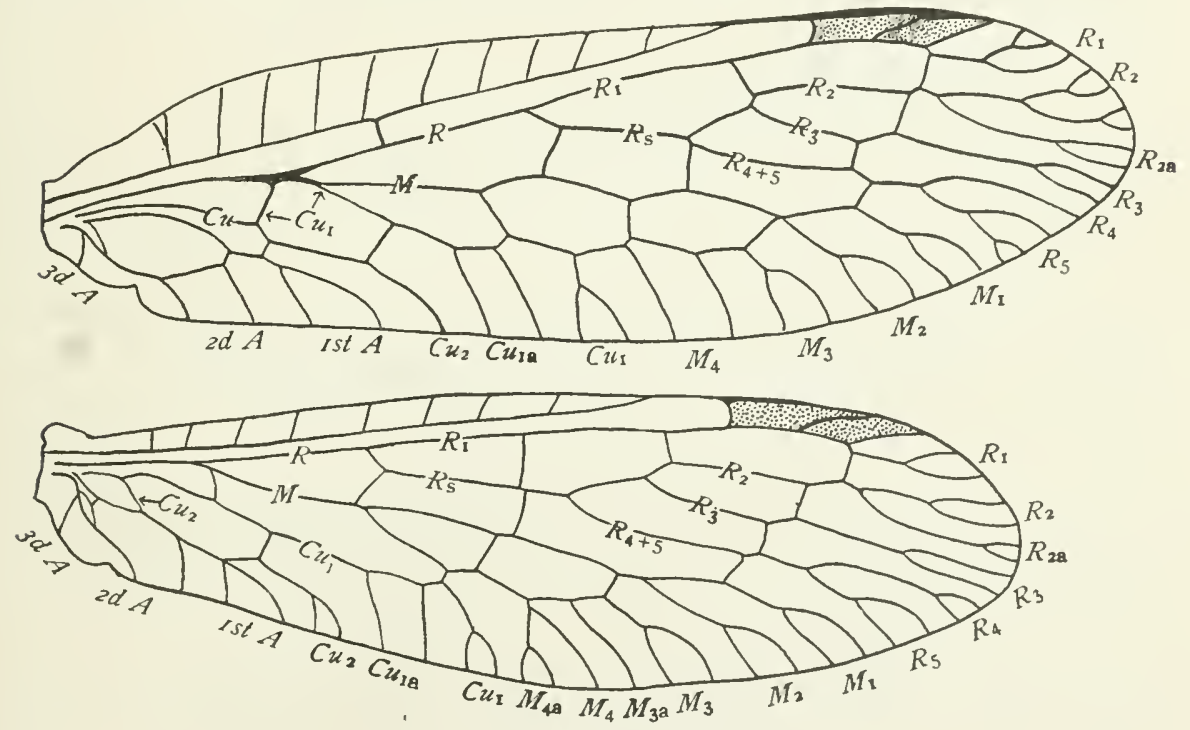

Fig. I68.-Wings of Raphidia adnixa.

An obvious distinction between Inocellia and Raphidia, pointed out by Albarda (' $9 \mathrm{I}$ ), is that in Raphidia the pterostigma is traversed by a branch of vein $\mathrm{R}_{1}$, which is lacking in Inocellia.

In both genera the cross-veins are greatly reduced in number; and there is a marked tendency towards the alignment of those in the outer part of the wing in a gradate series; this is well shown in the hind wing of Raphidia adnixa. 


\section{(e) THE WINGS OF THE MANTISPIDE}

The wings of Climaciella brunnea (Fig. I69) can be taken as an illustration of the type of wings found in this family. The two pairs of wings are similar in form and agree in the more general features of their venation.
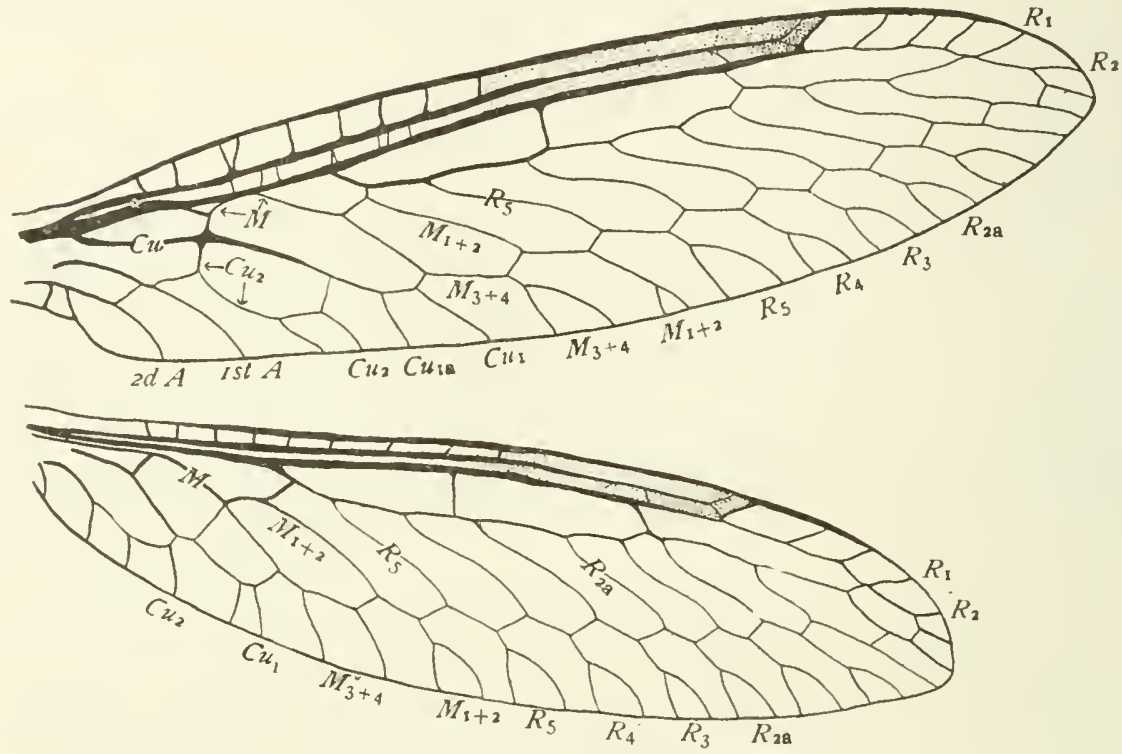

Fig. I69.-Wings of Climaciella brunnea.

They are long and narrow; a pterostigma is present, but the limits of it are not sharply defined; the subcosta extends midway between the costa and the radius to near the end of the pterostigma, where it is forked; the radial sector is pectinately branched; most of its branches are divided at the tip; the base of media coalesces with radius for a short distance at the base of the wing; in the fore wing, media after separating from radius and extending down for a short distance bends up sharply and anastomoses with radius, thus forming a small triangular cell.

The media is apparently four-branched in both wings; but the divisions of veins $\mathrm{M}_{1+2}$ and $\mathrm{M}_{3}+_{4}$ are short and may be merely accessory veins, corresponding with the divisions of the branches of the radial sector.

A large cell $R_{1}$ is a characteristic feature of the wings of insects of this family; as a rule this cell is divided by three cross-veins, but in the wings figured here the third cross-vein has been eliminated by the anastomosing of veins $R_{1}$ and $R_{2}$ near the apex of the wing.

The number of the branches of the radial sector that are given off opposite the Ist cell $R_{I}$ has been used as a diagnostic character; but this number 
is not constant; it sometimes varies in the wings of the two sides of the same individual.

The wings of the Mantispidre resemble in some respects those of Raphidia; the ontlines of the wings are similar; and the two resemble each other and differ from other neuropterous wings in the transverse bracing of the basal part of the fore wing in each by striking modifications of the courses of principal veins, although this result is brought about in very different ways in the two families.

The wings of the Mantispidx are much more highly specialized than are those of the Raphididæ; the discussion of them has been taken up at this point merely because there seems to be no better place in the series to include it.

In the Mantispidæ the pectinate condition of the radial sector is very perfect, as is also the development of a gradate series of cross-veins, and a comparatively regular margin of accessory veins.

\section{(f) THE WINGS OF THE ITHONID $E$}

Newman in I 853 established the family Ithonesidæ for the reception of his genus Ithone (Zoologist, vol XI, Appendix p. CCII). Recently
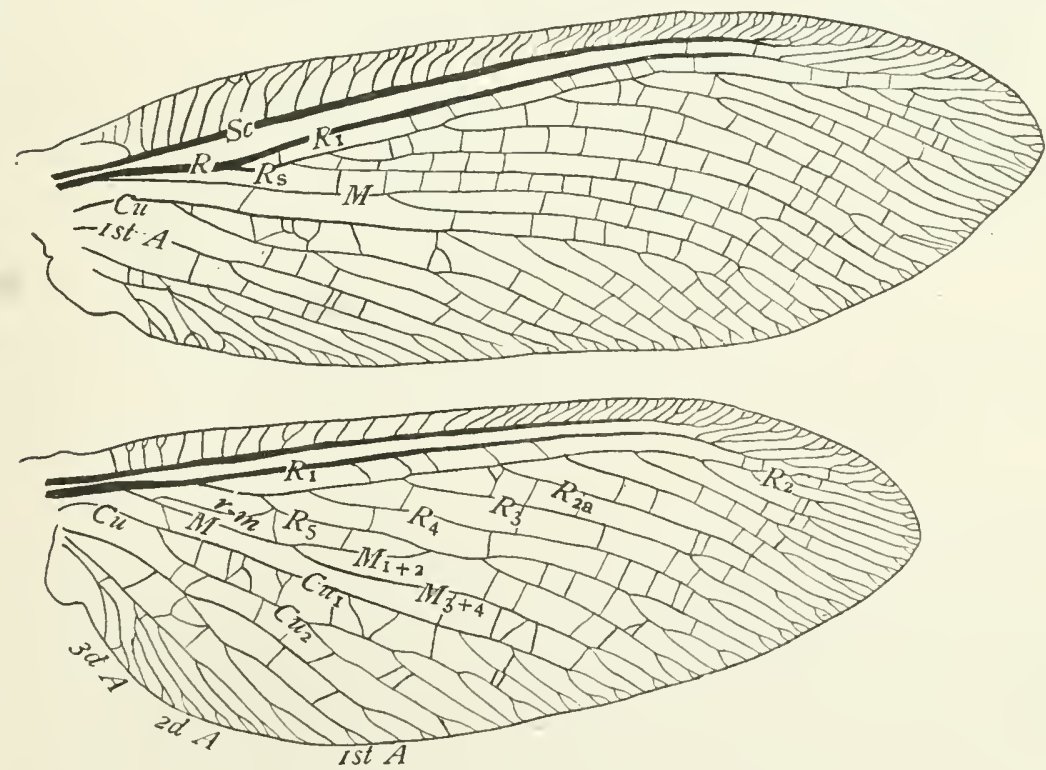

Fig. 170.-Wings of Ithone fusca.

Tillyard ('I6) reestablished the family under the name of Ithonidæ. As the name proposed by Tillyard conforms to the modern rules of nomenclature it is adopted here. 
The type of the genus Ithone is the species described by Newman under the specific name fusca; the wings of this insect are figured here (Fig. I 7o).

The wings of Ithone fusca bear a superficial resemblance to those of the Corydalinæ; but in Ithone the humeral vein of the fore wings is recurved and branched and veins $S c$ and $R_{1}$ do not coalesce at their tips.

In this species there is a single radial sector, which is pectinately branched; and most of the branches of this vein are forked at the tip. Media is two-branched in both wings; and vein $\mathrm{Cu}_{1}$ is very stout.

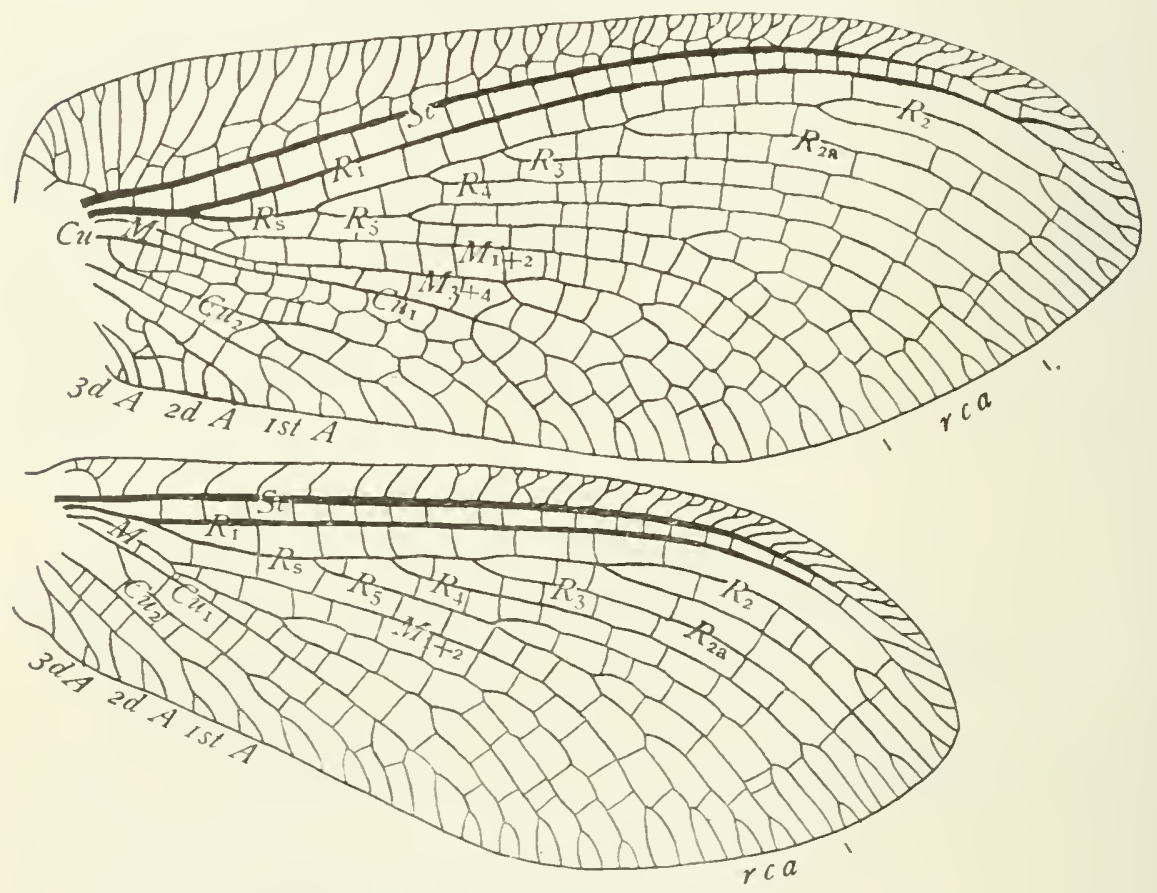

Fig. 171.-Wings Rapisma viridipennis; rca, radial cuneate area.

This species is found in Australia and in Tasmania, and has been until recently the only species of the genus Ithone known.

Tillyard ('I6) describes another Australian insect under the name Ithone fulva. But although the general appearance of the wings of this insect, as figured by Tillyard, is similar to that of Ithone, the differences in structure are so great that it is doubtful if the two are congeneric. The most important difference is that in the fore wings of Ithone fulva the first and second branches of the radial sector arise separately from the main stem of radius, the radius having three sectors. In the hind wings veins Sc and $R_{1}$ coalesce throughout the distal half of their length.

The limits and distinguishing characteristics of the Ithonidæ must be determined by a study of other characters as well as those presented by the 
wings, and does not fall within the scope of this essay. Until this is done, I suggest the inclusion in this family provisionally of another remarkable insect; this is Rapisma viridipenmis.

The genus Rapisma was established by McLachlan to receive a species from the East Indies that had been described by Walker under the name Hemerobius viridipennis. Dr. Needham has obtained this species from the East Himalayas and I give here a figure of its wings (Fig. I $7 \mathrm{r}$ ).

In Rapisma the costal area of the fore wings is more expanded than in Ithone; but the courses of the terminal portions of veins $\mathrm{Sc}$ and $\mathrm{R}_{1}$ are similar in the two genera, as are also most of the other more general features of the wings.

The chief reason for giving a figure of the wings of Rapisma in this discussion of the wings of the Neuroptera is to call attention to one feature of the structure of the radial sector. This is the fact that the primitive dichotomy of this sector appears to have been retained although the development of its other pectinate features has progressed far. This appearance is especially striking in the fore wing where what appears to be the forks of veins $R_{2}+3$ and $R_{4}+_{5}$ are opposite.

A little consideration will suggest that it is not probable that the position of the fork of the first branch of the radial sector, vein $R_{4}+5$, would remain so nearly in its primitive position while the other features of the pectinate vein were being developed.

The explanation of the condition in question is that in each of the wings of Rapisma there has been developed a radial cuneate area; and that in the fore wing the first fork of vein $R_{5}$ has extended nearly to its base. In the hind wing this forking of vein $\mathrm{R}_{5}$ has not extended so far.

The extent to which the development of a radial cuneate area has progressed in the wings of Rapisma and the transverse position of the first radio-medial cross-vein of the hind wings are the most striking differences between these wings and those of Ithone.

\section{(g) THE WINGS OF THE SISYRIDA}

Until quite recently the members of this family have been included in the family Hemerobiidæ; but several recent writers have separated them as a distinct family. The structure of their wings warrants this separation, as the distinctive characteristic of the hemerobiid wings is not exhibited by them.

The type of wing-venation characteristic of the Sisyridæ is well illustrated by the wings of Sisyra flavicomis, a species found in British India (Fig. I 72). The more striking characteristics of these wings are the following: The costal area of the fore wings is not greatly broadened. The humeral vein is not recurrent and is not branched. Veins Sc and $R_{1}$ coalesce near the apex of the wing. The dichotomy of the radial sector has 
been suppressed in both wings, evidently by the splitting back of vein $R_{5}$ so that it arises from the main stem of the radial sector distinct from vein $R_{4}$. The splitting back of vein $R_{5}$ has progressed farther in the fore wing than it has in the hind wing

The condition of the radial sector in Sisyra is much more generalized than it is in the wings of the Hemerobiidæ, for in Sisyra it is only fourbranched, no definitive accessory veins having been developed, although marginal accessory veins are present. In fact the radial sector in these wings differs from the typical form only in the fact that the dichotomy has been suppressed.

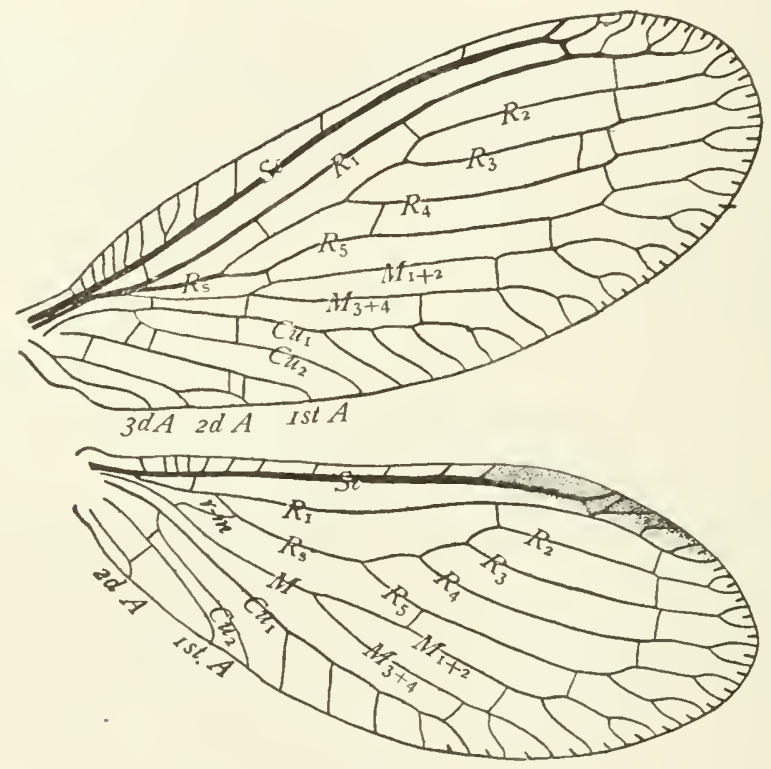

Fig. 172.-Wings of Sisyra flavicornis.

Media is two-branched in both fore and hind wings, and in each case the tips of the branches are forked.

The beginning of the development of a secondary cubital fork is clearly indicated, especially in the fore wing; but vein $\mathrm{Cu}_{2}$ is well preserved.

Marginal dashes are present in the outer margin of the wing.

The extended migration of the base of vein $R_{5}$ of the fore wing towards the base of the wing and the beginning of the formation of a secondary cubital fork are specializations that are carried much farther in the Hemerobiidæ.

(h) THE Wings OF THE SYMPHEROBIID

Even after the separation of the Sisyridæ and the Dilaridæ from the Hemerobiidæ, as is now commonly done, there remains in this family 
several genera that do not exhibit the method of specialization of the wings that is distinctively characteristic of the Hemerobiidæ, but on the other hand exhibit a type of specialization distinctively characteristic of this group of genera. To this group belong the American genera Sympherobius and Psectra, the genus Annandalia from Calcutta, and the Australian genus Notiobiella. I suggest that these genera and such other genera as may be found to exhibit the same type of specialization of the wings be grouped in a separate family to be known as the Sympherobiidæ.
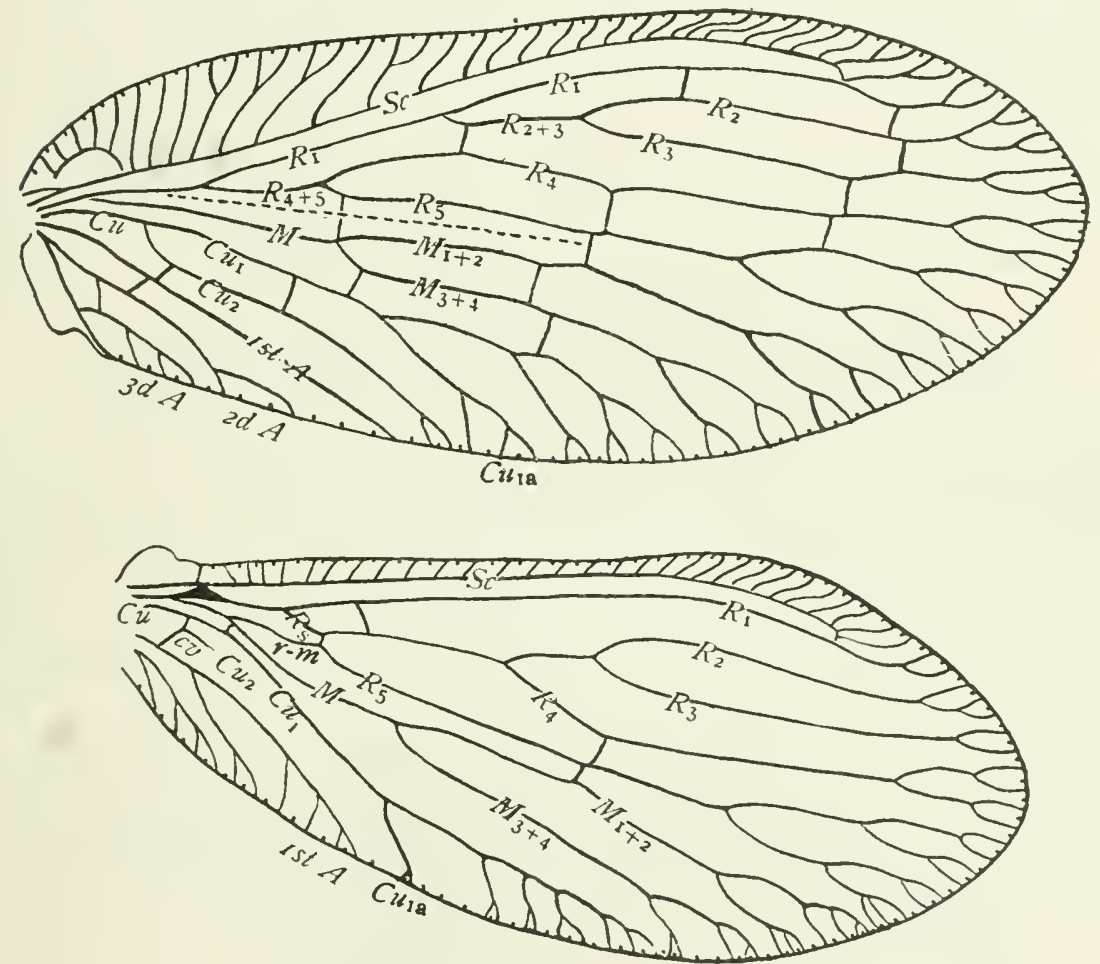

Fig. 173.-Wings of Sympherobius amiculus.

The distinctive characteristic of the Sympherobiidæ is that vein $R_{2}+3$ of the fore wings has become separated from the remainder of the radial sector and is attached separately to vein $R_{1}$. This results in the radius of the fore wing having two sectors each of which is forked (Fig. I73).

In each case where this switching of the base of vein $R_{2}+3$ from the stem of the pectinate radial sector to vein $R_{1}$ has occurred there is a crossvein extending from vein $R_{2+3}$ to the stem of the radial sector. It is probable that the switching occurred by the way of this cross-vein, and that after vein $R_{1}$ was reached by vein $R_{2}+_{3}$ the base of the latter vein migrated a short distance towards the base of the wing. 
This peculiar method of specialization of the radius may be termed the division of the stem of the radial sector.

The radial sector of the fore wing of Sympherobius is very similar to that of Sisyra (Fig. 172), except for the switching of the base of vein $\mathrm{R}_{2}+3$.

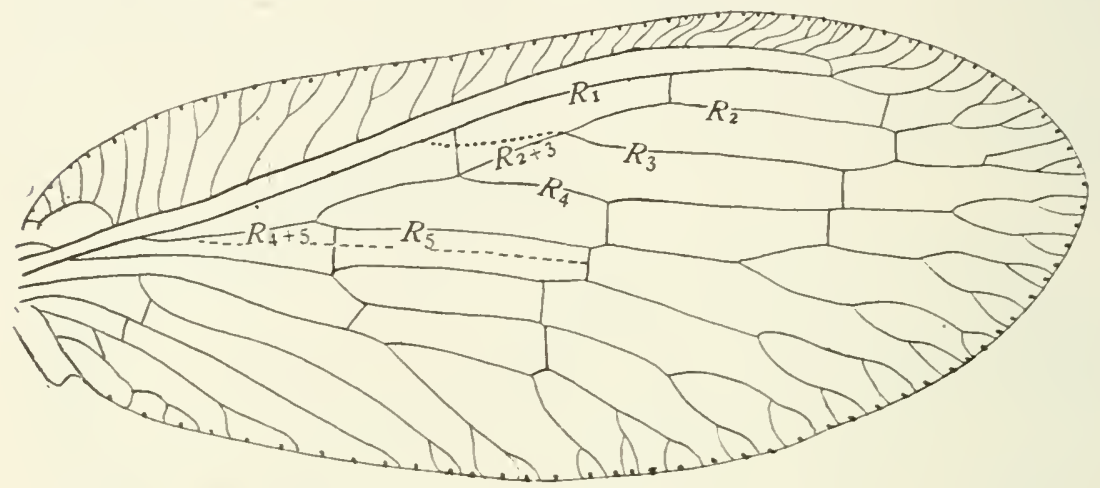

Fig. 174.-Fore wing of Sympherobius showing the probable primitive type of radial sector, the dotted line indicates the present course of vein $R_{2}+3$.

Figure 174 is a copy of the figure of the fore wing of Sympherobius amiculus given above (Fig. 173) except that a slight change is made in the course of the base of vein $\mathrm{R}_{2}+3$ and of the cross-rein associated with it the two veins being brought into their probable position before the switching of vein $\mathrm{R}_{2}+3$ began; with these changes in Sympherobius the radial sectors of the two genera are strikingly alike. The dotted line in Figure 174 indicates the present position of vein $R_{2}+3$.

In the Sympherobiidæ the number of the branches of the radial sector has not been increased;" this vein being four-branched in both fore and hind wings; but the tips of all of the branches are forked. The costal area of the fore wings is broad toward the base of the wing; the humeral vein is recurved and branched; and marginal dashes are present.

\section{(i) THE Wings of the Henierobidde}

After the separation from the Hemerobiidæ of the Sisyridæ, Sympherobiidæ, Dilaridæ, and Polystœechotidæ, all of which were included in this family until quite recently, there remains a group of genera that is characterized by a distinctive manner of specialization of the radius of the fore wings. This feature is a coalescence of vein $R_{1}$ and the stem of the pectinately branched radial sector, which results in what may be termed the suppression of the stem of the radial sector.

In this family the migration of the base of vein $R_{5}$ towards the base of the wing that is seen in the two preceding families has progressed to an even greater extent. The combination of this factor with the suppression of the 
stem of the radial sector has resulted, in the fore wings, in the separate origin of from three to many branches of the radial sector from what appears to be the main stem of radius, but what is really the coalesced vein $R_{I}$ and the stem of the radial sector.

A comparatively simple example of this condition is exhibited by Hemerobius humuli; in the fore wings of this species (Fig. I75), veins $R_{5}$, $R_{4}$, and $R_{2}+3$ arise separately from what appears to be the main stem of radius.

In systematic works treating of the Hemerobiidæ, a radius like that of the fore wing of Hemerobius humuli is described as possessing three radial sectors; such a statement suggests that the two branches that arise separately are not a part of the primitive radial sector, as is maintained by a recent writer, which is unfortunate.

This usage is so firmly fixed, however, and is withal so convenient, as the number of the branches that arise separately is an important taxonomic
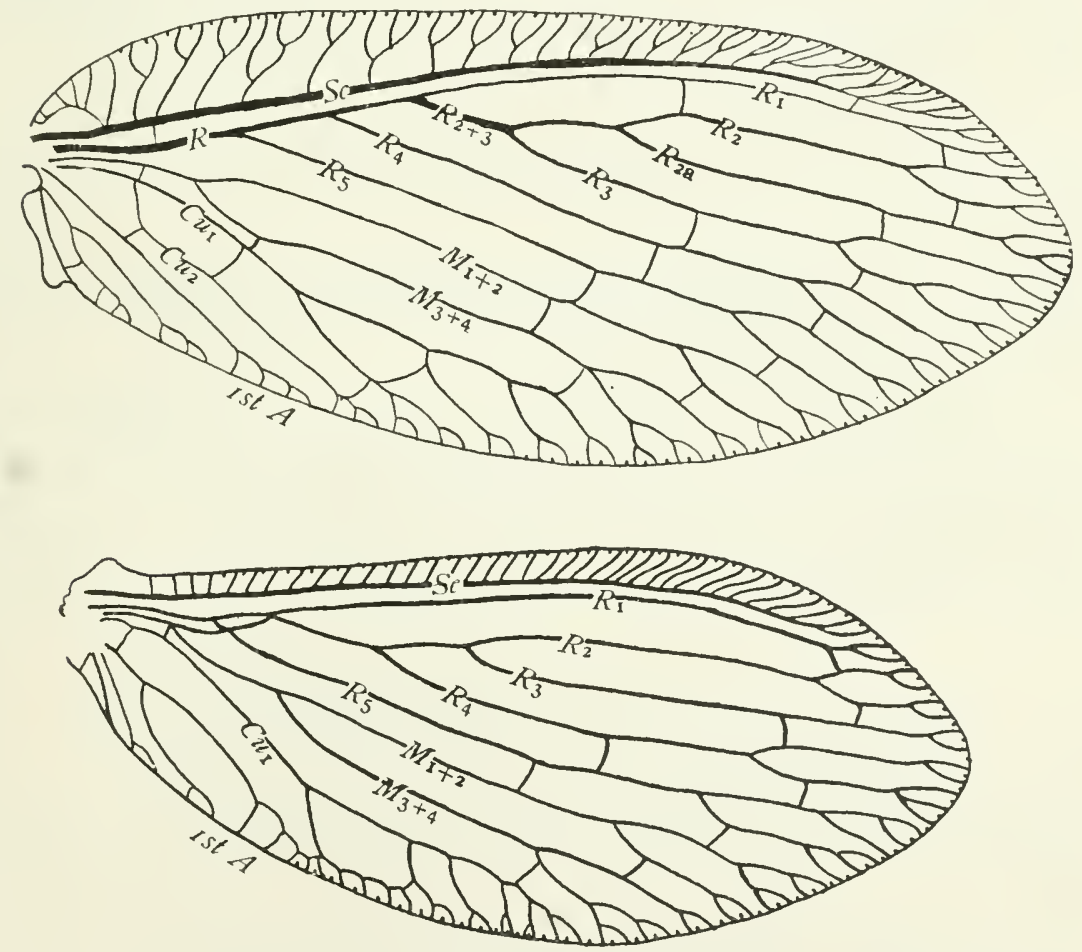

Fig. 1 75.-Wings of Hemerobius humuli.

character, that it is not probable that it will be abandoned; and no harm will be done by following it if the origin of the various "sectors" be kept in mind. 
It has been shown, in the preceding section of this chapter, that in the Sympherobiidæ the radius of the fore wings has two sectors; but this result in that family has been brought about in a very different way than that

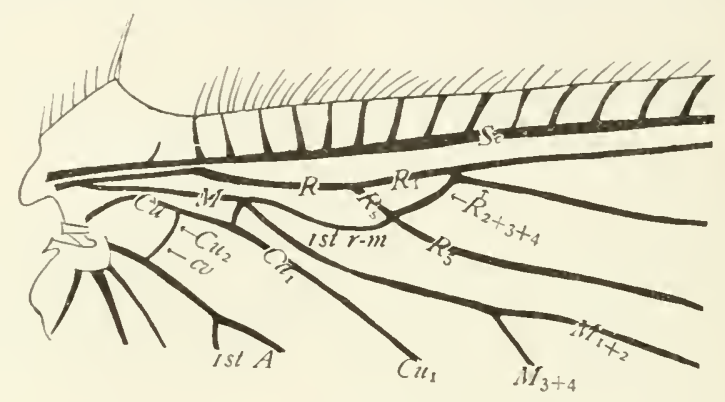

Fig. I 76.-Base of hind wing of Hemerobius humuli.

just described. In the one case there is a division of the stem of the radial sector; in the other, a suppression of this part of the sector, 'by its coalescence with vein $R_{1}$.

The separate origin of one or more branches of the radial sector occurs also in the wings of the Dilaridæ described in the next section of this chapter, and in an Australian insect recently described by Tillyard (' 6 p. 279), under the name Ithone fulva. In both of these cases there appears to have been a splitting back of the branches that arise separately, and not a suppression of the stem of the radial sector. This, however, is not perfectly clear in the case of Ithone fulva.

An early stage in the suppression of the stem of the radial sector is shown in the hind wing of Hemerobius humuli (Fig. I $_{75}$ ), where vein $\mathrm{R}_{5}$ has split back nearly to the base of the radial sector, so that it separates from the remainder of the sector, $i$. e. vein $\mathrm{R}_{2}+_{3}+_{4}$ nearly opposite the anterior end of the first radio-medial cross-vein (Fig. ${ }_{17} 6$ ). From the point of

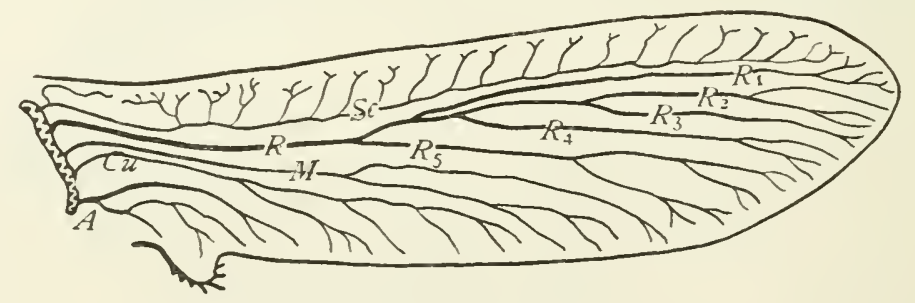

Fig. 177.-Tracheation of a hemerobiid wing (After C. \& N.).

separation of veins $R_{5}$ and $R_{2}+_{3}+_{4}$, the latter extends obliquely forward and anastomoses with vein $R_{1}$ thus forming a small cell opposite the cell closed by the first radio-medial cross-vein. The extending of the union of veins $R_{1}$ and $R_{2+3}+{ }_{4}$ from the point where they now anastomose towards 
the base of the wing, so as to obliterate the small cell between them and also towards the apex of the wing for a certain distance would produce the condition that exists in the fore wing.

A stage intermediate between that of the radial sector in the hind wing of Hemerobius humuli and that of the fore wing of the same species, where the coalescence of the stem of the radial sector and vein $R_{1}$ is carried so far that
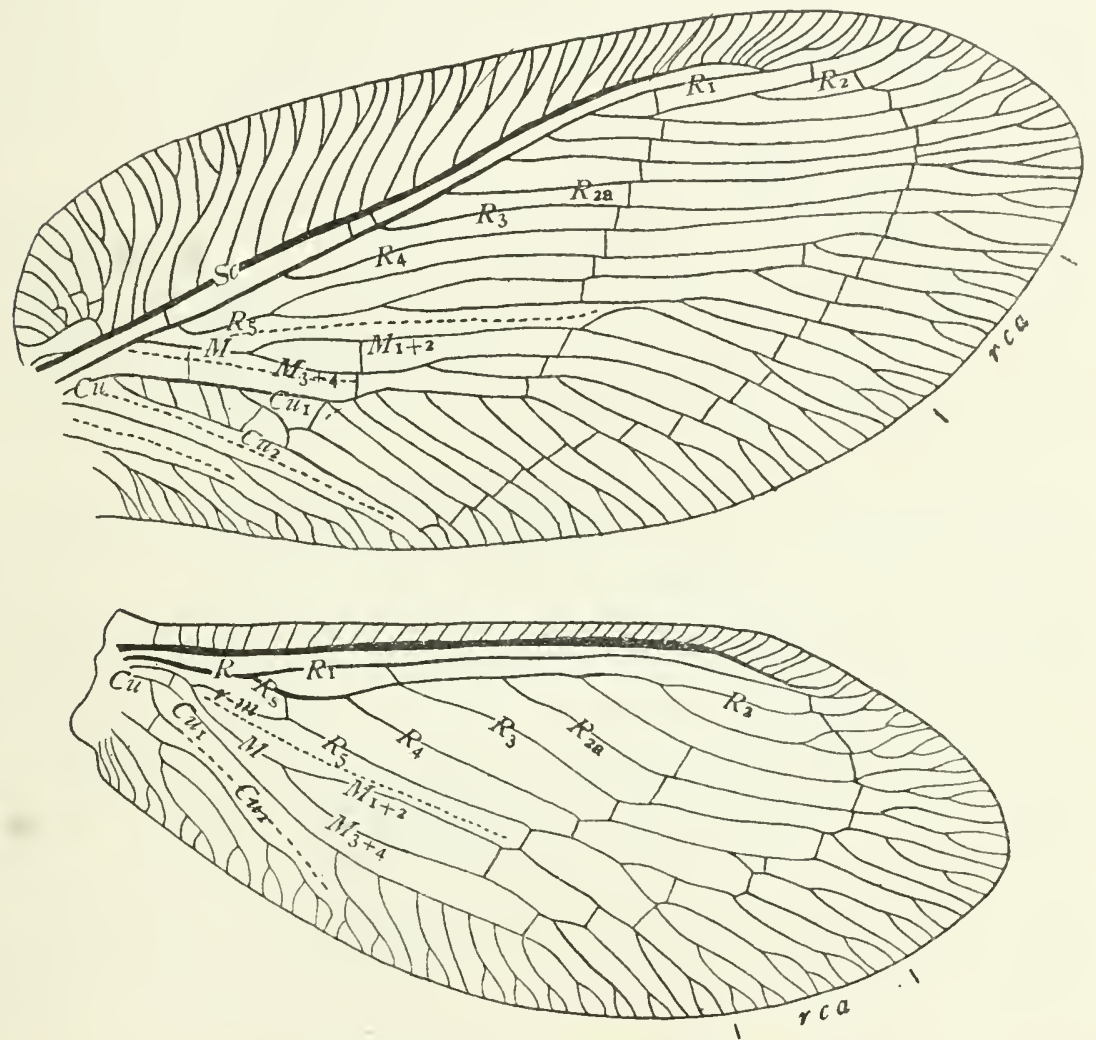

Fig. 178.-Wings of Megalomus mostus.

both veins $R_{5}$ and $R_{4}$ arise separately, is presented by a hemerobiid pupal wing figured by Comstock and Needham (Fig. I 7 7). Here only trachea $\mathrm{R}_{5}$ arises separately.

In the more specialized members of the Hemerobiida a large number of definitive accessory veins have been developed upon the radial sector or upon the coalesced veins $R_{1}$ and $R_{s}$; this development of accessory veins has progressed much farther in the fore wings than in the hind wings. The two pairs of wings differ also in the fact that in the hind wings the stem of the radial sector is not suppressed. 
The wings of Hemerobius hummli (Fig. 175 ) are very instructive in that they show the beginning of the specialization of the hemerobiid wings by the development of accessory veins. In the hind wing, the radial sector bears only the four primitive branches. In this enumeration the marginal accessory veins are not counted. In the fore wing, there is a single definitive accessory vein, vein $R_{2_{a}}$.

The wings of Megalomus mestus (Fig. I7 8 ) will serve as an example of the more specialized hemerobiid wings. In the hind wing, veins $R_{1}$ and $R_{s}$ do not coalesce. As the radial sector is seven-branched, it is evident that three accessory reins have been developed upon it. In the fore wing, there is a complete coalescence of vein $R_{1}$ and the stem of vein $R_{s}$, and a greater number of radial accessory veins have been developed.

The tips of all of the branches of radius are forked in both fore and hind wings. This forking is especially marked in the case of vein $R_{5}$, and has resulted in the formation of a radial cuneate area of considerable size (Fig. $\left.{ }_{17} 8, r c a\right)$. In the more generalized Hemerobius humuli, the tip of vein $\mathrm{R}_{5}$ is not markedly more forked than are the tips of other branches of the radial sector (Fig. 175).

Correlated with the prominent part played by the secondary cubital fork in the hemerobiid group of families, there is frequently a tendency for vein $\mathrm{Cu}_{2}$ to atrophy. In the hind wing of Megalomus mestus (Fig. I 78 ), the base of vein $\mathrm{Cu}_{2}$ is preserved, but the greater part of this vein is represented by a fold, indicated in the figure by a dotted line. In the hind wing of Sympherobius (Fig. 173), only the base of vein $\mathrm{Cu}_{2}$ is preserved, there is no vestige of the remaining portion. In this case the base of vein $\mathrm{Cu}_{2}$ is no longer curved, as is usually the case, but a part of it is aligned with a cubitoanal cross-vein. In the hind wing of Hemerobius humuli (Fig. I75) only that part of the base of vein $\mathrm{Cu}_{2}$ that is aligned with the cubito-anal crossvein is preserved, so that there appears to be only a cross-vein in this position. In Figure ${ }_{7} 76$ the two parts of this apparent cross-vein are lettered to indicate their homologies.

\section{(j) THE WINGS OF THE DILARIDE}

This is a small family and one that is not well represented in collections. There is only one species known from North America, and this is exceedingly rare. I have before me wings of two species from Japan and figures of two other species. The following statement is based on this limited amount of material.

Although the radius of the fore wings has from one to three sectors, the increase in the number of sectors appears to be due to a splitting back of one or two branches of vein $R_{s}$ rather than to a coalescence of reins $R_{1}$ and $R_{s}$, as is the case in the Hemerobiidæ. But as we do not know what was 
the primitive position of the radial fork in this family we can not be sure that this is the case.

In the Dilaridie the forking of the branches of the radial sector has progressed to a much greater extent than in the Hemerobiidæ.

These two features are well shown in Dilar nohirce (Fig. I79), from Yoshino, Japan, wings of which were kindly given to me by Mr. Waro Nakahara, the describer of the species.

A remarkable feature of the wings of Dilar nohire is the fact that the radius of the hind wings has two sectors. This is also the case in the wings

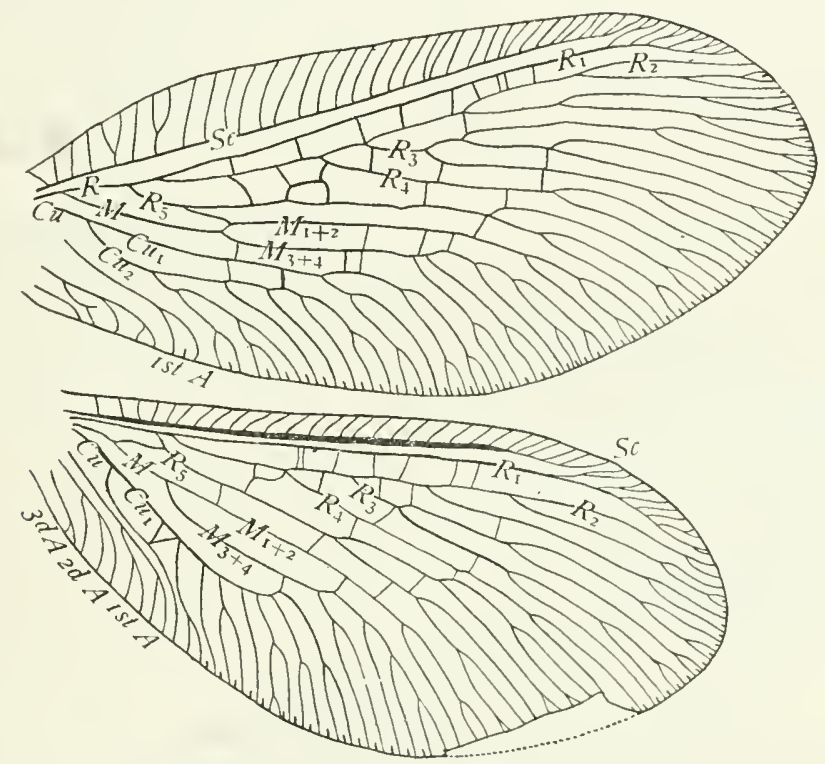

Fig. 179.-Wings of Dilar nohire.

of Rexavius japonicus. In none of the Hemerobiidæe is there more than one radial sector in the hind wings.

The following remarkable series of variations in the structure of the radial sector exists in the Dilaridæ.

In Dilar americanus, as described by McLachlan, there is a single fivebranched radial sector in both fore and hind wings.

In Dilar turcius, as figured by Handlirsch ('06), the radius of the fore wings bears two sectors, the second of which is five-branched. The radius of the hind wings bears a single five-branched sector.

In a species of Dilar figured by Brongniart ('93), the radius of the fore wings bears three sectors; the third sector is six-branched, making eight branches in all. The radius of the hind wings bears a single seven-branched sector. 
In Dilar nohire and in Rexavins japonicus the radius of both fore and hind wings bears two sectors.

In all of these species the branches of the radial sector are so deeply forked that it seems probable that accessory veins are being interpolated.

Marginal dashes are present.

\section{(k) THE WINGS OF THE BEROTHID}

The type species of the Berothidæ is Berotha insolita, the wings of which are figured here (Fig. I80). These wings present some striking features, most of which, however, are foreshadowed in various genera of the hemerobiid group of families. The wings of Berotha differ from those of the hemerobiids in that the first radio-medial cross-vein of the hind wings is transverse, not longitudinal and sigmoid, as it is in those families.

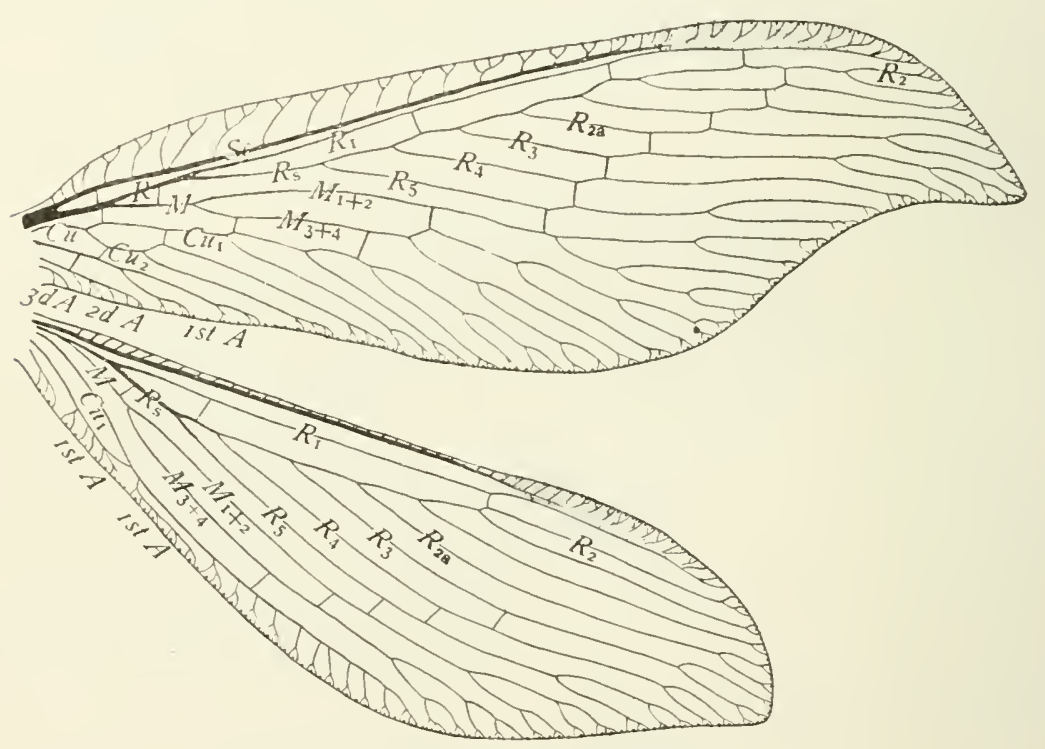

Fig. 180.-Wings of Berotha insolita.

The most striking features of the wings of Berotha are the following: the absence of a recurved costal vein; the atrophy of the terminal portion of the subcosta; the great reduction in the number of cross-veins, those of the radial area being reduced to a single series of gradate veins; the fanlike branching of the tips of veins; prominent marginal dots alternating with the twiglike branches of the veins; the loss of vein $\mathrm{Cu}_{2}$ of the hind wings; the anastomosis of the first anal vein and vein $\mathrm{Cu}_{1}$ in the hind wings; and, in the hind wings, the extending of vein $\mathrm{Cu}_{1}$ and the first anal vein quite closely parallel with the inner margin of the wing, leaving 
only a narrow area between these veins and the margin of the wing, which is largely occupied by the fanlike branched portion of the accessory veins.

In Berotha the subcosta enters the pterostigma and then atrophies; the tip of the preserved portion is distinct from vein $\mathrm{R}_{1}$; the accessory branches of the atrophied portion are preserved, but are free at the base. A short distance before the end of the preserved portion of the subcosta there is a cross-vein extending from the subcosta to vein $\mathrm{R}_{1}$. In some allied genera veins $S c$ and $R_{1}$ become united at this point so that they appear to coalesce.

The loss of vein $\mathrm{Cu}_{2}$ of the hind wings occurs also in the hemerobiids, where all stages of the atrophy of this vein are to be found.

There are several genera of Neuroptera that present the same type of wing-venation as that shown by the wings of Berotha, and which, for this reason I believe should be included in the family Berothida. These are the following: Lomamyia, Spemophorella, Trichoma, and Stenobiella.

The most available recognition characters of this family are presented by the hind wings, these are the following: the transverse course of the first radio-medial cross-vein; the absence of vein $\mathrm{Cu}_{2}$; the narrowness of the area of the wing between veins Ist $\mathrm{A}$ and $\mathrm{Cu}_{1}$ and the margin of the wing, this area being largely occupied by the fanlike tips of the accessory veins; and $a$ bend in the outer part of the first anal rein which results either in an anastomosis of this vein with vein $\mathrm{Cu}_{1}$ or in these two veins being closely approximate where they are joined by a cross-vein.

The shape of the wings varies greatly in this family; in Berotha, Lomamyia, and Trichoma the wings are falcate; in Spermophorella they are oblong, with the terminal portion rounded; and in Stenobiella, they are very long and narrow.

In Berotha the terminal portion of the subcosta is atrophied and the tip of the preserved portion is free; in Lomamyia and Spermophorella, the tip of the subcosta joins vein $\mathrm{R}_{1}$; and in Trichoma and Stenobiella the subcosta ends in the margin of the wing.

The representatives of this family are widely distributed. Berotha is found in India, Lomamyia is represented by two speeies in the United States, and the other three genera are Australian.

\section{(l) The Wings of the polystechotide}

The wings of our common Polystochotes punctatus (Fig. I $8 \mathrm{I}$ ) represent the type of wing-venation characteristic of the family Polystoechotidæ. In these wings the humeral cross-vein is recurved and branched; veins Sc and $R_{1}$ coalesce at the tip; the radial sector is pectinately branched; the number of cross-veins is greatly reduced; but there is in both fore and hind wings a very perfect series of gradate veins; and marginal dots are present, these are not represented in the figure. 
In these wings the development of definitive accessory veins on the radial sector and the regularity of the border of marginal accessory veins have reached a very high degree of perfection.
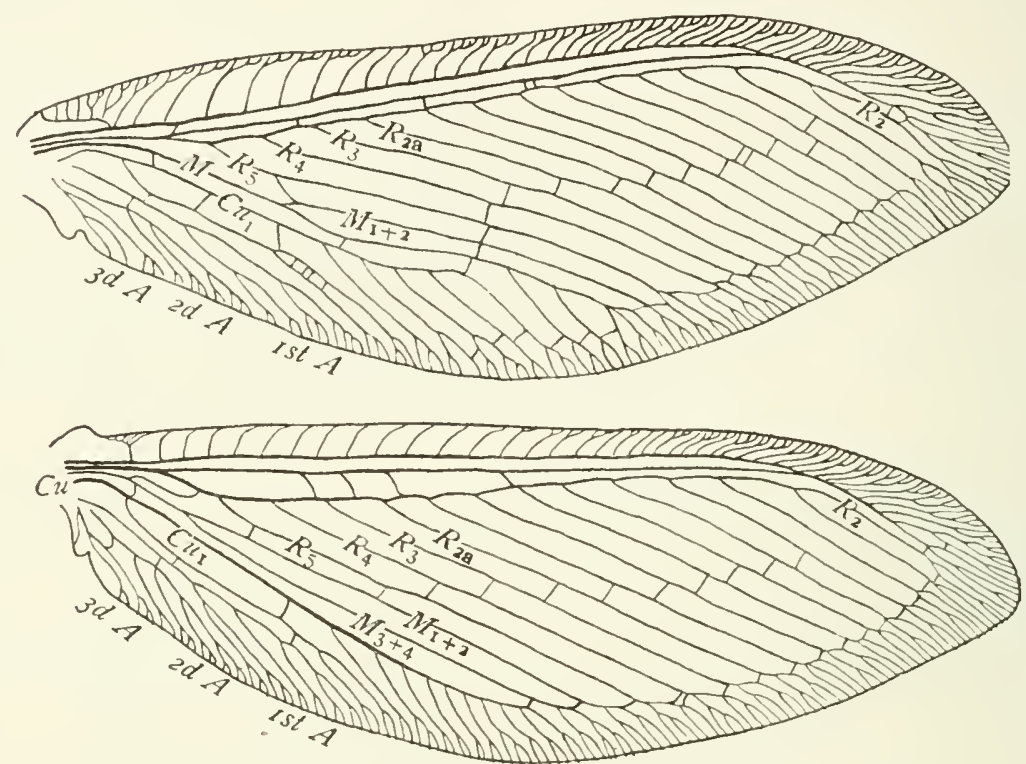

Fig. I 8 I.-Wings of Polystcechotes punctatus.

\section{(m) THE WINGS OF THE PSYCHOPSIDA}

Among the remarkable types of wings that have been developed in the Neuroptera that of the Psychopsidæ is one of the most striking. I have selected as an illustration of this type the wings of an undetermined psychopsid from West China (Fig. I 82 ), as in this species the venation of the wings is not obsctred by blotches of color as it is in the only species of Psychopsis in our collection.

The more striking features of these wings are their rounded form; the unusual width of the costal area throughout its length; a peculiar nexus of the tips of veins $\mathrm{Sc}, \mathrm{R}_{\mathrm{I}}$, and $\mathrm{R}_{\mathrm{s}}$; the presence of two series of gradate veins; the irregular distribution of the radial cross-veins in both wings and of the cross-reins in the subcostal area of the fore wings; and the unusual length of the stalk of media, especially in the hind wings.

The branches of the radial sector are very regular except that one in the fore wing, the sixth, is split nearly to its base, indicating that an accessory vein is being interpolated.

Nearly all of the veins are forked at the tip; and marginal dots are present. 


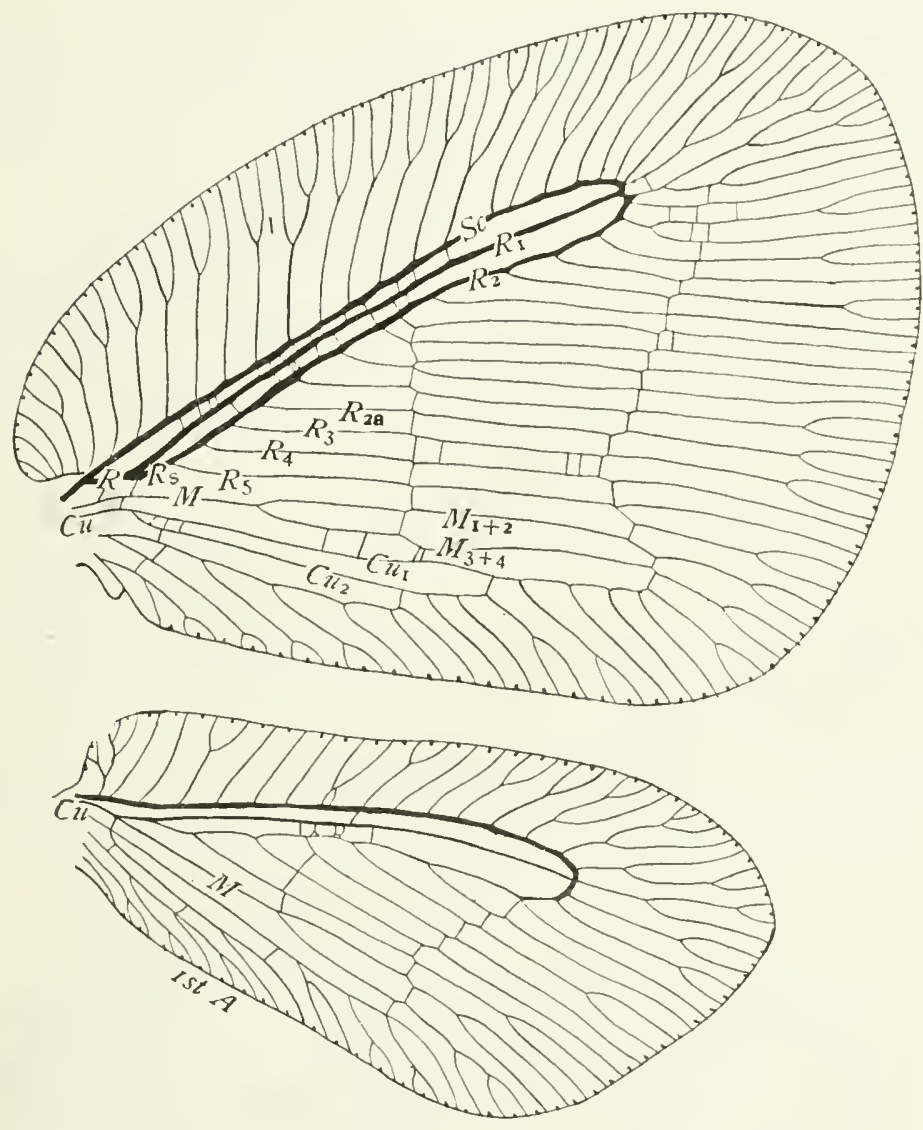

Fig. 182.-Wings of a psychopsid.

\section{(n) THE Wings of THE CHRYSOPIDAE}

The wings of the Chrysopidæ are characterized by a very remarkable and distinctive type of specialization, the details of which can be understood only by a study of the tracheation of the wings.

A brief account of the wings of Chrysopa plorabunda showing the essential features of this type of specialization was published by McClendon ('o6); and, quite recently, a much more extended one, based on an Australian species, Chry'sopa signata, has been published by Tillyard ('r6). So that now the structure of these wings is well understood.

In the preparation of the present account I have made use of the papers just cited, and I have been materially aided also by Mr. R. C. Smith, who during the year previous to the appearance of Tillyard's paper devoted himself to the study of this problem. Mr. Smith has bred many individuals 
of several species of Chrysopa, and has kindly furnished me with the material upon which the accompanying figures were based.

A superficial examination of a wing of an adult Chrysopa (Fig. I83) reveals the presence of two longitudinal veins between the radial sector and

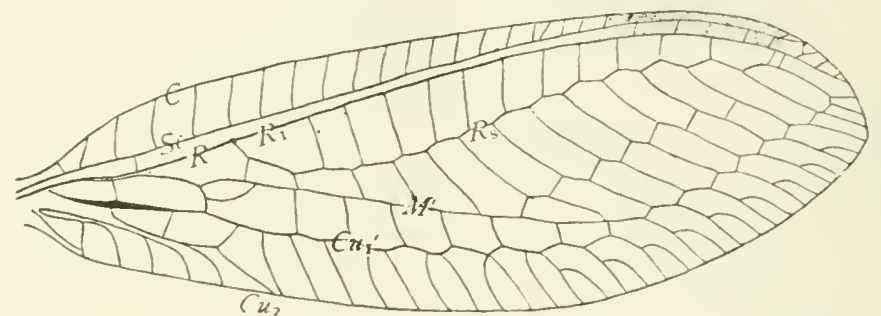

Fig. I 83.-Fore wing of Chrysopa nigricornis; $\mathrm{MI}^{\prime}$, pseudo-media; $\mathrm{Cu}^{\prime}$, pseudo-cubitus.

the inner margin of the ming, one of which appears to be the media and the other vein $\mathrm{Cu}_{1}$; but each of these, as is shown later, is a serial vein composed of sections of several veins.

As it would be impracticable to apply to these veins names indicating their composition they have been designated by Tillyard ('i6) as the psendo-media and the pseudo-cubitus respectively; and he makes use of the notation $\mathrm{MI}^{\prime}$ for the pseudo-media, and $\mathrm{Cu}^{\prime}$ for the pseudo-cubitus. This

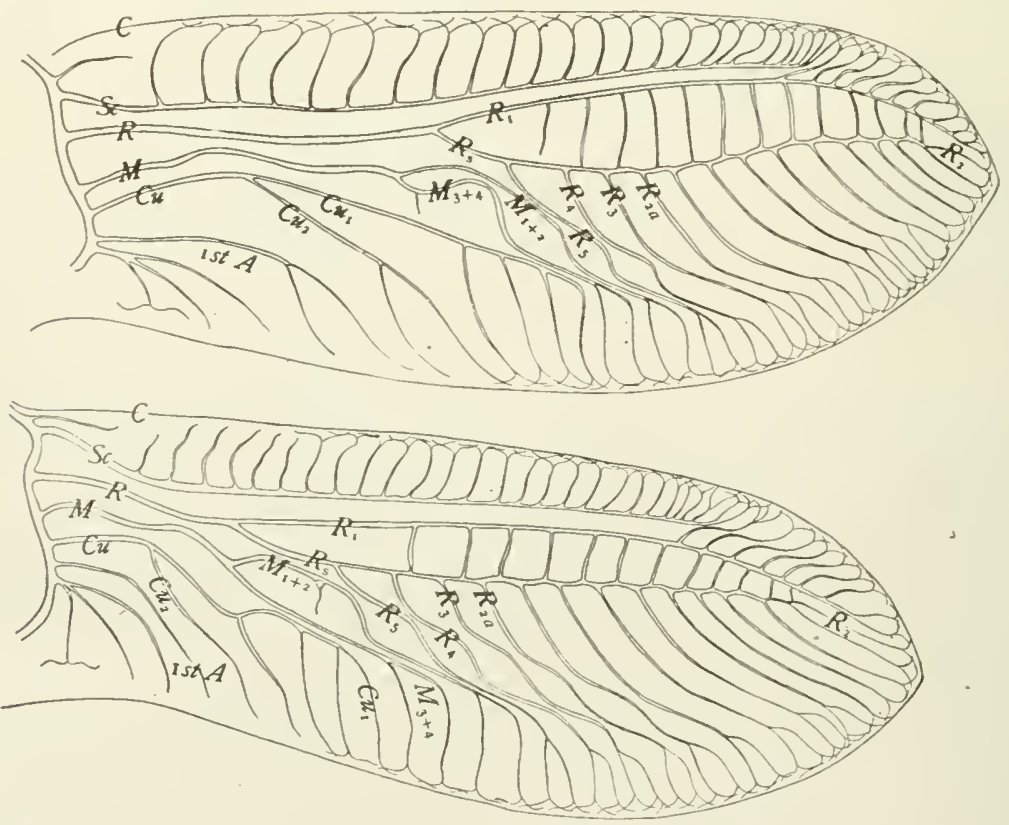

Fig. 184.- Tracheation of the wings of a pupa of Chrysopa nigricornis. 
designation of these two reins is a happy one and I gladly adopt it with one slight change. As the pseudo-cubitus really appears to be vein $\mathrm{Cu}_{1}$, I make use of the notation $\mathrm{Cu}_{1}{ }^{\prime}$ instead of $\mathrm{Cu}^{\prime}$.
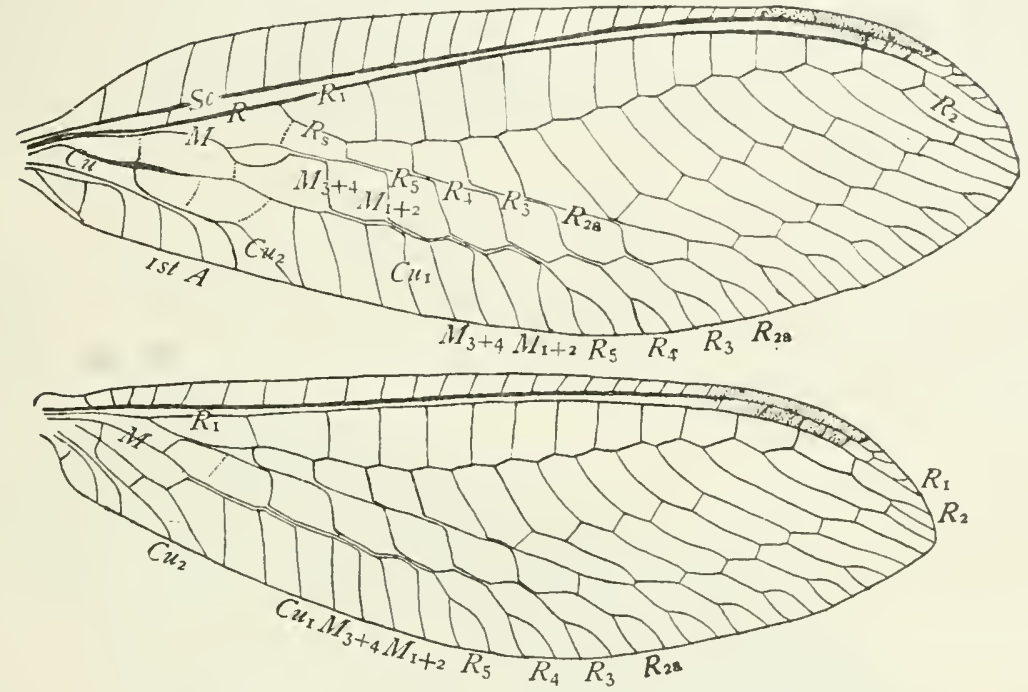
Fig. I 85.-Diagram of the wings of Chrysopa nigricornis showing
coalesced veins slightly separated.
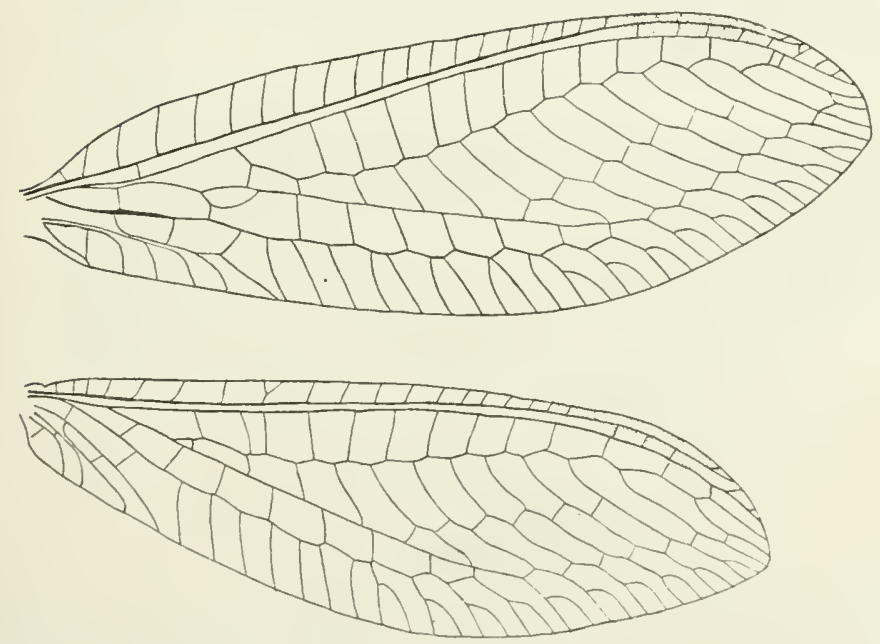

Fig. 186.-Wings of Chrysopa nigricornis.

An examination of the tracheation of the wings of a pupa of Chrysopa reveals the nature of the two serial veins pseudo-media and pseudo-cubitus. 
Figure ${ }_{1} 8_{4}$ is a reproduction of camera lucida draivings of the pupal wings of Chrysopa nigricornis made by Mr. R. C. Smith.

In order to show more definitely the composition of the two serial veins a diagram of an adult wing is given (Fig. 185 ) in which the elements of the coalesced veins are represented slightly separated, and the cross-veins connecting the coalesced veins are represented by dotted lines. By comparing this diagram with Figure I 86 the homologies of the different veins can be recognized.

\section{(o) THE WINGS OF THE OSAYlide}

The Osmylidæ is a moderately large family and is composed of very beautiful insects. The wings of Osmylus hyalinatus (Fig. I87) can be taken as an illustration of the type of wings characteristic of this family. There
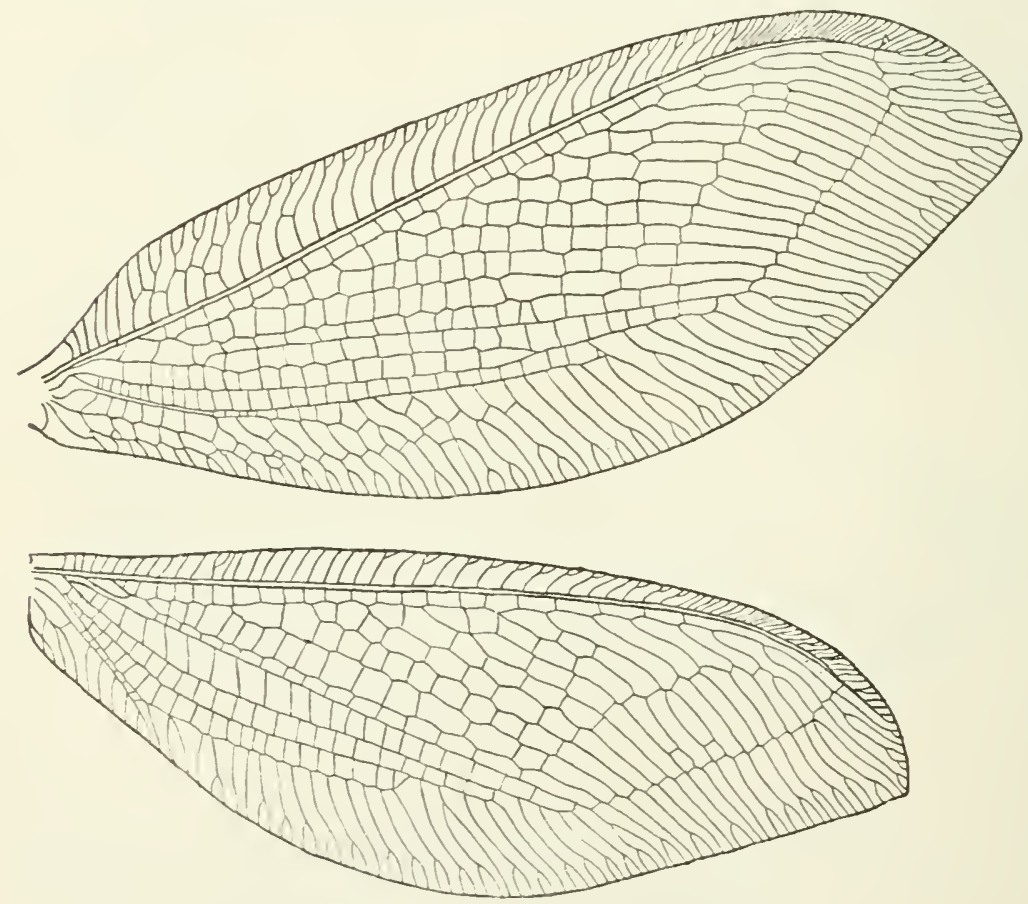

Fig. I 87.-Wings of Osmylus hyalinatus.

is no difficulty in recognizing the identity of the veins in these wings; but the more important ones are lettered in Figure i88.

The subcosta and vein $R_{1}$ are closely parallel and are somewhat stouter than the other veins; they constitute the supporting axis of the wing. These two veins coalesce at the tip. The humeral vein is not markedly recurved and is not branched. The costal area is broad and the accessory 
veins of the subcosta are forked, and sometimes they are connected by cross-veins. Many cross-veins are present in the other parts of the wing, excepting the subcostal area in which they are lacking. In the outer third of the wing the cross-veins are reduced in number, consisting chiefly of a series of gradate veins. Many definitive accessory veins have been developed upon the radius and upon the veins back of this vein; the tips of most of these are forked. The marginal accessory veins form a quite regular border.

The media is two-branched in both wings. In the fore wing the medial fork is a little beyond the first fork of the radial sector in the specimen figured, but it varies slightly in different individuals. In the hind wing the medial fork is quite near the base of the wing; it is not, however, quite so near the base of the wing as it appears to be in this figure; for, owing to a fold in the wing, the base of media is concealed by the base of radius, which overlaps it. A result of this overlapping of the base of media by the base of radius is that the first radio-medial cross-vein appears to join the radius instead of joining media, as it really does.

The cubital fork is near the base of the wing in both fore and hind wings; and the anal veins are much branched.

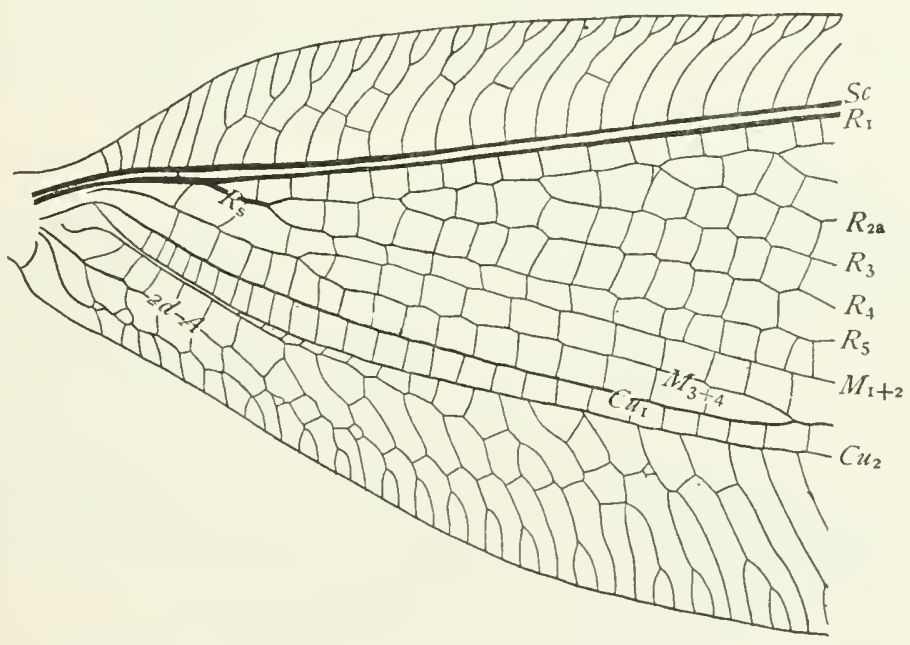

Fig. I 88.-Base of fore wing shown in Figure 187 enlarged.

\section{(p) The Wings OF THE MYIODACTylide}

The type of this family is Myiodactylus osmyloides, an Australian species described by Fr. Brauer in I 866 . This species I have not seen; but through the kindness of Mr. Nathan Banks I have been able to study a closely allied species, Myiodactylus pubescens, the wings of which I figure here (Fig. 189). This species is from Port Darwin, Australia. 
The wings of Myiodactylus resemble those of Osmylus (Fig. I87) in their general appearance and in most of their structural details. The most important differences are that in Myiodactylus there are many cross-veins in
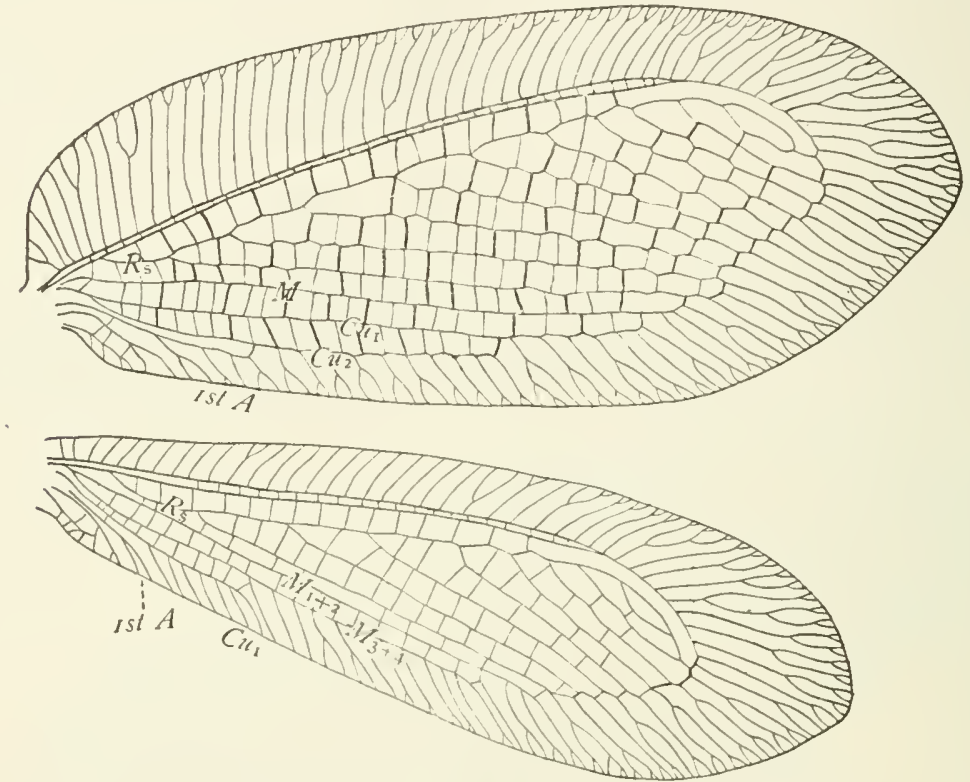

Fig. 189.-Wings of Myiodactylus pubescens.

the subcostal area, the media of the fore wings is not forked, and vein $\mathrm{Cu}_{2}$ of the hind wings is lost.

The most striking features of the wings of Myiodactylus are a broad border of accessory veins that extends completely about the wing and which is free from cross-veins and a discal area which is abundantly supplied with cross-veins. In this respect the wings resemble those of Osmylus (Fig. I 87); but the border is more complete than in Osmylus, due to the fact that vein $\mathrm{Sc}+\mathrm{R}_{1}$ is curved back so that it does not interrupt the border, being continued to the margin of the wing only by accessory veins.

The humeral vein of the fore wing is forked but it is not of the recurved type. A series of gradate veins extends from the tip of vein $\mathrm{Sc}+\mathrm{R}_{1}$ to the tip of media; this is quite similar to the condition in Osmylus, except that in Osmylus vein $\mathrm{Sc}+\mathrm{R}_{1}$ extends beyond the end of the series of gradate veins.

In the fore wings, media extends free from radius to the base of the wing; it is not forked, and there is no oblique vein representing vein $\mathrm{M}_{3}+4$. The cubital fork is near the base of the wing, and there are three separate anal veins. 
The hind wings differ from the fore wings in that media is distinctly two-branched, and it appears to arise from radius, at least the two are so closely oppressed that I can see no space between them; the cubitus is greatly reduced in length and is not forked, probably vein $\mathrm{Cu}_{2}$ has atrophied; and the base of the first anal vein is vestigial. It is quite possible that the forked vein lettered ist $\mathrm{A}$ in the figure is vein $\mathrm{Cu}_{2}+$ Ist $\mathrm{A}$. With only a single specimen before me I am unable to decide this point.

In the fore wing some of the cross-veins are much more prominent than the others; this is largely due to their being colored brown, but they are also slightly stouter.

\section{(q) THE WINGS OF THE NYMPHID}

The Nymphidæ is a small family of insects that is restricted to Australia. I have been able to study only a single representative of it; this is Nymphes myrmeleonides. The wings of this species are represented in the accompanying figure (Fig. I90).

These wings are long and narrow and are furnished with many crossveins; they possess also many definitive accessory veins and many marginal accessory veins; the latter are very numerous and regular in the apical portion of the wings and add greatly to their beauty.

In general form and appearance the wings of Nymphes resemble those of the Myrmeleonidæ; but they are sharply distinguished from myrmeleonid
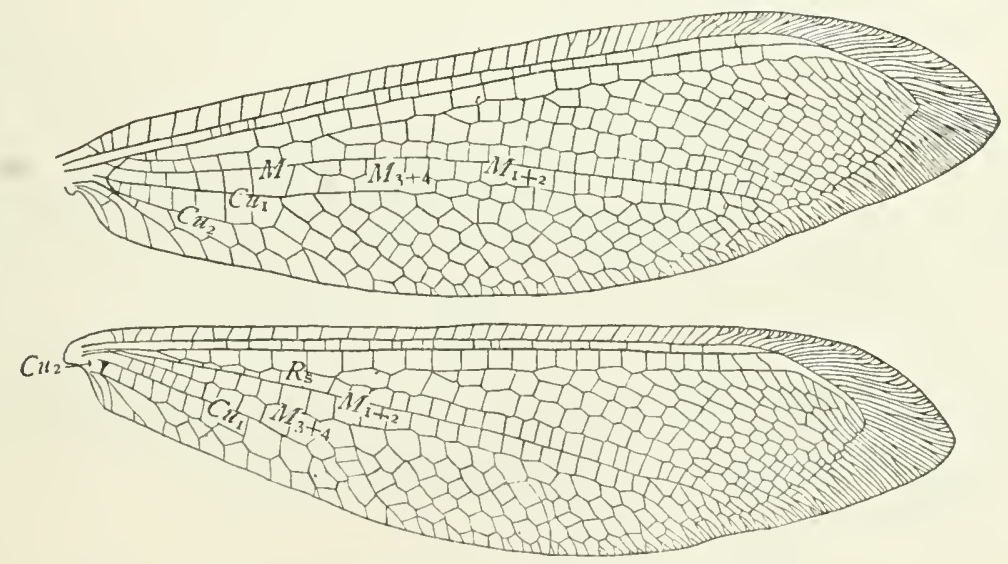

Fig. 190.-Wings of Nymphes myrmeleonides. See Figure I9I for the labeling of the veins of the fore wing.

wings by the following characteristics: first, the subcostal area is traversed by many cross-veins, while this area is free from cross-veins in the Myrmeleonidæ; second, the media of the fore wings is obviously two-branched in Nymphes; in the Myrmeleonidæ it is apparently, though not actually, unbranched. 
In the fore wings of Nymphes (Fig. I9I), the radial fork is quite near the base of the wing; there is a fairly well developed secondary cubital fork; and the primary cubital fork is near the base of the wing; vein $\mathrm{Cu}_{2}$ is easily recognized; it branches off from vein $\mathrm{Cu}$ nearly opposite the first medio-

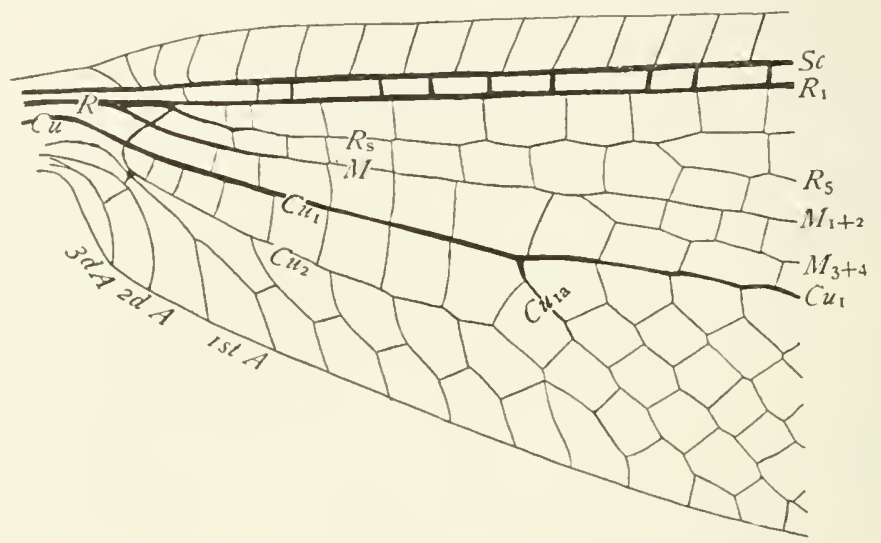

Fig. 191.-Base of fore wing of Nymphes myrmeleonides.

cubital cross-vein, and the basal part makes a sweeping curve; it touches the first anal vein at the end of this curved portion, and then extends free from it. There are three anal veins; vein ist $A$ is forked.

In the hind wings (Fig. rgo), media is two-branched, a fact that has not been understood, vein $\mathrm{M}_{3+4}$ having been mistaken for vein $\mathrm{Cu}$. This mistake was due to two facts: first, the medial fork is very near the base of the wing and has been overlooked; second, vein $\mathrm{M}_{3+4}$ bears prominent accessory veins which cause it to closely resemble vein $\mathrm{Cu}_{\mathrm{l}}$ of the fore wing.

The cubital fork, as in the fore wing, is very near the base of the wing; and the basal part of rein $\mathrm{Cu}_{2}$ is transverse, appearing like a cross-vein except that it is much stouter ; it resembles in this respect this vein in many of the Myrmeleonidæ. The anal veins are similar to those of the fore wing.

Marginal dots are present in the wings of Nymphes; this seems remarkable as they are absent in the other families of the myrmeleonid group; the marginal dots are not represented in the figures given here.

\section{(r) THE WINGS OF THE MYRMELEONIDE}

In the Myrmeleonidæ the wings are long and narrow and delicate in structure; they are furnished with many accessory veins, both definitive and marginal, and with very many cross-veins (Fig. 192); the radial sector is pectinately branched.

Although the wings of myrmeleonids have been much studied no one has published as yet a correct and complete determination of the homologies 
of the principal wing-veins of these insects; but I am convinced that at last this problem is solved; and now that it is solved, it seems a comparatively simple one, so simple that there can be no doubt as to the correctness of the conclusions. The causes of the earlier and incorrect conclusions are indicated in the following discussion.

The determination of the identity of the costa, subcosta, radius, and the radial sector presents no difficulties, and no change in the commonly accepted view regarding these veins is necessary. This is true of these veins in both the fore and hind wings. With regard to the other principal veins it is necessary to discuss the fore and hind wings separately

Media of the fore wings. - In the fore wings media appears to be a single unbranched vein; but it has been demonstrated, by a study of the tracheation of the wings of pupæ, that what appears to be an oblique cross-vein and which is lettered $o$ in the figures, is a branch of media, and consequently that media of the fore wings of ant-lions is two-branched, as it is in most other Neuroptera.

The significance of the oblique vein in the fore wings of myrmeleonids was first discovered, twenty years ago, by Dr. Needham and myself, by a study of pupal wings, when we were collecting material for our series of articles on the wings of insects. We did not include our myrmeleonid material in that series of articles, as it was not needed to illustrate the fundamental principles that we were discussing; but I made use of it a little later in a laboratory manual;* and Figure 194 is based on a photomicrograph that we made at that time. Recently Tillyard has studied the
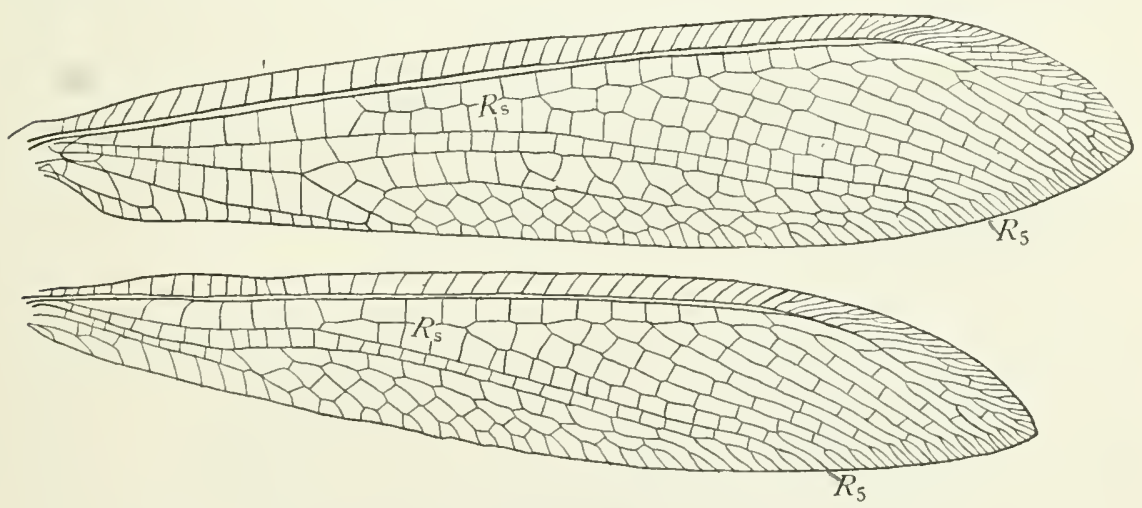

Fig. 192.-Wings of Myrmeleon, sp. From Katihar, British India.

tracheation of the wings of myrmeleonids and discovered independently that the media of the fore wings is two-branched (Tillyard I9I6, p. 739).

*The Elements of Insect Anatomy by John Henry Comstock and Vernon L. Kellogg, Third Edition I9OI. On page II6 of this work I indicated the significance of this blique vein. 
During the past year Dr. Needham and I have reviewed our study of the wings of myrmeleonid pupæ by the examination of fresh material and Figure 193 is based on one of our recent photomicrographs.

In no pupal myrmeleonid wing examined by us, and we have examined many, were we able to detect the costal trachea. The subcostal and radial tracheæ were prominent in all, so too were the accessory tracheæ of the subcosta. In some of the forming cross-veins there were distinct tracher but in most cases the trachex in the cross-veins were so indistinct that we are not warranted in representing them in the figure.

Returning to a study of the medial trachea, it can be seen by an examination of Figure 193 that this trachea is two-branched; that trachea $\mathrm{M}_{1+2}$ is a direct continuation of the main stem of this trachea and that trachea $\mathrm{M}_{3+4}$ first traverses the oblique vein and then after making a sharp bend extends lengthwise the wing in line with the basal part of trachea $\mathrm{Cu}_{1}$. From this it can be seen that the vein which in the adult wing appears to

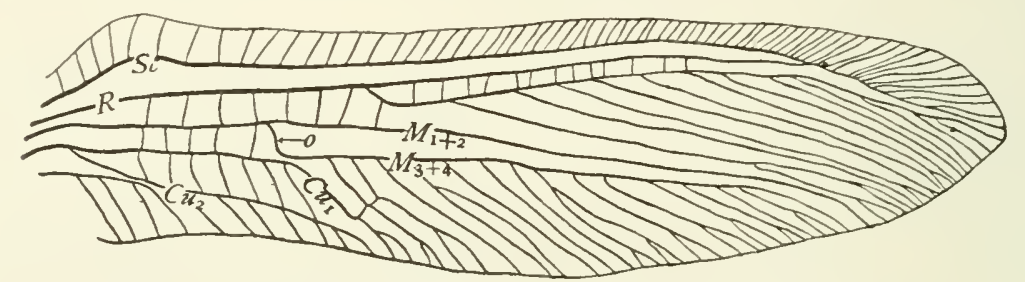

Fig. 193.-Tracheation of a fore wing of a pupa of a myrmeleonid.

be vein $\mathrm{Cu}_{1}$ is really a serial vein consisting in part of vein $\mathrm{Cu}_{1}$ and in part of vein $\mathrm{M}_{3}+_{4}$; to this serial vein Tillyard has applied the designation cubitomedian and makes use of the notation $\mathrm{Cu}_{1}+\mathrm{M}_{2}$. I see no objection to the application of the term cubitomedian to this vein; but as the notation $\mathrm{Cu}_{1}+\mathrm{M}_{2}$ indicates an ordinary coalescence of veins side by side and not the formation of a serial vein, I regard the notation $\mathrm{Cu}_{1} \& \mathrm{M}_{3}+_{4}$ as more appropriate.

It will be noted that Tillyard designates the branch of media that unites with vein $\mathrm{Cu}_{1}$ in this case as $\mathrm{M}_{2}$. This is an unfortunate failure to apply the uniform terminology; and there are several other authors who are guilty of the same error in similar cases. The two branches of media formed by the first forking of this vein are veins $\mathrm{M}_{1+2}$ and $\mathrm{M}_{3}+_{4}$; it is obvious that these branches are homologous with those thus designated when media preserves its typical four-branched form. If one designates the two branches of media as veins $\mathrm{M}_{1}$ and $\mathrm{M}_{2}$ the question what has become of veins $M_{3}$ and $M_{4}$ is suggested.

In the wing represented by Figure 193 the tracheæ $\mathrm{M}_{3}+_{4}$ and $\mathrm{Cu}_{1}$ were distinct although they came very near together at the end of the oblique vein and the veins formed about them anastomose at this point. In the 
wing represented by Figure 194 a somewhat different condition exists; in this wing trachea $\mathrm{Cu}_{1}$ and $\mathrm{M}_{3}+{ }_{4}$ extend closely parallel in the same vein

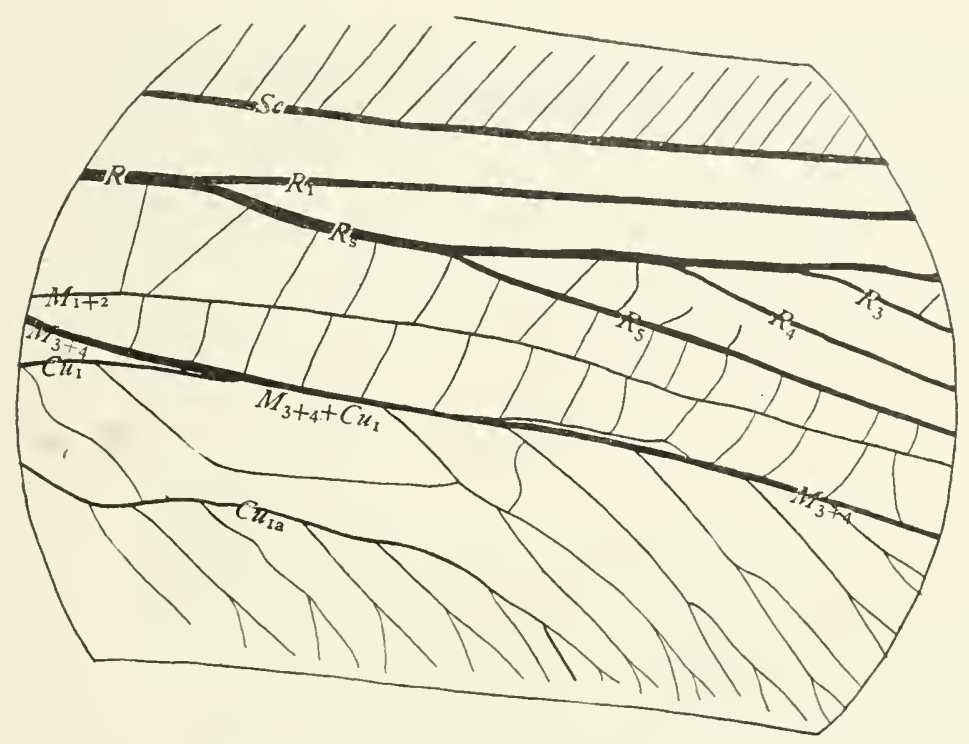

Fig. 194.-Detail of a pupal wing of a myrmeleonid showing union of tracheæ $\mathrm{M}_{3}+4$ and $\mathrm{Cu}_{1}$.

cavity. In this case the serial vein consists of three differing sections; the basal part of this vein extending from the cubital fork to the point where it

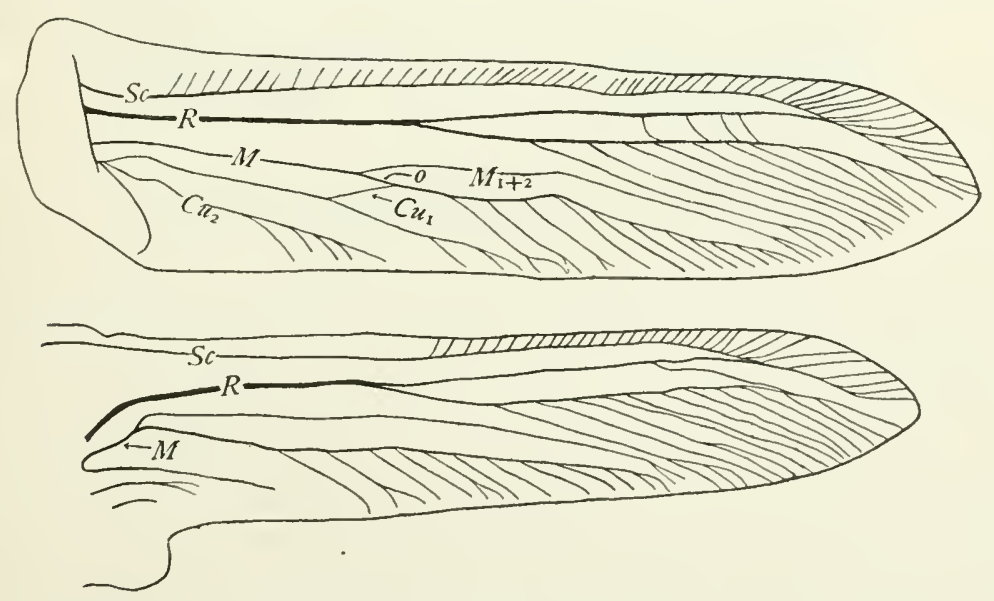

Fig. 195. - Tracheation of the wings of a pupa of a myrmeleonid.

is joined by the oblique vein is simply vein $\mathrm{Cu}_{1}$; then follows a section in which this vein is compound, consisting of veins $\mathrm{Cu}_{1}$ and $\mathrm{M}_{3}+_{4}$ united; 
and finally, there is a section consisting simply of vein $\mathrm{M}_{3}{ }_{4}$. Figure 195 represents in the fore wing a condition similar to that shown in Figure 194.

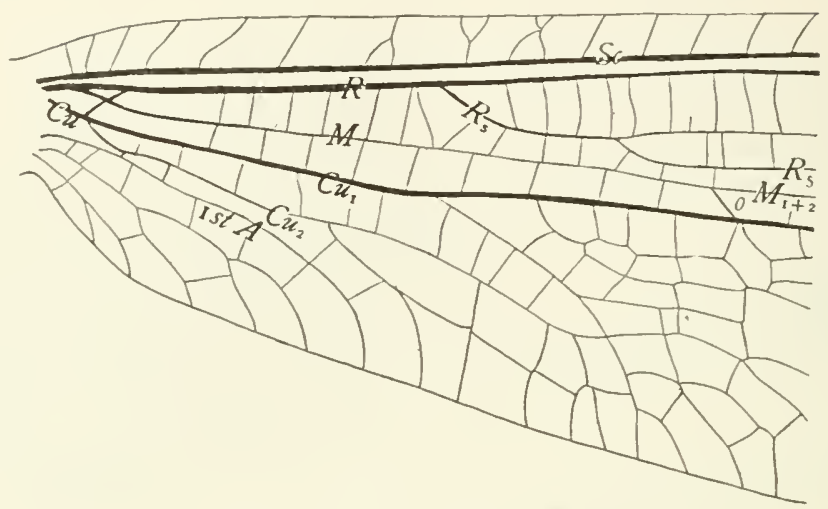

Fig. I96.-Base of a fore wing of Tomatares clavicornis.

In the wings represented by Figure 195 the tracheation of the anal area was obscured in both wings.

Cubitus of the fore wings. - In all of the myrmeleonids that I have studied the cubital fork is very near the base of the wing and in many of them vein $\mathrm{Cu}_{2}$ is greatly reduced. In the wing represented by Figure I93, trachea $\mathrm{Cu}_{2}$ is quite prominent and extends nearly one-third of the length

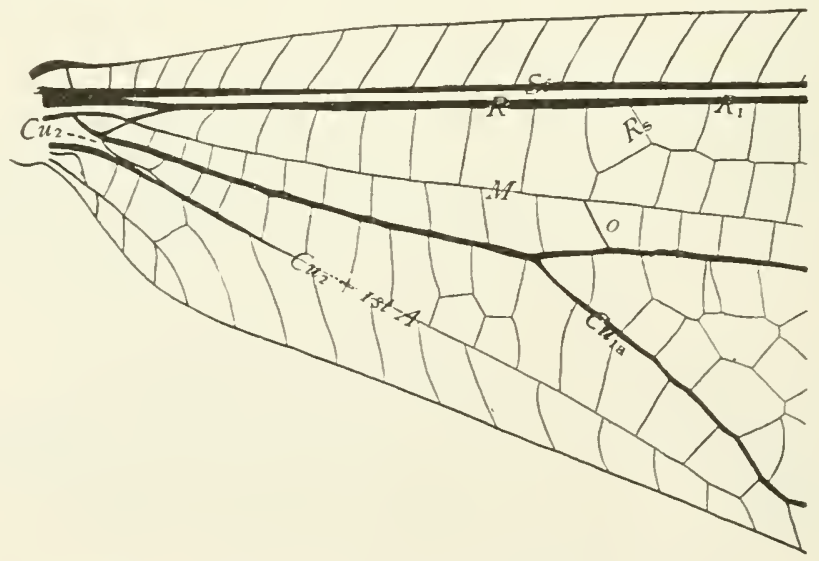

Fig. 197.-Base of a fore wing of Balaga micans.

of the wing. I reared several pupæ of this kind from larvæ obtained at Gulfport, Florida; but I do not know the adult of this species. The following series of figures will serve to illustrate different stages in the reduction of vein $\mathrm{Cu}_{2}$. 
In the fore wing of Tomatares clavicornis (Fig. ${ }_{196}$ ), vein $\mathrm{Cu}_{2}$ is still a well-developed vein and is free from the first anal vein, except that the two are connected by cross-veins.

In the fore wing of Balaga micans (Fig. 197), vein $\mathrm{Cu}_{2}$ is reduced to a vestige, which extends closely parallel with the first anal vein for a short distance and then the two coalesce.

In the fore wing of Brachyncmurus longipalpus (Fig. 198), only the transverse basal part of vein $\mathrm{Cu}_{2}$ is distinct from the first anal vein; but this transverse part is still curved.

The almost complete coalescence of vein $\mathrm{Cu}_{2}$ with the first anal vein in the greater number of the Myrmeleonidx, as in Brachynemurus, is doubt-

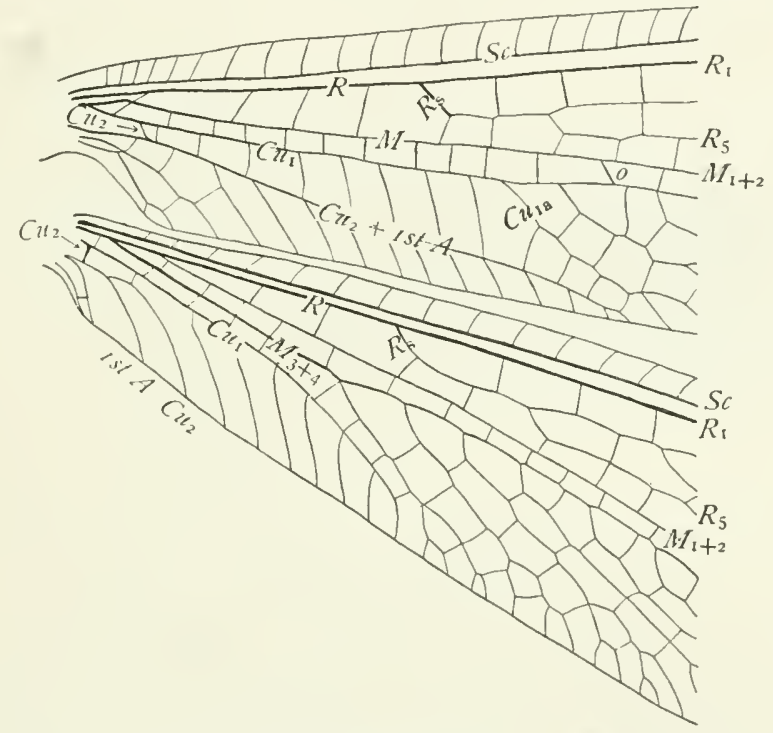

Fig. 198.-Base of the wings of Brachynemurus longipalpus.

less the reason that this vein has been overlooked by writers on this family. There is also another fact that has led to the overlooking of vein $\mathrm{Cu}_{2}$; in most of the Myrmeleonidæ vein $\mathrm{Cu}_{1}$ of the fore wings bears a prominent accessory vein, vein $\mathrm{Cu}_{1 \mathrm{a}}$ (Fig. I97), which has been mistaken for vein $\mathrm{Cu}_{2}$. Let us now pass to an examination of the hind wings.

Media of the hind wings.- Up to the present time the belief that media of the hind wings of myrmeleonids is reduced to an unbranched condition has been undisputed; and an explanation of the way in which this condition has come about has been eagerly sought; hundreds of myrmeleonid wings have been examined in the hope of finding an oblique vein in the hind wing like that of the fore wing, but without success; and an examination of pupal wings secmed to throw no light on the subject. This was the 
state of our knowledge of the subject at a time when this volume was about to be sent to the printer, when I made a reexamination of a series of myrmeleonid wings which revealed the explanation of the problem. This explanation is as astonishing as it was unexpected.

Media of the hind wings in these insects is two-branched and there is no anastomosis of vein $\mathrm{M}_{3}+_{4}$ with cubitus as there is in the fore wing. The medial fork is very near to the base of the wing; and what has been believed to be the cubitus is vein $\mathrm{M}_{3}+_{4}$. I had observed the medial fork but had regarded it as the result of the coalescence of veins $\mathrm{M}$ and $\mathrm{Cu}$; and had explained in the same way the forking of the medial trachea which I had observed in the hind wings of pupx (Fig. 195).

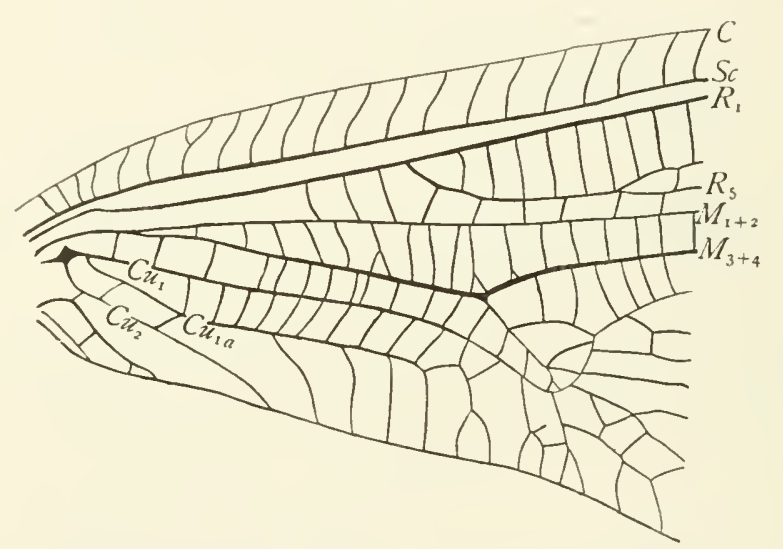

Fig. 199.-Hind wing of Symmathetes contrarins.

In wings mounted for study, as they are commonly mounted, the radial fork is concealed in many cases by an overlapping of it by the radius, due to a fold in the wing; but with a little care it can be easily seen. In the hind wing of Brachynemurus represented by Figure igs the medial fork is overlapped by the radius; the figure is a reproduction of a photograph and it represents the veins as they appear when seen from above. Figure I99 represents the base of a hind wing of Symmathetes contrarius; in this wing the forked condition of the media is obvious.

Cubitus of the hind wings.-A study of the cubitus of the hind wings confirms the conclusion regarding media given above, as in certain forms one finds a typical cubitus which is distinct from the vein that has been believed to be the cubitus and which is really vein $\mathrm{M}_{3+4}$.

In the hind wings of most myrmeleonids, as in the fore wings, vein $\mathrm{Cu}_{2}$ is greatly reduced, but a series illustrating different degrees of this reduction can be easily found. 
In the hind wing of Symmathetes contrarius (Fig. I99), vein $\mathrm{Cu}_{2}$ is wellpreserved, being about one-half as long as vein $\mathrm{Cu}_{1}$. There is also in this wing a prominent vein $\mathrm{C}_{1_{\mathrm{a}}}$.

In the hind wing of Brachynemurus longipalpus (Fig. I98), veins $\mathrm{Cu}_{2}$ and Ist $\mathrm{A}$ anastomose and the basal part of vein $\mathrm{Cu}_{2}$ appear like an unusually stout cross-vein.

In concluding this discussion of the veins $\mathrm{M}$ and $\mathrm{Cu}$ of the myrmeleonids, I wish to call attention to a very interesting feature of the wings of these insects, which has doubtless been an important factor in delaying the determination of the homologies of the wing-veins.

Examine the figure of the wings of Brachynemurus longipalpus (Fig. I98) and note the similarity in structure of the fore and hind wings. If we omit in each case a study of the base of the wing, the venation of the two wings appear to be almost identical except that in the fore wing there is an oblique vein. Behind the radius and the radial sector there is in each case an apparently unbranched vein, formerly regarded as an unbranched media; behind this simple vein there is a forked vein, formerly regarded in each case as the cubitus. It is not strange that the similarity in form of these two veins should have led to the belief that they are homologous. But it has been shown above that the forked vein in the fore wing is vein $\mathrm{Cu}_{1}$ and the forked vein in the hind wing is vein $\mathrm{M}_{3}+_{4}$. There has been developed in these two wings a similar bracing of each by the use of very different material in the two wings.

Generalizations and definitions of special terms.-In the descriptions of wings in which peculiar methods of specialization have arisen, it becomes necessary to make use of special terms in referring to the resulting structures. Several such terms have been proposed by Dr. Needham, who has prepared an extensive monograph on the wing-venation of the Myrmeleonidx. As the publication of this monograph has been delayed it seems desirable to introduce these terms here, so that they may become available. I also include some generalizations kindly handed to me by Dr. Needham.

\section{Myrmeleonid Venation}

"The more striking characters of the venation of the Myrmeleonidæ are:

"I. The apical fusion of veins $\mathrm{Sc}$ and $\mathrm{R}_{1}$ and the clearing out of all cross-veins from the inclosed space.

"2. The development behind the point of fusion of an elongate truss cell of variable form but constant position.

"3. The extensive development of branches upon the radial sector, pectinately arranged, and diminishing in length from the base outward. The basal branch is much more extensively forked and more deeply forked at its tip than are any of the others. In the subfamily Palparinæ and in a few scattering genera (Myrmecalurus, etc.) that portion of the radial sector distal to the base of the truss cell, becomes switched upon a cross-vein, and attached to Vein $R_{1}$, so as to stimulate a second sector [see Figure 200]. 
"4. The reduction of media in the fore wing to an apparently simple vein, the base of $\mathrm{MI}_{3}+4$, appearing as an oblique cross-vein joining $\mathrm{Cu}_{1}$. When this ceases to be oblique, the forking of media is entirely obscured.

"5. The development of a triangular brace across the basal third of both wings, similar in form but unlike in composition. This is a striking example of parallelism in vein development. This brace is formed about a strong secondary fork in a principal vein. The vein is $\mathrm{Cu}_{1}$ in the fore wing, $\mathrm{N}_{3}+{ }_{4}$ in the hind wing. Beyond the fork this vein in the fore wing fuses with $\mathrm{N}_{3}+_{4}$ in such manner and to such extent that the boundaries between the two are no longer traceable. In the hind wing vein $\mathrm{M}_{3}+{ }_{4}$ is continued free to the wing margin.

"The secondary posterior branch is joined at its more or less decurrent tip to the vein behind it-to $\mathrm{Cu}_{2}$ in the fore wing; to $\mathrm{Cu}_{1}$ in the hind wing-thus forming an elongate and sinuous enclosure or loop in the posterior and basal side of the brace.

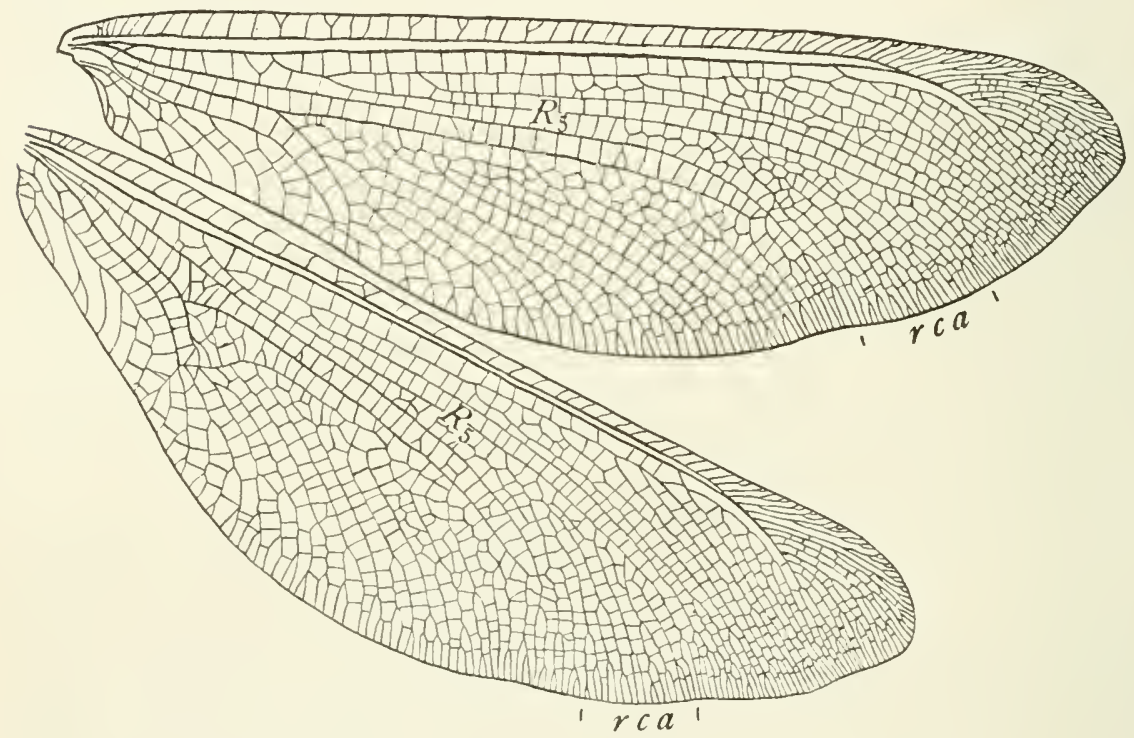

Fig. 200.- Wings of Palpares aeschnoides, var. libelluloides.

From the outer end of this loop often a short secondary vein springs forward and outward transecting the area of the fork. Since homologies are different in the two wings while the braces are closely parallel, the parts may be conveniently designated as follows: [See Figure 200.]

"The entire structure may be called the trigonal brace.

"The strong fork (in $\mathrm{Cu}_{1}$, fore wing; in hind wing $\mathrm{M}_{3}+_{4}$ ) may be called the trigonal fork.

"The continuation of the vein beyond the fork may be called the trigonal vein.

"The enclosure behind the fork may be called the trigonal loop.

"The curved vein arching forward from near the apex of the trigonal loop may be called the trigonal arc.

"6. The development of gradate series of cross-veins in four different wing areas:

“a) A series of costal gradates in the costal space before the stigma, these crossveins connecting in regular series the small branches that spring from vein Sc. [See Figure 156 .] 
“b) A series of apical gradates joining the branches that spring from the apical spur vein formed by fusion of tips of Sc and $R_{1}$. [See Figure ${ }_{5} 56$. .]

“c) An outer gradate series, paralleling the outer wing margin connecting the branches of the radial sector just proximal to the base of their terminal forks.

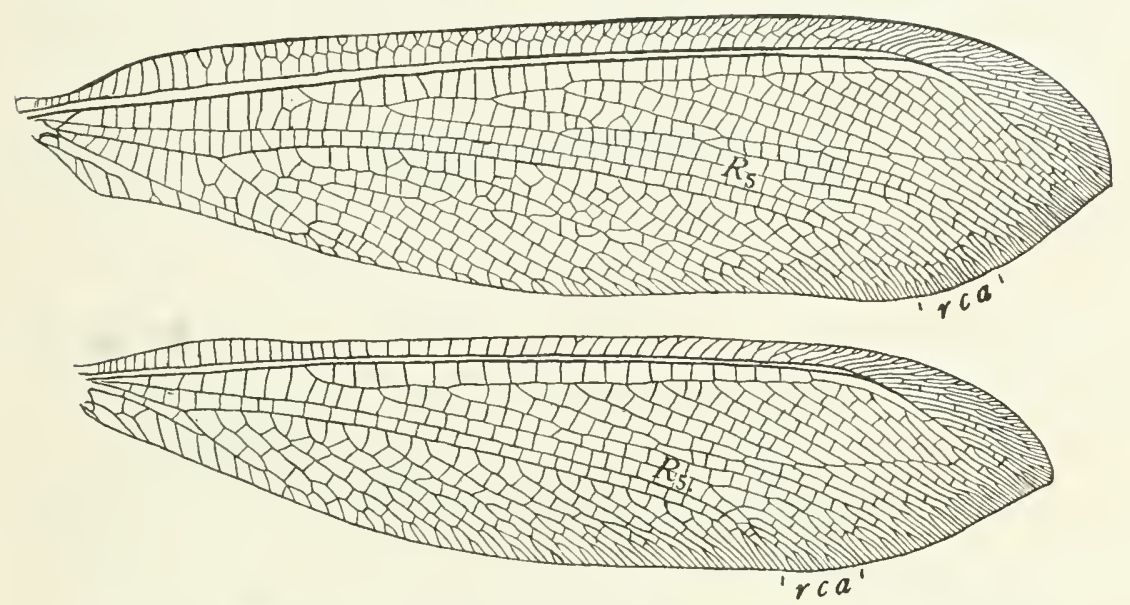

Fig. 201.-Wings of Acanthaclisis, a species from the Seychelles Islands.

“d) A longitudinal series extending lengthwise of the area between the truss cell and the radial planate. [See Figure 202.]

"7. The development of planates in two of the larger areas of the wing, thro the shortening of cross veins, the approximation of adjacent longitudinal branches, until
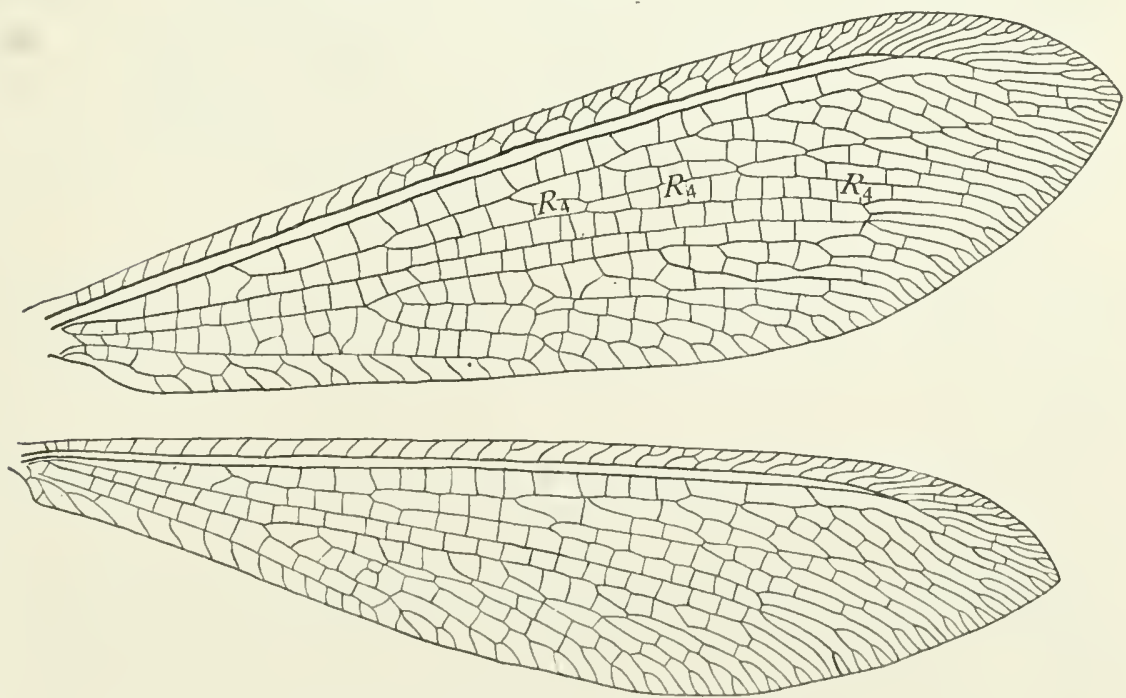

Fig. 202.-Wings of Cryptoleon nebulosum. 
both cross-veins and the bent veins connecting them come to lie in a more or less straight longitudinal line:

“a) The radial planate traverses the interradial area, crossing the branches of the radial sector, in the direction of the wing apex. [See Figure 202.]

"b) The trigonal planate traverse the area of the trigonal fork, crossing and uniting the branches that spring from the trigonal vein, to which vein it is more or less closely parallel. The trigonal planate is more or less closely joined at its proximal end to the trigonal arc.

"8. A median nexus or conjunction of adjacent veins, joins the tip of vein $\mathrm{M}_{1+2}$ with the vein on each side of it, and an interradial nexus in the more specialized Palparinæ similarly joins the tip of the first and second branches of the radial sector.

\section{(s) THE Wings OF THE ASCALAPHIDE}

Although the family Ascalaphidæ is distinctly separated from the Myrmeleonidæ, the wings of ascalaphids resemble quite closely those of the
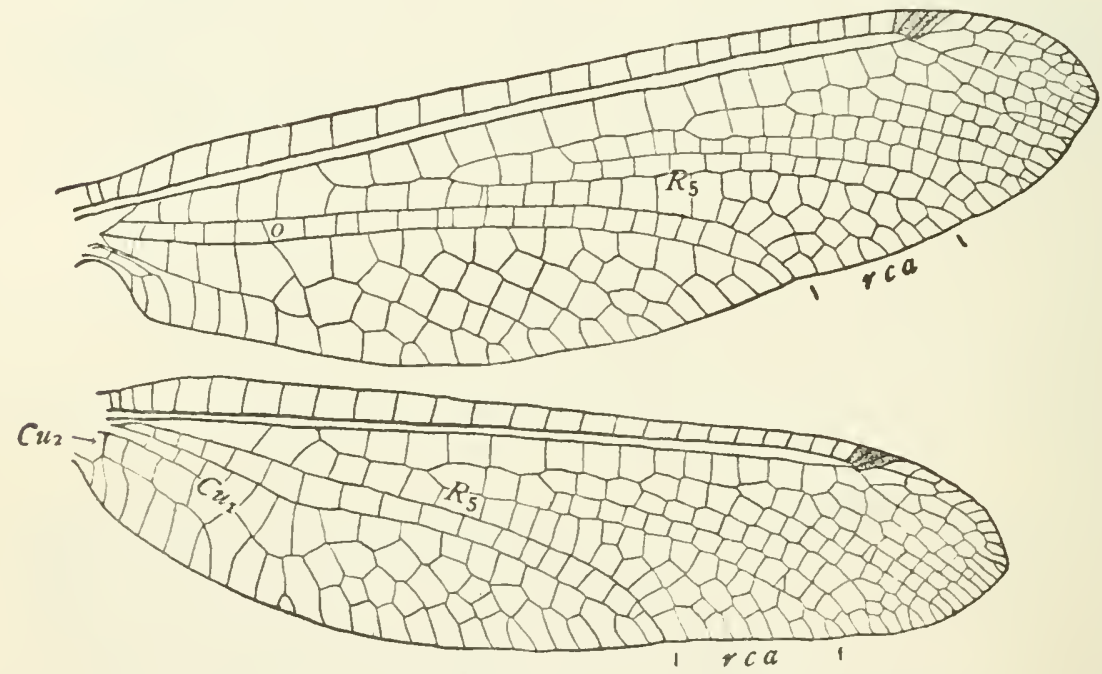

Fig. 203.-Wings of Ululodes hyalina.

myrmeleonids. The only feature that sharply distinguishes the wings of ascalaphids from those of myimeleonids is the fact that in the Ascalaphidæ there is no greatly elongated cell behind the point of fusion of veins Sc and $R_{1}$.

In the Ascalaphidæ, the obliquity of the base of vein $\mathrm{M}_{3+4}$ is frequently not well-marked; it is obvious in Ululodes hyalina (Fig. 203, o), but in Ogcogaster tesselata (Fig. 204) it is less so.

In this family the radial cuneate area is always present, although in a few cases, as in the genus Puer, it is small. It is in nearly all cases irregular in form, as in Clulodes (Fig. 203), appearing to be behind the first branch of the radial sector; rarely it has the appearance of being between two 
forks of the first branch of the radial sector. One of the best examples of this is in the wings of Ogcogaster tesselata from India (Fig. 204).

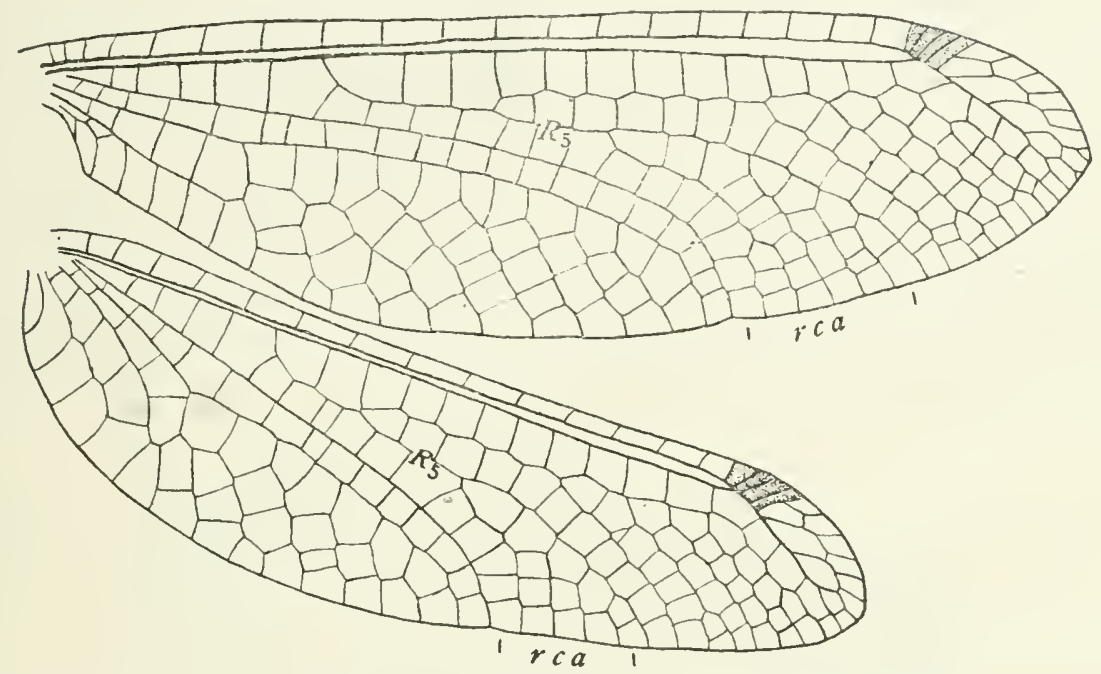

Fig. 204.-Wings of Ogcogaster tessellata.

In the hind wings the medial fork is near the base of the wing and vein $\mathrm{M}_{3}+_{4}$ remains separate from vein $\mathrm{Cu}_{1}$, as in the Myrmeleonidæ (Fig. 203).

All of the variations in the form of cubitus described as occurring in the Myrmeleonidæ are to be found in this family. Thus in the fore wing of Ascalaphus italicus, vein $\mathrm{Cu}_{2}$ is comparatively well-preserved and is distinct from the first anal vein; but the two veins are closely parallel for a considerable distance. In the fore wing of Albardia furcata, vein $\mathrm{Cu}_{2}$ is distinct from the first anal vein for about one-fourth of its length, after which the two veins coalesce (Fig 205).

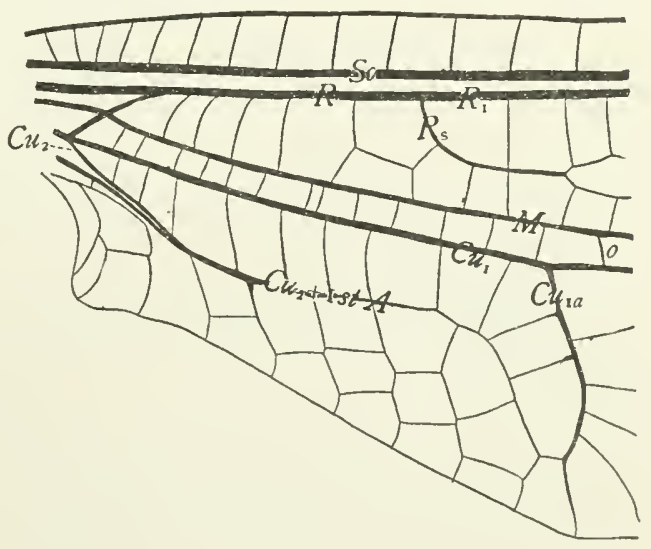

Fig. 205.-Base of a fore wing of Albardia furcata.

A similar condition exists in the fore wing of Ululodes hyalina (Fig. 203). In the hind wing of Ululodes hyalina the base of vein $\mathrm{Cu}_{2}$ appears like a very stout cross-vein. 


\section{( $t$ ) THE Wings OF THE Nenopterid}

The members of the Nemopteridx are most beautiful insects which present a striking appearance on account of the distinctly characteristic form of their hind wings. These are exceedingly long and narrow, ribbonlike or thread-like; sometimes they are enlarged before the extremity; in this case the narrow part is termed the petiole and the enlarged part the spatula.

The fore wings are triangular in outline (Fig. 206) and are furnished with many cross-veins. In the more general features of their venation they show striking resemblances to the wings of the myrmeleonids.

The subcosta and rein $\mathrm{R}_{1}$ coalesce near the apex of the wing; the subcostal cell is free from cross-veins: the radial sector is pectinately branched;

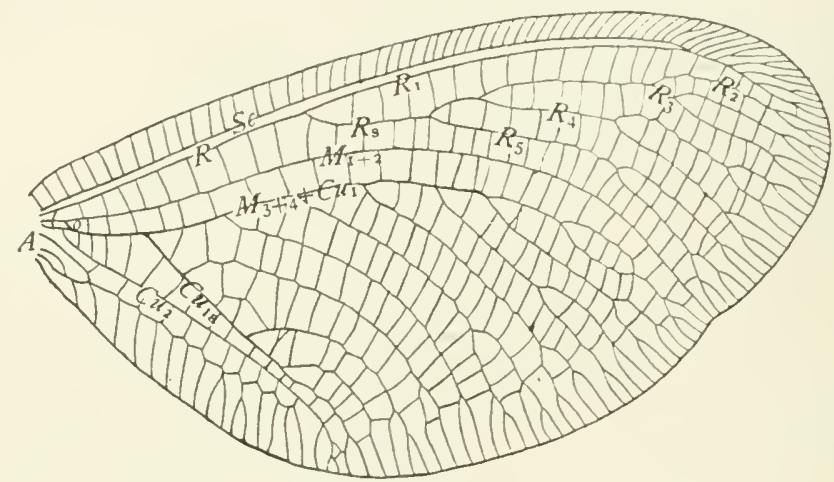

Fig. 206.-Fore wing of Nemoptera sinuata; o, oblique vein, vein $\mathrm{MI}_{3}+4$.

the media is of the same type as in the Myrmeleonidæ and Ascalaphidæ, vein $\mathrm{M}_{3}+_{4}$ coalescing with vein $\mathrm{Cu}_{1}$, and the basal part of vein $\mathrm{M}_{3}+_{4}$ appearing like an oblique cross-vein. The position of this oblique vein varies greatly; in Nemoptera (Fig. 206) and in Oliverina (Fig. 207) it is near the base of the wing; in Croce (Fig. 208) it is beyond the secondary cubital fork.

Vein $\mathrm{Cu}_{1} \& \mathrm{M}_{3}+_{4}$ is pectinately branched, and the first accessory vein is usually stouter than the others, forming a secondary cubital fork.

Vein $\mathrm{Cu}_{2}$ is not reduced in Nemoptera (Fig. 206) and in Oliverina (Fig. 207); but in Croce (Fig. 208), it coalesces with the first anal vein, the basal part of vein $\mathrm{Cu}_{2}$ being reduced to the condition of a very stout oblique cross-vein.

In the hind wings the renation is somewhat reduced, as would be expected, owing to their extremely narrow form. The maximum number of longitudinal veins is found in Nemoptera and in Oliverina; in these genera they are five in number. 
The first three longitudinal veins of the hind wing are easily recognized (Fig. 209), the costa by its marginal position, the subcosta and radius by

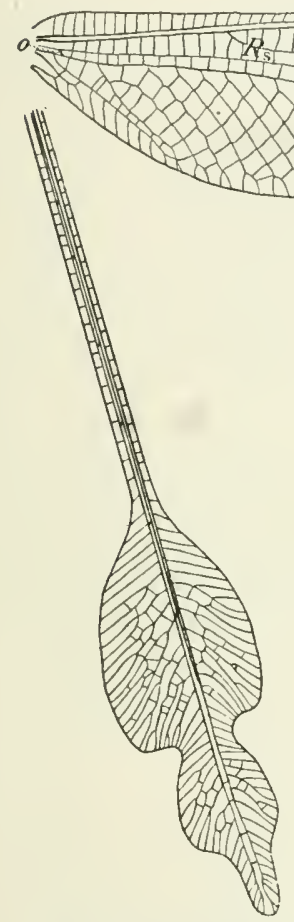

Fig. 207.-Wings of Oliverina extensa; 0 , oblique vein, vein $\mathrm{N}_{3}+4$.

the fact that they coalesce near the apex of the wing, as they do in the fore wing, and also by the fact that the area between them is free from crossveins as also is the case in the fore wing. I term the third vein radius instead of vein $R_{1}$, which is the vein that coalesces with the subcosta in the fore wing, for this reason: Between the third and the fourth longitudinal veins there is a series of cross-veins; the distal members of this series are transverse and have the appearance of ordinary cross-veins; but the proximal members are oblique, which suggest that they may be branches of the third vein; it seems probable, therefore, that in the narrowing of the wing vein $R_{1}$ and the stem of the pectinate radial sector have been brought together, and that the oblique cross-veins are vestiges of the branches of the radial sector. It seems proper, therefore, to term the combined veins $R_{1}$ and $R_{s}$ as vein $R$. The fourth vein is probably vein $M$. In the other members of the myrmeleonid group of families, the two branches of vein $\mathrm{M}$ are closely parallel in the hind wings, so closely parallel that the two could not be expected to remain apart in the greatly narrowed wing. Vein $\mathrm{Cu}$ is probably lost, it is usually greatly reduced in the allied families. The fifth vein is probably an ambient vein corresponding with the ambient vein of the

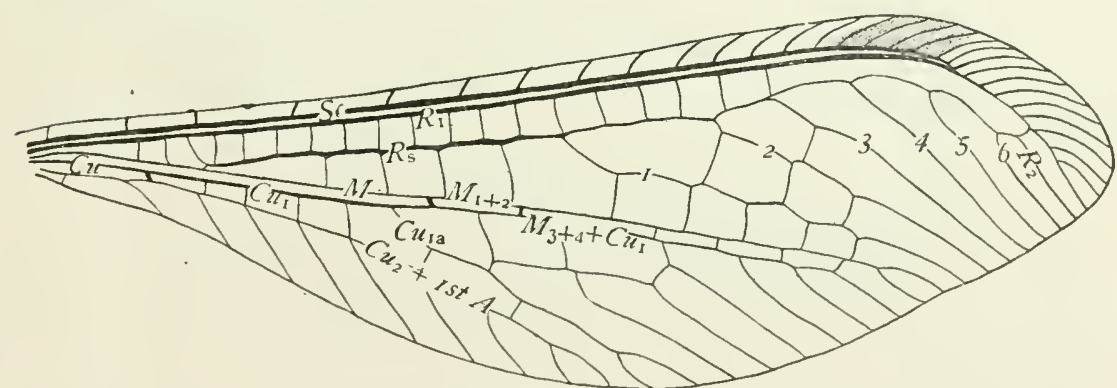

Fig. 208.-Fore wing of Croce filipennis.

fore wing. Considering the greatly reduced condition of the anal area in the allied families it is not at all probable that this vein is an anal vein. 
In addition to the five longitudinal veins that have been retained there are many marginal accessory veins; these are especially well developed in the spatula when this part of the wing is broad (Fig. 207).

There is one feature in the venation of the fore wings that merits fuller discussion than is given in the general statement given above, that is the

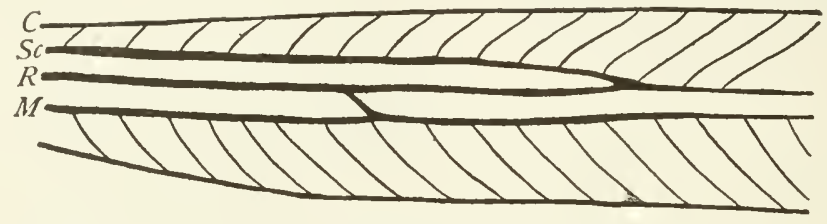

Fig. 209.-Part of a hind wing of Nemoptera sinuata.

probable method of increase in the number of the branches of the radial sector. In Nemoptera (Fig. 206), the radial sector is four-branched; as this is the typical number of branches, there is no difficulty in determining their homologies; they are doubtless veins $R_{5}, R_{4}, R_{3}$, and $R_{2}$ respectively, as is indicated in the figure. But each of these branches is deeply forked; and it is obvious that if the splitting of the branches were carried much farther the number of the branches of the radial sector would be increased by the interpolation of branches, instead of by the addition of branches at the distal end of the series, which is the more usual method.

The probability that the addition of branches to the radial sector in this family is by the interpolation of branches makes it difficult if not impossible to determine the homologies of the branches when there are more than four of them; in such cases, the branches may be numbered (Fig. 207 and 208).

In having the number of the branches of the radial sector increased by interpolation, the Nemopteridx resembles the Dilaridx. In this respect the family Nemopteridæ differs from the other members of the myrmeleonid group of families, and the Dilaridæ from the other hemerobiid families; each of these cases is an illustration of the fact that in the order Neuroptera different families exhibit very different methods of specialization of the wings.

\section{(u) THE WINGS OF THE APOCHRYSIDE}

The type of wing-venation characteristic of the Apochrysidæ is exhibited by the wings of A pochrysa crasus (Fig. 210). This is one of the most beautiful of neuropterous insects, with a wing expanse of $65 \mathrm{~mm}$; it is found in Japan.

In general appearance the wings of this insect bear some resemblance to those of Chrysopa; but when they are carefully studied they are found to present the essential features of the wings of the myrmeleonid group of families. 
The fore and hind wings of Apochrysa are very similar in appearance except that the hind wings are narrower than the fore wings and have fewer cross-veins. In spite of the striking similarity in appearance of the fore and hind wings they differ in structure. Here, as in the Myrmeleonidæ, similar results have been attained by the use of different material.

In A pochrysa veins $\mathrm{Sc}$ and $\mathrm{R}_{1}$ do not coalesce at the tip; and, in the fore wings at least, there are a few cross-veins in the subcostal area. In Apochrysa crosus (Fig. 210), there is no hypostigmatic space in the fore wings, but there is one in the hind wings. In Apochrysa matsumure, there is a hypostigmatic space in both fore and hind wings. These are the only members of the family that I have studied. In both wings the radial, medial, and cubital forks are very near the base of the wing.

In the fore wings vein $\mathrm{M}_{1}+_{2}$ extends nearly parallel with the inner margin of the wing. Vein $\mathrm{M}_{3}+{ }_{4}$ coalesces with vein $\mathrm{Cu}_{1}$, as in the Myrmeleonidæ; the free part of vein $\mathrm{M}_{3+4}$, the oblique vein, is very near the base of the wing (Fig. $2 \mathrm{Io}, \mathrm{o}$ ). Vein $\mathrm{M}_{3}+_{4}+\mathrm{Cu}_{1}$ is closely parallel with vein $M_{1+2}$. It is the forward curve in the course of these veins that produces

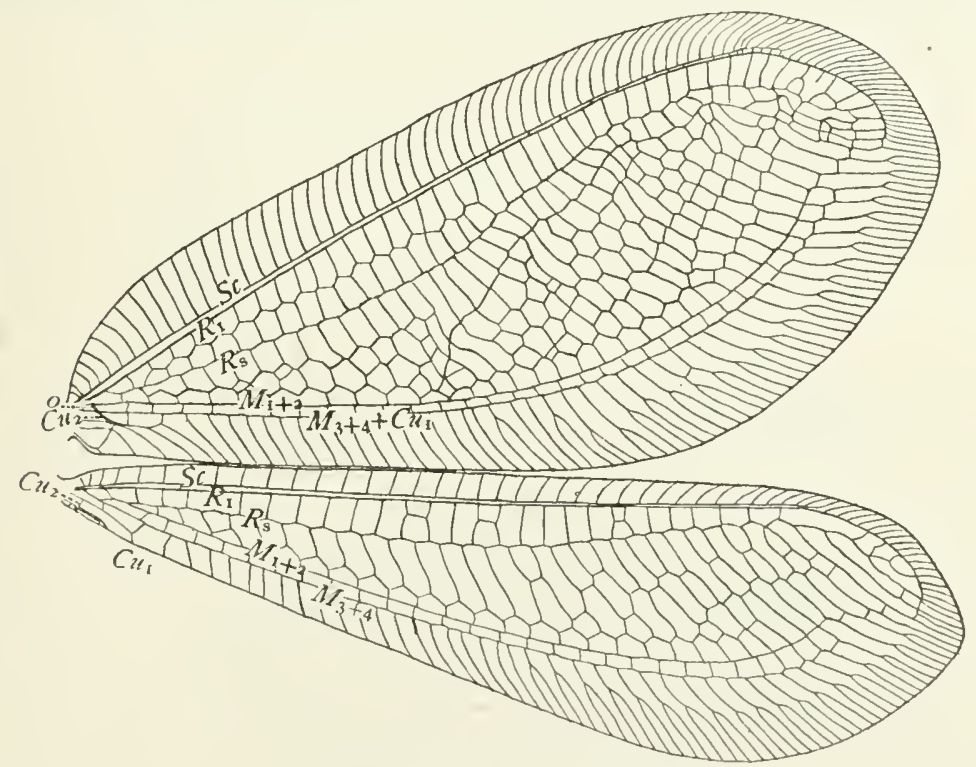

Fig. 210.-Wings of A pochrysa croesus.

the resemblance of these wings to those of Chrysopa. Vein $\mathrm{Cu}_{2}$ is greatly reduced in length ( $\mathrm{Fig} .2 \mathrm{I} 0, \mathrm{Cu}_{2}$ ), it appears to anastomose with the first anal vein, but a microscopic examination of the two species before me shows that the two veins are separate; the space between them, however, is so 
narrow that it was impracticable to represent it in the figure without exaggerating it. There are three anal veins.

In the hind wings vein $\mathrm{M}_{1+2}$ anastomoses with the radial sector a short distance beyond the radial fork. Vein $\mathrm{M}_{3}+_{4}$ is a direct continuation of the stem of media and extends parallel with vein $\mathrm{M}_{1+2}$ nearly to the tip of the wing. The cubitus is greatly reduced in length; the basal portion of vein $\mathrm{Cu}_{2}$ is transverse, appearing like a cross-vein. Here, as in the fore wing, veins $\mathrm{Cu}_{2}$ and Ist $\mathrm{A}$ are so closely parallel that it is impracticable to represent them separate in the figure.

A superficial examination of the wings of this insect would lead one to believe that the two longitudinal veins parallel with the inner margin of the wing are homologous in the two wings. This is true of the first of these veins, this is vein $\mathrm{M}_{1}+_{2}$ in both wings; but the second vein is vein $\mathrm{M}_{3}+_{4}+$ $\mathrm{Cu}_{1}$ in the fore wings and vein $\mathrm{M}_{3+4}$ in the hind wings. This condition of structures similar in appearance but differing in composition is quite analagous to the condition in this part of the wing in the Myrmeleonidæ.

\section{(v) THE WINGS OF THE CONIOPTERYGIDE}

The family Coniopterygidæ includes a small number of very aberrant

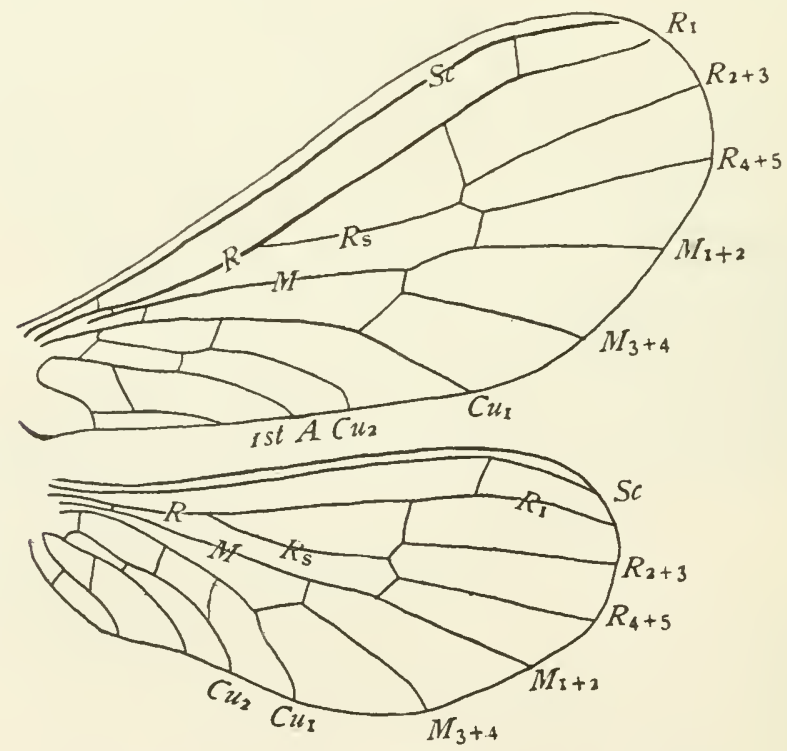

Fig. 211.-Wings of Semidalis aleurodiformis (After Enderlein).

members of the order Neuroptera. They are the smallest members of the order, and in all of them the venation of the wings is considerably reduced. 
The wings, and the body as well, are covered by a powdery efflorescence, which gives the insects a very characteristic appearance.

The family has been monographed by Enderlein ('o6), who figures the wings of a large proportion of the known species. This author uses the wings of Semidalis aleurodiformis (Fig. 2 I I) to illustrate the type of wingvenation characteristic of the family. Although these wings represent as generalized a condition as is found in the family, even here the radial sector is reduced to a two-branched condition, and this is true also of the media; the second and third anal veins coalesce at the base; and there are but few cross-veins. No accessory veins are present. In this species the fore and hind wings are quite similar in venation.

Among the more striking modifications of this typical form are the following: In two genera, Aleuropteryx and Helicoris, vein $\mathrm{R}_{4+5}$ has the appearance of being a branch of media, the radial sector appearing to be unbranched and the media three-branched. Media is unbranched in both fore and hind wings of Coniocomposa and in the hind wing of Coniopteryx. In the genus Conwentzia, of which two species are known, the fore wings do not differ markedly from those of Semidalis, but the hind wings are very small and their venation is greatly reduced. 


\section{CHAPTER $\mathrm{X}$ \\ THE WINGS OF THE EPHEMERIDA}

(a) THE MORE GENERAL FEATURES OF THE WINGS OF THE EPHEMERIDA

In the order Ephemerida or May-flies the wings are triangular in outline, and delicate in structure; they are usually furnished with a considerable number of intercalary veins and with many cross-veins (Fig. 212.)

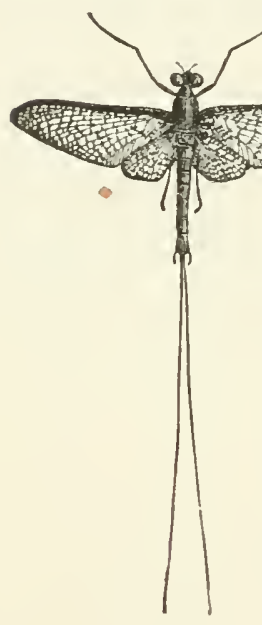

Fig. 21 2.-

A Mlay-fly.

The presence of intercalary veins is correlated with a corrugation of the wings by which the well known fan-like form has been produced; there being a remarkably perfect alternation of so-called convex and concave veins. When at rest, the wings are held upright; they are never folded over the abdomen. No anal furrow has been developed.

In this order a marked cephalization of the flight function has taken place, which has resulted in a great reduction of the hind wings of all living forms. In some cases (Conis et al.) this has gone so far that the hind wings are wanting (Fig. 2I3); but at least one pair of wings are present in all members of this order.

In a few genera (Oligoneuria et al.) both pairs of wings are furnished with but few veins. It requires only a little study, however, to convince one that these genera with few-veined wings are degraded and not generalized. It is in the fore wings of those forms in which many. wing-veins have been retained that the homologies of the wing-veins are most easily determined.

\section{(b) THE tRacheation of the Wings of THE EPHEMERIDA}

Comstock and Needham ('98) made the first attempt to determine the homologies of the wing-veins of May-flies by a study of the tracheation of the wings. In this paper we made the following statement:

"We have studied the tracheation of many nymphs of May-flies, but with results much less satisfactory than those we have reached in a study of other orders of insects with many-veined wings. In all nymphs of May-flies that we have examined, a greater or less reduction of the tracheæ appears to have taken place; and in many of them a large proportion of the longitudinal veins contain no tracheæ. And, too, the

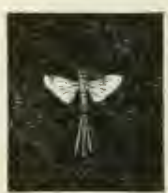

Fig. 2 1 3:Canis. presence or absence of a trachea in a vein appears to have little significance. As an example of this the wings of two nymphs are before the writer, in which 
the venation is so similar that there is not the slightest difficulty in tracing the homologies of the veins. In one, the radial sector and the media contain well preserved tracheæ; in the other, there is not the slightest trace of a trachea in these veins. On the other hand, in the latter, the cubital trachea is forked, one of the branches traversing vein $\mathrm{Cu}_{2}$; while in the former, the cubital trachea is simple.'

Our knowledge of the tracheation of the wings of May-flies remained in the unsatisfactory condition indicated above until quite recently; when Miss Anna H. Morgan published the results of an extended study of the tracheation of the wings of insects of this order (Morgan 'I2).

In the course of this study Miss Morgan examined with great care the wings of a large number of nymphs, representing fifteen genera. These

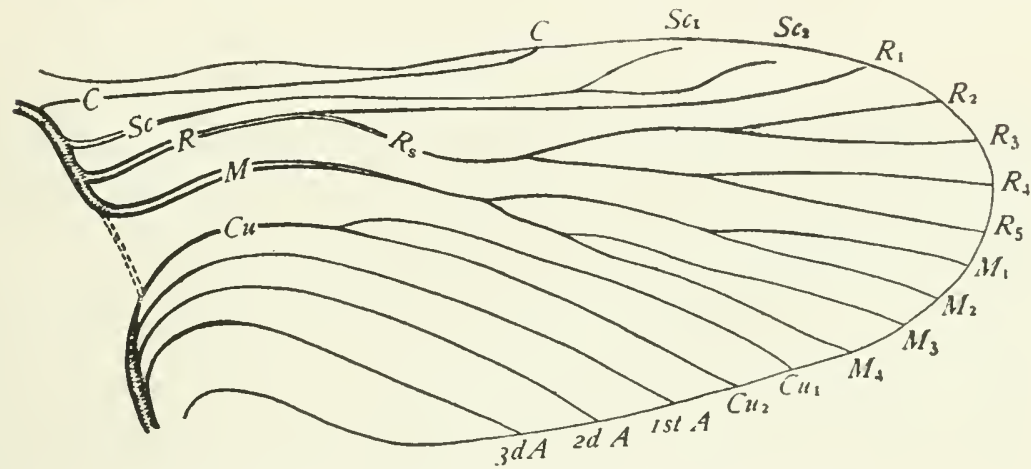

Fig. 214.-Hypothetical type of tracheation of wings of insects.

were Epeorus, Iron, Ameletus, Ephemera, Blasturus, Hexagenia, Polymitarcys, Ephemerella, Siphlurus, Callibetis, Chirotonetes, Heptagenia, Leptophlebia, Choroterpes, and Canis. Figures showing the tracheation of the wings of these nymphs and of the venation of the wings of the adults of the same genera are given in her paper.

This work was done in the entomological laboratory of Cornell University; and its progress was carefully followed by Dr. Needham and myself. We both accept Miss Morgan's conclusions, although in some respects they differ from those that we have published; and the homologies of trachere and wing veins indicated later are based on her conclusions.

The basal connections of the tracheæ of May-flies differ, as was shown by Comstock and Needham ('99), from those of all other insects in which they have been examined. In the May-flies a single large trachea enters each wing (Fig. 2 I 5 ). This trachea arises from the spiracular trunk of one side of the thorax and, after giving off a branch to the corresponding leg, 
passes directly to the base of the wing. Here it divides and subdivides into several branches which become the principal tracheæ of the wing.

In all other forms that we have studied there are two large tracheæ that enter the wing, each being the origin of a group of the principal longitudinal

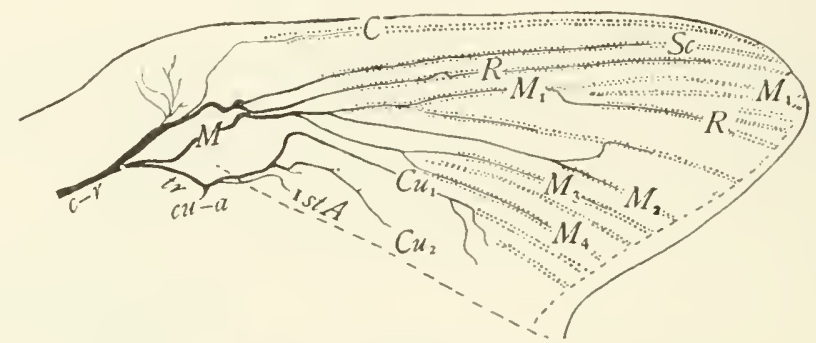

Fig. 2 I5.-Wing of nymph of Epeorus humeralis (After Morgan).

tracheæ. This has been shown in the discussion of the hypothetical type of wing tracheation (see page 16 ). The figure representing this hypothetical type is repeated here for convenience of reference (Fig. 214).

The two groups of principal tracheæ referred to above have been designated as the costo-radial group and the cubito-anal group, respectively. When the two groups are distinct, as is the case in the Plecoptera, in certain cockroaches, and in some of the Homoptera the medial trachea is a member of the costo-radial group. For this reason it is thus represented in the hypothetical type (Fig. 2 I 4). But in most insects there has been developed a transverse trachea connecting these two groups of tracheæ. The position of this transverse basal trachea of the wing is indicated in the figure of the hypothetical type by dotted lines. Frequently the transverse basal trachea is indistinguishable from the two main trunks which it connects; the three forming a single, continuous, transverse trachea, from which arise all of the wing tracheæ. When a transverse basal trachea is formed the medial trachea tends to migrate along it torvards the cubito-anal group of tracheæ, and often becomes united with that group. Examples of these different conditions are given elsewhere in this book.

With these facts in mind let us try to understand the origin of the unique condition of the air supply of the wings of May-flies. In the wings of nymphs of the genus Epeorus, Miss Morgan found a small trachea which springs from the cubito-anal branch and extends inward toward the body nearly parallel with the main stem (Fig. 2 I $5, c u-a$ ). This she suggests may be a remnant of the trachea from which the cubito-anal tracheæ originally branched.

If this conclusion be correct, the single large trachea (Fig. 21 5, c-r), which is now the chief if not only source of air supply for the wing, was 
developed from the stem of the costo-radial group of trachex; and that part of the branch of this stem that extends to the origin of the cubito-anal group of trachex, and from which the medial trachea arises, represents the transverse basal trachea (Fig. 2 I $5, t r$ ).

\section{(c) THE homologies of THE WING-VEINS OF THE FORE Wings OF the EPHEMERIDA}

Figure 2 I 5 represents the fore wing of a full grown nymph of Epeorus hmmeralis, in which the developing veins were visible. Although a considerable reduction of the tracheæ has taken place, the basal portion of each of the principal tracheæ is preserved. Figure 2 I 6 represents the venation of the wing of the adult of the same species. The lettering of these two figures will serve to indicate the now accepted view regarding the homologies of the tracheæ and of the wing veins.

Costa occupies its usual position on the front margin of the wing. The subcosta is closely parallel with the costa and is unbranched. The radius is also parallel with the costa; and it appears to be an unbranched vein. Media divides in the typical manner into four branches. The cubitus also has its typical form being two-branched. And three, more or less branched anal veins are present. Several intercalary reins are also present; the more prominent of which are $\mathrm{IM}_{1}, \mathrm{IR}_{\mathrm{s}}, \mathrm{IM}_{3}$, and $\mathrm{ICu}_{1}$.

In the Ephemerida, as in the Odonata, the branches of media have moved forward so as to occupy the field of the radial sector. The result of this modification is that radius appears to be an unbranched vein (Fig. $216, \mathrm{R}$ ).

Whether a vestige of the radial sector remains or not is an interesting problem. Between veins $\mathrm{M}_{1}$ and $\mathrm{IR}_{\mathrm{s}}$ there is a vein which appears to be a

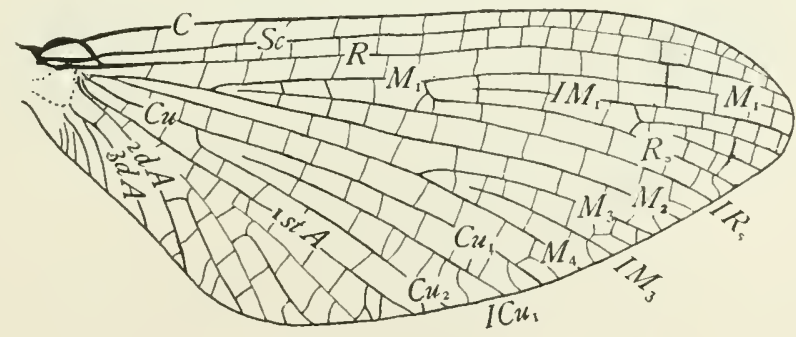

Fig, 216.-Wing of adult Epeorus humerulis (After MIorgan).

branch of vein $M_{1}$. This may be merely an intercalary vein; but there is good reason to believe, as pointed out by Miss Morgan, that this is a vestige of the radial sector; consequently it is designated as vein $R_{s}$. (Fig. $\left.2 \mathrm{I} 6, \mathrm{R}_{\mathrm{s}}\right)$. 
In the Odonata, where the area of the radial sector has been occupied by some of the branches of media, the complete history of this invasion can be

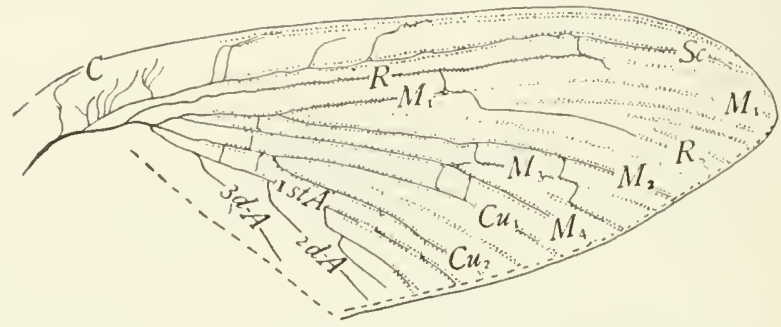

Fig. 217.- Wing of nymph of Heptagenia interpunctata (After Morgan).

seen by a study of the ontogeny of representatives of the suborder Anisoptera, as is demonstrated in the discussion of the wings of that order. Here the radial sector is preserved as an unbranched vein; and it retains its connection with the main stem of radius, although it occupies a position between certain of the branches of media, usually between veins $\mathbf{M}_{2}$ and $\mathrm{M}_{3}$.

In the suborder Zygoptera the distal portion of the radial sector is as well preserved as in the Anisoptera; but in this suborder the trachea $R_{s}$ has lost its connection with trachea $\mathrm{R}$ and has become joined to the medial trachea.

With this evidence of the switching of the base of the trachea $R_{s}$ to the medial trachea in the Zygoptera it is not difficult to believe that the invasion of the radial area by media in the Ephemerida has produced a similar result.

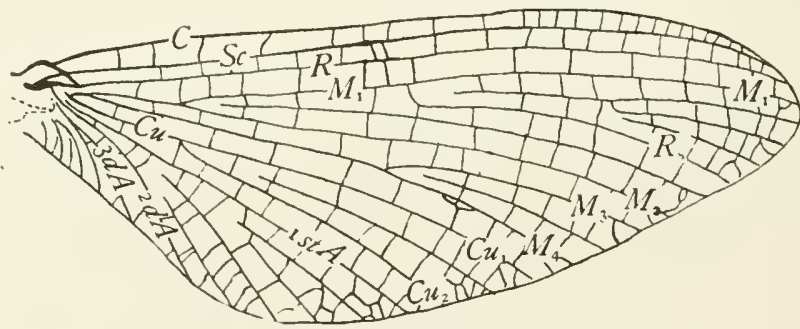

Fig. $218 .-$ Wing of adult Heptagenia interpunctata (After Morgan).

The truth of this conclusion would be firmly established if one could find generalized May-flies in which trachea $R_{\mathrm{s}}$ retains its connection with trachea $R$. The search for such forms was made by Miss Morgan, and resulted in the finding of one species in which the connection of trachea $R_{s}$ with trachea $\mathrm{R}$ frequently exists. This insect is Heptagenia interpunctata. A large number of the wing-pads of this species were examined; half of the 
wing-pads showed this connection, while half of them showed no sign of it. Figure 2 I 7 shows the tracheation of a wing of a nymph in which the connec-

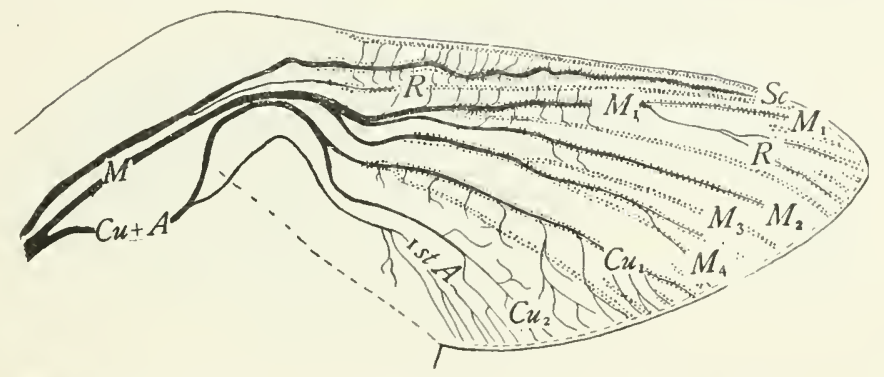

Fig. 219.-Wing of a nymph of Hexagenia (After Morgan).

tion of trachea $R_{\mathrm{S}}$ with trachea $\mathrm{R}$ was retained; and Figure $2 \mathrm{I} 8$ represents the venation of the adult of the same species.

It is evident that in Heptagenia interpunctata we have a species that illustrates a transitional stage in the switching of the basal connection of the trachea $R_{s}$. In some individuals the primitive connection of trachea $R_{s}$ with trachea $R$ is retained; in others, trachea $R_{s}$ has been transferred to trachea $M_{1}$. With this fact in view I have no doubt that the vein which Miss Morgan designated as vein $R_{s}$ ? is really vein $R_{s}$; and $I$ suggest the omission of the note of interrogation.

The series of wings of nymphs figured by Miss Morgan shows a remarkable evolution of the tracheation, which consists of a continuous reduction of large tracheæ and a replacement of them by small tracheal branches.

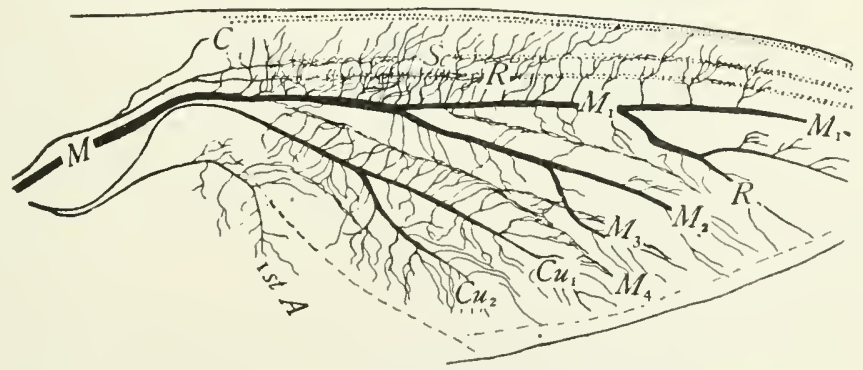

Fig. 220.-Wing of a nymph of Leptophlebia (After Morgan).

Three figures selected from the series given in her paper will serve to illustrate this, (Figs. 219,220 , and $22 \mathrm{I}$ ).

(d) THE CORRUGATIONS OF THE WINGS OF THE EPHEMERIDA

The fan-like structure of the ephmerid wings has been referred to by many writers. But it is worth while to point out in this place the degree 
of perfection that has been reached in the alternation of convex and concave reins. In the accompanying table the names of the convex veins, those

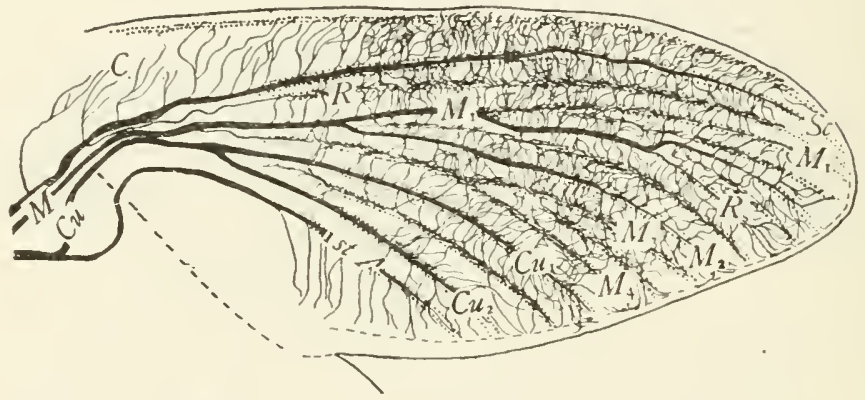

Fig. 221.-Wing of a nymph of Siphlurus (After Morgan).

reins that follow the crests of ridges, are printed in boldface type; while the names of concare veins, those that follow the furrows, are printed in ordinary Roman type.

TABLE OF THE WING-VEINS OF THE EPHEMERIDA

The convex veins are indicated by boldface type

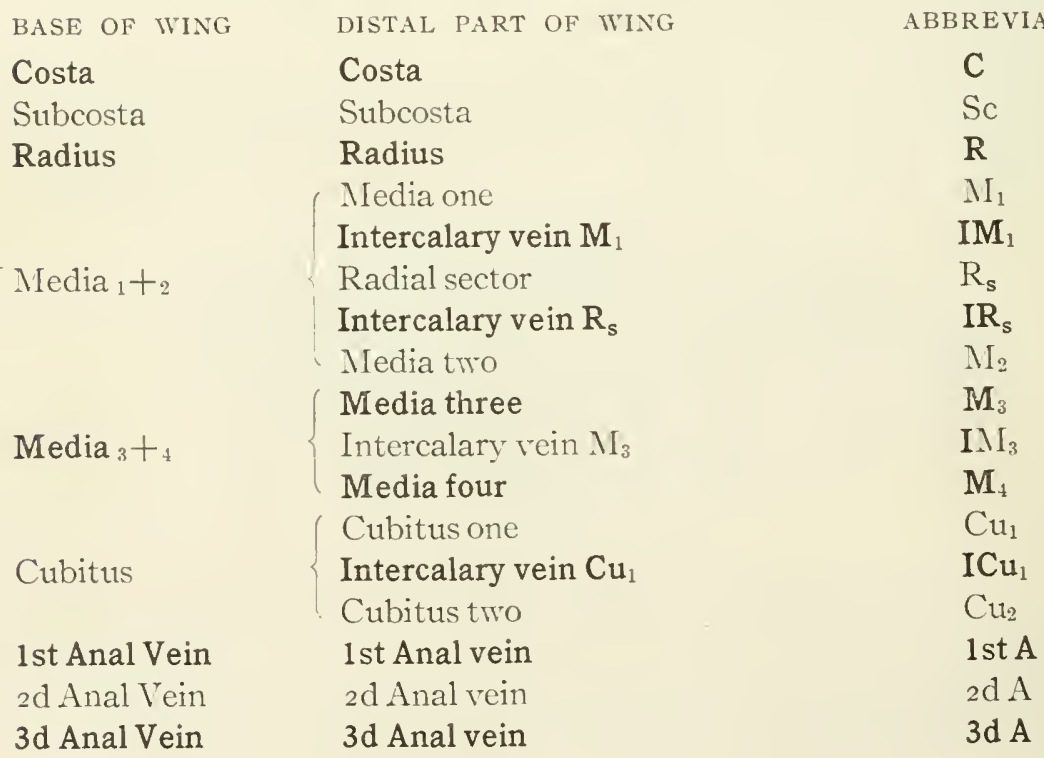

It will be seen by reference to the table that the alternation of convex and concave veins exists in all parts of the wing. In the basal portion of the wing convex and concave principal veins alternate except in the case of 
media, which forking at the base of the wing plays the part of two principal veins; vein $\mathrm{M}_{1+2}$ being concave and vein $\mathrm{M}_{3}+_{4}$, convex.

The chief branches of the principal veins, counting media as two veins, are of the same nature as the principal veins, except in the case of the radial sector; but an alternation of convex and concave veins has been attained by the development of intercalary veins, which in each case differ from the veins between which they are situated. In the area of vein $M_{1+2}$, where the supposed radial sector is interpolated, it requires two intercalary veins to complete the alternation, veins $I M_{1}$ and $I R_{s}$.

In addition to the intercalary veins enumerated in the table many other intercalary veins are developed at the margin of the wing in a more or less irregu'ar manner; but wherever a second intercalary vein extends far into the disk of the wing it is accompanied by a third, one being convex, the other concave, except in the anal area where intercalary veins are more of the nature of braces, like cross-veins.

Correlated with the development of a triangular form of wing, which involves an expanding of its outer margin, is the fact that the secondary longitudinal veins are all added distally in the May-flies. But the method of development of these veins appears to be radically different from what it is in the Neuroptera. There the accessory longitudinal veins are preceded by tracheæ, which arise as fine twigs at the tips of older trachex, and which in the course of phylogenetic development branch off from the parent trachea farther and farther from the margin of the wing, thus making room for the development of other twigs. Here, in the May-flies, the secondary longitudinal veins are evidently thickened folds, each of which arose more or less nearly midway between other veins, with which, at first, it had no connection.

A fact of prime importance in the study of the homologies of the wingveins of May-flies is that the corrugations of the wing are the most persistent features of it. Hence the most important criterion for determining the homology of a vein is whether it is a concave or a convex one. This is especially true of the hind wings where a variable number of the veins have been lost.

The stiffening of the costal margin of the wing by the formation of a subcostal furrow has been attained in most of the orders of insects; and in several of them the formation of folds has extended, to a greater or less degree, to other parts of the wing. But as a rule, the latter method of specialization has not been the most important one in perfecting the wing. In the Odonata it has been carried farther than elsewhere except in the Ephemerida. But in the Odonata it has been supplemented by other methods of specialization, with the result that an exceedingly efficient organ of flight has been developed in that order; while in the Ephemerida the cephalization of the flight-function and the corrugating of the wings have 
been the chief lines along which specialization has extended. The former has doubtless added much to the efficiency of the wings; but a too close adherence to the latter method of specialization has resulted in the formation of a rather indifferent organ; although it is the most perfect development of its peculiar type.

\section{(e) THE homologies of the Wing-veins of THE hiNd Wings of the EPHEMERIDA}

The hind wings of the Ephemerida are always reduced in size and in venation; even in the most generalized forms some of the wing-veins are wanting. This fact has made it difficult to determine the correspondence of the veins of the fore and hind wings.

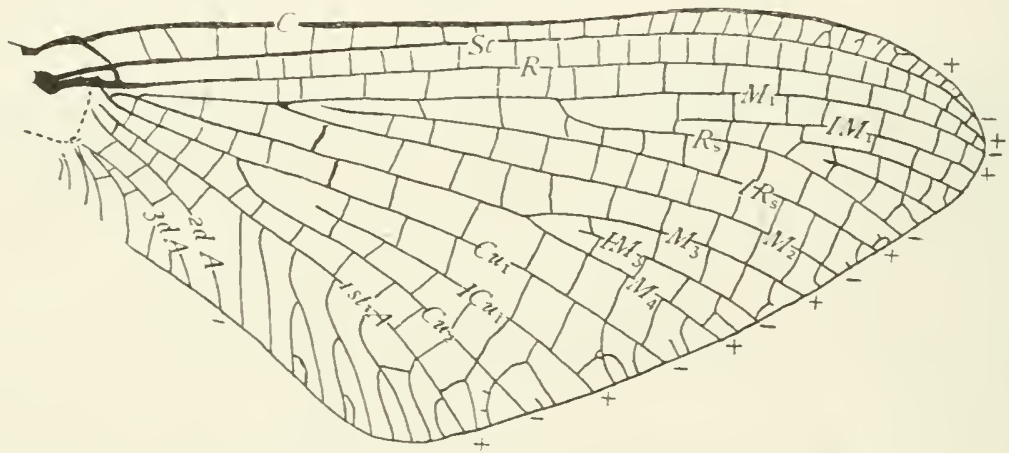

Fig. 222.-Fore wing of Chirotonetes albomanicatus (After Morgan).

In the course of the preparation of this account, it occurred to me to make use, for this purpose, of a criterion that had not been previously employed, that is the corrugations of the wings.

It is probable that in the evolution of the fan-type of wing in this order the two pairs of wings became corrugated in a similar manner; this we know to be the case in the Odonata; that is, the same veins become convex or concave, as the case may be, in the two pairs of wings.

After the corrugations had become established, it is not at all probable that in the course of the reduction of the hind wings concave veins should become convex or that convex should become concave.

In the table on page 220 the nature of the veins, whether concave or convex is indicated; and in Figure 222, which represents a fore wing, and Figure 223, which represents a hind wing, both of Chirotonetes albomanicatus the convex veins are designated by plus signs and the concave veins by minus signs.

A study of these two figures shows that there is a quite close correspondence between the venation of the two wings. The more striking 
features in the reduction of the hind wing are the following: the base of vein $M_{1+2}$ has atrophied; veins $R_{\mathrm{s}}$ and $I R_{\mathrm{s}}$ are entirely lost; and vein

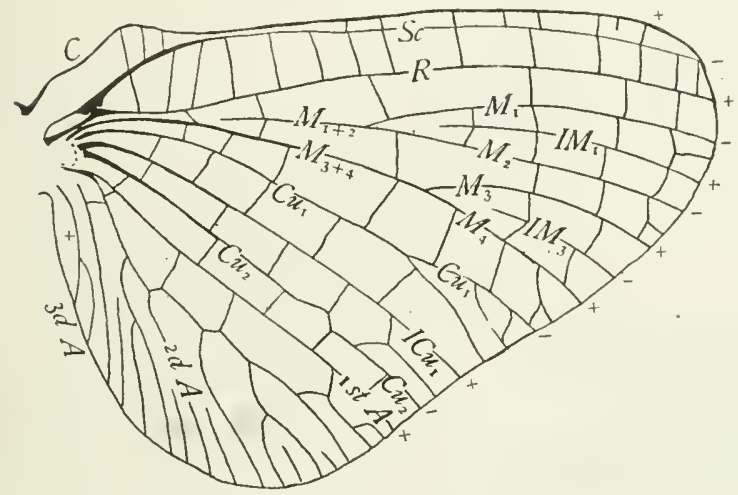

Fig. 223.-Hind wing of Chirotonetes albomanicatus (After Morgan).

$\mathrm{ICu}_{1}$, extends to the base of the wing.

The correctness of the conclusions regarding the homologies of the veins of the hind wing indicated above are confirmed by a study of the tracheation of the wings of the nymph of this species as figured by Miss Morgan (Fig. 224). Note especially the absence of trachea between tracheæ $M_{1}$ and $\mathrm{M}_{2}$, correlated with the loss of veins $R_{s}$ and $I R_{s}$, and also the separation of tracheæ $\mathrm{Cu}_{1}$, and $\mathrm{Cu}_{2}$ close to the base of the wing-pad, which admits of the extension of the intercalary vein $\mathrm{ICu}_{1}$, to the base of the wing of the adult.

These two features, the loss of vein $R_{s}$ and $I R_{s}$ and the basal extension of vein $\mathrm{ICu}_{1}$ are the ones that rendered difficult the recognition of the homologies of the veins of the hind wings before use was made of the corrugations of the wings for this purpose. Unfortunately the value of this criterion did not occur to us at the time Miss Morgan's paper was written, which accounts for the differences between her conclusions regarding the homologies of the veins of the hind wings and those stated here.

In concluding this account of the hind wings of May-flies, I wish to call attention to the prominent, forward

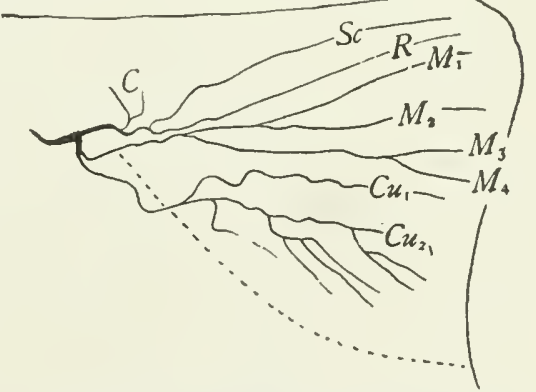

Fig. 224.-Tracheation of a hind wing of a nymph of Chirotonetes albomanicatus (After Morgan). projection of the humeral angle. This is a specialization which insures the synchronous action of the two wings of each side, as it causes the wings to overlap to a great extent. 


\section{CHAPTER XI}

\section{THE WINGS OF THE ODONATA}

\section{(a) THE MORE General features of the inings of the odonata}

In the Odonata the wings are long and narrow and are finely netted with cross-veins; the hind wings are as large as or larger than the fore wings;

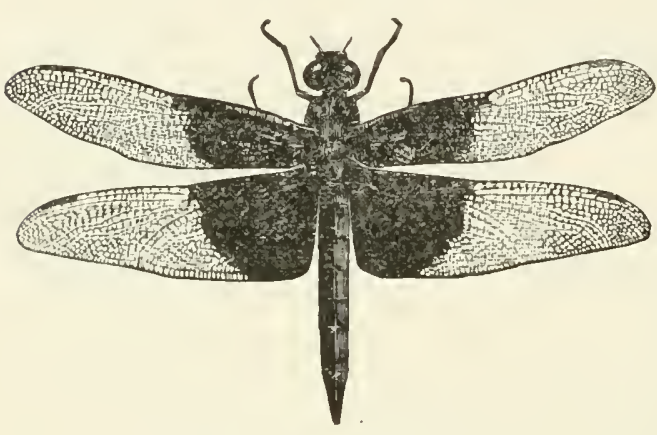

Fig. 225.-A dragon-fly. and each wing has on its costal margin a joint-like structure, the nodus.

In the dragon-flies, suborder Anisoptera, the wings are held extended at right angles to the length of the body when the insect is at rest (Fig. 225).

In this suborder the wings are exceedingly efficient organs of flight; few if any insects exceeding the dragon-flies in rapidity of flight. The damsel-flies, suborder Zygoptera, are furnished with more delicate wings, which, as a rule, are folded together above the abdomen when not in use (Fig. 226), although in the Lestinæ they are partly spread.

The most distinctive feature of the wings of the Odonata is the fact that in the course of their ontogenetic development one or more, usually two, of the branches of the medial trachea invade the area of the radial sector. This results in vein $R_{s}$ occupying a position behind one or more, usually two, of the branches of media. This remarkable phenomenon is discussed more at length a little later. There are reasons to believe that a similar invading of the area of the radial sector by media takes place in the Ephemerida. With this exception it is distinctively characteristic of the Odonata.

The growth of our knowledge of the homologies of the wing-veins within the order Odonata has been

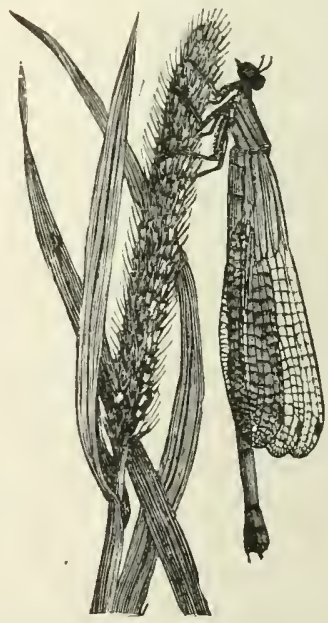

Fig. 226.-A damsel-fly.

a gradual one and is the result of the contributions of many authors; chief among whom are Hagen, Walsh, and Baron de Selys-Longchamps. But a complete understanding of the correspondence in detail of the wingveins of the Odonata with those of the wings of insects of other orders 


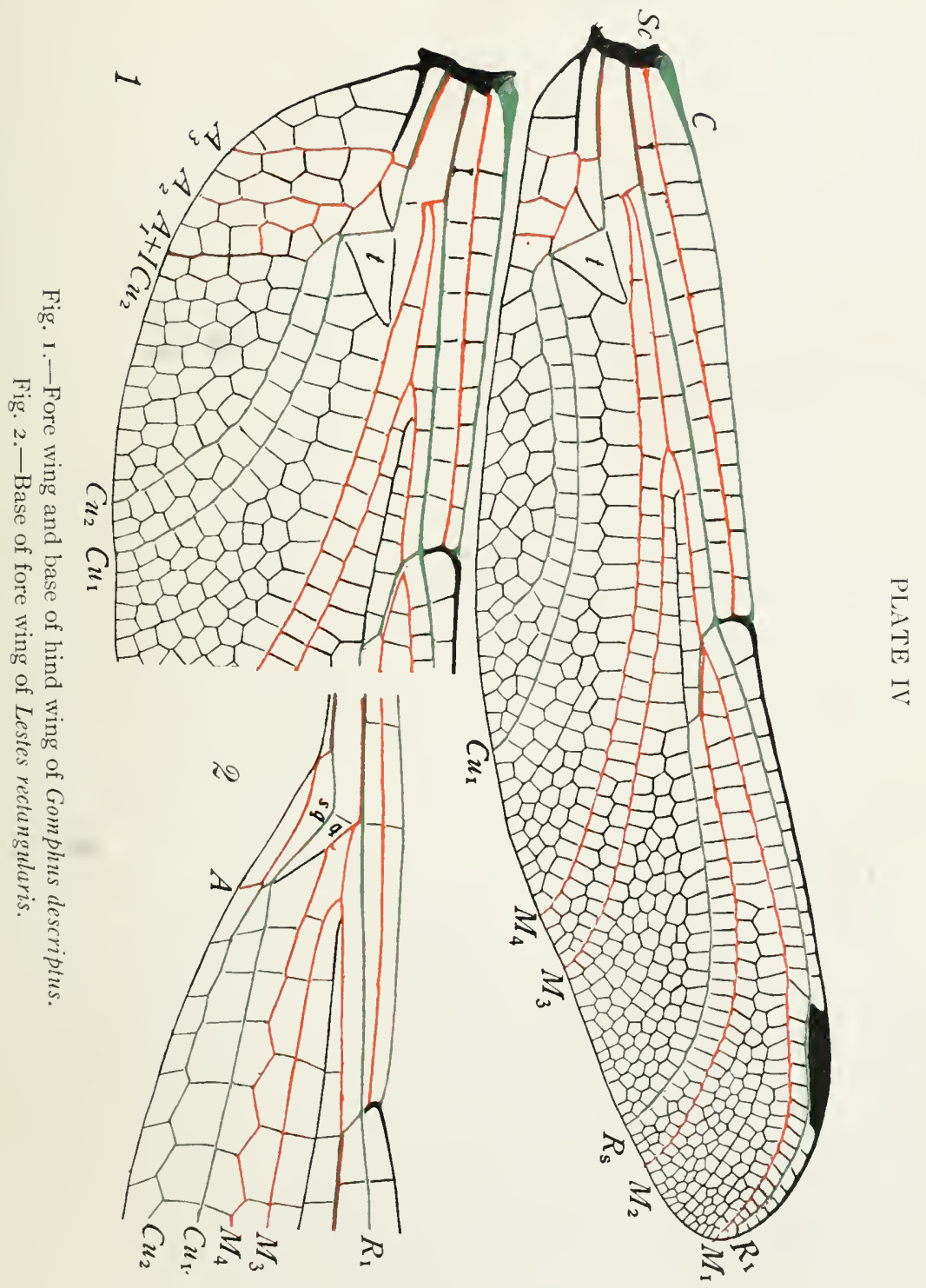



based upon irrefutable ontogenetic evidence is largely due to the labors of Professor J. G. Needham. This author, in collaboration with the writer, first traced the development of the venation through a series of nymphal stages (Comstock and Needham '98-'99), and in a later paper (Needham '०3) he greatly extended his observations on the venation of the wings of insects of this order. More recently, Tillyard ('I4) has made some emendations and additions to the nomenclature of parts of the anal area. The following account is based on these three papers.

While it is easy to recognize the homology of some of the wing-veins of Odonata by a study of wings of adults, there are other veins whose identity was not suspected until the ontogenetic studies referred to above were made.

The richly veined wing of a dragon-fly, at first sight, shows little in common with the hypothetical type. And even when the tracheation of the wing of an old nymph is studied, there are found some striking dis-

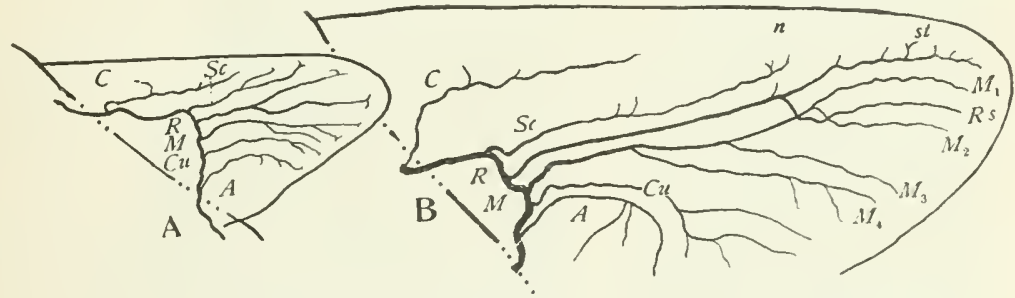

Fig. 227.-Wings of nymphs of Gomphus descriptus, early stages

(From C. \& N.)

crepancies. But in the budding wing of a young nymph we find an arrangement of the tracheæ which is almost that of the typical wing.

Figure 227 represents the tracheation of two nymphs of Gomphus descriptus. The wing figured at A was only one millimeter in length. Here is a costal trachea with some anterior twigs, a subcostal trachea with a terminal fork, a radial trachea with its sector unbranched, a threebranched medial trachea, a cubital trachea which is two-branched in the usual way, and a single anal trachea with three branches, which may represent the three anal trachea, fused at the base.

At $B$ in this figure is represented the tracheation of a somewhat older wing, one measuring three millimeters in length. Here the trachea $\mathrm{M}_{1}{ }_{2}$ has shifted its position and lies across the base of trachea $R_{s}$; and trachea $M_{1}$ lies in front of trachea $R_{\mathrm{s}}$. The medial trachea is now four-branched. The costal and anal trachere are outrun by the others in the occupation of the new territory formed by the growth of the wing, and remain relatively short.

In the wing of a grown nymph (Fig. 228) is seen the culmination of these tendencies. Trachea $\mathrm{M}_{2}$ has followed trachea $\mathrm{M}_{1}$; both of them now lying 
in front of trachea $R_{s}$. The costal trachea is greatly reduced or, rather, outstripped by its competitors; the same is true in a less degree of the subcostal and anal tracheæ. At this stage the veins, which are not represented in this figure, appear as pale brownish thickenings; surrounding all of the principal tracheæ, and also surrounding the small tracheæ and anastomosing tracheoles, which tend to group themselves in the positions of the cross-veins.

Plate $\mathrm{V}$ is a reproduction of a photograph of the wings of a grown nymph of Gomphus descriptus in which both the tracheæ and the forming wing-veins can be seen. A comparison of this figure with Figure 229, which

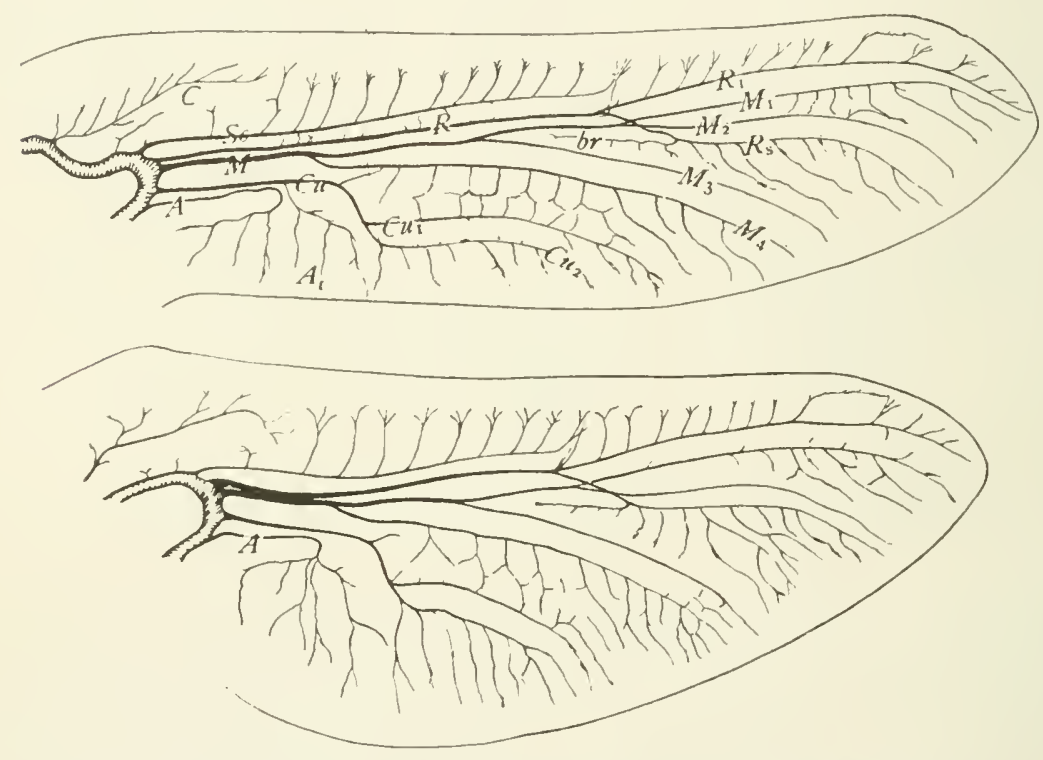

Fig. 228.-Tracheation of the wings of a grown nymph of Gomphus descriptus (After Needham 'o3). In the specimen figured the first branch of the anal vein of the fore wing was switched to vein $\mathrm{Cu}$. In the hind wing this branch was normal.

represents the wings of the adult, and also with the two preceding figures (Figs. 227 and 228) will enable the reader to see the correctness of the conclusions regarding the homologies of the wing-veins, which are indicated by the lettering of Figure 229 and Figure 230. See also Plate IV, Fig. I.

An important factor in the strengthening of the wings of the Odonata is the development of a series of corrugations. This has resulted in certain veins becoming convex and others concave; that is the wings are of the spread fan-like type. In fact the wings of the Odonata are the most perfect examples of this type known. 

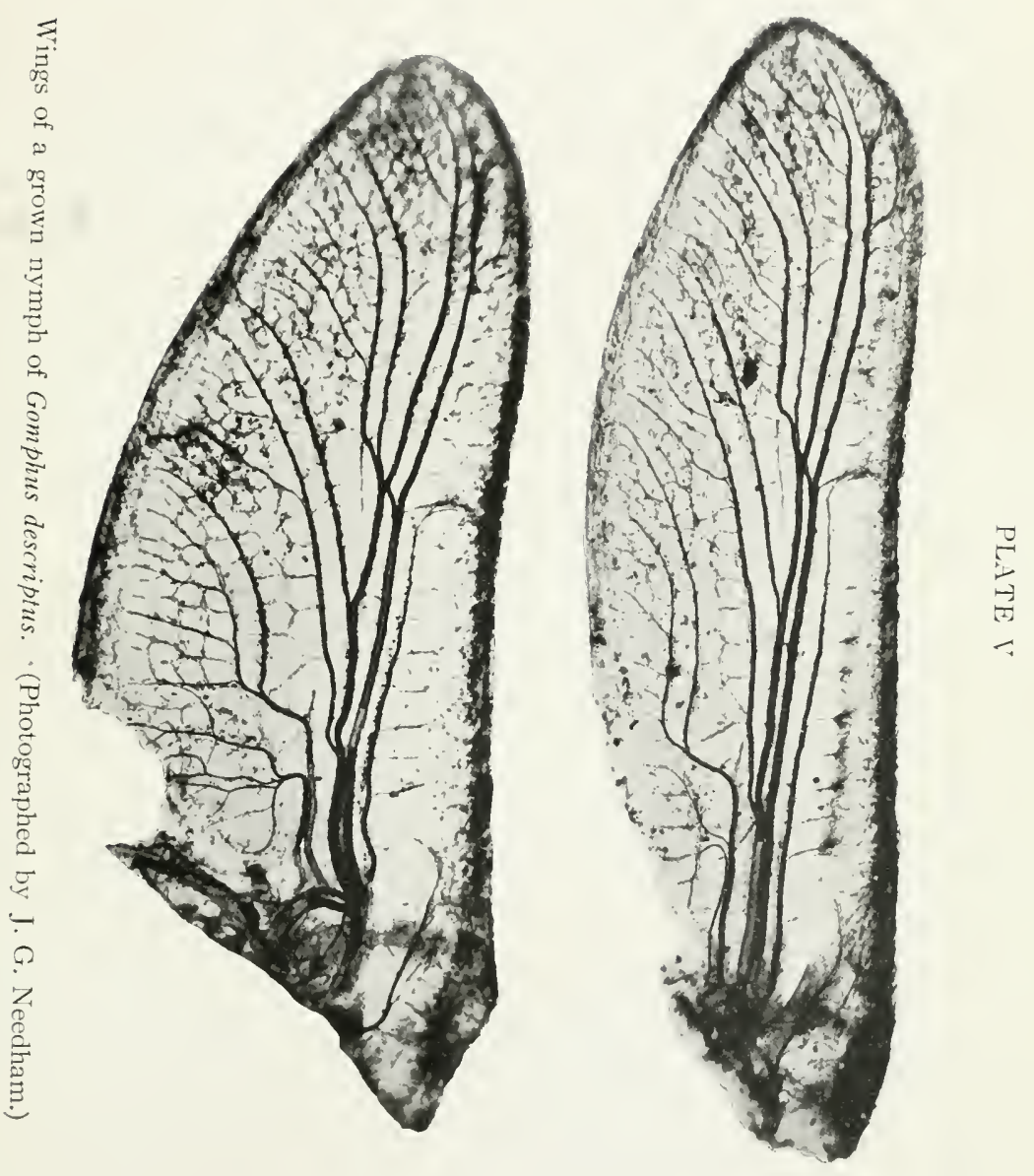

The degree of perfection of the alternation of convex and concave veins that has been evolved in the wings of these insects is shown in the following table by the use of two kinds of type, one indicating convex veins and the other concave veins.

As a branch of a convex vein may be concave, or a branch of a concave vein be convex, it is necessary, in order to indicate the relation of the corru-

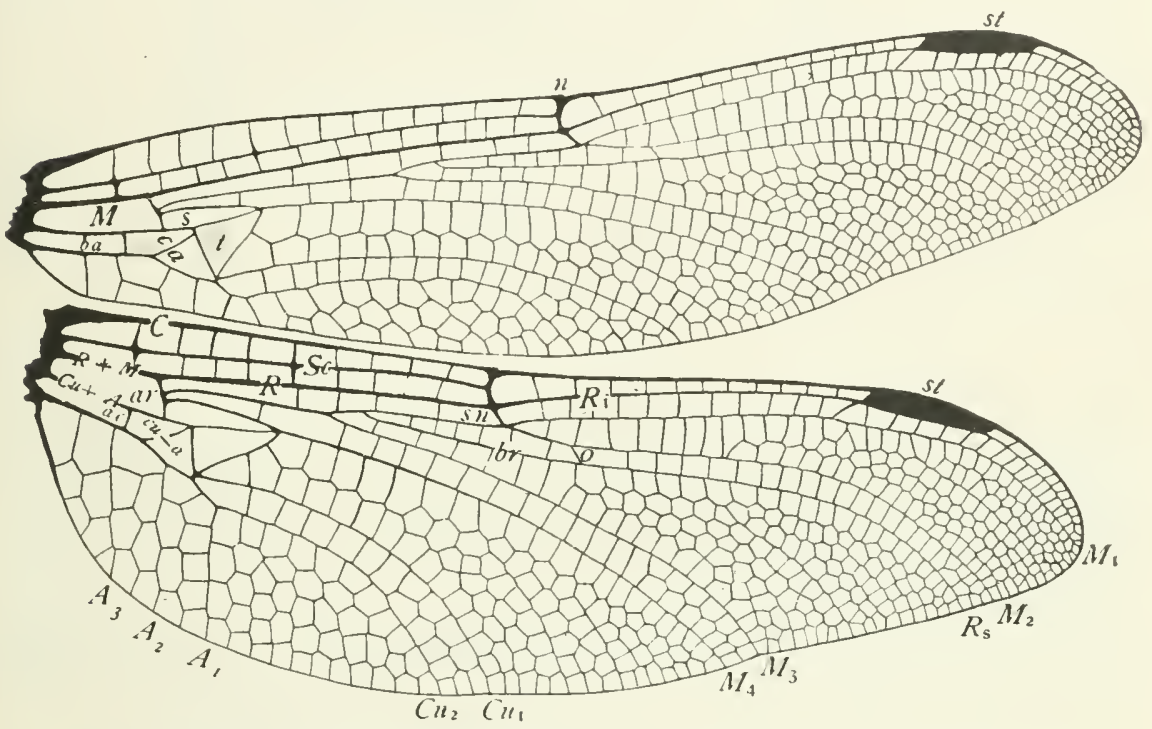

Fig. 229.-Wings of Gomphus descriptus. In the front wing cells or areas are labeled; in the hind wing, veins.

gations to the venation, to indicate the nature of each vein in different parts of the wing. For this purpose four transverse lines have been selected and the nature of the veins crossed by each is indicated in a separate column.

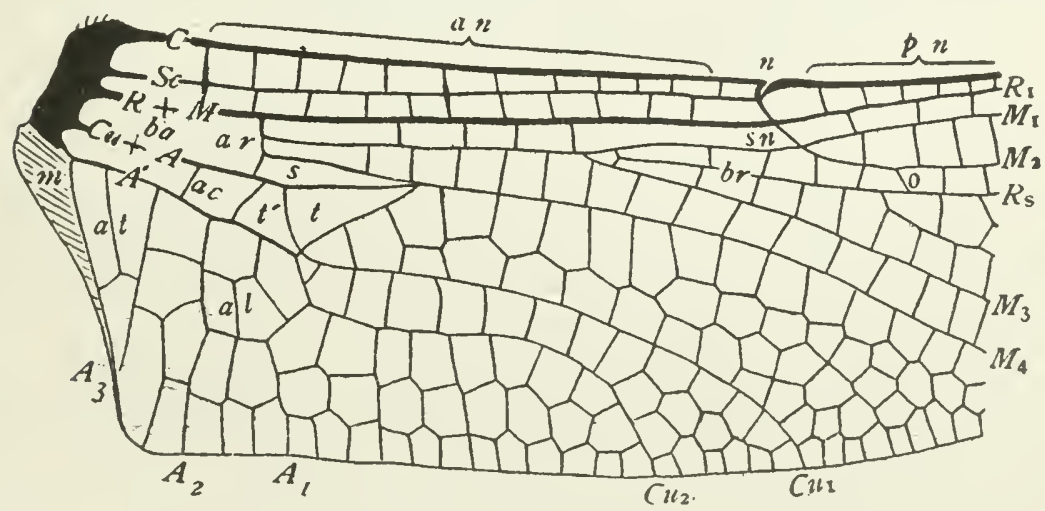

Fig. 230.-Base of wing of Cordulegaster sayi. 
TABLE OF THE WING-VEINS OF THE ODONATA

The convex veins are indicated by boldface type

BASE OF WING BEYOND ARCULUS BEFORE NODUS BEYOND NODUS

Costa

Subcosta

$\mathrm{R}+\mathrm{M}$

$\mathrm{Cu}+\mathrm{A}$

\section{Costa}

Subcosta

$\mathrm{R}$

$\mathrm{Cu}$
Costa

Subcosta

R

Costal margin

$\mathrm{R}_{1}$

$\mathrm{M}_{1}$

IM $_{1}$

$\mathrm{M}_{2}$

$\mathrm{R}_{\mathrm{s}}$

$\mathrm{NI}_{3}$

$\mathrm{M}_{4}$

$\mathrm{Cu}_{1}$

$\mathrm{Cu}_{2}$

$\begin{array}{ll}\mathrm{Cu}_{1} & \mathrm{Cu}_{1} \\ \mathrm{Cu}_{2} & \mathrm{Cu}_{2}\end{array}$

$\mathrm{A}^{\prime}$

Beyond the nodus, there are present, in addition to the veins listed in the last column, a variable number of intercalary veins. As a rule these are alternately convex and concave where more than one are present between two primary longitudinal veins.

The alternation of convex and concave veins, as shown in the table, is perfect in each of the four selected regions of the wing. In the attainment

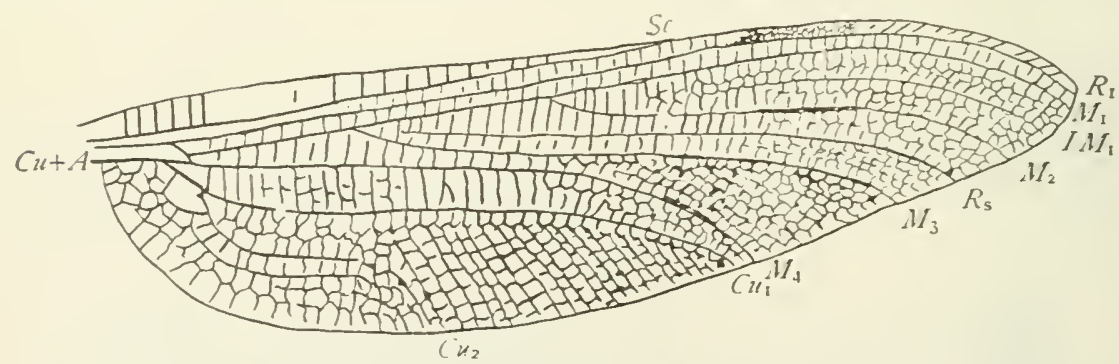

Fig. 231.-Wing of Diasiatomma liasina. (Westwood's figure enlarged.)

of this result some remarkable changes in the nature of reins have taken place. When the convex vein M separates into two stems beyond the arculus, vein $\mathrm{M}_{1+2}+3$ becomes concave while vein $\mathrm{M}_{4}$ remains convex. The concare rein $\mathrm{Cu}$ separates into the concave $\mathrm{Cu}_{1}$ and the convex $\mathrm{Cu}_{2}$.

It is impracticable to introduce the intercalary veins into this table on account of their variability in number and extent of development in different members of the order. An exception has been made in the case of vein $\mathrm{IM}_{1}$, in the last column. This has not been done merely to make perfect the alternation of convex and concave veins listed in this column; although 
it serves this purpose well. In the oldest member of this order known, Diastatomma liasina (Fig. 23r), this intercalary vein is well-developed. It may be regarded, therefore, as one of the primitive veins of this order. Its appearance antedates the development of the nodus, and also that of the secondary anal vein, two of the most distinctive features of modern dragonfly wings. In most of the recent Odonata, however, this vein is less distinct than it is in Diastatomma.

This table will be found useful for the purpose of identifying the veins when in doubt; as the nature of a vein, whether convex or concave, and its relative position with regard to other more easily recognizable veins will serve as sure criteria.

The corrugations of a wing can be best seen by examining it from a point a little above or below its outer end. When viewed in this way, the wing is seen to present a series of prominent, alternating ridges and furrows.

\section{(b) THE SPECIAL FEATURES OF THE WINGS IN THE OdONATA}

In general the veins and areas of the wings of the Odonata are designated as in the accounts of the wings of other orders of insects; but there are certain features in the wings of insects of this order that are peculiar to them, and that have made necessary the adoption of a set of special terms, which are here defined. The following list indicates the abbreviations used to designate these special features of the wings of the Odonata in the illustrations.

Abbreviations.-A', secondary anal vein; ac, anal crossing; al, anal loop; $a l^{\prime}$, supplemental anal loop; $a n$, antenodal cross-veins; $a r$, arculus; $a s p l$, apical supplement; $a t$, anal triangle; $b a$, basal anal area; $b r$, bridge; $c a$, cubital area; cu-a, chief cubito-anal cross-vein; cual, cubito-anal loop; cuspl, cubital supplement; $I M_{1}, I R_{\mathrm{s}}$, etc., intercalary veins; $m$, membranule; $m s p l$, median supplement; $n$, nodus; $o$, oblique vein; $p n$, postnodal cross-veins; $q$, quadrangle; $r s p l$, radial supplement; $s$, supertriangle; $s n$, subnodus; $s q$, subquadrangle; 'st, stigma; $t$, triangle; $t^{\prime}$, subtriangle; $x$, trigonal supplement.

The stigma.-The stigma of the Odonata, like that of certain other insects, is a limited area on the costal margin of the wing, between the middle of its length and the apex of the wing, which is more dense and usually darker in color than the other parts of the wing (Fig. 229, st). The stigma is termed the pterostigma by many writers.

"The stigma is developed upon the cutting edge of the wing at the point of greatest impact against the air. It would seem to serve the double purpose of firmly uniting the veins of the front margin and of increasing the efficiency of the wing stroke by adding weight at this striking point. Its shape and extent vary considerably and are often characteristic of groups; but the stigma seems not to contain in itself such characters for the critical 
determination of the course of specialization as are furnished by surrounding parts." (Needham 'o3).

The nodus. - "The nodus is the stout cross-vein near the middle of the costal border of the wing, joining the costa, the subcosta, and the radius. It is traversed by a more or less evident suture, making a flexible and elastic joint which, without loss of strength in the parts which need rigidity, would seem to allow more effective flexion of the distal parts of the wing" (Needham 'o3), (Fig. 230, n).

The subnodus.- That portion of the radial sector which unites the lower end of the nodus with the median vein is the subnodus (Fig. 230, sn).

The oblique vein. - The short oblique portion of the radial sector appearing as a cross-vein behind vein $\mathrm{M}_{2}$ is the oblique vein (Fig. 230,o).

It should be observed that the radial sector fuses with vein $M_{2}$ for a little way, carrying the oblique vein a variable distance beyond the subnodus.

The bridge.-The vein secondarily developed to connect the radial sector proximally with a branch of media, usually vein $\mathrm{M}_{1+2}$, is termed the bridge (Fig. 230, br).

The formation of the bridge.- "In the adult wing the bridge exhibits no evidence of an origin different from that of the radial sector, with which it is strictly continuous. But a study of the tracheation of the wings of nymphs reveals the secondary nature of the origin of the bridge Plate VI, Fig. 2 is a reproduction of a photograph of a portion of a wing of Anax junius, showing the crossing of the radial sector, and the origin of the trachea that precedes the bridge. The latter is a small twig which arises from the distal end of that portion of the radial sector which becomes the oblique vein, and extends towards the base of the wing in a direct line to the media. This method of formation of the bridge is characteristic of the Aeschnidæ.

"In most Libellulidæ a trachea, or a bunch of tracheoles, descends from near the base of the radial sector and forks at the level of the bridge, one branch going to the distal end of the oblique vein, the other going in a diametrically opposite direction to the media, (Plate VI, Fig. I).

"The illustrations just given exhibit the structure of these parts in nymphs of the suborder Anisoptera. In the suborder Zygoptera (Calopterygidæ and Agrionidæ) there exists a striking difference. If we compare adult wings of the two suborders, there can be no question as to the identity of vein $R_{s}$, or as to its homology in the two groups. But in the suborder Zygoptera, so far as known to us, the tracheæ $R_{s}$ is a branch of the medial trachea. The base of $R_{s}$, however, forms an oblique vein, and a bridge is developed secondarily, as in the Anisoptera. It is probable that there has been a switching of the base of the trachea $R_{s}$ from trachea $R$ to trachea $M$. One has only to examine a well-mounted wing of any dragon-fly nymph to 


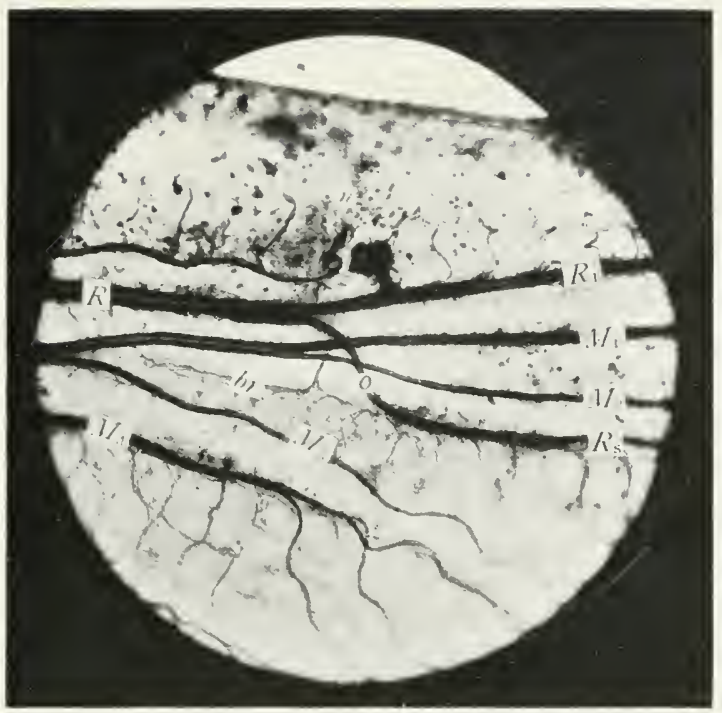

Fig. 1. - The region of the nodus in a right wing of a nymph of Libellula pulchella (From C. and N.)

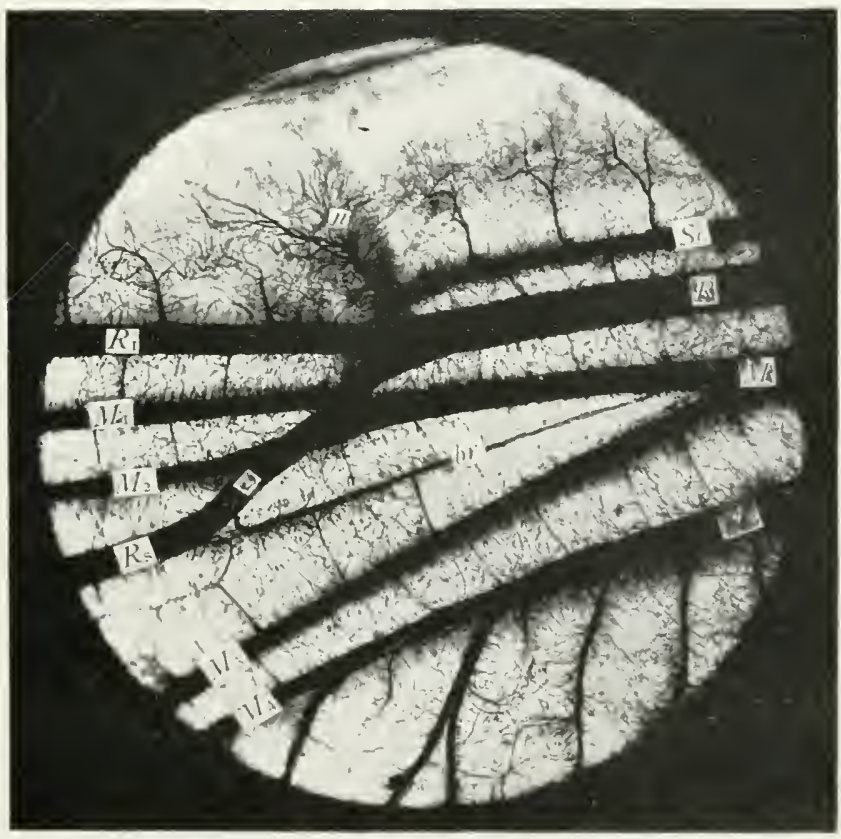

Fig. 2. - The region of the nodus in a left wing of a nymph of Anax iunius. (From C. and N.) 

see in the universal anastomoses of tracheoles, communications already set up between principal tracheæ, any one of which might be enlarged, should necessity arise for the entrance of air from a new quarter. Following this, the atrophy of the old connection would complete the switching; which, we believe is what has happened in the Zygoptera. It follows from this that, so far as this portion of the wing is concerned, the Zygoptera depart more widely from the primitive type than do the Anisoptera" (Comstock and Needham '98).

Plate VII, Fig. I represents a part of a left wing of a grown nymph of Lestes rectangularis and shows the radial sector trachea attached to the median trachea; but it also shows a developing vein in the typical position of the subnodus. And in the wing of the adult (Fig. 232) the position of this vein and its oblique direction, differing in this respect from the cross-veins

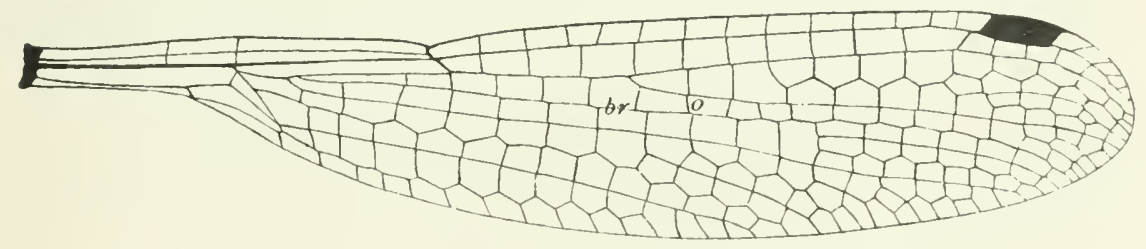

Fig. 232.- Wing of Lestes rectangularis.

between veins $\mathrm{R}_{1}$ and $\mathrm{M}_{1}$ clearly indicate that it is the subnodus. Evidently this part of the radial sector has been preserved although its trachea has been lost.

In his later work Dr. Needham ('o3) points out several modifications of this region of the wing in the Zygoptera. "Either the attachment of the radial sector to media was made at three different places, or else, since its reattachment, it has taken a different course in each of the three different series within the suborder Zygoptera. In the Lestinæ we find it separating from vein $\mathrm{M}_{2}$ far beyond the subnodus, the point of its departure marked by a more or less evident oblique vein, and a long bridge formed about numerous approximated tracheoles and small trachea, mainly derived from neighboring branches of the media. In the Agrioninæ (s. str.) it separates from vein $M_{1+2}$ near the nodus, and there is neither bridge nor oblique vein. In Calopteryx it separates from vein $\mathrm{M}_{1}+2$ far to the proximal side of the nodus, and about in the more usual position of the proximal end of the bridge; indicating that in this group at least a recurrent trachea, such as precedes the bridge in the Aeschnidæ, may have developed into the basal attachment of the radial sector to media."

In most Odonata the distal part of vein $R_{s}$ lies between veins $M_{2}$ and $M_{3}$, or in other words, only two branches of media have invaded the radial area of the wing. But in the Australian Neosticta canescens as figured by Tillyard both trachea $M_{1}+2$ and $M_{3}$ pass over the trachea $R_{s}$. 
On the other hand it is suggested by Tillyard that "forms like Diphlebia, which show a peculiar oblique vein under vein $M_{1}$ far distad from the subnodus, need also a thorough investigation; since in such cases the vein,

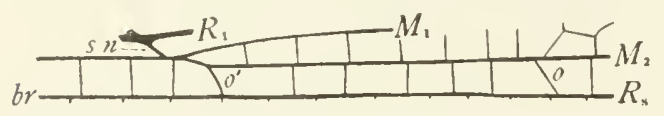

Fig. 233.-A detail from the region of the nodus of Petalura gigantea, showing the bridge and two oblique veins, $o$ ' and o (From Needham ' $o_{3}$ ). at present taken to be $\mathrm{M}_{2}$ may eventually prove to be none other than $\mathrm{R}_{\mathrm{s}}$ itself."

Returning to the Anisoptera, one more interesting modification of the radial sector will be noted. In the wings of some dragon-flies, there exist two oblique veins; this is well-shown in the wings of Petalura gigantea (Fig. 233).

The existence of two oblique veins is doubtless due to a division of the radial sector trachea into two branches one of which follows the course of trachea $\mathrm{M}_{2}$ for a greater distance than the other This condition was observed by Needham in the wing of a nymph of Cordulegaster diastatops (Fig. 234); but in the wing of the adult of this species only one oblique vein is recognizable; evidently the second has become transverse as is the case with the oblique rein in Lestes rectangularis (Fig. 232).

In connection with this division of the radial sector trachea, there arises a problem, the solution of which may be of considerable taxonomic importance. Is this condition a primitive one or has it been acquired? If it be a retention of a primitive condition, the second oblique vein is vein $R_{2}+3$ and the first is $R_{4+5}$; but even in this case the two branches coalesce so that in its distal part vein $R_{\mathrm{s}}$ is unbranched.

The intercalary reins.-A result of the development of the fan-like type of wing in this order is the development of a greater or less number of secondary longitudinal veins. Many of these veins appear to be of the accessory vein type; but there is no doubt that they arose as intercalary veins, and became attached directly to the principal veins secondarily.

All of the stages in the derelopment of an intercalary vein can be seen by studying the distal end of a few wings of members of this order. As a result of the formation of folds in the wing there is a marked tendency for the zigzag lines of crossveins between adjacent rows of cells to become straightened

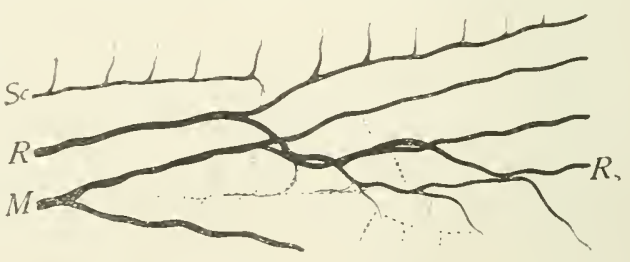

Fig. 234.-Tracheation of the nodal region of a wing of a nymph of Cordulegaster diastatops (From Needham 'o3). along the crest of a fold or along the bottom of a furrow, and thus an intercalary vein is formed. The proximal end of such a vein is usually connected by cross-veins to both of the two veins between which it is 
formed. Intercalary veins in this order do not end free as they commonly do in the Ephemerida.

Excellent illustrations of the modification of what is obviously an intercalary vein into one that appears to be an accessory vein can be seen by comparing homologous veins in the fore and hind wings of Chalcopteryx rutilans (Fig. 235), as was pointed out by Needham ('o3). In this species vein $I M_{1 b}$ of the hind wing is obviously an intercalary vein; but in the front wing this vein appears to be a branch of vein $\mathrm{M}_{2}$. The same difference eixsts between veins $I R_{\mathrm{sa}}$ of the two wings; that of the fore wing
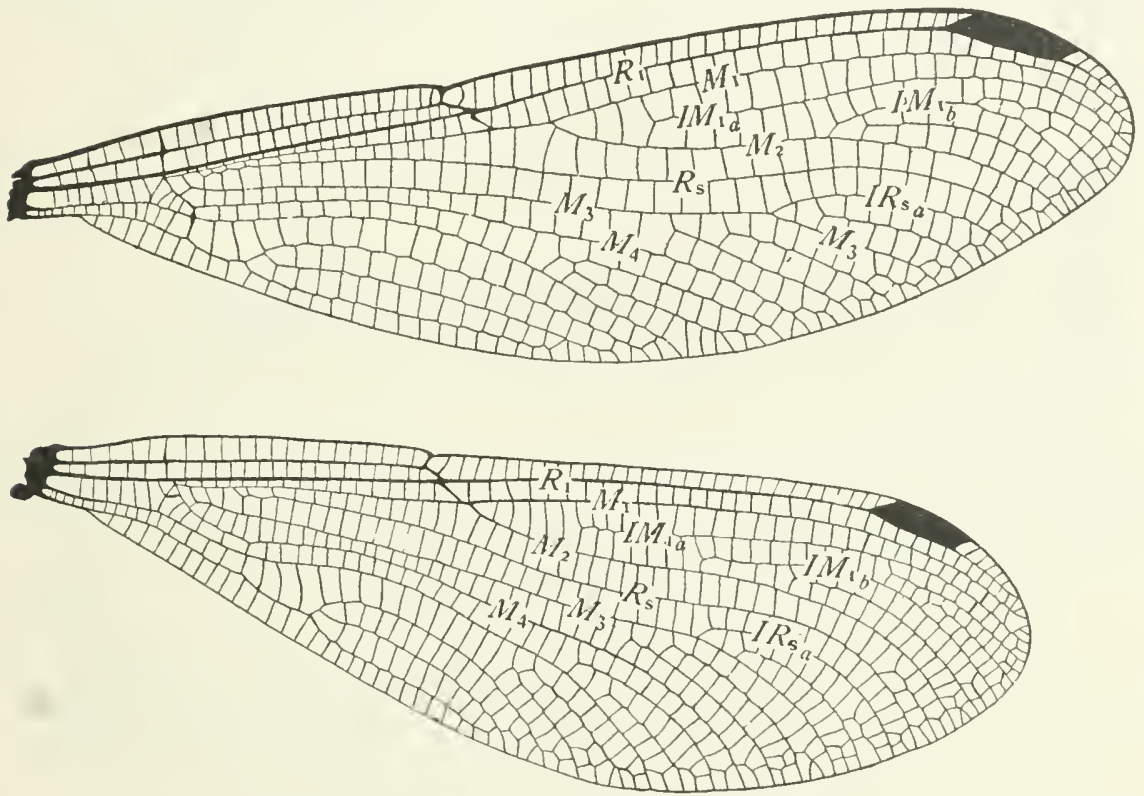

Fig. 235.-Wings of Chalcopteryx rutilans.

appearing to be a branch of vein $\mathrm{M}_{3}$, while that of the hind wing is but little more closely connected with vein $M_{3}$ than it is with vein $R_{5}$.

The resemblance of the intercalary veins to accessory veins is even more marked in the wings of nymphs of this order than in the perfected wings. This is due to the fact that in the Odonata there has been developed a most wonderful extension of the tracheation of the wings; not only are the principal veins traversed by tracheæ, but they penetrate every cross-vein as well. It is not strange, therefore, that branches of the principal tracher extend into the intercalary veins, giving them the appearance of accessory veins. This is well-shown in the wings of a nymph of Gomphus descriptus (Plate V).

The intercalary veins were termed interpolated sectors by Needham ('o3), the term sector being commonly used in the older terminologies for branches 
of veins in this order (see table at the end of this chapter). But for the sake of uniformity with descriptions of the intercalary reins of other orders, and because the intercalary veins are not primarily branches of principal veins, I have not used the term sector in this connection.

The supplements.- In many of the Odonata there exists in the broader areas of the wings secondary longitudinal veins of an adventitious nature;

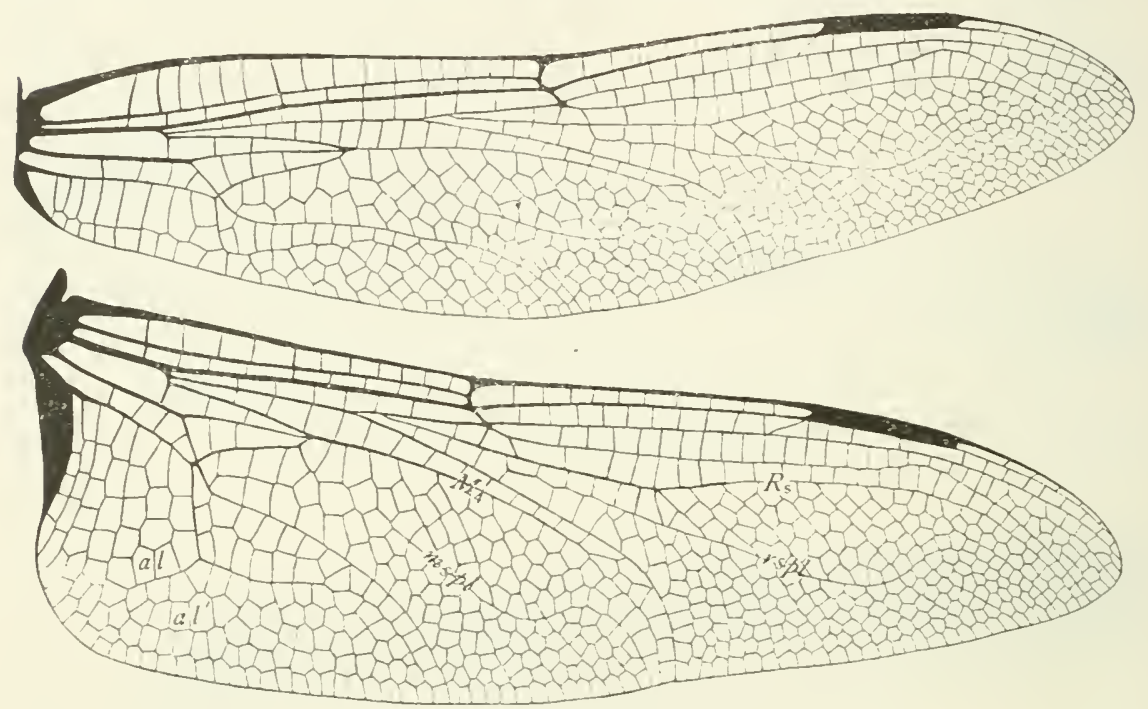

Fig. 236.- Irings of Anax junius.

these were termed supplements by Needham ('o3). The supplements are developed independently of tracheæ and may extend in a direction more or less transverse to that of the intercalary veins.

Five supplements have been named; two of these are shown in the wings of Anax junius. One, which is situated behind the radial sector, is the radial supplement (Fig. 236, rspl); the other, which is situated behind vein $\mathrm{M}_{4}$, is the median supplement (Fig. 236, mspl).

The third supplement is well-shown in the wings of Orthemis; this occurs in the area $M_{1}$ and resembles the two supplements just described; it is termed the apical supp.ement, Fig. 240, aspl. The fourth is the trigonal supplement; this starts from the outer side of the triangle and extends outward; it is, as a rule, less definite than the radial and median supplements, being more obviously the result of a straightening out of the zigzag line between two rows of cells. Sometimes it joins the median supplement; in other cases, there is one row of cells between its distal part and the median supplement; both conditions exist in the wings of Boyeria irene (Fig. 237, x, x); the former in the hind wings; the latter in the fore wings. 
The fifth named supplement is the cubital supplement. This is described later; it is found in the cubito-anal loop of the Libellulidæ.

The manner of development of a supplement is illustrated by Plate VIII, Fig. I which represents a part of the wing of a grown nymph of Anax junius. The principal trachea shown is the radial sector trachea, whose branches extend into intercalary veins; the strong developing vein that sets across them, bending toward the radial sector trachea at both ends, is the radial supplement $(r s p l)$. It will be seen to be a purely cuticular vein, without trachea of its own (Needham 'o3). In Fig. 2 of the same plate, both the radial and the median supplements are shown.

The antenodal cross-veins.- Much use is made in taxonomic work of the two series of cross-veins that are nearest the costal margin of the wing. Those of these cross-veins that are situated between the base of the wing and the nodus are termed the antenodal cross-ieins (Fig. 230, an). The first of these two series of antenodal cross-veins extend from the costa to the subcosta; the second, from the subcosta to the radius. The antenodal cross-veins are termed the antecubital cross-veins by some writers.

"Specialization is to be traced among these cross-veins in their reduction in number and matching in position in the two series, and in the hyper-

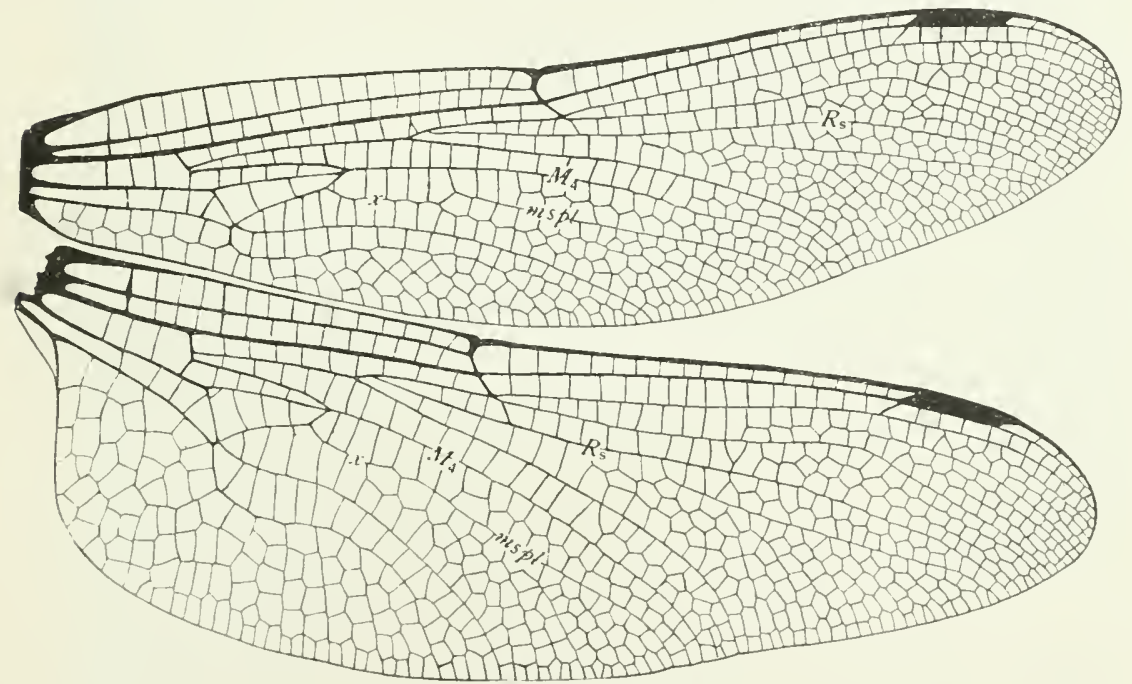

Fig. 237.-Wings of Boyeria irene.

trophy of some of them to form stout triangular trusses, which entirely fill, in section, the furrow between the costa and radius. Two antenodals, some distance apart, are thus hypertrophied in most Aeschnidæ, one at either side of the arculus; in the Thorinæ, but one, and that one meeting the arculus; in Synthemis, alternate antenodals are thickened, but to a less degree." (Needham 'o3). 
The postnodal cross-veins. - The two series of cross-veins nearest to the costal margin of the wing and between the nodus and the apex of the wing are termed the postnodal cross-veins (Fig. 230, pn). The first of the two series of postnodal cross-veins extend from the costa to vein $\mathrm{R}_{1}$; the second, from vein $R_{1}$ to vein $M_{1}$. The postnodal cross-veins are termed the postcubital cross-veins by some writers.

The arculus.-Near the base of each wing there is what appears to be a cross-vein extending from radius to cubitus and from which media appears to arise; this is the arculus (Fig. $230, a r$ ). The arculus is really composed of a section of media and a cross-vein.

For a short distance near the base of the wing radius and media coalesce (Fig. 230, $\mathrm{R}+\mathrm{M}$ ). The double nature of this vein is readily seen by an examination of the wings of an adult, and in the grown pupa the radial and medial trachea are closely parallel in this region of the wing (Fig. 228). At the point where the two veins separate media suddenly bends away from

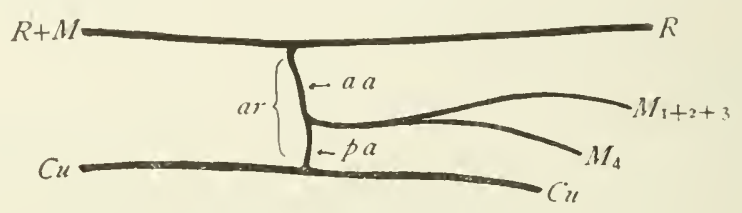

Fig. 238.-Diagram of the arculus.

the radius and extends for a short distance towards the inner margin of the wing; it then makes another sudden bend and extends towards the outer margin of the wing. Frequently, as in Cordulegaster (Fig. 230) the veins $\mathrm{M}_{1+2}+_{3}$ and $\mathrm{M}_{4}$ separate before the second bend is made in which case two veins appear to arise from the arculus. That part of the arculus that extends from this second bend in media to ctubitus is formed by a cross-vein; this cross-vein is termed the posterior arculus (Fig. $238, p a$ ).

The triangle of the Anisoptera.-In the suborder Anisoptera or dragonflies there is near the base of the wing, a well-marked area of the wing, which is usually triangular in outline (Fig. $230, t$ ); this area is termed the triangle. This name is applied to this area even when it is not triangular in outline. The various modifications of the triangle and of the adjacent cells are much used in taxonomic work.

The triangle is formed as follows: a short distance beyond the arculus, the cubitus makes a sudden bend and extends for a short distance towards the inner margin of the wing, to the point where it divides into veins $\mathrm{Cu}_{1}$ and $\mathrm{Cu}_{2}$. From each end of the short section of the main stem of cubitus that extends transversely to the length of the wing a cross-vein extends to vein $M_{4}$, the two cross-veins reaching $M_{4}$ at the same point or approximately 


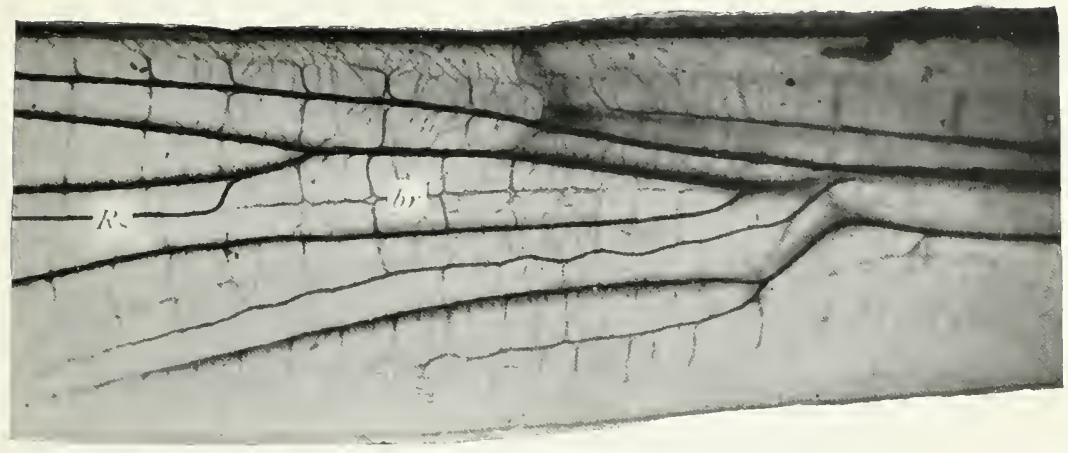

Fig. 1.-Basal part of a left fore wing of a nymph of Lestes rectangularis. (Trom Neadham, 'oz).

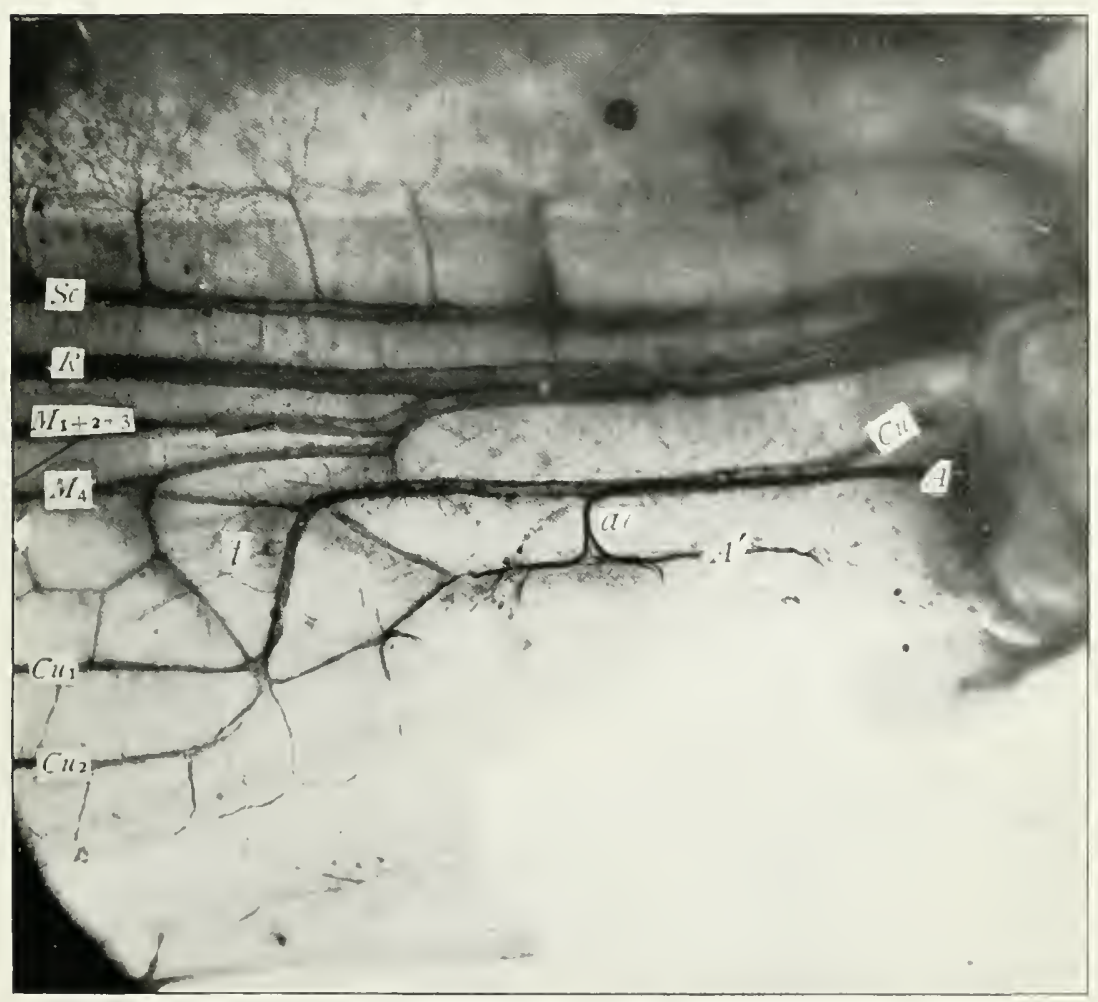

Fig. 2.-Basal part of a left fore wing of Lanthus parrulus.

(From Needham, 'O3). 

so. These two cross-veins and the transverse section of the cubitus outline the triangle (Plate IV, Fig. I).

The triangle in Gomphus consists of a single cell; but frequently this area is divided by one or more cross-veins into two or more cells (Fig. 237).

The supertriangle.-This term is applied to an area of the wing lying immediately in front of the triangle and extending towards the base of the wing to the arculus (Fig. 230, s). Like the triangle, this area of the wing may consist of a single cell, as shown in Figure 230 , or may be divided by one or more cross-veins (Fig. 237).

The anal veins. - In the course of the evolution of the anal area of the wings of insects of this order, there has been a specialization by reduction, which has resulted in the preservation of a single anal vein.

There is available no data showing the course of this reduction. In the youngest nymphs that we have studied there is a single branched vein in the anal area of each wing; and it is impossible to determine whether this represents one, two, or all three of the primitive anal veins. For this reason this vein is designated as the anal vein, without any predicate, and its principal branches as $A_{1}, A_{2}, A_{3}$, and $A_{4}$. The use of the terms ist $A$, $2 \mathrm{~d} \mathrm{~A}$, and $3 \mathrm{~d} \mathrm{~A}$, for this purpose would indicate homologies that we do not know to exist.

The anal crossing.- The anal vein coalesces with vein $\mathrm{Cu}$ for a short distance at the base of the wing (Fig. 230, Cu $+\mathrm{A}$ ); and then separates from vein $\mathrm{Cu}$ and extends another short distance transversely to the length of the wing (Fig. 230, ac); it then makes a second abrupt turn and extends outward. The short section of this vein that extends transversely has been designated by Tillyard ('I4) the anal crossing (ac). See also Plate IV, Fig. I).

The anal crossing has the appearance of a cross-vein, and has been regarded as one; it is the first cubito-anal cross-vein of Needham's paper ('o3). Needham, however, furnished the data upon which the conclusions regarding the course of the anal vein, as stated above, were based. His figures of the tracheation of the nymphal wing of Lanthus parvulus (Plate VII, Fig. 2) and of the nymphal wings of Gomphus descriptus (Plate V) were what first suggested these conclusions.

Although Needham recognized the course of the anal trachea, he believed, at the time he first figured it, that it did not indicate the course of the anal vein; but that the basal part of the anal trachea had been shifted forward from the position in which the anal vein is later developed, and that the vein marked $\mathrm{A}^{\prime}$ in Figure 230 is the basal part of the anal vein.

Tillyard (' 14 ) has shown, however, that the vein $\mathrm{A}^{\prime}$ is a secondarily developed bridge between the anal crossing and the base of the wing; a conclusion that was independently reached by the writer before Tillyard's paper was received in this country. 
It is difficult to see what should cause the anal trachea to assume so erratic a course if the direct channel remained open, as was assumed by the earlier view. There are well-known instances where the tracheation of the wings of pupæ do not correspond with the venation of the adult wings; the Hymenoptera is an excellent illustration of this. But in the Hymenoptera the developinent of the trachere of the wings has been retarded so that the formation of the rein carities precedes the tracheation of the wings. When the tracher push out into the previously formed wing-veins, they follow the most direct paths and do not preserve their primitive arrangement.

In the Odonata the derelopment of the tracheæ precedes the formation of the vein cavities and consequently the conditions are very different from what they are in the Hymenoptera. In other parts of the wings of Odonata there is a close correspondence between tracheation and venation; it is fair to assume that this is the case in the anal area also.

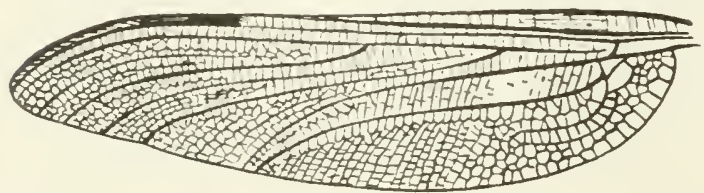

Fig. 239.-Westwood's figure of Diastatomma liasina (From Brodie).

The course of the anal vein, coalescing with cubitus for a space and then bending abruptly away, is quite analogous to the course of media which coalesces with radius for a space and then bends abruptly away to form part of the arculus; evidently the same forces have acted on these two pairs of veins to produce similar results.

The secondary anal iein.-The figures referred to above (Plate VII, Fig. 2 and Plate $V$ ) show that the anal trachea gives off a branch that extends from the distal end of the anal crossing towards the base of the wing. This is trachea $A_{4}$ of Tillyard ('I 4 ), and is the precursor of a longitudinal rein, which has been regarded as the anal vein. It is evident, howerer, that this is a secondary rein, which has been developed in a way analogous to the development of the bridge of the radial sector. It has been designated by Tillyard ('I 4 ) the secondary anal vein or vein $\mathrm{A}^{\prime}$.

If vein $A^{\prime}$ be a secondary vein, obviously there must have been a period in the phylogeny of the Odonata when it did not exist, fortunately there has been preserved a record of this condition.

The oldest fossil remains of the Odonata are from the Lower Lias. There are but few of these, Handlirsch lists six species, and in only two of them is the anal area of the wing well-preserved. But in one of these two, Diastatomma liasina (Fig. 23I and 239) the area back of the coalesced cubitus and anal veins is furnished with an irregular network of veins, and vein $\mathrm{A}^{\prime}$ is wanting.

This remarkable species was described and figured by Strickland ('40); but a more careful figure "drawn from the original" was made by Professor 
J. O. Westwood for the work on Fossil Insects by Brodie ('45). Figure 239 is a photographic reproduction of Westwood's figure.

It is evident from Professor Westwood's figure that while the venation of the wing is not wel'-preserved in some parts of the wing it is distinctly preserved in the anal area.

The basal anal area.-At the base of the wing there is a defintely outlined area, which is bounded in front by vein $\mathrm{Cu}+\mathrm{A}$, distally by the anal crossing, and behind by the secondary anal vein, vein $\mathrm{A}^{\prime}$. This may be termed the basal anal area (Fig. 230, ba).

The cubital area.-That area of the wing which lies between the main stem of cubitus and the anal vein, and which is bounded proximally by the anal crossing, may be termed the cubital area (Fig. 229, ca). This area corresponds to cell $\mathrm{Cu}$ of insects with few wing-veins. In many genera this area consists of two cells, the second of which is the subtriangle (Fig. 230, $t^{\prime}$ ).

The anal triangle.- In some of the Anisoptera there is a well-marked triangular area which is bounded in front by vein $\mathrm{A}^{\prime}$ and distally by vein $\mathrm{A}_{3}$; this is known as the anal triangle (Fig. 230, at).

The membramule.-In the Anisoptera there exists at the base of the anal area a portion of the wing which is not traversed by veins and which is usually of darker color than the adjacent parts of the wing; this is the membranule (Fig. 230, $m$ ).

The chief cubito-anal cross-vein.-There is a cross-vein that extends across the cubital area from the main stem of cubitus to the anal vein that is present in so large a proportion of the members of this order and which is of so much taxonomic importance that it merits a distinctive name. It has been termed the second cubito-anal cross-vein; but this name is no longer tenable, the so-called first cubito-anal cross-vein being a part of the anal vein, the anal crossing; the term chief cubito-anal-cross-vein is, therefore, suggested for this vein (Fig. 229, cu-a).

The subtriangle.-That part of the cubital area of the wing that is beyond the chief cubito-anal cross-vein, and which is bounded on one side by the triangle, is termed the subtriangle (Fig. 230, $t^{\prime}$ ). The subtriangle may be a single cell or it may be divided by cross-veins (Fig. 237).

The subtriangle is not so constantly a definite area of the wing as is the triangle; for in many genera it is not distinctly set off from the remainder of the cubital area, owing either to the absence of the chief cubito-anal cross-rein, or to the presence of several cross-veins, making it difficult to determine the chief cubito-anal cross-vein (Fig. 237).

The anal loop.-In many of the Anisoptera the broadly expanded anal arca of the hind wings is strengthened by an arrangement of certain of the veins which has been designated the anal loop. The anal loop is found especially in the subfamily Aeschninæ and throughout the family Libellulidæ, and varies greatly in form in the different members of these groups. 
The hind wing of Gomphus descriptus (Plate IV) may be taken as an illustration of a wing which lacks an anal loop. In this wing veins $A_{1}, A_{2}$, and $A_{3}$ extend in a nearly parallel direction to the inner margin of the wing.

In Cordulegaster sayi (Fig. 230) vein $\mathrm{A}_{1}$ coalesces with vein $\mathrm{Cu}_{2}$ for a short distance and then extends obliquely towards the anal angle until it is met by a branch of vein $A_{2}$, in this way there is enclosed a polygonal space between veins $A_{1}$ and $A_{2}$ and is formed what is termed the anal loop (Fig. 230, al).

The supplemental anal loop.-In some genera of the Aeschninæ there exists a second anal loop, which is termed the supplemental anal loop this is shown in the hind wing of Anax junius (Fig. 236, al').

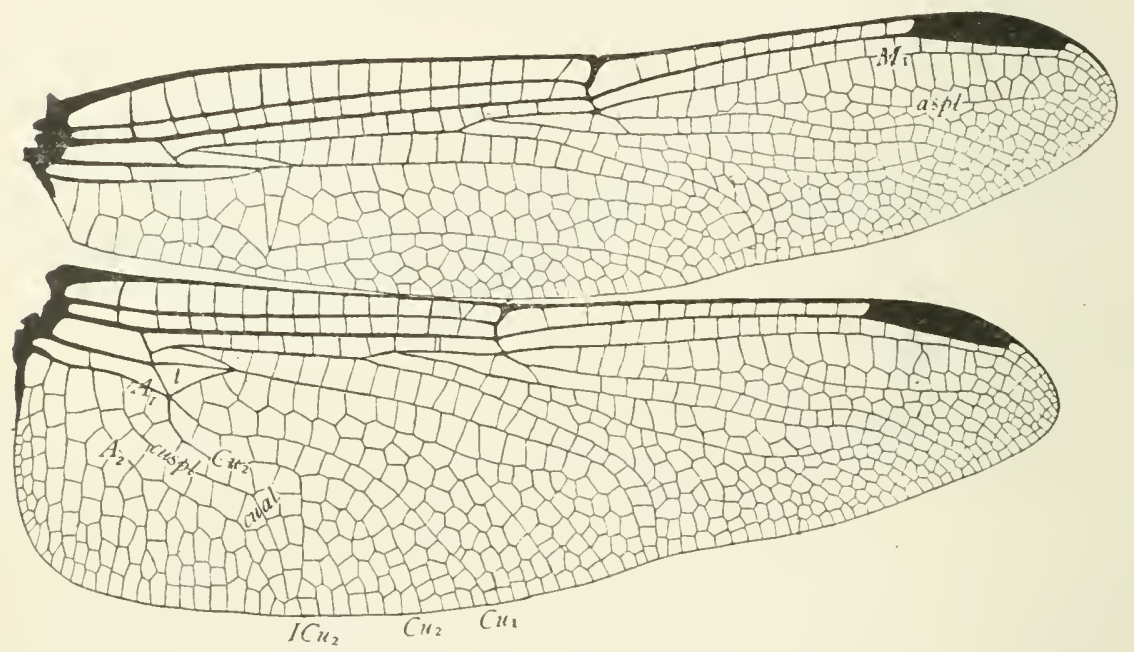

Fig. 240.-Wings of Orthemis ferruginea.

The cubito-anal or foot-shaped loop.-In the Libellulidæ vein $\mathrm{A}_{1}$ is greatly shortened; it ends at the point where it joins vein $\mathrm{Cu}_{2}$ at the posterior corner of the triangle (Fig. 240). The result of this is that the loop formed in the anal area is developed between veins $\mathrm{A}_{2}$ and $\mathrm{Cu}_{2}$; for this reason it is termed the cubito-anal loop (Fig. 240, cual). On account of its peculiar form it was termed by Needham the foot-shaped loop; and for the same reason 'Tillyard designates it the Italian loop, as it resembles in outline a map of Italy.

The cubital supplement.-The cubito-anal loop is divided longitudinally by a midrib-like vein, which is not formed about a trachea; this vein is termed by Tillyard ('I4) the cubital supplement (Fig. 240, cuspl).

The quadrangle of the Zygoptera.-In the suborder Zygoptera, or damselflies, the cubitus and its first branch, vein $\mathrm{Cu}_{1}$, extend in a comparatively direct course from the base of the wing outward (Plate IV, Fig. 2); the 


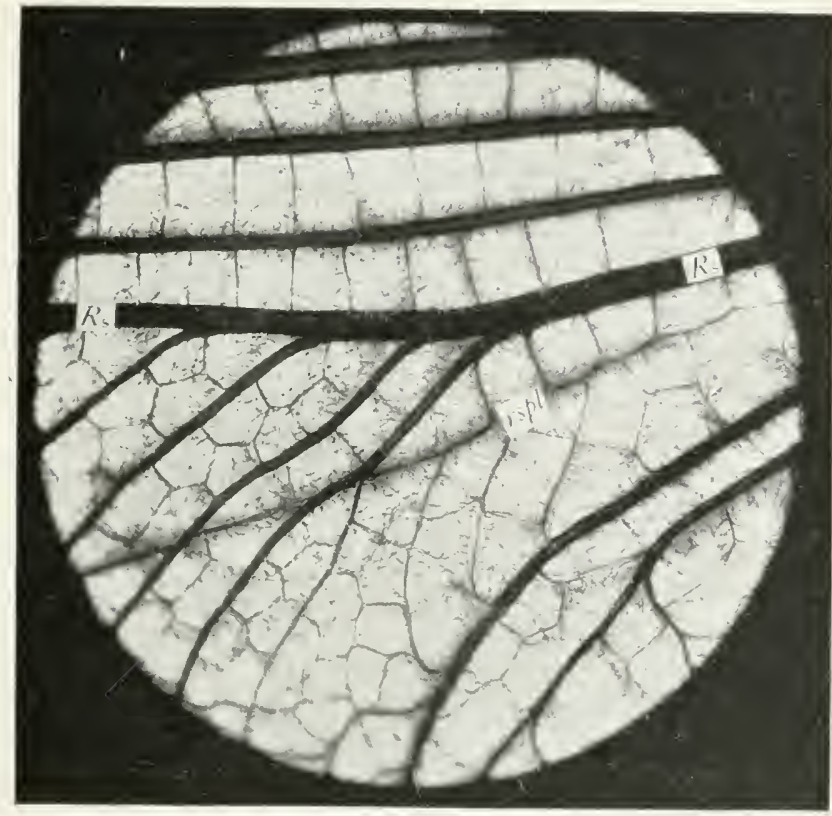

Fig. 1.-Small portion of a left wing of a nearly grown nymph of Anxw junius. (Photographed by J. G. Needham).

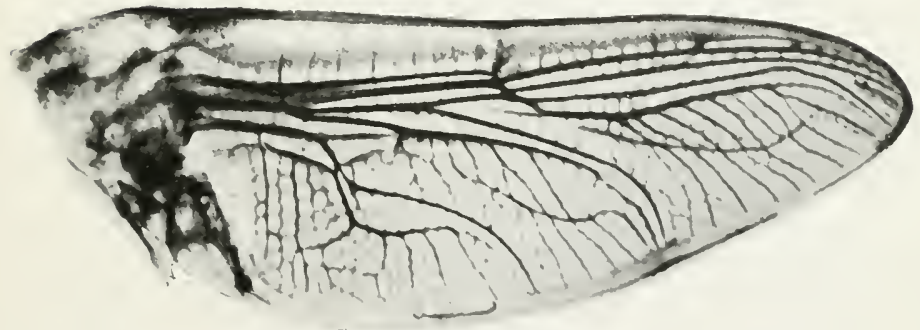

Fig. 2.-Right wing of a nymph of Anax junius. (Photographed by J. G. Needham). 

abrupt bends in these veins in the region of the triangle, which are so characteristic of the Anisoptera, are only slightly developed here. This results in the areas corresponding to the triangle and supertriangle of the

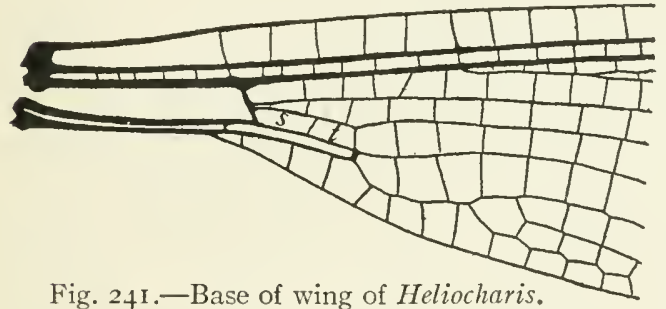

Fig. 241.-Base of wing of Heliocharis. Anisoptera being in a direct line and forming a quadrangular area, which is termed the quadrangle (Plate IV, Fig. 2, q).

In a large part of this order, the cross-vein separating the parts of the quadrangle corresponding to the triangle and the supertriangle of the Anisoptera is lacking, in which case the quadrangle consists of a single cell (Plate IV, Fig. 2, q). In some members of this suborder, as Heliocharis, it is present. In Figure 24I representing the base of a wing of a species of this genus, the two cells of the quadrangle are labeled $t$ and $s$ to facilitate comparison with figures of wings of Anisoptera. In certain other members of this suborder the quadrangle is divided into several cells by cross-veins (Fig. 242).

The subquadrangle of the Zygoptera.-The cubital area of the wing is usually quadrangular in outline in the Zygoptera, and is termed the subquadrangle, as it lies immediately behind the quadrangle (Plate IV, Fig. 2, $s q$ ). Like the quadrangle, it may consist of a single cell or it may be divided by cross-veins (Fig. 242).

\section{(c) THE Methods of specialization of the Wings of the odonata}

The more striking of those features that distinguish the wings of the Odonata are easily observed; and most of them do not occur in the wings of other insects. They are the following: the invading of the area of the radial sector by one or more of the branches of media, this probably occurs also in the Ephemerida; the peculiar arrangement of the veins that has resulted in the formation of the triangle of the Anisoptera and the quadrangle of the Zygoptera; the presence of the nodus, this is very distinctive in appearance, but a nodal furrow occurs in certain other insects, as in Cicada,

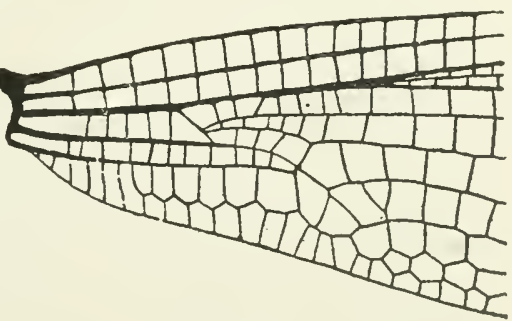

Fig. 242.-Base of wing of IIetcerina. for example; the development of a secondary anal vein; and the most perfect development of the spread fan-like type of wing. An approach to the latter is seen in the Ephemerida; and may have existed in the Protodonata, a group of insects of the Carboniferous period, that are 
believed to represent the connecting link between the Palæodictyoptera and the Odonata, and in which there was an even greater number of intercalary veins developed than exists in the Odonata.

The characteristics enumerated above exist in all wings of the Odonata known excepting one. In Diastatomma liasina (Fig. 23 T), which was found in the Lower Lias in England, there is neither a nodus nor a secondary anal vein. This is one of the oldest of the Odonata known, and may be regarded as the nearest approach to the stem form of the Odonata yet discovered. The presence in this wing of a well-developed intercalary vein in area $\mathrm{M}_{1}$ (Fig. 23I, IM $\mathrm{M}_{1}$ ) indicates that the perfection of the alternation of convex and concave veins had already been attained.

Passing from the consideration of those specializations that distinguish the order Odonata as a whole to those that mark its subdivisions, we come into a field that can be adequately treated only by those having a very extended knowledge of the order, a field that the writer will not presume to enter. A notable contribution to it has been made by Professor Needham in his "A Genealogic Study of Dragon-fly Wing-Venation" ('o3). As anyone working in this field will need to consult this fundamental paper, I will not take the space to abstract it here.

(d) Comparison of terminologies of the WING-VEINS OF the odonata

\begin{tabular}{|c|c|c|}
\hline De Selys-Longchamps & Redtenbacher & Comstock and Needham \\
\hline Nervus costalis & I & Costa \\
\hline " subcostalis & II & Subcosta \\
\hline "medianus & $\mathrm{III}_{1}$ & Radius; radius-one $R ; R_{1}$ \\
\hline Sector principalis & $\mathrm{III}_{2}$ & Media-one $\quad \mathrm{M}_{1}$ \\
\hline “ intercalaris & $\mathrm{III}_{3}$ & Intercalary $\mathrm{M}_{1}$ \\
\hline " nodalis & IV & Media-two \\
\hline " subnodalis & $\mathrm{V}$ & Radial sector \\
\hline " medius & $\mathrm{VI}$ & Media-three \\
\hline " brevis & VII & Media-four \\
\hline " trianguli superior & VIII & Cubitus-one \\
\hline " trianguli inferior & $\mathrm{IX}$ & Cubitus-two \\
\hline
\end{tabular}




\section{CHAPTER XII}

\section{THE WINGS OF THE PLECOPTERA}

(a) the more general features of the wings of the plecoptera

THE members of this order have four membranous wings (Fig. 243). In some genera the branches of the principal veins are reduced in number

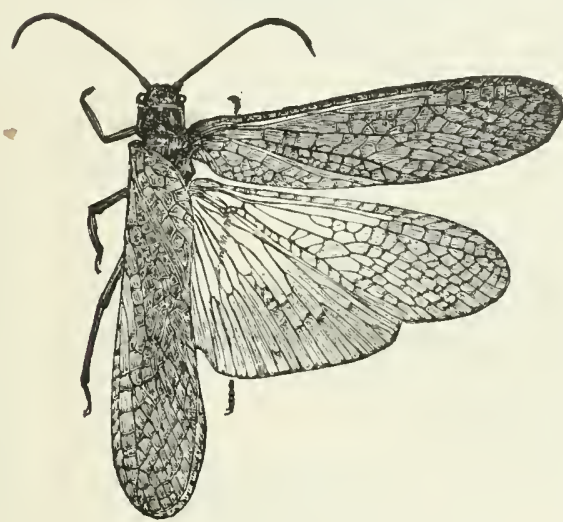

Fig. 243.-Pteronarcys dorsata. and there are comparatively few cross-veins; in others, accessory veins are developed and there are many cross-veins. The hind wings are a little shorter than the fore wings, but usually, owing to the expansion of the anal area, they are considerably larger than the fore wings. No organ for uniting the two wings of each side has been developed. When at rest the wings are folded over the abdomen. In a few members of the order the wings of the male are greatly reduced in size, and in some males the wings are wanting.

\section{(b) THE TRACHEation OF THE Wings OF THE PLecoptera}

The most striking feature of the tracheation of the wings of the Plecoptera is the absence of the basal transverse trachea; there being no connection between the costo-radial and the cubito-anal groups of tracheæ (Fig. 244). This is a generalized feature, which has been observed as yet only in this order, in certain cockroaches, and in some Homoptera. In each of these cases, the medial trachea is a member of the costo-radial group.

In the wings of nymphs of the Plecoptera, the cross-veins are not preceded by tracheæ (Fig. 244). It is easy therefore to distinguish the crossveins from the other veins in this order by a study of the wings of nymphs. It should be noted, however, that in certain genera, as Acroneuria and Pteronarcys for example, accessory veins are developed on the front side of subcosta and of the terminal portion of radius-one that are commonly called cross-veins; but as these are preceded by trachex and as the true crossveins in other parts of the wing are not preceded by trachex in this order, these are evidently accessory veins.

In some forms, as in Pteronarcys, tracheæ other than those that precede the wing-veins penetrate the wings; this is especially true in the area 
between the subcostal trachea and the costal margin of the wing and in the area between the subcostal trachea and the radial trachea. In some cases
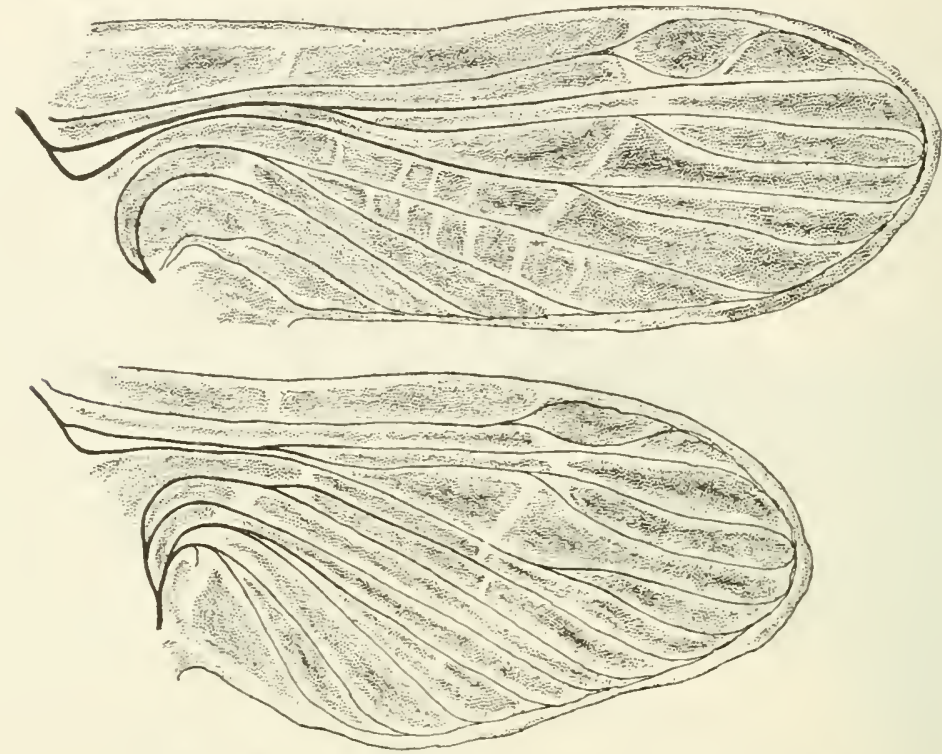

Fig. 244.-Wings of a nymph of Nemoura (From C. \& N.).

at least, these tracheæ do not arise from the same trunks as do those tracheæ that precede the wing veins.*

\section{(c) THE Classification OF THE PLECOPTERA}

As it is necessary in the following discussion of the wings of the Plecoptera to refer to the divisions of the order, and as the classification adopted here has not been included in any of the text books, I give a brief outline of it. It is the classification proposed by Dr. Günther Enderlein ('og).

Enderlein divides the order Plecoptera into two suborders, the Holognatha and the Systellognatha. In the former he includes three families; in the latter, two, as shown by the following table:

Suborder Holognatha

\section{Suborder Systellognatha}

$$
\begin{aligned}
& \left\{\begin{array}{l}
\text { Fam. Gripopterygidæ } \\
\text { Fam. Capniidæ } \\
\text { Fam. Nemouridæ }
\end{array}\right. \\
& \left\{\begin{array}{l}
\text { Fam. Pteronarcidæ } \\
\text { Fam. Perlidæ }
\end{array}\right.
\end{aligned}
$$

*I have been greatly aided in my study of the tracheation of the wings of the Plecoptera by the opportunity of examining an extended series of photographs and sketches of the wings of nymphs made by Mliss Lucy $\mathbb{W}$. Smith, which she kindly placed at my disposal and which supplement in several important particulars those made by Dr. Needham and myself. 
The family Gripopterygidæ is believed to include the most generalized of living Plecoptera, on account of their strongly developed mandibles; and the Capniidæ and Nemouridæ are associated with this family because in these families also the mandibles are well preserved. On the other hand, in the Pteronarcidæ and Perlidæ only vestiges of mandibles exist.

It may be that farther studies will show that this is not a. natural division of the order; but with the data at. hand it seems to be the best grouping of the families yet suggested.

The family Gripopterygidæ is restricted to the tropics and to the Southern Hemisphere; the other four families are well represented in the United States and Canada.

In my studies of the wings I have been unable to find any characters indicating a dichotomous division of the order; each of the methods of specialization observed exist in both the Holognatha and the Systellognatha.

\section{(d) THE Special Features of THE Wings of THE Plecoptera}

One of the more striking features of the venation of the wings of the Plecoptera is a lack of uniformity in the number and courses of the sub-
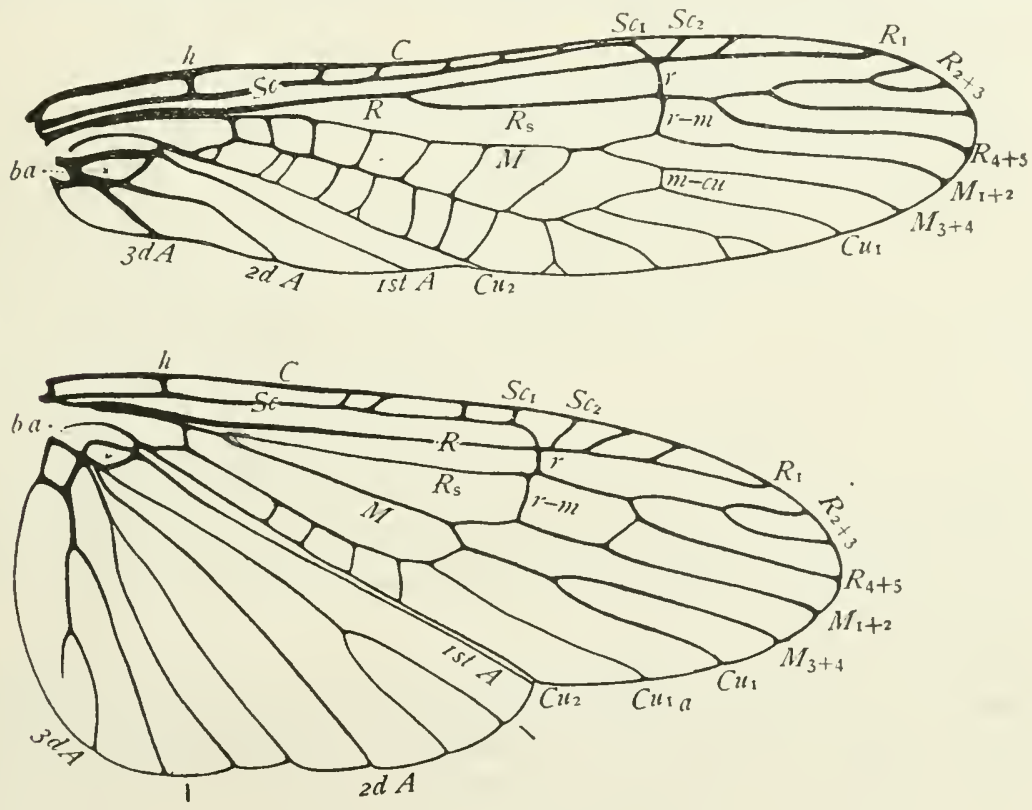

Fig. 245.-Wings of Isogenus sp.

ordinate veins. Not only are striking differences in wing-venation to be observed between different members of the same species, but frequently the wings of the two sides of an individual will vary greatly in venation. 
This is especially true as to the number of cross-veins and the branching of the veins in the distal parts of the wings. On the other hand, the characters presented by the trunks of the principal reins are quite constant.

There is one characteristic of the wings of the Plecoptera that is so constant that it may be considered an ordinal character. This is the fact that in the wings of the adult the radial sector of the hind wings is attached to media instead of to radius (Fig. 245).

This switching of the radial sector of the hind wings is true only of the venation of the adult. In the wings of nymphs the trachea $R_{s}$ is a branch of trachea R (Fig. 244).*

There are certain features of the wings of Plecoptera, which although not always constant, occur in so large a proportion of the members of the order that they may be considered characteristic; these are the following, all of which are represented in Figure 245:

The presence of the radial cross-vein (Fig. 245, $r$ ). The absence of cross-veins in cell $\mathrm{R}$ and in the basal part of area $\mathrm{R}_{1}$. Cross-veins are found in cell $\mathrm{R}$ in Pteronarcy's.

The strengthening in the fore wing of the area between media and vein $\mathrm{Cu}_{1}$ and of that between reins $\mathrm{Cu}_{1}$ and $\mathrm{Cu}_{2}$ by the development of many cross-veins.

The reduction of media to a two-branched condition.

The reduction of the radial sector to a two-branched condition. This fact is apparent only after an extended study of the wings of stone-flies. In many cases, of which the form represented by Figure 245 is one, accessory veins have been developed on vein $R_{2}+_{3}$, which appear to be the primitive branches of the radial sector. But these accessory veins are very inconstant in number and position. I am convinced that only the first forking of the radial sector, the division of it into veins $R_{2}+3$ and $\mathrm{R}_{4}+5$ has been retained from the stem form of the order. The farther branching of either of these veins is too erratic to be considered primitive, frequently differing in the wings of opposite sides of an individual insect.

The unbranched condition of the first anal rein in both fore and hind wings; rarely, as in some species of Pteronarcys, the first anal vein is branched at the tip.

In the unbranched condition of the first anal vein the Plecoptera resemble the Orthoptera. But the Plecoptera differ from the Orthoptera in that in the expansion of the venation of the anal area only accessory veins are developed; intercalary veins are not found in the Plecoptera; although in the Australian genus Eusthenia (Fig. 246) there are what appear to be

*In spite of this fact, Klapalek ('12) states: "Im Hinterflügel finden wir in dem reifen Flügel keinen Sektor radii, dafür ist die Media zweimal gegabelt." In carrying out this idea he incorrectly labels the branches of the radial sector and of media in his figure of the wing-venation. This is a remarkable example of a lack of appreciation of the value of ontogenetic facts. 
the first stages in the development of intercalary veins, in the anal area of the hind wings.

In concluding this brief summary of the special features of the wing of the Plecoptera it seems desirable to define some terms frequently used by writers on this order.

The transverse cord.- In many genera of this order there is a nearly continuous series of cross-veins extending across each wing just beyond the

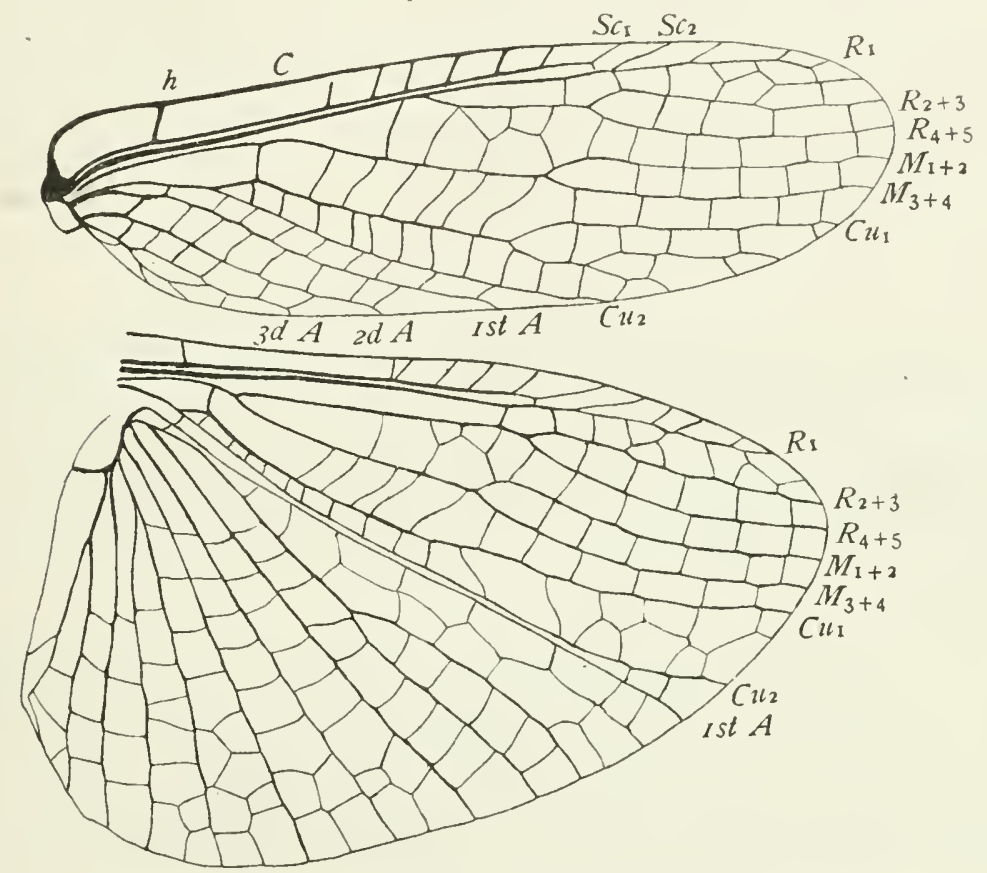

Fig. 246.-Wings of Eusthenia specatbilis.

middle of its length; this series of cross-veins is termed the anastomosis by writers on the Plecoptera. As it is not formed by an anastomosing of veins the use of the term, transverse cord, defined in chapter III, is preferable.

The pterostigma. - In most members of this order a specialized pterostigma has not been developed; but the term pterostigma is commonly applied to the cell beyond the end of the subcosta and between the costa and vein $R_{1}$, even though it is of the same color and texture as the remainder of the wing.

The basal anal cell. - A very constant feature of the anal area of the wings of Plecoptera is the presence of a cross-vein near the base of the wing, which extends from the first anal vein to the second. The cell that is closed by this cross-vein is termed the basal anal cell (Fig. 245, ba). 
Enderlein has introduced a new terminology of the reins of the anal area, which I think is unfortunate, as it tends to confusion. The veins of this area of all orders of insects have long been known as the "anal veins." When Comstock and Needham determined that these reins were typically three in number, w'e designated them as the first anal (Ist $A$ ), the second anal $(2 d \mathrm{~A})$, and the third anal $(3 d . A)$ respectively. This preserved the term anal, by which they were generally known, and at the same time afforded a specific designation for each.

Enderlein restricts the term anal (an) to the first anal vein; and designates the second anal vein the axillary $(a x)$, and the third anal vein the accessory (acce). He numbers the branches of the axillary vein from before backward, and those of the accessory rein in the opposite direction. (Zool. Anz. Vol. 28 p. Sio).

\section{(e) THE PRIMITIVE PLECOPTEROUS TYPE OF WINGS}

The logical method of determining the various ways in which the wings of the different members of an order of insects have been specialized is to discover what is the most generalized type of wing-venation to be found within the order and then to trace the various ways in which this type has been modified in the different divisions of the order. This method has been followed in the preparation of several of the chapters of this book.

In carrying out this method the type of wing-venation that most closely resembles the hypothetical primitive type (Fig. 6, p. I6) is considered the most generalized and is used as a starting point from which to trace the various methods of specialization found within the order.

In my efforts to apply this method to the study of the wings of the Plecoptera I have found what, at first, was a most perplexing array of facts. Forms were found that appeared to possess a generalized type of wingvenation. But when these forms were compared with closely allied forms, other species of the same genus for example, it was found that certain of the supposed generalized features were of little taxonomic value.*

The lack of stability of the wing-venation is most apparent in the number and distribution of the cross-veins and in the number and courses of the branches of the longitudinal veins near the margin of the wings. This is especially true of the secondary branches of the radial sector and

\footnotetext{
*The lack of stability of the wing-venation of stone-flies is apparent to any one that studies the order carefully. Ris ('96) in writing of the genus Dictyopteryx, after referring to the fact that it is practically impossible to find two specimens of the same species with identical wing-renation, and that seldom individuals are found that show the same network of veins in the wings of the two sides, remarks: "Es sieht so aus, als ob sich diese Thiere für die wenigen Tage, die sie als Imago zu leben haben, und für den geringen Gebrauch, den sie von ihren Flügeln machen, gar nicht den Luxus eines streng gesetzmāssig ausgebildeten Aderwerks gestatten könnten."
} 
the secondary branches of media. In this region of the wings there are frequently striking differences between the wings of the two sides of individual insects.

I am convinced, as already stated in the discussion of the special features of the wings of the Plecoptera, that only the first forking of the radial sector, the division of this vein into veins $R_{2}+3$ and $R_{4}+5$, is primitive; and that in those cases where the radial sector is more than twobranched, the additional branches have been developed secondarily.

It is also evident that only the first forking of media, the division of this vein into veins $\mathrm{M}_{1}+_{2}$ and $\mathrm{M}_{3}+_{4}$, is primitive, for the farther branching of these veins is too inconstant and erratic to be considered primitive.

The result of these conclusions is that forms that have only a twobranched radial sector and a two-branched media, like Nemoura for example, are believed to resemble more closely what must be regarded as the primitive type of the order than do those in which these veins are more than twobranched, even though among them individuals may be found that much more closely resemble the hypothetical primitive type. In other words the known facts indicate that the Plecoptera have been evolved from a form in which the radial sector and the media where each only two-branched. In some of the descendants of this primitive stone-fly the reduction of these veins has been carried still farther, in others, additional branches have been developed upon these veins, but in a very erratic manner.

As yet paleontology affords little data as to the form of the primitive members of this order, but what data we have tends to confirm the conclusions stated above. I do not, however, place much weight on the paleontological evidence; for so few ancient Plecoptera are known that we can not claim to have an adequate conception of the ancient plecopterous fauna. Remains of two nymphs and one adult have been found in Jurassic deposits; and this is all the data that we have from times preceding the Tertiary.

The adult from the Jurassic is Mesonemoura Maaki Brauer. The fore wing of this species is quite well-preserved and is quite similar to a wing of the recent genus Nemoura.

Less than a score of species are known from the Tertiary; all of these belong to existing genera, and the greater number of them belong to the Nemouridæ; the other species are placed in the genus Perla.

Returning to an examination of recent forms, from a study of which we must draw our conclusions, we find that the type of wing that I have concluded represents best the primitive plecopterous wing exists practically unmodified in one or both pairs of wings of representatives of four of the five families of the order; and in the fifth family, the Pteronarcidæ, where extended specialization by addition has taken place, the modification of it is comparatively slight. 
The important features in which the assumed plecopterous type of wing differ from the hypothetical primitive type are the reduction of the radial

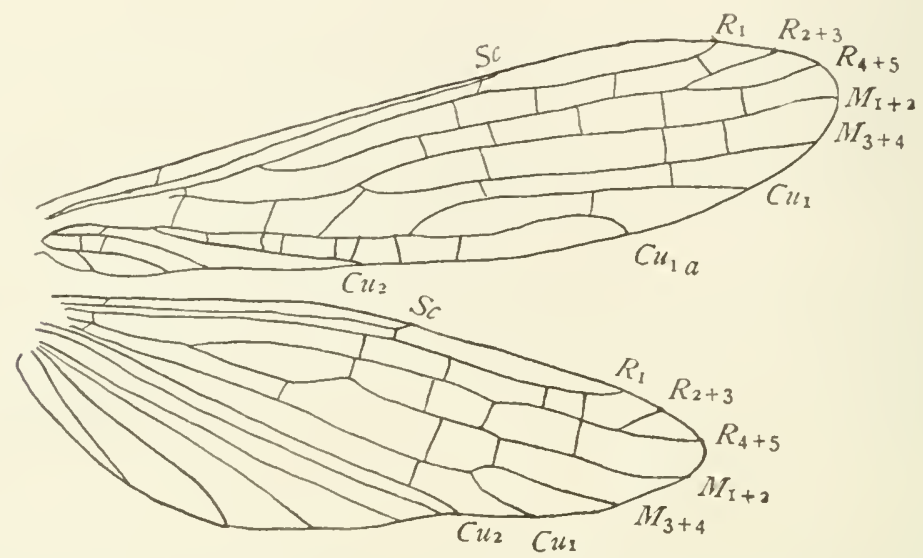

Fig. 247.-Wings of Gripopteryx tessellata (From Enderlein '05, but with some changes in the labeling of veins).

sector to a two-branched condition and a similar reduction of media to a two-branched condition. The following examples illustrate these features in each of the five families.

The Gripopterygidæ.--Figure 247 represents the venation of the wings of Gripopteryx tessellata as shown by Enderlein ('05). In the fore wing of
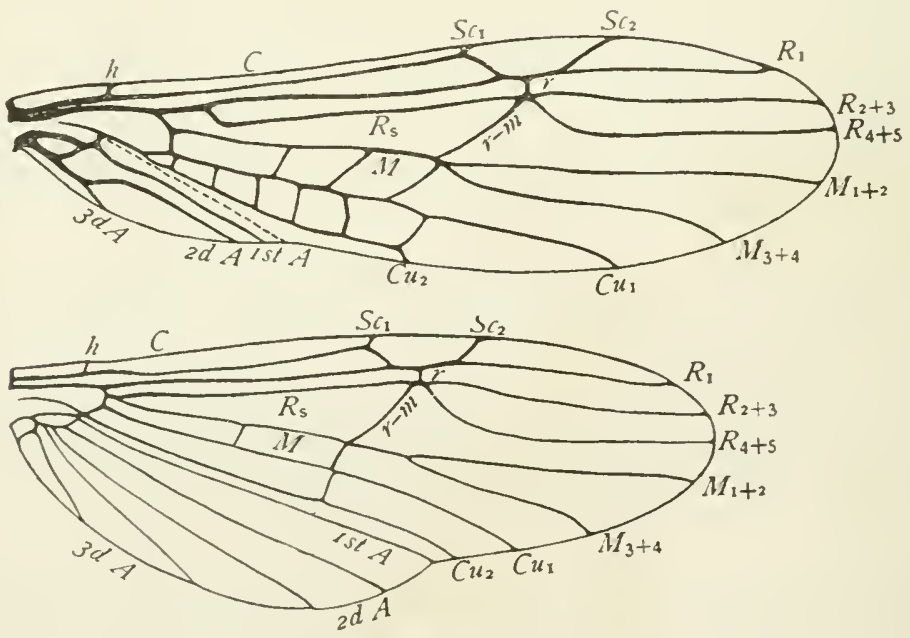

Fig. 248.-Wings of Nemoura.

this species the radial sector and media are each clearly two-branched; but the branches of the radial sector coalesce nearly to the apex of the wing. 
In certain closely allied forms, the coalescence is complete with the result that the radial sector is not branched. In the hind wing of this species the homology of the veins is somewhat obscured by an anastomosis of veins $\mathrm{M}_{3}+_{4}$ and $\mathrm{Cu}_{1}$.

In Eusthenia spectabilis (Fig. 246), the most "richly veined" member of the family that I have seen, the two-branched condition of both the radial sector and of media of both fore and hind wings is perfectly preserved.

The Nemouridæ.- In Nemoura (Fig. 248) the plecopterous type is perfectly preserved in both fore and hind wings. A detailed discussion of the wings of Nemoura follows on a later page.

The Perlidæ.- In the fore wing of Chloroperla sp. (Fig. 249), the radial sector and the media are clearly only two-branched; the same is true of the hind wing except that the homology of the veins is somewhat obscured, as in Gripopteryx, by an anastomosis of veins $\mathrm{M}_{3}+{ }_{4}$ and $\mathrm{Cu}_{1}$.
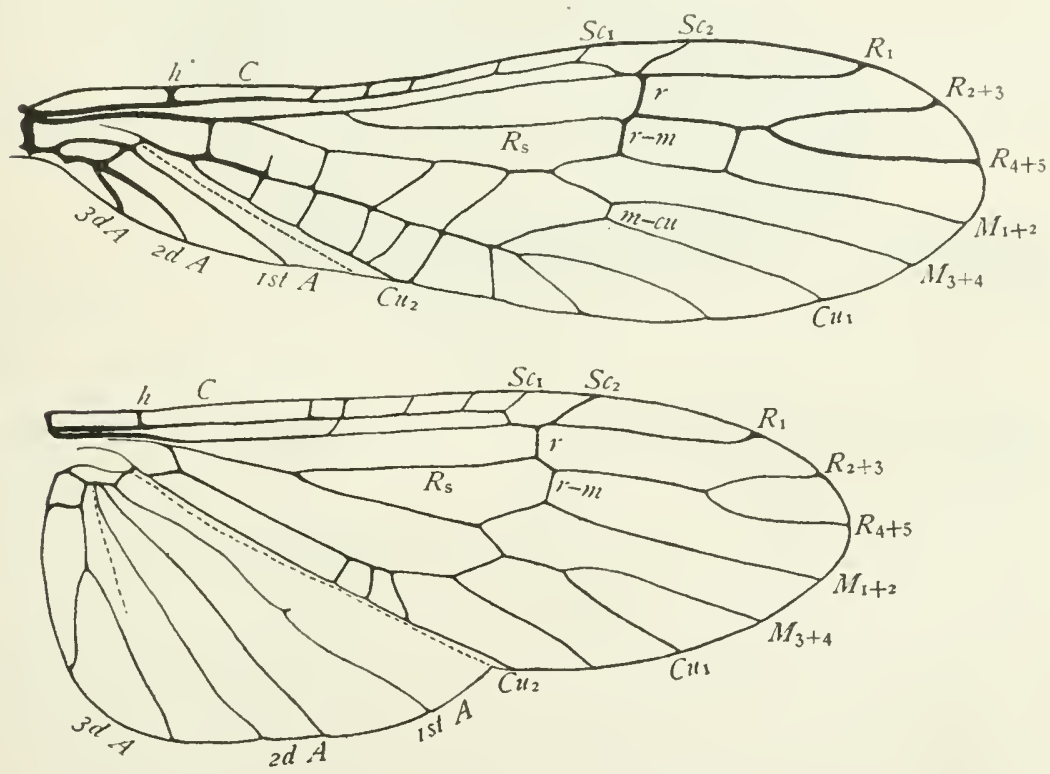

Fig. 249.-Wings of Chloroperla sp.

The Capniidæ.- In the Capniidæ there appears to be a degeneration of, the wing-venation, which has resulted in a remarkable lack of constancy in the courses of the veins, even within the limits of a single species. But it is easy to find examples, at least of fore wings, in which the plecopterous type of venation is fairly well preserved (Fig. 250). 


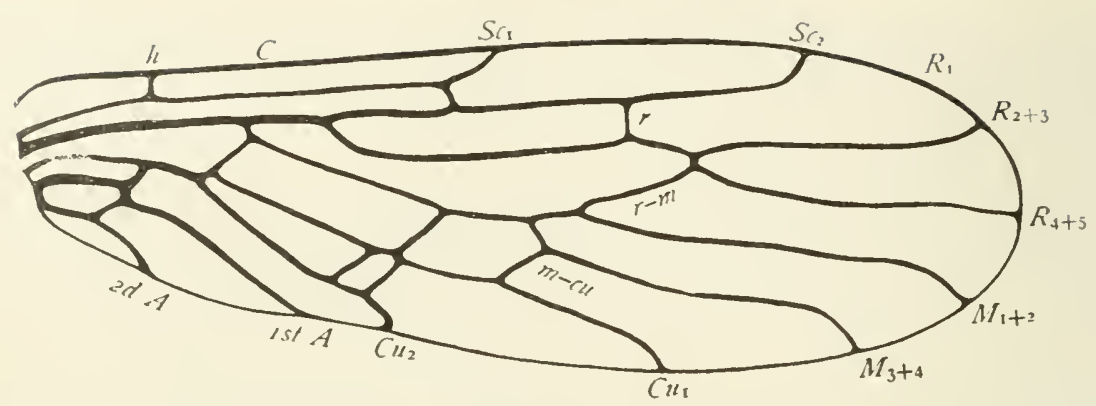

Fig. 250.-Wing of Capnia.

The Pteronarcidæ.-Of the three known genera representing this family, it is evident that so far as the venation of the wings is concerned the genus Pteronarcella is the most generalized.*

In Pteronarcella badia (Fig. $25 \mathrm{I}$ ) the plecopterous type of wing-venation is very slightly modified. Media is clearly two-branched in both fore and hind wings. The first branch of the radial sector, vein $R_{2}+3$, bears a few branches; but here, as elsewhere in the order, a comparison of allied species, or even of different individuals of the same species shows that these branches

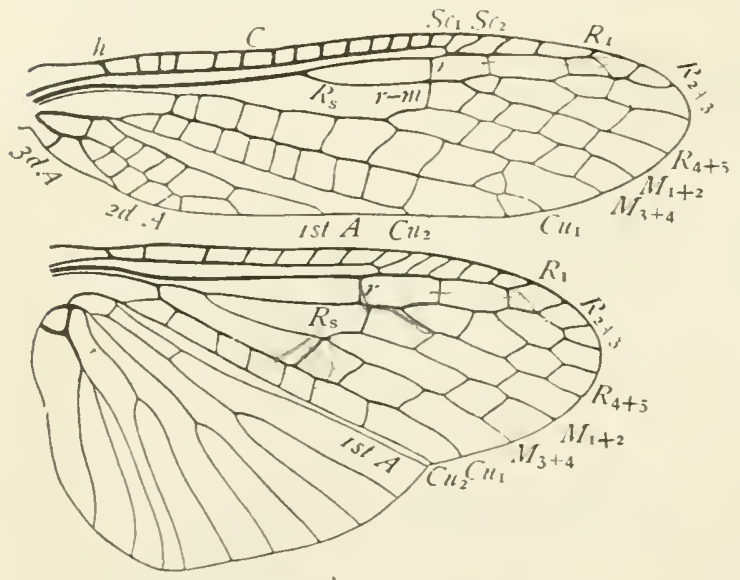

Fig. 251.-Wings of Pteronarcella badia.

can not be considered primitive.

The data given above show that in tracing the methods of specialization of the wing-reins in the Plecoptera we should start with a form in which the radial sector and the media are each only twobranched. I haveselected Nemoura, the betterknown representative of the more generalized suborder, as the form with which to make comparisons.

The tracheation of the wings of a nymph of Nemoura was figured by Comstock and Needham (Fig. 252). This represents very closely the hypothetical primitive type of tracheation except that the trachea of the radial sector and of media in both fore and hind wings are only two-

*I have seen neither specimens nor figures of Diamphipnoa, which occurs in Chile. But as this is said to resemble Pleronarcys in having cross-veins in cell $\mathrm{R}$ of the fore wings, I feel warranted in making the above statement. 
branched. But from the facts given above, this condition of the radial sector and of media may be considered as typical of the primitive plecopterous wings.

In Nemoura Comstock and Needham failed to find a costal trachea; but as we found a well-developed costal trachea in the closely allied genus

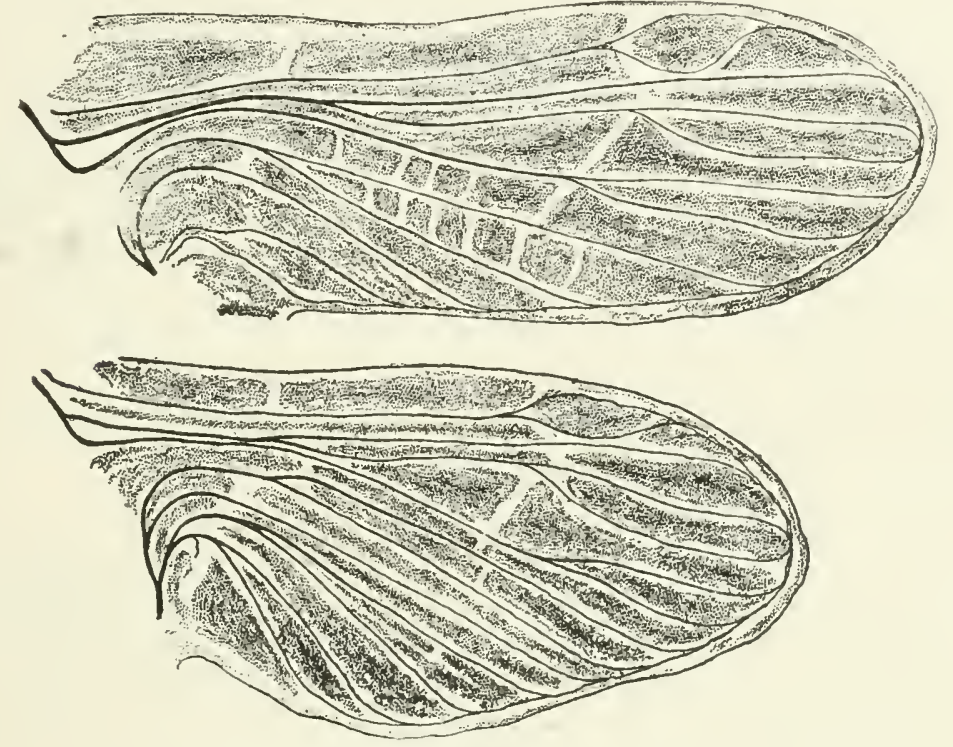

Fig. 252.-Wings of a nymph of Nemoura (From C. \& N.).

Taniopteryx, we may assume that this trachea was present in the primitive type of the order.

The more important features of the primitive type of tracheation of the wings of the Plecoptera may be described as follows:

The absence of tracheæ in the cross-veins.

The absence of a basal transverse trachea, and correlated with this, the origin of the medial trachea from the costo-radial group of tracheæ.

A typical two-branched subcostal trachea without accessory trachex. The trachea $\mathrm{Sc}_{1}$ extends to the margin of the wing; the trachea $\mathrm{Sc}_{2}$ extends towards trachea $R_{1}$ until it nearly reaches it, and then curving away from this trachea extends to the margin of the wing.

A typical radial trachea except that its sector is only two-branched. It should be noted that the radial sector trachea of the hind wing, like that of the fore wing, springs from the main stem of the radial trachea. But the switching of the radial sector of the hind wing to media is foreshadowed by the course of the forming vein (Fig. 252).

A typical medial trachea except that it is only two-branched. 
A typical two-branched cubital trachea.

Three unbranched anal trachex in the fore wing.

Three anal tracheæ in the hind wing; the first anal trachea is unbranched; the second and third anal trachex are each two-branched.

The characteristic features of the venation of the preanal area of the wings of the adult Nemoura (Fig. 248) need not be described in detail, as the veins follow quite closely the courses of the tracheæ that precede them, which have been described above. There is an anastomosis of veins $\mathrm{Sc}_{2}$ and $\mathrm{R}_{1}$ in the region where the trachea $\mathrm{Sc}_{2}$ was closely parallel with trachea $\mathrm{R}_{1}$; and the radial sector of the hind wing has been switched to media.

There are certain features of the venation of the anal area of the fore wing that merit special attention. In Nemoura, and in fact in the greater number of the genera of this order, the anal area of the fore wings contains three, and only three, unbranched anal veins. The first and second anal veins are connected by a cross-vein, near the base of the wing, which closes the basal anal cell. The third anal vein either coalesces with the second at the base of the wing; or, when the two veins are separate at the base, they anastomose opposite the basal anal cell.*

\section{( $f$ ) The methods of specialization of the Wings of the plecoptera}

If we accept the conclusion that the type of wings represented by Nemoura can be taken as illustrating the primitive plecopterous wings, there follows the conclusion that within this order the specialization of the wings has proceeded in opposite directions in different members of the order. In some there has been a farther reduction of the wing-venation; in others, a specialization by addition.

An equally remarkable fact is that differences in the direction of the specialization of the wing-venation do not indicate important divisions of this order. Within a single family forms exist in which there has been a reduction of the wing-venation and also others in which the specialization has been by addition.

A few illustrations of the more striking modifications of the primitive plecopterous type follow.

Specialization by reduction. - There are many cases of specialization by reduction in this order; a common example is the reduction of the radial sector of one or of both pairs of wings to an unbranched condition; this occurs in each of the five families.

* Much use is made by systematists of the characters presented by this part of the anal area. When the coalescence or anastomosis of the second and third anal vein does not extend beyond the end of the cell, as in Isogenus (Fig. 245), it is said that "two simple veins extend from the cell below," when the union of these two veins extends beyond the limits of the cell, as in Nemoura (Fig. 248), it is said that "a single forked vein extends from the cell below." The inclusion of the word below in these expressions is to indicate that the first anal vein is not included in the enumeration. 
A more striking example of specialization by reduction is afforded by certain forms in which the hind wings are so reduced in size that they are smaller than the fore wings and have fewer veins. An excellent illustration of this is the common Chloroperla cydippe (Fig. 253). In this species the radial sector of the fore wing is nearly reduced to an unbranched condition and in the hind wing this reduction is complete. The most remarkable feature, however, is the extreme reduction of the anal area of the hind wing, which results in the hind wing being much smaller than the fore wing.
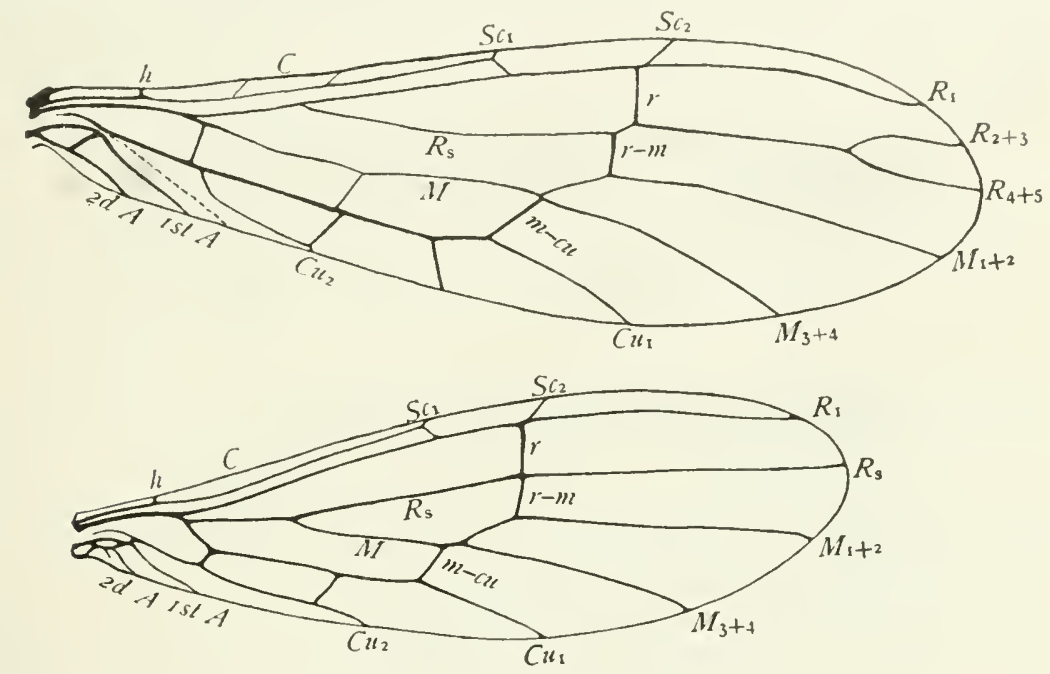

Fig. 253.-Wings of Chloroperla cydippe.

It is unnecessary to cite other examples of specialization by reduction, as they will be easily recognized when met.

Specialization by addition.-A few examples of specialization by addition are illustrated by the accompanying figures. The most convenient method of discussing these examples is to treat each of the principal veins of the wing separately.

The subcosta.-In many genera there are in addition to the very con- . stant humeral cross-vein other veins that extend from the subcosta to the costa. These are commonly termed cross-veins; but as they are preceded by tracheæ and the true cross-veins are not preceded by tracheæ in this order, they are morphologically accessory veins. These accessory subcostal veins are present in the wings of Isogenus (Fig. 245); and the presence of a trachea in each was clearly evident in a pupal wing of Acroneuria, which I studied.

The radius-one.-Accessory veins, closely resembling those described in the preceding paragraph, extend from radius-one to the costal margin of the wing in some genera. These are also shown in Figure 245. 
The radial-sector. Accessory veins are frequently developed upon the radial sector. In most cases when such veins are present they are borne by vein $R_{2}+3$; vein $R_{4+5}$ is, as a rule, unbranched. Occasionally the arrangement of the accessory veins is such as to give the radial sector the appearance of preserving its primitive four-branched condition. But as already stated this condition is merely fortuitous. In Isogenus (Fig. 245), vein $\mathrm{R}_{2}+_{3}$ bears two accessory veins in the fore wing and one in the hind wing. In certain species of Acroneuria and in Pteronarcys several accessory veins is borne by this vein. As a rule, these accessory veins extend in approximately parallel courses except near the apex of the wing. But in certain
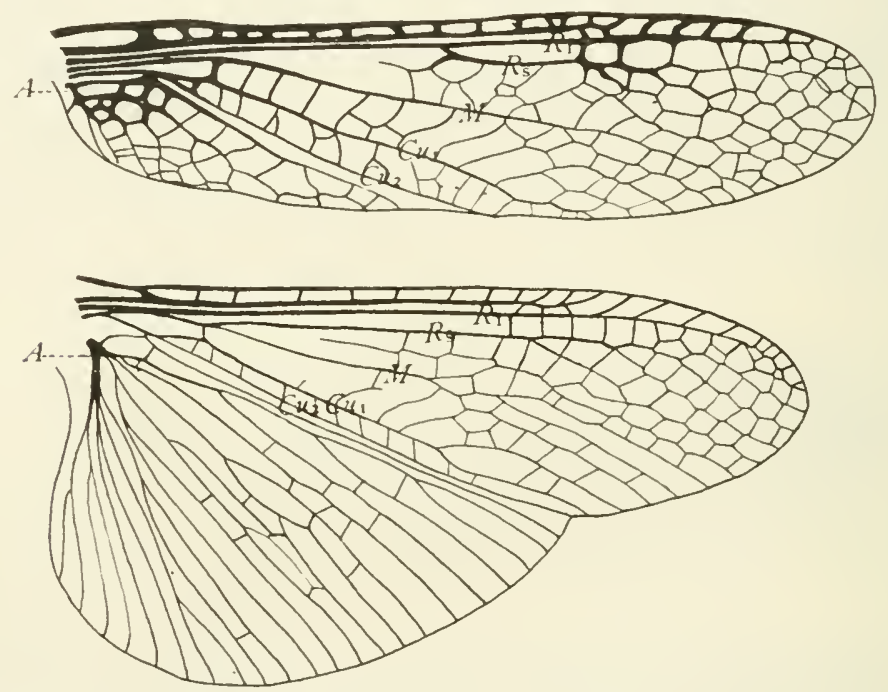

Fig. 254.-Wings of Pteronarcys dorsata, female (Drawn by Miss L. W. Smith).

forms, their courses are so irregular that in the adult wing the accessory veins and the cross-veins extending between them form a chaotic network. This is well-illustrated by the fore wing of Pteronarcys dorsata (Fig. 254); in the hind wing the confusion is not quite so great.

The media.-Accessory reins are comparatively rarely developed on the branches of media, this vein remaining two-branched even when both the radial and the cubital areas are expanded. This is well-shown by Acroneuria.

The cubitus.-Accessory veins are frequently developed on the distal part of vein $\mathrm{Cu}_{1}$. In Acroneuria for example, there are three such veins that are preceded by trachex beyond the ordinary cross veins extending between veins $\mathrm{Cu}_{1}$ and $\mathrm{Cu}_{2}$, which are not preceded by tracheæ. 
Correlated with the development of one or more accessory veins on vein $\mathrm{Cu}_{1}$ there is a tendency of this vein to curve forward towards media, which frequently results in an anastomosis of these two veins. In the fore wing of Isogenus (Fig. 245) this extension forward of vein $\mathrm{Cu}_{1}$ is marked; but the cross-vein $m-c u$ still persists. In the hind wing of this species, the cross-vein $m-c u$ has been obliterated by the anastomosis of veins $\mathrm{M}_{3}+_{4}$ and $\mathrm{Cu}_{1}$. The result of this anastomosis is to produce the appearance of media being three-branched; but what appears to be the third branch of media is vein $\mathrm{Cu}_{1}$.

The first anal vein.-Occasionally, as in some species of Pteronarcys, the first anal vein is forked at the tip; but, as a rule this vein is unbranched in both fore and hind wings.

The second and third anal veins.-The anal area of the fore wings is rarely expanded, the second and third anal veins remaining unbranched in most genera; but in a few cases, as in Pteronarcys (Fig. 254), these veins are branched.

In the hind wings, the anal area is expanded in many genera; and correlated with this expansion, there is a branching of both the second and third anal veins; this is shown in Isogenus (Fig. 245) and in Pteronarcys (Fig. 254).

The most remarkable expansion of the anal area of the hind wings that I have observed in this order is that of Eusthenia spectabilis (Fig. 246). There is here a certain resemblance to the hind wing of an orthopterous insect; for in several places there are what appears to be the beginnings of the development of intercalary veins. 


\section{CHAPTER XIII}

\section{THE WINGS OF THE CORRODENTIA}

THE winged members of this order have four membranous wings; the fore wings are larger than the hind wings; and both pairs when not in use are placed rooflike over the body, being almost vertical, and not folded in plaits. The wing-veins are prominent, but the venation of the wings is reduced.

The determination of the homologies of the wing-veins in this order was a problem that sorely puzzled all who worked upon it untilit was approached by the ontogenetic method by Comstock and Needham. As soon as we

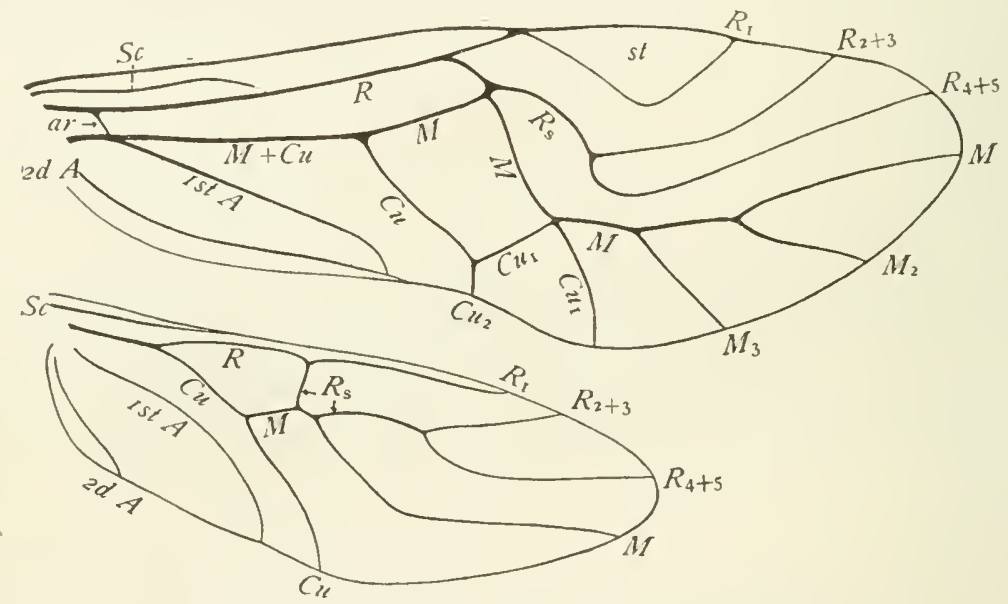

Fig. 255.-The wings of Psocus (After C. \& N.).

studied the tracheation of the wings of nymphs the difficulties vanished. These difficulties are due to the fact that what appear to be cross-veins are sections of longitudinal veins.

The type of venation of the wings characteristic of the Corrodentia is well-illustrated by the wings of Psocus (Fig. 255). In the fore wings the branching of the longitudinal veins corresponds quite closely with the hypothetical type except that there is a reduction in the number of the branches, subcosta being unbranched, and radius and media being each only three-branched. In the hind wings, the venation is much more reduced.

A study of Figures 256 and 257 , which represent two stages in the development of the fore wing of Psocus will convince one of the correctness of the homologies of the veins indicated in Figure 255. These figures were 
made from photographs of wings, which were so mounted that the developing wing-veins appeared as pale bands, and the wing-tracheæ as dark lines.

A remarkable feature of the fore wing of Psocus (Fig. 255) is that, although it is braced in every direction, there is not a single cross-vein in it,

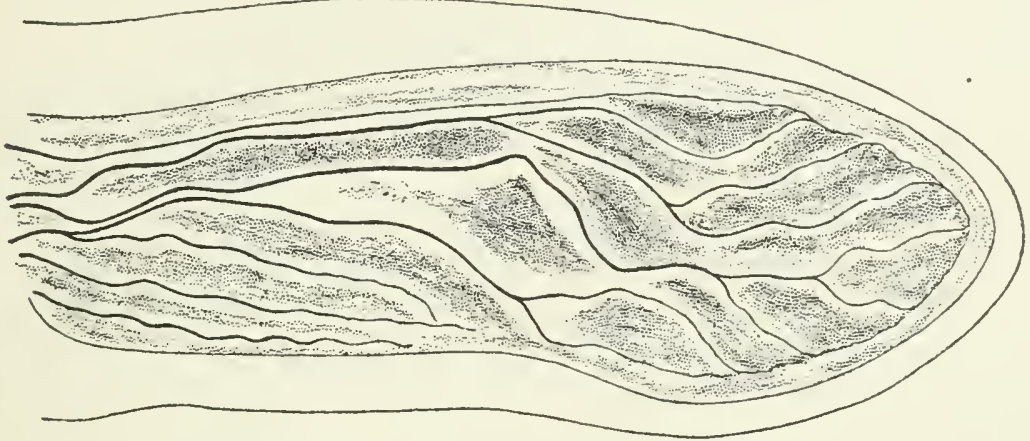

Fig. 256.-Fore wing of a nymph of Psocus (After C. \& N.).

the bracing being accomplished by the zigzag courses of the principal veins. There is an arculus (ar) near the base of the wing, which is formed of the base of media; and what appear as cross-veins in the central portion of the wing are sections of media and of cubitus. It was these apparent cross-veins that made the determination of the homologies of the wing-veins difficult before the tracheation of the wings was observed.

Although there are no cross-veins in the wing represented by Figure 255 , cross-veins exist in the wings of certain members of this order. In some genera the radial cross-vein is present and in some, instead of an anasto-

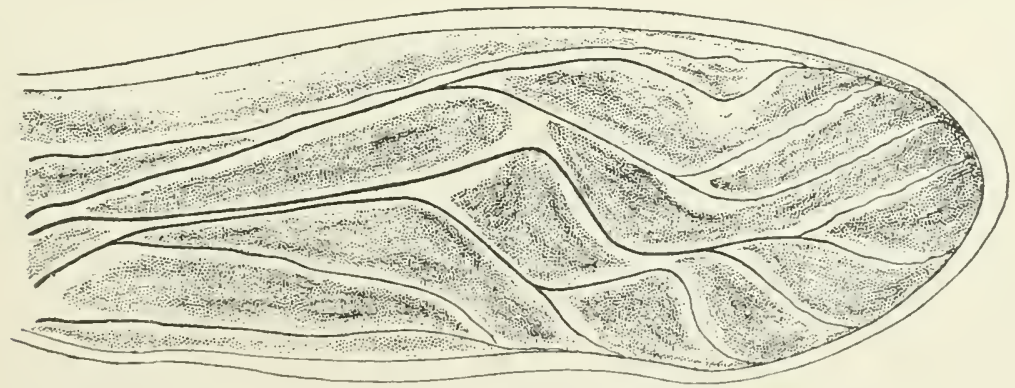

Fig. 257. - Fore wing of a full-grown nymph of Psocus (After C. \& N.).

mosis of veins $\mathrm{M}$ and $\mathrm{Cu}_{1}$, these veins are connected by a medio-cubital cross-vein. Both of these cross-veins exist in the fore wing of Stenopsocus (Fig. 258). 
In the remarkable genus Neurostigma described by Enderlein ('oo) from Peru, the pterostigma of the fore wing is crossed by from eight to ten crossveins.

Enderlein ('o3) in a paper on the Corrodentia of the Indo-Australian fauna adopts the uniform terminology of the wing-veins and gives an extended discussion of the venation of the wings of this order; this has been of much aid in the making of the following generalizations:

The costa.-In Psocus, according to the observations of Comstock and Needham, the margin of the adult wing is tubular throughout, there being

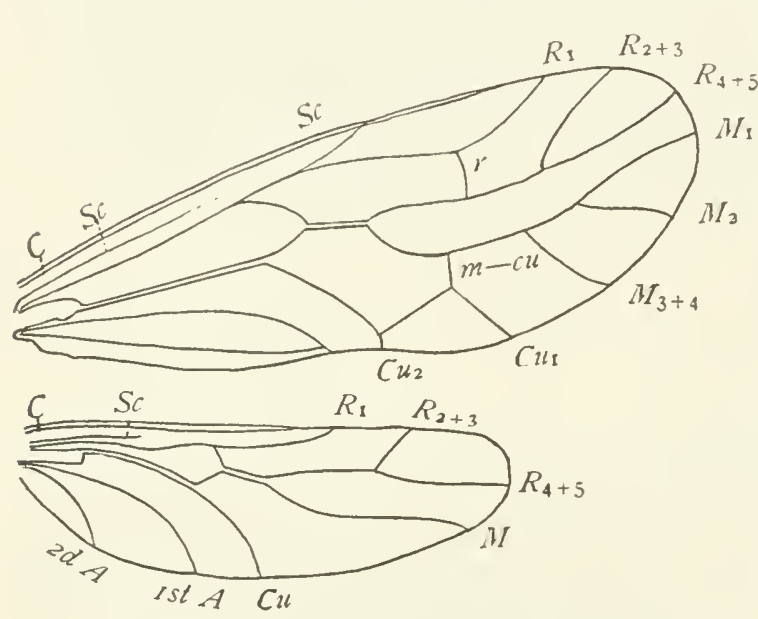

Fig. 258.-Wings of Stenopsocus (After Enderlein '03). A diagram in which the coalesced veins are represented separate.

present an ambient vein. The costal and anal portions of this vein doubtless represent the costa and the third anal vein respectively, although the corresponding tracheæ are apparently lost. The distal portion of this ambient vein was preceded by the anastomosing tips of all of the wing tracheæ, as is shown in the figures of the wings of nymphs.

The subcosta.-The subcosta is not forked. In the fore wings of nymphs of Psocus (Fig. 256 and 257), the subcostal trachea extends unbranched to the apex of the wing, where its tip enters the forming ambient rein. In the wings of an adult Psocus (Fig. 255), the subcosta is short, and its tip coalesces with the radius in the fore wing and with the costa in the hind wing. In many genera the subcosta consists of two parts: a basal part which lies in the basal part of the costal cell and a distal part which extends from vein $R_{1}$ to the costa at the base of the pterostigma, the intermediate part of the vein being lost. This condition is well shown in the fore wing of Stenopsocus (Fig. 258).

The radius. - The first forking of the radius, the separation into veins $R_{1}$ and the radial sector, is quite typical. In the fore wing vein $R_{1}$ curves back from the costa, bounding the pterostigma; in the hind wing the pterostigma is wanting. The radial sector is usually reduced to a twobranched condition, as in Psocus (Fig. 255); in some forms it is reduced to an unbranched condition, and in others it is not reduced, the four branches remaining separate. 
The media. - The media coalesces with radius for a short distance at the base of the wing; it then bends backward and joins cubitus with which it coalesces for a considerable distance; it is usually three-branched in the fore wings, but in Ptiloneura bidorsalis, described by Enderlein ('oo) from Peru, it is eight-branched. This is a remarkable departure from the almost universal method of specialization in this order; and even in this genus, where accessory veins have been developed upon media, the radial sector is reduced to a two-branched condition.

In the hind wings, media is usually reduced to an unbranched condition; but in some forms it is forked.

The cubitus. - The cubitus is quite widely separated from media at the base of the wing; this is well shown in the wing of a nymph of Psocus (Fig. 257); but it soon joins media, with which it coalesces for a considerable distance. In the fore wing, vein $\mathrm{Cu}_{1}$ anastomoses with media in some forms (Fig. 255), in others the two reins are connected by the mediocubital cross-vein (Fig. 258), and in other forms there is no connection between veins $\mathrm{M}$ and $\mathrm{Cu}_{1}$. Vein $\mathrm{Cu}_{2}$ is short when present; it is wanting in some forms. In the hind wings cubitus is reduced to an unbranched condition.

The anal veins.-As a rule the first and second anal veins are present in both fore and hind wings; in a few genera a short third anal vein is present in the fore wings. All of the anal veins are unbranched. In the fore wings, the first and second anal veins usually end at the same point in the margin of the wing. 


\section{CHAPTER XIV \\ THE WINGS OF THE EMBIIDINA}

THE winged members of this order have two pairs of wings, which are quite similar in form and structure. The wings are elongate, membranous, extremely delicate, and folded on the back when at rest. The venation of the wings is considerably reduced; this reduction has been brought about
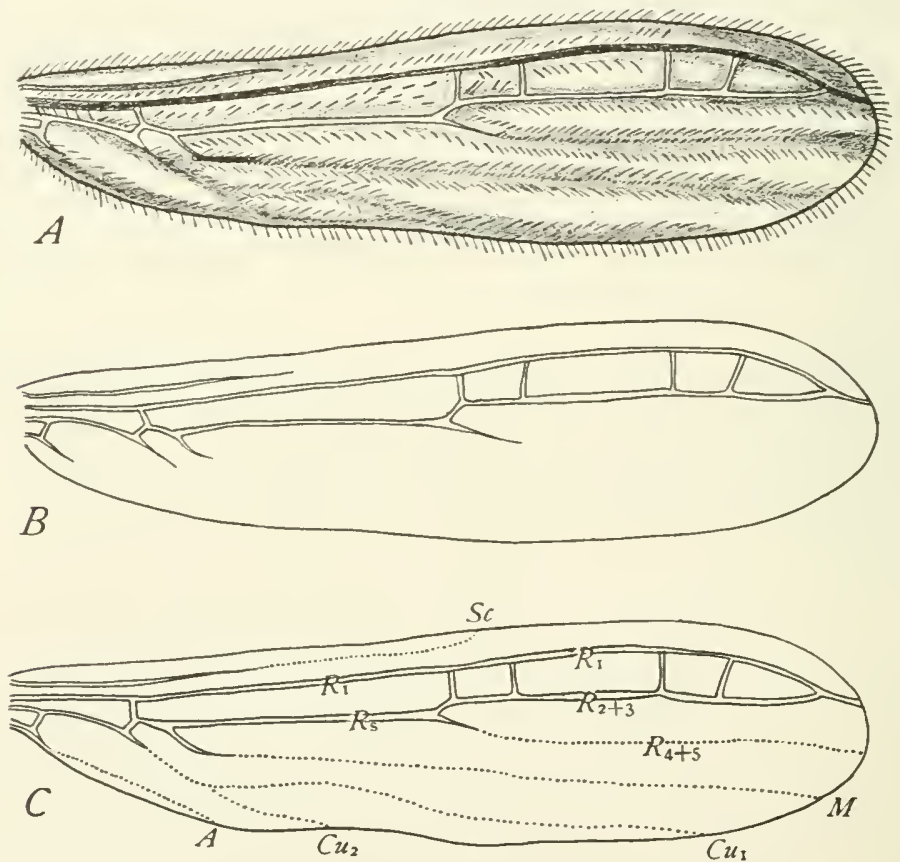

Fig. 259.-Fore wing of Oligotoma saundersi: A, the wing; B, outline of the wing showing the existing venation; $\mathrm{C}$, outline of wing showing the venation restored (After Wood-Mason).

both by the coalescence of veins and by the atrophy of veins. In a single species, Clothoda nobilis from South America, the cubitus bears accessory veins; but even in this species the radial sector is only three-branched and the media is reduced to an unbranched condition. The cross-veins are comparatively few in number. The females are always wingless; and in two of the eleven known genera both sexes lack wings.

Each of the veins of the wings extends along the middle of a brown band; between these bands the membrane of the wing is pale in color. 
The alternating brown and pale bands give the wing a very characteristic appearance (Fig. 259, A).

In those forms where the venation of the wings has been reduced by the atrophy of veins, the brown bands persist after the veins have faded out; hence it is easy to determine by these bands the former position of veins that have been lost. In Figure 259 , A represents the appearance of a wing of Oligotoma saundersi; $\mathrm{B}$, the existing venation; and $\mathrm{C}$, a restoration of the venation based on a study of the brown bands. Here and in other figures that follow, the restored veins are indicated by dotted lines.

On each side of vein $R_{1}$ there is a narrow line of deeper color than the brown bands; these lines have been termed, by Enderlein, the fore and hind radial border lines (Radiussaumlinie), respectively; these are represented in the following figures by series of dots, parallel with vein $R_{1}$.

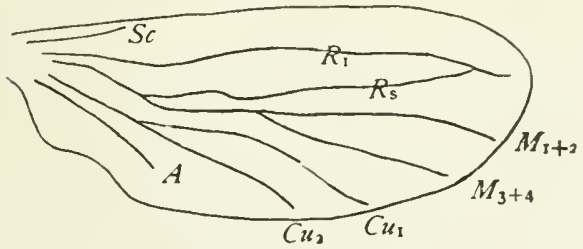

Fig.260.-Wing of a pupa of Embia texana (After Melander).

The membrane of the wing is clothed throughout with fine setæ, and along each vein and along each margin of each brown band there is a series of larger setæ.

The tracheation of wings of nymphs has been studied by Melander ('o2), who has figured that of Embia texana (Fig. 260).

As the order is very poorly represented in the collections to which I have access, I have been forced, in my studies of the wing venation of members of it, to depend almost entirely on the published figures of wings of these insects. Fortunately there has recently appeared a monograph of the order by Enderlein ('r2) in which figures of the wings of representatives of eight of the nine winged genera are given, and the wings of the remaining winged genus are described in detail. The following account is based on the data given by Enderlein. I have not seen the monograph of this order published by Dr. H. A. Krauss ('I I); but have made use of one figure which is copied from it by Enderlein.*

The wings of Embia sabulosa (Fig. 26I) will serve to illustrate the features of the wing-venation most commonly found in the wings of insects of this order. The subcosta is well-preserved, but is unbranched; the radial sector arises near the base of the wing and is only three-branched, veins

*In copying the figures of Enderlein I have made some slight changes in the lettering of the wing-veins. The vein that he designates the "Cubitalstamm (cust)" is vein Cur: the accessory veins borne by vein $\mathrm{Cu}_{1} \mathrm{I}$ have designated as $\mathrm{Cu}_{1 \mathrm{a}}$ and $\mathrm{Cu}_{1 \mathrm{~b}}$ instead of $\mathrm{Cu}_{2}$ and $\mathrm{Cu}_{3}$, his vein $\mathrm{Cu}_{2}$ in this case is not homologous with the vein $\mathrm{Cu}_{2}$ of the uniform terminology; and the vein that he designates as the "Axillaris $(a x)$ " is the second anal vein of the uniform terminology. The modification of the terminology of the veins of the anal area by this author is discussed in the chapter on the wings of the Plecoptera (p. 248 ). When media is two-branched, the two branches are doubtless veins $\mathrm{M}_{1}+2$ and $\mathrm{N}_{3}+4$, and not veins $\mathrm{M}_{1}$ and $\mathrm{MI}_{2}$ as labeled by Enderlein. 
$R_{2}$ and $R_{3}$ coalescing to the margin of the wing; the media is reduced to an unbranched condition; there is what appears to be a typical arculus at the base of the wing; the cubitus is two-branched; the first anal vein is

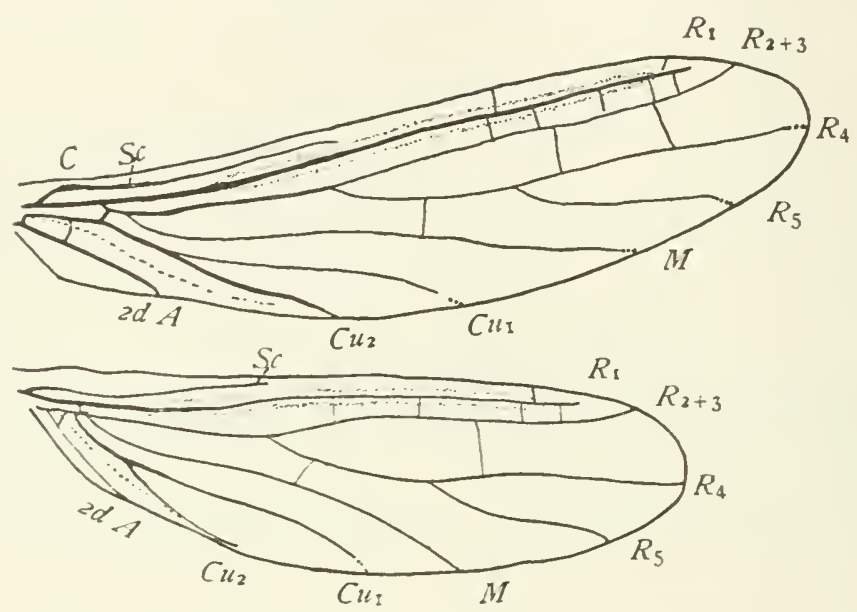

Fig. 261. - Wing of Embia sabulosa (After Enderlein, with some changes in the lettering of the veins).

replaced by an anal furrow; the second anal vein is well-developed; and there are comparatively few cross veins.

Illustrations of the more important modifications of the type of wingvenation possessed by Embia sabulosa are shown in the following figures.

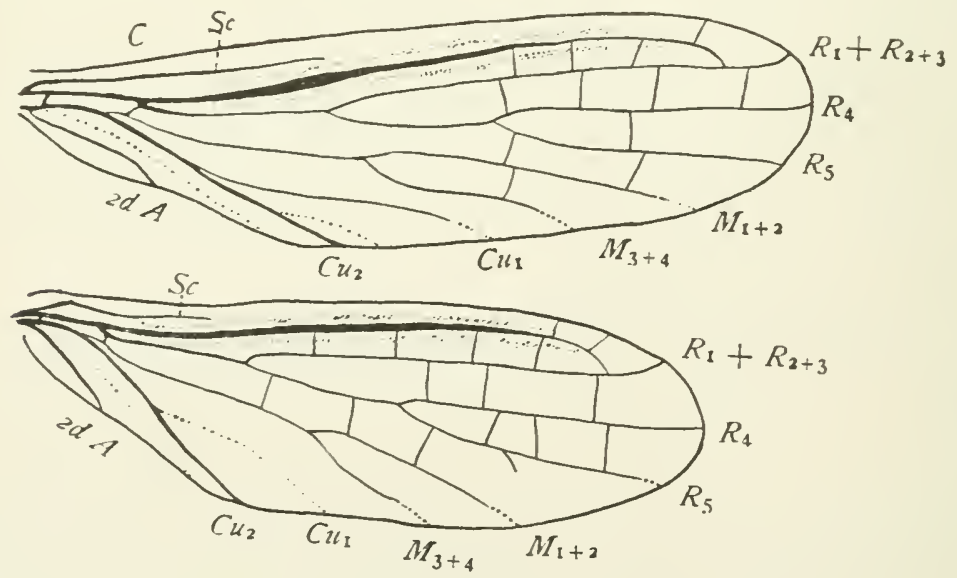

Fig. 262.-Wings of Donaconethis abyssinica (After Enderlein).

In several genera veins $R_{1}$ and $R_{2}+_{3}$ coalesce at the tip; this condition is shown in Figures 259 and 262. 
Enderlein states that in the subfamily Embiinæ, vein $R_{4}$ or $R_{5}$ is forked in some very rare cases; in Figure 262 a vestige of an accessory vein is shown on vein $R_{5}$ of the hind wing.

While the media is usually reduced to an unbranched condition, in the genus Donaconethis (Fig. 262) it is two-branched.

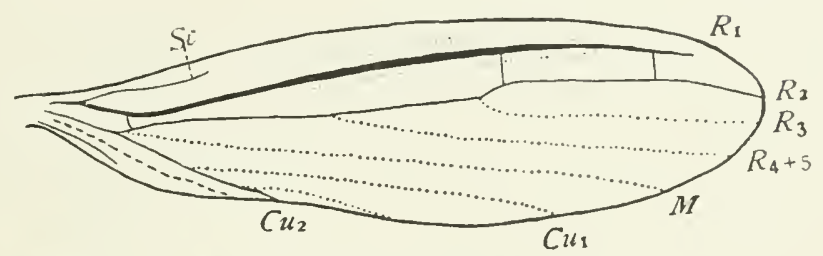

Fig. 263.-Wing of Teratembia geniculata (From Enderlein after Kraus).

Vein $\mathrm{Cu}_{1}$ is reduced to a vestigial condition in many forms; this is the case in the hind wing of Donaconethis (Fig. 262).

The radial sector is reduced to a two-branched condition in Oligotoma (Fig. 259); but is usually three-branched. In those forms where it is threebranched, it is almost invariably veins $R_{2}$ and $R_{3}$ that coalesce completely; but in the genus Teratembia (Fig. $26_{3}$ ) veins $R_{2}$ and $R_{3}$ are separate, while veins $R_{4}$ and $R_{5}$ coalesce throughout their length.
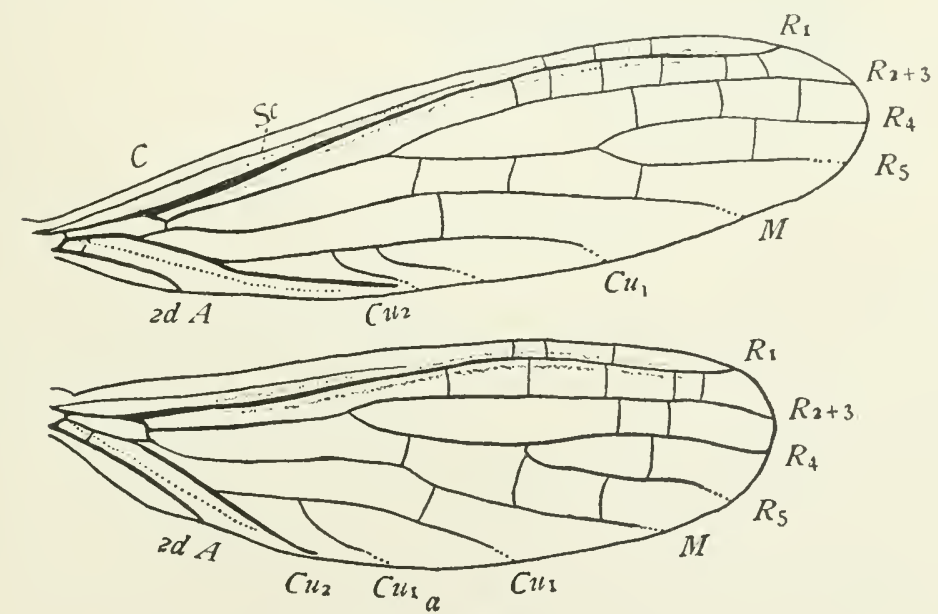

Fig. 264.-Wings of Clothoda nobolis (After Enderlein).

In the genus Clothoda (Fig. 264), of which only a single species is known, vein $\mathrm{Cu}_{1}$ bears two accessory veins in the fore wing and one in the hind wing.

In Teratembia (Fig. 263) and in some species of Embia there appears to be a vestige of an accessory vein borne by vein $\mathrm{Cu}_{2}$. 
The presence of accessory veins in the preanal area of the wings of Clothoda and occasional occurrence of vestiges of accessory veins in other genera raises a question as to the position of this order in the table of the methods of specialization of the wings characteristic of the orders of insects given at the close of Chapter VI, and upon which the linear arrangement of the orders adopted in this essay is based.

In spite of the presence of accessory veins in the preanal area of the wings in the cases mentioned, it is evident that the characteristic method of specialization of the wings in this order is by reduction; even in Clothoda the number of the wing-veins is greatly reduced, the radial sector being only three-branched and the media reduced to an unbranched condition. 


\section{CHAPTER XV}

\section{THE WINGS OF THE THYSANOPTERA}

THE winged members of this order have four wings; these are similar in form, long, narrow, membranous, not plaited, with but few or with no veins, and only rarely with cross-veins; they are fringed with long hairs, and in some species are armed with spines along the veins or along the lines from which veins have disappeared.

The two wings of each side are united by spines, the arrangement of which are described by Hinds ('O3) as follows: "Upon the costa of the hind wing, near its base, stand about five short spines in the Terebrantia and two or three in Tubulifera, which are hooked at their tips. When the wings are spread in flight these tiny hooks engage a membranous fold on the underside of the scale [anal area] of the fore wing. Beyond these small

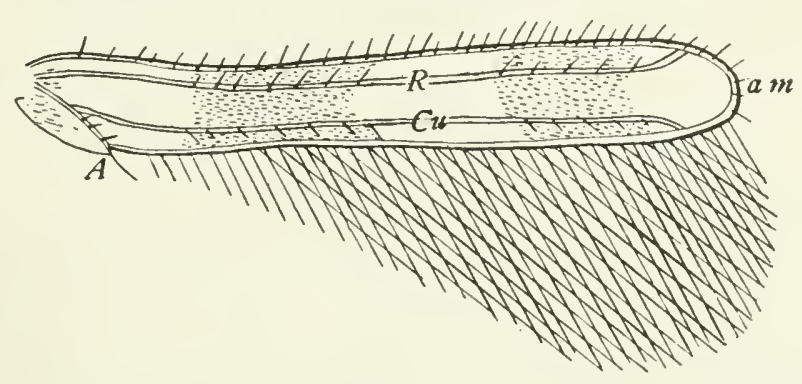

Fig. 265.-Fore wing of Elothrips nasturtii (After Jones).

The lettering is original.

hooks stand a single stouter spine which also forms a hook. From the hind angle of the scale of the fore wing proceed two long, stout spines, standing so closely together as to often appear like one, and these engage the solitary stouter hook on the hind wing. Thus united the wings move together, but as the connection is so near the bases of the wings it can not be very strong." When at rest the wings are folded back flat upon the abdomen. Although the wings are usually present in adults, certain species are apterous.

Even in the most generalized forms the venation of the wings is greatly reduced. A fore wing of Eolothrips nasturtii, one of the more generalized members of the order, will serve as an illustration of this fact (Fig. 265). This figure is a copy of one given by Jones ('I2), to which I have added letters indicating my conclusions regarding the homologies of the wingveins.

The costal vein is present and is continued by an ambient vein, which margins the entire preanal area of the wing (Fig. 265, am). The ambient 
vein is termed the "ring vein" by writers on this order, although the term ambient vein has been long in use for reins in this position.

There is a short longitudinal rein separating the anal and preanal areas (Fig. $26_{5}, \mathrm{~A}$ ) ; this is doubtless the anal rein. Between the costa and the anal vein, there are only tro longitudinal reins (Fig. $265 R$ and $C u$ ); of the four longitudinal veins that typically traverse this area, the subcosta, radius, media, and cubitus, the radius and cubitus are almost invariably the more persistent when there is a reduction of the wing renation. I therefore conclude that these two veins are the radius and the cubitus respectively. These two reins hare been designated as the anterior longitudinal rein and

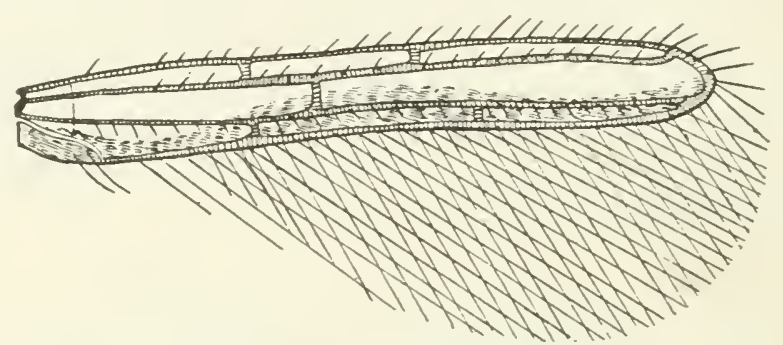

Fig. 266.-Fore wing of Erythrothrips arizonce (After Mloulton).

the posterior longitudinal rein respectively; but it is obvious that terms that pertain to the uniform terminology are preferable so long as there is no reasonable doubt as to the homologies of the veins.

In some members of the order there are a few reins extending transversely to the length of the wing. It is possible that these are branches of the longitudinal veins that have become transverse by a coalescence of their distal portions with adjacent reins; but in the absence of any data to confirm this suggestion, it is better to designate them simply as cross-veins. A good illustration of this type of wing is that of Erythrothrips arizonce, figured by Moulton ('I I) (Fig. 266). 


\section{CHAPTER XVI \\ THE WINGS OF THE HOMOPTERA}

(a) The more general features of the wings of the homoptera

IN the order Homoptera the two pairs of wings are usually similar in texture, and each wing is practically of the same thickness throughout. This is in marked contrast to the conditions in the Heteroptera, where the two pairs of wings differ in structure, the basal half of the front wings being thickened. It was this difference in the structure of the wings of the two groups that suggested the contrasting names Homoptera and Heteroptera for what were regarded until recently as two suborders of a single order, the Hemiptera.

The wings are usually membranous, but in some the front wings are subcoriaceous. In these cases, however, they are of quite uniform texture throughout, and not thickened at the base as in the Heteroptera.

A striking difference between the wings of the Homoptera and those of the Heteroptera is that in the Homoptera when an anal furrow is developed it occupies the usual position, that is behind the cubitus, along the first anal vein instead of in front of the cubitus, as in the Heteroptera.

Many wingless forms exist in this order; in the

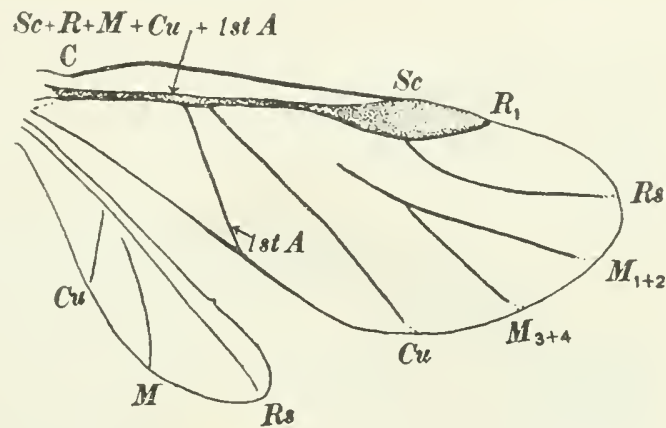

Fig. 267.-The wings of an aphid (After Patch). family Coccidæ the females are always wingless; and in the family Aphididæ the males may be either winged or wingless, while the females and certain generations of the agamic forms are wingless. In the Coccidæ the males have only a single pair of wings, the hind wings being represented by a pair of club-like halteres. Each of these is furnished with a bristle, which in all of the species that I have studied is hooked, and fits in a pocket on the wing of the same side.

If only the wings of adult Homoptera be studied, the venation of these wings appear to depart widely from the hypothetical primitive type. There seems to be little in common with this type in the wings of an aphid (Fig. 267), of a membracid (Fig. 268), or of a cicada (Fig. 269). But in each case when the tracher that precede the wing-veins are studied it is easy to determine the homologies of the wing-veins. 


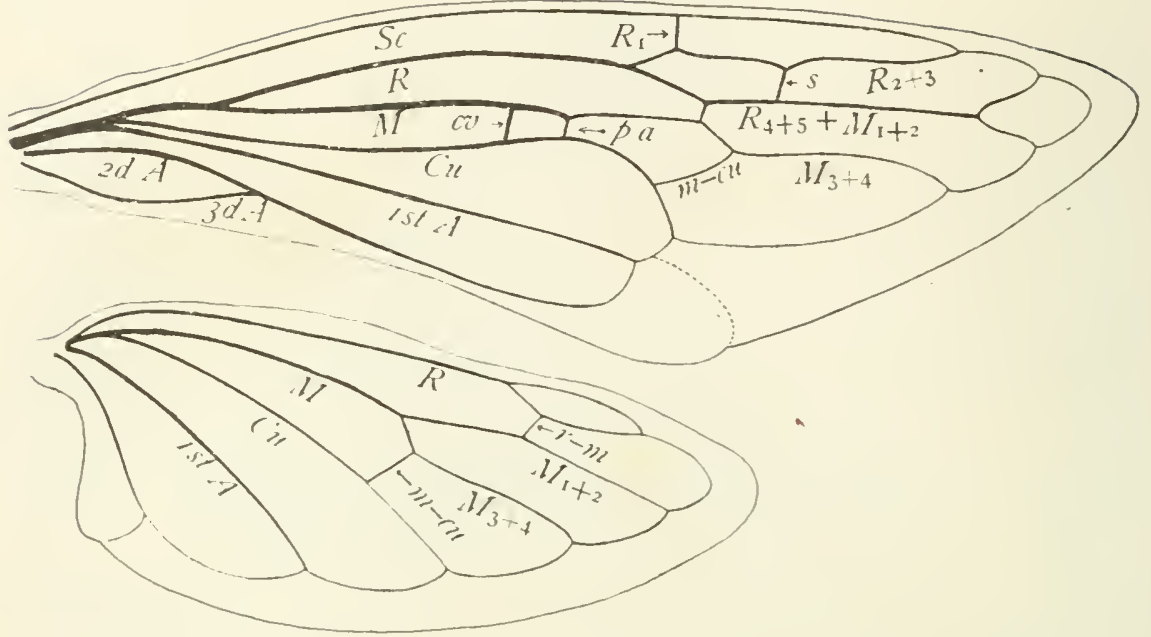

Fig. 268.-The wings of a membracid, Thelia bimaculata (After Funkhouser).
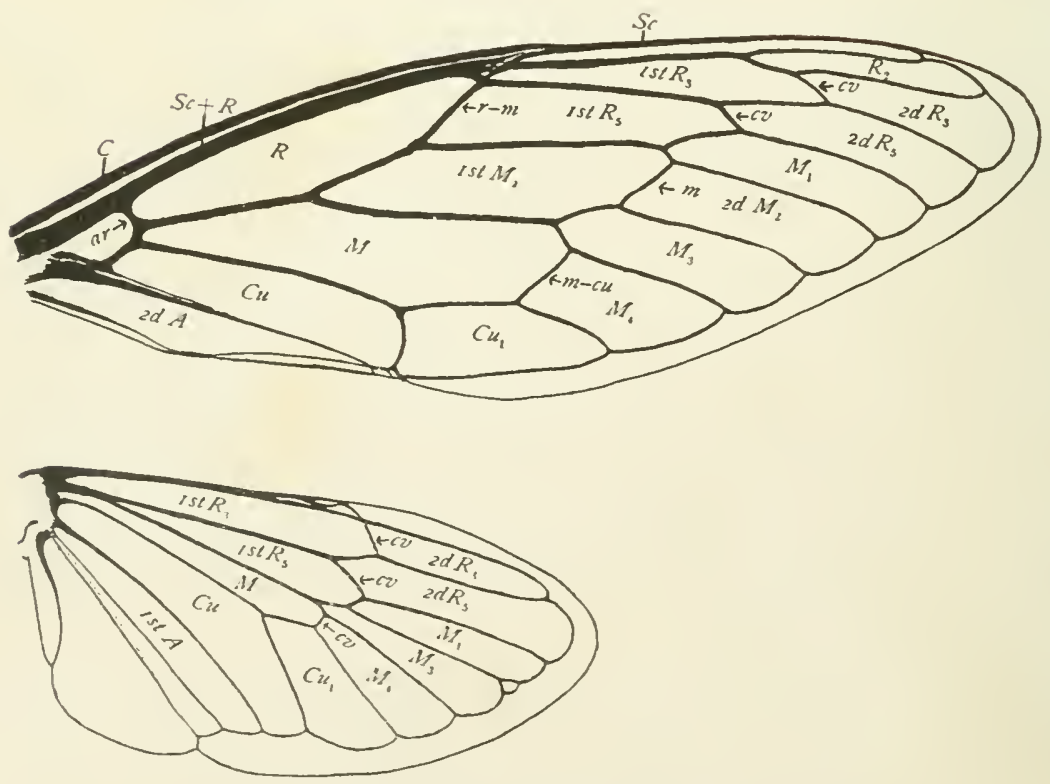

Fig. 269.-The wings of a cicada (After C. \& N.). 
This has now been done in the case of representatives of each of the families of this order, with the result that the homopterous type of wingvenation is now well-known. The first work of this kind in this field was by Comstock and Needham ('98-'99) who traced the development of the wing-veins of a cicada. Ten years later Miss Patch ('og) studied the development of the wing-veins of Aphididæ, Psyllidæ, Aleurodidæ, and Coccidæ; and still later, Funkhouser ('I3) determined the homologies of the wing-veins of the Membracidæ. In the same year there appeared two papers by Professor Z. P. Metcalf, one on the wings of the Jassidæ (Metcalf 'I $3 a$ ), and one on the wings of the Fulgoridæ (Metcalf 'I 3 b); and more recently this author has completed the series by a paper on the wing-veins of the Cercopidæ (Metcalf ' 16 ). Abstracts of each of these papers except those on Fulgoridæ and Cercopidæ are given in the following pages.

In addition to these papers, each of which treats of the wings of a family of the Homoptera, Dr. Karel Sulc ('II) has made a careful study of the tracheal development in the successive stages in the development of the wings of a cercopid, Philemus lineatus.

\section{(b) THE WINGS OF A CICADA}

The development of the wing-veins of a cicada was traced by Comstock and Needham by a study of a series of nymphs of different ages and recently

?

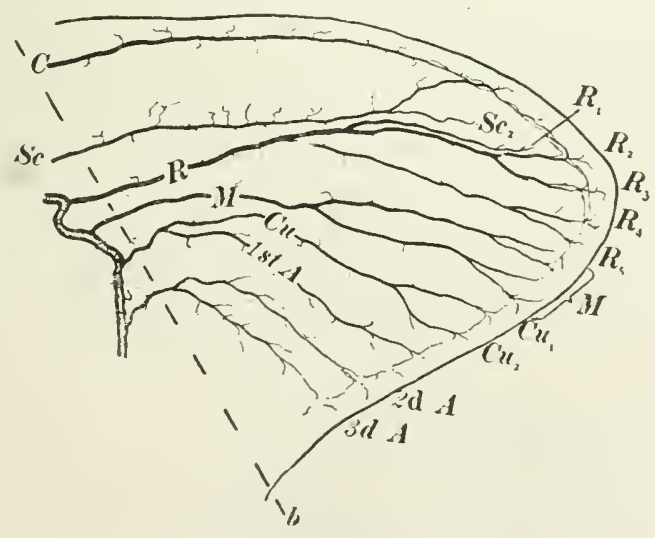

Fig. 270.-The fore wing of a young nymph of a cicada (After C. \& N.). emerged adults. The results obtained were exceedingly gratifying. We had anticipated encountering much difficulty in determining the homologies of the wing-veins of the Homoptera. We were filled with delight, therefore, when we found within this order, preserved almost unchanged, what we had come to regard, from a study of other orders, as the primitive type of wing-venation. The following account of the development of the wing-veins of a cicada is abstracted from our joint paper.

The close correspondence of the wing-venation of a cicada with the primitive type is not obvious if one studies only the wings of the adult (Fig. 269); for in this stage there is a massing of several veins along the costal margin of the wing, and the cross-veins have the same appearance as the branches of the primary veins. 
In the wings of a young nymph, on the other hand, the trachex that precede the veins are not massed as they are later; and in the older nymph, where the forming veins appear as pale bands the cross-veins contain no tracheæ, and can be thus easily distinguished from the longitudinal veins.

Figure 270 represents the tracheation of the fore wing of young nymph; and Figure $27 \mathrm{I}$, that of the hind wing. In each of these figures the dotted line $a-b$ indicates approximately the line along which the hinge of the wing of the adult is formed.

In the fore wing of this young nymph the only departures from the typical branching of the tracheæ are the following; trachea $\mathrm{R}_{1}$ coalesces with the radical sector to a point beyond the separation of trachea $\mathrm{R}_{4+5}$; the first anal

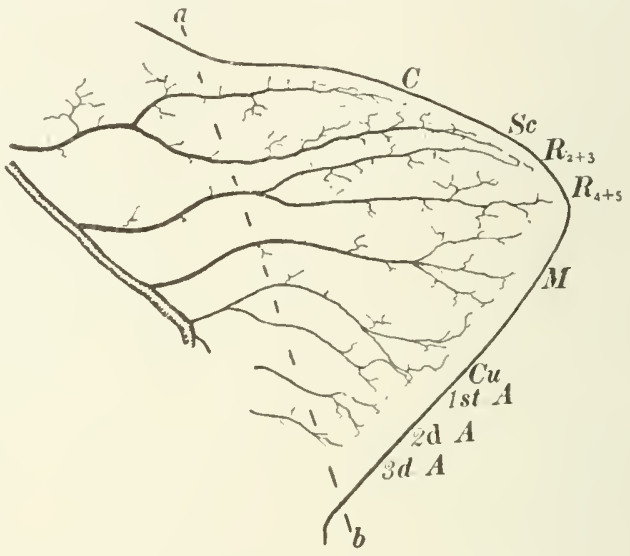

Fig. 271.-The hind wing of a young nymph of a cicada (After C. \& N.). trachea coalesces with trachea $\mathrm{Cu}$ for a short distance; and the second and third anal tracheæ are united at the base. These differences are remarkably slight compared with the great changes that have taken place in the specialization of the mouth-parts and other organs of the adult cicada.

In the hind wing the tracheation is much more reduced. An especially striking feature is the complete loss of trachea $R_{1}$, which is considerably reduced in the fore wing.

In a wing of a mature nymph (Fig. 272 ) trachea $\mathrm{R}_{1}$ is completely aborted. In fact one of the most characteristic features in the venation of the Homoptera, and of the Heteroptera also, is the absence or very great reduction of vein $R_{1}$ in the adult wings of most members of the order. The

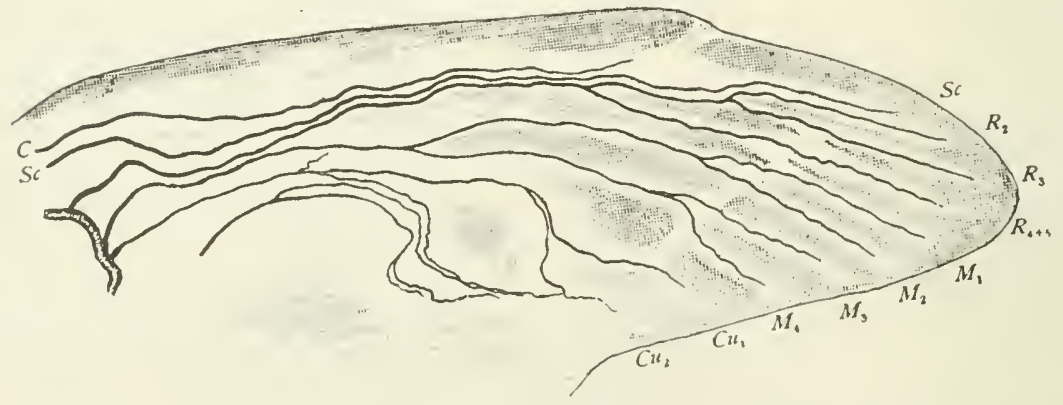

Fig. 272.-The fore wing of a mature nymph of a cicada (After C. \& N.). 
ontogeny of the cicada indicates the course by which this specialization has been reached.

From a study of the two nymph wings (Fig. 270 and 272 ), it is an easy

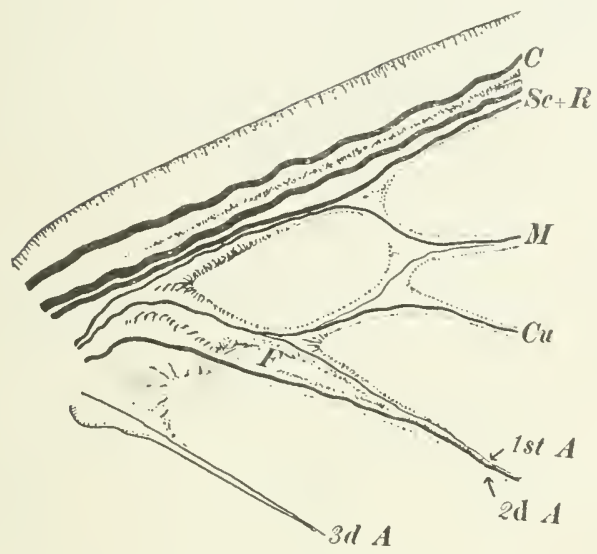

Fig. 273.-The base of a fore wing of an adult cicada (After C. \& N.). matter to trace the homologies of the veins and cells of the fore wing of the adult; these are indicated by the lettering in Figure 269 ; in those cases where the veins are not numbered, these homologies are indicated by the numbering of the cells behind them.

The more difficult features of the venation of the fore wing are elucidated by Figure 273, which represents the base of the fore wing of an adult, and Figure 274 , which represents the region of the nodal furrow of the same wing. These figures are based on a study of the wings of an adult which was killed at the moment of emergence from the nymph skin, and in which the wing-tracheæ were distinctly visible within their corresponding wing-veins.

These figures show well the coalescence of sub-costa and radius from the base of the wing to a point near the nodal furrow; this is a feature which occurs in a large proportion of the families of the Homoptera and Heteroptera.

The changes that have taken place in the hind wings of Cicada are much greater than those of the fore wings, and it would be exceedingly difficult to understand them without an examination of the tracheation of immature wings. Figure $27 \mathrm{I}$ represents the tracheation of the hind wing of a young nymph and Figure 275 that of the base of the hind wing of an adult.

By comparing Figures 270 and $27 \mathrm{I}$, it will be observed that the forking of trachea $\mathrm{R}$ takes place much nearer the hinge line $(a-b)$ in the hind wing than it does in the fore wing. Upon this fact depends the most striking differences in the venation of the fore and hind wings of the adult.

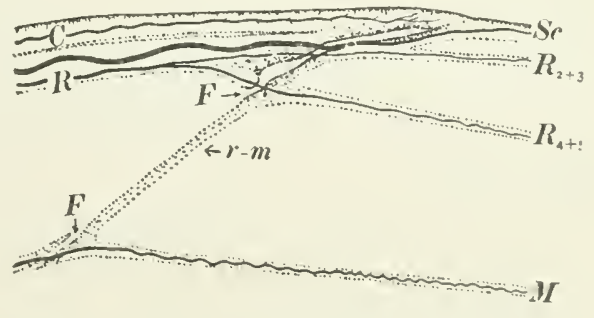

Fig. 274.-The nodal furrow of a fore wing of an adult cicada (After C. \& N.).

In the fore wing the subcosta and radius coalesce to a point near the nodal furrow (Fig. 269). But in the hind wing it is only vein $R_{2}+3$ that 
coalesces with the subcosta. (It should be remembered that vein $R_{1}$ is lost). The posterior half of radius, vein $R_{4}+5$, separates from vein $R_{2}+3$ very near the base of the wing, and coalesces with media for a short distance, after which it traverses the wing as a separate vein. A result of this

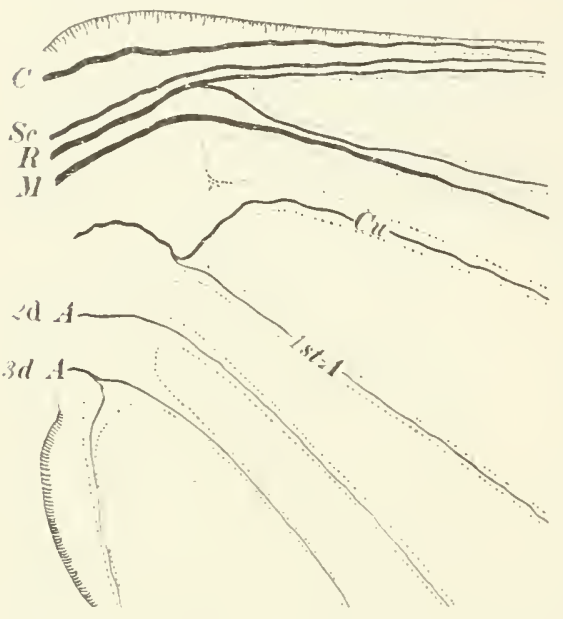

Fig. 275.-The base of a hind wing of an adult cicada ( $A$ fter C. \& N.).

is that while the ist cell $R_{3}$ of the fore wing lies beyond the nodal furrow, in the hind wing it reaches the base of the wing; and Ist cell $R_{5}$ occupies a similar position.

Other features of interest in the hind wing are the following: The media is only three-branched as a rule, but in some specimens there is a small remnant of cell $\mathrm{M}_{2}$, which is ordinarily crowded out by the coalescence of rein $\mathrm{M}_{2}$ and $\mathrm{M}_{3}$. The first and second anal veins are widely separate; and the third anal vein is forked.

In the course of the development of the wing of Cicada, there is an excellent illustration of the migration

of trachea M, which is discussed in Chapter II (p. I ). In the young nymph (Fig. 270) this trachea arises from the transverse basal trachea midway between the radial and cubital tracheæ. In the mature nymph (Fig. 272 ) the base of the medial trachea has reached the cubital trachea.

\section{(c) THE WINGS OF THE MEMBRACIDE}

The homology of the wing-veins of the Membracidæ has been thoroughly worked out by Funkhouser ('13), who gives in his paper many figures of the tracheation of the wings of nymphs and of the venation of the wings of adults. As the wings of representatives of five of the six subfamilies of this family recognized by systematists are figured by him with the homologies of the reins indicated in each case, comparatively little remains to be done in this field.

Only the more general features of the results obtained by Funkhouser will be given here; students of this family should consult his paper for details.

The basal connections of the tracheæ of the wings.--One of the most striking results of Funkhouser's studies was the demonstration of the fact that the Membracids have retained the primitive condition of the basal connections of the tracheæ of the wings; a transverse basal trachea has not been developed, the tracheæ arising from two distinct main trunks; from 
the anterior trunk arise the costal, sub-costal, radial, and medial tracheæ; and from the posterior trunk, the cubital and anal tracheæ. This condition exists in all Plecoptera that we have examined and in certain cockroaches, but had not been found elsewhere until observed by Funkhouser in the Membracidæ. A study of a long series of wings of many genera and species of this family revealed only this condition; hence it is probably characteristic of the family.

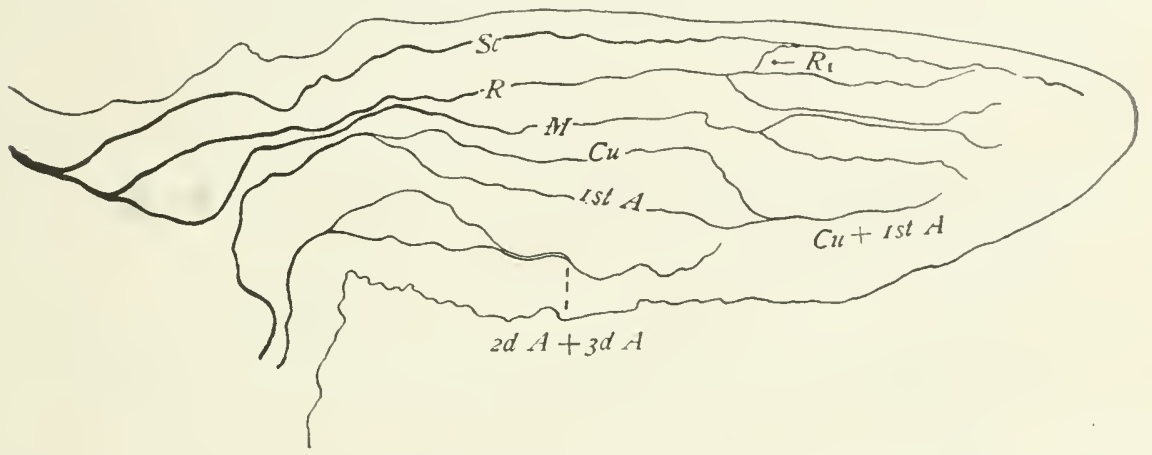

Fig. 276.-The tracheation of the fore wing of a nymph of Thelia bimaculata (Based on two figures by Funkhouser).

In Figure 276, which represents the tracheation of the fore wing of a nymph of Thelia bimaculata, the basal connection of the costo-radial group of tracheæ is well-shown; and in Figure 277 , which represents the fore wing of a nymph of Ceresa borealis the basal connection of the cubito-anal group of tracheæ is shown. The incompleteness of these and other figures of the tracheation of the wings of nymphs is due to the fact that they are based on

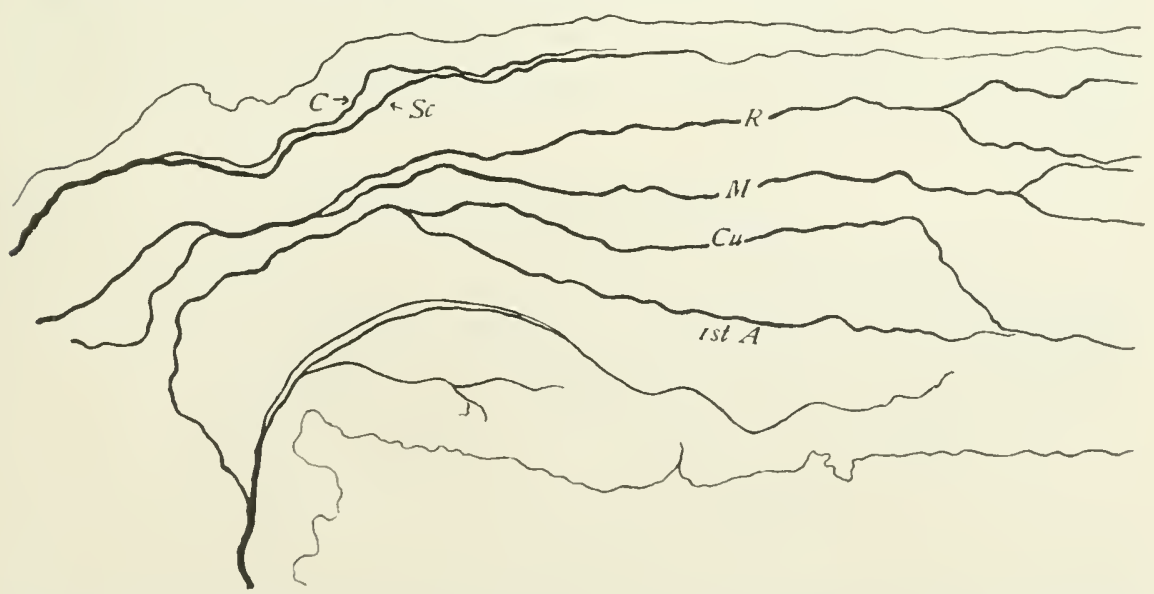

Fig. 277.-The tracheation of the fore wing of Ceresa borealis (After Funkhouser). 
photographs, and as, in the membracid wing, there is a sharp bend at the point at which the trachea enter the body, it is difficult to secure a mount in which the base and tip of the wing can be brought into focus at the same time.

It should be noted that in the membracid wing, as in the other cases where a transverse basal trachea has not been developed, the medial trachea is a member of the costo-radial group.

A comparison of Figures 2,6 and 277 with the diagram of the hypothetical primitive type (Fig. 2,8 ) is of interest in this connection.

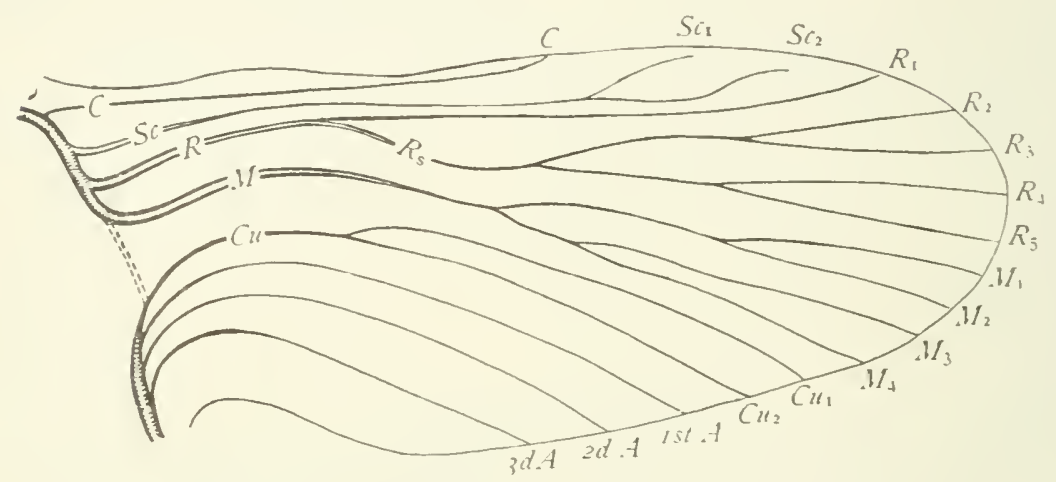

Fig. 278 . - The hypothetical primitive type of the tracheation of the wings.

A general view of the wings.-Figure 279 represents the venation of the fore wing of Thelia bimaculata and will serve to illustrate the type of the wing-renation of members of this family. A comparison of this figure with Figure 276 , which represents the tracheation of the wing of a nymph, will indicate the reasons for the conclusions regarding the homologies of the wing-reins. As the cross-reins are not preceded by tracheæ in the Membracidæ, the cross-veins shown in Figure 279 are not represented in Figure 276 .

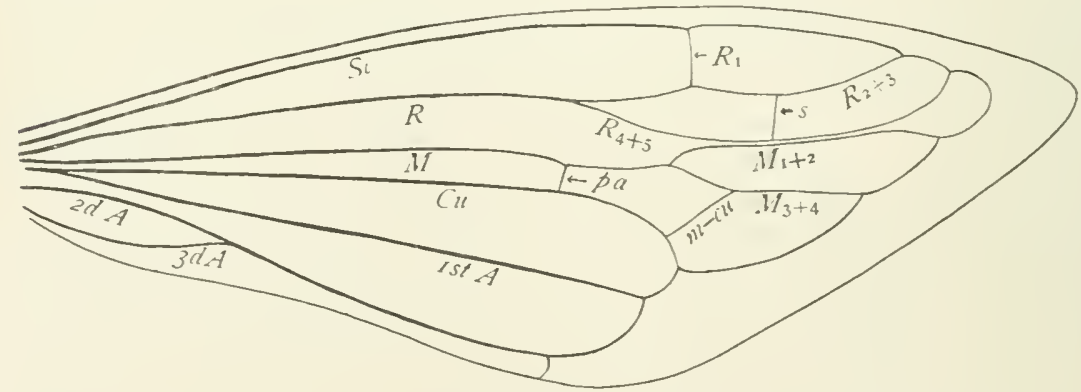

Fig. 279.-The venation of a fore wing of Thelia bimaculata (After Funkhouser). 
In the hind wings a greater reduction of the tracheation and the venation than is the case in the fore wings has taken place. Figure 280 repre-

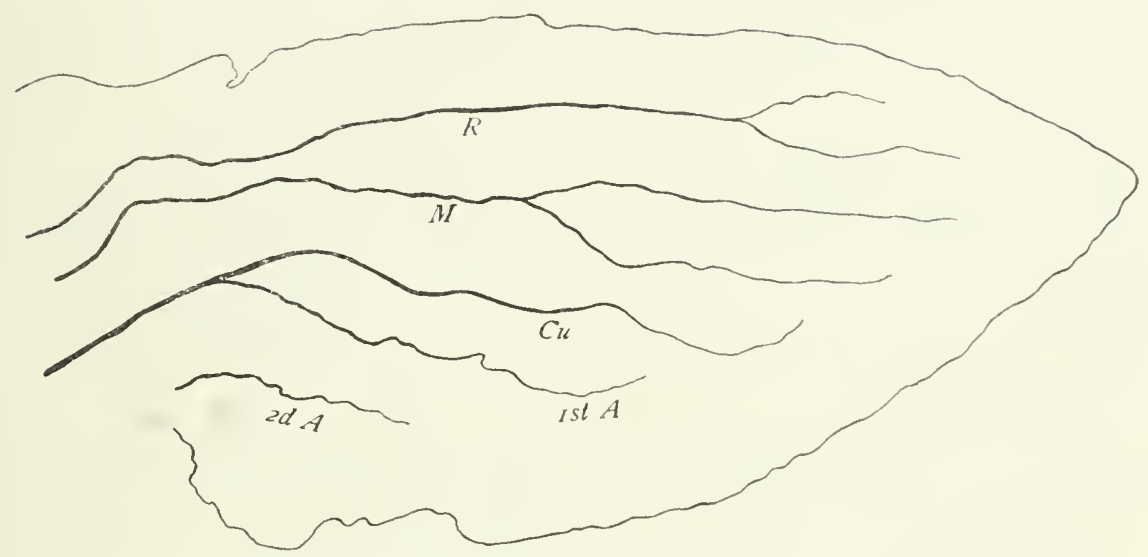

Fig. 280.-The tracheation of the hind wing of a nymph of Thelia bimaculata (After Funkhouser).

sents the tracheation of a hind wing of a nymph of Thelia bimaculata; and Figure 28I, the venation of a hind wing of the adult of this species.

A discussion of each of the principal veins separately will indicate more completely the reasons for the conclusions regarding their identity.

The costa.-There is a great reduction of the costa in this family. In the wings of nymphs the costal trachea sometimes persists, but it is more often lacking. Figure 282 represents the tracheation of a fore wing of a

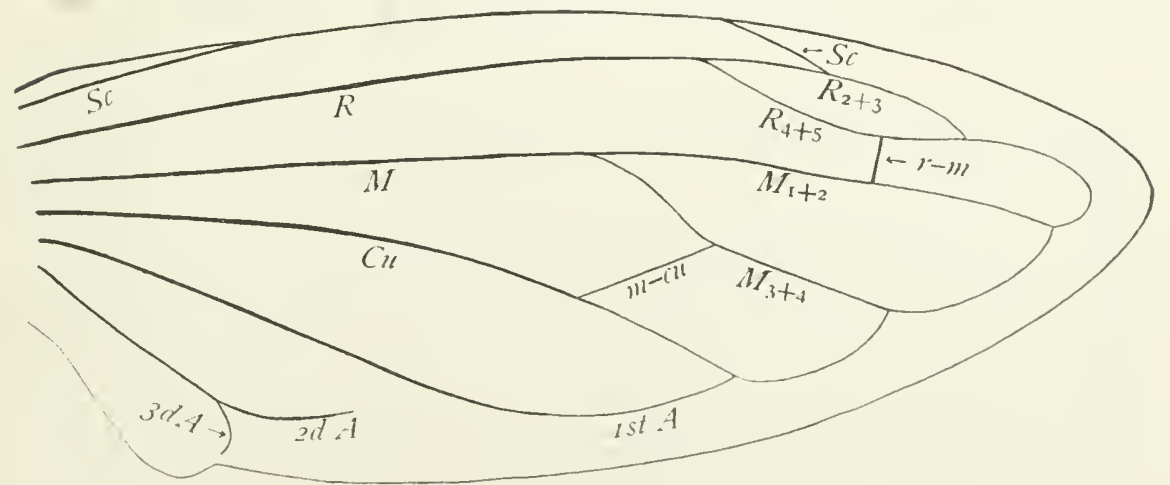

Fig. 281.-The venation of a hind wing of Thelia bimaculata (After Funkhouser).

nymph of Thelia bimaculata in which there was a distinct costal trachea; but it extends only a short distance into that part of the wing which becomes the wing of the adult. In a fore wing of a nympl of Ceresa borealis 
(Fig. 27\%), there is a costal trachea; but is is closely oppressed to the subcostal trachea.

This reduction of the costal trachea is eridently correlated with an even greater reduction of the corresponding vein in the adult wing. Funkhouser states that "Costa never appears as a separate vein in the adult wing." "In such genera as Thelia, Acutalis, and Glossonotus in which a slight membrane is found cephalad of subcosta but no thickened ridge is present, the rein is probably atrophied. In Ceresa, Micrutalis, Telamona, etc., in which subcosta forms the cephalic margin, the tracheæ for costa and subcosta hare coalesced. In Heliria, Vanduzea, and Enchenopa the trachea has had an influence on the costal margin to form a thickening near the base of the wing."

The subcosta.- "Subcosta is constant in character throughout the family. It is strong, straight, and unbranched, and extends the full length of the wing. It is the anterior vein of the wing, owing to the atrophy of costa, and as such often forms the cephalic margin."

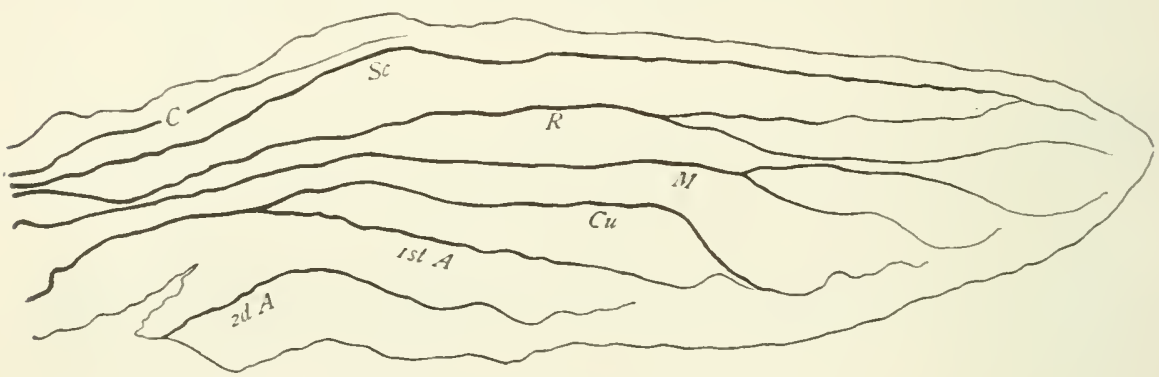

Fig. 282.-The tracheation of the fore wing of a nymph of Thelia bimaculata (After Funkhouser).

The Radius. - An exceedingly interesting result obtained by Funkhouser was the elucidation of the structure of the radius in this family. Here the radius appears, as a rule, to be reduced to a two-branched condition with what appears to be a cross-rein connecting the cephalic branch with subcosta. An extended study of this region of the wing revealed the fact that this transverse vein is really vein $R_{1}$ as indicated in the lettering of Figure 279.

The identity of vein $R_{1}$ was not apparent at first, as the trachea that precedes it is frequently lacking (Fig. 282), and when present it appears to arise in an abnormal position (Fig. 276 ).

"The solution was first found in the wings of I'anduzea arquata and later this peculiar condition was rerified in other genera. The trachea representing $R_{1}$, as will be seen from the figure $\left(28_{3}\right)$, is weak and apparently greatly reduced. It leares the main stem in the normal position, but runs in close juxtaposition to the radial sector beyond the point at which the 
latter branches. Here it turns cephalad and runs across to subcosta where it again turns outward and closely parallels subcosta for some distance in its course toward the tip of the wing. The sharp turns made by the trachea in following this course (Fig. $28_{3}$ ) are remarkable, and in the veins which enclose this region of the wing, the bridge from the radial sector to subcosta gives every appearance of a cross-vein."

From the above it is evident that the two principal branches of radius represent the radial sector and are veins $R_{2}+_{3}$ and $R_{4}+_{5}$ respectively. Although the tracher that precede these branches are represented simple on the figures copied here, Funkhouser states that both of them "showed constant and unmistakable signs of further subdivision at their tips," and in a few cases he found veins corresponding to these subdivisions; thus in Telamonanthe pulchella and in Smilia camelus, veins $R_{2}$ and $R_{3}$ end separately.

The media.-The medial trachea is easily recognized by its position in the costo-radial group of trachea (Fig. 276); this position

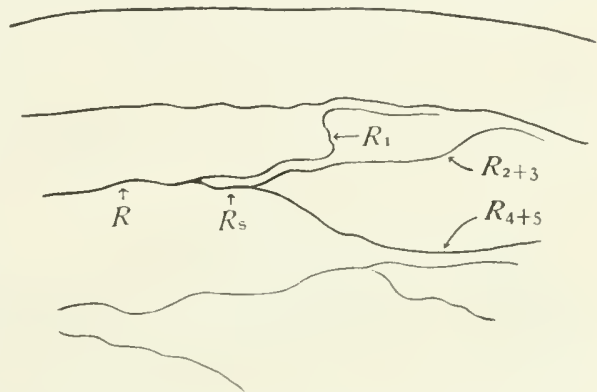

Fig. 283.-Highly magnified portion of fore wing of a nymph of Vanduzea arquata showing the region of trachea $R_{1}$.

being that of the radial trachea in the Plecoptera and in those cockroaches in which a transverse basal trachea has not been developed, and which was adopted in the construction of the hypothetical type (Fig. 278).

In the Membracidæ, media is usually reduced to a two-branched condition; and in most members of the family vein $M_{1}+_{2}$ unites with vein $R_{4}+5$ for a distance (Fig. 268).

In a few genera media is three-branched; as in Jantholobus trilineatus, where vein $\mathrm{M}_{1+2}$ is forked, and in Archasia belfragei, where vein $\mathrm{M}_{3+4}$ is forked.

The cubitus.-An examination of the tracheation of the wings of nymphs shows that the first member of the cubito-anal group of tracher is a large branched trachea which at first sight appears to be the cubital trachea (Fig. 276 and 277); but the branching of this trachea occurs proximad of what becomes the hinge line of the adult wing; so that the two branches represent two distinct veins of the adult wing, $i$. $e$. veins $\mathrm{Cu}$ and ist $\mathrm{A}$. This condition is almost identical with what exists in the cicada (Fig. 270, p. $27 \mathrm{I})$.

The recognition of cubitus in the Membracidx is more difficult than in the cicada, because in the Membracidx this vein is reduced to an unbranched condition. But Funkhouser found that the cubital trachea is 
branched in the wings of many nymphs. This is well shown in his figure of the wing of a nymph of Ceresa diceros. This interpretation of the identity of cubitus makes the position of the anal furrow, namely along the first anal vein, in the membracid wing agree with that found in those other families of the Homoptera in which an anal furrow is developed.

The anal reins. - In most members of this family the three anal veins are preserved more or less distinct in both fore and hind wings. In the wings of many nymphs the third anal trachea is branched (Fig. 277); but in the wings of the adults the third anal vein is simple.

The tip of the first anal vein usually coalesces with cubitus, thus forming a part of the "marginal veins." (Fig. 279). In the fore wings of the larger number of the genera the second and third anal veins are separate at the base of the wing but coalesce throughout the greater part of their length (Fig. 279); but in the hind wings they frequently coalesce at the base and end separately (Fig. 28I ).

The cross-veins.-Funkhouser states that "Of the cross-veins which appear in the fore wing, three only are constant and characteristic of the family, the others being peculiar to certain genera and species and of little comparative importance." These three cross-veins are shown in Figure 279 ; they are the sectoral $(s)$, the medio-cubital $(m-c u)$, and the posterior arculus $(p a)$.

This last cross-rein is usually in the basal third of the wing but is surprisingly variable in position sometimes migrating beyond the middle of the wing. Funkhouser makes no suggestion as to its identity; to me it seems probable that it is the posterior arculus moved out of its typical position. I am led to this conclusion by a comparison of the membracid wings with that of the cicada in which the arculus is typical.

The marginal vein.-A very characteristic feature of most membracid wings, and of the wings of cicadas also, is the presence of an undulating vein parallel with the outer margin of the wing. This vein is formed by the united tips of the longitudinal veins, and is termed the marginal vein, as it forms the edge of the veined part of the wing.

\section{(d) THE WINGS OF THE JASSID}

An extended study of the wing-venation of the Jassidæ has been made by Metcalf ('I3), who figures in his published account the tracheation of the wings of nymphs of representatives of twenty genera and also the wings of adults of a larger number of genera. These represent all of the subfamilies and tribes of the Jassidæ commonly found in Eastern North America. I reproduce here one of his plates illustrating the tracheation of the wings of nymphs (Fig. 284). The results of this investigation are briefly as follows: 


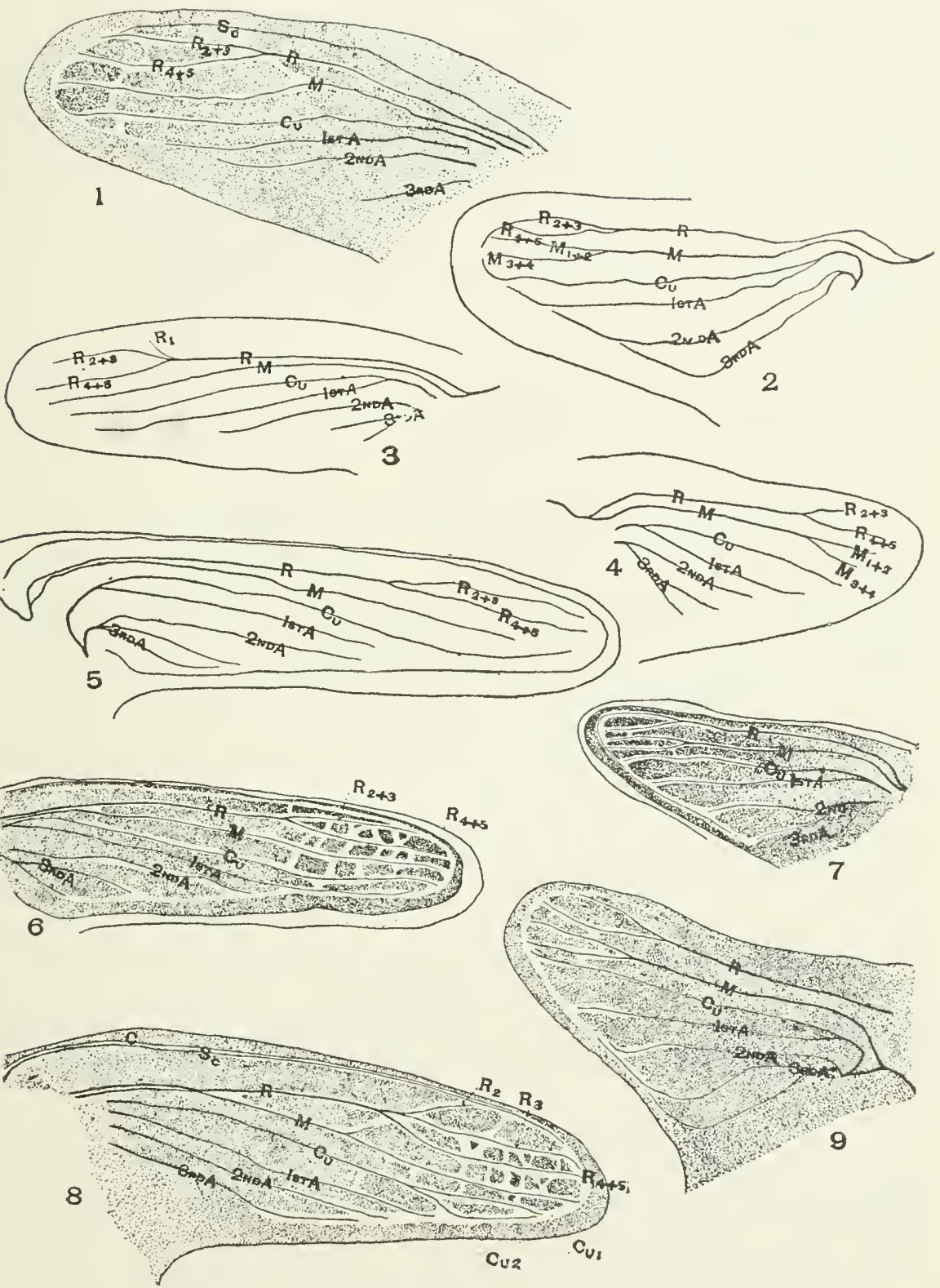

Fig. 284.-Wings of nymphs of jassids: I, fore wing of A gallia 4-punctata; 2, hind wing of A gallia 4-punctata; 3, fore wing of Oncometopia undata; 4, hind wing of Oncometopia undata; 5, fore wing of Diedrocephala coccinea; 6, fore

wing of Draeculacephala mollipes; 7 , hind wing of Draeculacephala mollipes; 8, fore wing of Gypona 8-lineata; hind wing of Gypona 8-lineata (After Metcalf). 
The wings of the Jassidæ show marked specialization by reduction. This reduction is usually accompanied by the atrophy of one of the branches of one of the main tracheæ and the shifting of a branch of a neighboring trachea until it occupies the region of the atrophied trachea. The atrophy of these trachex with the subsequent shifting of other trachea which take their places gives to the wings of the Jassidæ their characteristic aspect.

The costa of the fore wing.-The costal trachea was absent in all of the jassid wings examined with the exception of Gypona (Fig. 284, 8). This indicates that the costal trachea has practically disappeared from the Jassidæ.

The subcosta of the fore wing.- A subcostal trachea was found in only six of the genera examined; among these are Agallia (Fig. 284, I) and Gypona (Fig. $28_{4}, 8$ ). A subcostal vein, however, is well developed in all of the adult wings studied, and it shows very clearly as a distinctly lighter area in all of the older nymphs examined.

The radius of the fore wing. - The radial trachea of the fore wing of Jassidx is typically two-branched although in some forms three or even four branches do occur. The two branches of the typical radius represent $\mathrm{R}_{2+3}$ and $\mathrm{R}_{4+5}$. $\mathrm{R}_{1}$ has almost completely disappeared from the fore wings in this family. It does occur, as a delicate branch in a few genera (Fig. 284,3 ) but gives rise to a very characteristic cross-rein between subcosta and radius, which is known currently as the "nodal vein."

The media of the fore wing.-The medial trachea is typically two branched in the Jassidæ. These branches are $\mathrm{M}_{1+2}$ and $\mathrm{M}_{3}+4$. Trachea $\mathrm{M}_{1+2}$ is well developed in only a few genera; in Gypona (Fig. $28_{4}, 8$ ) it is restigial; in the other fore wings represented in this figure the medial trachea is reduced to an unbranched condition; and this is the case in most of the forms examined by Metcalf.

The cubitus and the first anal of the fore wings. - In all of the genera of the Jassidæ examined the cubital and the first anal tracheæ were the most constant and formed one of the best landmarks in the study of the relations of the tracheæ. They coalesce for some little distance from the base of the wing.

The cubital trachea is frequently two-branched (Fig. 284,8 ); but in the greater number of genera studied by Metcalf it is reduced to an unbranched condition. The presence of forms in which trachea $\mathrm{Cu}_{2}$ is reduced to a mere spur indicates that it is this branch that is lost in those forms where the cubital trachea is unbranched.

The first anal wein of the fore wings.-The first anal vein lies along the anal border of the claral suture. It has not been usually recognized as a distinct vein owing to the fact that as a vein it is rather inconspicuous while the claval suture or fold is very distinct. It is, however, preceded by a conspicuous trachea in all of the genera studied. 
The second and third anals of the fore wing.-The second and third anal trachex in the fore wing are well developed and the third anal is frequently two-branched (Fig. 28, 3).

The costa and the subcosta of the hind wings.-In all of the Jassidæ proper the hind wing is very uniform. No costal or subcostal tracheæ have been discovered although the subcostal vein was well defined in all of the older nymphs studied (Fig. 284, 9).

The radius of the hind wing.-The radial trachea of the hind wings is typically two-branched in this family. In a single genus Spangbergiella, the radial trachea is unbranched. No indication of trachea $R_{1}$ was observed in the hind wing.

The media of the hind wing.--The medial trachea of the hind wing is two branched in all of the genera examined.

The cubitus of the hind wing.-The cubital trachea of the hind wing is reduced to an unbranched condition in all of the genera examined.

The anal trachece of the hind wings. - The first anal trachea and the cubital trachea coalesce for a distance as in the fore wing. The second and third anal tracheæ are also present in nearly all cases; and the third anal trachea is frequently two-branched. In the adult wing the second anal vein and the anterior branch of the third anal frequently coalesce at the base or anastomose near the middle of their course.

The basal connections of the trachea of the wings. - The above abstract, which consists largely of quotations from the paper by Metcalf, indicates the more important conclusions reached by this writer. A study of his illustrations indicates another conclusion not mentioned by him; this is that in the Jassidæ, as in the Membracidæ, a transverse basal trachea has not been developed. With one exception, in all of the forms where the basal connections of the tracher were traced, the costo-radial and the cubito-anal groups of trachea are not connected by a transverse basal trachea, and the medial trachea is a member of the costo-radial group. Several illustrations of this are on the single plate reproduced here. (Fig. $284,2,5$ ), and there are many of them on the other plates in Metcalf's paper.

The one exception to this arrangement of the tracheæ indicated by Metcalf's figures is that of the hind wing of Gypona (Fig. 284, 9). As the basal connections of the trachea are only partly shown in this figure the evidence presented by it is not conclusive.

\section{(e) THE Wings OF THE PSYLLID}

We are indebted to Miss Patch ('og) for the working out of the homologies of the wing veins of the Psyllidx. The following account is based on her paper. See note on page $29 \mathrm{I}$. 
A general view of the wings.--Figure 285 represents the tracheation of a fore wing of a nymph of Psylla floccosa. All of the principal trachea except the third anal are present and each arises separately from a transverse basal

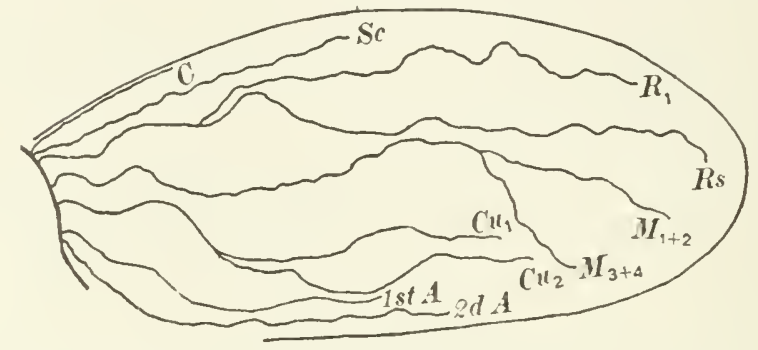

Fig. 285.-The tracheation of a fore wing of a nymph of Psylla floccosa (After Patch).

trachea. The subcostal trachea is not branched; the trachea that precedes radius-one is well developed; the radial sector trachea is reduced to an unbranched condition; the medial trachea is reduced to a two-branched condition; the cubital trachea is typical; and the two anal tracheæ are unbranched.

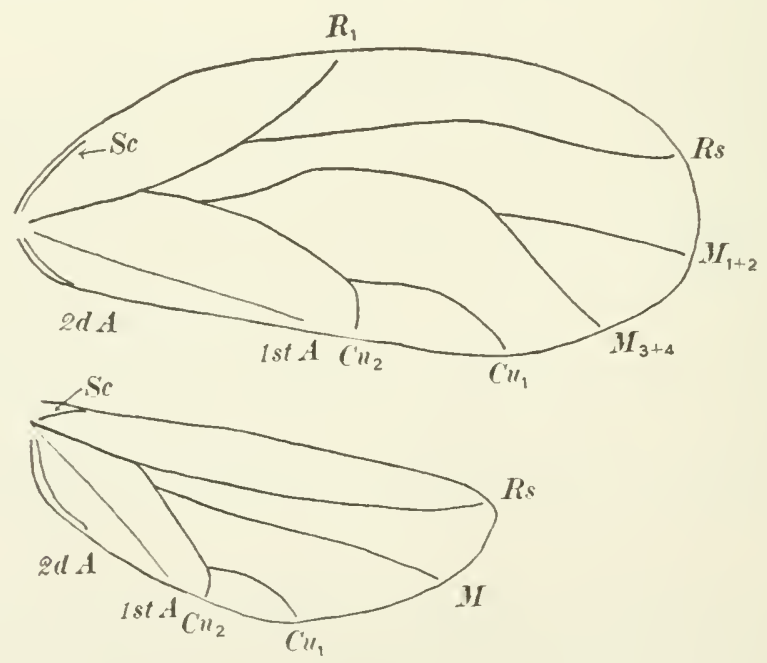

Fig. 286.-The tracheation of the wings of a freshly emerged Psylla floccosa (After Patch)

The wings of a newly emerged adult show remarkable changes in the tracheæ, due to the reduction of some and to the coalescence of others (Fig. 286). The tracheation in this stage corresponds very closely with the definitive renation; the venation of the fore wing is represented by Figure 287 . 
In the adult wing the first anal vein is not developed as a vein but is represented by the anal furrow, or the calval suture as it is termed by writers on the Homoptera. The other changes are indicated by the lettering of Figure 287 .

The stigma.- In some of the Psyllidæ the costal margin of the fore wing is strengthened by a stigma.

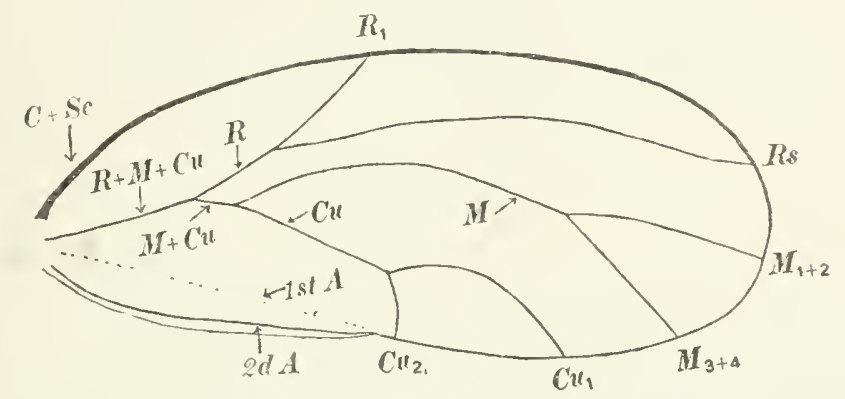

Fig. 287.- The venation of a fore wing of Psylla floccosa (After Patch).

\section{(f) THE WINGS OF THE APHIDIDE}

The tracing of the homologies of the wing veins of the Aphididæ was the subject of a painstaking investigation by Miss Patch ('og); in the course of which approximately roo species representing I 7 genera were studied,

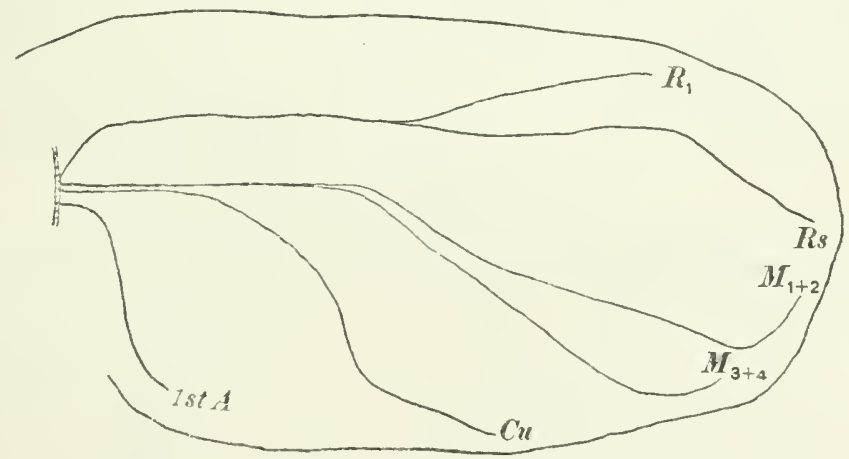

Fig. 288. - The tracheation of a wing of a nymph of Schizoneura rileyi (After Patch).

and wings of many nymphs and of more than 2000 newly emerged aphids were examined. The following brief summary is based on this paper.

A general view of the wing.-The most generalized aphid wing figured by Miss Patch is that of a nymph of Schizoneura rileyi (Fig. 288). In this wing there are four main tracheal trunks, which arise from a transverse basal trachea. The costal and subcostal trachex are lacking; and only 
one anal trachea is present. The trachea of the radial sector is unbranched; that of media is only two-branched; and that of cubitus is not forked.

In the wing of a newly emerged adult (Fig. 289) all the tracheæ of the cubito-anal group coalesce at the base of the wing.

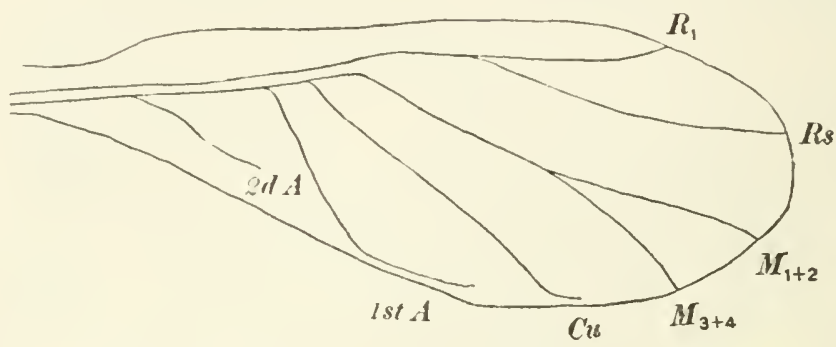

Fig. 289. - The tracheation of a freshly emerged adult Schizoneura rileyi (After Patch).

It should be observed that here, as is usually the case where there is a transverse basal trachea, the medial trachea becomes a member of the cubito-anal group.

In two other cases the basal connections of the tracheæ are figured by Miss Patch. Figure 290 represents the tracheation of the fore wing of a newly emerged Aphis; and Figure 29I the tracheation of the hind wing of a newly emerged Chaitophorus populicola.

The data given above furnishes the key to an understanding of the tracheation of the wings of Aphids. The two principal tracheæ, which extend from the base of the wing outward parallel to each other and to the costal margin of the wing, represent respectively the costo-radial and the

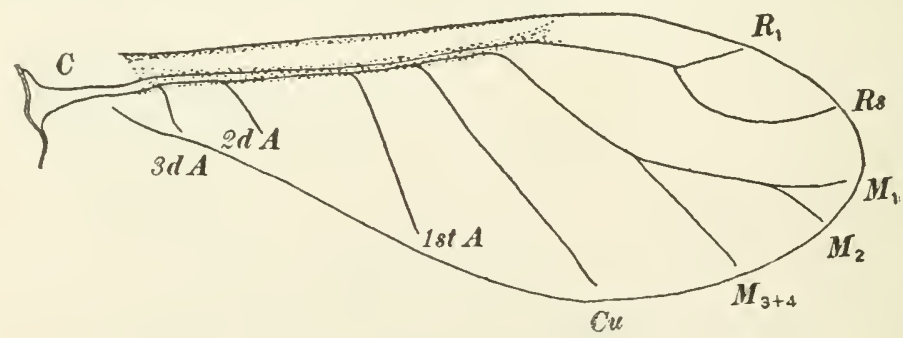

Fig. 290.-The tracheation of a fore wing of a newly emerged Aphis (After Patch).

cubito-anal groups of tracheæ. Of the former only the radial trachea is preserved in this family; to the latter belong the medial as well as the cubital and anal tracheæ.

A comparison of Figure 292, which represents the wings of an adult Schizoneura americana, will serve to show the relation of the tracheation of 
the wing to the definitive venation. This relation will be made more clear by the following discussion of the separate veins.

The costa.-A costal trachea was not found in any of the wings examined. But Miss Patch observed that not only is the costal margin of the wing stiffened by a vein-like structure, but this part of the wing contains what appears to be a vein-cavity; as was shown by the fact that in severing the

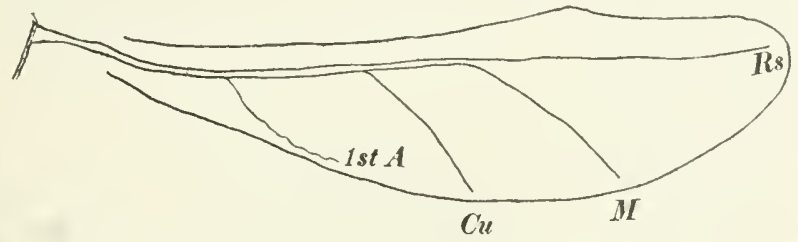

Fig. 29r.-The tracheation of a hind wing of a newly emerged Chaitophorus populicola (After Patch).

wing from a freshly killed aphid, the yellow body fluids frequently flow into this vein and extend along to about the region of the stigma (Fig. 290).

The subcosta.-No subcostal trachea was found in any member of this family. It may be that the subcostal vein is completely lost, or, as Miss Patch concluded, this "is present in the large main vein channel of the wing, and extends from the base. of the wing to the stigma wh rre it approaches the margin of the wing.". The lettering of her figures is based on this conclusion.

The radius.-In the more generalized members of the family, as shown by the figures given above, radius is two-branched, in the fore wings radius-one being preserved, and the radial sector being unbranched. In the hind wings, radius-one is lost.

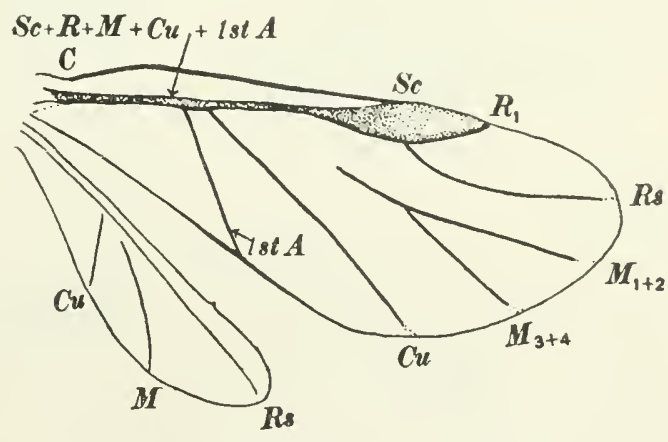

Fig. 292-The wings of Schizoneura americana (After Patch).

In the Chermesinae, vein $R_{1}$ is wanting in the fore wings as well as in the hind wings. Figure 293 represents the tracheation of a fore wing of Chermes abietis; Figure 294, the tracheation of a hind wing of Chermes pinifolic; and Figure 295, the definitive venation of both wings of a Chermes. See note on page 291 .

A striking feature of the tracheation of the wings of Chermes is the presence of many secondary branches of the tracheæ. This feature was observed in other genera also. 
The media.--The data upon which the identification of media is based is given above. As to the nature of this vein, it may be three branched, as

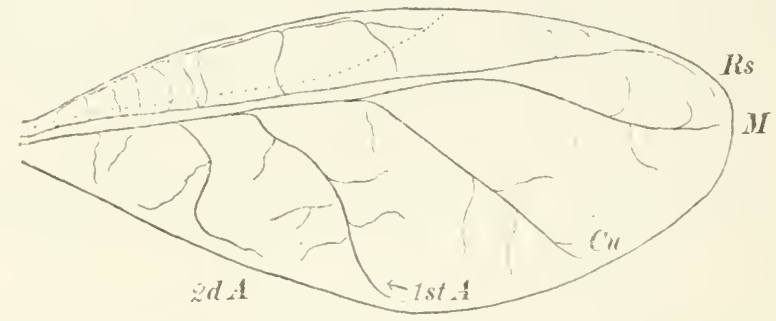

Fig. 293.-The tracheation of the fore wing of Chermes abietis (After Patch).

in Aphis (Fig. 290), or two-branched, as in Shizoneura (Fig. 292), or it may be reduced to an unbranched condition, as in Chermes (Fig. 295).

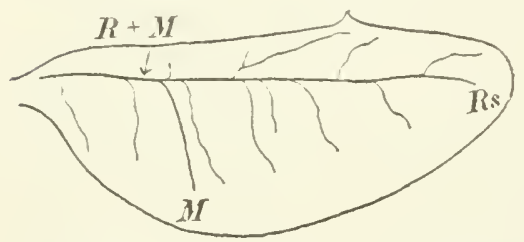

Fig. 294.-The tracheation of a hind wing of a nymph of Chermes pinifolice (After Patch).

The cubitus.- "Cubits is present in all genera of Aphididx and in all of them unbranched."

The anal veins.-A single anal vein is dereloped in this family. That this is the first anal vein was demonstrated by the finding of the second and third anal trachere in wings of newly emerged aphids (Fig. 290); but veins are not developed about these tracheæ.

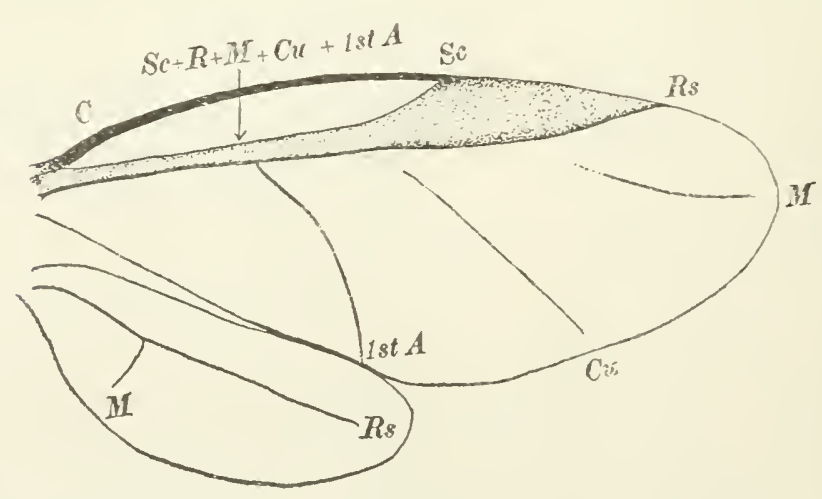

Fig. 295.-The venation of the wings of Chermes (After Patch). 
COMPARISON OF TERMINOLOGIES OF THE WING-VEINS OF THE APHIDIDE

The following table is given by Miss Patch:-

$\begin{array}{ll}\text { After Buckton } & \begin{array}{c}\text { Current terminology } \\ \text { FORE WING }\end{array} \\ \text { Costal Nervure } & \text { Costal } \\ \begin{array}{l}\text { Cubitus or post-costal } \\ \text { nervure }\end{array} & \text { Subcostal vein }\end{array}$

Stigmatic

First furcal

Second furcal

Cubital nervure

Second oblique
First oblique

Stigmal vein

First branch

Second branch

Third discoidal or cubital

Second discoidal

First discoidal

\section{HIND WING}

Cubitus or post costal Stubcostal vein nervure

Second oblique

First oblique
Second discoidal

First discoidal
Comstock-Needham

Costa (C.)

Subcosta (Sc)

Radius $_{1}\left(\mathrm{R}_{1}\right)$ (together with basal portions ofthe remaining wing veins).

Radial sector ( $\mathrm{Rs}$ )

Media $\left(\mathrm{M}_{1}\right)$

Media $\left(\mathrm{M}_{2}\right)$

Media (M)

$\operatorname{Media}_{3+4}\left(\mathrm{M}_{3}+4\right)$

Cubitus (Cu)

First Anal (ist A.)

(g) THE Wings of the ALEURODIDAE

In the fore wings of freshly emerged Aleurodes, Miss Patch found four fine but distinct tracheæ, the costal, subcostal, radial, and cubital (Fig. 296,a). All of these extend separate to the base of the wing. The medial trachea is suggested merely by a very faint and delicate but constantly appearing tracing in the wing.

In the definitive venation of the fore wing (Fig. 296, b), costa, subcosta, vein $R_{1}$, and media are lacking, only the main stem of radius, the radial sector, and cubitus being developed.

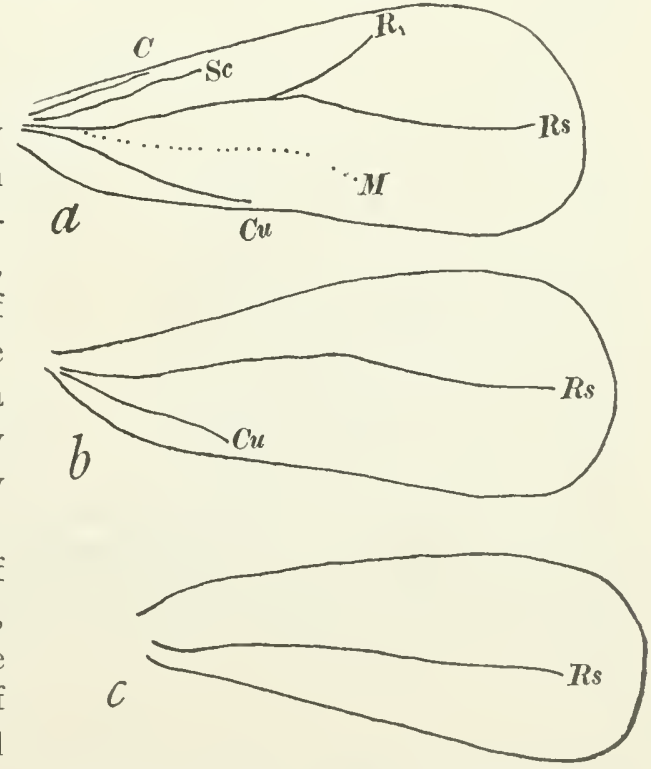

Fig. 296. - Wings of Aleurodes (After Patch). 
The hind wing of Aleurodes (Fig. 296, c) has but one trachea and one vein; this is doubtless the main stem of radius and the radial sector.

\section{(h) THE WINGS OF THE COCCIDE}

The tracheation of the wings of a species of Dactylopius found on cactus is figured by Miss Patch (Fig. 297); and the definitive venation of the same species is also figured (Fig. 298). The following is from her account.

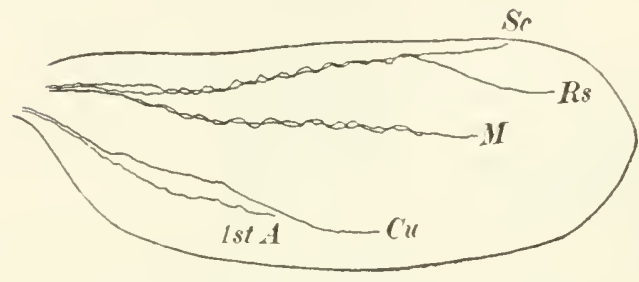

Fig. 297.-The tracheation of a wing of Dactylopius (After Patch).

"The tracheæ in the wing of this coccid remain distinct until after the veins begin to form so that the relation of the two is at once discerned. One vein follows the general trail of the subcostal and radial tracheæ. This vein very evidently represents the radius." (In her figure it is labeled $\mathrm{R}_{\mathrm{s}}$.

I have taken the liberty of changing the designation to $\mathrm{R}$ ).

"The second vein follows the base of the first tracheal group to about the point where the medial trachea separates from the subcostal and radial. The vein here takes a direct line for the middle of the caudal margin of the wing. For slightly less than one-third the length of this vein it frequently joins the path of the cubital trachea. This corresponds most closely with media.

"Besides these two main veins a short spur representing the subcosta is present.

"In a wing so highly specialized as the coccid wing it is not improbable that the tracheation has lost its value as a basis for the renation. Certainly in the species studied there seems no necessary connection between the tracher and the veins which are found later."

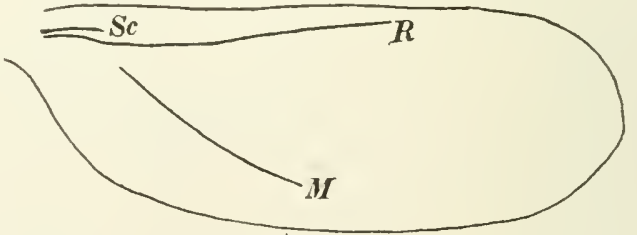

Fig. 298.-The venation of a wing of Dactylopius (After Patch).

The fact that the medial trachea is a member of the costo-radial group of tracheæ suggests, in the light of the condition found by Funkhouser in the Membracidæ, that perhaps in the Coccidæ a transverse basal trachea has not been developed. 


\section{(i) SUPPlementari NOTE}

It has been shown in the preceding pages that in a Cicada, the Membracidæ, and Jassidæ, vein $R_{1}$ is either absent or greatly reduced and that, as a result of this, the two principal branches of radius are veins $R_{2}+3$ and $R_{4}+5$. This fact suggests the possibility that the two branches of the radius in the Psyllidæ and the Aphididæ are veins $R_{2}+_{3}$ and ${ }_{4}+5$ and not veins $R_{1}$ and $R_{s}$ as indicated in the accounts of the wings of these families given above. But as I know of no observation demonstrating the atrophy of vein $R_{1}$ in these families, $I$ have not felt free to change the determinations of homologies of the branches of radius published by Miss Patch; and I merely suggest that the method of the reduction of the radius in these and allied families be investigated farther. 


\section{CHAPTER XVII}

\section{THE WINGS OF THE HETEROPTERA}

(a) THE MORE GeNeral FEATURES OF THE Wings of THE HETERoptera

In the Heteroptera there is a remarkable difference in the texture of the two pairs of wings, which suggested the name of the order. The basal half

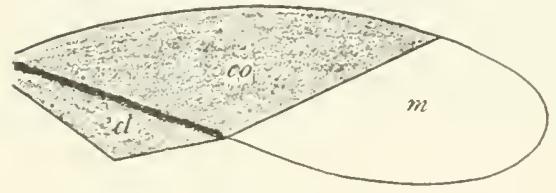

Fig. 299.-Diagram of a front wing of a bug; $\mathrm{cl}$, clavus; $c o$, corium; $m$, membrane. of the front wings is thickened so as to resemble the elytra of beetles, only the terminal half being winglike. The hind wings are membranous, and are folded beneath the front wings. On this account the front wings are often termed wingcovers; they are also termed hemely-

tra, a word suggested by their structure.

The front wings present characters much used in the classification of these insects; and consequently special names have been applied to the different parts of them. The thickened basal portion is composed of two pieces joined together at their sides; one of these is narrow and is the part next to the scutellum when the wings are closed (Fig. 299, cl); this is distinguished as the clavus.

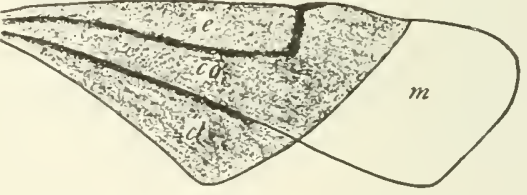

Fig. 300.-Diagram of a front wing of an acanthiid: $e$, embolium; $c o$, corium; $c l$, clavius; $m$, membrane.

The other broader part is the corium (Fig. 299, co). The terminal portion of the front wing is designated as the membrane (Fig. 299, $m$ ). In cer-

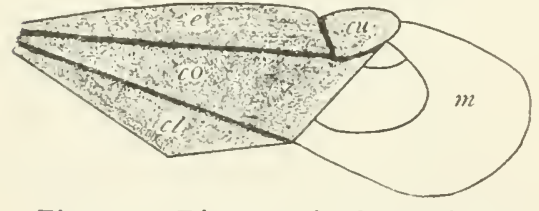

Fig. 301.-Diagram of a front wing of a capsid; $c u$, cuneus; $e$, embolium; $c o$, corium; $c l$, clavus; $m$, membrane. tain families, the Acanthiidæ for example, a narrow piece along the costal margin of the wing is separated by a suture; this is the embolium (Fig. $300, e$ ). In certain other cases as the Capsidæ, for example, a triangular portion of the terminal part of the corium is separated as a distinct piece; this is the cuneus (Fig. 30I, cu).

\section{(b) THE TRACHEATION OF THE WINGS OF THE HETEROPTERA}

The wings of the Heteroptera exhibit remarkable departures from the primitive type of wing-venation. So great are these that, at first, one sees very little in common between the wings of a bug and those of insects of 
any other order. But an examination of the tracheation of the wings of nymphs of bugs shows that these wings are merely modifications of the primitive type.

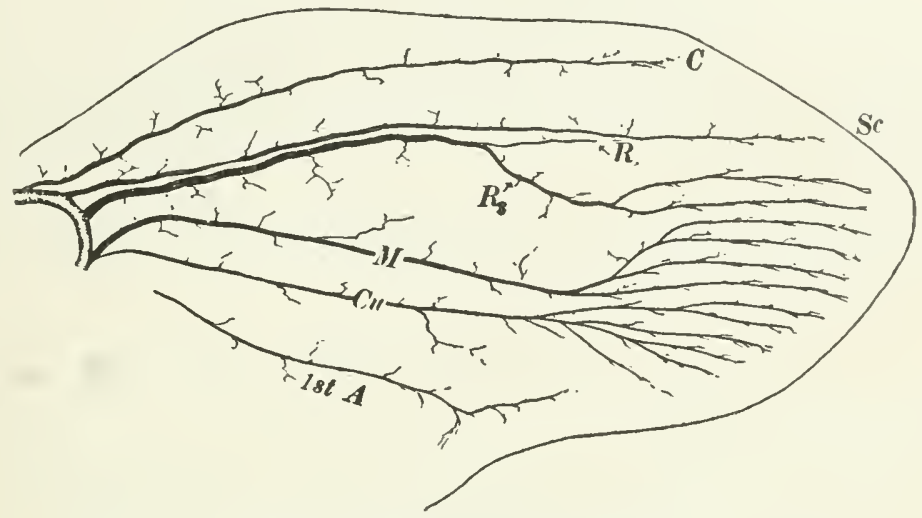

Fig. 302.-Tracheation of a fore wing of a pentatomid nymph (After C. \& N.).

A quite extended study of the development of wings of the Heteroptera was made by Comstock and Needham; and as I have no additional data that tend to modify our conclusions I will abstract our account of the results of this investigation.*

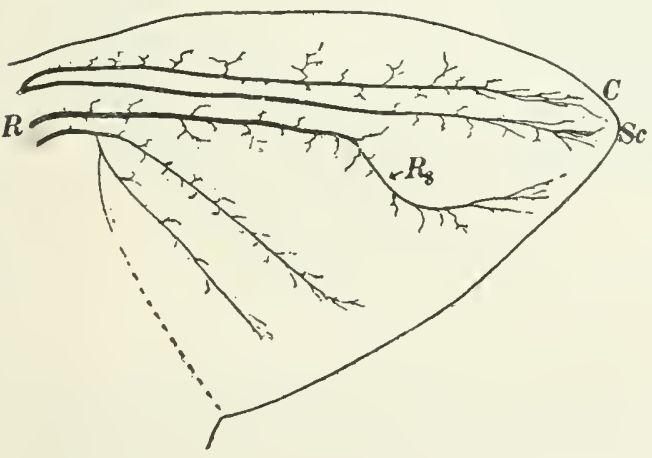

Fig. 303.-Tracheation of a hind wing of a pentatomid nymph (After C. \& N.).

In our studies of Heteroptera we examined nymphs of the following families: Notonectidæ, Nepidæ, Belostomidæ, Reduviidæ, Nabidæ, Capsidæ, and Pentatomidæ. Of these there is no doubt that the most generalized condition of wing-venation is found in the family last named, but further studies in other families may reveal a still more primitive type.

The tracheation of the fore wing of a pentatomid nymph is represented by Figure 302 , and that of the hind wing by Figure 303. In the fore wing trachea $\mathrm{C}$ is well-preserved. Trachex $\mathrm{Sc}$ and $\mathrm{R}$ are closely approximate in the basal half of the wing, foreshowing the coalescence of subcosta and radius. In the distal half of the wing trachea Sc traverses that part of the

*Handlirsch ('06-'08) figures the tracheation of the wings of Lygæus (Lygæidæ), Syromastes (Coreida), and Nepa (Nepida). 
wing which would be traversed by Trachea $R_{1}$ were it weli developed. Trachea $R_{1}$ is present, but is reduced to a vestigial condition. It is evident that a supplanting of vein $R_{1}$ by the subcosta takes place here as in Cicada. Trachea $R_{s}$ has its characteristic bend at the base, and is two-branched. Trachea $M$ is typical except that the branch $M_{3}$ coalesces with $M_{1+2}$ for a short distance. Trachea $\mathrm{Cu}$ is six-branched; it is evident that a specialization by addition has taken place here. Only a single anal trachea has been preserved.

The hind wing of the same nymph (Fig. 303) presents a very similar arrangement of tracheæ, except that their branches are reduced.

\section{(c) THE VEINS AND FURROWS OF AN ADULT WING}

In those pentatomids in which we have been able to trace the courses of the tracheæ of the wings, the wing-veins of the adult are comparatively inconspicuous. It is better on this account to take as an illustration of an adult wing that of a coreid, Harmostes reflexulus, in which the tracheæ are distinctly visible within well-developed veins; the courses of the veins are indicated in Fig. 304.

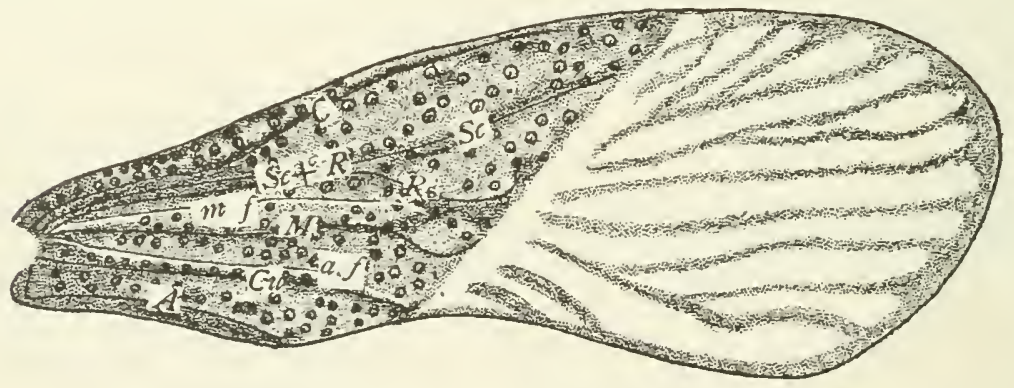

Fig. 304.-Fore wing of an adult coreid, Homostes reflexus (After C. \& N.).

The median furrow of the wing is in its typical position between radius and media. In the pentatcmids that we have studied it is more closely parallel with the radius and extends across the radial sector, showing that its position is not determined by the ccurses of the veins. The anal furrow is in front of cubitus instead of in its more usual position, behind this vein. In fact, in all of the Heteroptera that we have examined, when an anal furrow is distinctly developed it is in front of the cubitus.

The anal furrow is the line of division between the corium and the clavus; the median furrow when well-developed separates the embolium from the corium; and the development of a nodal furrow limits the corium still more by cutting off the cuneus. 


\section{CHAP'TER XVIII}

\section{THE WINGS OF THE DERMAPTERA}

THE winged members of this order have four wings. The first pair of wings are leathery, very short, without veins, and when at rest meet in a straight line on the back, resembling the elytra of staphylinid beetles; the second pair are large, with radiating veins, and when at rest are folded both lengthwise and crosswise. The radiating veins extend from a point near the middle of the length of the wing (Fig. 305). When the wing is not in use that part over which these veins extend is folded in plaits like a fan, after which the wing is folded twice crosswise.

The part of the wing traversed by the radiating veins is the greatly expanded anal area. The preanal area is much reduced and contains only two longitudinal veins; this area is quite densely chitinized.

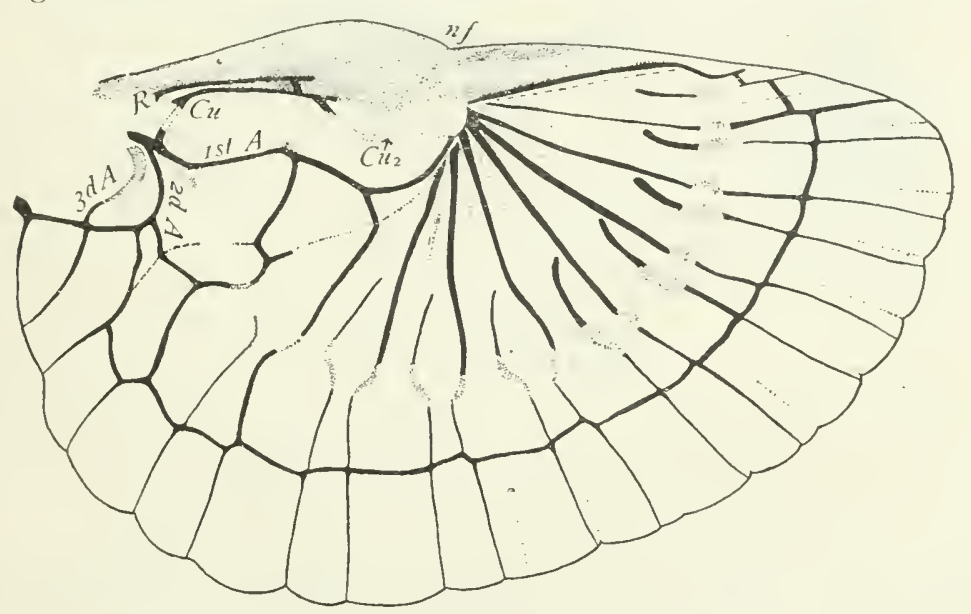

Fig. 305.-Hind wing of an earwig.

The tracheation of a hind wing of a nymph is represented by Figure 306. There is a transverse basal trachea (Fig. $306, t b$ ) connecting the costo-radial and the cubito-anal tracheæ. The tracheæ of the cubito-anal group all coalesce at the base forming a single large trachea, from which, however, the cubital trachea soon separates (Fig. 306, Cu). The anal trachea is twelve-branched.

In the wing of the adult there are three distinct anal veins (Fig. 305). The first anal vein is ten-branched; eight branches form a group of radiating veins, and the other two branches arise separately between this group of radiating veins and the base of the wing. The trachex in the wing of the nymph (Fig. 306) corresponding to the ten branches of the first anal vein 
are easily recognized, as they occupy exactly similar positions. The two remaining branches, those that arise near the base of the wing, are doubtless the tracheæ that precede the second and third anal veins respectively.

The costo-radial group of tracheæ is represented by a single trachea; this I believe to be the radial trachea. It is surely not the costal trachea, as the vein that it precedes is far from the margin of the wing of the adult; and of the other three reins of the costo-radial group of reins, the radius is the more persistent one in other orders of insects.

In the adult wing the preanal area is divided into two parts by the nodal furrow (Fig. 305, nf), a basal part and an apical part.

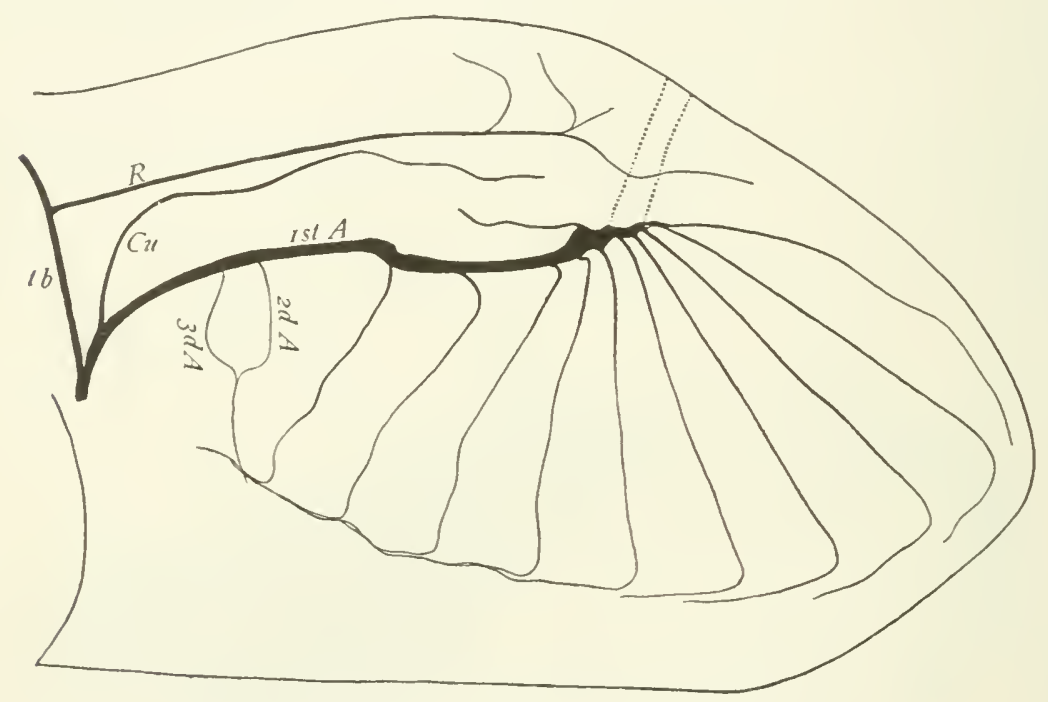

Fig. 306.-Tracheation of the hind wing of an earwig.

The radius extends about one-half the length of the basal part of the preanal area; it is connected with the cubitus by a cross-vein or a branch near the tips of the two veins.

The cubitus arises from the first anal vein and extends transversely until it nearly reaches the radius and then extends longitudinally a little more than half the length of the basal part of the preanal area. It is forked near its end, and the posterior fork is connected with the anal vein by a restige of a rein, which may be the remnant of vein $\mathrm{Cu}_{2}$.

A striking feature of the adult wing is a series of intercalary veins alternating with the branches of the first anal vein. There is no indication of the presence of these veins in the wing of the nymph. Neither is there in the wing of the nymph any indication of the series of cross-veins that extends parallel with the margin of the wing and connects the alternating branches of the first anal vein and the intercalary veins. 


\section{CHAPTER XIX}

\section{THE WINGS OF THE COLEOPTERA}

THE members of this order have four wings; the first pair of wings, which are called elytra, are greatly thickened and meet in a straight line down the back (Fig. 307); the second pair of wings are folded beneath the elytra when not in use.

The great modifications in form and structure of the wings of the Coleoptera make the study of the wing-venation of these insects a difficult one. Correlated with the loss of the flight function of the elytra in the course of their change to thickened protective organs, there has been a reduction of their venation; and in the case of the hind wings, the fact that in most cases they are transversely folded when at rest has resulted in a great modification of the courses of the veins and in the formation of secondary vein-like thickenings of the wing.

In spite of the difficulties just referred to, the problem of determining the homologies of the wing-veins of the Coleoptera is not an insuperable one if use be made of the ontogenetic method of study. In the pupal wings, so far as they have been examined, the principal trachex are comparatively well-preserved; and a study of these

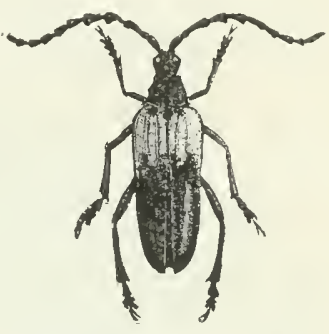

Fig. 307.-Desmocerus palliatus. tracheæ furnishes data for determining the homologies of the wing-veins.

The beginning of the application of this method of study to the wings of the Coleoptera was made by Comstock and Needham ('98). Our discussion of the matter, however, was brief and devoted largely to a demonstration of the fact that the elytra are modified wings and not the greatly enlarged paraptera of the mesothorax, as was believed by Meinert ('8o).

The most conclusive evidence that we found regarding the homology of the elytra was presented by their development. We traced the development of the two pairs of wings in a coccinellid beetle, Hippodamia I3punctata; and found that previous to their emergence from the larval wingpockets, there is no appreciable difference between the fore and the hind wings; after this, however, the elytra show a distinctly thicker layer of hypodermis on their dorsal side, and the thinness of the hind wings steadily increases with their expansion in area. The hind wings are greatly - expanded at their final transformation, while the elytra are almost as large in the pupa as in the imago (C. \& N. '99, p. 850).

Further evidence is the fact that a very close correspondence exists between the tracheation of the elytra and that of the hind wings; and what 
is especially striking is that similar modifications occur in the two pairs of organs. We figured the tracheation of the wings of two cerambycid pupæ; these figures are repeated here (Fig. 308 and 309 ).

"In the species represented by Figure 308 , the radial trachea is the most prominent one in both elytra and hind wings. On the other hand, in
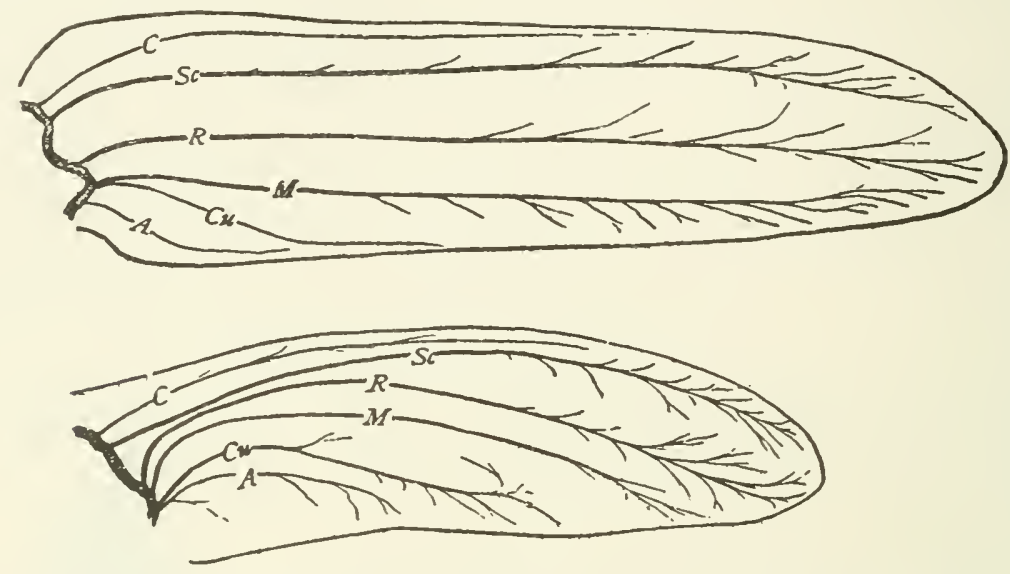

Fig. 308.-Tracheation of the wings of a cerambycid pupa (From C. \& N.).

the species represented by Figure 309, the radial trachea is reduced in both elytra and hind wings to a mere vestige. If the elytra and hind wings were not homodynamous organs, it is not probable that the modifications of the two would be so closely correlated.

"In comparing the tracheation of the elytra with that of the hind wings, the most striking difference observed is the greater reduction of the anal
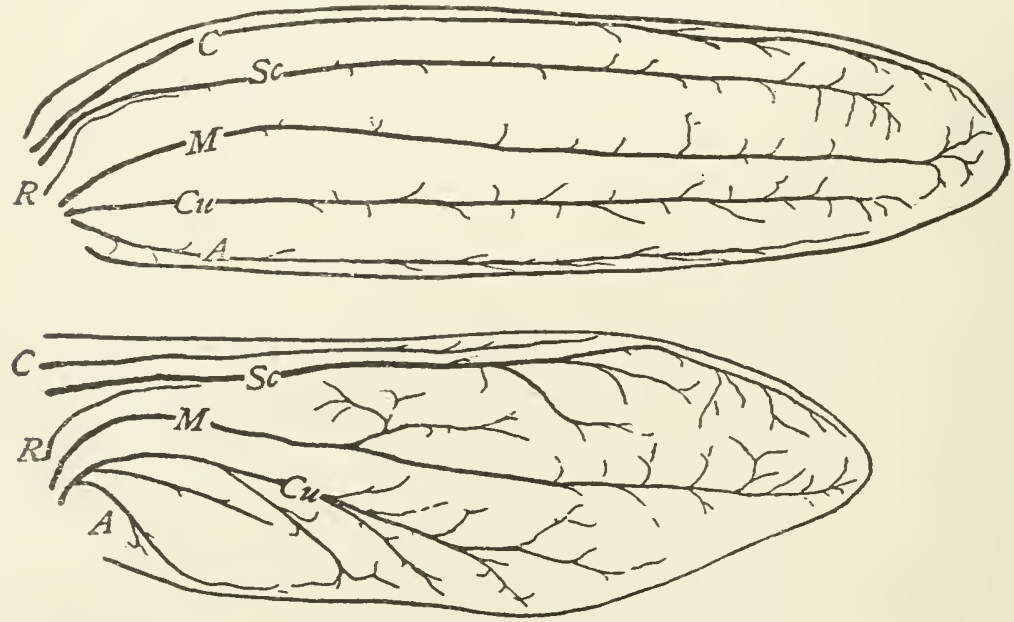

Fig. 309.-Tracheation of the wings of a cerambycid pupa (From C. \& N.). 
area of the former. This is doubtless due to the fact that the meeting of the elytra, when at rest in a straight line along the middle of the back does not admit of an expanded anal area.

"The extent of the correspondence between the venation and the tracheation of the hind wing of a full-grown pupa is shown by Figure 3 Io. The principal tracheæ are within the veins, but the branches of these tracheæ extend irregularly through the wing. In the region where the wing is to be folded the secondary vein-like thickenings are only partly supplied with tracheæ." (C. \& N.)

Contemporaneous with the publication of the series of articles by Comstock and Needham, Kruger ('98) presented to the University of Göttingen a thesis on the development of the wings of insects with especial reference to the elytra of beetles. This author studied the development of the wings of Tenebrio molitor and of two species of Lema; and, notwithstanding the fact that he found that the hind wings and elytra arise simultaneously and develop in an exactly similar manner for a major part of the

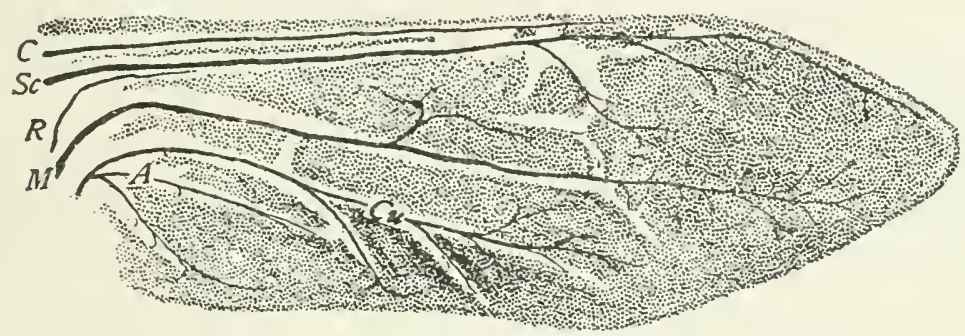

Fig. 310.-Hind wing of a pupa of a beetle (From C. \& N.).

larval life, reached the unwarranted conclusion that the elytra are divergent structures and not specialized wings. This conclusion was based on differences in structure between the fore wings and hind wings that appear late in their development and which are correlated with the specialization of the elytra as wing covers.

Since the publication of the papers referred to above, several papers have appeared in which the development of the wings of Coleoptera are discussed; these are by Needham ('oo), Tower ('o3), and Powell ('o4). As these all confirm our conclusion that the elytra are modified wings, and as none of them discuss the homologies of the wing veins, it is not necessary to review them here.

The elytral tracheation of the tiger beetles (Cicindelidx) has been described in two papers by Shelford (' ${ }_{3} 3$ and ' 15 ). These studies are based on examinations of adult dried elytra. In only two genera (Amblychila and Mantichora) were all of the six principal tracher found. Of course the basal connections of the tracheæ could not be seen. 
An extended series of papers on the venation of the hind wings of Coleoptera has been published by Kempers ('99-'o9). This contains excellent figures of the venation of the hind wings of representatives of many families. But as these studies are based entirely on studies of the wings of adult insects, it is desirable that the conclusions regarding the homologies of the wing-veins should be confirmed by ontogenetic studies.

There has recently appeared, however, a contribution to our knowledge of the tracheation of the wings of Coleoptera based on a study of the wings of pupæ; this is by Kühne (' I 5). This author gives figures of the tracheation of the fore wings of pupæ of four genera of beetles and of the hind wings of pupæ of seven genera; but in only one genus (Cantharis) are the basal connections of the principal tracheæ shown.

In this genus the radial trachea has not followed the medial trachea in its migration along the transverse basal trachea towards the cubito-anal group of trachere to so great an extent as Comstock and Needham found it had in the cerambycid pupal wings represented by Figure 308. This is markedly the case in the hind wings of Cantharis as figured by Kühne; but in one of the fore wings of Cantharis figured by this author, his Figure 7 , the radial trachea has evidently begun its migration towards the cubito-anal group of tracheæ.

With this limited amount of data before him Kühne concludes that the labeling of the tracheæ of cerambycid pupæ given by Comstock and Needham is an incorrect one, and that the radial trachea always remains a member of the costo-radial group of tracher.

When we consider the great differences in the extent of the migration of trachea $\mathrm{R}$ within the order Orthoptera, as is shown in Chapter VII, one is not warranted in making generalizations regarding the conditions in the Coleoptera after studying the basal connections of the tracheæ in the wings of a single genus of beetles. As yet I see no reason for changing the labeling of the tracher in Figures 308 and 309.

It is evident from this review of the literature of the subject that much remains to be done before our knowledge of the homologies of the wingveins of the Coleoptera can be regarded as firmly established.

The solution of the problem is rendered difficult by the fact that in no coleopterous pupa yet examined have the principal wing-tracheæ retained the mode of branching characteristic of the hypothetical primitive type; in most cases the tracheæ extend in nearly direct lines with only small, irregularly arranged branches. It seems also to be made more difficult by another factor, namely; that the observations that have been made indicate that in the Coleoptera, as in the Hymenoptera, the renation of the wings precedes their tracheation. The courses of the tracheæ, therefore, are determined by the nature of the highly modified renation. 


\section{CHAPTER XX}

\section{THE WINGS OF THE STREPSIPTERA}

In this order the fore wings, which are termed elytra by some writers and pseudo-halteres $\mathrm{t} y$ others, are reduced to slender club-shaped appendages. The hind wings are large, compared with the size of the tiny body, fan-shaped, furnished with radiating wing-veins, and folded longitudinally.

The venation of the wings is degenerate. There is a variable number of radiating veins, which in the most generalized wings are eight in number. These are supposed, by Pierce ('og), to be the eight principal veins of the typical wing, the costa, subcosta, radius, media, cubitus, and the three anal veins, respectively, and are so designated by him in his most excellent monograph of the order. With our lack of knowledge of the tracheation

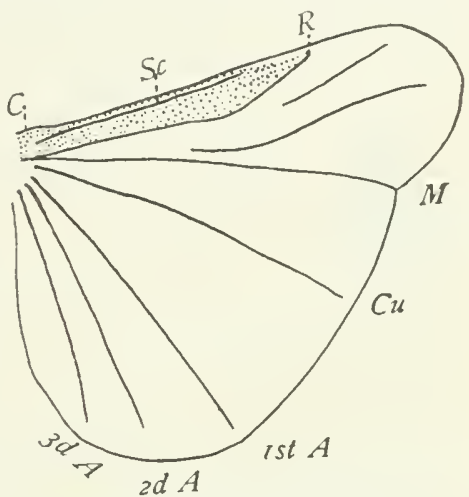

Fig. 311.-Wing of Paraxenos eberi (From Pierce after Saunders). of the wings, this conclusion can hardly be questioned. There are no crossveins. The veins are rarely forked; but there are usually detached veins in

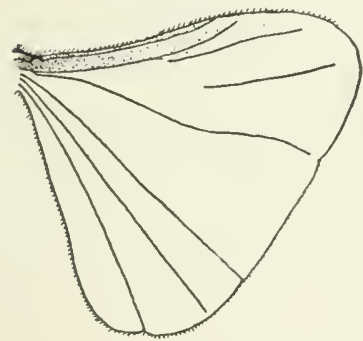

Fig. 312.-Wing of Acroschismus hubbardi (From Pierce). the outer half of the wing. These extend longitudinally in the area between the radius and the media (Fig. 3II).

The detached veins are usually one or two in number. Pierce makes no suggestion as to the homology of these veins; but the arrangement of the veinsin the wing of Acroschismus hubbardi (Fig. 3I2) leads me to believe that the first detached vein is the radial sector; and the second one, a branch of media. As this conclusion, however, is not incontrovertible, it will probably be best, in descriptions of species, merely to state the number of detached veins between the radius and the media, without attempting to determine their homologies. 


\section{CHAPTER XXI \\ THE WINGS OF THE MECOPTERA}

(a) THE more general features of the Wings of the mecoptera.

In nearly all of the winged members of the Mecoptera the wings are long, narrow, membranous, and furnished with a considerable number of

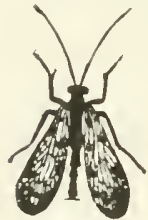

Fig. 313.Panorpa. cross-veins. The two pairs of wings are similar in form and nearly equal in size; the hind wings are usually a little shorter than the fore wings. In many species the wings are conspicuously spotted or banded (Fig. $3{ }^{1} 3$ ). In a few forms the wings are either absent or vestigial.

In two genera Merope and Notiothamma, the representparatively broad. atives of which are very rare insects, the wings are com-

(b) THE venation of the Wings of the typical Mecoptera

Our conclusions regarding the homologies of the wing-veins of the Mecoptera are based entirely on a study of the wings of adults; for, as yet, the tracheation of the wings of pupæ has not been observed. It is not probable, however, that a study of pupal wings would modify these con-
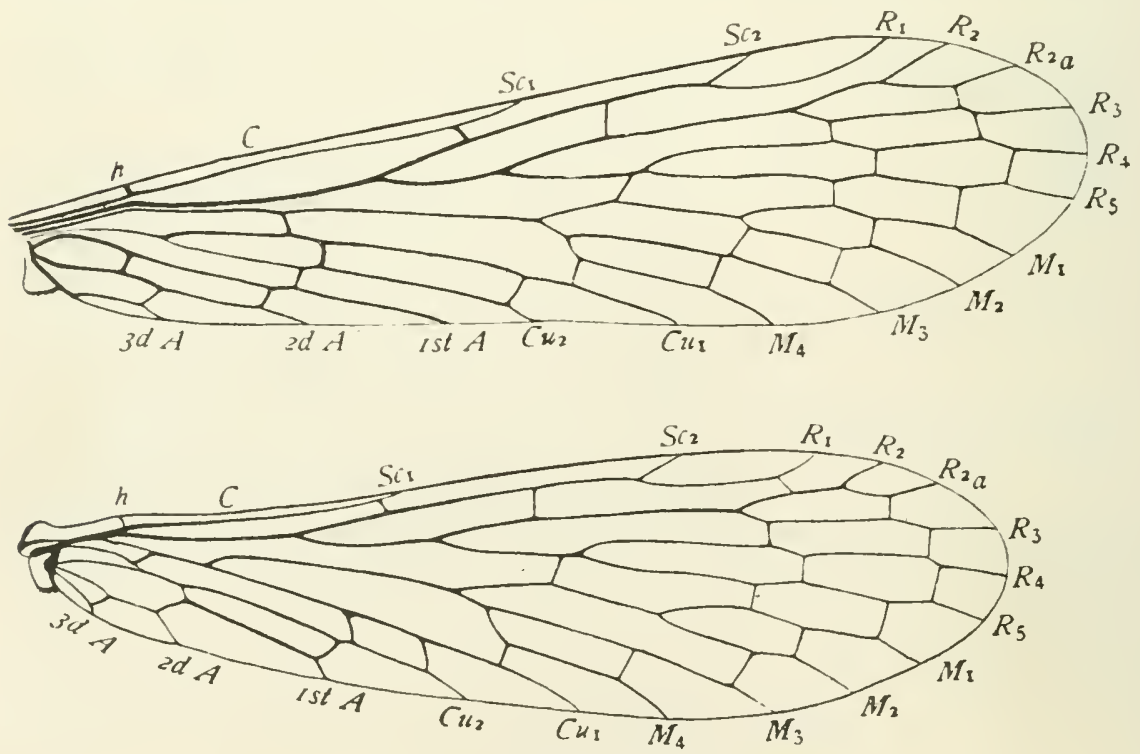

Fig. 314.-The wings of Panorpa.

(302) 
clusions, as the venation of the wings is so nearly typical that the identification of the veins presents no difficulties.

In some cases, as in the fore wings of certain species of Panorpa, the number and the arrangement of the wing-veins is that of the hypothetical primitive type, with the addition of a considerable number of cross-veins; and in all cases, excepting the aberrant genera Merope and Notiothauma, the modifications of this type are comparatively slight.

The most obvious modification of the primitive type is the presence

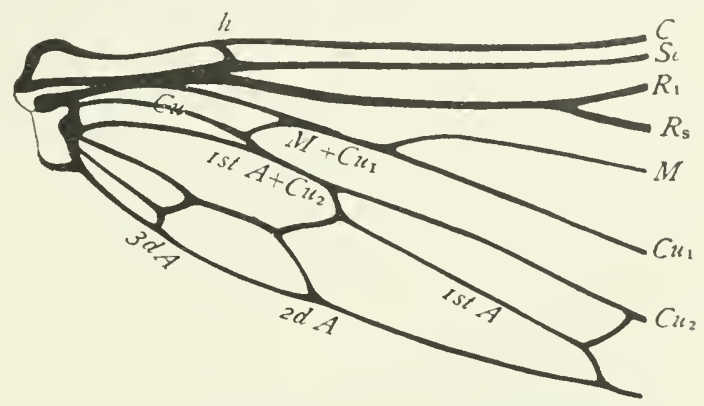

Fig, 31 5.-Base of a hind wing of Panorpa. of one or two accessory veins on one or more of the branches of the radius. These are borne most frequently by vein $R_{2}$.

Another modification of the primitive type that exists commonly is the anastomosing of one or of both branches of the cubitus with the adjacent vein; that is vein $\mathrm{Cu}_{1}$ anastomoses with vein $\mathrm{M}$, and vein $\mathrm{Cu}_{2}$ with the first anal vein. In the fore wing of Panorpa (Fig. 3I4) each of the principal veins extends separately from the base of the wing; but in the hind wing each of the branches of the cubitus anastomoses with the adjacent vein. This is shown more clearly in the enlarged figure of the base of the hind wing (Fig. 315).

The relation of the branches of the cubitus to the adjacent veins in the three common winged genera was pointed out by Miyake ('r3). In the fore wings of Panorpa and of Panorpodes the principal veins extend separately from the base of the wing. In the fore wing of Bittacus, veins $\mathrm{Cu}_{1}$ and $\mathrm{M}$ anastomose, but vein $\mathrm{Cu}_{2}$ is separate from the first anal vein. In the hind wings of all of these genera, each of the branches of the cubitus anastomoses with the adjacent vein.

\section{(c) THE ABERRANT MECOPTERA}

There are two genera of insects which, although they differ greatly in appearance from the typical members of the Mecoptera, are doubtless members of this order. These are Merope and Notiothamma.

The genus Merope is represented by a single species, Merope tuber which was described by Newman in I\$28 (Ent. Mag. V. p. r8o). Newman was unable to decide as to the zoological position of the genus. Later Westwood ('4I), from a study of the mouth parts decided that it should be placed in the Panorpida. 
Merope tuber is an American insect. Although it is quite widely distributed in the Atlantic States, less than a score of individuals are known to exist in collections. Professor Needham had the good fortune to collect one at Ithaca; and I am indebted to him for an opportunity to study its wings and to give a figure of the insect (Fig. 3 I6).

A striking feature presented by the wings is the presence of a minute semicircular tuberculous appendage near the base of the inner margin of the fore wing. It was this that suggested the specific name of the species.

The wings of Merope tuber (Fig. 3 I 7 ), at first sight, appear to be quite different from those of the typical Mecoptera. But when they are examined in detail it is found that, aside from the fact that they are less elongate and that they bear an unusually large number of cross-veins, the only

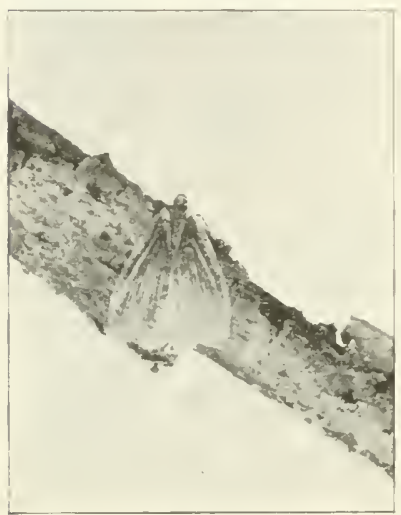

Fig. 316.-Merope tuber, slightly enlarged (Photographed by J. G. Needham). important difference is that the costal area of the wings is broad and resembles this area of neuropterous insects more than it does that of Panorpa. This resemblance is increased by the presence of many cross-veins extending from the subcosta to the costa and a smaller number of cross-veins between the subcosta and vein $R_{1}$.

The presence of one or two accessory veins on one or more of the branches of the radius and the anastomosing of cubitus with the adjacent veins, which were pointed out above as characteristic of the Mecoptera, are also to be found in this genus.

In the Ithaca specimen, vein $R_{2}$ of all of the wings bears a single accessory rein. In the specimen figured by Westwood, vein $\mathrm{R}_{2}$ bears two accessory reins in the fore wing and only one in the hind wing. But Dr. Asa Fitch, who had both sexes of this species, states in his "Fourteenth Report," that both pairs of wings are liable to vary in the number of these branches. In fact in his female specimen the fore wing of the left side and the hind wing of the right side had each one more branch than the corresponding wing of the other side.

In the fore wing of the specimen taken at Ithaca cubitus and the first anal vein coalesce for a short distance. Immediately after vein $\mathrm{Cu}$ separates from ist $\mathrm{A}, \mathrm{Cu}_{1}$ extends transversely to the long axis of the wing and anastomoses with vein $\mathrm{M}$ for a considerable distance. Tein $\mathrm{Cu}_{1}$ bears one accessory vein on the right wing and two on the left wing. The anal furrow is along the first anal vein. There are three anal veins, all unbranched. 
In the hind wing of this specimen vein $\mathrm{Cu}_{1}$ anastomoses with vein $\mathrm{M}_{4}$ for a short distance. Vein $\mathrm{Cu}_{1}$ bears one accessory vein on the right side, but is unbranched on the left side.

Dr. Fitch gave the popular name Earwig-fly to this insect on account of the stout pair of forceps at the caudal end of the abdomen of the male.
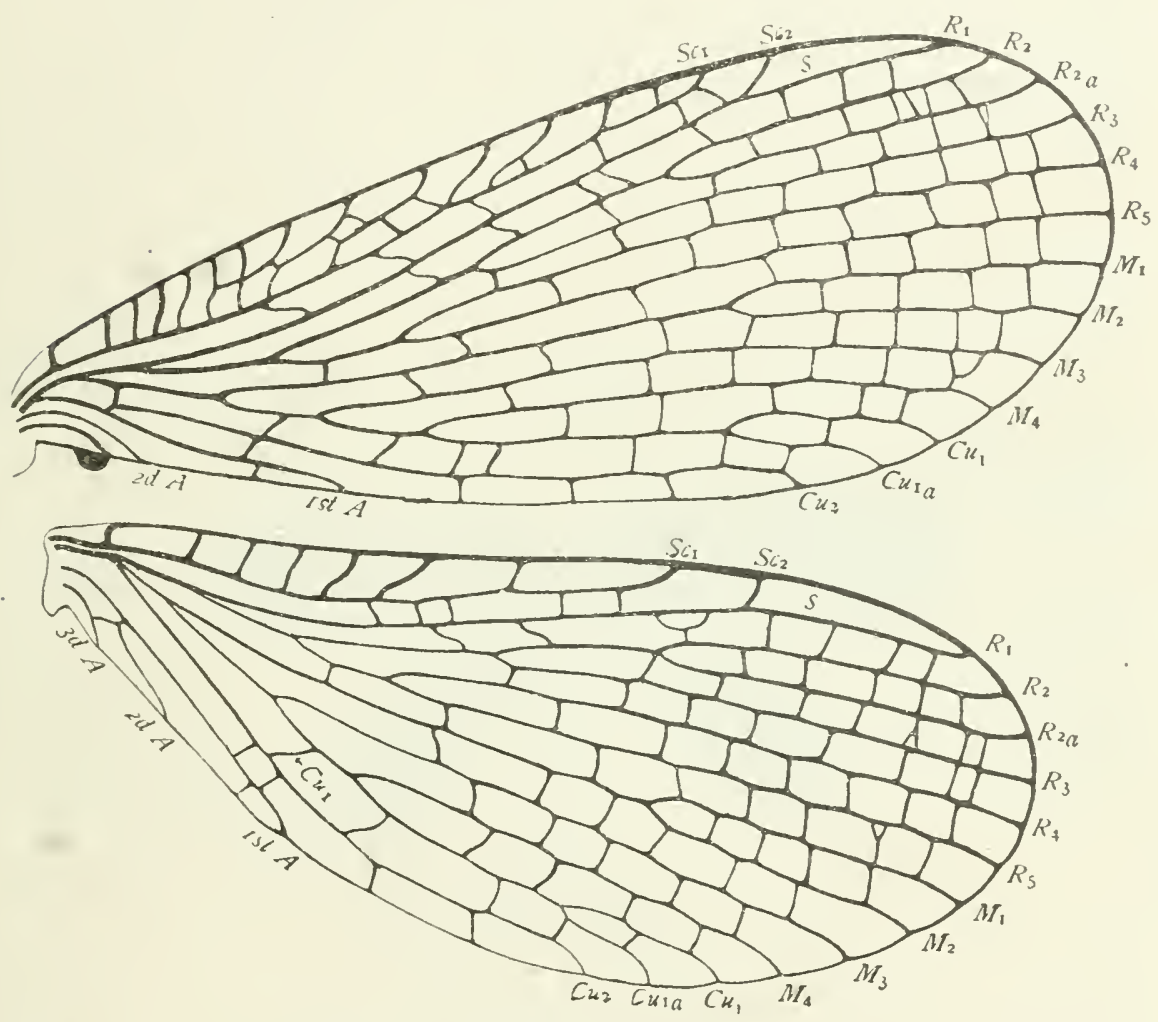

Fig. 317.-Wings of Merope tuber.

The genus Notiothauma was established by McLachlan (' 77 ) to receive a remarkable insect from Chili, which he named Notiothanma Reedi. Only a single mutilated individual was known, the head and pronotum of which were nearly entirely destroyed. But the form of the wings and the presence of a well-developed, nearly semi-circular lobe at the base of the inner margin of the fore wings indicated that the species was allied to Merope tuber. McLachlan gave a figure of his specimen, which was carefully copied by Brongniart ('93). I reproduce Brongniart's copy, as it is better suited for reproduction by photoengraving than the original (Fig. 3 I S). 
The wings of Notiothauma resemble those of Merope in their more general features; but they present a much more intricate network of crossveins; and in some parts of the wing it is difficult to distingaish the longitudinal reins from the cross-reins. A similar condition exists in the wings of certain Plecoptera of which Pteronarcys dorsata (Fig. 254) is a good example.

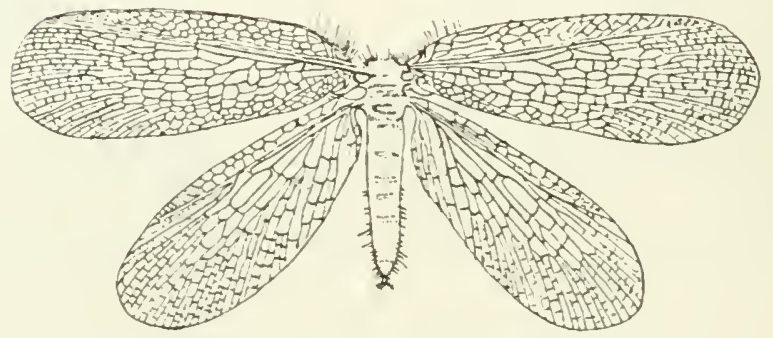

Fig. 3I8.-Notiothauma Reedi (After McLachlan by Brongniart). 


\section{CHAPTER XXII}

\section{THE WINGS OF THE TRICHOPTERA}

THE order Trichoptera as heretofore recognized includes those insects the larvæ of which are commonly known as caddice-worms and the adults as caddice-flies. This is a well-defined, homogeneous group of insects. There is, however, a group of moth-like insects that have been included in the order Lepidoptera which so far as the structure of their wings is concerned and in some other respects are more closely allied to the Trichoptera than they are to the Lepidoptera, this is the Micropterygina.

To continue to include the Micropterygina in the Lepidoptera raises a question of phylogeny to which I can find no answer; while the transference of this family to the Trichoptera removes this difficulty. This phase of the subject is discussed later, in the concluding part of this chapter.

Although the Micropterygina are closely allied to the caddice-flies, there are differences between the two groups that warrant the regarding of each as a distinct suborder. I therefore propose the division of the Trichoptera into two suborders, the Phryganeina or aquatic Trichoptera and the Micropterygina or terrestrial Trichoptera.

The distinction in habits between the Phryganeina and the Micropterygina is not an absolute one. Among the Phryganeina the larvæ of the genus Enoicyla live under moss at the foot of trees, chiefly in woods and often at great distance from water; and, on the other hand, the known larvæ of the genus Micropteryx, as now restricted, might be considered as semi-aquatic since they live in wet moss.

\section{SUBORDER PHRYGANEINA}

\section{The Aquatic Trichoptera}

The suborder Phryganeina includes those Trichoptera in which the wings are clothed with long silky hairs, the tracheation of the wings of the pupæ is reduced, and the larvæ are aquatic.

\section{(a) The hore general features of the wings of the Phryganeina}

The two pairs of wings are membranous and usually more or less densely clothed with long silky hairs. The fore wings are denser than the hind wings and are often slightly coriaceous; in a few forms the wings are naked. The hind wings are shorter than the fore wings; but they are usually broader; this is due to an expansion of the anal area of the hind wings. In a few species the hind wings are reduced so that they are smaller than the fore 
wings; in one species the female is apterous and in another the wings of the female are vestigial. When not in use the wings are folded roof-like over the abdomen.

The posterior lobe of the fore wings is specialized as a fibula, which is well-developed in the more generalized forms, as Rhyacophila, but mare or less reduced in the more specialized genera. The costal border of the hind wings is furnished with hamuli in some forms, as in the Leptoceridæ and in the Macronematinæ.

\section{(b) THE TRACHEATION OF THE WINGS OF THE PHRYGANEINA}

It was shown by Comstock and Needham that the tracheation of the wings bears but little relation to the ring-renation; this being one of the

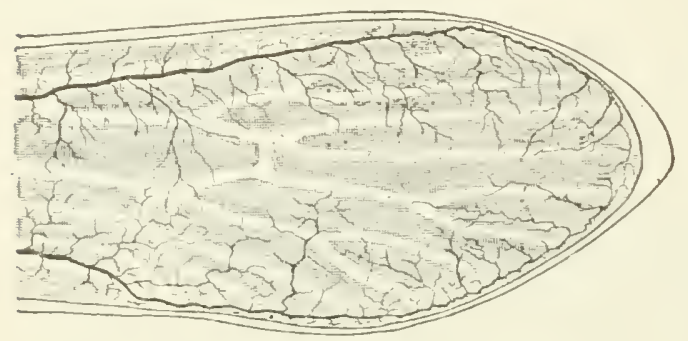

Fig. 319.- - Tring of a pupa of a caddice-fly. orders in which the tracheation of the wings is greatly reduced. If a wing of a pupa of a caddice-fly be examined after the carities of the developing wing-reins have been formed it will be seen that usually only two or three main tracheæ are present; and that although these may coincide with forming veins, their branches bear no relation whatever to the veins (Fig. 319).

\section{(c) THE PHRYGANEID TYPE OF WING-VENATION}

As the tracheation of the wings of pupæ of the aquatic Trichoptera affords no help in the determination of the homologies of the wing-reins, we are forced to base our conclusions regarding these homologies on studies of the wings of adults. Fortunately in the more generalized members of this suborder it is easy to identify the reins; and the conclusions that have been reached regarding the homologies of the wing-veins of the Phryganeina are confirmed by a study of wings of terrestrial Trichoptera in which the wing-tracheæ are preserved.

The wings of Rhyacophila fuscula (Fig. 320) can be taken as illustrating the phryganeid type of wing-renation. Beginning at the costal margin of the fore wing and proceeding backward the following features can be observed.

The subcosta of the fore wing is forked; the forking takes place near the tip of the vein; and vein $\mathrm{Sc}_{2}$ is connected with vein $\mathrm{R}_{1}$ by a cross vein. Near the middle of the length of the subcosta, an accessory vein (Fig. 
$320 ; a)$ is given off, which extends to the margin of the wing. The humeral vein is present in its usual position.

The radius of the fore wing is typical; the radial fork is quite near the base of the wing; and the radial sector is dichotomously four-branched. The media is also typical, being dichotomously four-branched.

The cubitus and the first anal vein coalesce at the base, where they traverse the cubito-anal sulcus. From the point where these two veins separate rein $\mathrm{Cu}$ extends in an oblique direction torvards media, which it nearly reaches, and then making a bend extends in a longitudinal direction to the outer margin of the wing. It is of the typical two-branched form.
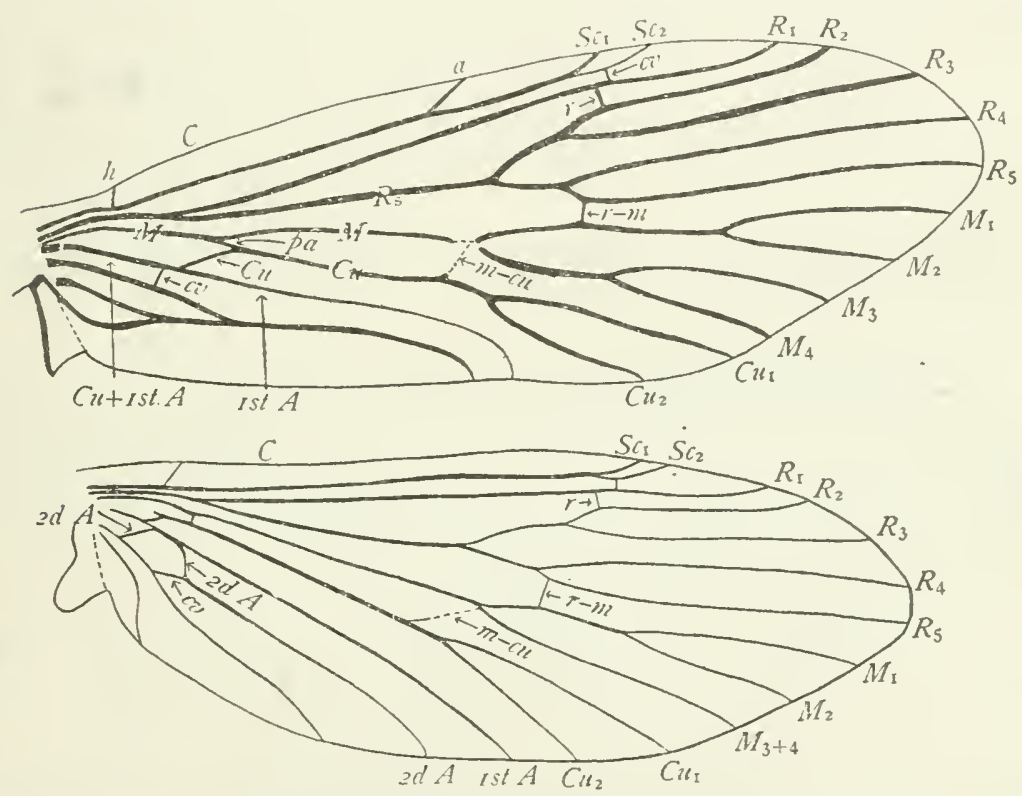

Fig: 320.-Wings of Rhyacophila fuscula.

The basal part of the free portion of vein $\mathrm{Cu}$ appears very much like a cross-vein. This appearance is accentuated by the fact that a serial vein has been developed, which consists of three parts, the basal part of media, a short cross-rein connecting media and vein $\mathrm{Cu}$ (Fig. 320, pa), and the longitudinal part of vein $\mathrm{Cu}$. This results in the longitudinal part of vein $\mathrm{Cu}$ appearing to be a nearly direct continuation of the stem of media. The short cross-vein connecting media and cubitus corresponds to the posterior arcultus of those orders in which an arculus is developed.

The separate portion of the first anal vein is a direct continuation of vein $\mathrm{Cu}+$ Ist $\mathrm{A}$ and extends in the bottom of the cubito-anal fold to the margin of the wing. The outer portions of the second anal vein and of two branches of the third anal vein coalesce, forming a single vein, which ends 
in the margin of the wing near the tip of the first anal vein. A third branch of the third anal vein supports the margin of the posterior lobe of the wing, the fibula. In some species of Rhyacophila the terminal portion of this third branch of the third anal vein extends across the fibula to the axillary furrow.

The disposition of the anal reins of the fore wings is one of the most distinctive characteristics of the order Trichoptera.

In the hind wing the subcosta resembles the subcosta of the fore wing except that it bears no accessory vein. The radius also resembles the corresponding vein of the fore ring. The media is only three-branched, veins $\mathrm{MI}_{3}$ and $\mathrm{M}_{4}$ coalescing to the margin of the wing. The cross-rein connecting media and cubitus near the base of the wing, the posterior arculus, is transverse. Veins $\mathrm{Cu}$ and ist $\mathrm{A}$ coalesce at the base of the wing for a much shorter distance than in the fore wing. The anal veins differ from those of the fore wing in that they all end separately in the margin of the wing.

There is one feature in the disposition of the anal veins of the hind wing which, like the coalescence of the tips of anal reins in the fore wing, is a distinctively ordinal characteristic; this is the course of the second anal vein. This vein, near the base of the wing, extends forward until it reaches the first anal vein, with which it anastomoses for a considerable distance; it then bends away from the first anal vein abruptly and extends obliquely until it is joined by a cross-vein, it then bends again and extends longitudinally to the margin of the wing. The cross-vein connecting the second and third anal veins is nearly longitudinal.

The interpretation of the homologies of the wing-veins given above differs in one respect from that which has been commonly accepted. This is the recognition of the fact that in the fore wings veins $\mathrm{Cu}$ and Ist $\mathrm{A}$ coalesce at the base of the wing and what appears to be an oblique crossvein between veins $\mathrm{Cu}$ and ist $\mathrm{A}$ is really the base of the free part of vein $\mathrm{Cu}$.

This conclusion does not necessitate any change of view regarding the homologies of the terminal portions of cubitus and the first anal vein; consequently the lettering of figures of wings that is placed at the tips of veins will remain as before.

The necessity for reopening the question of the homologies of the wingveins of the Trichoptera was suggested by Dr. Cornelius Betten, who reached the conclusion that the vein designated here as vein $\mathrm{Cu}+$ ist $\mathrm{A}$ is the cubitus and that designated as the first anal vein is vein $\mathrm{Cu}_{2}$. This necessitated the conclusion that what heretofore has been regarded as vein $\mathrm{Cu}_{2}$, and which I still believe to be this vein, is a definitive accessory vein, which Dr. Betten terms rein $\mathrm{Cu}_{\mathrm{1a}_{\mathrm{a}}}$.

Although Dr. Betten's discussion of this question is not yet published, he has published a figure in which the veins of the fore wing of a species of 
Rhyacophila are lettered in accordance with this interpretation (Betten 'I3.)

During my studies of this subject Dr. Betten has aided me in every possible way, placing in my hands portions of his manuscript and figures and many mounted wings. I am under great obligation to him for this assistance.

(d) THE More general features in the specialization of the Wings OF THE PHRYGANEINA

The wings of Rhyacophila fuscula (Fig. 320) probably resemble very closely the wings of the primitive Trichoptera, as they resemble in their more general features the hypothetical primitive type of insect wings. The more important modifications of this type are the following.

In the fore wing the tips of the second anal vein and two of the branches of the third anal vein coalesce. This is a distinctively characteristic feature of the wing-venation of the Trichoptera. The subcosta bears an accessory vein; this, however, is unimportant; accessory veins borne by

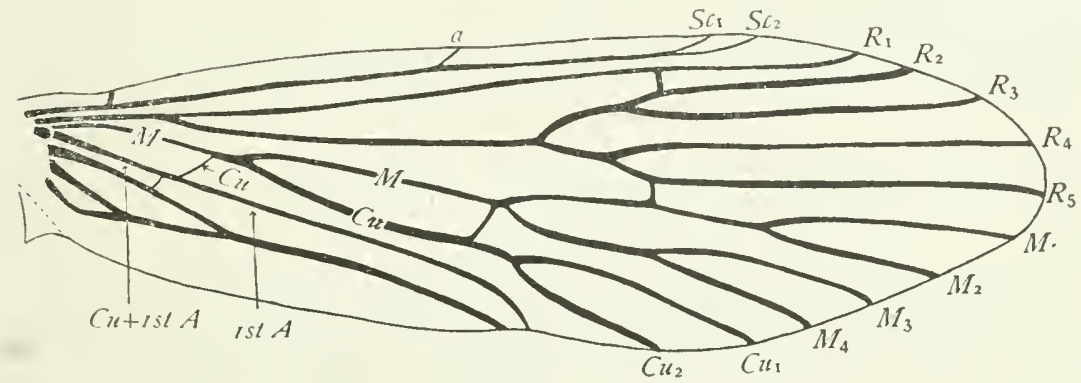

Fig. 321.-Fore wing of Rhyacophila sp.

the subcosta exist in only a few genera of this order; in some there are several of these veins, as in the Japanese genus Perissoneura, figured by Ulmer ('o7). The coalescence of veins $\mathrm{Cu}$ and ist A at the base of the wing and the formation of the serial vein consisting of the base of media, the posterior arculus, and the distal part of vein $\mathrm{Cu}$ is an ordinal characteristic. In the hind wings media has been reduced to a three-branched condition by the coalescence of veins $\mathrm{M}_{3}$ and $\mathrm{M}_{4}$.

By comparing more specialized forms with Rhyacophila fuscula it will be seen that in the preanal area the specialization of the venation of the wings is always by reduction. In the anal area of the hind wings the specialization is in some cases by addition, resulting in a broadly expanded anal area, in others it is by reduction. It is unnecessary to indicate, in this place, the methods of specialization of the wings in the different families of this order, as this has been done by Ulmer, Betten, and others. 
There is, howerer, one method of specialization, which has been elucidated by Dr. Betten and to which he has called my attention, that should be referred to here. It is the modifications of the basal part of the free

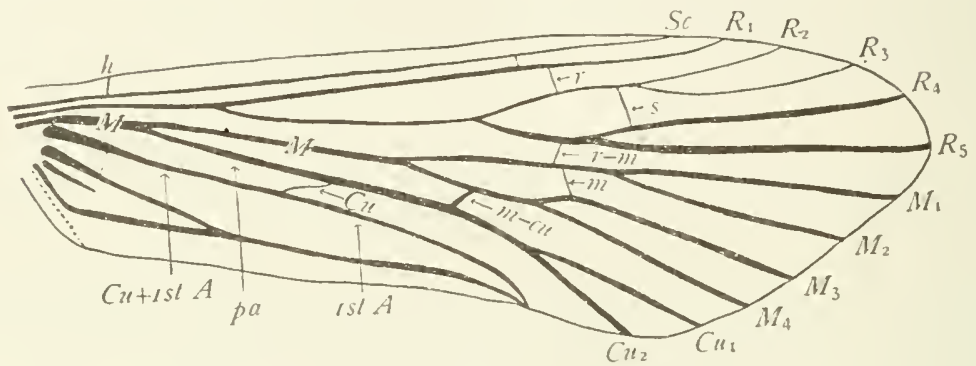

Fig. 322.-Fore wing of Hydromanicus dilatus.

portion of vein $\mathrm{Cu}$ of the fore wings, that part which appears to be an oblique cross-vein.

In the hind wing of Rhyacophila fuscula veins $\mathrm{M}$ and $\mathrm{Cu}$ are connected near the base of the wing by a transverse cross-vein (Fig. 320). In the fore wing of this species this cross-vein has become longitudinal and forms a part of the serial rein $\mathrm{M}-\mathrm{Cu}$. In a species of Rhyacophila from India, in Dr. Betten's collection, this cross-vein has been obliterated by the anastomosis of veins $\mathrm{M}$ and $\mathrm{Cu}$ (Fig. 32I), and the basal part of vein $\mathrm{Cu}$ simulates a cross-rein so completely that but for the evidence presented by forms in which veins $M$ and $C u$ do not anastomose its identity would not be suspected. This is the usual condition of the base of vein $\mathrm{Cu}$ in the fore wing.

More remarkable still is the fact, also discovered by Dr. Betten, that after the basal part of rein $\mathrm{Cu}$ is transformed into a cross-rein, it may

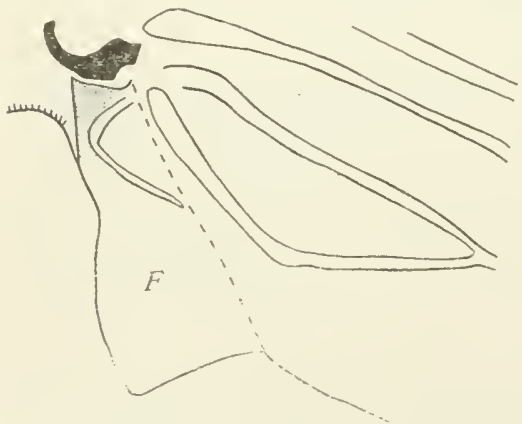

Fig. 323.-Fibula of Rhyacophila fuscula. migrate from its first position. Thus in Hydromanicus (Fig. 322 ) it has moved a considerable distance toward the outer margin of the wing, following along the longitudinal part of $\mathrm{Cu}$. This results in the posterior arculus becoming greatly lengthened.

\section{(e) The methods of Uniting the TWO WINGS OF EACH SIDE}

In Rhyacophila the posterior lobe of the fore wing forms a well-developed fibula (Fig. 323). This is hatchetshaped and supported by the third branch of the third anal vein; in some individuals the third branch of the third anal vein extends along the free margin of the fibula (Fig. 320 ), in others it is curved so as to extend across 
the fibula (Fig. 323). The axillary furrow is immediately behind the second branch of the third anal rein. It is evident that this fibula is fitted to clasp the anterior tuberosity of the hind wing.

There are two facts that indicate that this is the most primitive form of fibula that exists among the living Phryganeina: first, the generalized condition of the wing-renation of Rhyacophila; and second, the fact that this fibula is identical in structure with that of Mnemonica, one of the most generalized of the terrestrial Trichoptera. It is evident that Rhyacophila and Muemonica resemble in the renation of their wings and in the form of their fibulæ the stem form from which the Phryganeina and the Micropterygina have been evolved.

When more specialized Phryganeina are studied it is found that there is a marked reduction in the size of the fibula and a modification of its form. In Hydromanicus, for example, the posterior lobe of the fore wing (Fig. 322) is greatly reduced in size and has little appearance of being a fibula. It is evident that the uniting of the two wings of each side is being attained in other ways than by a fibula alone. In some cases this is by the overlapping of the wings; in some cases as in Phanostoma and Leptocerus there is a series of prominent hamuli on the costal margin of the hind wing; and in others, as in Gera, there are strong spines borne at the hutmeral angle of the hind wing, which probably function as a frenulum.

\section{SUBORDER MICROPTERYGINA}

\section{The Terrestrial Trichoptera}

The suborder Micropterygina includes those Trichoptera in which the wings are clothed with scales, the tracheation of the wings is preserved, and the larvæ are not aquatic; it is represented by a single family, the Micropterygida.*

The Micropterygidæ is a small family of minute moth-like insects which are generally believed to belong to the order Lepidoptera, although several writers have suggested the close affinity of these insects to the Trichoptera. $\dagger$

*The genus Micropteryx and its allies were long considered as constituting a single family the Micropterygidæe. In $189+$ Chapman proposed the separation of this family into two families, the Micropterygidæ and the Eriocephalidæ (Trans. Ent. Soc. Lond. 1894, p. 336). In 1912 Meyrick in his monograph of this group (Genera Insectorum, Fascicule 132) regards it as constituting a single family, the Micropterygidæ, which he divides into three subfamilies as follows: the Mnesarchæinæ, which includes a single genus, Mnesarchæa, represented by three species in New Zealand; the Eriocraniinæ, which corresponds to the Micropterygidæ of Chapman; and the Micropteryginæ, which corresponds to the Eriocephalidæe of Chapman. This shifting of family or subfamily names is due to the conclusion that the generic name Eriocephala is a synonym of Micropteryx. For the sakc of simplicity I follow Meyrick in regarding the Micropterygina as including a single family, although it is highly probable that ultimately the mandibulate and haustilate members of this group will be placed in separate families.

†Note especially the remarks of Dr. Sharp and Mr. McLachlan (Proc. Ent. Soc. London, I896, p. XVII), and Dr. T. A. Chapman (Trans. Ent. Soc. London, 1896, p. 569). 
(a) THE VENATION OF THE WINGS OF THE MICROPTERYGID $£$

The family Micropterygidæe has been monographed recently by Meyrick ('I2), who recognizes eight genera represented by fifty-five species. This author calls attention to the resemblance of some of the more generalized forms, as Sabatinca, to Rhyacophila; but does not suggest the transference of this family from the Lepidoptera to the Trichoptera.

The wings of a species of Mnemonica (Fig. 324) can be taken as illustrating the more generalized type of wing-venation found in the Micropterygidæ. The fore and hind wings are quite similar in form and renation. The subcosta is distinctly forked in the fore wing and slightly so in the hind wing. Vein $R_{1}$ in both wings bears an accessory vein, vein $R_{1_{a}}$; the pres-
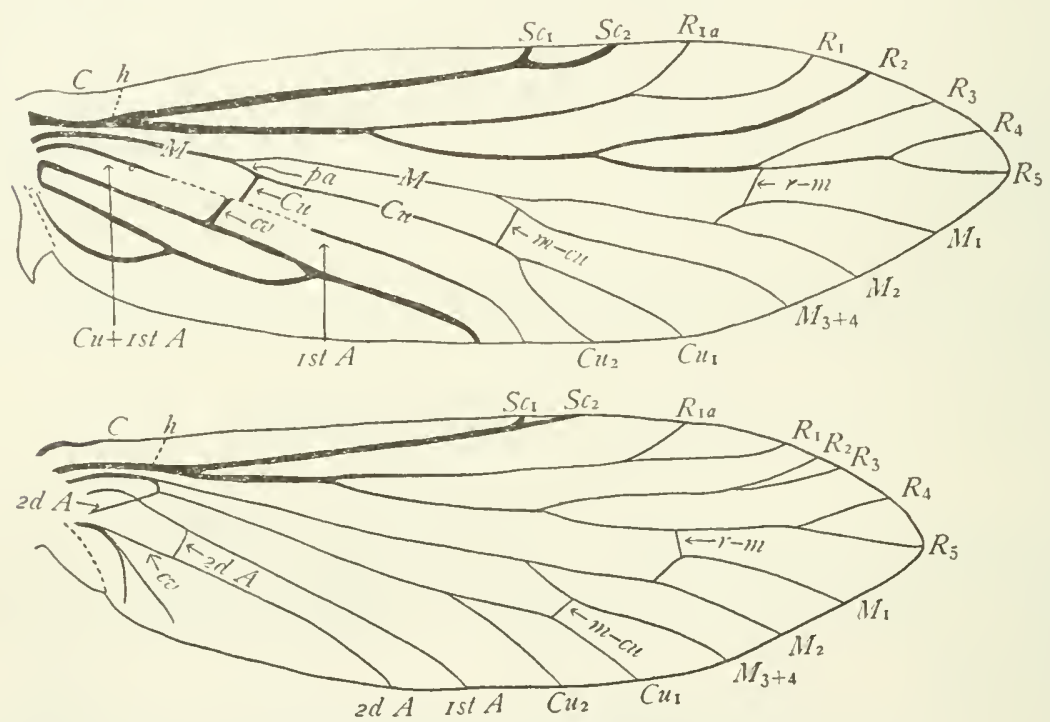

Fig. 324.-Wings of Mnemonica sp.

ence of this accessory vein is limited to the more generalized members of the family. The radial sector is four-branched in both fore and hind wings; in the fore wings of the individual figured here vein $R_{3}$ arises from vein $\mathrm{R}_{4}+5$, but this is an exceptional feature; usually the forking of the radial sector is dichotomous. The media is reduced to a three-branched condition in both fore and hind wings, by the coalescence of veins $M_{3}$ and $M_{4}$. In the fore wings veins $\mathrm{Cu}$ and rst $\mathrm{A}$ coalesce at the base of the wing; the base of the free part of vein $\mathrm{Cu}$ appears like a cross-vein; and a serial vein is formed by the base of media, the posterior arculus, and the longitudinal part of the cubitus. In the fore wings the tips of the second and of the first two branches of the third anal vein coalesce, forming a single vein, which reaches the margin of the wing near the tip of the first anal vein. 
There are two features of the venation of these wings that are of especial interest: first, the course of cubitus in the fore wing, described above; and second, the course of the second anal vein of the hind wing, which anastomoses with the first anal vein near the base of the wing, in the same manner as in Rhyacophila, described on an earlier page.

The fibula of Mnemonica (Fig. 325) is identical in structure with that of Rhyacophila (Fig.320). It ishatchet-shaped, the axillary furrow is immediately behind the second branch of the third anal vein, and

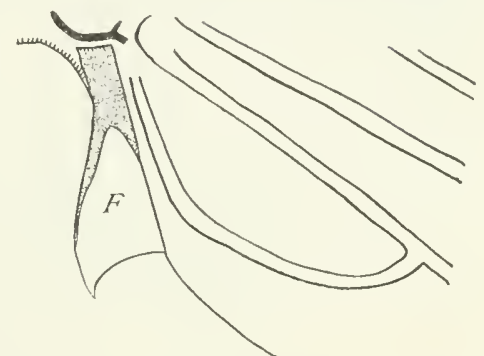

Fig. 325.-Fibula of Mnemonica sp. the longitudinal margin is supported by the third branch of the third anal vein.

(b) THE TRACHEATION OF THE WiNgS OF THE MiCROPTERYGINA

A study of the tracheation of the wings of Mnemonica confirms the conclusions reached regarding the homologies of the wing-veins of this insect and of those of Rhyacophila.*

In Figures 326 and 327 which represent the basal portion of the wings of Mnemonica, the trachex are shown in the wing-veins in so far as they can be clearly distinguished in the specimen figured.

In the fore wing, no costal trachea was found. There is a single trachea in the subcosta, which is not clearly visible except in the basal fourth of the vein, where it is distinct. At the base of the radius there is a single trachea, but this forks just before the point where subcosta and radius diverge. At about one-third of the distance from this point to the radial fork, one of these two trachex again divides. A little farther distad the other of the two branches divides. All four of these branches pass into the radial sector. I am unable to find any trace of trachea $R_{1} \uparrow$ In the basal part of the stem of media there is a single trachea; this divides into two a considerable distance before the cross-vein that extends to vein $\mathrm{Cu}(p a)$ is reached; one of the two again divides a short distance beyond this crossvein; and the other divides into two a little farther on; all of these tracheæ

*I am indebted to Dr. W. T. M. Forbes for an opportunity to study a preparation of the wings of a species of Mnemonica, in which the tracher can be clearly seen in the basal portions of most of the wing-veins. Dr. Forbes placed this preparation in my hands with the suggestion that the tracheation of these wings indicates the nccessity of a modification of the commonly accepted view regarding the homologies of some of the wing-veins of the Micropterygida. A careful study of this specimen has fully confirmed Dr. Forbes' suggestion.

†A similar forking of trachea near the base of the wing which results in the stem of a forked vein containing several parallel trachex, one for each of its branches, occurs in the Sesiidæ, and in some hepialids, at least. 
become invisible before the medial fork is reached. The cubital and first anal tracheæ coalesce for a short distance at the base of the wing and then separate; the cubital trachea divides into two a short distance before the

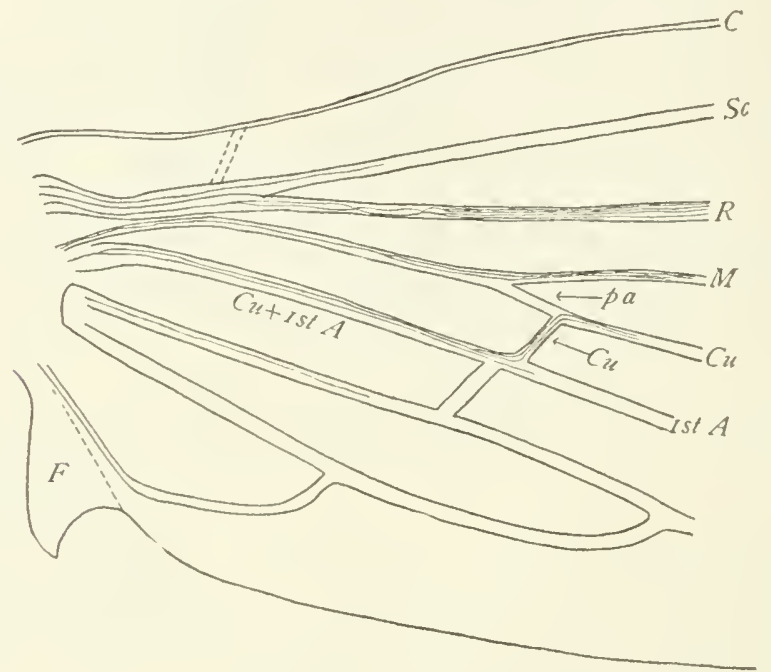

Fig. 326.-Base of the fore wing of Mnemonica.

point where vein $\mathrm{Cu}$ separates from the first anal vein and both branches follow the Z-shaped course of this vein. There is no trachea in the pos-

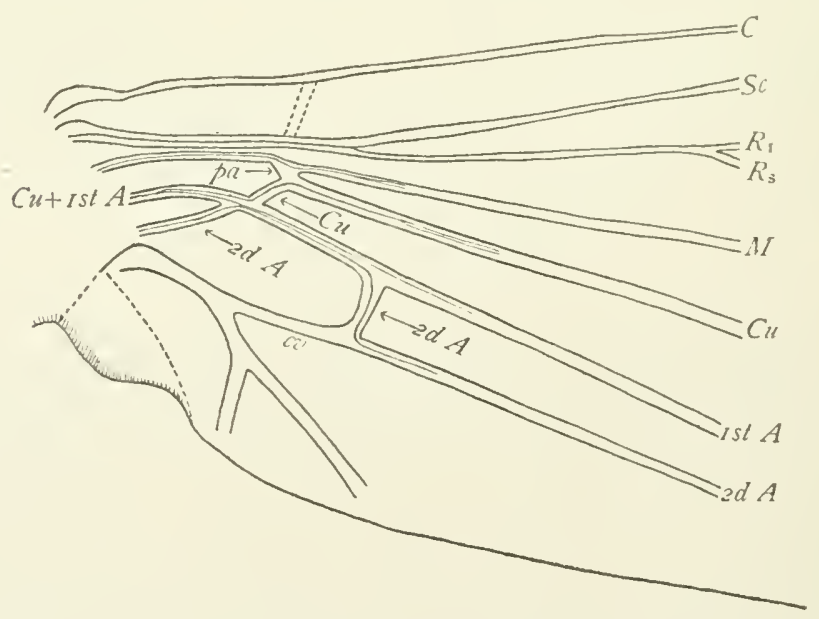

Fig. 327.-Base of hind wing of Mnemonica.

terior arculus. The first anal trachea I am unable to trace beyond the point where vein $\mathrm{Cu}$ branches off, owing to the atrophied condition of the first anal vein. The second anal trachea is clearly visible. 
In the hind wings the cubital and first anal tracheæ coalesce for a short distance, but the two soon separate; they extend parallel in the coalesced vein until the point is reached where the two veins separate and then each follows its vein. The base of the free part of rein $\mathrm{Cu}$ makes a sharp curve towards the base of media bit does not quite reach it, the two veins are connected by a short posterior arculus in which there is no trachea. Directly opposite the point of separation of the cubitus and the first anal reins, the first anal vein is joined by the second anal vein, the trachea of which is perfectly distinct. The tracher of the two veins continue parallel until the two veins separate and then the second anal trachea follows its vein.

\section{(c) THE ZOOLOGICAL POSITION OF THE MICROPTERYGIDE}

If the wings of Mnemonica, one of the more generalized of the Micropterygidx (Fig. 324), be compared with those Rlyacophila, one of the more generalized of the Phryganeina (Fig. 320), it will be seen that they agree in the more essential features of their renation; the more striking characteristics of the one are presented by the other. These characteristic features are the following. In the fore wings, the coalescence of reins $\mathrm{Cu}$ and ist $\mathrm{A}$ at the base of the wing; the $\mathrm{Z}$-shaped course of vein $\mathrm{Cu}$; the formation of a serial vein consisting of the base of media, the posterior arculus, and the longitudinal part of vein $\mathrm{Cu}$; the coalescence of the tips of the second anal vein and of two of the branches of the third anal rein; and the cross-vein between the first and second anal veins. In the hind wings, the coalescence of veins $\mathrm{Cu}$ and Ist $\mathrm{A}$ at the base of the wing; the $\mathrm{Z}$-shaped course of the cubitus; the anastomosis of the first and second anal veins; the longitudinal direction of the cross-vein connecting the second anal rein and the first branch of the third anal vein; and the form of the branching of the third anal vein. In addition to these common venational features the fibulæ of the two insects are identical in structure.

The possession of this remarkable series of common features of their wings by these representatives of the Phryganeina and the Micropterygina, and which is found in no insect not belonging to one of these two groups, can be explained only by assuming that it indicates a community of descent of the two groups. This conclusion is confirmed by the results of Dr. T. A. Chapman's studies of pupæ.*

For these reasons, the Micropterygina must be regarded as more closely allied to the Phryganeina than they are to any other group of insects; that is, they are obviously trichopterous insects.

It is also obrious that the Phryganeina and the Micropterygina represent two quite distinct lines of descent from the common stem of the order and should be regarded as distinct suborders.

\footnotetext{
*Trans. Ent. Soc. London, I 896, p. 569.
} 
If the Micropterygidæ be retained in the order Lepidoptera they must be considered the most generalized members of the order, being near the stem form from which the Trichoptera and the Lepidoptera have been evolved. This view necessitates the explanation of the manner in which the Hepialidæ, with their peculiar jugum, and the Frenatæ were evolved from a form having a well developed fibula, like that of Mnemonica and Rhyacophila. This must be done if the Lepidoptera, including the Micropterygidæ, is to be shown to be a monophylitic group. 


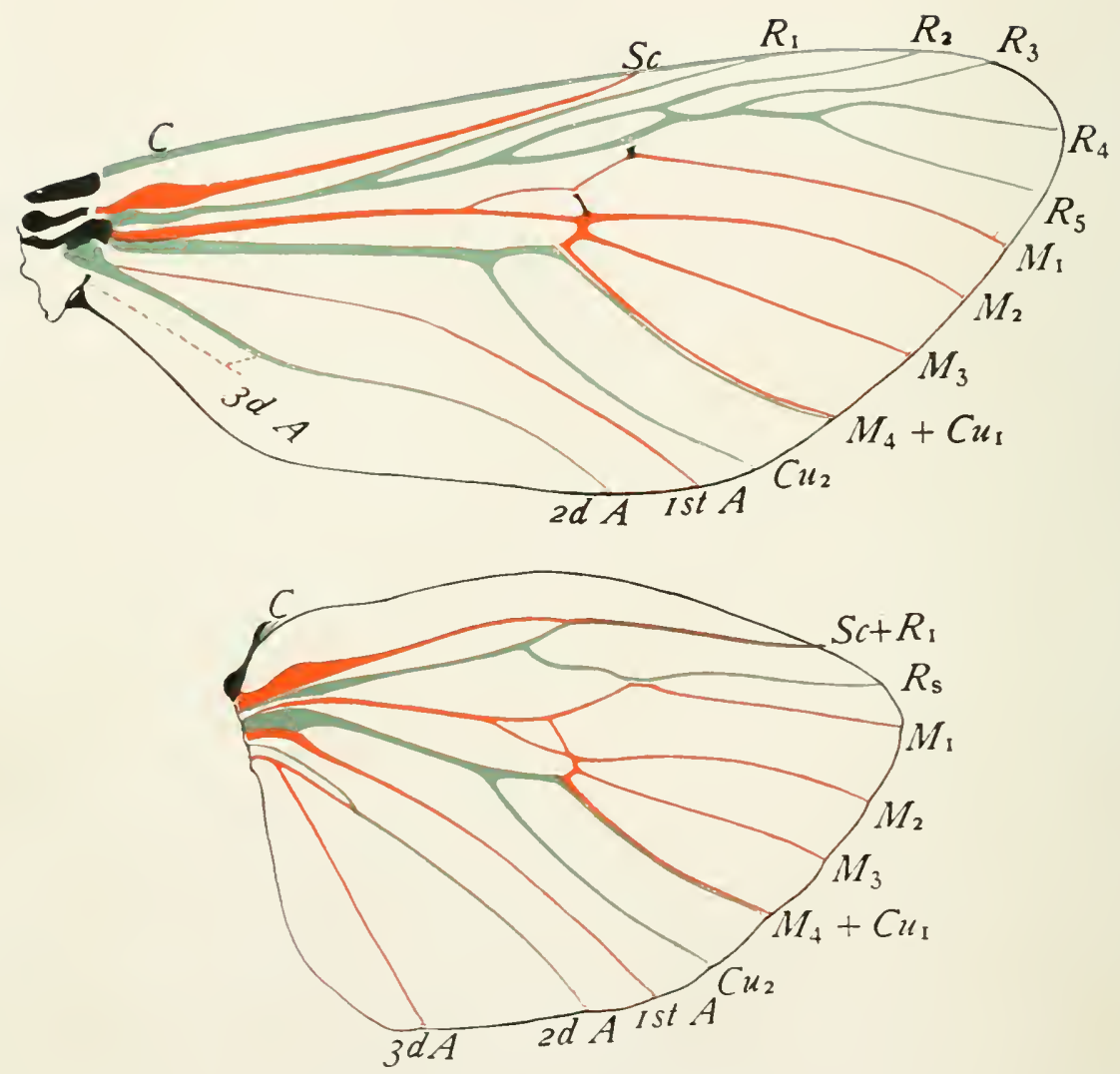

The wings of Prionoxystus robinia. 


\section{CHAPTER XXIII}

\section{THE WINGS OF THE LEPIDOPTERA}

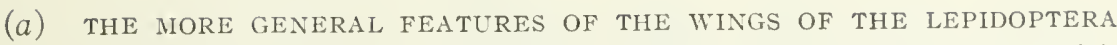
In the Lepidoptera the wings are membranous and are covered with overlapping scales. They are usually broadly expanded; but in some of smaller forms they are long and narrow. When at rest, the wings are variously disposed in the different members of the order. In a few species the males are wingless.

The wing-venation is comparatively simple; the only puzzling features are due either to the coalescence of veins or to the atrophy of veins. If we except the humeral veins, which are described later, in no family is there normally a specialization of the venation by the development of either accessory or intercalary veins; and only the principal cross-veins are present.

The most striking departure from the hypothetical primitive type is the fact that media is only three-branched. In this respect this order agrees with the Diptera; but the Lepidoptera differs from the Diptera in its characteristic method of coalescence of veins. In this order the coalescence of veins almost invariably procedes outward; while in the Diptera it often procedes from the margin of the wing towards the base of the wing.

\section{(b) THE Clothing of the Wings of the LepidopterA}

The clothing of scales.-The most distinctive feature of the wings of the Lepidoptera is the coating of scales with which they are covered. This coating of scales is the dust that comes off upon one's fingers when a moth or butterfly is handled.

When this dust is examined with a microscope it is found to be composed of very minute scales of various forms but regular in outline; and when a wing is looked at in the same way, the scales are seen to be arranged with more or less regularity upon it (Fig. 328). Thebody, the legs, and other appendages are also covered with scales.

It is well-known that these scales are merely modified setæ. That is, they are

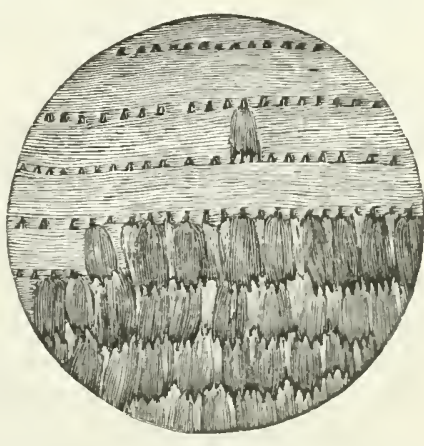

Fig. 328.-Part of a wing of a butterfly greatly magnified. setæ which, instead of growing long and slender as setæ usually do, grow very wide as compared with their length. Every gradation in form can be found from that of the ordinary seta, which occurs most abundantly 
upon the body, to the short and broad scale, which is best seen upon the wings (Fig. 329). This fact was pointed out by Réaumur nearly two hundred years ago (Memoires $\mathrm{V}$. I. I734); and in more recent times the

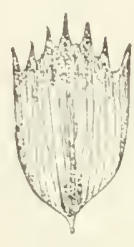
morphological identity of setxe and scales has been established by studies of their derelopment. This identity was inferred by Semper ('57) and Landois (' 7 I ). Schäffer ('s9) pointed out that both scales and hairs are evaginations of greatly enlarged hypodermal cells and figured one stage in the development Fig. 329.-Scales of Euclea cippus (After of the scales. Mayer ('96) gave a complete account of the derelopment of scales and illustrated his paper by most excellent figures of all stages of this derelopment.

The structure of scales is what would be expected from the fact that they are modified setæ, the scales, like setæ, being hollow; and the manner of their attachment to the cuticula of the body and its appendages is the same as that of the setæ, each scale being provided with a pedicel which fits into a cup-like socket in the cuticula.

A striking feature of the scales of Lepidoptera is the markings that exist on their exposed surface. These may consist merely of many, very fine, longitudinal ridges (Fig. 329); or there may be series of transverse ridges between the longitudinal ones (Fig. 330).

A cross section of certain scales indicates that the ridges are produced by foldings of the outer wall $(i . e$. the wall of the scale that is exposed when the scale is in place on the wing). Figure 33 I represents cross sections of a scale illustrating this condition. In some scales, however, the lumen of the scale has been filled to a considerable extent by chitin, and the origin of the ridges is not so obvious.

The scales of the Lepidoptera were probably developed from that type of setæ known as clothing hairs, and were primarily merely protective in function. This is doubtless

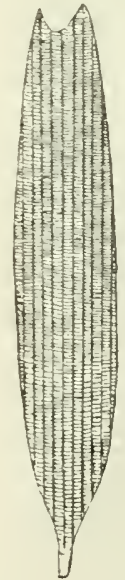

Fig. 330.--Scale of Lycomorpha constans (After Kellogg). their chief, if not only, function on most parts of the body, where they form a very perfect armor. 
The development of ridges on the surface of scales adds greatly to their stiffness, and thus increases their efficiency as a protective covering, as the corrugations in the sheets of iron used for covering the sides of buildings adds to the stiffness of the metal.

Upon the wings a covering of rigid scales would serve not merely to protect the wings but would tend to stiffen them, and thus arose a secondary function of scales which has resulted in the perfecting of their arrangement upon the wings in the more specialized members of the order as already indicated.

There are great differences among the insects of this order regarding the regularity of the arrangement of the scales upon the wings. With some of the more generalized moths the scales are scattered irregularly over the surface of the wings. But if a wing of one of the more specialized butterflies be examined with a microscope the scales will be found arranged in regular overlapping rows; the arrangement being as regular as that of the scales on a fish or of the shingles on a roof. Figure 328 represents a small portion of a wing of one of the more specialized butterflies, where the arrangement of the scales is most perfect. In the upper part of the figure the membrane is represented with the scales removed.

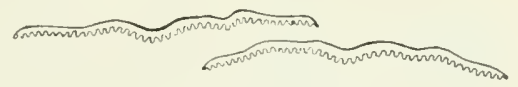

Fig. 331.-Cross-section of scales of Parnassius smintheus (After Kellogg).

Even in those insects in which a very perfect arrangement of the scales upon the wings has been attained, great differences in the degree of perfection of this arrangement exists in the two wings of the same side and in the different parts of the same wing. The arrangement is most perfect in those wings and in those parts of each wing that are subjected to the greater strain during flight. And is more perfect in swift flying species that it is in those of slow flight.

The taxonomic value of these differences in the arrangement of the scales of the wings of the Lepidoptera and also of the different types of scales found in different divisions of the order was investigated by Professor Kellogg ('94), to whose extended account the reader is referred for a discussion of this phase of the subject.

A secondary use of the scales of the Lepidoptera is that of ornamentation; for the beautiful colors and markings of these insects are due entirely to the scales, and are destroyed when the scales are removed.

The various colors of insects, and of other animals are produced in quite different ways; and classifications of these colors have been proposed based on the methods of their production. The literature of this subject is too extensive to be referred to in detail here. A most enjoyable, popular account is given by Professor Kellogg in his American Insects (Kellogg 'o8, pp. 583-6I4) and a detailed analysis of the methods of the production of 
color is given by Professor Tower in his Colors and Color-patterns of Coleoptera (Tower 'o3).

Following the classification of Tower the colors of the scales of the Lepidoptera may be either chemical, physical, or chemico-physical. The chemical colors are produced by pigments in the scales; the physical colors are produced either by reflection, refraction, or diffraction of light; and the chemico-physical colors are produced by either a reflecting, refracting, or diffracting structure orerlying a layer of pigment. There are also what Tower calls combination colors due to a combination of the causes just mentioned.

As the production of colors by pigments is the most obvious method in nature, it is the one to which the colors of the Lepidoptera are commonly attributed. But it is now well-known that a large proportion of the most beautiful colors of these insects are either physical or chemico-physical; this is true of the various metallic and iridescent colors so commonly found in butterflies and many moths.

Explanations of the methods of production of physical colors are given in text books on physics; it is, therefore, only necessary here to point out a feature in the structure of the scales of Lepidoptera that results in the production of these colors. This feature is the presence of the fine longitudinal strix described abore. When the striæ are very fine and close together they act in the same way as does a diffraction grating, producing the beautiful iridiscent colors. Kellogg ('94) found that on certain scales from a species of Morpho the striæ were from $.0007 \mathrm{~mm}$. to $.00072 \mathrm{~mm}$. apart or at the rate of about 35.000 to the inch.

The fact that certain colors are due to the way in which light is reflected from the scales can be shown by the following experiment. Place on the stage of a microscope the wing of a bright blue butterfly, and shade the specimen so that it is viewed only by transmitted light from the mirror of the microscope; when examined in this way the blue color will be absent. This is due to the fact that the light passing directly through the scales is not broken up and only the colors produced by pigment are visible.

There is still another function of the scales of Lepidoptera; they may serve as the outlets of scent glands. As the scales that serve this purpose are found chiefly on the wings of males, they have received the special name of androconia, signifying male dust.

Androconia are most readily found in the "brand" of the wings of males of the subfamily Pamphilinæ, the skippers with a discal patch; in the costal fold of males of the Hesperiinæ, the skippers with a costal fold; and in the discal patch of the wings of certain Lycenidæ, the blues. They occur, however, in many other situations.

The androconia are of various shapes (Fig. 332); they are frequently fringed at the distal end, with each tip of the fringe finely divided. This is 
probably a provision for insuring the rapid evaporation of the product of the scent gland. Androconia have been figured and described by many authors.

Associated with the patches of androconia there are frequently covering scales of various forms.

In many Lepidoptera the scales are lacking on portions of the wings; familiar examples of this are most of the Sesiidæ and certain members of the Sphingidæ.

The clothing of fixed hairs.-In addition to the clothing of scales, Kellogg ('94) discovered upon the wings of Micropteryx, which at that time was believed to belong to the suborder jugatæ of the Lepidoptera, and Hepialus "a covering of very fine hairs differing radically from the scales in size, arrangement, and mode of attachment to the membrane, and agreeing essentially with the fixed hairs of the Trichoptera."

Kellogg applied the term fixed hairs to this type of clothing, as the hairs are directly continuous with the cuticula of the wing instead of being jointed at the base, as are setæ. The fixed hairs are much smaller than are the scales. In Micropteryx unimaculella they average .005 $\mathrm{mm}$. in length, and are distant from each other at their bases a length approximately equal to the length of the hairs. The scales of $M$. unimaculella average from .I $\mathrm{mm}$. to . I $5 \mathrm{~mm}$. in length. In Hepialus sylvimus, he found that the fixed hairs were about one-tenth as long as the scales.

As Kellogg was unable to find the fixed

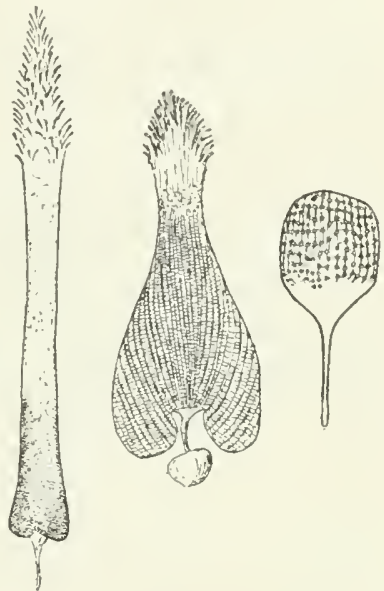

Fig. 332.-Androconia from the wings of male butterflies (After Kellogg). hairs on the wings of any of the Frenatæ examined by him he concluded that their presence was a distinctive character of the Jugatæ.

In a paper published a year later, Spuler ('95), who evidently had not seen Kellogg's paper, describes the fixed hairs under the name Stacheln, and indicates their occurrence not only in the Micropterygidæ and the Hepialidæ, but also distributed over the entire wings in certain Tineids (Incurvaria, Adela, Nematois, Nemophora, and in the Nepticulidæ, and in limited areas on the wings of certain other Lepidoptera, in what he terms the "Haftfeld" or holding area, on the lower side of the inner margin of the front wing. The "Haftfeld" of Galleria mellonella is especially mentioned.

The fixed hairs are referred to by Busck ('I4), in his paper On the Classification of the Microlepidoptera, as the aculei; and the Lepidoptera that are characterized by their presence on the wings are designated as the 
Aculeata. The introduction of these two terms in this connection is unfortunate on account of their long and very general use in another sense in works on the Hymenoptera. The term, fixed hairs, used by Kellogg is perfectly satisfactory.

The mode of origin and development of the fixed hairs has not been studied. They may be merely elongated cuticular nodules; but Spuler states that they are hollow, which indicates a different mode of origin from that of the ordinary cuticular nodules. The fixed hairs are designated by Marshall ('I 5) as the small surface hairs.

(c) THE METHOdS OF SPECiAlization OF THE WiNGS OF THE LEPIDOPTERA

The Lepidoptera belong to the series of orders in which the number of wing-veins does not exceed that of the hypothetical primitive type, the divergences from this type being the result of specialization by reduction.

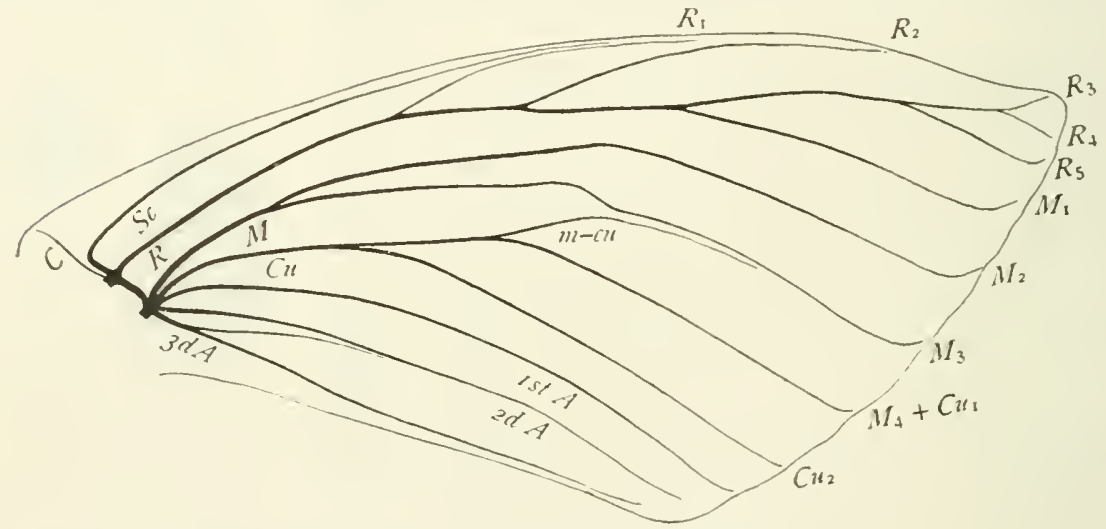

Fig. 333.-Fore wing of a pupa of Pieris rapa.

Neither accessory nor intercalary veins are normally developed in this order; and only the principal cross-veins are present. In some cases, however, there appear to be four anal veins, which indicates that one of the anal veins is two-branched.

That this was more generally the case in the primitive Lepidoptera than it is in recent forms is shown by the fact that, although there is only one anal vein in the fore wing of the adult Pieris, in the pupal wing there are three anal tracheæ and the third is two-branched. (Fig. 333).

Although accessory veins are never normally present in members of this order, abnormal specimens have been found, especially of hepialids, in which there are extra branches on the branched veins.

Reduction in the number of veins is of frequent occurrence, and is the result either of the coalescence of adjacent veins or of the fading out of veins. Reduction by the coalescence of veins is the more usual method of 
reduction; and, as already stated, this coalescence almost invariably proceeds outward. This method of the coalescence of the branches of a vein is often shown, by a study of a series of allied forms in which different degrees of it can be observed, the point of separation of two branches being nearer to the margin of the wing in successire forms until the margin is reached and a single vein remains where there were two before.

There are also many instances where the reduction is due to the fading out of veins. Frequently where a vein has atrophied a vestige of it remains, either as a faint line in the position formerly occupied by the vein, or as a short fragment of the vein; but in other cases no trace of the lost vein exists.

THE PRIMARY DIVISIONS OF THE LEPIDOPTERA INDICATED BY THE STRUCTURE OF THE WINGS

In papers published in ${ }_{1} 892$ and ${ }_{1} 893$ I called attention to the fact that in certain moths the two wings of each side are united by an organ borne by the fore wing which I termed the jugum and in all other Lepidoptera the wings are united either by an organ borne by the hind wing, which had long been known as the frenulum, or by a substitute for the frenulum, a greatly expanded humeral angle of the hind wing.

The discovery of the fact that there are two distinct modes of uniting the wings during flight suggested the inference that in the primitive Lepidoptera the wings were united in neither way; for it is not easy to see how one mode could have been developed from the other.

Correlated with each of the two methods of uniting the two wings of each side there is a distinctive feature of the wing-venation. In those moths in which the wings are united by a jugum the venation of the two pairs of wings is similar; in other Lepidoptera there is a striking difference in the venation of the two pairs of wings, due to the fact that in the hind wings the radius is greatly reduced.

If in the primitive Lepidoptera there were neither a jugum nor a frenulum, and in some of the descendants of these primitive Lepidoptera there was developed a jugum and in others a frenulum, there arose in this manner two distinct lines of descent. These supposed two lines of descent I considered of subordinal value and proposed the terms Jugatce and Frenatce for them respectively.

Suborder Jugatæ.-The suborder Jugatæ includes the descendants of those ancient Lepidoptera in which a jugum was developed and in which the venation of the two pairs of wings is similar (Fig. 334).

To these, the most obvious characteristics of the Jugatæ, can be added the following: In the Jugatæ the cubitus and the first anal vein of the fore wings coalesce at the base of the wing; the basal portion of the free part of cubitus has the appearance of being an oblique cross vein; and a 
serial vein is formed consisting of three parts, the basal part of media, what appears to be the posterior arculus, and the longitudinal part of cubitus.

The suborder Jugatæ includes only a single family of moths, the Hepialidæ. I formerly included the family Micropterygidæ in the Jugatæ, because I accepted the general belief that they are lepidopterous insects, and because they agree with the Hepialidæ in the similarity of the venation of the fore and hind wings, and also because the posterior lobe of the fore wings serves as an organ for uniting the fore and hind wings. But a more
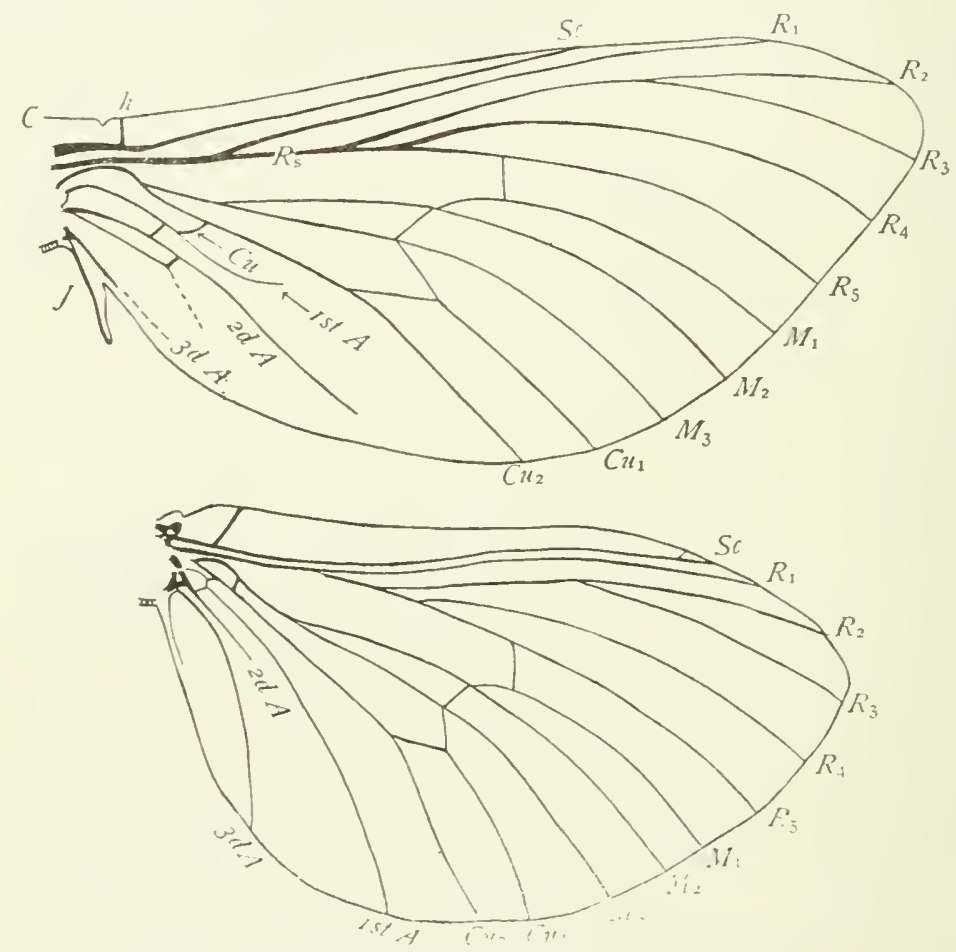

Fig. 334.-Wings of a hepialid, Pielus labyrinthecus.

careful study of this family has convinced me that it belongs to the order Trichoptera; the reasons for this conclusion are set forth in the preceding chapter.

Suborder Frenatæ.-The suborder Frenatæ includes the descendants of those ancient Lepidoptera in which a frenulum was developed, and in which the venation of the two pairs of wings is different, owing to the reduction of the radius of the hind wings.

The Frenatæ differ from the Jugatæ in the fact that the cubitus and radius of the fore wings do not coalesce at the base and also in the fact that a serial vein $\mathrm{M}-\mathrm{Cu}$ is not formed. 
The suborder Frenatæ includes the greater part of the living Lepidoptera. Within this suborder are found great differences in the form of the wings, in the details of wing-venation, and in the manner of uniting the fore and hind wings. But, in spite of this, it is a very homogeneous group; all of the variations in the structure of the wings are modifications of a common type, which is represented by living members of the suborder.

\section{(e) THE Wings of the JUGATA}

In the wings of the Jugatæ the posterior lobe of the fore wing is a slender, finger-like organ, the jugum, which aids in uniting the fore and hind wings; and the venation of the fore and

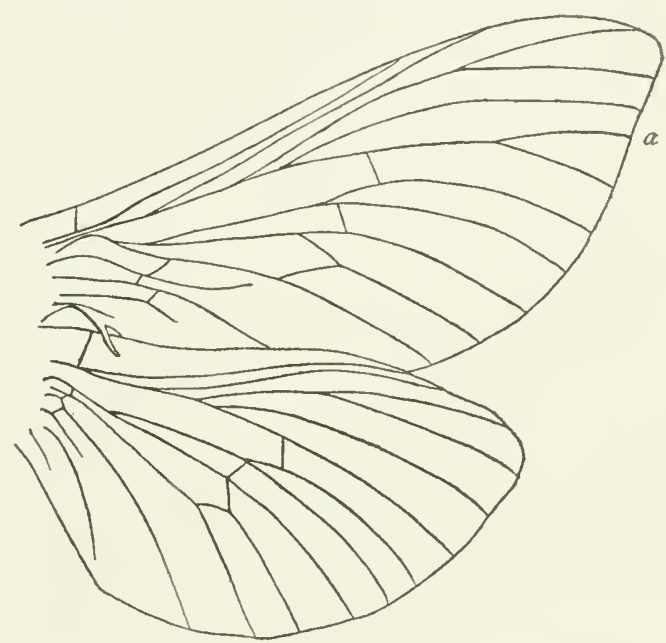

Fig. 335.- - Wings of ${ }^{\circ}$ a hepialid, Pielus labyrinthecus, seen from below. $a$, abnormal accessory vein. hind wings is quite similar, the radial sector of the hind wing being fourbranched, like that of the fore wing.

The jugum.--The jugum is a peculiar type of the posterior lobe of the fore wing that is found only in the Hepialidæ. It is slender and projects beneath the costal margin of the hind wing. As the greater part of the inner margin of the fore wing overlaps the hind wing, the hind wing is held between the two. This is shown in Figure 335, which represents the wings

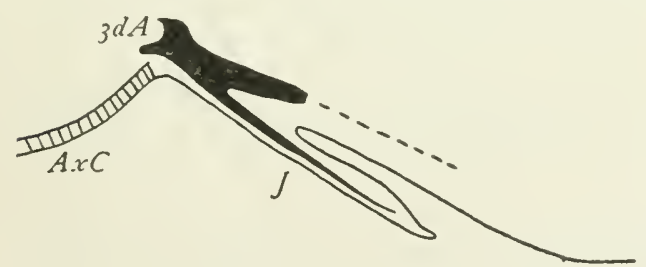

Fig. 336.-Jugum of a hepialid. of one side seen from below. The jugum is behind one of the two principal branches of the third anal vein, which may be designated as vein $3 \mathrm{dA}_{1}$, and is supported by the second of these two branches, which may be designated as vein $3 \mathrm{dA}_{2}$ (Fig. 336).

The tracheation of the wings of pupæ.-The tracheation of the wings of pupx of Hepialus thule was studied by Dr. A. D. MacGillivray ('I2), who gives figures showing the courses of the trachcæ in the forming wing-veins of both the fore and hind wings. This is the only paper that has been published on the tracheation of the pupal wings of a member of the Jugatæ. 
In sereral adult hepialids that I have studied the tracheæ are visible in the wing-reins. The results of my studies of these specimens differ in scme details from those reached by Dr. MacGillivray. It is quite possible that these differences are due to the fact that the material studied by Dr. MacGillivray had been preserved in formal and may not have been in good condition. It is obriously desirable that fresh pupal wings be studied.

The most important of the differences referred to is the fact that in all cases where I have seen tracheæ in the wing-reins of hepialids what appears to be the posterior arculus is traversed by a branch of the medial trachea, which extends towards the margin of the wing in the longitudinal part of the cubitus, and parallel with the cubital trachea. I am unable to explain satisfactorily the presence of this trachea in this position. It may have originated as an adrentitious trachea; but if so, it has become a definitive part of the tracheation of the wing for it is as large as or larger than the cubital trachea. It may be the trachea of the missing vein $\mathrm{M}_{4}$, which has been separated from the other branches of the medial trachea. An aralogous splitting back of a trachea is that of trachea $R_{4+5}$ in the butterflies. I leave the problem until more data bearing on it is obtained.

In some hepialids there is a forking of tracheæ near the base of the wing which results in the stem of a forked rein containing sereral parallel branches. In a wing of Sthenopis that I have examined there are two tracheæ in radius at the base of the wing, and these divide into four a short distance beyond the humeral rein.

The venation of the wings of hepialids.- In the hepialids the subcosta is often forked; the radius of both fore and hind wings is of the hypothetical primitive type; media is reduced to a three-branched condition in both fore and hind wings; and in the fore wings reins $\mathrm{Cu}$ and ist $\mathrm{A}$ coalesce at the base, as in the Trichoptera.

The way in which media has been reduced in the hepialids is still an open question. Dr. MacGillivray, as a result of his studies of tracheation of Hepialus thule, reached the conclusion that the reduction is the result of the coalescence of veins $M_{3}$ and $\mathrm{M}_{4}$; but had he found the branch of the medial trachea that traverses the posterior arculus he probably would have reached a different conclusion.

Comstock and Needham concluded that the reduction of media had been attained by the coalescence of reins $\mathrm{M}_{4}$ and $\mathrm{Cu}_{1}$, and figured the wings of an abnormal Sthenopis in which the tips of veins $\mathrm{M}_{4}$ and $\mathrm{Cu}_{1}$ are separate in the hind wing (Fig. 337), believing that this condition is atavistic. The value of this evidence is seriously questioned by Dr. MacGillivray; but the presence of the trachea that traverses what appears to be the posterior arculus, described above, adds weight to it.

Until this question is more definitely settled, it will be best to omit any reference to vein $\mathrm{M}_{4}$ as is done in Figure 334 . 
In the fore wings, veins $\mathrm{Cu}$ and ist $\mathrm{A}$ coalesce at the base, where they lie at the bottom of the cubito-anal sulcus (Fig. 334). From the point of separation of the two reins, the cubitus extends at first in an oblique direetion, appearing like a cross-vein; when it has nearly reached the media, it bends abruptly and extends longitudinally to the outer margin of the wing.

The cubitus is joined to the media by a short vein, which appears to be homologous with the posterior arculus of the Trichoptera; but which, as it contains a branch of the median trachea, may be the base of vein $\mathrm{M}_{4}$, the more distal part of vein $\mathrm{M}_{4}$ coalescing with vein $\mathrm{Cu}$. I have been unable to find anything corresponding to the posterior arculus in the Frenatæ; for

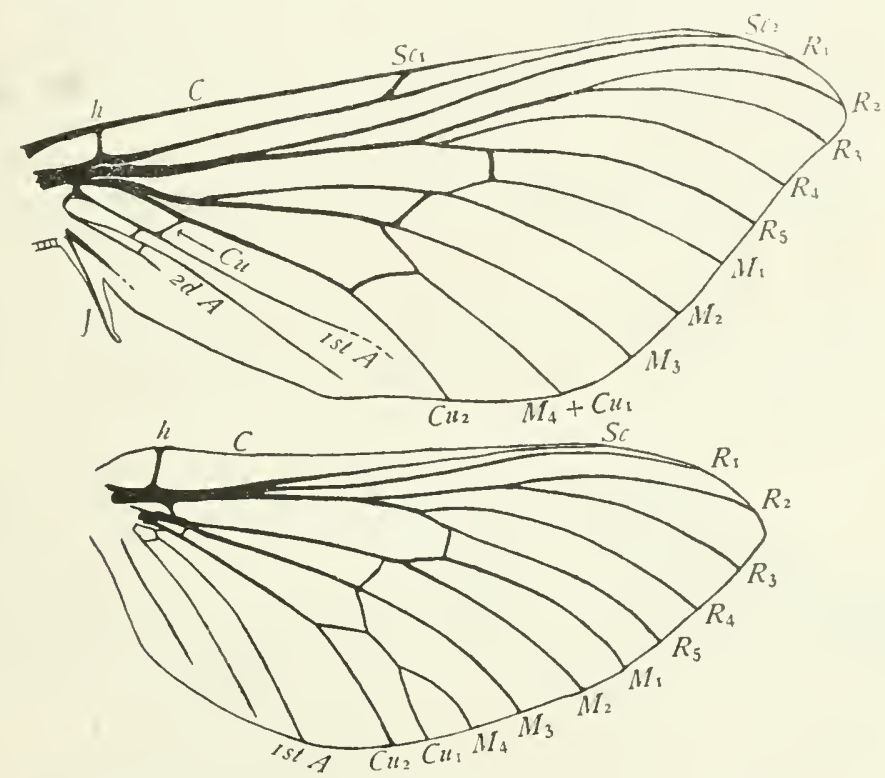

Fig. 337.-Venation of an abnormal individual of Sthenopis.

this reason it seems probable to me that it has not been developed in the Lepdioptera; and that what appears to be the posterior arculus in the hepialids is a seetion of vein $\mathrm{M}_{4}$.

Lest the similarity of the course of vein $\mathrm{Cu}$ in the fore wing of the hepialids to that of this vein in the Trichoptera be given undue weight, I call attention to the fact that in the fore wing of the Cicada (Fig. 269) where veins $\mathrm{Cu}$ and ist $\mathrm{A}$ are erowded together in the cubito-anal sulcus and coalesce there, the free part of vein $\mathrm{Cu}$ follows a similar course.

There are three anal veins in the fore wings of the hepialids. The first anal vein is aligned with vein $\mathrm{Cu}+$ Ist $\mathrm{A}$ and extends a short distance in the cubito-anal fold, but the distal part of it has atrophied. No distinct anal furrow exists in any of the hepialids that I have studied; there is 
merely a cubito-anal fold. The second anal vein is apparently simple; but in an adult wing before me it contains two tracheæ, one of which extends into the cross-rein between this rein and vein $\mathrm{Ct}+\mathrm{Ist} \mathrm{A}$. This may indicate that the second anal vein was formerly forked and that the cross-vein is a portion of one of the forks. The third anal vein is forked; the second branch of it supports the jugum, as already described.

The posterior tuberosity of the fore wing is divided by the second anal vein; the elevated portions of this tuberosity are between veins; this is an unusual condition.

The venation of the hind wings (Fig. 334 ) resembles very closely that of the fore wings except for some differences at the base of the wing. The vein whicht appears to be homologous with the posterior arculus but which may be the base of vein $M_{4}$ extends transversely, instead of longitudinally as it does in the fore wing; reins $\mathrm{Cu}$ and ist $\mathrm{A}$ do not coalesce at the base; the third anal rein is forked as in the fore wing, but as there is no axillary excision the second branch of this vein is not in a detached portion of the wing.

\section{(f) THE WIXgs OF THE FRENATE}

In the Frenatæ the two wings of each side are united by an organ, which is termed the frenulum, or by a substitute for this organ, the greatly
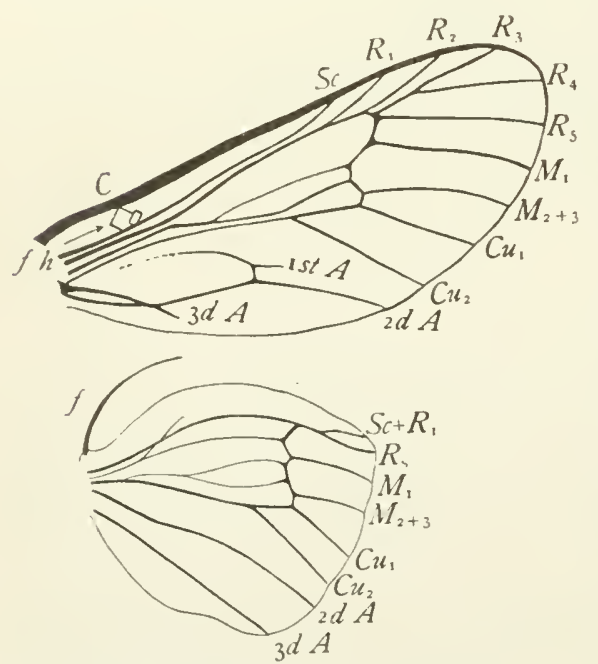

Fig. 338.-Wings of Thyridopteryx; $f$, frenulum; $f h$, frenulum hook.

expanded humeral angle of the hind wing; the fore and hind wings differ greatly in venation, due to a reduction of the radius of the hind wings; the media of both fore and hind wings is reduced to a threebranched condition; and the base of the first anal vein does not coalesce with the cubitus.

The frenulum and the frenulum hook.--The fronulum (Fig. 338, f) is a strong spine-like organ or a bunch of bristles borne by the hind wing at the humeral angle, and which projects beneath the fore wing. In the males of certain moths, where the frenulum is highly developed, there is a membranous fold on the fore wings for receiving the end of the frenulum, and thus more securely fastening the two wings together; this is the fremulum-hook (Fig. 338, $f h$ ).

Except in the Microlepidoptera the frentulum of the male consists of a single strong spine-like organ; and that of the female, of two or more bristles. 
The bristles of which the frenulum of the female is composed are spinelike setæ. This is shown by their basal articulation, and by the fact that they are hollow. Frequently when a wing is mounted in Canada balsam, the cavity in each bristle can be easily seen. That the spine-like frenulum of the male consists of united bristles is also shown in the same way, the spine-like organ containing two or more longitudinal cavities.

Evidently the frenulum of the male is the more highly specialized form of the organ. This is doubtless correlated with the more active flight of the males, in seeking their mates. This also explains the development of a frenulum hook in the male; while as a rule this organ has not been attained by the female.

In the family Sesiidæ, where both sexes fly swiftly, the bristles composing the frenulum are consolidated in the female as well as in the male. The female also possess a frenulum hook; but this is not so highly specialized as that of the male.

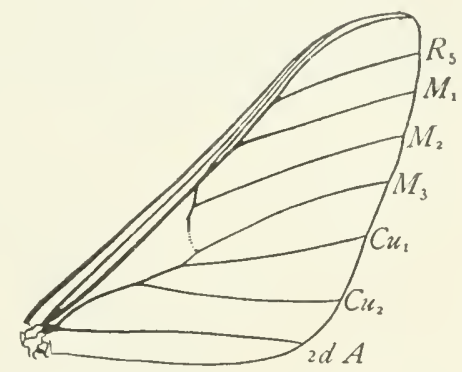

The loss of the frenulum in certain of the Frenatæ.--The loss of the frenulum in certain members of the Frenatx has followed the development of a substitute for it. It is obvious that if the two wings of each side overlap to a great extent, their acting together will be assured by this fact. And this is what has taken place with the butterflies, the skippers, and certain moths. With these insects the humeral angle of the hind wing has been greatly enlarged, so that it projects far beneath the fore wing (Fig. 339). When this has taken place there is no longer any need of a frenulum, and consequently this organ is no longer preserved by natural selection. We find, therefore, that several families of the Lepidoptera that belong to the suborder Frenatæ, being descendants of ancient frenulum-bearing moths, no longer possess a frenulum. These are classed in the Synopsis of the Lepidoptera, given in the writer's text book of entomology as the "frenulum-losers."

It is a very interesting fact, and one that bears out the theory just stated, that in the more generalized of the frenulum-losing moths, as the Bombycidæ, the frenulum has not yet entirely disappeared but is preserved in a vestigial condition (Fig. 340 ).

Objection has been urged to the establishment of the suborder Frenatæ because many of the forms included in it do not possess a frenulum. Those 
who make this objection ignore the following taxonomic principle set forth by the writer at the time the establishment of the suborders Jugatæ and Frenatæ was proposed, viz.:

"There will arise, I believe, in a work of this kind a necessity for distinguishing between the essential characters of a group and those characters which are used by the systematist merely to enable students to recognize members of the group. For it seems to me that the essential characters of a group of organisms do not lie necessarily
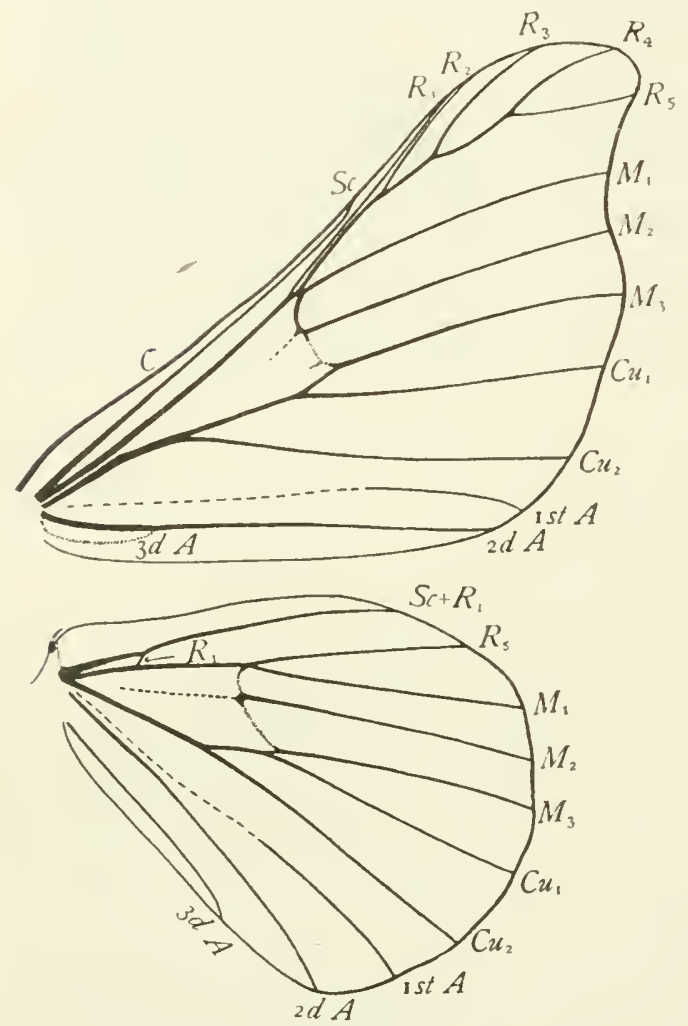

Fig. 340.-Wings of Bombyx mori. in the presence or absence of any structure or structures, or in the form of any part or parts of the body of the living members of the group; but rather in the characteristic structure of the progenitor of the group, and in the direction of specialization of the descendants of this progenitor.

"Thus, to use again the illustration given above, the Jugatæ are essentially characterized as the descendants of those ancient Lepidoptera in which the wings of each side were united by a jugum; and they are also characterized by a tendency towards an equal reduction of the veins of the two pairs of wings. While the Frenatæ are essentially characterized as the descendants of those ancient Lepidoptera in which the wings of each side were united by a frenulum; and they are also characterized by a tendency towards a greater reduction of the veins of the hind wings than of the fore wings, or, in other words, by a tendency towards a cephalization of the powers of flight. The fact that in many of the Frenatæ the frenulum has been lost, does not invalidate in the least the truth of this characterization. The loss of the frenulum, however, in certain Frenatæ renders necessary the use of some other character or characters by the systematist as recognition characters."

The reduction of the radius of the hind wings. - Throughout the suborder Frenatæ the radius of the hind wings is so greatly reduced that it appears to be unbranched. This reduction of the radius is due to two facts; first, vein $R_{1}$ coalesces with the subcosta; and second, all of the branches of the radial sector coalesce so as to form a single vein. 
The coalescence of vein $R_{1}$ and the subcosta was not suspected until the tracheation of pupal wings was studied; it then became evident. Figure

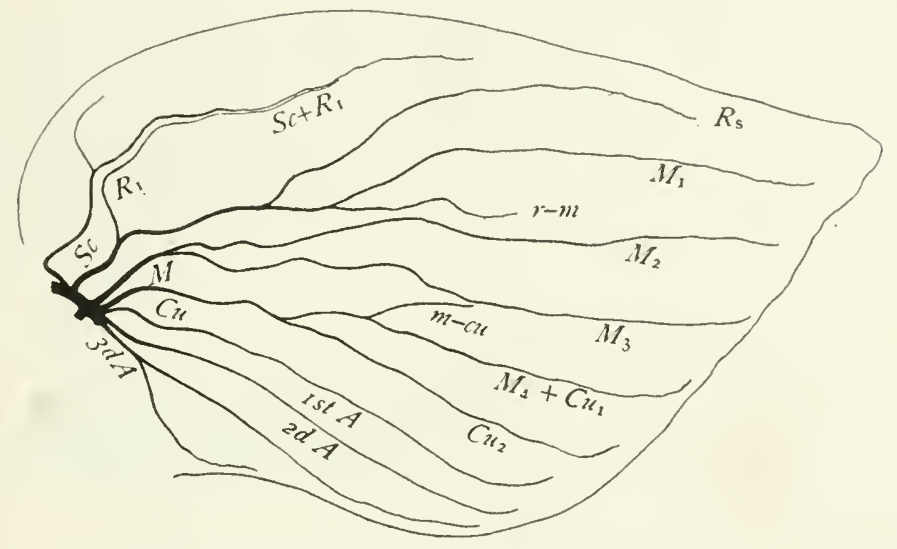

Fig. 341.-Hind wing of a pupa of Pieris rapre.

34 I represents the tracheation of a hind wing of a pupa of Pieris rapa. In this wing, trachea $R_{1}$ extends from the radial fork directly towards the costal margin of the wing until it nearly reaches the subcostal trachea; it then bends outward and extends closely parallel with the subcostal trachea. A single vein is formed about these two trachex; this vein appears to be the subcosta, but the evidence presented by the tracheation of the pupal wing shows that it is vein $\mathrm{Sc}+\mathrm{R}_{1}$. Figure 342 represents the wings of the adult of the closely allied Pontia protodice, in which it can be seen that a single vein, $\mathrm{Sc}+\mathrm{R}_{1}$ occupies the position of the two tracher just described.

In the adult wings of

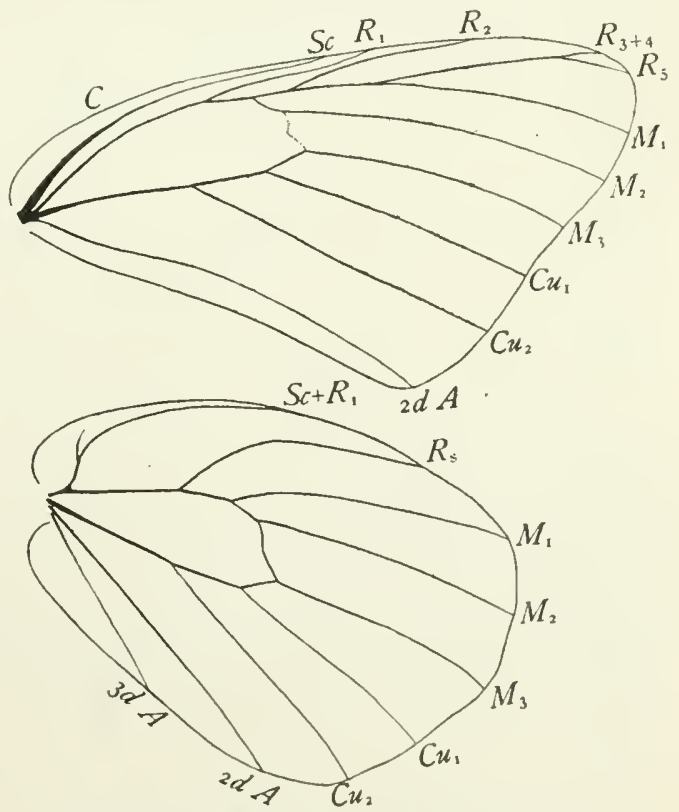

Fig. 342.-Wings of Pontia protodice. the greater number of the Frenatæ there is no indication of the coalescence of veins $\mathrm{Sc}$ and $\mathrm{R}_{1}$ of the hind wings; this is the case in Pontia 
protodice. But in a considerable number of these insects the radial fork is evident; but in these the free part of rein $R_{1}$ has the appearance of being a cross-rein (Fig. 340).

In all pupal wings of the Frenatæ the trachea of the radial sector of the hind wings is reduced to an unbranched condition; but in many cases trachea $M_{1}$ has been transferred to it (Fig. $3+\mathrm{I}$ ); this is correlated with the atrophy of the main stem of media in the adult, which is discussed later.

The reduction of media to a three-branched condition.-In the Frenatæ as in the Jugatie the media of both fore and hind wings has been reduced to a three-branched condition.

It is quite possible that this reduction has taken place independently in the two suborders; for the separation of these suborders doubtless occurred very early in the course of the evolution of the Lepidoptera. For this reason, in attempting to determine the manner in which this reduction has taken place in the Frenatie I submit only data drawn from the study of representatives of this suborder.

A study of the method of branching of media in the Frenatæ shows that the reduction of this rein is the result of the loss of vein $\mathrm{MI}_{4}$ as a distinct vein. There is no reason to believe that this rein has atrophied; the reduction has doubtless been brought about either by the coalescence of veins $\mathrm{M}_{3}$ and $\mathrm{M}_{4}$ or by the coalescence of veins $\mathrm{M}_{4}$ and $\mathrm{Cu}_{1}$.

One naturally turns to a study of the tracheation of the wings of pupæ to find a solution of the problem; but in none of the many lepidopterous pupæ examined is media more than three-branched; this suggests the conclusion that reins $\mathrm{MI}_{3}$ and $\mathrm{MI}_{4}$ have coalesced. But in the course of a renewed investigation of this subject I have found data that lead me to believe that the reduction of media in this suborder is a result of the coalescence of veins $\mathrm{M}_{4}$ and $\mathrm{Cu}_{1}$, and that consequently the rein that has been commonly designated as rein $\mathrm{Cu}_{1}$ is really vein $\mathrm{M}_{4}+\mathrm{Cu}_{1}$.

The nature of this data is well-shown by the tracheation of the wings of Pieris rape. In the hind wing (Fig. $3+\mathrm{r}$ ) there are, in addition to the tracheæ that are the anlagen of the principal reins and their branches, two short trachere designated in the figure as $r-m$ and $m-c u$, respectively. Trachea $r-m$ is obviously a vestige of a secondary connection between the medial and radial tracheæ. Note that what is here considered as trachea $r$ - $m$ arises from trachea $R_{\mathrm{s}}$ and that trachea $\mathrm{MI}_{1}$ arises from trachea $r-m$ a considerable distance from its base; the letters $r-m$ in the figure are placed at the tip of this trachea. This connection was probably, at first, transrerse, occupying the position of the cross-rein $r-m$ in more generalized wings, as in the fore wings of Prionoxystus (Fig. $3+3$ ) and in the hind wing of Packardia (Fig. 348). Correlated with a lessening of the air supply through the main stem of the medial trachea, or with whatever the cause may be that results in the atrophy of the main stem of rein $\mathrm{M}$, the base of 
trachea $M_{1}$ migrated along this connection towards trachea $R_{s}$ and became separated from trachea $M_{2}$, receiving its air via trachea $R_{\mathrm{s}}$. At the same time trachea $r-m$ migrated along trachea $\mathrm{R}_{\mathrm{s}}$ towards the base of the wing, thus affording a more direct course for the air and becoming longitudinal instead of transverse. This series of events, regarding which there is little room for doubt, as all of the stages in the switching of vein $M_{1}$ to vein $R_{s}$ exist in living Lepidoptera, throws light on the question of the significance of trachea $m-c u$. The position of this trachea, which is closely analagous to that of trachea $r-m$, indicates that it is a vestige of a secondary connection between the medial and cubital trachex.

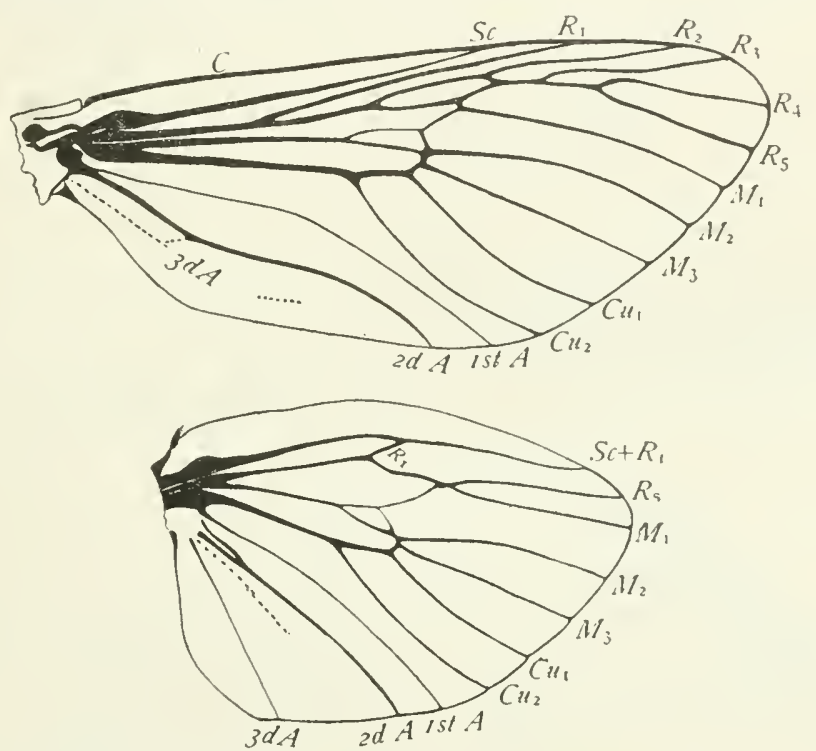

Fig. 343.-Wings of Prionoxystus robinice.

It is evident that trachea $m-c u$ is not a vestige of a connection between coalesced tracheæ $\mathrm{M}_{3}$ and $\mathrm{M}_{4}$ and trachea $\mathrm{Cu}_{1}$, because trachea $\mathrm{M}_{3}$ still retains its primitive connection with the main stem of the medial trachea, which would not be the case if at any time it had become connected directly with trachea $\mathrm{Cu}_{1}$. The connection must have been between tracheæ $\mathrm{M}_{4}$ and $\mathrm{Cu}_{1}$. The two intermediate branches of the medial trachea, $\mathrm{M}_{2}$ and $\mathrm{M}_{3}$ retain their connection with the main stem of this trachea, while on either side a branch has become connected to another trachea, $M_{1}$ to trachea $R_{s}$ and $\mathrm{M}_{4}$ to trachea $\mathrm{Cu}_{1}$.

In each case the transferred branch has migrated along the secondary connection towards the trachea with which it has become connected. In the hind wing of Pieris rape the base of trachea $M_{1}$ has progressed a considerable distance towards trachea $R_{i}$, but is still distinct from it, arising 
from trachea $r-m$. In the fore wing (Fig. 333) trachea $M_{1}$ has reached the radial trachea and coalesces with it for a considerable distance. If this

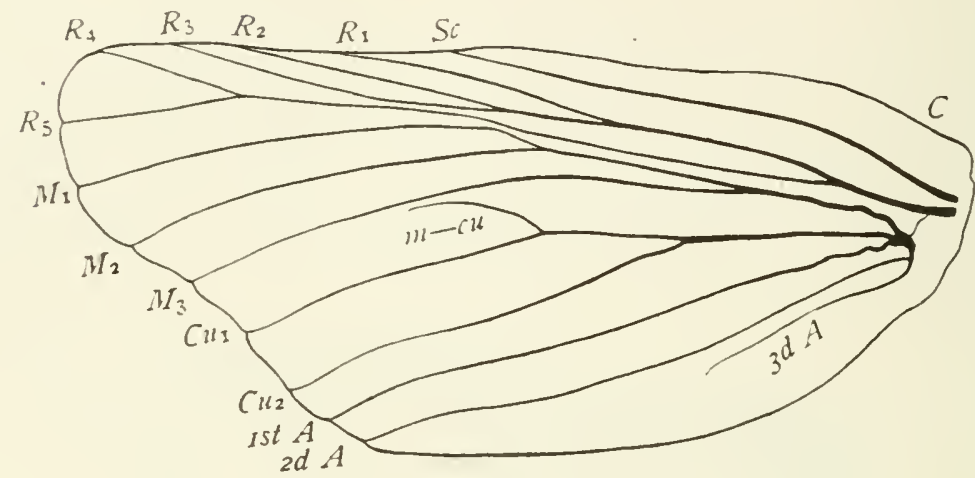

Fig. 344.-Tracheation of a fore wing of Anosia.

coalescence were to continue to the margin of the wing, vein $\mathrm{M}_{1}$ would be lost as completely as is vein $\mathrm{M}_{4}$.

From these facts I conclude that in both fore and hind wings trachea $\mathrm{M}_{4}$ has reached trachea $\mathrm{Cu}_{1}$ and has

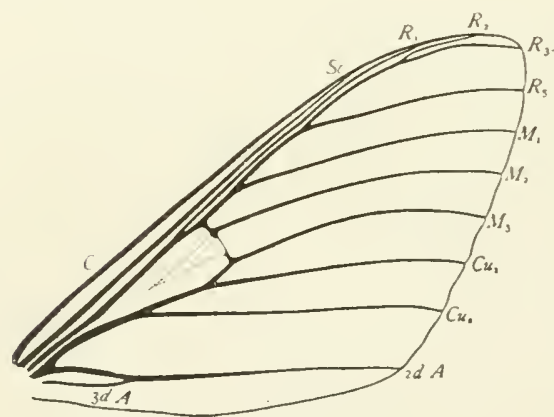
coalesced with it completely. In other words the reduction of media is the result of the coalescence of veins $\mathrm{M}_{4}$ and $\mathrm{Cu}_{1}$; hence the vein that is commonly designated as $\mathrm{Cu}_{1}$ in the Lepidoptera is really vein $\mathrm{M}_{4}+\mathrm{Cu}_{1}$.

In the fore wing of Pieris rape (Fig. 333), the vestige of the secondary connection between the medial and the radial tracheæ has been lost,

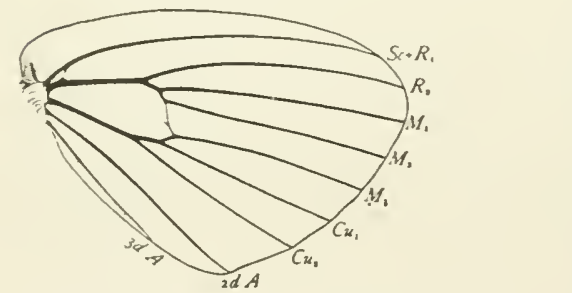
although that between the medial and cubital tracher has been retained. Both of the vestiges are commonly lost; but one or both of them are retained in many lepidopterous pupæ. That between the medial and cubital tracheæ is well-

Fig. 345.-Wings of Citheronia regalis. preserved in the pupa of Anosia for example (Fig. 344).

Although I firmly believe that the vein in lepidopterous wings that is commonly designated as vein $\mathrm{Cu}_{1}$ is really vein $\mathrm{M}_{4}+\mathrm{Cu}_{1}$, for the sake of simplicity, it seems better to designate it ordinarily as vein $\mathrm{Cu}_{1}$. This is in 
accordance with the plan adopted in the discussion of hymenopterous wings, where frequently a compound vein is designated merely by the term indicating its most obvious element, in order to avoid the use of a more cumber-

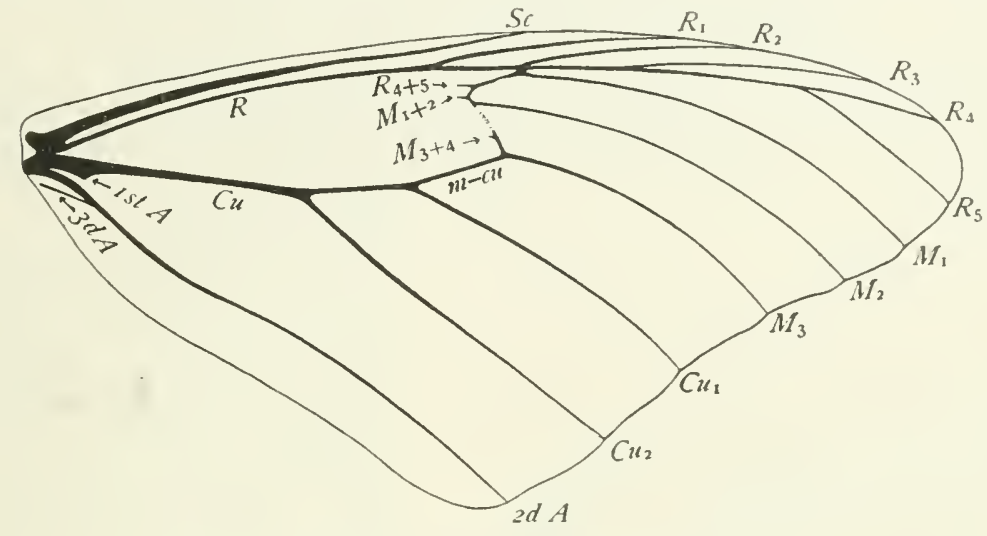

Fig. 346.-Fore wing of Anosia.

some terminology. In this chapter, I have used the complete designation $\mathrm{M}_{4}+\mathrm{Cu}_{1}$ in the few cases where I wish to indicate my conclusion regarding

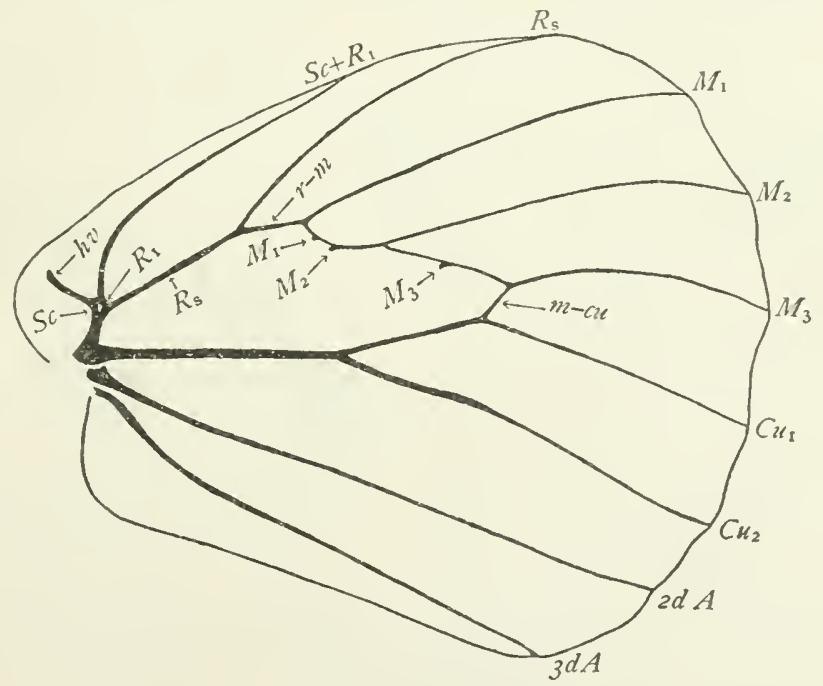

Fig. 347.-Hind wing of Anosia.

the fate of vein $\mathrm{M}_{4}$ in the Lepidoptera; but ordinarily it is designated as vein $\mathrm{Cu}_{1}$.

The atrophy of the main stem of media.-In a few families, as for example in the Cossidæ (Fig. 343) and the Psychidx (Fig. 338) the main 
stem of media is well-preserved; and in some other families as the Megalopygidæ, Eucleidæ, and Pyromorphidæ, it is preserved in some members

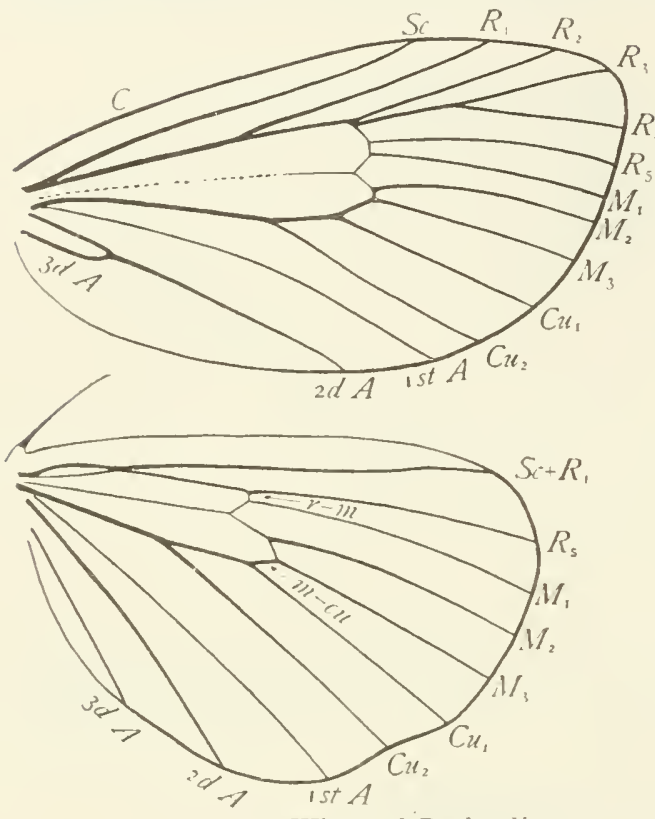

Fig. 348. - ITings of Packardia. of the family and lost in others. The retention of the main stem of media is obviously a character indicating a comparatively generalized condition of those families in which it exists.

In very many cases where the main stem of media is lost no trace of it remains; but frequently the position formerly occupied by it is indicated by a faint line or scar; such a line exists in the fore wing of Citheronia regalis (Fig. 345). Less frequently restiges of the basal part of media remain as short stumps, projecting into cell $\mathrm{R}+\mathrm{M}$, from the outer end of this cell; vestiges of this

lind are present in the wings of Anosia (Fig. 346 and 347).

The transfer of the branches of media to adjacent veins.-Correlated with the atrophy of the base of media is the coalescence of its branches with the adjacent reins. It follows from this that the extent to which this coalescence has gone is an indication of the degree of departure of a form from the primitive type. Compare, for example, the hind wing of Packardia (Fig. 348 ) with the hind wing of Adoneta (Fig. 349), two genera of the family Eucleidæ. In Packardia, where a remnant of the base of media still persists vein $M_{1}$ is merely connected with the radial sector by a cross-rein. But in Adoneta, where the base of media of the hind wing is lost

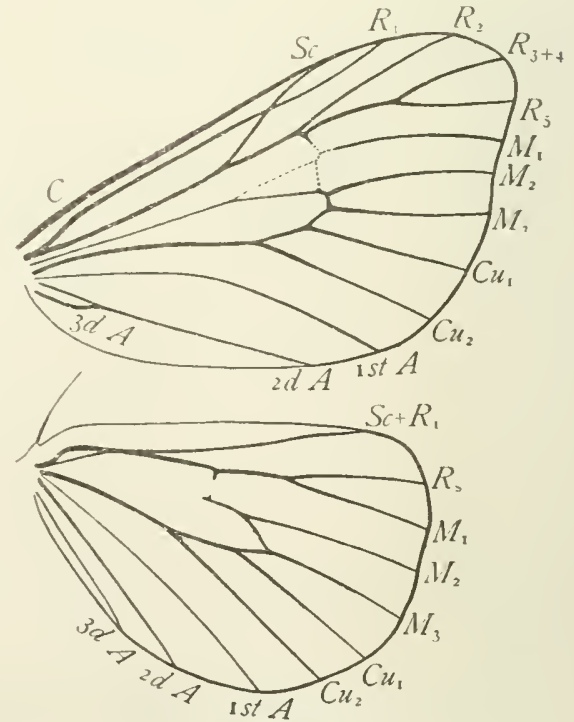

Fig. 349.- Wings of Adoneta. 
vein $\mathrm{M}_{1}$ coalesces with the radial sector for a considerable distance. It is obvious that in this respect, the extent of the coalescence of veins $M_{1}$ and $\mathrm{R}_{\mathrm{s}}$, Adoneta is the more highly specialized of the two genera.

It is an interesting fact that in cases like Anosia (Fig. 346) where the vestiges of the basal part of media are short spurs projecting into the discal cell, the branches of media are often discontinuous with these spurs. It is obvious that the spurs indicate the positions formerly occupied by the branches of vein $\mathrm{M}$ and that they have been left stranded upon the discal vein while the functional parts of the branches to which they correspond have moved into new positions. This is especially marked in the case of vein $M_{3}$ of the fore wing of Anosia.

The union of vein $M_{1}$ with radius and of vein $\mathrm{M}_{3}$ with cubitus after the atrophy of the base of media is what would be expected. But in which direction would one expect the base of vein $\mathrm{M}_{2}$ to migrate? Occupying an intermediate position between radius and cubitus it may go either way. It is like a stream in the middle of a level plain, a trifle may change its course. And thus we find that in some families it migrates towards cubitus making this vein apparently four-branched, while in other families it goes towards radius, leaving cubitus apparently three-branched. The
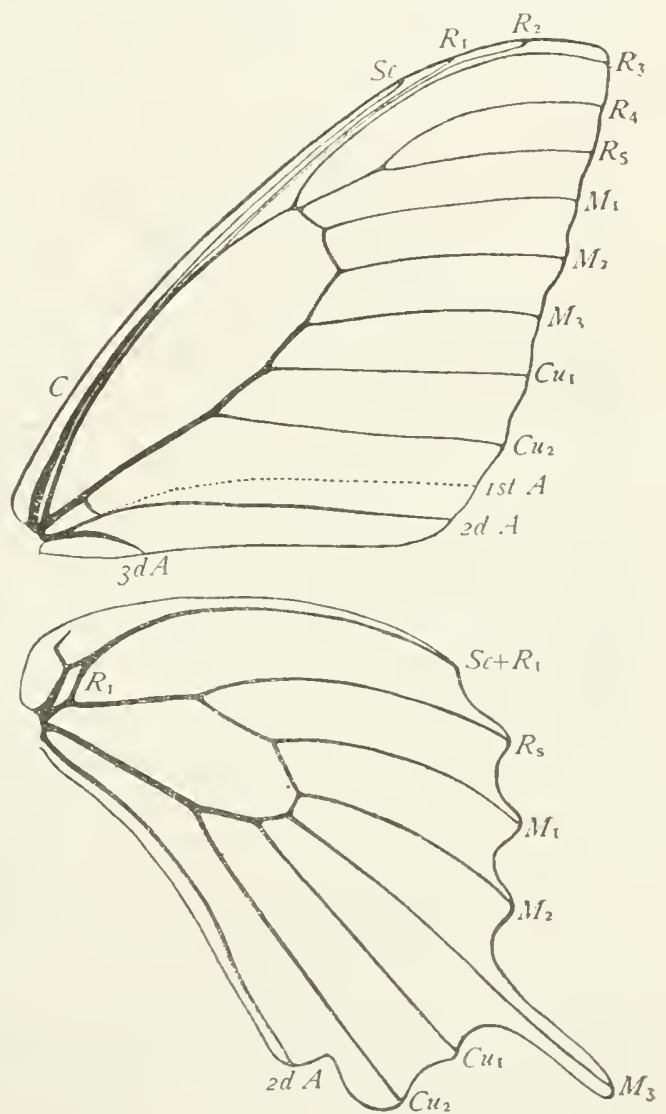

Fig. 350.-Wings of Papilio polyxenes. former condition exists in the Papilionidre (Fig. 350); the latter, in the Pieridæ (Fig. 342).

This difference may be looked upon as a difference in kind of specialization, and is of high value as indicating a dichotomous division of the line of descent. It is obvious that in a family where vein $\mathrm{M}_{2}$ has migrated far towards cubitus and has thus established its chicf source of air supply in that direction, it is not probable that genera will arise in which vein $\mathrm{M}_{2}$ is 
more closely united to radius than to cubitus. To resume the figure, the plain through which the stream is flowing is an elerated plateau; a pebble may determine which of two slopes it shall descend; but when well started down one, it cannot traverse the other.

This character, however, must be used with care. In families where the direction of the migration of the base of vein $\mathrm{N}_{2}$ has been established, as in the Saturniidæ (Fig. 345), and in the Lasiocampidæ (Fig. 35r), it is decisive. One need not hesitate a moment in determining to which of these two families a genus belongs. But there are other families in which the

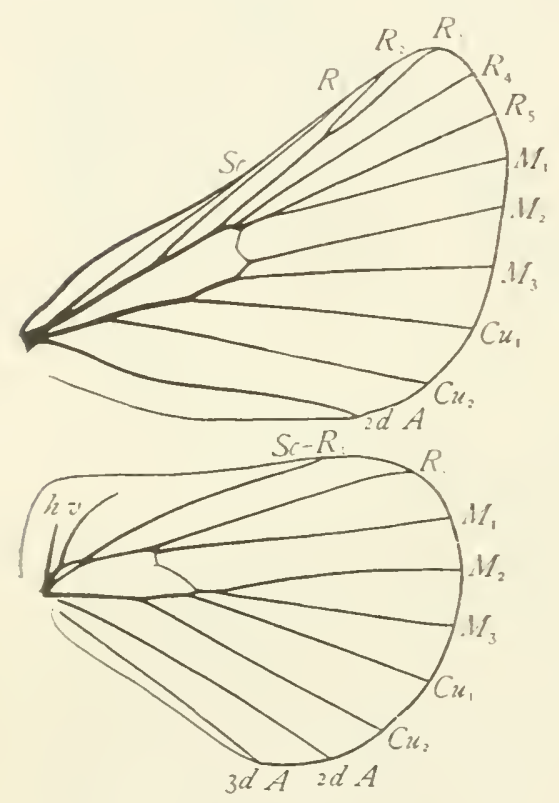

Fig. 351.- Wings of Clisiocampa americana. directions of this migration is not yet fixed; and here the character is of subordinate value.

The first anal vein and the anal furrow. - In the Frenatæ the first anal vein, when it is present, traverses the cubito-anal sulcus and extends along the bottom of the cubito-anal fold to the margin of the wing.

In those Frenatæ in which the first anal vein is atrophied a vestige of it remains as a distinct anal furrow. An intermediate condition exists in the rings of Bombyx mori (Fig. 3.0) in which the terminal part of the first anal rein is retained; the anal furrow is indicated in the figure by a dotted line.

The reduction of the anal area.Another method of specialization that occurs to a greater or less extent in most of the families of the Frenatæ is a reduction in the number of anal veins. In some of the more generalized Frenatæ the three anal veins are preserved in both pairs of wings; but in the far greater number of families a reduction in the number of these reins has occurred in one or both pairs of wings.

As a rule the first anal rein is the first to be lost, and this loss takes place by atrophy. Frequently a restige of this rein persists as a narrow channel. This is the anal furrow of this suborder, and when distinct is represented in the figures by a dotted line.

The second anal rein is the most persistent of the three anal reins. It is frequently retained when no restige of either of the others remains.

The second anal rein frequently appears to be forked at the base. This is due to its coalescence with the third anal vein, or with the first branch of 
the third anal vein when this vein is two-branched. The distal parts of the two reins coalesce, while the basal parts remain separate; and thus is formed a single vein which is forked at the base.

The wings of Cacecia (Fig. 353), illustrate several of the eonditions described above. In the fore wing, the first anal vein is represented by the anal furrow, except at the tip where a short vestige of it remains; in the hind wing this rein is well-preserved. In both wings, the second anal vein is forked at the base. In the fore wing the third anal vein is represented only by the hind branch of this fork; while in the hind wing both branches of the two-branched third anal vein persist; the first branch being joined to the second anal vein and the second branch extending free to the margin of the wing. In a case of this kind, the identity of the first branch of the third anal vein is not obrious; but studies of the tracheation of the wings of pupæ show clearly that the apparent forking at the base of the second anal vein is due to the coalescence of this vein with the first branch of the third anal rein. This is shown in the figure of the fore wing of a pupa of Pieris (Fig. 333).

While the extent to which the reduction of the anal area has proceeded may merely indicate the degree of divergence from the primitive type, a wing having two anal reins being more specialized than one having three and less specialized than a wing having a single anal rein, a comparison of the extent of the reduction in the two pairs of wings in different insects may show a difference in kind of specialization indicating a dichotomous division of a line of descent.

As an illustration of an application of this principle the separation of the families Papilionidæ and Pieridx, which were formerly classed together as a single family, may be cited. In the fore wings of the Papilionidæ (Fig. 350) all three of the anal veins are at least partly preserved, while in the hind wings there is only a single anal vein. On the other hand in the Pierida (Fig. 342) the anal area of the fore wings is more reduced than the anal area of the hind wings, the former having a single anal vein, the latter two. From this it follows that in the Papilionidæ the reduction of the anal area of the hind wings preceded the reduction of the anal area of the fore wings; while in the Pieridre the reverse was the case. It is evident therefore that at the time the separation of these two families occurred there had been no reduction of the anal areas of either pair of wings.

The difference in the direction of the migration of the base of vein $M_{2}$ in these two families, already indicated, confirms the conclusion that their separation occurred very early in the history of that division of the Frenatx represented by the butterflies. At the time when it occurred there had been no reduction of the anal areas, and vein $M_{2}$ had not begun its migration towards either radius or cubitus. This is as generalized a condition of wing structure as exists in any of the living Frenatx. 
The anastomosis of veins.--In many genera of this order the branches of radius of the fore wings anastomose so as to form one or more closed cells; these have been termed the accessory cells.

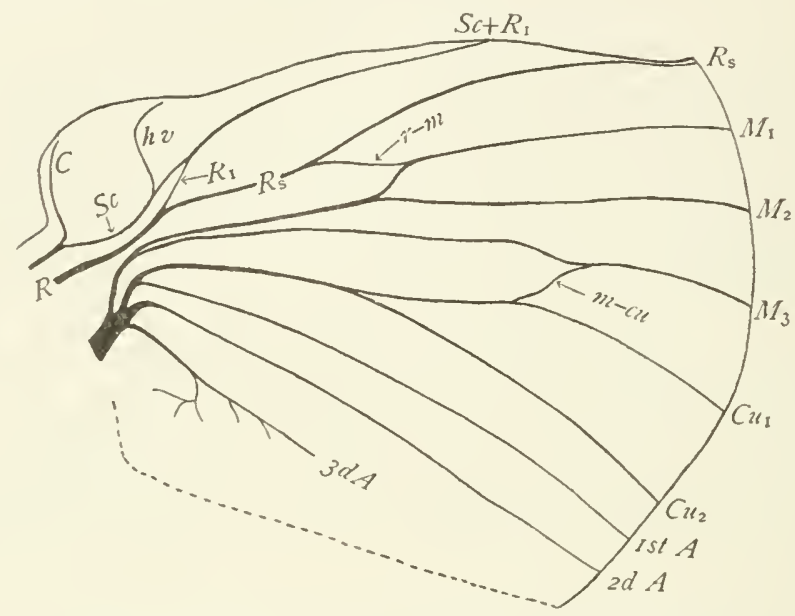

Fig. 352.-Base of a hind wing of a pupa of Anosia.

By an application of the uniform terminology, the homology of the accessory cells can be indicated. Thus in Prionoxystus (Fig. 343), where
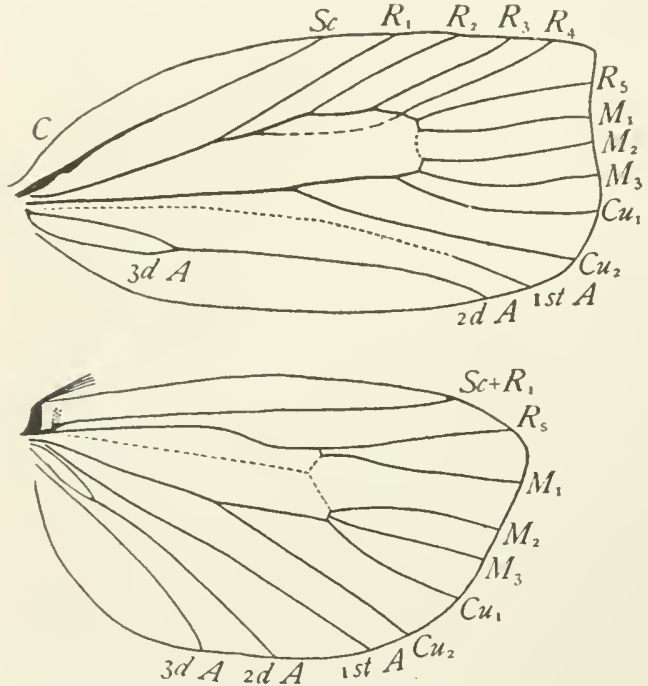

Fig. 353.-Wings of Cacacia cerasivorana. veins $R_{3}$ and $R_{4}+5$ anastomose, cell $R_{3}$ is divided into two parts, and the accessory cell is evidently ist cell $\mathrm{R}_{3}$.

The costa of the hind wings.--Except at the base of the wing in certain members of this order, the costal margin of the hind wings is not thickened appreciably; it may be said, therefore, that the costal vein is either very greatly reduced in length or is lost entirely in the hind wings of the Lepidoptera. In the hind wings of some pupæ, as that of the monarch butterfly, for example, there is a distinct costal trachea (Fig. 352); but in the hind wing of the adult of this species there is no indication of a costal vein. 
In some members of this order, the extreme base of vein $\mathrm{C}$, that part that I have termed the costal sclerite, is well-developed in the hind wings as well as in the fore wings. This sclerite is represented, but not lettered, in the figure of the wings of Prionoxystus (Fig. 343); it is also prominent in the hind wing of Cacccia (Fig. 353). When well-developed in hind wings it serves as a support of the frenulum if a frenulum is present. The costal sclerite is very prominent in the hind wings of Castnia.

The humeral veins. - In some members of the Frenatæ in which the frenulum has been supplanted by a broadly expanded humeral angle of the hind wing, this part of the wing is stiffened by one or more accessory veins; these are termed the lnmeral veins.

Humeral veins are present in the Lasiocampidæe (Fig. $35 \mathrm{I}$ ); in this family they vary in number. In the butterflies there is commonly a single humeral vein in each hind wing; this vein is represented in Figures 342 , 347, and 350. The trachea that preceded it is shown in Figure 352. In butterflies the humeral vein is often forked.

It has been suggested that the single humeral vein of the hind wings of butterflies is vein $\mathrm{Sc}_{1}$; but this does not seem to me to be at all probable. The humeral veins of the Lasiocampidæ are obviously accessory veins. The fact that there are frequently several of them, the number varying in closely allied genera, and their evident function as a support of the secondarily developed expansion of the humeral angle of the wing clearly indicate that they are secondarily developed veins.

In the butterfies the conditions are similar to those found in the Lasiocampidæ. The frenulum has been supplanted by a broadly expanded humeral angle of the wing, and this area is stiffened by a vein; the striking difference is that in the butterflies there is a single humeral vein while in the lasiocampids the number of these veins is variable.

In no member of the Frenatæ known to me is the primitive forking of the subcosta preserved in the fore wings; even in the most generalized moths, as the Cossidæ, the subcosta of the fore wings is simple. It does not seem at all probable that this primitive feature, which is lost in the fore wings, should be preserved in the hind wings, in which there is a marked reduction of the subcosto-radial areas. It is more probable that correlated with the expanding of the humeral angle of the hind wing an accessory vein has been developed to stiffen this part of the wing.

The splitting of the radial sector in butterflies. - A remarkable specialization of the radial sector of the fore wings that appears to the distinctively characteristic of the Rhopalocera was pointed out by Headlee ('o7). This specialization consists of a splitting of the radial sector which results in vein $\mathrm{R}_{4}+_{5}$ arising from the main stem of the radius near the base of the wing.

Owing to the total or nearly complete atrophy of the base of vein $R_{4+5}$ in wings of adults, this splitting back of it is not obvious if only mature 
wings be examined. But it is clearly indicated by the tracheation of the wings of pupæ; and after one has learned what has taken place by a study of pupal wings, it is easy to find restiges of the lost part of vein $R_{4}+5$ in the wings of adults.

The wings of Anosia plexippus illustrate well these facts. Figure 354 is a reproduction of a photograph of a wing of a pupa of this species, and

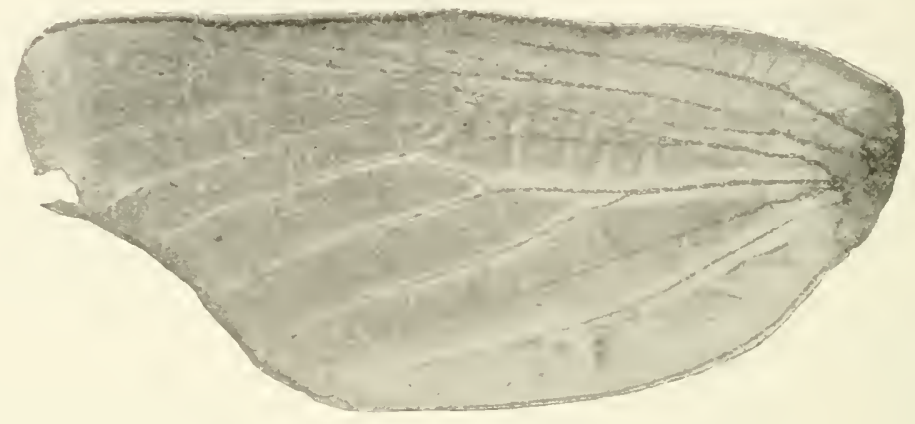

Fig. 35+-Fore wing of a pupa of Anosia plexippus.

Figure 355 illustrates the tracheation of this wing. In this wing, trachea $\mathrm{R}_{4+5}$ separates from the radial trachea near the base of the wing. Figure 346 represents the adult $\pi$ ing of the same species. In this wing a vestige of rein $R_{4}+5$ is to be seen near the end of the discal cell.

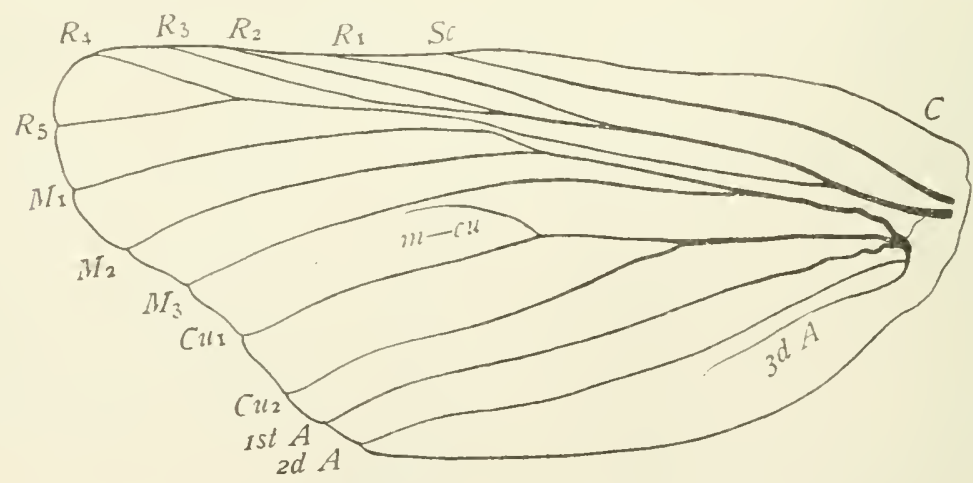

Fig. 355.-Tracheation of the wing represented in Figure 354 .

An extended examination of the wings of Lepidoptera made by Headlee led to the conclusion that this splitting back of vein $R_{4}+5$ has taken place throughout the Rhopalocera, and has not occurred in the Heterocera. 
(g) Comparison of terminologies of the Wing-Veins of the LEPIDOPTERA

I. PRINCIPAL VEINS

\begin{tabular}{|c|c|c|c|c|c|}
\hline British & German & Redtenbacl & & Spuler & Comstock \& \\
\hline & & Costa, & I & & Costa, C \\
\hline Costal & Costale & Subcosta, & II & I & Subcosta, Sc \\
\hline Subcostal & Subcostale & Radius, & III & II & Radius, R \\
\hline & & Media, & V & III & Media, M \\
\hline Median & Mediana & Cubitus, & VII & IV & Cubitus, $\mathrm{Cu}$ \\
\hline & & & VIII & $\mathrm{V}$ & Ist Anal, ist A \\
\hline nternal & Submediana & & IX & $\alpha$ & 2d Anal, 2d A \\
\hline & Interandsader & & $\mathrm{XI}$ & 6 & 3d Anal, 3d A \\
\hline
\end{tabular}

The system chiefly used by British naturalists, excepting those who have adopted the Comstock-Needham system, is based on that used by Herrich-Schäffer in his "Systematische Bearbeitung der Schmetterlinge von Europa" ( $8_{43}-{ }_{1} 8_{5} 6$ ).

The German system given here is that adopted by Staudinger and Schatz in their "Exotische Schmetterlinge" (1892).

It should be noted that the costal and subcostal reins of the writers on the Lepidoptera who have not adopted the uniform terminology correspond to the subcosta and radius, respectively, of that system.

II. VEINS THAT EXTEND TO THE MARGIN OF THE WINGS

\begin{tabular}{|c|c|c|c|c|c|}
\hline British & Germant & $\begin{array}{l}\text { Redtenbacher } \\
\text { I }\end{array}$ & Spriler & $\begin{array}{l}\text { Comstock } \mathcal{O} \\
\text { Costa }\end{array}$ & $\begin{array}{l}\text { Needham } \\
\text { C }\end{array}$ \\
\hline I 2 & C & II & I & Subcosta & $\mathrm{Sc}$ \\
\hline I I & $\mathrm{SC}_{1}$ & $\mathrm{III}_{1}$ & $\mathrm{II}_{1}$ & Radius-one & $\mathrm{R}_{1}$ \\
\hline IO & $\mathrm{SC}_{2}$ & $\mathrm{III}_{2}$ & $\mathrm{II}_{2}$ & Radius-two & $\mathrm{R}_{2}$ \\
\hline 9 & $\mathrm{SC}_{3}$ & $\mathrm{III}_{3}$ & $\mathrm{II}_{3}$ & Radius-three & $\mathrm{R}_{3}$ \\
\hline 8 & $\mathrm{SC}_{4}$ & $\mathrm{III}_{4}$ & $\mathrm{II}_{4}$ & Radins-four & $\mathrm{R}_{4}$ \\
\hline 7 & $\mathrm{SC}_{3}$ & $\mathrm{III}_{5}$ & $\mathrm{II}_{5}$ & Radius-five & $\mathrm{R}_{3}$ \\
\hline 6 & OR & $V_{1}$ & $\mathrm{III}_{1}$ & Media-one & $\mathrm{M}_{1}$ \\
\hline 5 & UR & $\mathrm{V}_{2}$ & $\mathrm{III}_{2}$ & Media-two & $\mathrm{M}_{2}$ \\
\hline 4 & $\mathrm{M}_{3}$ & $V I I_{1}$ & $\mathrm{III}_{3}$ & Media-three & $\mathrm{M}_{3}$ \\
\hline 3 & $\mathrm{M}_{2}$ & $\mathrm{VII}_{2}$ & $\mathrm{IV} \mathrm{V}_{1}$ & Cubitus-one & $\mathrm{Cu}_{1}$ \\
\hline 2 & $M_{1}$ & $\mathrm{VII}_{3}$ & $\mathrm{IV}_{2}$ & Cubitus-two & $\mathrm{Cu}_{2}$ \\
\hline IC & & VIII & V & Ist Anal & Ist A \\
\hline Ib & $\mathrm{SM}$ & $\mathrm{IX}$ & $\alpha$ & 2d Anal & $2 \mathrm{dA}$ \\
\hline Ia & IA & XI & 6 & 3d Anal & $3 \mathrm{~d} A$ \\
\hline
\end{tabular}


The significance of the abbreriations given in the column indicating the German system are as follows: C, Costale; SC, subcostale; OR, Oberer Radiale; UR, Unter Radiale; M, Mediana; SM, Submediana; IA, Innerandsader.

In the hind wings vein $S C+R_{1}$ of the uniform terminology is vein 8 of the British system and rein $C$ of the German; vein $R_{s}$ is vein 7 of the British system and rein $\mathrm{SC}$ of the German. The other veins are designated as indicated in the abore table, which refers to the fore wings.

As is shown on an earlier page, vein $\mathrm{Cu}_{1}$ of the Comstock-Needham system is in reality rein $\mathrm{M}_{4}+\mathrm{Cu}_{1}$.

The accompanying figures, copied from Sharp ('99), will serve to illustrate the British and the German systems of terminology of the wing-veins. Fig. 356, I, is after Hampson, and illustrates the British system. Fig. $35^{6}$, II, is after Staudinger and Schatz, and illustrates the German system.
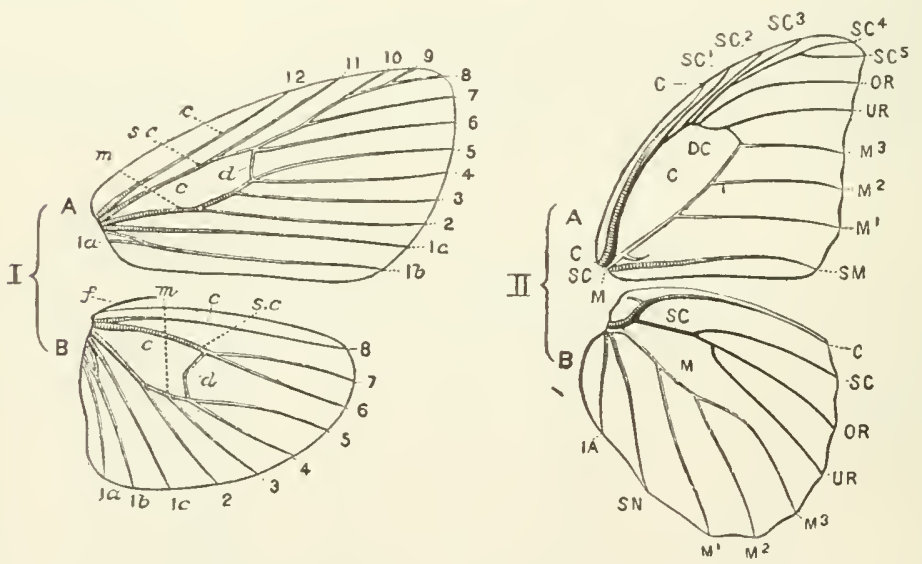

Fig. 356.-Figures illustrating the British (I) and the German (II) systems of terminology of the wing-veins of the Lepidoptera. 


\section{CHAPTER XXIV}

\section{THE WINGS OF THE DIPTERA}

\section{(a) the More General features of the Wings of the Diptera}

THE most distinctive feature of the wings of the Diptera is the fact that only the first pair are developed as organs of flight; the second pair being greatly reduced in size. The second pair of wings are known as the halteres, they are thread-like, enlarged at the end, and are probably organs

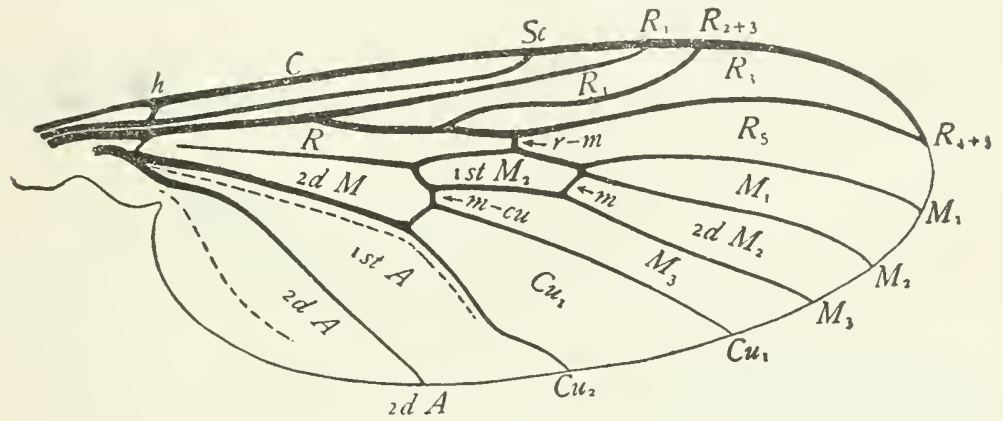

Fig. 357.-Wing of Rhyphus.

of special sense. They are present in nearly all members of the order, even when the front wings are wanting.

The fore wings are thin, membranous, and usually either naked or clothed with microscopic setæ; but with mosquitoes the wings bear a fringe of scale-like setæ on the margin and usually also on each of the wingveins, and in the moth-like flies (Psychodidx) and in some others the clothing of setæ is very conspicuous.

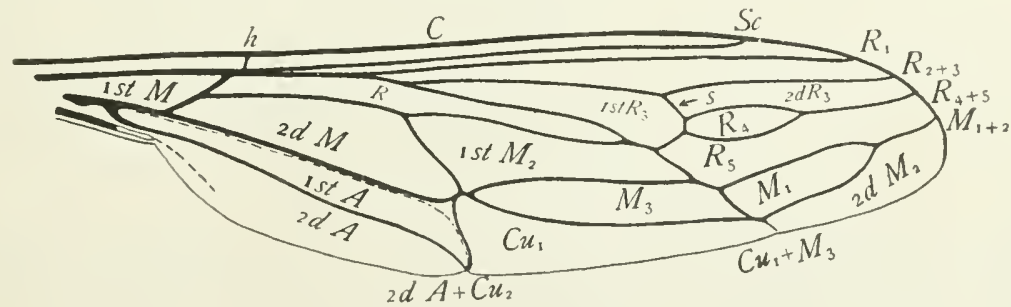

Fig. 358.-Wing of Rhynchocephalus.

In the more generalized members of the order, the wing-venation is simple, the only departures from the hypothetical primitive type being the result of a reduction in the number of veins by the coalescence of adjacent veins; this is well-shown by the wings of Rhyphus (Fig. 357). Neither 
accessory nor intercalary veins are ever developed, and only the principal cross-reins are present. In more specialized forms the typical arrangement of the reins has been greatly modified by the approaching and coalescing of the tips of adjacent reins. Remarkable instances of this occur in the Nemistrinidæ (Fig. 358).

\section{(b) The methods of specialization of the Wings of the diptera}

In the discussion of the methods of specialization of the wings of the Diptera reference will be made only to the specialization of the fore wings, as a discussion of the structure of the halters does not fall within the scope of this work.

Ordinal specializations.-In all Diptera the venation of the wings is more or less reduced, in none has there been a specialization by addition.

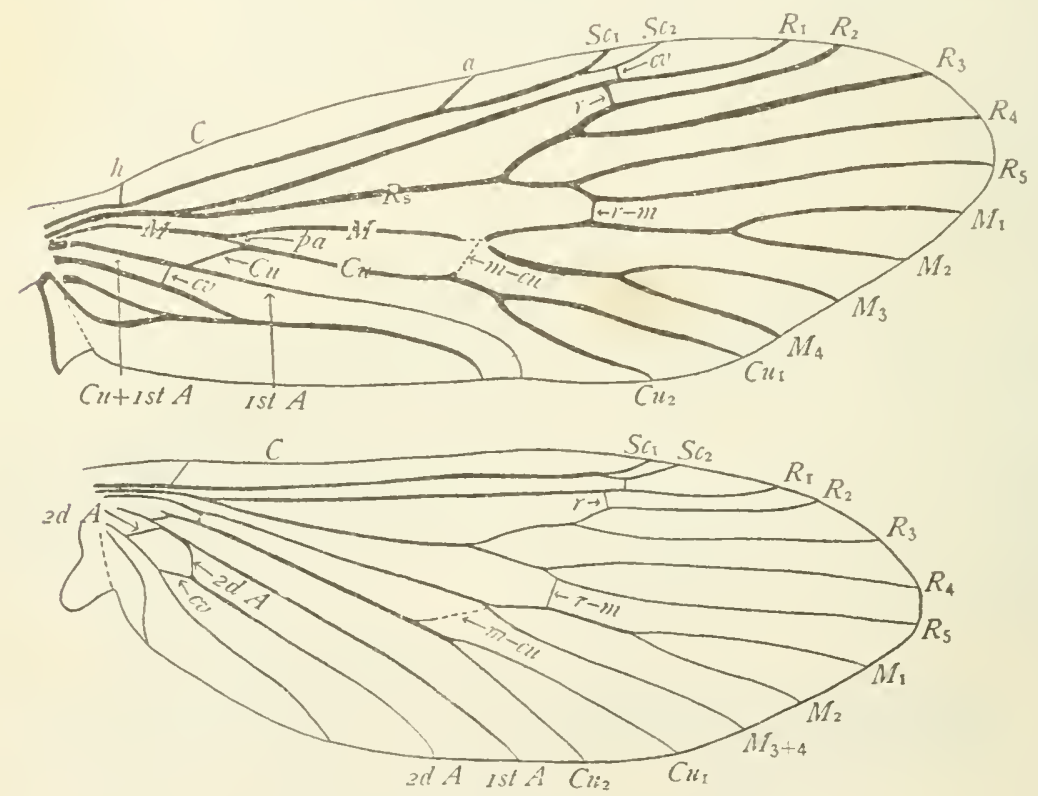

Fig. 359. - ITings of a caddice-fly.

Even in the most generalized forms, with the possible exception of Protoplasa, media is only three-branched; and the anal area is always more or less reduced, that is, in none are there three well-developed anal veins.

The loss of vein $M_{4}$.-A study of the method of branching of media in the more generalized forms, as, for example, in Rhyphus (Fig. 357), shows that veins $M_{1}$ and $M_{2}$ are preserved distinct, and that the third branch of this vein is either vein $M_{3}$, in which case veins $M_{4}$ and $C u_{1}$ have coalesced; or vein $M_{3+4}$, veins $M_{3}$ and $M_{4}$ having coalesced. 
The truth of the conclusion that in Rhyphus veins $\mathrm{M}_{1}$ and $\mathrm{M}_{2}$ are distinct is made evident by a comparison of the wing of this insect with the fore wing of a caddice fly (Fig. 359), in which media is not reduced. In this comparison, the position of the medial cross-vein should be noted. It will be seen that this cross-vein divides cell $\mathrm{M}_{2}$; and consequently the two branches of media in front of the cell divided by this cross-vein are veins $\mathrm{M}_{1}$ and $\mathrm{M}_{2}$.

Owing to the fact that in the Diptera a great reduction of wing tracheæ has taken place, it is not possible to determine by a study of the tracheation of the wings of pupæ whether vein $M_{4}$ has coalesced with vein $M_{3}$ or with

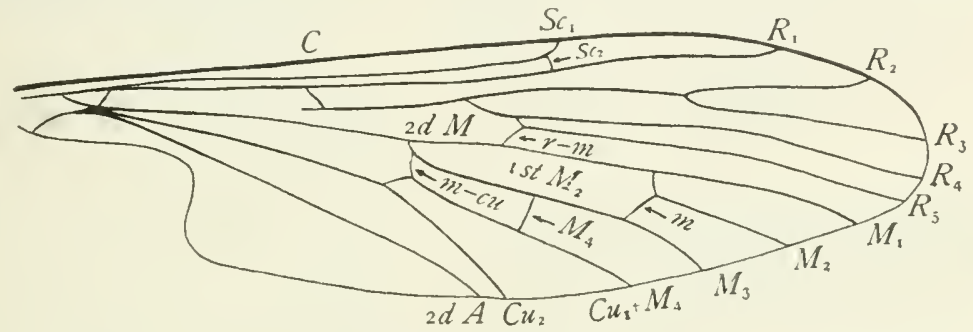

Fig. 360.- Ting of Protoplasa fitchii.

vein $\mathrm{Cu}_{1}$; our conclusions, therefore, must be based on a study of wings of adults.

Among the dipterous wirgs that are ccmparatively little modified are those of Rliyphus. An examination of a wing of this insect (Fig. 357) would lead one to believe that the three-branched condition of the media is due to a coalescence of veins $M_{3}$ and $M_{1}$ and that consequently the vein labeled $\mathrm{M}_{3}$ is really $\mathrm{M}_{3}+4$.

That the reduction of media may have been attained in another way is indicated by a study of the wings of Protoplasa fitcliii (Fig. 360). This species is one of the most generalized members of the order Diptera; this is shown by the fact that the subcosta is two-branched and that all of the branches of the radius are retained distinct. The suggestive feature indicating that vein $\mathrm{M}_{4}$ may have coalesced with vein $\mathrm{Cu}_{1}$ is the presence of a vein extending from near the middle of the length of vein $\mathrm{M}_{3}$ to vein $\mathrm{C} 1_{1}$.

This vein has the appearance of a cross-vein; but it is quite possible that it is a section of vein $\mathrm{M}_{4}$, the more distal part of this vein having coalesced with vein $\mathrm{Cu}_{1}$. Such a coalescence would be quite in accord with what commonly takes place in this order. There are many instances where the distal part of a rein has coalesced with an adjacent vein, the coalescence beginning at the margin of the wing and proceding towards the base of the wing; with the result that the frce part of the vein is pulled out of its earlier position and comes to occupy one transierse to the length of the wing; illustrations of this are given later. If this is what has taken 
place here, the third branch of media is vein $M_{3}$ and the vein behind it is rein $\mathrm{Cu}_{1}+\mathrm{M}_{4}$. This, as shown in the preceding chapter, is probably the method of reduction of media that has taken place in the suborder Frenatæ of the Lepidoptera; but there the coalescence of the two veins proceded outward.

The figure of a wing of Protoplasa (Fig. 360) is labeled in accordance with this theory. But until more eridence as to the fate of vein $\mathrm{M}_{4}$ is
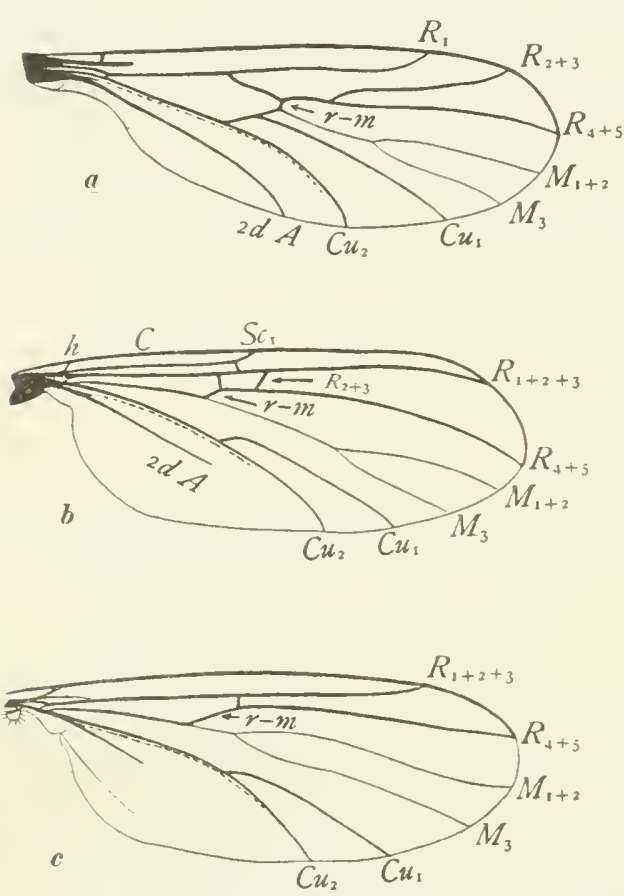

Fig. 361.- WTings of fungus gnats. obtained it seems best to omit any reference to this rein in the designation of the veins of the Diptera.

\section{Specializations within the} order.- Thile a partial reduction of the anal area and the loss of rein $\mathrm{M}_{4}$ as a distinct rein are characteristic of recent Diptera as a whole, the greater number of specializations exhibited by the rings of Diptera have arisen within the order and have been carried to widely different degrees in different members of the order. The most practicable way of discussing these specializations is to treat of the modifications of each of the principal reins separately.

The costa.-The costa is marginal. I have no data to give regarding modifications of its extent.

The subcosta.-The primitive, two-branched condition of the subcosta is preserved in a very few forms; one of these is Protoplasa (Fig. 360). In most members of the order it is not branched. In some cases the tip of the simple subcosta ends in the margin of the wing, indicating that rein $\mathrm{Sc}_{2}$ is lost; In other cases the tip coalesces with rein $R_{1}$, indicating that vein $\mathrm{Sc}_{1}$ is lost. Frequently the subcosta is greatly shortened.

Three widely different conditions of the subcosta exist in the three wings of fungus-gnats represented in Figure $36 \mathrm{I}$; in the first it is greatly shortened, in the second it is two-branched, and in the third it coalesces with radius for the greater part of its length.

The radius.- In a few genera of flies the radius retains its primitive, five-branched condition; the genus Protoplasa of the Tipulidæe has already 
been cited as an illustration of this; and in the Psychodidæ (Fig. 362) all of the branches of radius remain distinct.

But usually the number of the branches of this vein is reduced by a coalescence of some of the branches of the radial sector. Thus in many families the radial sector is three-branched, in others it is only two-branched

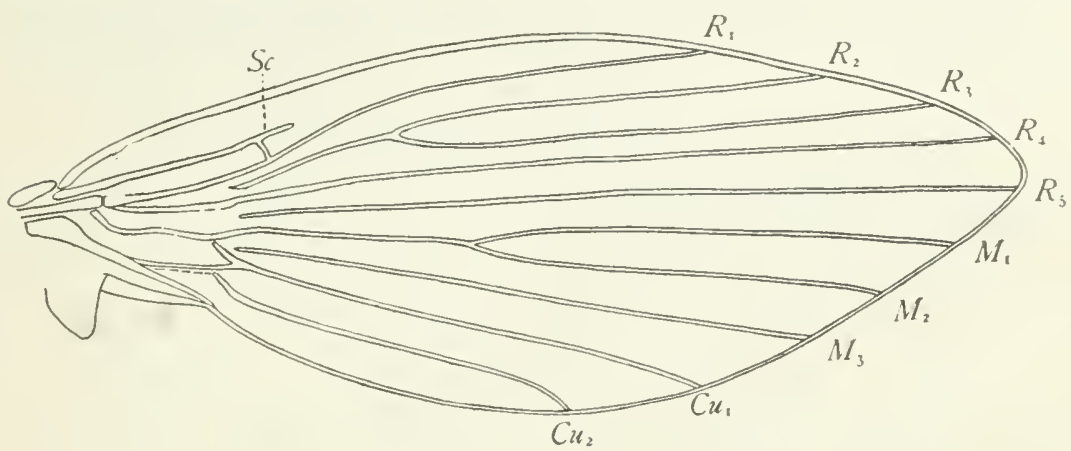

Fig. 362.-Wing of a moth-like fly.

and in the gall gnats (Cecidomyiidæ) it is reduced to a simple, unbranched condition (Fig. 363).

As this variation in the number of the branches of this vein is due to a greater or less degree of coalescence among them, it is evident that here is a character of considerable taxonomic importance serving as it does to indicate degrees of divergence from the primitive type.

Not only do we find differences in degree of reduction of this vein, but differences in the method of reduction are also shown. If the wings of

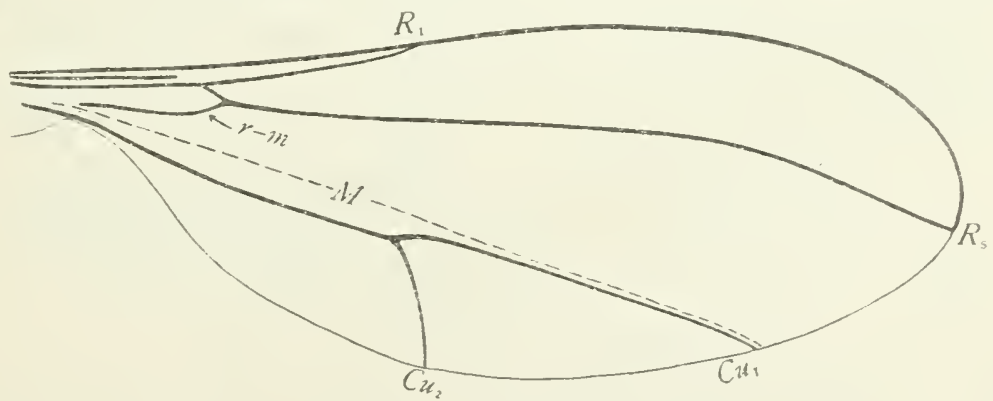

Fig. 363.-Wing of a gall-gnat.

Leptis (Fig. 364) and of Dixa (Fig. 365) be compared it will be seen that although in each the radial sector is only three-branched, the reduetion has been brought about in a different way in the two genera. In Leptis reins $\mathrm{R}_{2}$ and $\mathrm{R}_{3}$ have coalesced; while in Dixa it is reins $\mathrm{R}_{4}$ and $\mathrm{R}_{5}$ that have grown together. This is a difference in kind of specialization. which 
indicates that the two forms belong to different lines of descent. The common progenitor of these two genera had a four-branched radial sector; in some of the descendants of this primitive form one method of reduction has taken place, while in other descendants another method has been followed.

That this differentiation took place comparatively early in the history of the order is shown by the fact that in all Nematocera that have a three-

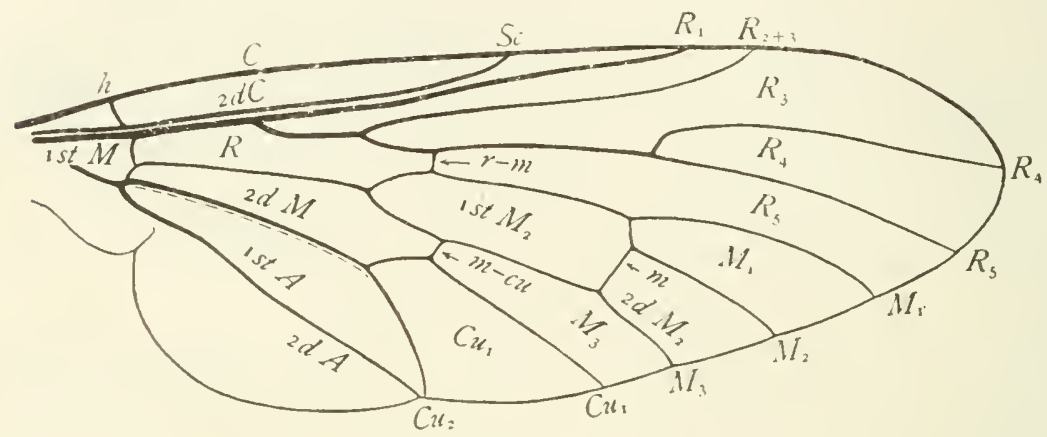

Fig. 364.-Wing of Leptis.

branched radial sector veins $R_{2}$ and $R_{3}$ remain distinct; while in those Brachycera that have a three-branched radial sector veins $R_{4}$ and $R_{5}$ are separate.

It is evident that as a rule any reduction in the number of the branches of radius is the result of a coalescence that has proceded outward, the

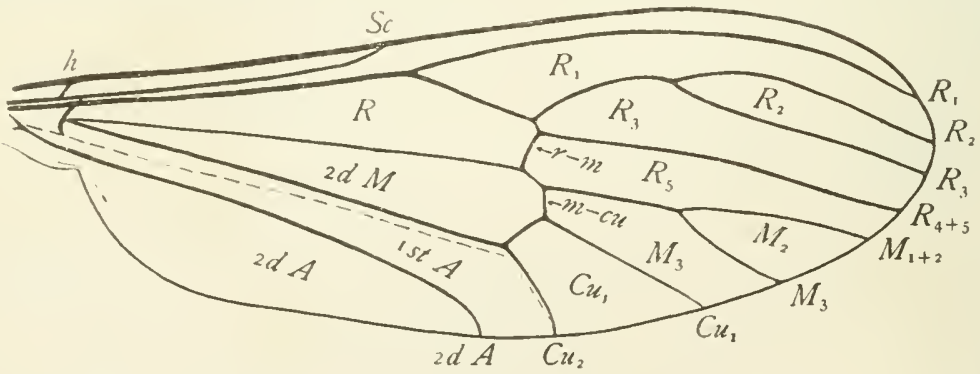

Fig. 365.-Wing of Dixa.

method of reduction being the same as that which commonly takes place in the Lepidoptera. But this is not always the case. In some of the fungusgnats, for example, there is shown the result of a coalescence that began at the margin of the rring and proceded inward. This is illustrated by the wings represented in Figure 36I. In the wing shown at $a$ in this figure, vein $R_{2}+3$ occupies the usual position of this vein; but in the wing shown at $b$ it coalesces with rein $R_{1}$, and it is evident that the coalescence began 
at the margin of the wing. The result of this coalescence is the reduction of cell $R_{1}$ to a small quadrilateral area; in the wing shown at $c$, the coalescence of veins $R_{1}$ and $R_{2}+3$ is complete and cell $R_{1}$ is obliterated.

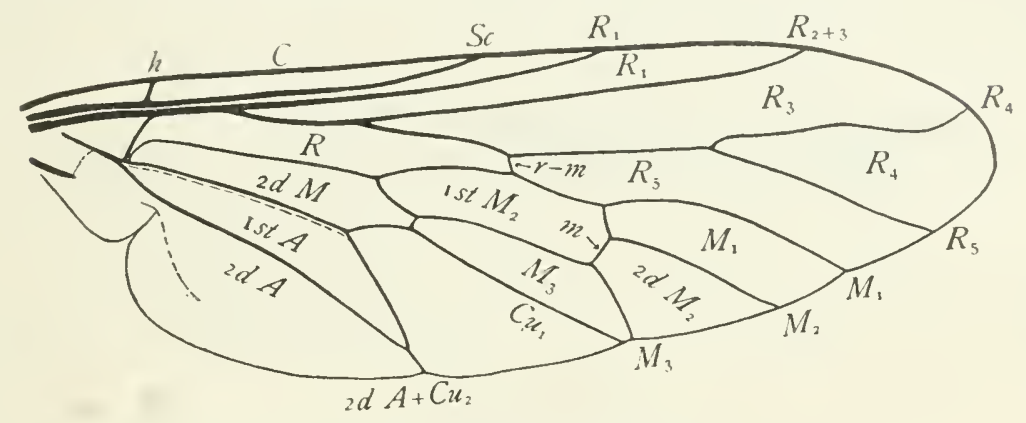

Fig. 366.-Wing of Thereva.

The media.-A comparatively generalized condition of media exists in the wings of Rhyphus (Fig. 357 ), which differs from the hypothetical primitive type only in the fact that vein $\mathrm{M}_{4}$ has coalesced either with vein $\mathrm{M}_{3}$ or with vein $\mathrm{Cu}_{1}$.

The three-branched condition of media is preserved in many families of this order and is illustrated by several of the figures given later.

In the reduction of media in this order each of the different methods known has taken place. In Dixa (Fig. 365) and in the fungus gnats represented in Figure ${ }_{3} 6 \mathrm{r}$, veins $\mathrm{M}_{1}$ and $\mathrm{M}_{2}$ have coalesced. It is probable that this coalescence proceded outward. In Rhynchocephalus (Fig. 358), veins $M_{1}$ and $M_{2}$ coalesce at the margin of the wing and the coalescence is proceding inward. In the gall-gnat represented by Figure $36_{3}$, only a slight vestige of media remains; here the last stage of the reduction was doubtless due to atrophy. And in the insects discussed in the following

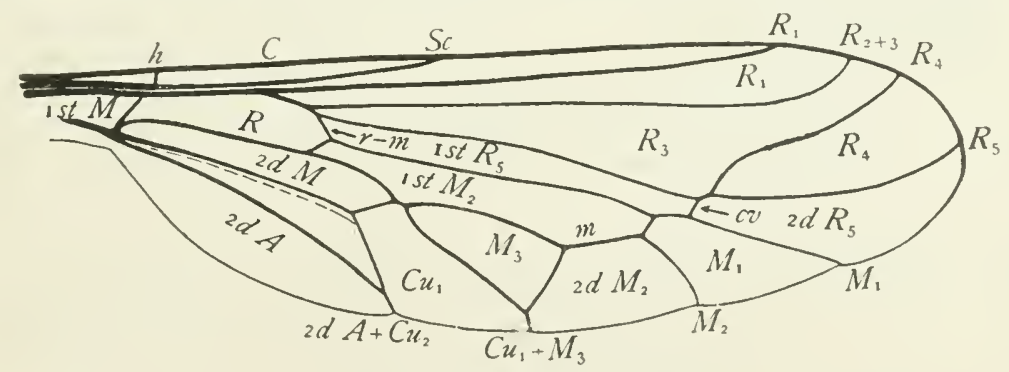

Fig. 367.-Wing of Eulonchus.

section of this chapter media is reduced by coalescence with an adjacent vein.

The coalescence of reins $M_{3}$ and $C u_{1}$.- One of the most striking of the modifications of the wings of Diptera is the coalescence in certain forms of 
rein $\mathrm{M}_{3}$ and $\mathrm{Cu}_{1}$. The result of this coalescence where it is carried to its extreme limit is the production of a type of wing in which the homologies of the veins concerned is so obscured that they were not understood until the method of study used here was employed. But by beginning with a

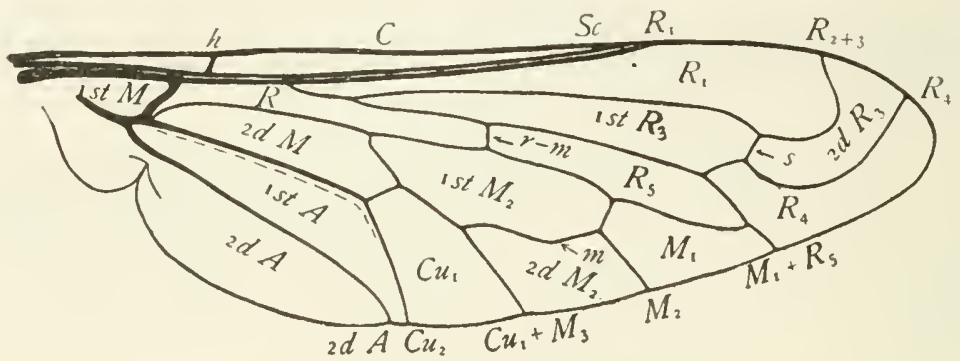

Fig. 368.-Wing of Pantarbes.

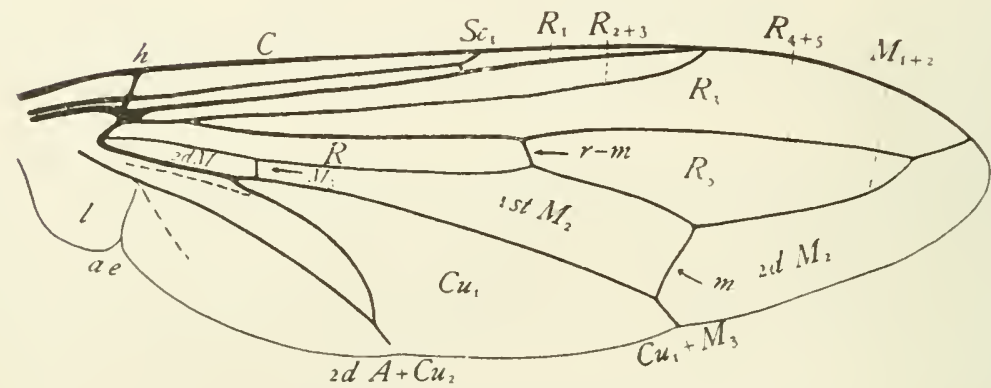

Fig. 369.-Wing of Conops.

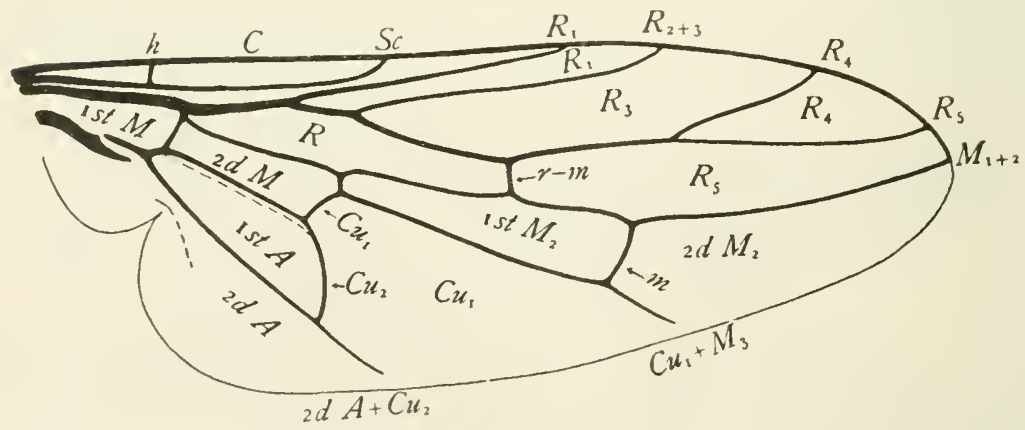

Fig. 370.-Wing of Scenopinus.

generalized form in which the homologies of the wing-veins are easily understood and by selecting a series of forms illustrating varying degrees of modification of this form an understanding of the most specialized form is attained. 
In Rhyphus (Fig. 357 ) veins $\mathrm{M}_{3}$ and $\mathrm{Cu}_{1}$ retain their primitive position, extending nearly parallel and ending remote from each other at the margin of the wing. (For reasons given in an earlier paragraph no account is taken of vein $\mathrm{M}_{4}$ in this discussion). In Thereva (Fig. 366) an approximation of the ends of these veins has taken place, which results in a narrowing of the outer end of cell $\mathrm{M}_{3}$. In Eulonchus (Fig. $36_{7}$ ) the tips of the two veins coalesce, and cell $\mathrm{M}_{3}$ is thus closed. In Pantarbes (Fig. 368) the two veins coalesce for the greater part of their length, and cell $\mathrm{M}_{3}$ is completely obliterated.

The coalescence of veins $C \imath_{2}$ and the second anal vein.-Quite closely correlated with the coalescence of veins $\mathrm{M}_{3}$ and $\mathrm{Cu}_{1}$ there exists a coalescence of vein $\mathrm{Cu}_{2}$ and the second anal vein. In Rhyphus (Fig. 357) these

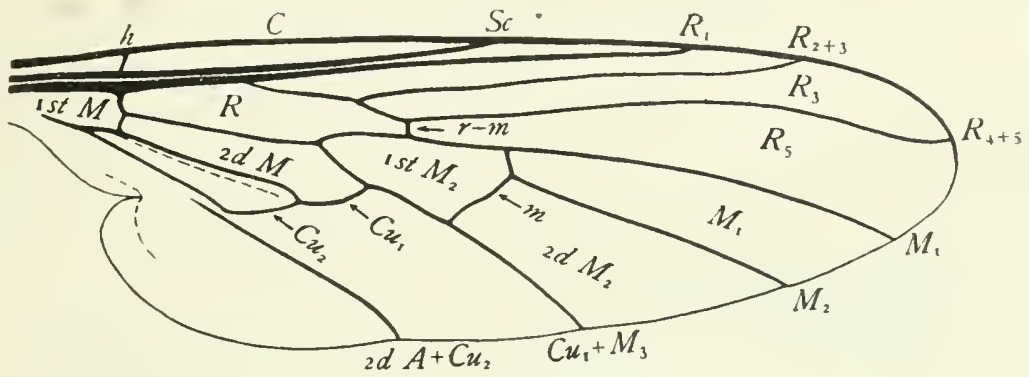

Fig. 371.-Wing of Rhamphomyia.

two veins retain their primitive position. In Leptis (Fig. 364 ) the tips are approximate. In Thereva (Fig. 366) the tips coalesce for a short distance. In Conops (Fig. 369) the coalescence is more striking. In Scenopinus (Fig. 370 ) it is carried still farther. While in Rhamp.zomyia (Fig. 37 I) it has proceeded so far that vein $\mathrm{Cu}_{2}$ extends towards the base of the wing and presents the appearance of a cross-vein.

The reduction of the number of cells in a wing.-A reduction of the number of cells in the wings has taken place in the wings of nearly all Diptera. This is the result of two causes: first, the coalescence of veins; and second, the atrophy of veins. The following will serve as illustrations of this process.

In the Brachycera, the coalescence of veins $R_{2}$ and $R_{3}$ results in the obliteration of cell $R_{2}$; and in the Nematocera, a similar coalescence of veins $R_{4}$ and $R_{5}$ results in the loss of cell $R_{4}$.

The atrophy of a vein separating two cells results in the uniting of these cells and a consequent reduction in the number of distinct cells. In the wing of Musca domestica (Fig. 372) cells M and Ist $\mathrm{M}_{2}$ are saparate 1 by the free part of rein $\mathrm{M}_{3}$. In the wing of Psilopodius sip'no (Fig. 373), there remains only a short spur representing the free part of vein $\mathrm{M}_{3}$; and in the wing of Dolichopus coquilletti (Fig. 374), the free part of vein $\mathrm{M}_{3}$ is completely 


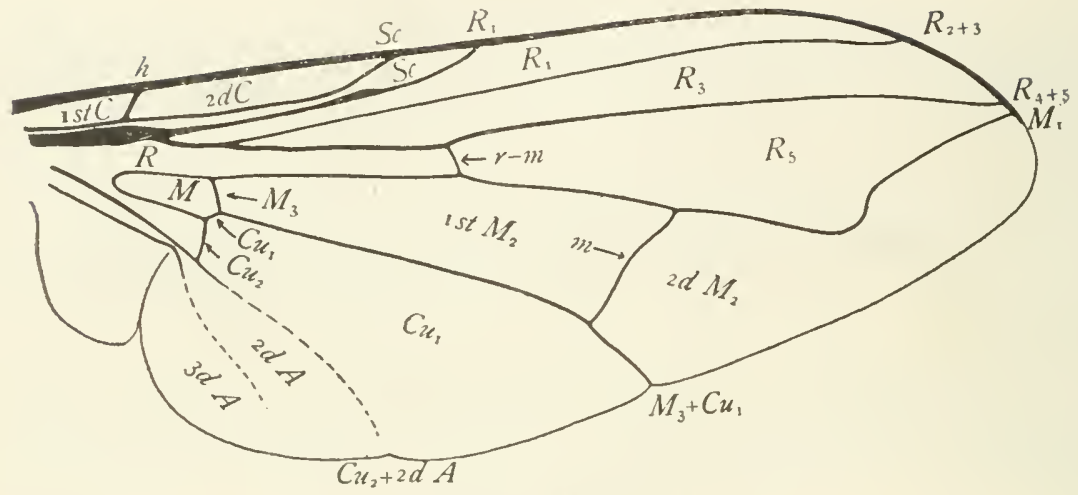

Fig. 372.-A wing of Musca domestica.

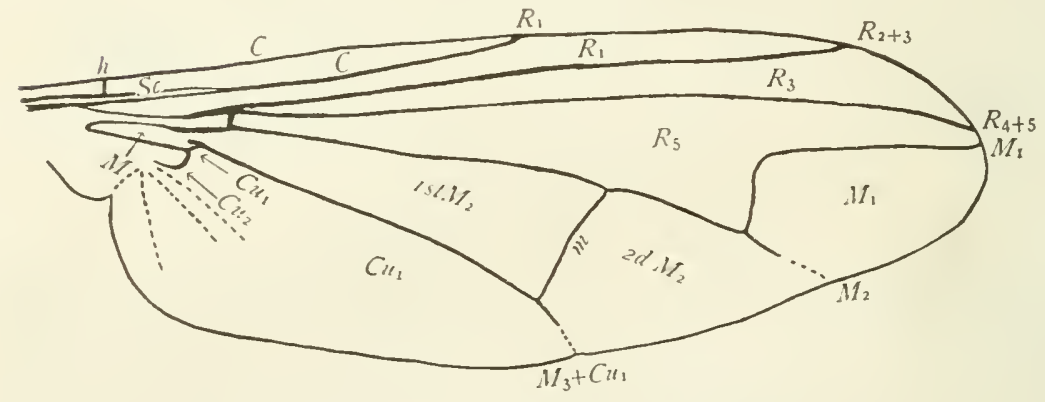

Fig. 373.-A wing of Psilopodius sipho.

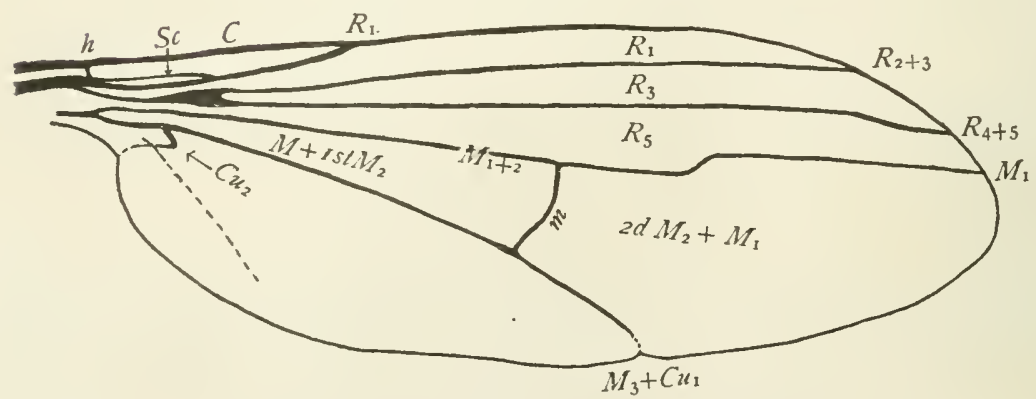

Fig. 374.-A wing of Dolichopus coquilletti. 
atrophied and cells $\mathrm{M}$ and $\mathrm{Ist} \mathrm{M}_{2}$ are united into a single cell, cell $\mathrm{M}+$ Ist $\mathrm{M}_{2}$.

The anal veins.-In all Diptera known to me there is a greater or less reduction of the anal area; for in none that I have seen are there present three well developed anal veins that extend to the margin of the wing.

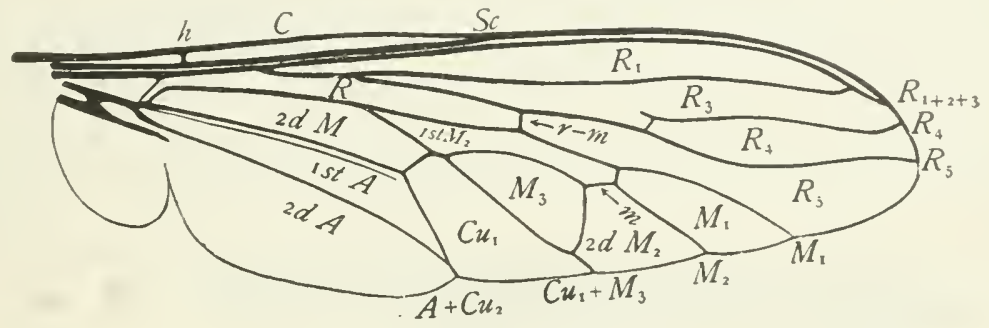

Fig. 375.-Wing of Erax.

In most Diptera the first anal vein is wanting as a distinct vein but in many there is a suture-like line, the anal furrow, immediately back of cubitus and closely parallel with this vein; this is a vestige of the first anal

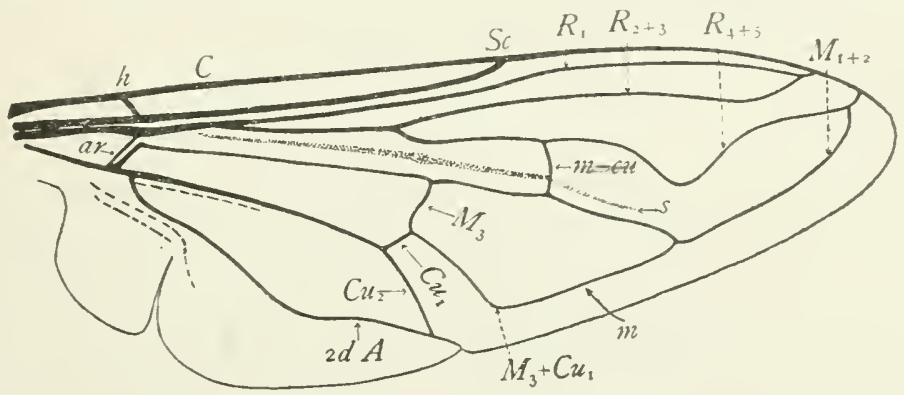

Fig. 376. -A wing Eristalis.

vein; this furrow is represented in several of the figures in this chapter by a dotted line. The first anal vein is retained, however, in certain Asilidæ; where, although somewhat shortened, it is a distinct vein extending from the base of the wing to near the point where vein Cu forks (Fig. 375).

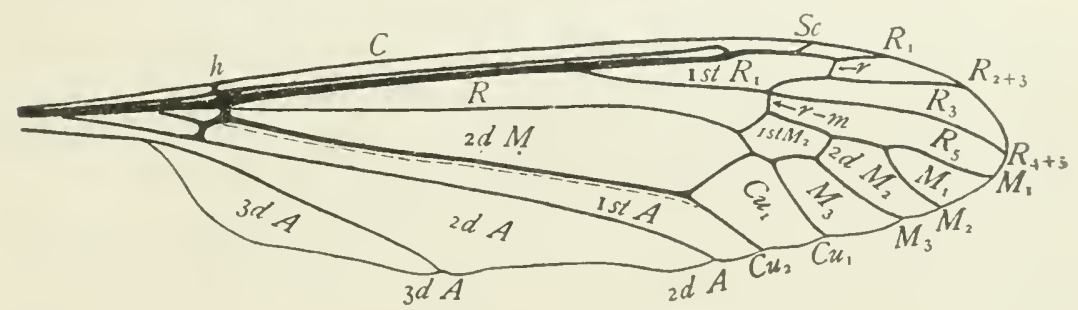

Fig. 377.-Wing of Tipula. 
The second anal vein is the most persistent of the three anal veins; it is well-preserved in many families; and is represented in several of the figures in this chapter.

The third anal vein is well-preserved in comparatively few forms, although a vestige of it exists in many. It is well-preserved in Tipula (Fig. 377), and is fairly well-preserved in Stratiomyia (Fig. 378).

The arculus.-There is a well-developed arculus in the Diptera; but owing to the reduced condition of the tracheation in this order the elements that enter into its formation can not be definitely determined. In labeling the cells at the base of the wing, I have assumed that the structure of the

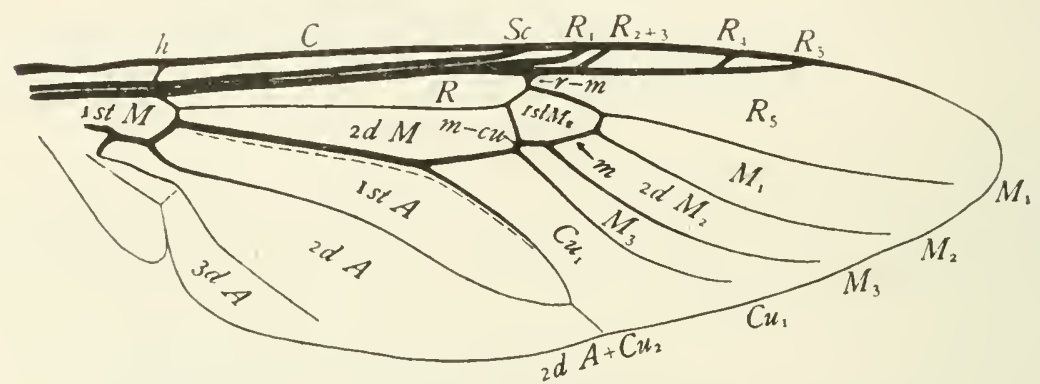

Fig. 378.-Wing of Stratiomyia.

arculus is the same as in those orders where its composition is well-known. According to this interpretation veins $R$ and $M$ coalesce from the base of the wing to the arculus; and, consequently, the cell behind the coalesced veins $\mathrm{R}$ and $\mathrm{M}$ is rst cell $\mathrm{M}$ (Fig. 378 ).

In many of the Diptera, the base of the free part of the media has migrated along the arculus so far that it appears to arise from the cubitus (Fig. 375).

The spurious vein.-In the Syrphidæ there is a longitudinal thickening of the wing between the radius and the media; this is termed the spurious vein (Fig. 376, s).

(c) COMPARISON OF TERMINOLOGIES OF THE WING-VEINS OF THE DIPTERA.

It is practically impossible to make in a single table a comparison of the various terminologies of the wing-veins of the Diptera that have been used by the prominent writers on this order. This is due to the fact that none of the older authors succeeded in determining the homologies of the different veins throughout the order; the result is that homologous veins are designated differently in the discussions of different families. This was frankly admitted by Osten-Sacken ('69, p. 32) in the following remarkable statement. 
"This study of the homologies has two distinct aims in view: the scientific aim of showing that the ground-plan of the venation is the same in all of the families of the order; and the practical aim of adopting a terminology for descriptive purposes. We cannot carry out a terminology on solely theoretical grounds; we will have to vary the details of it according to the peculiarities of structure occurring in different families, the main plan remaining the same. This is done in all the departments of zoology, and I do not see why the venation of the Diptera should be treated differently."

Owing to the lack of uniformity in the terminologies used by different authors and to the fact that even in the writings of a single author homologous veins are designated differently in the discussions of different families,

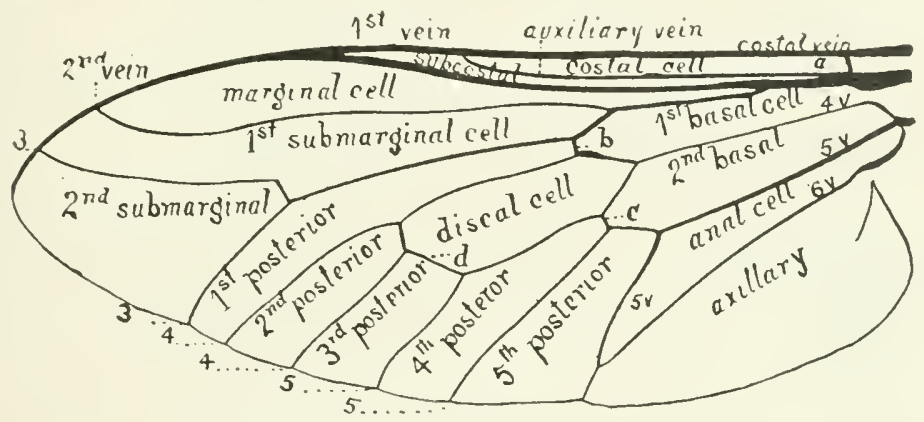

Fig. 379.-Wing of Tabanus (After Williston).

it is necessary for the student using any of the works in which the uniform terminology has not been adopted to make a study of the system used in that particular work.

The system that has has been most used in this country is that which was adopted by Loew ('62) and modified by Osten-Sacken ('69). Figure 379 from Williston ('o8) illustrates this system as applied by him to the wing of Tabanus. In the following table this system and that of Redtenbacher are compared with the uniform terminology.

Redtenbacher in his efforts to recognize the concave veins IV and VI of his system was led into inconsistences in his determinations of the homologies of the branches of media. The equivalents given in the following table are based on his figure of the wing of Stratiomys. 


\begin{tabular}{|c|c|c|c|}
\hline $\begin{array}{l}\text { TILLISTON } \\
\text { (Tabanus) }\end{array}$ & $\begin{array}{l}\text { REDTENBACHER } \\
\text { (Strationy's) }\end{array}$ & \multicolumn{2}{|c|}{$\begin{array}{c}\text { COMSTOCK AND NEEDHAM } \\
\text { (Allfamilies) }\end{array}$} \\
\hline Costal & I & Costa & $\mathrm{C}$ \\
\hline Auxillary & II & Subcosta & $\mathrm{Sc}$ \\
\hline First longitudinal & $\mathrm{III}_{1}$ & Radius-one & $\mathrm{R}_{1}$ \\
\hline Second lonoitudinal & $\mathrm{III}_{2}$ & Radius-two & $\mathrm{R}_{2}$ \\
\hline secono longituomal ; & $\mathrm{III}_{3}$ & Radius-three & $\mathrm{R}_{3}$ \\
\hline Third longitudinal & $\mathrm{III}_{4}$ & Radius-four & $\mathrm{R}_{4}$ \\
\hline Inird longitudinal & $\mathrm{III}_{5}$ & Radius-five & $\mathrm{R}_{5}$ \\
\hline Fourth longitudinal & IV & Media-one & $M_{1}$ \\
\hline rourtn longicuand ? & $Y^{r}$ & Media-two & $\mathrm{M}_{2}$ \\
\hline & VI & Media-three & $\mathrm{M}_{3}$ \\
\hline Fifth longitudinal & $\mathrm{VII}_{1}$ & Cubitus-one & $\mathrm{Cu}_{1}$ \\
\hline & $\mathrm{VII}_{2}$ & Cubitus-two & $\mathrm{Cu}_{2}$ \\
\hline & VIII & First Anal & Ist $\mathrm{A}$ \\
\hline Sixth longitudinal & IX & $\begin{array}{l}\text { Second Anal } \\
\text { Third Anal }\end{array}$ & $\begin{array}{l}2 \mathrm{dA}^{-} \\
3 \mathrm{dA}\end{array}$ \\
\hline Humeral cross-vein $a$ & & Humeral cross-vein & $h$ \\
\hline Anterior cross-vein $b$ & & Radio-medial cross-vein & $r-m$ \\
\hline Discal cross-rcin $c$ & & Medio-cubital cross-rein & $m-c u$ \\
\hline Posterior cross-rein $d$ & & Medial cross-vein & $m$ \\
\hline
\end{tabular}

(d) COMPARISON OF TER MINOLOGIES OF THE CELLS OF THE WINGS OF THE DIPTERA

The writers on the Diptera have made use of very complete terminologies of the cells of the wing. As examples of these I give in the following table those used in three important American works, and indicate the equiralents of the terms used in the uniform terminology. 


\begin{tabular}{|c|c|c|c|}
\hline $\begin{array}{l}\text { LOEW ('62) } \\
\text { (Ortalis) }\end{array}$ & $\begin{array}{c}\text { OSTEN-SACKEN ('69) } \\
\text { (Cladura) }\end{array}$ & $\begin{array}{l}\text { WILLISTON ('os) } \\
\text { (Tabamus) }\end{array}$ & $\begin{array}{l}\text { COMSTOCK AND } \\
\text { NEEDHAM }\end{array}$ \\
\hline Ist costal & & & ist C \\
\hline $2 \mathrm{~d}$ costal & Costal & Costal & $2 \mathrm{dC}$ \\
\hline $3 \mathrm{~d}$ costal & Subcostal & Subcostal & $\mathrm{Sc}$ \\
\hline Ist basal & Ist basal & Ist basal & $\mathrm{R}$ \\
\hline Marginal & $\begin{array}{l}\text { Marginal } \\
\text { Ist submarginal }\end{array}$ & Marginal & $\begin{array}{l}\mathrm{R}_{1} \\
\mathrm{R}_{2}\end{array}$ \\
\hline Submarginal & $2 \mathrm{~d}$ submarginal & $\begin{array}{l}\text { Ist submarginal } \\
\text { 2d submarginal }\end{array}$ & $\begin{array}{l}\mathrm{R}_{3} \\
\mathrm{R}_{4}\end{array}$ \\
\hline Ist posterior & Ist posterior & Ist posterior & $\mathrm{R}_{5}$ \\
\hline $2 \mathrm{~d}$ basal & $\begin{array}{l}2 \mathrm{~d} \text { basal } \\
2 \mathrm{~d} \text { posterior }\end{array}$ & $\begin{array}{l}2 \mathrm{~d} \text { basal } \\
2 \mathrm{~d} \text { posterior }\end{array}$ & $\begin{array}{l}\mathrm{M} \\
\mathrm{M}_{1}\end{array}$ \\
\hline $\begin{array}{l}\text { Discal } \\
2 \text { d posterior }\end{array}$ & $\begin{array}{l}\text { Discal } \\
3 \mathrm{~d} \text { posterior } \\
4 \text { tli posterior }\end{array}$ & $\begin{array}{l}\text { Discal } \\
3 \mathrm{~d} \text { posterior } \\
\text { 4th posterior }\end{array}$ & $\begin{array}{l}\text { Ist } M_{2} \\
2 \mathrm{~d} M_{2} \\
M_{3} \\
\mathrm{Cu}\end{array}$ \\
\hline $3 \mathrm{~d}$ posterior & 5 th posterior & $5^{\text {th }}$ posterior & $\mathrm{Cu}_{1}$ \\
\hline Anal & Anal & Anal & Ist A \\
\hline Axillary & $\begin{array}{l}\text { Axillary } \\
\text { Spurious }\end{array}$ & Axillary & $\begin{array}{l}2 \mathrm{dA} \\
3 \mathrm{dA}\end{array}$ \\
\hline
\end{tabular}

The difference in the application of the terms first submarginal and second submarginal in the terminologies of Osten-Sacken and Williston arises from the fact that in each case the cell lying next to the marginal cell is termed the first submarginal; but this is not the same cell in the two genera used to illustrate their terminologies. The genus used by OstenSacken is a Tipulid; and in all Nematocera that have a three-branched radial sector veins $R_{2}$ and $R_{3}$ remain distinct; hence the cell next to the marginal cell is cell $\mathrm{R}_{2}$. On the other hand the genus used by Williston belongs to the Brachycera; and in this division of the order veins $R_{2}$ and $R_{3}$ coalesce throughout their entire length, and consequently the cell immediately behind the marginal cell is cell $R_{3}$. 


\section{CHAPTER XXV \\ THE WINGS OF THE HYMENOPTERA}

\section{(a) THE General FeAtures of the Wings of the HyMenoptera}

THE members of this order have four wings (Fig. $3 \mathrm{SO}$ ); these are membranous, and have the wing-venation more or less reduced. In the more generalized families the reduction of the wing-venation is slight; in the

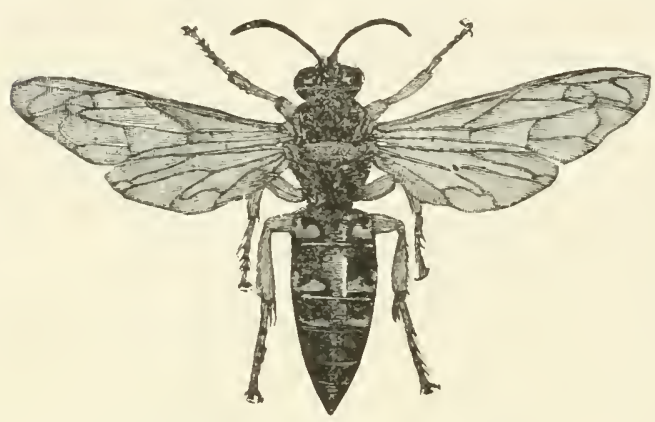

Fig. 380.-Sphecius speciosus. more specialized families, it is extreme. The two pairs of wings are similar in texture. The wings of each side are held together by a row of hooks, the hamuli, on the front margin of the hind wing (Fig. $38 \mathrm{I}, h$ ); these hooks fasten to a fold in the hind margin of the front wing, so that the two wings present a continuous surface. The hind wings are smaller than the fore wings, and have a more reduced venation.

Some forms are apterous.

\section{(b) THE VENATION OF THE WINGS OF THE MORE GENERALIZED HYMENOPTERA}

The suborder Chalastogastra has been recognized as the more generalized of the two suborders of this order independently of any consideration of the characters presented by the wings. This conclusion has been confirmed by studies of the wings; for within this suborder are to be found the most generalized wings that exist among living representatives of the Hymenoptera.

In the wings of certain sawflies of the families Xyelidæ and Lydidæ we find a close approximation in the number of the wing-veins to that of the hypothetical primitive type of wingvenation. But even here the courses of the branches of the forked veins

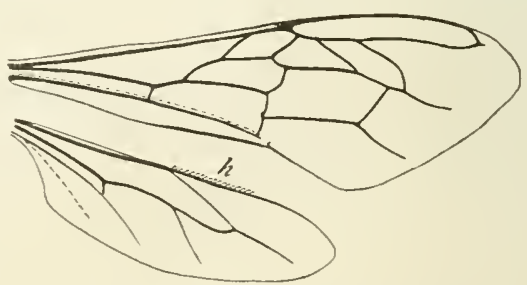

Fig. 381.-IVings of A pis showing hamuli. have been greatly modified. These changes have been so great that the determination of the homologies of the wing-veins in this order was one of the most difficult problems of this kind that arose in the course of the study of the wings of insects. 


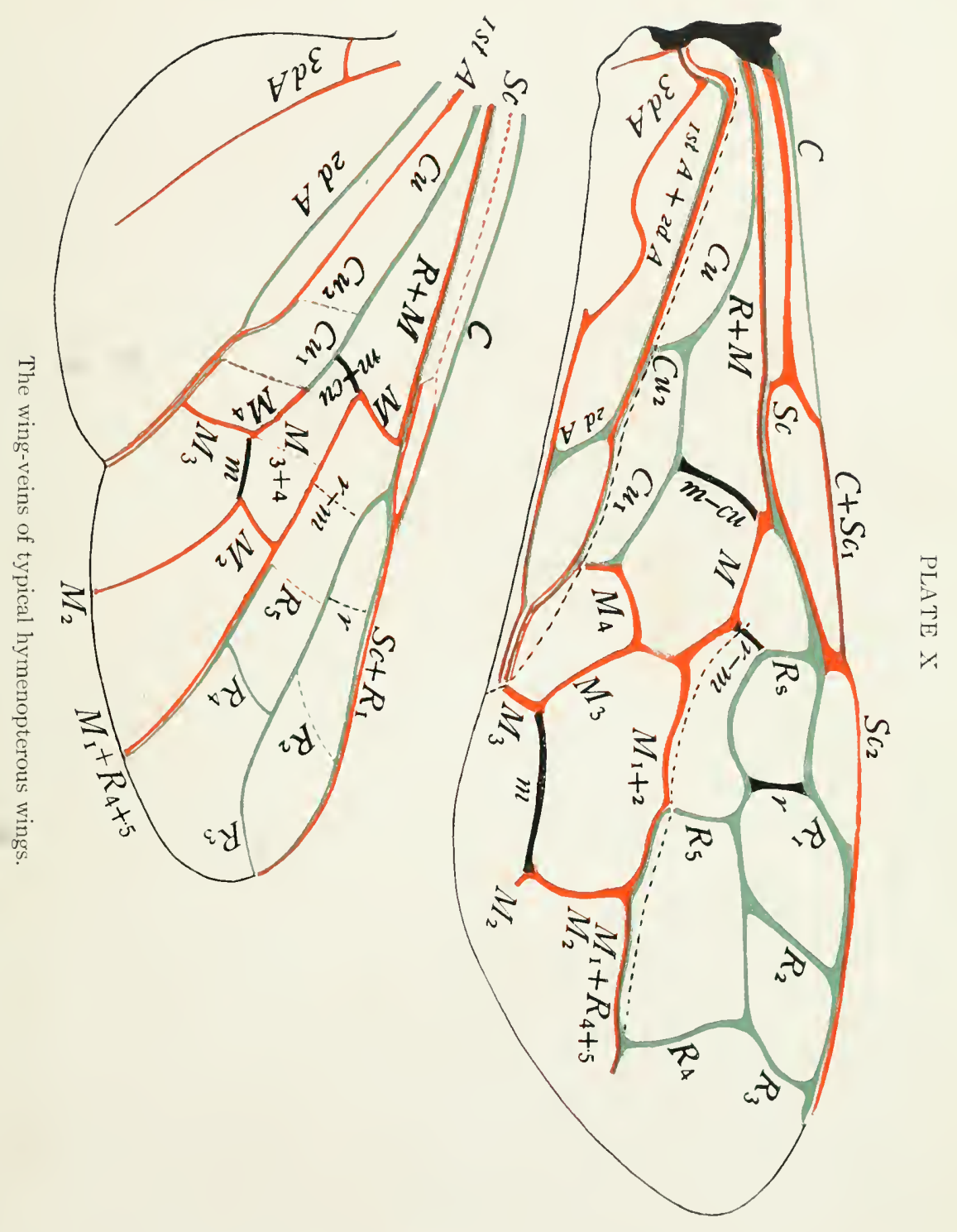



This determination was made by the writer, from an examination of the wings of adult insects, and published in a text-book* before the ontogenetic study of wings was undertaken by Dr. Needham and myself.

The results of this later study did not modify the conclusions that I had reached from the study of adults alone. In fact, we found, as will be shown later, that the courses of the trachea of the wings of hymenopterous pupæ have not been modified in the same way as have the courses of the veins; and that, for this reason we are still forced to determine the homologies of the wing-veins in this order by a comparative study of the wings of adult insects.

An understanding of the hymenopterous type of wing-venation was not derived from a study of the wings of Hymenoptera alone. Even in the most generalized of the living members of this order, the wings are so highly specialized that the homologies of certain veins would never have been suspected but for help from another source.

Fortunately the most characteristic method of modification of the courses of the wing-veins in the Hymenoptera is illustrated by the wings of certain Diptera also. And in the Diptera examples of every stage in the modification of the courses of veins by this method can be seen; while in the Hymenoptera only the later stages are shown.

Reference is made here to the coalescence of veins from the margin of the wing towards the base of the wing. This results frequently in a branch of a longitudinal vein becoming transverse, so that it appears like a cross-vein; and in some cases, where the coalescence has been carried still farther, a branch of a longitudinal vein has been so diverted from its primitive course that it extends towards the base of the wing. Among living Diptera there are preserved examples of all of the stages of this modification of the course of a vein. The series of figures illustrating the coalescence of veins $\mathrm{Cu}_{2}$ and $2 \mathrm{~d} A(\mathrm{p} .355)$ shows this.

With this data before us let us proceed to an examination of hymenopterous wings. The most generalized condition of the venation of the wings that is known in the Hymenoptera occurs in the two genera Pamphilius, of the family Lydidæ, and Macroxyela, of the family Xyelidæ. There is preserved in the fore wings of cach of these genera of sawflies all of the primitive wing-veins with a single exception; and as it is not the same vein that has been lost in the two genera, a figure of a typical hymenopterous wing can be made from a study of the two. Figures $38_{2}$ and ${ }_{3} 8_{3}$ represent such a wing; in the former the veins are lettered; in the latter, the cells. See also Plate X, where the courses of the veins are made more evident by the use of alternating colors.

The typical hymenopterous wing represented in the accompanying figures is a figure of the fore wing of Pamphilius (Fig. 39 I) except that vein

\footnotetext{
*Comstock: A Manual for the Study of Insects. (1895), pp. 603-607.
} 
$\mathrm{R}_{2}$, which is lacking in this genus, is added. This vein is well-preserved in Macroxyela (Fig. 392); but in Macroxyela vein $\mathrm{Cu}_{2}$ is lost; the position of the lost forking of the cubitus is indicated, however, by a bend in this vein.

In the wings of these sawflies, the anal furrow and the median furrow are both well-marked, and are in the typical positions; that is, the anal

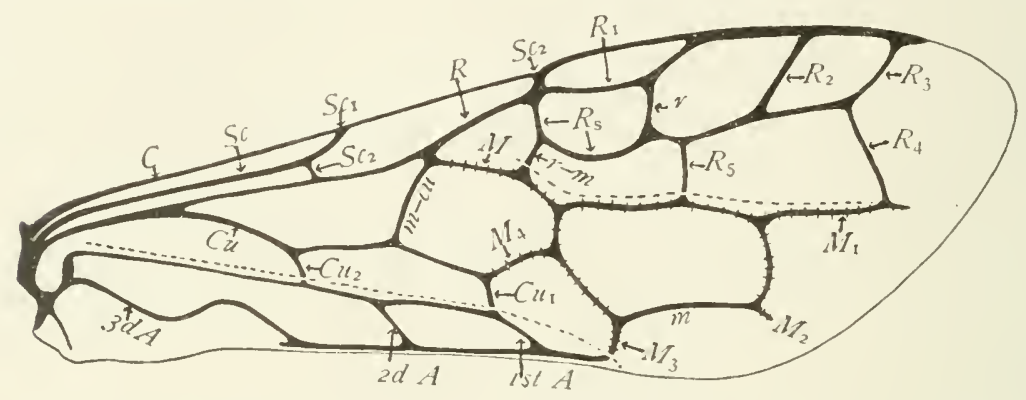

Fig. 382.-The veins of a typical hymenopterous wing (From C. \& N.).

furrow is immediately in front of the first anal vein and the median furrow in front of the media. The furrows are represented by dotted lines in Figures $38_{2}$ and $38_{3}$.

In the anal area the three typical veins are preserved; but they coalesce to a considerable extent, both at the base and near the margin of the wing.

In the basal part of the prenal area, the stems of the principal veins are as follows: the costa coincides with the costal margin of the wing and extends from the base of the wing to the stigma (Fig. $\left.38_{2}, \mathrm{C}\right) ;$ the subcosta

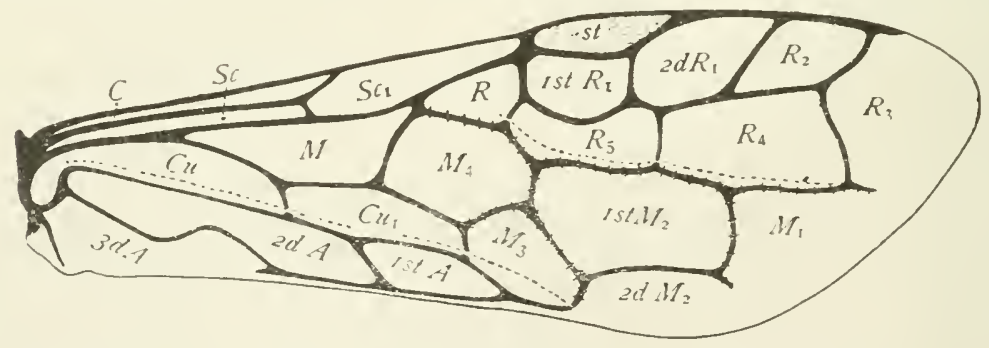

Fig. 383.-The cells of a typical hymenopterous wing (From C. \& N.).

(Fig. $382, S c$ ) is well-preserved and is forked; back of the subcosta is a strong stem formed by the coalescence of the other three veins of the preanal

*It is impossible to state whether the costa extends beyond the beginning of the stigma or not. Both MacGillivray and Bradley believe that it ends at or shortly before the beginning of the stigma. This conclusion is based on the fact that, while costa in all insect wings, when present, lines the margin of the wing, in the Hymenoptera there is frequently a strip of free membrane of varying width extending from the nodal furrow to the apex of the wing. This strip is quite wide in the wings of the female of Tiphia, for example; and widens into the appendiculate cell in some wings. 
area; the cubitus (Fig. $382, \mathrm{C} u$ ) soon separates from this stem, extending in a curve towards the anal furrow; while the radius and the media coalesce for about half their length. In order to make these veins more distinct in the figure the free portion of the media is marked with cross lines; see also Plate X.

When we pass from a consideration of the main stems of the veins to a study of the branches, we meet a much more complicated problem, a problem that could not have been solved by a study of Hymenoptera alone. But a knowledge of the methods of specialization of the wings of Diptera gives, as already stated, a key to an understanding of the wings of Hymenoptera.

If the reader will examine the series of figures illustrating the coalescence of veins $\mathrm{Cu}_{2}$ and $2 \mathrm{~d} \mathrm{~A}$ in the Diptera (page 355 ), he will find it easy to understand what has taken place in the Hymenoptera. In the Hymenoptera, however, both branches of the cubitus coalesce with the first anal vein; and

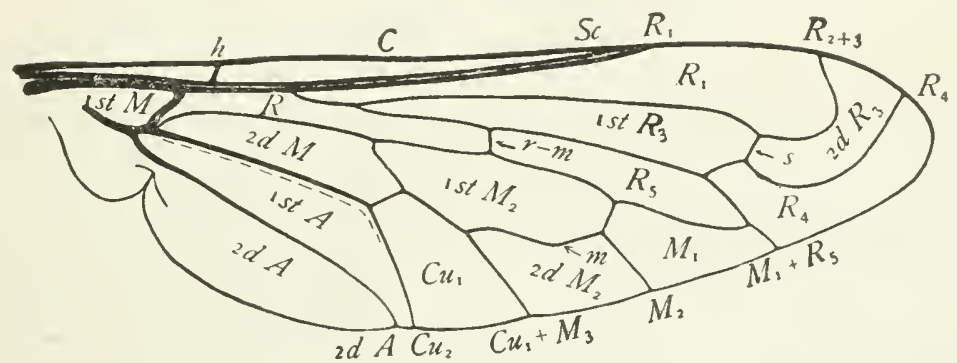

Fig. 384.-Wing of Pantarbes.

this coalescence has proceeded so far that both branches cross the anal furrow, and end in the anal vein remote from the margin of the wing.

It should be noted that vein $\mathrm{Cu}_{2}$ is comparatively rarely preserved in this order. Dr. MacGillivray, in his very extended study of the wings of the Tenthredinoidea, (MacGillivray 'o6, p. 552), notes its presence in representatives of several genera of the Lydidx; but in most of the Tenthredinoidea all traces of it are lacking.

If the branches of the media be now examined, it will be seen that rein $\mathrm{M}_{1}$ (Fig. 382) extends longitudinally near the center of the distal part of the wing, its primitive course being modified slightly if at all. Vein $\mathrm{M}_{2}$ follows a course similar to the course of this rein in the dipterous genus Pantarbes (Fig. $38_{4}$ ). Vein $M_{3}$ extends across the anal furrow near the margin of the wing and coalesces with the first anal vein. It is evident that the forces that are causing the branches of the cubitus to migrate along the first anal vein towards the base of the wing are exerting a similar influence on this vein. It is also evident that veins $\mathrm{M}_{4}$ and $\mathrm{Cu}_{1}$ coalesce at the tip, and that the migration of the united tips of these veins (marked $\mathrm{Cu}_{1}$ in the figure) 
towards the base of the wing has so modified the course of that part of vein $\mathrm{M}_{4}$ which is still free that it extends towards the base of the wing. This change is very similar to the change in the course of vein $\mathrm{Cu}_{2}$ in the dipterous genus Rhamphomyia (Fig. 385).

A curious result of this change in the direction of the course of vein $\mathrm{M}_{4}$ is that the cell $\mathrm{M}_{4}$ has been closed and pressed back to the center of the wing

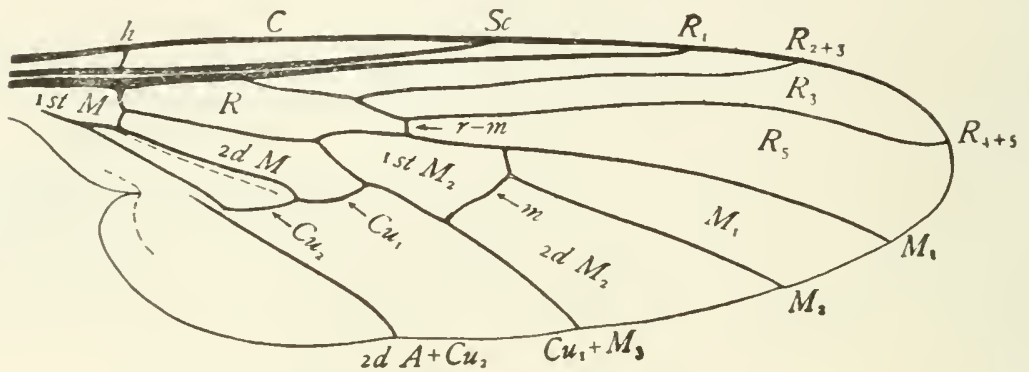

Fig. 385.-Wing of Rhamphomyia.

(Fig. $38_{2}, M_{4}$ ), and now lies in front of the free portion of vein $M_{4}$ instead of behind it. A somewhat similar modification of cell $\mathrm{MI}_{3}$ is found in the dipterous genus Eulonchus (Fig. 386).

Let us now consider the courses of the branches of the radius. Here again we can gain help from a study of dipterous wings. Observe in Pantarbes (Fig. ${ }_{3} 8_{4}$ ) the coalescence of the tips of veins $R_{5}$ and $M_{1}$. In the Hymenoptera a similar coalescence of veins $R_{5}$ and $M_{1}$ has occurred; but it has proceeded much farther, so that the free portion of vein $\mathrm{R}_{5}$ in Pamphilius

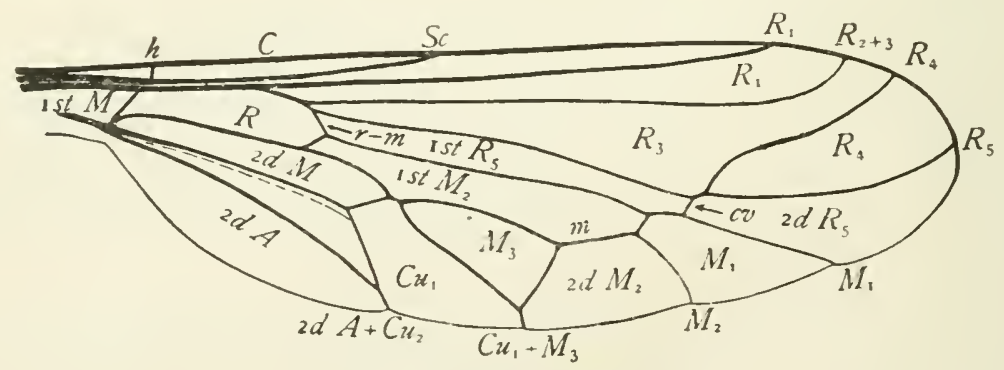

Fig. 386.-Wing of Eulonchus.

(Fig. 39I, $R_{5}$ ) is remote from the end of the wing and has the appearance of a cross-rein.

In the Hymenoptera vein $R_{5}$ has been followed in its migration along vein $M_{1}$ by vein $R_{4}$, which has now reached a stage in Pamphilius that is quite similar to that reached by vein $R_{5}$ in Pantarbes; but like vein $R_{5}$ it has the appearance of a cross-vein. In the fore wing of the honey-bee (Fig. 
$3 \delta_{7}$ ) veins $R_{4}$ and $R_{5}$ still retain the appearance of branches of a forked vein

In Pamplitius vein $\mathrm{R}_{1}$ is curved away from the costal margin of the wing to make room for a stigma (Fig. $39 \mathrm{I}$ and Fig. $38_{2}$, st), and vein $R_{3}$ ends in

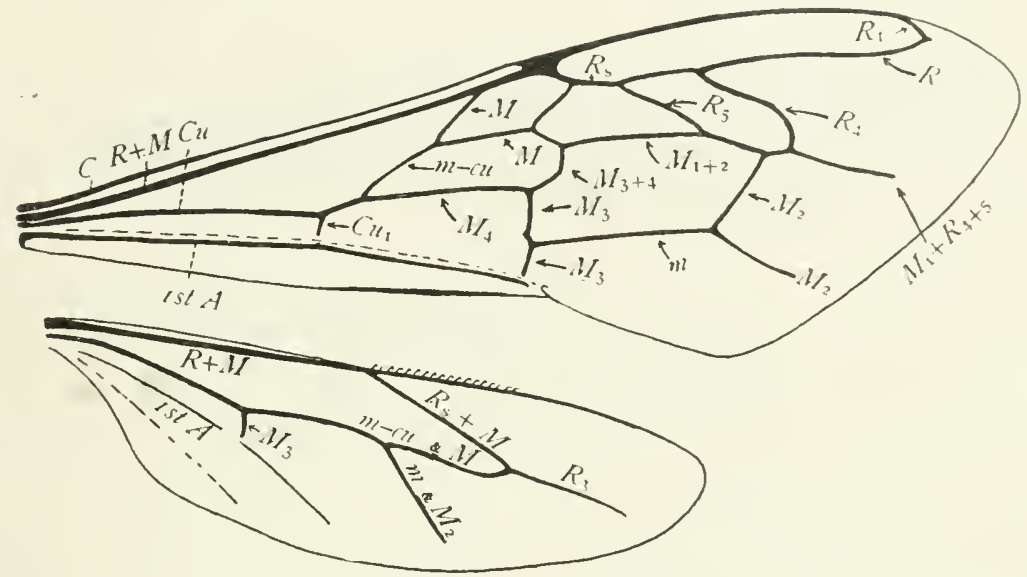

Fig. 387.-Wings of a honey-bee (From C. \& N.).

the costal margin a short distance before the apex of the wing. Vein $R_{2}$ has been lost in this genus but as it is well-preserved in the closely allied genus Macroxyela (Fig. 392) it is represented in the figure of the typical hymenopterous wing (Fig. 382 ).

While the tips of the branches of the radial sector have migrated away

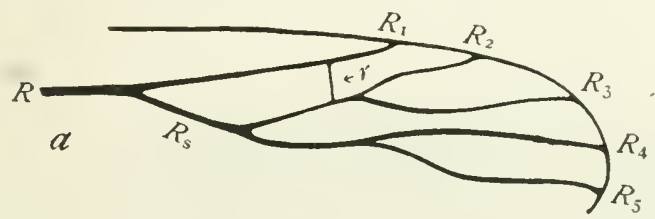
from the apex of the wing, the bases of these branches coalesce in the opposite direction; from these two causes results the transverse bracing of the radial a rea of

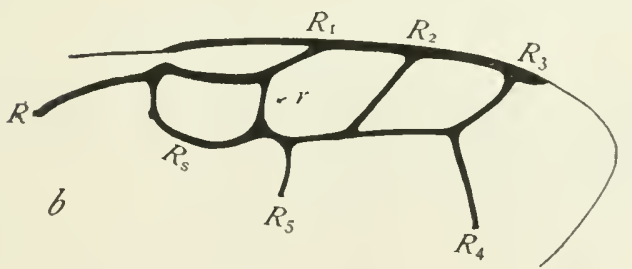

Fig. 388.-Diagrams of the radius: a, typical; $b$, hymenopterous (After C. \& N.). the wing, which is a very characteristic feature of the venation of the wings of this order.

The details of these changes will be made clear by an examination of Figures $388 \mathrm{a}$ and $388 \mathrm{~b}$. The former represents the primitive mode of branching of the radius; the latter, the radial area of the typical hymenopterous wing. As the radial cross-vein is usually present in the Hymenoptera, it is represented in these figures. In the hymenopterous type, veins $R_{2}+3$ and $R_{4+5}$ of the primitive type coalesce so far that the 
branches of the radial sector arise from a common stem; and the tips of all of them have moved away from the apex of the wing, veins $R_{2}$ and $R_{3}$ following the costal margin of the wing, and veins $R_{4}$ and $R_{5}$ following vein $M_{1}$.

Reference has been made above to the curving of vein $\mathrm{R}_{1}$ away from the margin of the wing to make room for a stigma (Fig. ${ }_{3} s_{3}$, st). The stigma is bounded in front and at its base by the tip of vein $\mathrm{Sc}_{2}$, which anastomoses with the radius for a considerable distance but separates from that vein at the base of the stigma.

In the above account reference has been made only to the venation of the fore wings. In the hind wings of most Hymenoptera the venation has been so greatly reduced that it is exceedingly difficult to determine the homologies of the wing-veins.

The suborder Chalastogastra includes those Hymenoptera in which the reduction of the renation of the hind wings is least. The extended study of the wings of this suborder made by MacGillivray ('o6) enabled him to prepare a diagram of a typical hymenopterous hind wing, which is of great value as an aid to the determination of the venation of the hind wings of Hymenoptera, this diagram was followed in the preparation of Plate X. The lacking veins are indicated by dotted lines.

From the foregoing account it will be seen that eren in the most generalized of living Hymenoptera there exists a highly modified wing-renation. But notwithstanding this it is possible to determine the homologies of all of the wing-reins.

Some of the modifications of this primitive hymenopterons type will be discussed in a later section of this chapter.

\section{(c) THE tRaChEATION OF THE Wings OF THE HYMENOPTERA}

The tracheation of the wings of the Hymenoptera was studied by Comstock and Needham in order to ascertain if the courses of the tracheæ furnish any data regarding the homologies of the wing-veins in this order. We had found, as shown in preceding pages, that in the more generalized insects there is a close correlation between the venation and the tracheation of the wings; and that it can be accepted as a firmly established fact that the courses of the wing-reins of primitive insects were determined by the courses of preexisting tracheæ.

But we also found that in the Trichoptera there is little correlation between the venation and the tracheation of the wings, a remarkable reduction of the wing-tracheæ having taken place. A similar reduction of the tracheæ of the wings exists in most families of the Diptera; and eren when a large portion of the tracheæ are retained, as in certain Asilids, they afford little aid in determining the homologies of the wing veins. 
Again, in the Hymenoptera, we found that the courses of the tracher cannot be depended upon for determining the homologies of the wing-veins, notwithstanding the fact that in the more generalized members of the order a very complete system of wing-tracheæ exist. The wings of a pupa of

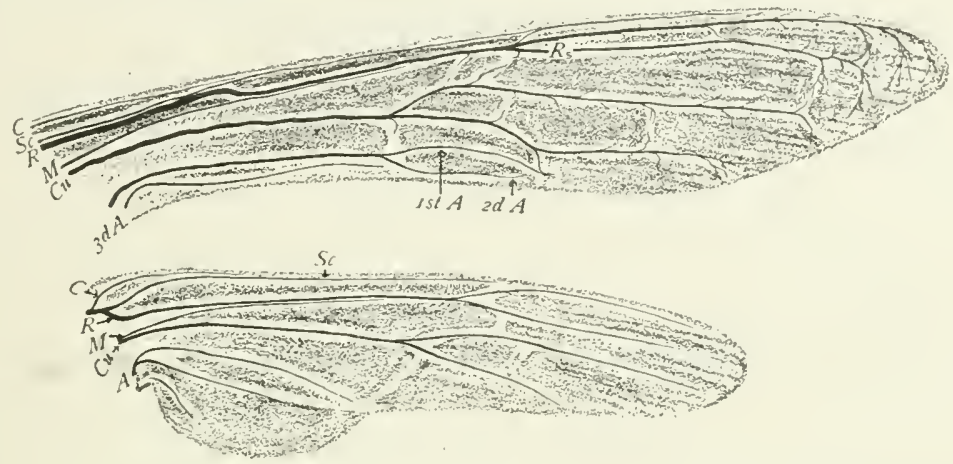

Fig. 389.-Wings of a pupa of Tremex (From C. \& N.).

Tremex (Fig. 389 ) illustrate the extent to which the tracheæ are retained in the more generalized members of the order; and the wings of Apis (Fig. 390) illustrate the tracheation of the vings in a more specialized"form.

The most striking feature of the courses of the main tracheæ in the wings of Tremex is that each extends in a nearly direct line from the base of the wing to near its outer margin; and that while in most cases the basal part of each lies in the cavity of the vein with which it corresponds, this correspondence does not extend to the branches of the principal veins.

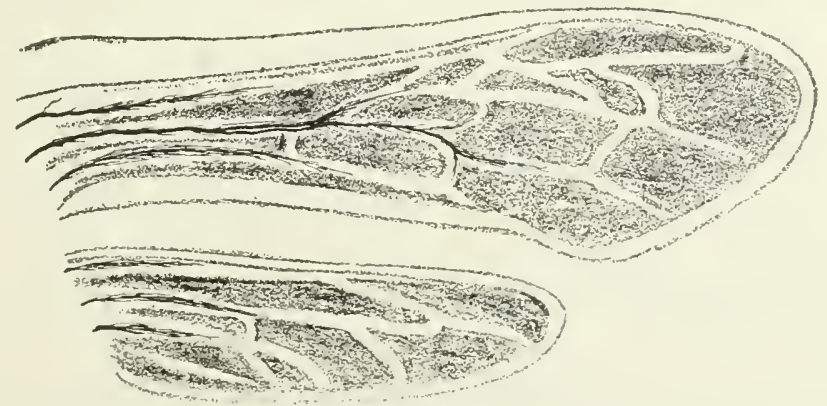

Fig. 390.-Wings of a young pupa of Apis (From C. \& N.).

Even in the case of the principal veins, this correspondence is not complete; for the basal part of the radial trachea of the fore wing lies in what is without doubt the cavity of subcosta; and in both wings the medial trachea does not cxtend into the branches of the modia.

In the course of a study of the development of the wings of the honeybee, Dr. Needham and I discovered the cause of the lack of correspondence 
between the tracheation and venation of the wings in the Hymenoptera. An examination of the wings of young pupæ of this insect revealed the fact that in this insect the laying out of the wing-venation precedes the tracheation of the wing. After the wing-veins reach that stage of development in which they appear as pale bands, the tracheæ grow out from the base of the wing into them. Figure 390 represents the wings of a pupa taken at a stage that illustrates this pushing out of the trachere into the previously formed wing-vein cavities.

It is obvious that tracher developed after the rein-cavities are formed will follow the paths offering the least resistance to their progress; and it is not to be expected that they will preserve their primitive arrangement under these conditions.

This brings us to the conclusion already announced, that in determining the homologies of the wing-veins in the Hymenoptera we are forced to base our conclusions on a study of the veins.themselves; and that a method of study which is of the highest importance in determining the homologies of the wing-reins in many other insects, is of little use here for this special purpose.

METhODS OF MODIFICATION OF THE PRIMITIVE HYMENOPTEROUS TYPE OF WING-VENATION

The working out of the details of the modification of the wing-venation in the several families of the Hymenoptera can only be done by those who make extended studies of these families, a work that does not fall within the scope of this essay. I wish merely to indicate, in this chapter, the essential features of the hymenopterous type of wing-venation, the more prominent of the methods by which this type is modified, and to illustrate by a few examples the nature of the results that have been attained in the modifications of the primitive hymenopterous type. If this is done, data will be available that will facilitate more extended studies in this field.

Our knowledge of the various modifications of the primitive hymenopterous type of wing-renation that occur in the more generalized of the two suborders of this order, the Chalastogastra, is very complete. This is due to the labors of Dr. A. D. MacGillivray, who has published the results of a very extended and detailed study, illustrated by nearly one hundred figures of the wings of members of this suborder (MacGillivray 'o6). This most excellent work, with its great wealth of details, furnishes all the data needed for an understanding of the venation of the wings of the Chalastogastra, and gives an invaluable basis of comparison for the study of the wings of the more specialized suborder, the Clistogastra.

I shall not attempt to give an abstract of Dr. MacGillivray's paper; because a mere abstract could not take the place of the complete memoir, 
which should be consulted by anyone making a study of the wing-venation of members of this suborder. But I shall have occasion, in the course of the later discussion, to quote some of his results.

Passing to the suborder Clistogastra, we find it comparatively easy to determine the homologies of the wing-veins in many forms, that is in those in which the venation is not greatly reduced, by making use of the data obtained in the study of the Chalastogastra. But there are many forms with greatly reduced wing-venation in which the problem is exceedingly difficult. Much has been done in this field by Professor J. Chester Bradley, but unfortunately only a part of his results has been published.

In his monograph of the Evaniidæ (Bradley 'o8), Professor Bradley has figured all of the types of wings known to occur in this remarkable family. In another very extended work, entitled The Wings of Hymenoptera with particular reference to the Ichneumon Flies, some of the more perplexing problems that have arisen in the study of the modifications of the venation of the wings of the Hymenoptera are discussed in a very thorough manner; but this work is not yet published.

The more important of the methods by which the primitive type of wing-venation has been modified in the Hymenoptera are the following:

A reduction in the number of the wing-veins by the atrophy of one or more veins.

A reduction in the number of the wing-veins by the coalescence of adjacent veins in one or more areas of the wing.

A change in the course of a vein by the coalescence of its base with an adjacent vein.

Changes in the courses of veins by the coalescence of the tip of each with an adjacent vein.

The formation of serial veins.

The following examples will serve to illustrate the results of the modification of the primitive type of wing-venation by these several methods. It is an interesting fact that the wings of the most generalized of living Hymenoptera show modifications by each of these methods. The wonderfully modified wings of the more specialized Hymenoptera are merely the result of carrying to an extreme methods of modification already inaugurated in the most primitive Hymenoptera known to us.

Reduction by atrophy - In the Hymenoptera one result of the specialization of the renation of the wings is a reduction of the number of wing-veins; in no case are either accessory veins or intercalary veins developed; and even in the most generalized members of the order known to us not all of the wing-veins are retained.

The reduction in number of the wing-veins, however, is slight in the more generalized members of the order; as already indicated, in some only vein $R_{2}$ is lacking, in others, only veins $\mathrm{Cu}_{2}$ has been lost. This refers to 


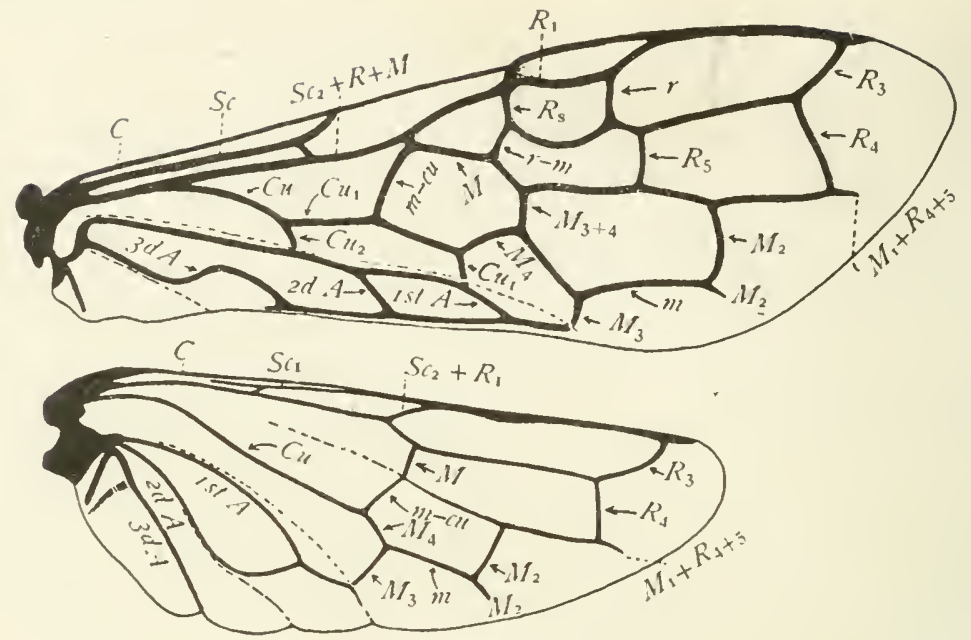

Fig. 39I.-Wings of Pamphilius. The veins are lettered.
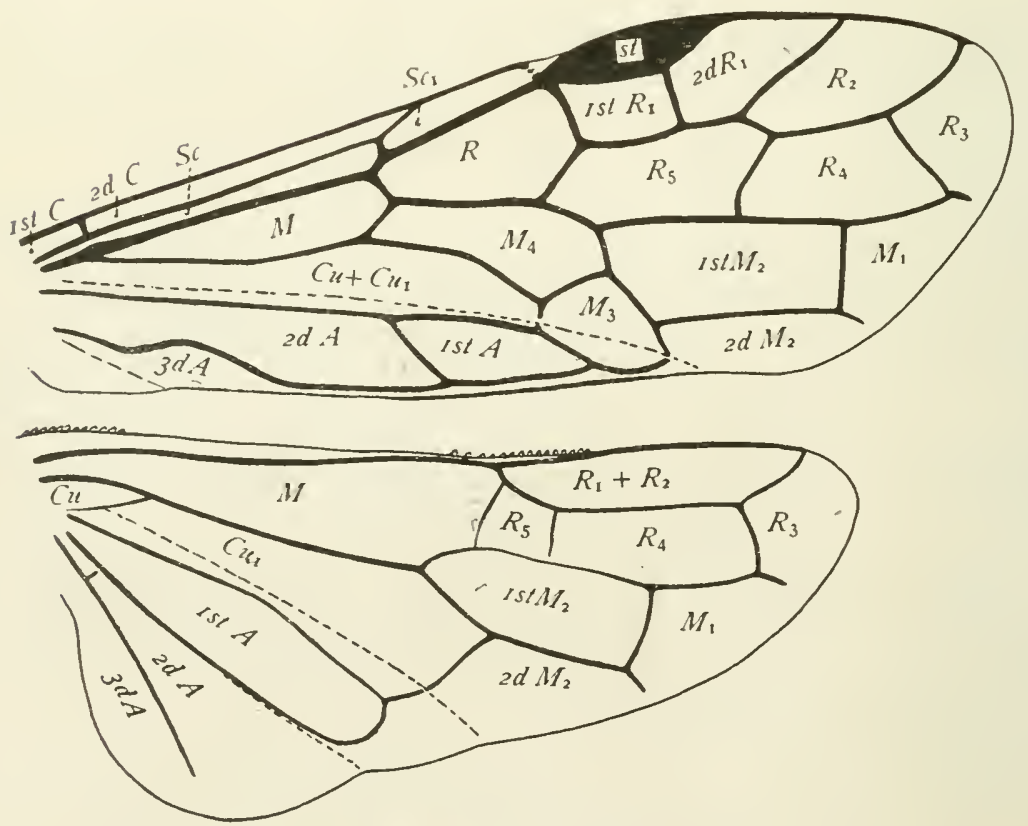

Fig. 392.-Wings of Macroxyela. The cells are lettered. 
the fore wings; in the hind wings, the reduction of the venation is greater than this in all cases. The hind wing of Pamplitius (Fig. 39r) is an example of the most generalized condition found in the hind wings of Hymenoptera.

While the reduction of the venation of the fore wings is slight in the more generalized members of the order, it is extreme in the more specialized

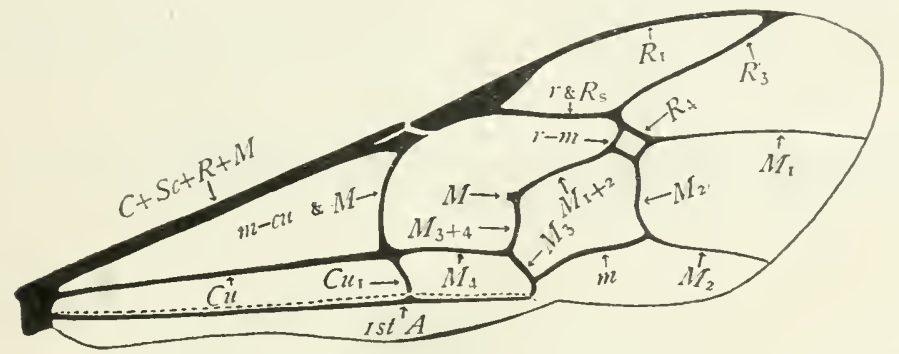

Fig. 393.-Wing of an ichneumon-fly.

families, as in the Chalcididæ, where frequently only a vestige of the wingvenation remains.

In the Hymenoptera, as in other orders where the specialization of the wing-venation is by reduction, the lessening of the number of wing-veins is the result partly of the atrophy of veins and partly of the coalescence of adjacent reins.

The beginning of the atrophy of a vein is illustrated by the subcosta of the hind wing of Pamphilius (Fig. 39I), the basal part of which has faded out. In the hind wing of Macroxyela (Fig. 392) the atrophy of the subcosta is complete. In the fore wing of Pamphilius vein $\mathrm{R}_{2}$ has been lost; and in the fore wing of Macroxyela vein $\mathrm{Cu}_{2}$ is lacking. A comparison of these two wings makes evident the fact that in each case a vein has atrophied.

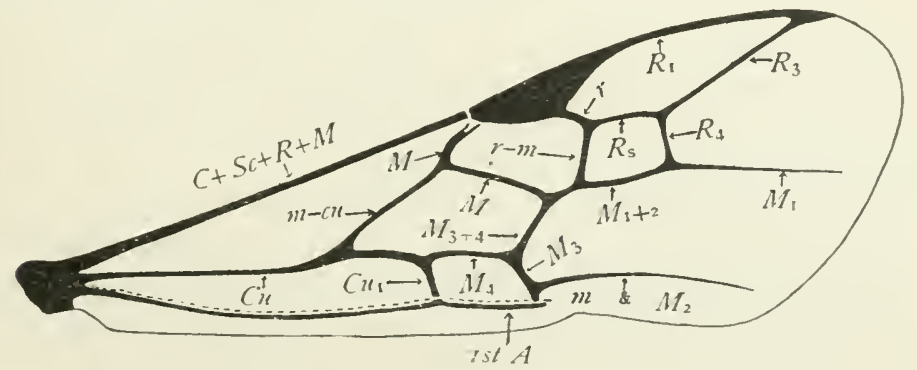

Fig. 394.- - Wing of a braconid.

In Phamphilius no vestige of the lost vein $\mathrm{R}_{2}$ remains. In Macroxyela a bend in the cubitus indicates the position of the former forking of this vein. In many other cases, however, vestiges of lost veins remain either as short spurs or as faint lines. 
Reduction by coalescence.--An excellent illustration of the reduction in number of distinct wing-reins by the coalescence of adjacent reins is to be seen in the fore wing of an ichneumon-fly (Fig. 393), where the thickened margin of the wing, between its base and the stigma, is formed of the united costa, subcosta, radius, and media. A similar condition exists in the fore wing of a braconid (Fig. 394).

In many of the Clistogastra in which the costa remains separate, the subcosta, ladius, and media ccalesce frcm the base of the wing to the stigma.

Modification of the course of a vein by coalescence at base.-Perhaps the best illustration of the modification of the course of a rein by the

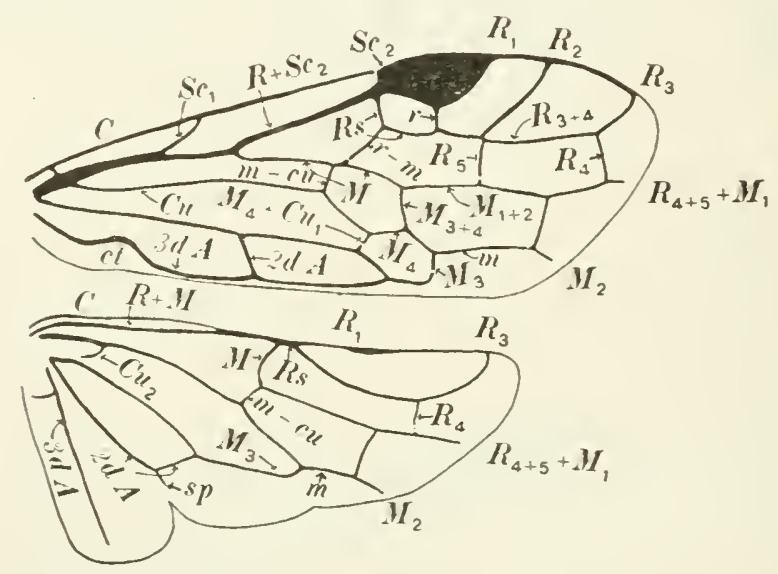

Fig. 395.-Wings of Manoxyela (From MacGillivray).

coalescence of its base with an adjacent rein is that of the media of the fore wing; for in this case a very complete record of the change exists among living Hymenoptera. Correlated with the modification of the course of media are certain changes in the relations of the medio-cubital cross-rein; hence the two reins will be treated together.

In Manoxy'ela, as was shown by Dr. MacGillivray (Fig. 395), the main stem of the media retains a quite primitive course except that the basal part coalesces with the radius for a considerable distance; for from the point where it separates from the radius it extends directly toward the outer margin of the wing. In this genus, the medio-cubital cross-vein also retains a comparatively primitive position (Fig. $395, m-c u$ ).

In Macroxyela (Fig. 392), the medio-cubital cross-rein has migrated towards the base of the wing, the coalescence of the media with the radius has been extended somewhat, and the section of the media between the radius and the medio-cubital cross-vein has become nearly transverse. 
In Apis (Fig. 396), the position of the medio-cubital cross-vein is nearly the same as in Macroxyela; but the coalescence of the media with the radius has extended much farther, with the result that the section of the media that is between the radius and the medio-cubital cross-vein extends backward from the point where it separates from the radius to its junction with the medio-cubital cross-vein; from this point the media extends outward as in the more generalized forms. This results in the course of the main stem of media being Z-shaped.

In the forms in which the condition just described exists, and this is true of a very large portion of the members of the order, the section of the media that is between the radius and the medio-cubital cross-veins forms with this cross-vein what appears to be a cross-vein, extending from the radius to the cubitus, from which the main stem of the media appears to arise. But it is now obvious that this apparent cross-vein is a serial vein consisting of a section of the media and the medio-cubital cross-vein.

In Apis, and in many other genera of the more specialized Hymenoptera, the shortening of the cubitus as a result of an extending of the coales-

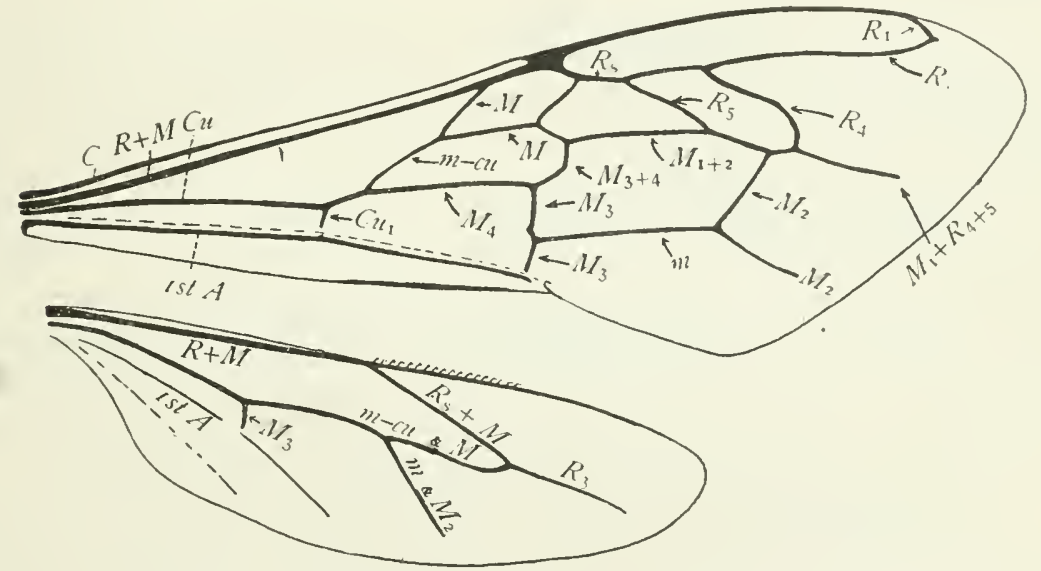

Fig. 396.-Wings of A pis. See Fig. 397, for more detailed lettering.

cence of veins $\mathrm{Cu}_{1}$ and Ist $\mathrm{A}$ has left the cubital end of the medio-cubital cross-vein stranded upon vein $\mathrm{M}_{4}$.

Modification of the course of a vein by the coalescence of its tip with an adjacent vein.-Examples of this, kind of modification of the courses of veins have been described in the discussion of the venation of the wings of the more generalized Hymenoptera. Attention was called there to the changes that have taken place in the courses of the branches of the radial sector, the branches of media, and the branches of cubitus. Some of the modifications of the courses of veins which are evident in the more generalized Hymenoptera are greater in the more specialized Hymenoptera. Note 
for example the course of vein $\mathrm{M}_{4}$ in Apis (Fig. 396). Here this vein extends towards the base of the wing, with the result that the free part of it appears to be a continuation of the cubitus.

Serial veins.-Perhaps the most astonishing and perplexing of the results that have followed the changes in the courses of veins in the wings of the Hymenoptera are those that have resulted in the formation of serial veins; that is reins that appear to be simple veins but which in reality are compound veins composed of sections of two or more reins joined end to end.

Serial veins are discussed in Chapter III (page 69). In addition to the serial vein described there, vein $m \& \mathrm{M}_{2}$ of the braconid wing, the following examples may be cited.

In the fore wing of A pis (Fig. 396), the cubitus appears to extend from the base of the wing to a point near the middle of the wing. But, as shown above, only the basal part of this vein is cubitus, the distal part being vein $\mathbf{M}_{4}$. If reference is made to this rein as a whole, it should be designated as rein $\mathrm{Cu} \& \mathrm{MI}_{4}$.

In the case just cited the formation of the serial vein is the result in a change in the course of one element of it. Another method of the formation of serial veins is by the atrophy of a section of a vein, which leaves the terminal portion of the rein stranded upon some other vein. Vein $m \&$ $\mathrm{M}_{2}$ of the braconid wing was formed in this manner.

A remarkable instance of the atrophy of a section of a vein and the consequent formation of a serial vein that has the appearance of being a simple one is that described by MacGillivray ('o6) as the switching of the base of the radial sector. This example of the formation of a serial vein is of especial interest; for this switching of the base of the radial sector has occurred in the wings of nearly all members of the suborder Clistogastra, and is found in only a few members of the suborder Chalastogastra.

A very complete series illustrating the switching of the radial sector was found by MacGillivray and is shown in Figure 397. Before studying this series, however, let us examine the fore wing of Pamphilius (Fig. 39r) and note the point of origin of the radial sector and the position of the radial cross-vein in what we have accepted as a typical hymenopterous wing.

An examination of this wing and of the very extended series of wings of Chalastogastra figured by MacGillivray, shows that the radial sector separates at or before the base of the stigma, and that the radial cross-vein extends from near the middle of the stigma or from a point beyond the middle, in a more or less nearly transverse direction, to the radial sector.

In Figure 397, $a, b$, and $c$ show a part of the fore wing of three members of the Cephidæ, one of the more specialized families of the Chalastogastra; and $d$ represents the same part in Oryssus, of the Oryssidæ, the family in which the greatest reduction of the wing-venation found in the Chalasto- 
gastra occurs. The other two figures, $e$ and $f$, represent this part of the wing in two members of the suborder Clistogastra, Pelopeus and Apis respectively.

In Macrocephus satyrus (Fig. 397, a) the direction of both the basal part of the radial sector and of the radial cross-vein is oblique; and the radial cross-vein has the appearance of being a longitudinal vein branching from the stigma, and not that of a cross-rein, a foreshadowing of its function in more specialized forms.

In Janus cynosbati (Fig. $397, b)$, a short section of the base of the radial sector near the stigma has faded out. In Janus abbreviatus (Fig. 387 , c), a longer section of this vein is lacking. And in Ory'ssus abietinus (Fig. 397, d), all of the radial sector proximad of the radial cross-vein is lacking; and this cross-vein appears to be the base of the radial sector. Thus is formed a serial vein, consisting of the radial cross-vein and the remnant of the radial sector, which has the appearance of a simple rein. This is the
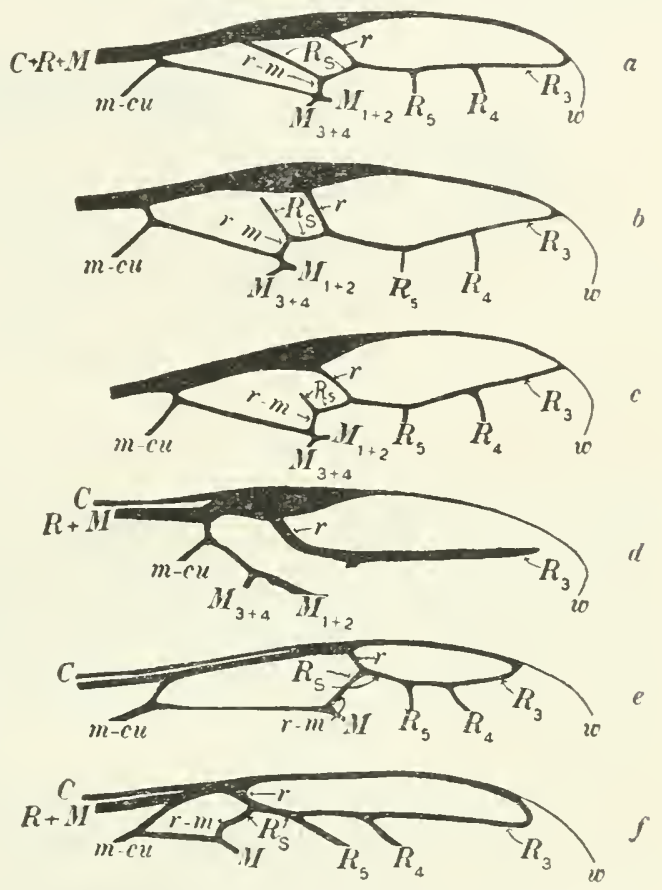

Fig. 397.-The switching of the base of the radial sector (From MacGillivray).

condition that exists in all of the Clistogastra and is illustrated by Pelopæus cementarius (Fig. 397,e) and Apis mellifica (Fig. 397, f)

Figures 398 and 399 , representing two entire wings, will illustrate two stages in this switching of the base of the radial sector. In Janus abbreviatus (Fig. 398), the atrophy of the section of the radial sector between the point where it is joined by vein $r-m$ and the stigma has begun; in Odontaulacus cditus (Fig. 399) the atrophy of this part of the radial sector is complete.

Corrclated with the series of changes just described are changes in some adjacent parts that merit description, and which were also pointed out by Dr. MacGillivray. The parts referred to are the radio-medial cross-vein and that part of the radial sector that lies between the radio-medial crossvein and the radial cross-vein. 
In Oryssus (Fig. 397, d), a form in which there has been a great reduction of the wing-veins, these parts are both wanting. But in the other forms shown in Figure 397 these parts are retained. In the first three (Fig. 397, $a, b, c)$ these two parts taken together constitute a slightly bent rein; in the fifth (Fig. 397, e) they form a perfectly straight vein; and in the last (Fig. $397, f$ ), one that is slightly bent.

In the last two forms, and in nearly all other members of the Clisto-

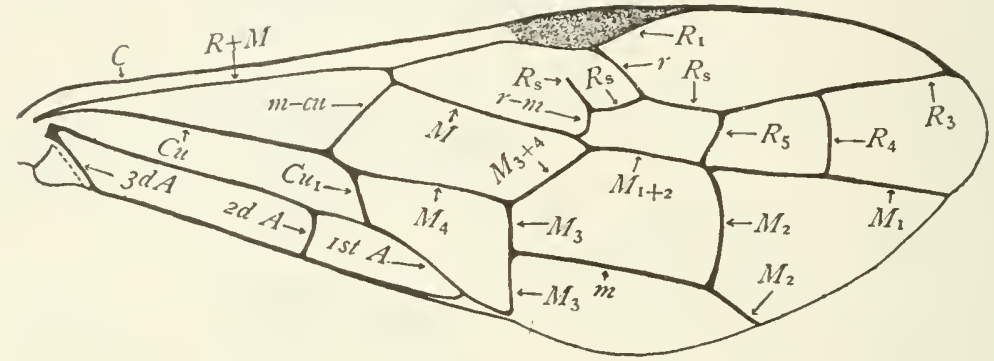

Fig. 398.-A fore wing of Janus abbreviatus.

gastra, there is no trace of that section of the radial sector extending from the radio-medial cross-vein to the stigma; hence there is nothing to indicate the compound nature of the vein composed of the radio-medial cross-rein and that section of the radial sector betreen this rein and the radial crossrein. For this reason this serial vein was formerly believed to be merely the radio-medial cross-vein. It should now be designated as vein $r-m$ $\& R_{\mathrm{s}}$.

The switching of the base of the radial sector and the changes described in the two preceding paragraphs were not understood until the publication of Dr. MacGillivray's paper in I906. As Comstock's Mamual for the Study

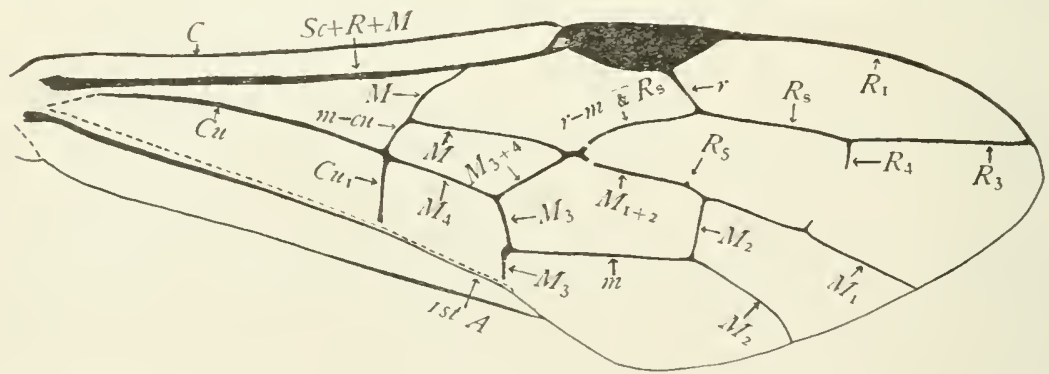

Fig. 399.-A fore wing of Odontavlacus editus.

of Insects, in which was made the first attempt to apply the uniform terminology of the wing-veins to the wings of Hymenoptera, was published in I $_{95} 5$. the figures of wings of the Clistogastra in that work are, in some respects, incorrectly lettered. 


\section{(e) AN ILlUStration OF THE REDLCTION OF THE WING-VENATION IN} HYMENOPTERA

Having determined the homologies of the wing-veins in the more generalized members of the Hymenoptera and having attained an understanding of the various ways in which the typical wing-venation is modified in the more specialized forms, it is now comparatively easy to trace the

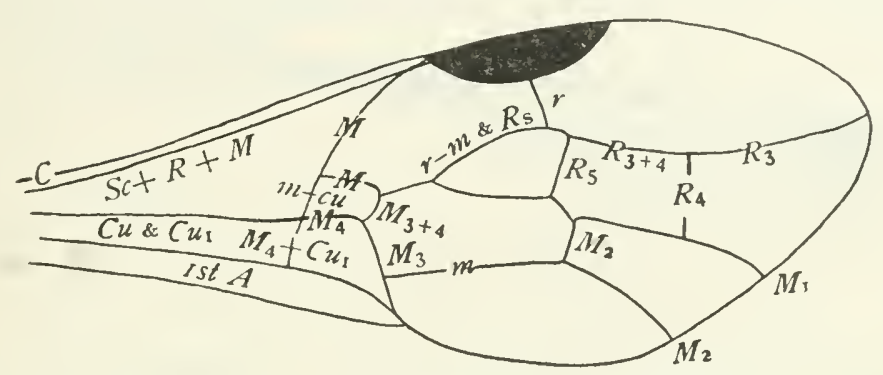

Fig. 400.-Fore wing of Aulacinus fusiger (After Bradley).

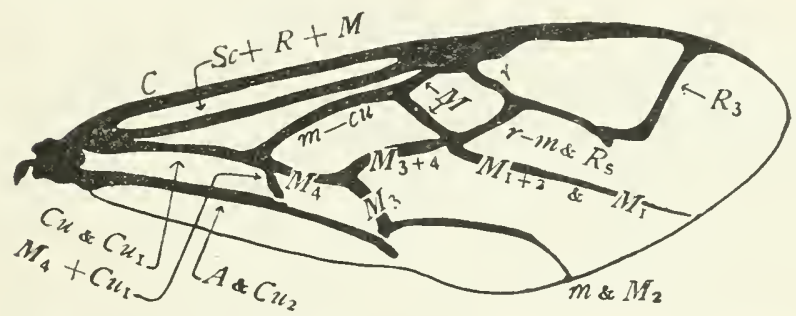

Fig. 401.-Fore wing of Evania appendigaster (After Bradley).

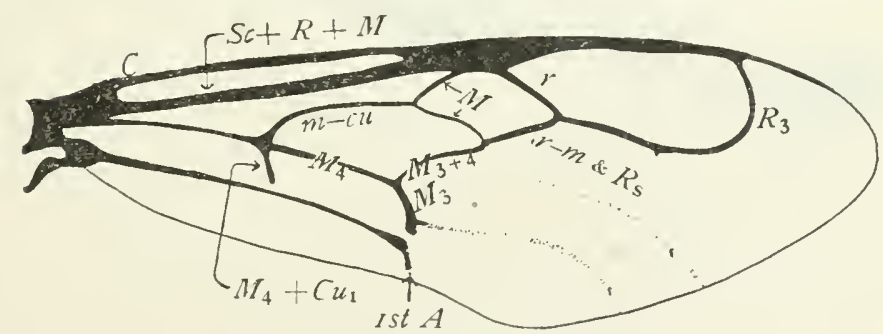

Fig. fo2.-Fore wing of Acanthinevania princips.

homologies of the wing-reins in all of the families of this order in which the venation of the wings is not greatly reduced.

There are, however, certain families in which the various methods of modifying the primitive type of wing-renation have progressed so far that it is cxceedingly difficult to determine the nature of the result and the steps by which it has been reached. It is in this field that lies the greater amount of the work that remains to be done to complete our understanding of the 
wing-venation of the Hymenoptera, an understanding which will doubtless make available much data of great value in working out the relationships of the various divisions of the order.

The only way in which the identity of the remaining reins in a wing in which the renation is greatly reduced can be satisfactorily determined is by comparison with allied forms in which the reduction has not been carried so far. And the more complete the series that can be found illus-

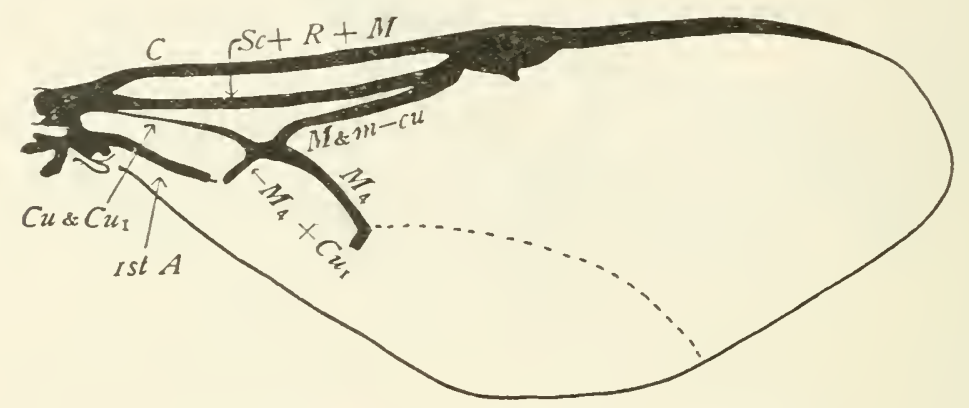

Fig. 403.-Fore ring of Semcodogaster bartirensis.

trating the successive steps in the modification of the wing-venation the more satisfactory will be the conclusion.

As an illustration of this method of study and of the results that can be obtained by it I include here a series of figures taken from Professor Bradley's monograph of the Evaniidæ (Bradley 'o8).

Figure 400 represents the renation of the fore wing of Aulacinus fusiger,

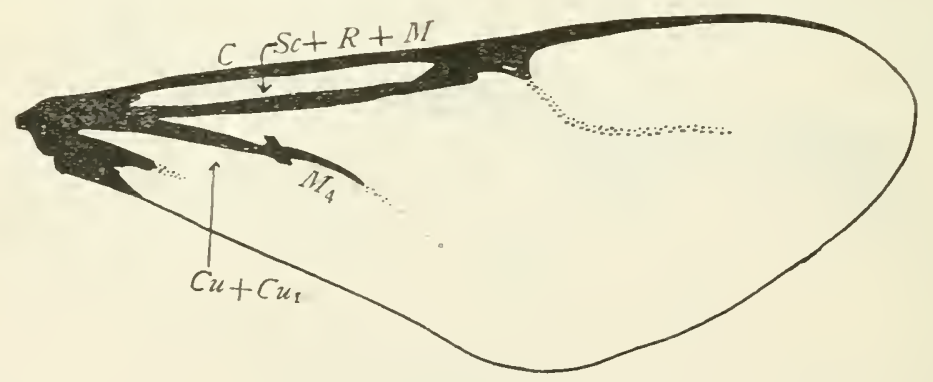

Fig. 404.-Fore wing of Ilyplia.

a member of the subfamily Aulacinæ. This is selected as the first of the following series as it is the most generalized wing of the family. Note that veins $R_{4}, R_{5}$, and all of vein $I_{2}$ are present.

It is in the subfamily Evaniinæ that the most extensive modification of the wing-renation is found; for this reason the remaining members of this series of figures have been selected from those illustrating this subfamily. 
Figure 401 represents the venation of the fore wing of Evania appendigaster; in this wing the modifications of the evaniid type as illustrated by Aulacimus are not great. Veins $R_{4}$ and $R_{5}$ are lost, and also the transverse part of vein $\mathrm{M}_{2}$. The coalescence of media with radius has progressed

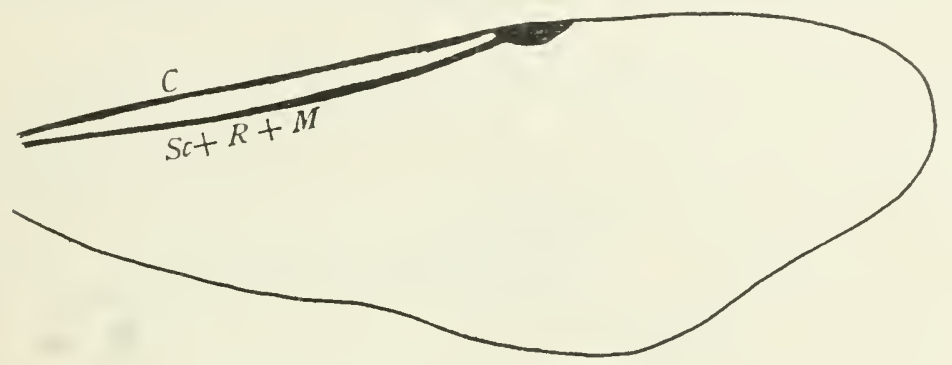

Fig. 405.-Fore wing of Evaniellus.

farther; this has resulted in a striking change in the direction of the crossvein $m-c u$.

The reduction of the wing-renation by the atrophy of veins which is well under way in Erania has been carried farther and farther in the successive forms represented in this series of figures (Fig. 402, 403, 404, and 405) until in the last, Eraniellus, only two veins are left; these are the costa and vein $\mathrm{Sc}+\mathrm{R}+\mathrm{M}$. 


\section{CHAPTER XXYI}

\section{THE TEACHING OF THE UNIFORM TERMINOLOGY OF THE WING-VEINS OF INSECTS}

\section{SLGGESTIONS TO TEACHERS}

$\mathrm{MtCH}^{\mathrm{C}}$ use is now made in systematic entomology of the characters presented by the wing-reins of insects. It is important, for this reason, that the student should acquire, early in his study of insects, a clear knowledge of the fundamental type of wing-venation, of the ways in which this type has been modified in the different orders of insects, and of the uniform terminology used in describing the wing-reins.

The following outline of a course of study in this field is offered in the hope that it may be of service to teachers; it is based on an outline that has been in use in the entomological laboratory of Cornell University for many years, where the work indicated in it has formed a part of the introductory courses in entomology.

These courses have been planned to meet the needs of two classes of strdents: first, those students who are specializing in entomology; and second, those students who take only a general lecture course and the accompanying practicums in this subject.

The students who are specializing in entomology are furnished mounted specimens of the wings to be studied whenerer it is practicable to do so, and are required to make drawings of them representing the wing-renation. In those cases where wings are not available for use in the laboratory, figures of the wings in which the veins are not lettered are furnished. In either case the student determines the homologies of the wing-veins and records his conclusions by lettering the veins in his figures. Each figure is criticised by the instructor before a nother wing or figure is issued for study. This is of prime importance; for without such criticism an error made in one figure is likely to be repeated in the next, and an incorrect conclusion becomes established in the mind of the student.

The course outlined here is merely an introductory course in which the student becomes grounded in the fundamental principles of the study of wing-venation. The wings to be studied in it have been selected with a view to illustrate the various ways in which the primitive type of wingvenation has been modified in the course of the evolution of recent forms.

This course of study, or one of similar scope, should be completed before the student is encouraged to undertake an investigation of the wing-renation of a particular group of insects, as a family or an order; he should be impressed with the fact that the interpretation of renational characters must be based upon a knowledge of the various ways in which the wing- 
venation has been modified in other groups of insects than that which he is studying; and that the easiest way to gain this knowledge is by a study of a carefully selected series of wings illustrating these modifications.

Having obtained the essential preliminary knowledge, the student can then proceed profitably with his investigation. He should first determine which are the most generalized wings to be found in the group of insects that is being studied, the wings that most closely resemble the hypothetical primitive type; and when this has been done, he should determine the various ways in which the more specialized wings have been modified.

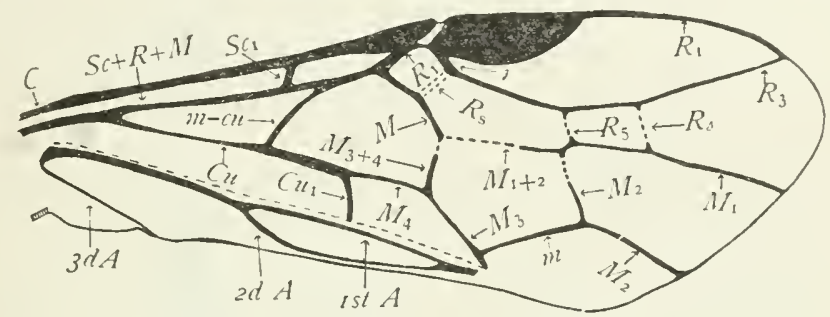

Fig. 406.-Fore wing of Pteronidea ribesii.

In planning the work to be done in practicums accompanying a general introductory lecture course, one is hampered by the limited amount of time that can be devoted to each division of the more general subject. It is obviously impracticable to require the students to make many drawings of wings; on the other hand, it is essential that they should have practice in determining the homologies of the wing-veins in a considerable number of

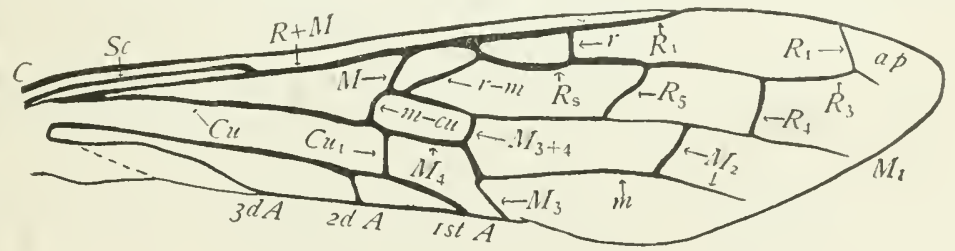

Fig. 407.-Fore wing of Sirex.

wings, if they are to gain a knowledge that will enable them to make use of the analytical tables in the text books in which wing-renational characters are used.

We have met this difficulty by requiring these students to make drawings of only one or two wings, just enough to give them a little experience in the study of actual wings, and then furnishing them with figures of wings in which the veins are not lettered. These figures are issued one at a time, and each is to be properly lettered before another one is issued.

Lettered figures of most of the wings used in this course are given in the preceding pages; the others, two in number, are represented by Figures 406 and 407 . 


\section{MATERIALS NEEDED FOR THIS COURSE}

A wall chart showing the hypothetical tracheation of a wing of the primitive nymph. This is a copy of Figure 4 I I of the following outline and is used in an introductory lecture in which the fundamental principles, briefly indicated in the introduction to the outline, are more fully explained.

Mounted wings to be studied by the students specializing in entomology. It is well to have several sets of these, so that more than one student can be studying the same kind of wing at the same time. If the mounts are carefully used, they will serve for many successive classes.

Mounted wings for use in practicums. A limited number of kinds will be required; but there should be as many mounts of each kind as there are students in a section of the class, as all will need the same kind of wing at the beginning of the practicum.

Sets of printed figures of wings for use in practicums, where the students do not have the time necessary for making original drawings of all of the kinds of wings studied, and for use in other cases when desired. These sets can be obtained of The Comstock Publishing Company, Ithaca, N. Y. Each figure is printed on a separate sheet. Figure 408 is a copy of one of these figures.

A printed outline, one for each student, of the laboratory work in this subject. This outline consists of a reprint of the following pages of this chapter. The preceding pages, being merely suggestions for the use of teachers, are not included in the outline of laboratory work. Copies of this outline can be obtained also of the publishers of this volume.

Red ink for marking the lines representing media and its branches in the figures of wings. The use of red ink for this purpose adds greatly to the clearness of the figures. In those cases where the stem of media or any of its branches coalesce with another vein, this fact should be indicated by drawing a red line, indicating the course of media, closely parallel with the black line indicating the course of the rein with which media coalesces. Red ink is also used for lettering the cells of the wings.

Blank paper uniform in size with that upon which the figures are printed for use in making the notes called for in the outline. This will permit the keeping together of the drawings and notes for reference. 


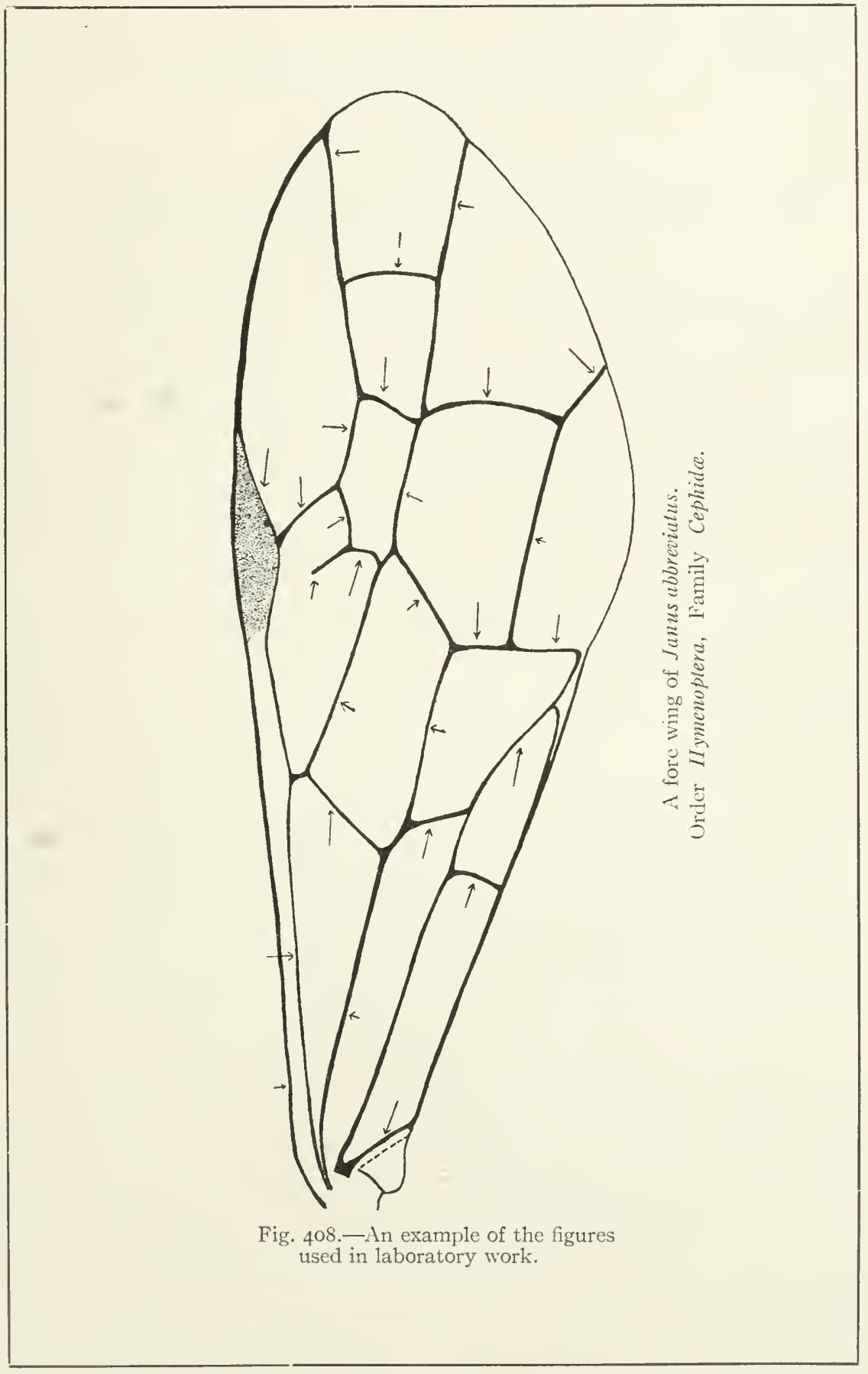





\section{OUTLINE OF LABORATORY WORK IN THE STUDY OF THE VENATION OF THE WINGS OF INSECTS*}

\section{INTRODUCTION}

In form an insect's wing is a large, membranous appendage, which is thickened along certain lines. These thickened lines are termed the veins or nerves of the wing; and their arrangement is described as the venation or neuration of the wings.

It has been found that the venation of the wings of closely allied insects is very similar, and that great differences in this respect exist between insects remotely connected. Hence, the wings afford excellent characters for use in the classification of insects. In fact, as slight differences in venation are easily observed, the wings being spread out like an open page, these differences are probably the most available characteristics of winged insects for taxonomic work. It is important, therefore, that the student of entomology should learn early in his course the more important facts regarding this subject.

A careful study of the wings of many insects has shown that the fundamental type of venation is the same in all of the orders of winged insects. But this fact is evident only when the more primitive or generalized members of different orders are compared with each other. In most of the orders of insects the greater number of species have become so modified or specialized as regards the structure of their wings that it is difficult at first to trace out the primitive type.

Note.-The student should have a clear idea of the significance of the terms generalized and specialized, which are now much used in biology. Generalized indicates a primitive condition, a nearness to ancestral forms. Thus, the most generalized member of a group (as a family or an order) is that member which most clearly resembles the ancient progenitor of that group. Specialized, on the other hand, indicates remoteness from the primitive type, an adaptation to more special conditions of existence. Thus, the most specialized member of a group is the one that departs most widely from the ancient progenitor of that group.

These terms are used in a comparative sense; thus, a highly specialized form may be regarded as generalized when compared with forms that are still more highly specialized.

This agreement in the important features of the venation of the wings of the generalized members of the different orders of insects is still more evident when the wings of nymphs and pupæ are studied. It has been demonstrated that in the development of the wings of generalized insects the longitudinal wing-veins are formed about preexisting trachex. In the course of the development of the wing, these trachere grow out into the wing-bud, and later the wing-veins are formed about them.

*'The material for this outline has been drawn largely from The Elements of Insect Anatomy, by John Henry Comstock and Vernon L. Kellogg, published by the Comstock Publishing Company, Ithaca, N. Y. 
The wings of nymphs and pupæ are broad at the base, and consequently the tracher that precede the wing-reins are not crowded together as are the wing-reins at the base of the wings of adults. For this reason the identity of the ming-reins can be determined more surely in the wings of nymphs and

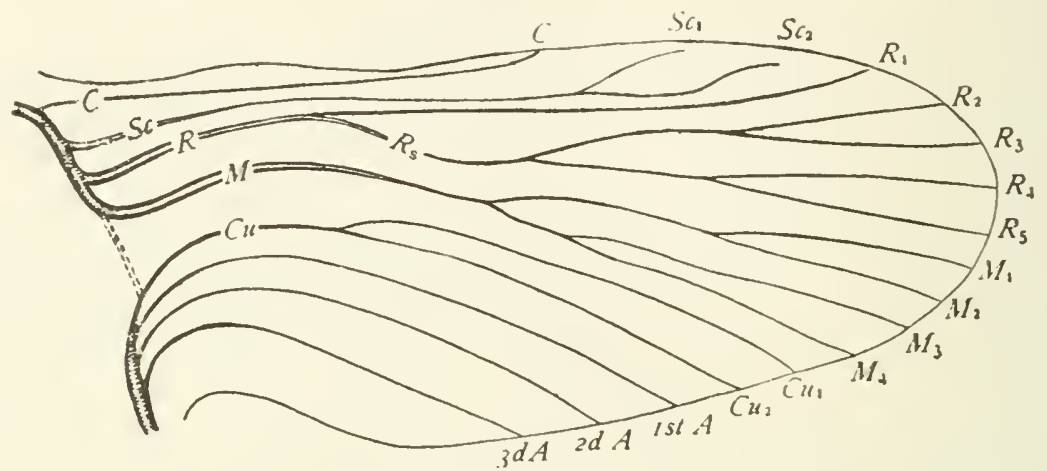

Fig. 409.-Hypothetical tracheation of a wing of the primitive nymph.

pupæ than they can be in the wings of adults. This is especially true where two or more veins coalesce in the adult wing while the tracheæ that precede these veins are distinctly separate in the immature wing.

A study was made of the tracheation of the wings of nymphs and pupæ of representatives of most of the orders of insects, and, assuming that those features that are possessed by all of these must have been inherited from a common ancestor, a diagram was made representing the hypothetical tracheation of a nymph of the primitive winged insect, (Fig. 409). In this diagram the tracher are lettered with the abbreviations used in designating

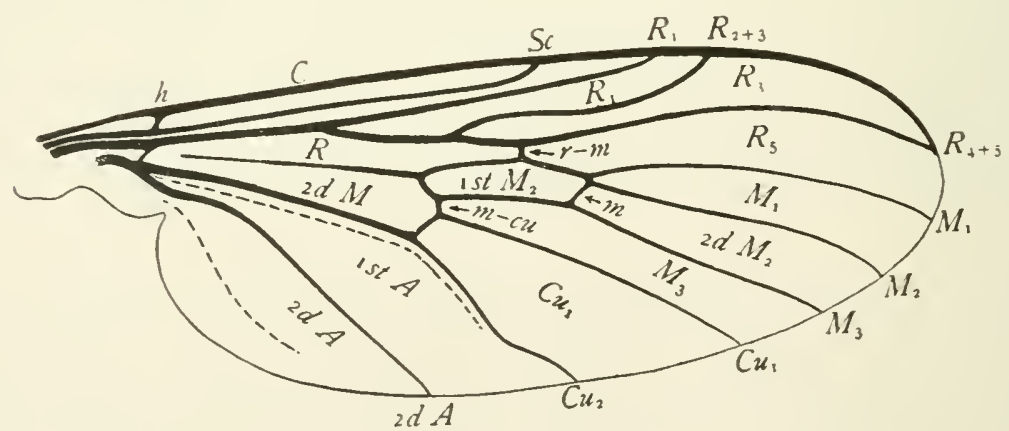

Fig. 410.-A wing of Rhyphus, with the veins and cells lettered.

the veins that are formed about them in the course of the development of the wing. The diagram will serve, therefore, to indicate the typical renation of an insect wing, except that the tracheæ are not crowded together at the base of the wing as are the veins in the wings of adults. 
Figure 4 IO represents the wing of an adult fly of the genus Rhyphus. This wing is comparatively generalized, but in several respects it departs from the primitive type; the radius has been reduced to a three-branched condition; the media is also reduced to a three-branched condition; only vestiges of the first and third anal veins remain; these are represented by dotted lines; and a part of the stem of media is atrophied.

By studying a wing of Rhyphus and the accompanying figure (Fig. 4ro) the student can gain a good idea of the type of the wings of insects balonging to the order Diptera, and have a standard with which to compare wings of insects of other orders.

Longitudinal veins and cross-veins. - The veins can be grouped under two heads: first, longitudinal veins, those that normally extend lengthwise the wing; and second, cross-veins, those that normally extend more or less nearly transversely. In Figure +10 , three of the cross-veins are indicated by arrows, near the middle of the wing; two other cross-veins are represented near the base of the wing. All other veins represented in this figure are longitudinal veins.

The insertion of the word normally in the above definitions is important; for it is only in comparatively generalized wings that the direction of a vein can be depended upon for determining to which of these two classes it belongs. A little later the student will study wings in which the direction of some of the longitudinal veins has been so modified in the course of specialization that they extend transversely (i.e., cephalo-caudad), and some cross-veins extend in a longitudinal direction (i.e., proximo-distad).

Simple veins and branched veins.--Veins are either simple or branched. The veins lettered $S c$ and $2 d A$ in Figure 4 Io are simple veins; between these there are three branched veins.

In the case of branched veins the entire vein, including all of its branches is often referred to as a single vein. Thus the third vein in the wing Rhyphus, counting the thickened, cephalic margin of the wing as the first vein, is termed the radius or vein $R$; and by this expression we include both the main stem of the vein and its three divisions. On the other hand, each division of a branched vein is often termed a vein. Thus the first division of the radius, counting from the cephalic margin of the wing, is termed radius-one or lein $R_{1}$, and the second division, radius-tws or vzin $R_{3}$, and so on till all are numbered.

Note.-In the most generalized flies known to us, the radius is five-branched. But in most flies some of the branches of this vein coalesce so that the number of apparent branches is less than five. In Rhypus veins $R_{2}$ and $R_{3}$ coalesce so as to appear as a single vein. In order to indicate that this apparently simple vein is composed of two vcins, and in order that homologous veins in different insects shall bear the same designation, this compound vein is termed radius-two-plus-three or vein $R_{2}+3$. In the same way, what appears to be the third branch of the radius in Rhyphus is really the fourth and fifth coalesced, and is, therefore, designated as radius-four-plus-five or vein $R_{4}+5$. . The tracing out of thehomologies of the branches of veins is often very difficult; but it is of the greatest importance in determining the relationships of different genera or of families. 
Names of the longitudinal wing-veins.- There have been many different sets of names applied to the reins of wings. Not only have the students of each order of inscets had a peculiar terminology, but in many cases different writers on the same order have used different sets of terms. This condition of affairs was incident to the beginning of the science, the period befcre the correspondence of the reins in the different orders had been worked out. But now the time has come when it is practicable to apply a uniform terminology to the longitudinal wing-veins of all orders; and the following set of terms has been proposed for that purpose:

Costa.-The vein extending along the cephalic or costal margin of the wing is the costa.

Subcosta.-Immediately caudad of the costa and extending parallel with it, is a rein, which is usually simple in flies; this is the subcosta (Fig. 410, Sc).

Radius.-Immediately caudad of the subcosta there is a rein which in generalized insects is always branched; this is the radius. In Rhy'phus, the radius is three-branched (Fig. 4 Io, $R_{1}, R_{2}+3$, and $R_{4}+5$.)

The radial sector. - When the radius preserves its primitive mode of branching, it separates at its first fork into two unequal parts; the first of these is vein $R_{1}$; the other gives rise to the remaining four branches of the radius (Fig. 408). This second part of the radius, including its branches, is termed the radial sector or iein $R_{\mathrm{s}}$.

Media.-Traversing the middle of the wing there is a longitudinal rein which is always branched in generalized insects; this is the media. In Rhyphus the media is only three-branched (Fig. $410, M_{1}, M_{2}$, and $M_{3}$ ) and a part of its stem is atrophied.

Cubitus.-The third and last of the branched veins in flies is the cubitus. This rein is two branched in Rhyphus (Fig. $410, C u_{1}$ and $C u_{2}$ ).

Anal reins.-Caudad of the cubitus there is in Rhyphus a single welldeveloped vein; this is termed an anal vein. As in more generalized insects there are three anal veins, and as this is the second of the series, it is designated the second anal vein (Fig. 4Io, 2d A). Vestiges of the first and third anal veins persist in Rhyphus; these are indicated in the figure by dotted lines.

Designation of the longitudinal wing-veins by numbers.-Several writers have designated the longitudinal wing-veins by numbers. In Comstock's Manual for the Study of Insects both the names given above and numbers are used. The following table indicates the correspondence of the names and numbers.
Costa $=$ vein $I$.
Cubitus $=$ vein VII
Subcosta $=$ vein II.
Radius $=$ vein III.
Media $=$ vein $\mathrm{V}$.
Ist anal vein $=$ vein VIII.
$2 \mathrm{~d}$ anal vein $=$ vein $\mathrm{IX}$.
$3 \mathrm{~d}$ anal vein $=$ vein $\mathrm{X}$.

It will be observed that in the above table the numbers IV and VI are omitted. At the time the Manual for the Study of Insects was published, it was believed that 
two other longitudinal veins (the so-called premedia and postmedia) were present in certain orders of insects, and the numbers IV and VI were applied to these veins. It has since been determined that this conclusion was based on an error.

Certain writers number the wing veins without omitting the numbers IV and VI, designating the media as vein IV and the cubitus as vein $\mathrm{V}$.

There are still other writers who do not regard the costa as a true vein, and, therefore, designate the subcosta as vein I.

The result is that there are three distinct systems of numbering the wing-veins, in addition to several old systems which were applied to single orders. It seems better, therefore, to designate the wing-veins by names, and use abbreviations of these names in lettering figures.

Names of the cross-veins. - In the wings of certain insects, as the dragon-flies, the May-flies, and others, there are many cross-veins; it is impracticable in cases of this kind to name them. But in several of the orders of insects there are only a few cross-veins, and these have been named. Figure 4II represents the hypothetical primitive type of wing-

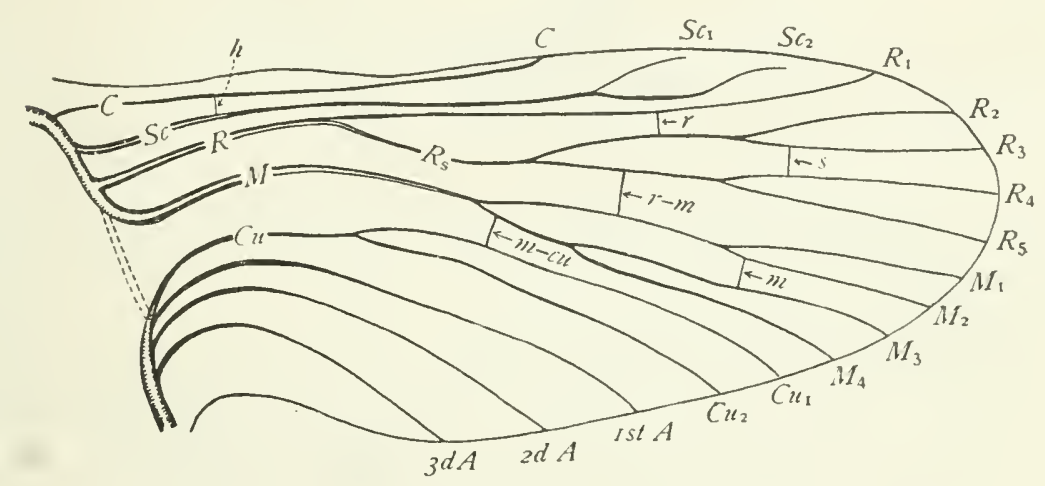
Fig. 411.-Hypothetical type of wing-venation with the named cross-
veins added.

venation with the named cross-veins added in the positions in which they normally occur; these are the following:

The humeral cross-vein. - This extends from subcosta to costa near the humeral angle of the wing (Fig. 4I I, $h$ ).

The radial cross-vein.- This extends between the two principal divisions of radius, $i$. e. from vein $\mathrm{R}_{1}$ to vein $\mathrm{R}_{\mathrm{S}}$ (Fig. $4 \mathrm{II}, r$ ).

The sectorial cross-vein. - This extends between the principal divisions of the radial sector, $i$. e. from vein $R_{2}+3$ to vein $R_{4}+5$ or from vein $R_{3}$ to vein $R_{4}$ (Fig. 4II, s).

The radio-medial cross-vein.-This extends from radius to media, usually near the center of the wing, (Fig. 4II, $r-m$ ). When in its typical position this cross-vein extends from vein $\mathrm{R}_{4+5}$ to vein $\mathrm{M}_{1+2}$.

The medial cross-vein. - This extends from vein $\mathrm{M}_{2}$ to vein $\mathrm{M}_{3}$ (Fig. $4 \mathrm{II}, \mathrm{m})$. This cross-vein divides cell $\mathrm{M}_{2}$ into cells ist $\mathrm{M}_{2}$ and $2 \mathrm{~d} \mathrm{M}_{2}$; see Figure 4Io, where the cells are lettered. 
The medio-cubital cross-vein.-This extends from media to cubitus (Fig. $4 \mathrm{I}, \mathrm{m}-\mathrm{cul})$.

The arculus.-In many insects there is what appears to be a cross-vein extending from the radius to the cubitus near the base of the wing. This has been termed the arculus by writers on the Odonata, and the use of this term has been extended to all orders in which there is a similar arrangement of the veins in this part of the wing. The arculus is designated by the abbreviation ar. Usually when the arculus is present the media appears to arise from it. The fact is, the arculus is compound, being composed of a section of the media and a cross-vein. The structure of this part can be clearly seen in the Odonata (Fig. 412). In Rhyphus (Fig. 410) the arculus appears as a simple cross-vein extending from the radius to the cubitus, and a part of the base of the media is atrophied.

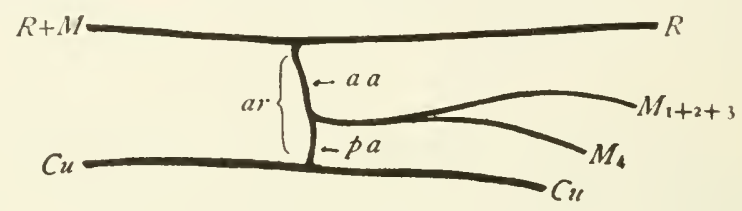

Fig. 412.-The arculus of a dragon-fly.

That part of the arculus which is a section of media is designated as the anterior arculus (Fig. 412, $a$ a), and that part formed by a cross-vein, the posterior arculus (Fig. 412, $p a$ ).

Designation of the cells of the wing.-The thin spaces of the wings which are bounded by the veins are called cells. In descriptions of wings it is often desirable to refer to one or more of the cells. It is necessary, therefore, to have a terminology of the cells of the wing, as well as of the wingveins.

Having named the wing-veins, the simplest possible method of designating the cells of the wing is to apply to each the abbreviation of the name of the vein that forms its cephalic (front) margin. It should be borne in mind, however, that by modifications of the typical arrangement of the wing-veins, a vein that normally forms the cephalic margin of a cell may bear a very different relation to it; and this must be taken into account if we are to apply the same term to homologous cells throughout the insect series.

The cells of the wing fall naturally into two groups: first, those on the basal part of the wing; and second, those nearer the distal end of the wing. The former are bounded by the principal veins; the latter, by the branches of the forked veins; a corresponding distinction is made in designating the cells. Thus the cell lying behind the main stem of the radius and on the basal part of the wing is designated as cell $R$; while the cell lying behind radius-one is designated as cell $R_{1}$. 
It should be remembered that the coalescence of two veins results in the obliteration of the cell that was between them. Thus when veins $R_{2}$ and $R_{3}$ coalesce, as in Rhyphus (Fig. $4 \mathrm{IO}$ ), the cell lying behind $R_{2}+3$ is cell $R_{3}$, and not cell $R_{2}+3$, cell $R_{2}$ having been obliterated.

When one of these principal cells is divided into two or more parts by one or more cross-reins, the parts may be numbered, beginning with the proximal one. Thus in Rlyyphus (Fig. 4 Io) cell $M_{2}$ is divided by the medial cross-vein into two parts, which are designated as cell ist $M_{2}$ and cell $2 d M_{2}$, respectively.

There are many cases where two or more adjacent cells have been united by the atrophy of the rein or reins separating them. A compound cell thus formed is designated by a combination of the terms applied to the elements of the compound cell. When, for example, the stem of media is atrophied, the cell resulting from the combination of cells $R$ and $M$ is designated as cell $\mathrm{R}+\mathrm{M}$.

The application of this system of naming cells of the wing is an easy matter
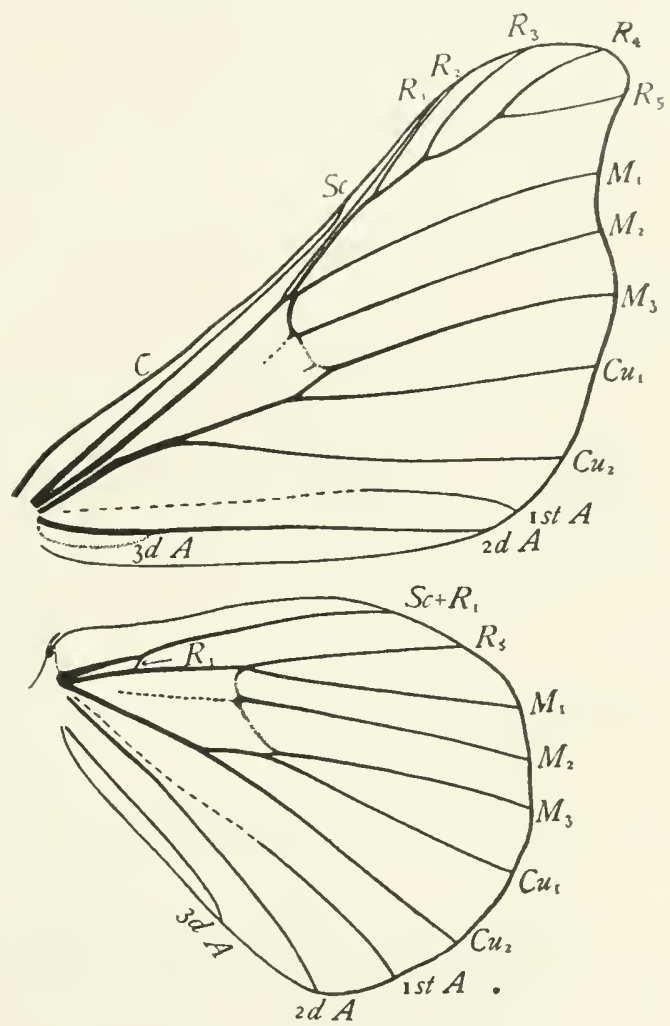

Fig. 413.-Wings of Bombyx mori. in those orders where the wings have few veins; but in those orders where many secondary veins are developed it is more difficult of application. In the latter case we have to do with areas of the wing rather than with separate cells. Thus, for example, it will be seen later that in certain Neuroptera the area $R_{2}$ is divided by several longitudinal veins, which are connected by many cross-veins, the area $R_{2}$ (which is strictly homologous with cell $\mathrm{R}_{2}$ ) being composed of a large number of secondary cells.

The corrugations of the wings. - The wings of comparatively ferv insects present a flat surface; in most cases we find that the membrane is thrown into a series of folds of corrugations. This corrugating of the wing in some cases adds greatly to its strength. This is well shown by the wings of 
dragon-flies; and in most orders, the costal margin of the wing is strengthened by a fold between the costa and the radius, the subcostal fold. In other cases, the corrugations are the result of a folding of the wing when not in use; this is well shown in the anal area when this part is broadly expanded.

It rarely happens that there is occasion to refer to individual members of either of these classes of folds, except, perhaps, to the one that has just been designated as the subcostal fold.

The furrows of the wings. - There are found in the wings of many insects one or more suture-like grooves in the membrane of the wing; these are termed the furrows of the wing. The following furrows have received distinctive names. They occur chiefly in the fore wings.

The anal furrow.-The anal furrow is usually either between the cubitus and the first anal vein or it is coincident with the first anal vein which it may supplant in forms in which the renation of the anal area is reduced. This is the case in the Lepidoptera and the Diptera, and is well-shown in the

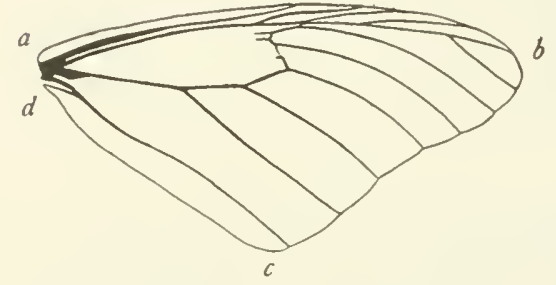

Fig. 4I 4.-Diagram of a wing showing margins and angles. wings of Bombyx mori (Fig. 413), in which a vestige of the first anal rein is preserved near the margin of the wing.

The median furrow.-This is a longitudinal furrow which is usually between the radius and the media. It is well-marked in many of the Hemiptera, where it separates the embolium from the remainder of the coirum; and in the Hymenoptera its course is marked by a series of weak spots (bullæ) in certain veins.

The nodal furrow.-This is a transverse suture beginning at a point in the costal margin of the wing, corresponding to the nodus of the Odonata, and extending towards the inner margin of the wing. It crosses a varying number of veins in different orders of insects.

The axillary furrow. -The axillary furrow is a suture-like line extending from the base of the wing to the inner margin; it ends at the axillary excision (a notch near the base of the wing) when this is present.

Margins of wings. - An insect's wing is more or less triangular in outline; it, therefore, presents three margins; the costal margin (Fig. 414, $a-b$ ); the outer margin (Fig. $414, b-c$ ); and the inner margin (Fig. 414,c-d).

Angles of wings.- The angle at the base of the costal margin (Fig. $4 \mathrm{r} 4, a)$ is the humeral angle; that between the costal margin and the outer margin (Fig. 4I4, b) is the apex of the wing; and the angle between the outer margin and the inner margin (Fig. $4 \mathrm{I} 4, \mathrm{c}$ ) is the anal angle. 
IDENTIFICATION OF THE WING-VEINS AND OF THE CELLS OF THE WINGS IN DIFTERA

The Diptera constitute a highly specialized order of insec ts in which only one pair of wings has been preserved as organs of flight, and in most cases the venation of the remaining pair of wings exhibits striking variations from the primitive type. But in some members of the order the venation of the wings is nearly typical; and, as varying degrees of departure from the typical form exist, by studying a carefully selected series of wings one can obtain a knowledge of the manner in which the more striking variations from the primitive type have been evolved.

In the wings of Protoplasa fitchii, one of the most generalized members of the order Diptera, the va riations from the typical form are comparatively slight (Fig. 4I5).

Note that while the costal trachea in the wings of nymphs and pupre extends parallel with the costal margin of the wing, but at some distance from it, as shown in Figure 409 , in the wings of adults the costal vein coincides with the costal margin of the wing (Fig. 4I5, C).

In Protoplasa fitcliii the subcosta is forked and the radius is fivebranched; these are two generalized features rarely found in the Diptera, usually the subcosta is not forked and the number of the branches of the radius is reduced.

In all Diptera known to me except Protoplasa fitchii, media is only threebranched. In lettering his drawings, the student may omit any reference to vein $\mathrm{M}_{4}$, as is done in the figure of the rving of Rhyphuts above.

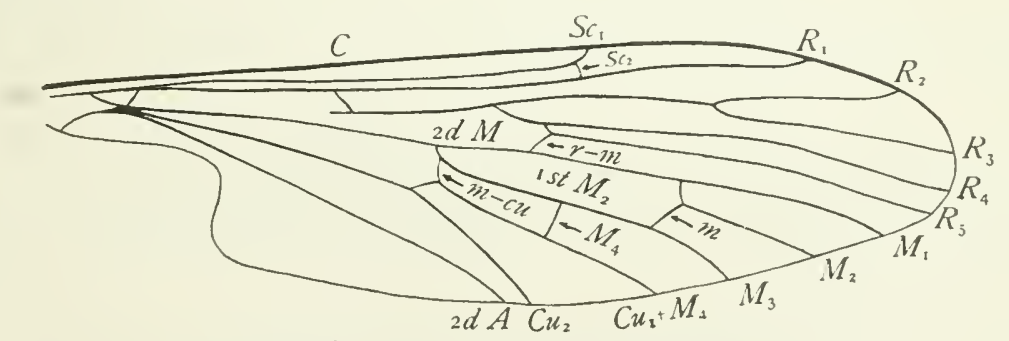

Fig. + I 5. - A wing of Protoplasa fitchii.

In most Diptera the first anal vein has atrophied; but there is usually a vestige of it, which is a suture-like line parallel with rein $\mathrm{Cu}$; this is known as the anal furrow; it is represented in the figure of the wing of Rhyphus by a dotted line. In Rhyphus there is also a vestige of the third anal vein, represented in the figure by a dotted line.

Directions for the study of wings.- Make a drawing of the wing, based upon a careful study of it with a compound microscope, using a low power. The drawing should be first made with a pencil; after it has been criticised by the teacher, the lines should be inked; ink the lines representing media 
with red ink. Make the drawings on a sufficiently large scale so that each rein can be represented distinctly, and on paper uniform in size with that used for the printed figures of wings used in this course.

Letter each vein and cell of the wing, using black ink for the veins and red ink for the cells.

Note the more important features of its venation, and especially the more important departures from the primitive type of the order as indicated by the generalized form first studied. In the Diptera the wing of Rhyphus (Fig. 4ro) may be used as a generalized type, although in certain respects other wings will be found to be more generalized.

The following are some of the more important points to be noted: Whether the subcosta is simple or forked at the tip; the number of the branches of the radius; in this connection determine which of the radial cells has been obliterated by the coalescence of branches of the radius (study Fig. 409); the position of the radio-medial cross-vein; the number of the branches of the media; the division or not of cell $\mathrm{M}_{2}$; the presence or absence of cell $\mathrm{M}_{3}$; the courses of the branches of the cubitus; the extent of the anal furrow, which is a vestige of the first anal vein; and the extent and course of the second anal vein.

Wing of a tabanid.-A specimen of one of the horse-flies, Tabanus, will be given the student for examination. Observe the subcostal fold, and note that this corrugation stiffens the wing.

Make a drawing of a mounted Tabanid wing, which will be furnished on application to the instructor. Note that in the mounted wing the subcosta is more or less concealed by the radius, although the two veins are distinct, as was seen in the unmounted specimen. Represent these two veins as slightly separated in your drawing.

Note a case of coalescence of veins not exhibited by Rhyphus.

In the description of this wing, state in what respect it is more generalized than that of Rhyphus, and in what respect it is more specialized.

Wing of an asilid.-A wing of a robber-fly of the genus Erax will be used as an example.

There is a spur projecting from one of the branches of radius in this wing. This is a secondary development. Such spurs are not uncommon in the Diptera; there is one near the base of the radial sector in the wings of Protoplasa fitchii, (Fig. 4I 5). Not all spur-like veins are secondary developments; in many cases a spur is a vestige of a vein that is partly atrophied.

Wing of a bombyliid.-The example used is a wing of Pantarbes, one of the bee-flies.

Wing of a scenopinid.-The wing used is that of a common window-fly, Scenopinus.

Wing of an empidid.-The wing used is that of Rhamphomyia, one of the dance-flies. 
Wing of a muscid.- The wing used is that of the common house-fly, Musca domestica.

Wings of dolichopodids. - The wings of two of the long-legged flies will be used. The first belongs to the genus Psilopodius; the second to the genus Dolichopus.

Wing of a syrphid.-The wings of a fiy of the genus Eristalis will be used. Note the vein-like structure between the radius and the media; this is termed the spurious rein.

Wing of Dixa.- The wing of a dixa-midge is used as an example of the renation of the midge-like flies. If a wing of Dixa is not available, use one of a mosquito. In the midge-like flies the number of the branches of the radial sector is reduced in a way different from that seen in the families previously studied. Compare with the asilid, the lombyliid, and the scenopinid.

\section{REVIEW OF WORK ON WINGS OF DIPTERA}

In the preceding studies of wings of Diptera illustrations have been seen of various ways in which these wings have been modified in the course of their evolution. It will clarify the subject if some of the more important of these methods of modification of the primitive type be studied separately.

Reduction of the radial sector.--Note the following facts:-

In Protoplasa fitchii (Fig. 4I5) the radial sector is not reduced, being four-branched as in the hypothetical typical form of this vein.

In Tabanus the radial sector is only three-branched. This is the result of the coalescence of two of the branches of this vein.

In Dixa also the radial sector is reduced to a three-branched condition by the coalescence of two of its branches; but in Dixa not the same branches coalesce as in Tabanus.

These two genera represent two kinds of specialization, which indicates that they belong to different lines of descent. The common progenitor of these two genera had a four branched radial sector; in some of the descendants of this primitive form one method of reduction has taken place, while in other descendants another method has been followed.

That this differentation took place comparatively early in the history of the order is shown by the fact that in all Nematocera that have a threebranched radial sector veins $R_{2}$ and $R_{3}$ remain distinct; while in those Brachycera that have a three-branched radial sector veins $R_{4}$ and $R_{5}$ are separate. The Nematocera and the Brachycera are the two chief divisions of the order.

In both divisions of the order the reduction of the radial sector is carried farther in many cases. Thus in Rhyp'nus the radial sector is only twobranched (Fig. 410).

Two methods of coalescence of veins. - There are two methods of coalescence of wing-reins. By one method the coalescence proceeds out- 
wards, the point of separation of two veins moving nearer and nearer to the margin of the wing until it is reached and the two veins are completely united. The existence of this method of coalescence has been demonstarted by studies of series of allied forms in which the successive stages are shown; such series are easily found in the Lepidoptera, and it was probably by this method that the number of the branches of radius was reduced in Rhyphus and the other Diptera studied in this course.

$\mathrm{By}$ the other method the coalescence begins at the margin of the wing and procedes towards the base of the wing; two series illustrating this method of coalescence are indicated below.

Coalescence of veins $\mathrm{Cu}_{2}$ and $2 \mathrm{~d} \mathrm{~A}$. - Study your drawings of the following named wings:--

In the wing of Rhyphus veins $\mathrm{Cu}_{2}$ and $2 \mathrm{~d} \mathrm{~A}$ are widely separated at the tip.

In the wing of Pantarbes veins $\mathrm{Cu}_{2}$ and $2 \mathrm{~d} \mathrm{~A}$ are approximate at the margin of the wing but are still separate.

In the wing of Erax these two veins coalesce for a short distance at the margin of the wing.

In the rving of Scenopinus the coalescence of these two veins has progressed to a considerable distance.

In the wing of Rhamphomyia the coalescence of these two veins has progressed so far that vein $\mathrm{Cu}_{2}$ extends towards the base of the wing.

Coalescence of veins $\mathbf{M}_{3}$ and $\mathbf{C u}_{1}$.-Arrange your drawings of the wings of Tabanus, Erax, and Pantarbes in the order named and note the successive stages in the coalescence of veins $\mathrm{MI}_{3}$ and $\mathrm{Cu}_{1}$ and in the obliteration of cell $\mathrm{M}_{3}$.

The uniting of cells.-Arrange your drawings of the wings of Musca domestica, Psilopodius sipho, and Dolichopus coquilletti in the order named. Note that in Musca cells $\mathrm{M}$ and Ist $_{\mathrm{M}_{2}}$ are separated by the free part of vein $\mathrm{M}_{3}$; in Psilopodins the free part of vein $\mathrm{M}_{3}$ is partly atrophied, only a short spur remaining; and in Dolichopus the free part of vein $\mathrm{M}_{3}$ is entirely lost and consequently cells $\mathrm{M}$ and ist $\mathrm{M}_{2}$ are completely united.

IDENTIFICATION OF THE WING-VEINS AND OF THE CELLS OF THE WINGS IN LEPIDOPTERA

As the wings of Lepidoptera are covered with scales, it is difficult to determine the nature of their venation without specially preparing them for this purpose. After a student has become familiar with the type of venation characteristic of the order, he can usually determine the course of any particular vein by putting a drop of chloroform on the part of the wing to be examined; this will render the veins more distinct for a few seconds. Or the scales can be removed from a small part of the wing with a small, 
artist's, sable brush. But when a very careful study of the venation of a wing is to be made, it should be bleached and mounted on a card or on a glass slip, in order that it may be studied with a compound microscope. The following is the method of bleaching wings:-

I. Remove the wings carefully so as not to break the frenulum if there be one; ${ }^{*}$ it is well to remove the patagium first. $\dagger$

2. Dip the wings in alcohol in order to wet them.

3. Immerse them for an instant in hydrochloric acid (muriatic acid). Use for this purpose dilute acid, one part acid to nine parts water.

4. Put them in Labaraque solution with the upper surface of the wings down, and leave them there till the color has been removed from the scales. If a wing bleaches slowly, the process can be hastened by dipping it in the dilute acid and returning it to the Labaraque solution from time to time. This solution can be procured of most druggists. It deteriorates if left exposed in strong sunlight. If it cannot be obtained, use an aqueous solution of chloride of lime.

5. When a wing is bleached, put it in alcohol and leave it there till after it floats. This is to wash off the Labaraque solution. The wing can then be mounted on a card. But it is better to mount it as described below.

6. Transfer the wing to a clearing mixture, if it is to be mounted in balsam, and leave it there five or ten minutes. This is to remove any water there may be on it. A good clearing mixture can be made by mixing two parts by measure of carbolic acid crystals and three parts of rectified oil of turpentine.

7. Put the wing on a glass slip with considerable clearing mixture under it to avoid bubbles; put Canada balsam on top, and cover with a cover glass. In the case of small wings, it is best to transfer them from one solution to another, and to the glass slip by means of a camel's-hair brush. $\neq$

$W$ ings bleached and mounted in this way make an important addition to a collection. The slides should be carefully labelled; and the insect from which the wings were taken should be kept with the slide. It is our practice to remove always the wings from the right side, and then to mount the slide in the collection at the right of the insect from which the wings were taken. Uniformity in this respect adds greatly to the appearance of the collection.

Wings of a hepialid.-Figure 416 represents the wings of a hepialid, Pielus labyrinthecus, one of the most generalized members of the order Lepidoptera. It is introduced here to show that there exists among living Lepidoptera forms in which the venation of the wings is not greatly changed

*The frenulum is a strong spine or bunch of bristles borne by the hind wing at the humeral angle in most moths.

tThe patagia are scale-like appendages at the base of the fore wings.

In the case of very small wings, as those of Tincids, the very fine veins are more distinct when mounted in glycerine-jelly than when mounted in Canada balsam. 
from that of the hypothetical primitive type. The most striking modification of the primitive type is the fact that in both fore and hind wings there are only three separate branches of media. Vein $\mathrm{M}_{4}$ coalesces either with vein $\mathrm{M}_{3}$ or with vein $\mathrm{Cu}_{1}$. As there is doubt regarding the fate of vein $\mathrm{M}_{4}$ the student in lettering his drawings of lepidopterous wings may omit any reference to this vein.

Wings of Prionoxystus. - Make a drawing of each wing.

Note that the fore and hind wings differ greatly in venation. This is
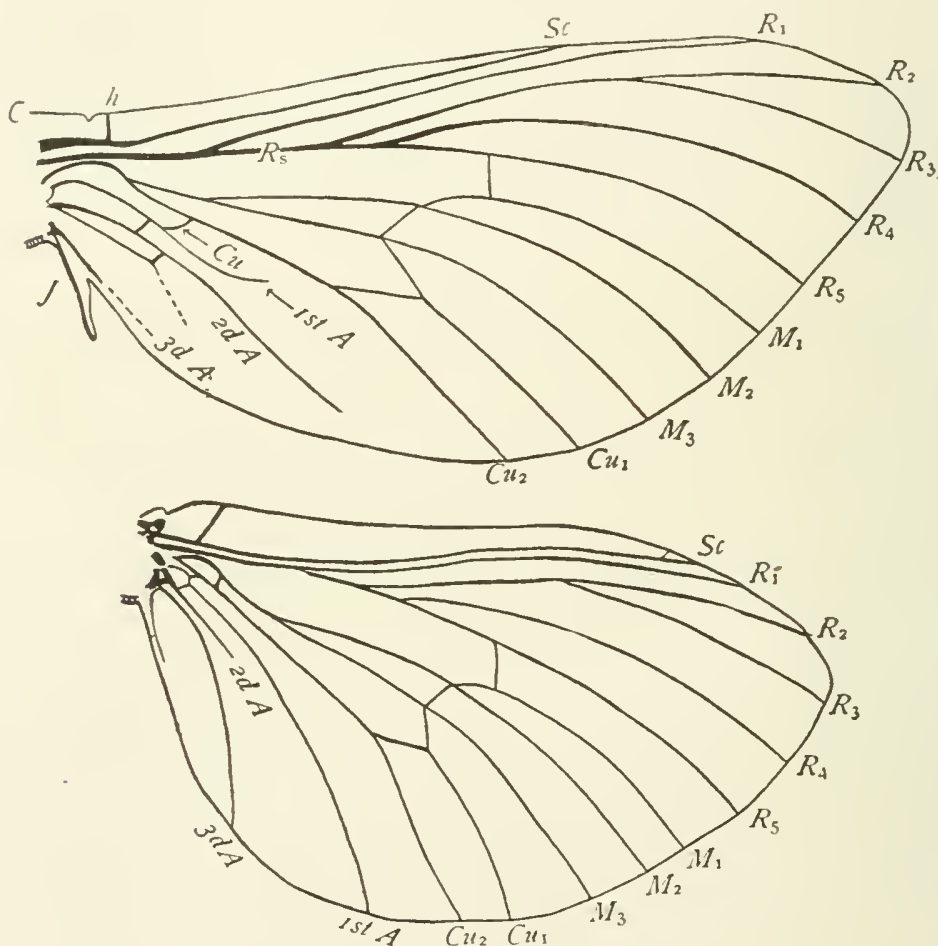

Fig. 4I6.- Wings of Pielus labyrinthecus.

true of the wings of all Lepidoptera except one small family, the Hepialidæ, of which Peilus labyrinthecus, the wings of which are represented in Figure 416 , is a member.

Letter the veins of the fore wing. Note the anastomosis of veins $R_{3}$ and $\mathrm{R}_{4}+5$.

In the hind wing veins $\mathrm{Sc}$ and $\mathrm{R}_{1}$ coalesce in the outer half of the wing and the radial sector is not branched; these facts have been determined by studies of the tracheation of pupal wings. With this information before you, letter the veins of the hind wing. 
Wings of the Monarch Butterfiy, Anosia plexippus.--Make a drawing of each wing.

Study the fore wing first. Figure 4 I 7 is a reproduction of a photograph of a fore wing of a pupa of this species. In this figure the developing wingveins appear as pale bands and the tracheæ as dark lines. A study of the tracheation of this wing will aid in the determination of the wing-veins. In one respect the branching of the radial trachea differs markedly from that of the hypothetical type; this feature is distinctively characteristic of the fore wings of butterflies, it does not exist in moths.

Determine the significance of the three short spurs that project into the distal end of the large cell near the middle of the fore wing, the discal cell.

Letter the veins of the hind wing, and the spurs that project into the discal cell.

Note the vestige of the first anal vein at the base of cubitus.

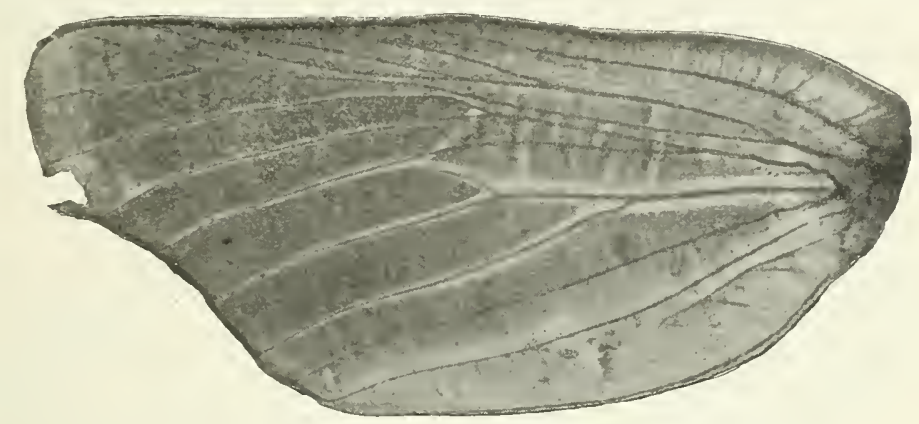

Fig. 417.- - Wing of a pupa of the Monarch butterfly.

The reduction of media.- In a few of the more generalized families of the Lepdioptera the main stem of media is preserved; this condition exists in the wings Prionoxystus, already figured. But in most Lepidoptera the base of media is wanting in the wings of adults, although the medial trachea may be well-preserved in the pupæ; this condition exists in the wings of the monarch butterfly already studied.

Correlated with the loss of the stem of media its branches become more or less closely united with radius and cubitus. In the fore wing of the Monarch Butterfly the base of vein $\mathrm{M}_{3}$ has moved towards vein $\mathrm{Cu}_{1}$ and away from its former position indicated by a spur projecting into the discal cell.

\section{WINGS OF NEUROPTERA}

In the orders Diptera and Lepidoptera the more generalized members of each order possess the maximum number of wing-vains found in the order. It is those wings in which the maximum number of wing-veins exist that most closely resemble the hypothetical primitive type of wing-venation; 
the variations from this type are the result of either the coalescence of veins or the atrophy of veins or of both of these processes. This fact is expressed by the statement that in these orders the wings are specialized by reduction.

In certain other orders of insects, of which the Neuroptera is one, the wings that most closely resemble the hypothetical primitive type are those that have few wing-veins compared with the wings of other members of the order. In these orders the wings are specialized by addition.

In those wings where the specialization has been by addition there are usually many cross-veins; these, as a rule, are inconstant in number and position, consequently, except in the case of a few of the more important
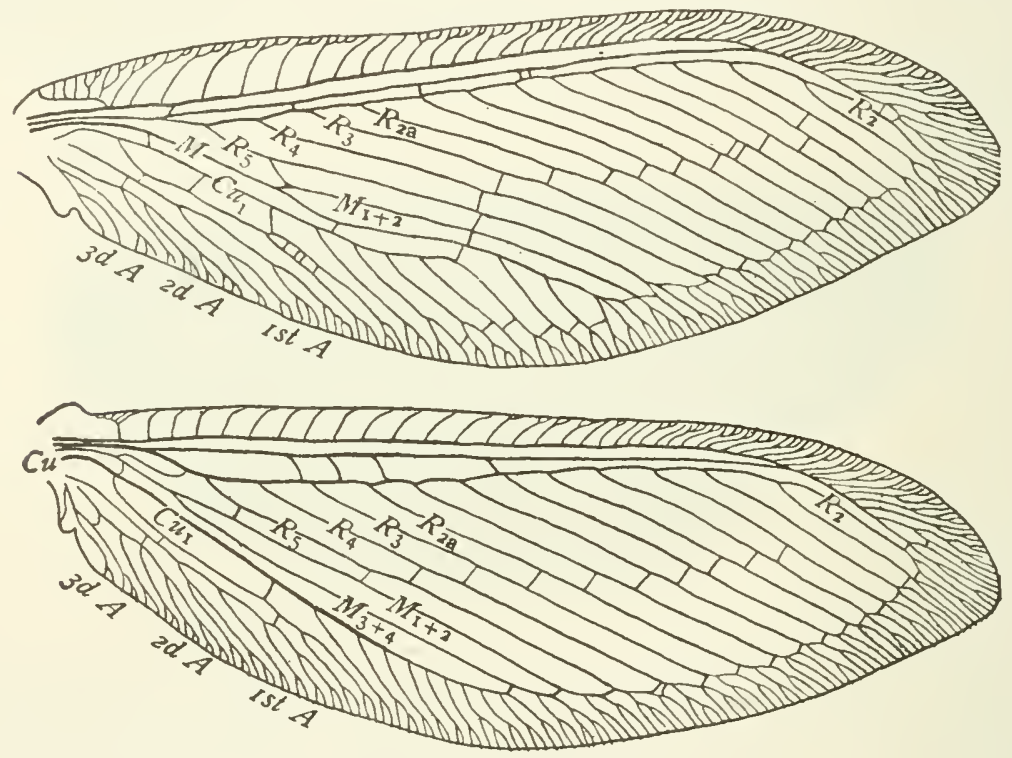

Fig. +18.-Wings of Polystochotes punctatus.

ones, which are not discussed in this brief introductory course, no effort is made to name them.

Accessory veins. - The added longitudinal veins are of two types, each characteristic of different orders of insects. In the order Neuroptera, the added longitudinal veins are of the type that has been designated as accessory veins; they are veins that have been developed as branches of the primitive longitudinal veins.

The wings of Polystochotes punctatus (Fig. 4I 8 ) can be taken as an illustration of wings that have been speeialized by addition. In these wings there are few cross-veins compared with what is usually the case in highly specialized neuropterous wings; but these wings illustrate well a high development of accessory veins. 
Study Figure 4 I 8 carefully and letter with a pencil veins $S c, R_{1}$, and the stem of $R_{s}$. Submit the lettering to the Instructor for criticism and make changes if necessary.

There are two types of accessory veins, which are designated as the marginal and the definitive respectively.

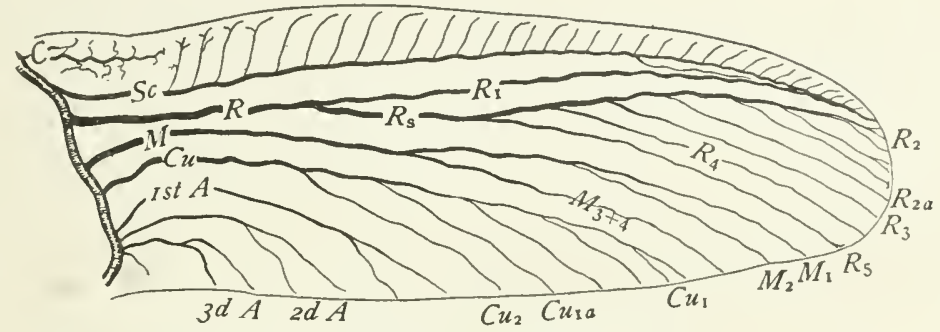

Fig. 419.-Wing of a pupa of Corydalus.

The marginal accessory veins are twig-like branches, that are the result of bifurcations of veins that have not extended far back from the margin of the wing. Many such short branches of veins exist in the wings of Polystachotes punctatus. The number and position of marginal accessory veins are not at all constant; they differ in the wings of the two sides of the same individual.

The definitive accessory veins differ from the marginal accessory veins in having attained a position that is comparable in stability to that of the primitive branches of the principal-veins; for this reason it is practicable

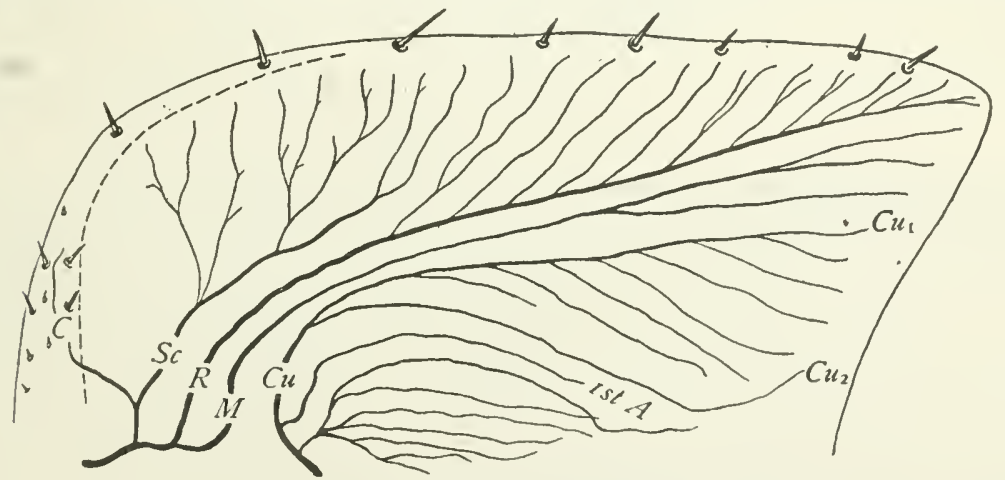

Fig. 420.-Wing of a nymph of a cockroach.

to designate them individually. In Figure $4 \mathrm{I} 8$ one of the definitive accessory veins is designated as $R_{2_{2}}$.

Accessory veins are added to the principal veins in two ways: first, in some insects they are added distally by successive splittings of the tip of a principal vein, thus forming a regular series; and second, the number of 
accessory veins may be increased in an irregular manner by interpolation, i. e. by the splitting of various members of a series of accessory veins.

Illustrations of the adding of accessory veins distally are to be seen in Corydalus and allied genera. The presence of fine twigs at the tip of trachea $\mathrm{R}_{2}$ in the pupal wing of Corydalus (Fig. 4I9) indicates the method of
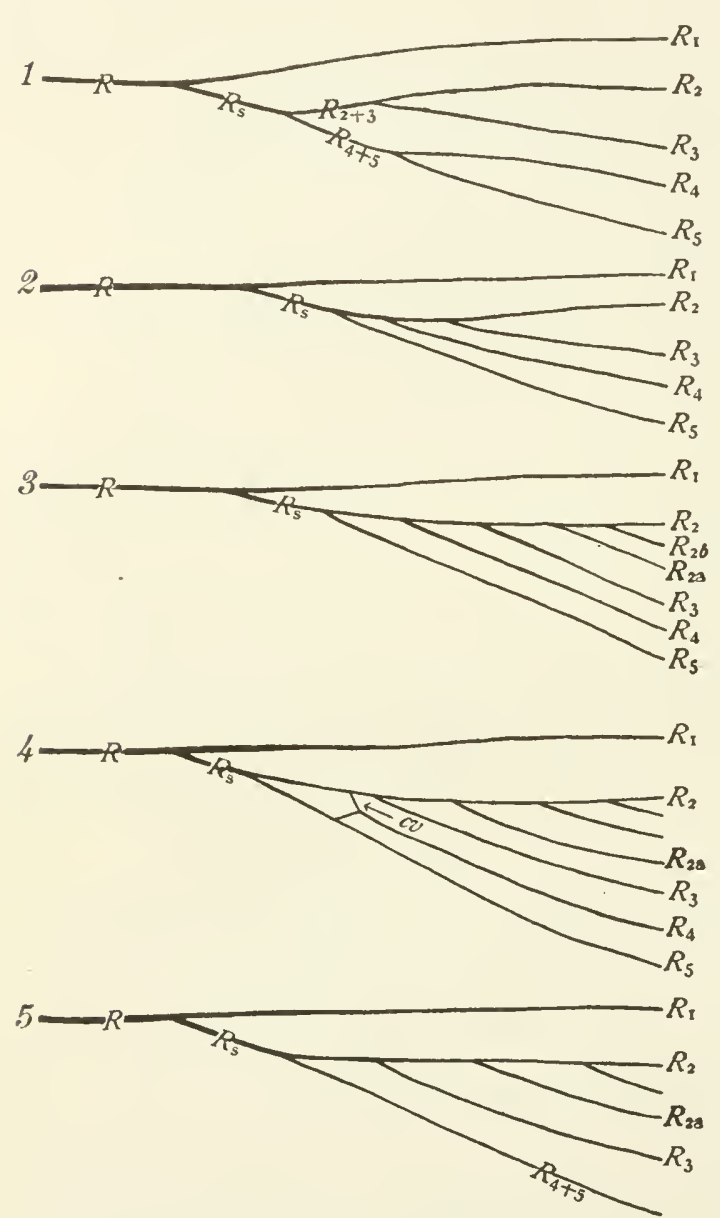

Fig. 421,-Diagrams of several types of radius. increase, which is doubtless as follows: the branches have been added one after another to the tip of trachea $R_{2}$, there being a migration of the base of each accessory trachea towards the base of the wing, thus making room for the addition of new branches. In this case the first accessory vein is the proximal one. It is the oldest accessory branch of the radial sector that is lettered $\mathrm{R}_{\mathrm{2}_{\mathrm{a}}}$ in Figure $4 \mathrm{I} 8$. The successive branches are $R_{2 b}, R_{2 c}, R_{2 d}$, etc.

In the wing of a nymph of a cockroach represented by Figure 420 there are many accessory tracheæ branching from the front side of the radial trachea. From the presence of the fine twigs near the apex of the wing, it is evident that accessory tracheæ are being added distally. It is also evident that the number of accessory tracheæ is being increased by the splitting of some of these accessory tracheæ, $i$. $e$. by ainterpoltion. In cases of this kind it is impracticable to designate the accessory veins individually.

The pectinate type of radial sector.-The order Neuroptera differs from all other orders of living insects in the fact that except in a few cases the radial sector has been so modified that it is of the form known as pectinate or comb-like; that is, it consists of a supporting stem upon which are 
borne a greater or less number of parallel branches. This type of radial sector is well-illustrated in the wings of Polystechotes punctatus (Fig. 4r8).

The transformation of a typical dichotomously branched radial sector into one that is pectinately branched is usually produced by a splitting apart of veins $R_{4}$ and $R_{5}$ so that they arise separately from the supporting stem of the pectinate veins thus formed.

In the accompanying series of diagrams (Fig. 42I), the first diagram represents the manner of branching of the typical radius in which the radial sector is dichotomously branched. The second diagram represents a radius in which the radial sector has become pectinate by the splitting apart of veins $R_{1}$ and $R_{5}$, so that they arise separately from the supporting stem of the pectinate vein thus formed. The third diagram represents a radial sector in which vein $R_{2}$ bears two accessory veins labeled $R_{2 a}$ and $R_{2 b}$.

The wings of Sisyra.-A figure of the wings of Sisyra flavicornis will be furnished the student for study. Label the veins of both fore and hind wings excepting the cross-reins and the marginal accessory veins. The radial sector in these wings is an example of the simplest type of a pectinate radial sector.

A wing of Chauliodes.-A figure of a fore wing of a pupa of Chauliodes will be furnished the student for study. Label the tracheæ. Note that the forming cross-veins are not preceded by tracher.

In what important respect does the radial sector of this insect differ from that of Sisyra.

A wing of Corydalus.-A figure of a front wing of Corydalus cormutus will be furnished the student for study. Label the veins.

Compare the radial sector in the wings of Sisyra, Chauliodes, Corydalus, and Polystochotes.

\section{WINGS OF EPHEMIERIDA}

Figure 422 represents the venation of a fore wing of a May-fly; this figure is introduced here merely to facilitate the discussion of two features of the wings of the Ephemerida; we will not enter upon the study of the homologies of the wing-veins of members of this order in this course.

Concave and convex veins.--Examine the wings of a May-fly and note that the wings are fan-like in form, due to a very regular series of corrugations. Each wing-vein follows either the crest of a ridge or the bottom of a furrow. A vein that follows the crest of a ridge is termed a convex vein, and one that extends along the bottom of a furrow, a concave vein. In Figure 422 the convex veins are marked with a plus sign and the concave veins with a minus sign.

Intercalary veins. - In the order Ephemerida the wings have been specialized by addition; but in this order the added longitudinal veins arise in a way that is very different from the manner in which the accessory veins 
of the Neuroptera are developed. In the Ephemerida the added longitudinal veins are developed in each case as a thickened line more or less nearly midway between two preexisting veins; for this reason they are termed intercalary veins.

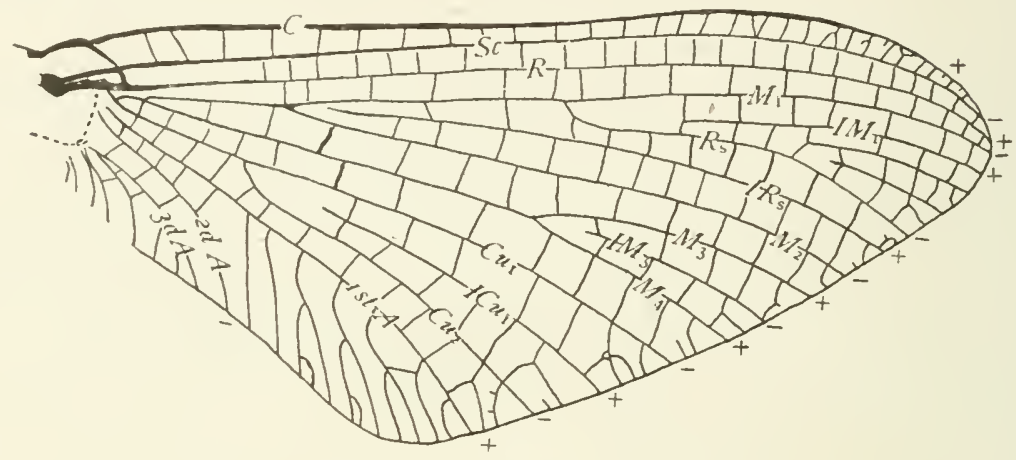

Fig. 422.-A fore wing of a May-fly. The convex veins are marked + ; the concave veins -

When it is desirable to refer to a particular intercalary vein it is done by combining the initial $\mathrm{I}$, indicating intercalary, with the designation of the area of the wing in which the intercalary vein occurs. For example, in the wings of most May-flies in which the venation is not reduced, there is an intercalary vein between veins $\mathrm{Cu}_{1}$ and $\mathrm{Cu}_{2}, i . e$. in the area $\mathrm{Cu}_{1}$. This intercalary vein is designated as $\mathrm{ICu}_{1}$. This and other intercalary veins are represented in Figure 422

IDENTIFICATION OF THE WING-VEINS AND OF THE CELLS OF THE WINGS IN HYMENOPTERA

The determination of the homologies of the wing-veins of Hymenoptera is very difficult, as even in the most generalized of the living members of the order the venation of the wings departs widely from the primitive type.

In the Hymenoptera, as in the Diptera and in the Lepidoptera, the specialization of the wings is by a reduction in the number of the wingveins, the more generalized forms possessing the maximum number of wingveins found in the order. In the more generalized families the reduction of the wing-renation is slight; in the more specialized families, it is extreme.

The most characteristic method of modification of the wings of Hymenoptera is by the coalescence of veins from the margin of the wing towards the base of the wing. This results frequently in a branch of a longitudinal vein becoming transverse, so that it appears like a cross-vein; and in some cases, where the coalescence has been carried still farther, a branch of a longitudinal vein has been so diverted from its primitive course that it 
extends towards the base of the wing. Both of these conditions has been reached in the most generalized of living Hymenoptera.

The existence of this method of specialization in the Hymenoptera and the extent to which it has been carried in this order were first recognized after an understanding of the methods of modification of the wings of the Diptera had been attained. Fortunately among the Diptera there are to be found examples of all degrees of this method of coalescence of veins; reference to some of these will be made later.

In the Hymenoptera, the hind wings are extremely modified, even in the

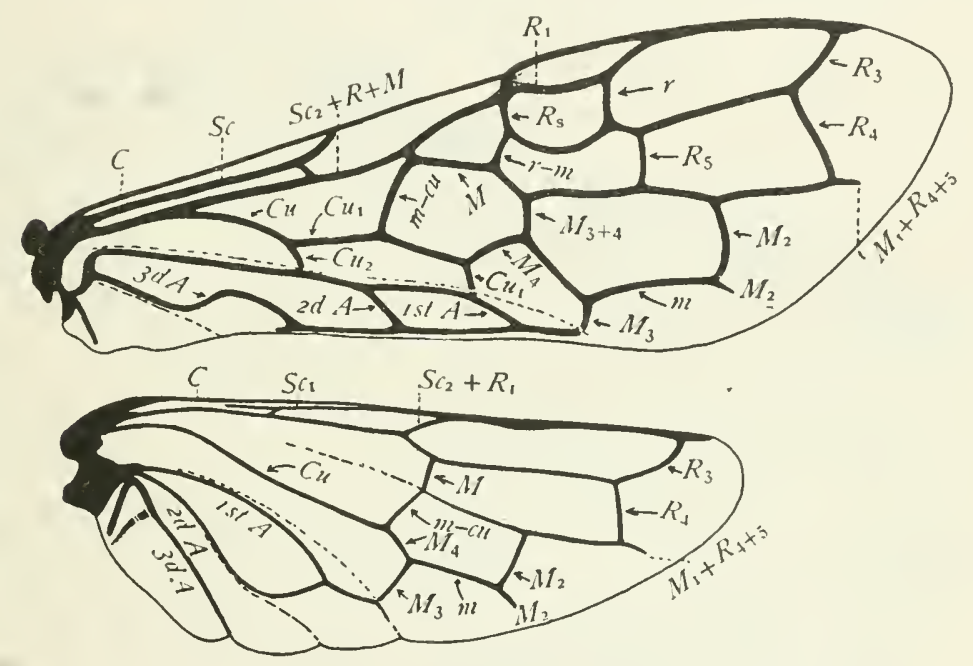

Fig. 423.-Wings of Pamphilius. The veins are lettered.

most generalized members of the order; on this account only fore wings of Hymenoptera will be studied in this introductory course.

Among the more generalized wings of Hymenoptera are those of the genera Pamphilius and Macroxyela, two genera of saw-flies. In each of these genera there is preserved in the fore wings all of the primitive wingveins with a single exception; and as in each it is a different vein that has been lost from that which is lacking in the other, by studying wings of the two genera all of the wing-veins can be observed.

Figure 423 represents the wings of Pamphilius; in this figure the veins are lettered. Figure 424 represents the wings of a Macroxyela; in this figure the cells are lettered. In Pamphilius vein $\mathrm{R}_{2}$ of the fore wings is lacking, but this vein is present in Macroxyela; on the other hand, in Macroxyela vein $\mathrm{Cu}_{2}$ of the fore wings is lacking, but this vein is present in Pamplitius. 
From a study of the fore wings of these two genera a diagram of a typical hymenopterous wing can be made. Figures 425 and 426 represent such a diagram; in the former the wing-veins are lettered, and in the latter, the cells of the wing. This diagram represents the venation of the fore wing of Pamplitius, except that rein $\mathrm{R}_{2}$, which is lacking in this genus, is added.

The cell lettered S in Figure 426 is the pterostigma or stigma; it is cell $\mathrm{Sc}_{2}$, but is designated as the stigma, on account of its usually being opaque in many genera of this order.

In the wings of these sawflies the anal furrow and the median furrow are

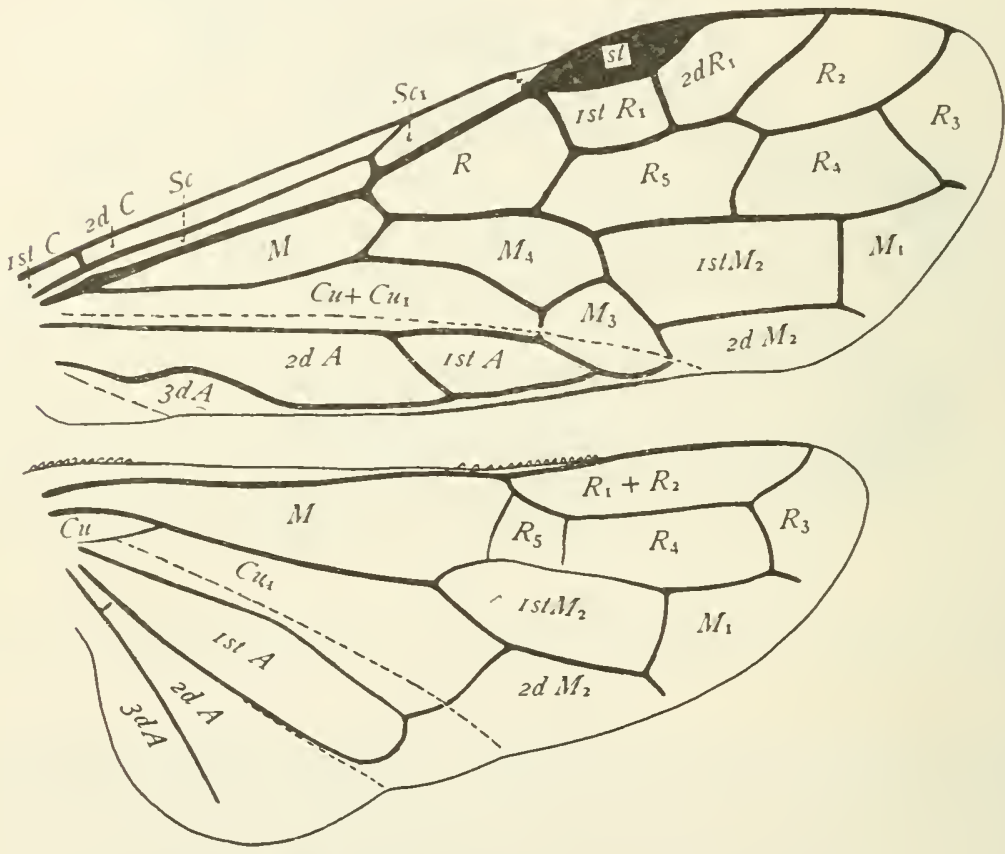

Fig. 424.--Wings of Macroxyela. The cells are lettered.

both well-marked; the anal furrow is immediately in front of the first anal vein, and the median furrow is in front of the media. The furrows are represented by dotted lines in the figures.

In the anal area ( $i . e .$, that portion of the wing back of the anal furrow) the three typical reins are preserved; but they coalesce to a considerable extent, both at the base and near the margin of the wing.

In the basal part of the pre-anal area $(i . e .$, that portion of the wing in front of the anal furrow) the stems of the principal veins are as follows: the costa coincides with the costal margin of the wing (Fig. 425, C); the subcosta (Sc) is well preserved and is forked; back of the subcosta is a strong 
stem formed by the coalescence of the other three veins; the cubitus $(\mathrm{Cu})$ soon separates from the stem, extending in a curve towards the anal furrow; while the radius and the media coalesce for about half their length. In order to make these veins more distinct in the figure the free portion of the media is marked with cross lines.

When we pass from the consideration of the main stems to a study of the branches, we meet a much more complicated problem, a problem which

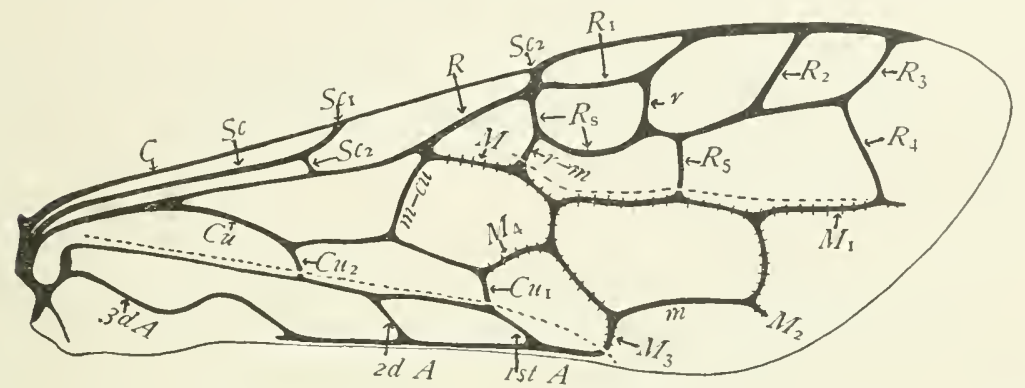

Fig. 425.-The veins of a typical hymenopterous wing; a fore wing of Pamphilius with vein $\mathrm{R}_{2}$ added.

could not have been solved by a study of Hymenoptera alone. But a knowledge of the methods of specialization of the wings of Diptera gives a key to an understanding of the wings of Hymenoptera.

We will study first the branches of the cubitus. Spread out before you your drawings of the wings of the following insects, and arrange them in the

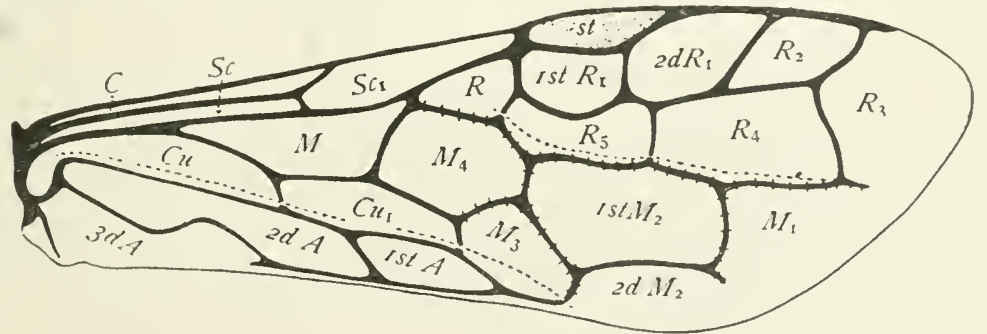

Fig. 426.-The cells of a typical hymenopterous wing; a fore wing of Pamphilius with vein $R_{2}$ added.

order named: a Bombyliid, a Scenopinid, and an Empidid. Now study the figure of a wing of Rhyphus (Fig. 410) and note that while in Rhyphus veins $\mathrm{Cu}_{2}$ and $2 \mathrm{~d} \mathrm{~A}$ retain their primitive position, in the three wings named above these two veins exhibit varying degrees of coalescence.

A similar method of specialization has taken place in the Hymenoptera, but in this order both branches of the cubitus coalesce with the first anal 
vein; and this coalescence has proceeded so far that both branches cross the anal furrow and end in the anal vein remote from the margin of the wing. (See Fig. 425).

It should be noted that vein $\mathrm{Cu}_{2}$ is rarely preserved in this order, even in the more generalized forms. In Macroxyela (Fig. 424) the position of the fork of the cubitus is indicated by a bend in this rein.

If the branches of the media be now examined, it will be seen that vein $\mathrm{MI}_{1}$ (Fig. 425) extends longitudinally near the centre of the distal part of the wing, its primitive course being modified slightly if at all. Tein $\mathrm{M}_{2}$ follows a course similar to the course of this vein in the Bombyliid; so also does the medial cross-rein (Fig. $425, \mathrm{~m}$ ). A comparison of the position of cells $\mathrm{M}_{1}$, Ist $\mathrm{M}_{2}$, and $2 \mathrm{~d} \mathrm{M}_{2}$ in the Bombyliid and in the typical hymenopterous wing (Fig. 426) is very instructive.

Returning to Pamphilius (Fig. 425 ), we see that vein $\mathrm{M}_{3}$ coalesces with the first anal rein, crossing the anal furrow near the margin of the wing. It is evident that the forces that are causing the branches of the cubitus to migrate along the first anal vein and towards the base of the wing are exerting a similar influence on this vein. It is also evident that vein $\mathbf{M}_{4}$ and $\mathrm{Cu}_{1}$ coalesce at the tip, and that the migration of the united tips of these veins (marked $\mathrm{Cu}_{1}$ in the figure) towards the base of the wing has so modified the course of that part of vein $M_{4}$ which is still free that this part of this vein extends towards the base of the wing. This change is very similar to the change in the course of vein $\mathrm{Cu}_{2}$ in the Empidid.

A curious result of this change in the direction of the course of vein $\mathrm{M}_{4}$ is that the cell $\mathrm{M}_{4}$ has been closed and pressed back to the centre of the wing (Fig. $426, M_{4}$ ), and now lies in front of the free portion of the vein $M_{4}$ instead of behind it.

Let us now consider the courses of the branches of the radius. Here again we can gain help from a study of dipterous wings. Observe in the Bombyliid (Pantarbes) the coalescence of the tips of veins $R_{5}$ and $M_{1}$. In the Hymenoptera a similar coalescence of veins $R_{5}$ and $M_{1}$ has occurred; but it has proceeded much farther, so that the free portion of vein $R_{5}$ in Pamphilius (Fig. $425, \mathrm{R}_{5}$ ) is remote from the end of the wing and has the appearance of a cross-vein.

In the Hymenoptera rein $R_{5}$ has been followed in its migration along vein $M_{1}$ by vein $R_{4}$, which has now reached a stage in Pamphilius that is quite similar to that reached by vein $R_{5}$ in Pantarbes. But like rein $R_{5}$ it has the appearance of a cross-rein.

From this it will be seen that the vein marked $M_{1}$ in Figure 425 is really compound, as it includes the tips of veins $R_{5}$ and $R_{4}$.

In Pamphilius rein $R_{1}$ is curved away from the costal margin of the wing to make room for a stigma (Fig. $426, \mathrm{~S}$ ), and vein $\mathrm{R}_{3}$ ends in the costal margin a short distance before the apex of the wing (Fig. 425). Vein $R_{2}$ 
has been lost in this genus, but is well-preserved in Macroxyela and is, therefore, represented in the figure.

While the tips of the branches of the radial sector have migrated away from the apex of the wing, the bases of these branches coalesce in the opposite direction; from these two causes results the transverse bracing of the radial area of the wing, which is a very characteristic feature of the venation of the wings in this order.

The details of these changes will be made clear by an examination of Figures $427 \mathrm{a}$ and $427 \mathrm{~b}$. The former represents the primitive mode of branching of the radius; the latter, the radial area of the typical hymenopterous wing (Fig. 425). In the hymenopterous type veins $\mathrm{R}_{\mathbf{2}}+_{\mathbf{3}}$ and $R_{4}+5$ of the primitive type coalesce so far that the branches of the sector arise from a common stem; and the tips of all of them have moved away from the apex of the wing, veins $R_{2}$
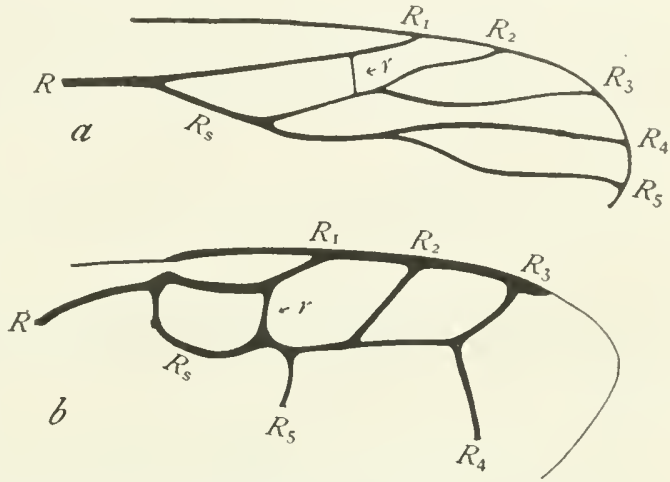

Fig. 427.-Diagrams of the radius: $a$, typical; $b$, hymenopterous. and $R_{3}$ following the costal margin of the wing; and veins $R_{4}$ and $R_{5}$ following vein $\mathrm{M}_{1}$.

In the Hymenoptera the radial cross-vein is frequently preserved; it is marked $r$ in figure 425 .

In descriptions of wings of Diptera and of Lepidoptera, in those cases where compound veins are formed by the coalescence of adjacent veins, the compound vein is designated by a term that indicates its composition. Thus in Rhyphus (Fig. 410), the vein formed by the coalescence of reins $\mathrm{R}_{2}$ and $\mathrm{R}_{3}$ is designated as vein $\mathrm{R}_{2+3}$; and in the wing of Eulonchus (see your drawing of this wing) the united tips of veins $\mathrm{Cu}_{1}$ and $\mathrm{M}_{3}$ is designated as vein $\mathrm{Cu}_{1}+\mathrm{M}_{3}$.

When it is desired to indicate the composition of a compound vein it can be readily done by the application of this system. But in descriptions of hymenopterous wings, where a compound vein may be formed by the coalescence of several veins the logical carrying out of this plan would result in a very cumbersome terminology, one that it is impracticable to use in ordinary descriptive work. In such cases the compound vein is designated by the term indicating its most obvious element. Thus, for example, in the fore wing of Pamphilius, where veins $\mathrm{M}_{4}, \mathrm{Cu}_{1}$ and $\mathrm{Cu}_{2}$ coalesce with the first anal vein, the united tips of these veins is designated as vein ist $A$, 
the first anal vein being its most obvious element (Fig. 425), although it is really rein $\mathrm{M}_{4}+\mathrm{Cu}_{1}+\mathrm{Cu}_{2}+$ ist $\mathrm{A}$.

The more important methods by which the primitive type of wingvenation has been modified in the Hymenoptera are the following:

(a) A reduction in the number of the wing-veins by the atrophy of one or more veins. The loss of vein $\mathrm{R}_{2}$ in the fore wing of Pamphilius (Fig. 423 ) and of vein $\mathrm{Ctt}_{2}$ in the fore wing of Macroxyela (Fig. 424) are illustrations of this.

(b) A reduction in the number of the wing-reins by the coalescence of adjacent veins in one or more areas of the wing. Examples of this will be indicated later. Such a reduction has nearly occurred in the fore wing of Pamphilius where the first and second anal reins coalesce for the greater part of their length.

(c) A change in the course of a vein by the coalescence of its base with an adjacent vein. The course of media in the fore wing of Pamplitius (Fig. 423) has been modified somewhat by its coalescence with radius; this modification has been carried much farther in some forms to be studied later.

(d) A change in the course of a vein by the coalescence of its tip with an adjacent vein. The changes in the direction of the branches of radius, media, and cubitus described above illustrate this.

(e) The formation of serial veins. Examples of this will be presented later.

The student who has followed this discussion and has understood it will be prepared to make original investigations of the venation of the wings of Hymenoptera. But no student should take up the work indicated below before everything in this discussion is clear to him.

Study the fore wings of the insects named below. It is not best to attempt to determine the homologies of the veins of the hind wings at first, owing to the great reduction of wing-veins that has taken place in these wings. The directions for the study of wings given on page 395 will apply here except that Figures 425 and 426 instead of Figure +10 will be used for comparison.

Examples of comparatively generalized hymenopterous wings.-The fore rving of a saw-fly and the fore wing of a siricid will be used as examples of comparatively generalized hymenopterous wings. In neither of these wings is the venation as generalized as in Pamphilius or in Macroxyela.

A fore wing of Pteronidca ribesii.--A fore wing of the currant saw-fly, Pteronidea ribesii, is selected for the study of an actual hymenopterous wing; a mounted wing will be furnished for study; printed figures of other wings to be studied will be issued as needed.

Make a drawing of the wing. 
Note the total atrophy of certain veins and the partial atrophy of others. Where veins have become very weak but are still visible this fact can be indicated by the use of dotted lines.

Determine the homologies of the veins and of the cells of the wing by an application of the knowledge gained by the study of the typical hymenopterous wing.

A fore wing of a siricid.-A printed figure of a fore wing of a horn-tail of the genus Sirex will be furnished for study.

Note that near the apex of the wing there is a short, compound vein formed by the coalescence of the tips of two veins, one of which extends back from the costal margin of the wing. The space between this compound vein and the costal margin of the wing is termed the appendiculate cell. It may be lettered $a p$ in your figure.

Letter each of the veins indicated by arrows in your figure and the tips of the anal veins.

Letter the cells of the wing.

An example of a change in the course of a vein by the coalescence of its base with an adjacent vein.-Note the course of media in the fore wing of Sirex. The coalescence of the base of this vein with radius has been carried so far that now media follows a Z-shaped course.

Examples of the specialization of wings by the atrophy of veins.-Even in the most generalized hymenopterous wings known one or two of the wing-veins have been lost. We will now study wings in which the atrophy of veins has proceeded farther than in those already studied.

A fore wing of Janus abbreviatus.-Letter the veins in your figure of the fore wing of this species.

A fore wing of Odontaulacus editus. - In this wing the anal furrow and the axillary furrows are distinct, the position of each of these furrows is indicated by a dotted line.

Compare your figure of this wing with that of Janus abbreviatus and indicate by penciled, dotted lines the probable former position of each of the veins that are wanting.

What is the probable composition of the single vein that is preserved in the anal area?

Letter this anal vein with the term indicating its most obvious element.

The switching of the base of the radial sector.-Compare the figures of the wings of Jamus and Odontaulacus with that of the typical hymenopterous wing and describe the change that has taken place in the support of the base of the radial sector of Odontaulacus.

This change is known as the switching of the base of the radial sector; it has taken place in all of the Clistogastra, the more specialized of the two suborders of the Hymenoptera.

The formation of serial veins.-In the wings of many Hymenoptera there exist what appcar to be simple veins that are really compound veins 
composed of two or more veins or sections of veins joined end to end with no indication of the point of union; such veins are termed serial veins. There are two serial veins in the fore wing of Odontaulacus editus; one of these consists of a part of the radial sector and the radial cross-vein; the other, of another part of the radial sector and the radio-medial cross-vein. The former is designated as vein $r \& R_{\mathrm{s}}$; the latter as vein $r-m \& R_{\mathrm{s}}$. The sign $\&$ is used in these designations instead of + , as the latter is used to indicate compound veins formed by the coalescence of veins side by side.

Complete the lettering of the veins in the figure of the wing of Odontaulacus editus.

The reduction in the number of the wing-veins by the coalescence of adjacent veins. - This method of specialization by reduction is well-shown in many Hymenoptera of which the following is an example.

The fore wing of an Ichneumon-fly.-A figure of a fore wing of an Ichneumon-fly, Exetastes fascipennis, will be provided for study. Compare your figures of the wings of Sirex, Odontaulacus and an Ichneumon-fly and determine the composition of that part of the thickened costal margin of the wing of an Ichneumon-fly that extends from the base of the wing to the stigma; letter this rein.

Additional examples of specialization by reduction.- Continue the study of the fore wing of an Ichneumon-fly.

The Ichneumon-flies belong to a series of families, the parasitic Hymenoptera, in which vein $\mathrm{R}_{5}$ is usually lost. In Odontaulacus editus, which also belongs to this series of families, there is a small vestige of this vein retained; but in the Ichneumon-flies it is lost completely. With this information in mind proceed to letter the veins in the figure of a fore wing of an Ichneumonfly.

A wing of a braconid.-A figure of a fore wing of a braconid, Rhogas parasiticus, will be provided for study.

Letter the reins in this wing.

Compare the figures of a wing of an Ichneumon-fly and a wing of a braconid and state in what features each wing is more generalized than the other.

THE TRACHEATION OF THE WINGS OF NYMPHS AND OF PUPE

It has been found that, in the course of the development of the wings of the more generalized insects, the tracheæ which traverse the principal veins are developed before the veins appear, and that later the veins are developed about these tracheæ. It is evident, therefore, that much light can be thrown upon questions regarding the homologies of wing-veins by studies of the tracheæ which precede them; and the following suggestions are given to aid students who wish to make such studies.

If a living pupa or nymph be placed in formol $(4 \%)$ the tissues of the wings will be rendered translucent in a short time. In the case of very 
delicate insects only a few hours are required for this, but with larger ones with more opaque wings it is necessary to leave them in the formol for several days, or even for several weeks. While the formol renders the tissues translucent, it does not soon penetrate the tracheæ, which are, therefore, left filled with air, and appear as dark lines when the wing is examined with transmitted light. Just after molting some wings are translucent, but there are few so clear that a short stay in formol will not make them clearer.

In order to study wings prepared in this way, they are removed from the body and mounted in glycerine-jelly, care being taken to cool the mount quickly so that the jelly will not penetrate the tracheæ. In this way most beautiful objects can be prepared, which will show the minutest ramifications of the tracheæ.

Not only can the tracheæ that precede the wing veins be studied in this manner, but, if the wings be taken at the right stage, the forming veins will appear as pale bands when viewed by transmitted light. This is due to the fact that at this time the veins are merely cavities, filled with lymph, and are more translucent than the spaces between them, which are occupied by tissue.

Unfortunately, however, this distinction is only temporary in most specimens. As a rule, the entire wing becomes transparent in a few hours after it is mounted in the glycerine-jelly. It is necessary, therefore, to make drawings or photo-micrographs promptly, in order to keep a record of the courses of the veins.

On the other hand, the trachere, as a rule, stand out more sharply twenty-four hours after mounting, because of the clearing effect of the glycerine-jelly upon the tissue of the wing. But the making of drawings or photo-micrographs of the tracheæ should not be delayed long; for the tracheæ soon become filled with the jelly, and are then practically invisible.

The preparation of specimens. - Collect living nymphs or pupx, place them in formol $(4 \%)$, and leave them for a time, as indicated above. The formol will make the wings of the insects more translucent; but it will not remove dark colors from chitin. It is well, therefore, to select, at first, the paler species for study.

When ready to mount a wing, spread a drop of melted glycerine-jelly on a slide and allow it to cool.

Dissect off the wing to be studied, taking with it just enough of the thorax to include the basal attachments of the tracheæ. The dissection may be made under water; but the wing should be removed from the water promptly, so that the tracheæ may not become filled with water.

Place the wing upon the solidified glycerine-jelly on the slide; and lower upon it a heated cover-glass, which will cause the jelly to melt enough to envelop the wing. 
Cool the mount quickly on ice, a marble slab, or some other cold object. Rapid cooling is imperative, for in melted glycerine-jelly the tracheæ soon become filled, and the smaller ones are then invisible.

It is imperative, also, that the wings be handled with care. Being saclike structures, the tracheæ are almost free within them, and a slight pinch with forceps in the middle of the wing may throw all of its trachex out of place. It is better to lift the wing by its thoracic attachments or upon a section lifter.

Not every nymphal wing is fitted for this study. Just before molting, and especially just before the last molting, the wing becomes so crumpled within its old sheath that the course of its tracheæ can be followed only with difficulty.

The method of study.-So far as is practicable, the studies of the tracheation of the wings of nymphs and of pupæ will be original investigations. For this reason, no particular species is suggested for study. The student will select the most available material, and will endeavor to make an addition to our knowledge of this subject.

Among the more available subjects for the beginner in this line of work, are the pupæ of moths and the nymphs of Orthoptera. The former illustrate specialization by reduction; the latter specialization by addition. During the winter, when it is difficult to collect Orthoptera, the nymphs of stone-flies (Plecoptera) may be used instead. These can be found under stones in the beds of streams.

In many insects the costal trachea is wanting or is but slightly developed. It does not follow, therefore, that the trachea nearest the costal margin of the wing is the costal trachea. In most cases, the radial trachea can be identified easily, and it will serve as a starting point for the determination of the homologies of the other principal tracheæ.

In most orders of insects the longitudinal veins can be distinguished from the cross-yeins by the fact that the cross-veins are not preceded by tracheæ.

In some of the many-reined insects, as Odonata, the cross-veins, as well as the longitudinal veins, are preceded by trachex; there being, in these insects, a great multiplication of tracheæ.

On the other hand, in the Trichoptera, Diptera, and most Hymenoptera, a great reduction of the tracheal system has taken place. It is not well, therefore, for the student to begin his studies of this subject with members of either of these orders.

In those orders where a specialization of wing-veins by addition has taken place, the accessory longitudinal veins are preceded by tracheæ.

Finally, it should be remembered that it is not safe to base conclusions upon the study of a single insect; a large series, representing as many genera and families as is practicable, should be investigated: 


\section{BIBLIOGRAPHY}

The following list includes only the titles of the books and papers to which references have been made in the preceding pages. These works are chiefly those bearing on the development of the uniform terminology of the wing-veins of insects. No effort has been made to include those papers in which this terminology has been used without modification.

Adolph, G. ERNSt. ('79). "Ueber Insectenflügel." Nova Acta der Ks1. Leop.-Carol.Deutschen Akademie der Naturf. Vol. 4I, pp. 215-29I, with six plates.

Albarda, Herman. ('9i). "Révision des Rhaphidides." Tijdschr. v. Entom. Vol. 34 (I89I), pp. 65-I 84 , with eleven plates.

Amans, P. C. ('85). "Comparisons des organes du vol dans la série animale." Ann. Sci. Nat. Sér. 6 Zool. 19 (I 885), pp. 9-222, with eight plates.

Brauer, F. ('68). "Verzeichniss der bis jetzt bekannten Neuropteren im Sinne Linne's." Verh. K. K. Zool-bot. Ges. Wien. I 868, pp. 359-4I6; 7 I I-742.

Brauer, F. ('85). "Systematische-zoologische Studien." Sitzb. der Kais. Akad. der Wissensch. Vol.9I, pp. 237-4I3.

Bauer, F. and Redtenbacher. ('88). "'Ein Beitrag zur Entwickelung des Flügelgeäders der Insecten." Zool. Anz. Vol. I I, I 888, pp. 444-447.

Berlese, A. ('og). "Gli Insetti, loro organazzazione sviluppo, abitudini e rapporti coll 'uomo." Società Editrice Libraria, Milano, 1906.

Bettin, CoRnelius. ('I3). "An Interesting Feature in the Venation of Helicopsyche, the Molannidæ, and the Leptoceridæ." Ann. Ent. Soc. Am. Vol. 6, pp. 65-73, with eight text figures.

Bradley, J. Chester. ('o8). "The Evaniidæ, ensign-flies, an archaic family of Hymenoptera." Trans. Am. Ent. Soc. Vol. 34, pp. I03-194, with eleven plates.

Bradley, J. C. ('i3). "The Siricidæ of North America." Jour. of Entom. and Zool. Vol. 5, pp. I-3o, with five plates.

Brodie, P. B. ('45). "A history of the fossil insects in the secondary rocks of England." London, $\mathbf{1} 845$.

Brongniart, Charles. ('93). "Recherches pour servir a l'histoire des Insectes Fossiles." Saint-Etienne, I 893.

Burmeister, H. ('78). "Examen special des Escales." Description Physique de la Republique Argentine 5me tome (Lepidopteres) Ire parte. pp. 2I-28. Buenos Ayres.

Busck, August. ('14). "On the Classification of the Microlepidoptera." Proc. Entom. Soc. Wash. Vol. I6 (1914), pp. 47-54.

Calvert, Philip P. ('I3). "The fossil odonate Phenacolestes, with a discussion of the venation of the legion Podagrion." Proc. Acad. of Nat. Sci. Phil. I9I3. pp. 225272 , with one plate.

Chabrier, J. (I820). "Essai sur le vol des insectes." Mem. du Mus. d' Hist. Nat. Vol. 6 (I 820), pp. $410-472$, with four plates.

Сомsтоск, J. H. ('92a). "Report of lecture before the California Zoological Club, Jan. 30, I892." Zoe. Vol. 3, pp. 84-86.

Comstock, J. H. ('92b). "The descent of the Lepidoptera; an application of the theory of natural selection to taxonomy." Proc. Amcr. Assoc., Adv. Sci. Vol. 4I, p. 199.

Comstock, J. H. ('93). "Evolution and Taxonomy; an essay on the application of the theory of natural selection in the classification of animals and plants, illustrated 
by a study of the evolution of the wings of insects and by a contribution to the classification of the Leipdoptera." In Wilder Quarter Century Book, I893, pp. $37-113$, with three plates.

Coмstock, J. H. ('95). "The Venation of the Wings of Insects." In "The Elements of Insect Anatomy" by John Henry Comstock and Vernon L. Kellogg. Ithaca, I 895, Chapter 7, pp. 75-91.

Comstock, J. H. and A. B. ('95). "A Manual for the Study of Insects." Ithaca, N. Y., I 895 . pp. $\mathrm{x}+20 \mathrm{I}$, with six plates and 798 wdets.

Comstock, J. H. and Needham, J. G. ('98-'99). "The Wings of Insects." A series of articles on the structure and development of the wings of insects, with special reference to the taxonomic value of the characters presented by the wings. Reprinted from The American Naturalist, with the addition of a table of contents. 124 pages, 90 figures. Ithaca, N. Y., I 899. (The articles appeared originally in The American Naturalist, Vol. 32, (1898), pp. 43, 81, 231, 237, 240, 243, 249, 253, 256, $335,+13,420,423,561,769,774,903$; Vol. 33, (1899), pp. II $8,573,8+5,85$ I, 853,858 .)

Comstock, J. H. ('оI). "The wings of the Sesiidæ." (In Mlonograph of the Sesiidæ by Wm. Beutenmuller. Memoirs Amer. Museum Nat. Hist. Vol. I, p. 220.)

Cramfton, G. ('I6). "The phylogenetic origin and the nature of the wings of insects according to the paranotal theory." Jour of the N. Y. Entomological Society. Vol. 24 (I916), pp. I-39.

DAvis, K. C. ('o3). "Sialididæ of North and South America." N. Y. State Museum bulletin, 68., pp. $+42-487$.

Desneux, J. ('oła). "A propos de la phylogénie des Termetides." Ann. Soc. Ent. Belg., Vol. 48 , pp. $278-289$.

Desnecx, J. ('ołb). "Isoptera" Genera Insectorum. Fascicule 25.

Dewitz, H. ('8I). "Ueber die Flügelbildung bei Phryganiden und Lepidopteren." Berl. Ent. Zeit. V'ol. 25.

Diмnоск, Geo. ('83). "The scales of Coleoptera." Psyche Vol. 4, pp. 3-11; 23-27; $43-47 ; 63-71$.

Enderleix, G. ('oo). "Die Psocidenfauna Perus." Zool. Jahrb. Syst. I4, pp. 133I60. pls. 8-9.

Exderleix, G. ('o2). "Eine einseitige Hemmungsbildung bei Telea polyphemus vom ontogenetischen Standpunkt." Zool. Jahrb. Anat. XVI, pp. 57I-6I 4, pl. 40-42.

ENderleix, G. ('o3). "Die Copeognathen des Indo-Australischen Fauengebietes." Annales historico-naturales Nlusei Nationalis Hungarici. Bd. I, pp. I79-34t, with twelve plates.

Enderlein, G. ('o5a). "Nonographie der Coniopterygidæ." Zool. Jahrb. Vol. 23. Abt. f. Syst.

Enderlein, G. ('o5b). "Die Plecopteren Feuerlands." Zool. Anz. Vol. 28, pp. 809815.

Enderlein, G. ('05c). "Monographie der Conopterygidæ." Zool. Jahrb. Jene. Abt. f. Syst. 23 (I 806), pp. 173-242.

Enderleis, G. ('og). "Klassification der Plecopteren, sowie Diagnosen neuer Gattungen und Arten." Zool. Anz. Vol. 34 (1909), pp. 385-394.

Enderlein, G. ('io). "Klassifikation der Mantispiden nach dem Material des Stettiner Zoologischen Museums." Stett. Entomolo. Zeit. Vol. 7I, (1910), pp. $341-379$.

Enderleix, G. ('12). "Embiidinen, Monographisch Bearbeitet." Collections Zoologiques, Selys Longchamps. Fasc. 3, 1912.

Froggatt, Walter W. ('i3). "White Ants." Farmers' Bulletin, No. 60 Department of Agriculture, New South Wales, Nov., I913. 
Funkhouser, W. D. ('I3). "Homologies of the Wing Veins of the Membracidæ." Ann. Ent. Soc. Am. Vol. 6, pp. 74-97, with five plates.

Ganin, M. ('76). "Naterialien zur Kenntniss der postembryonalen Entwicklungsgeschichte der Insecten." (Russian). Abdruck bei Hoger in Jahresber. der Anat. u. Phys. von Hoffman und Schwalbe. Vol. 5 und in Zeit. f. wiss. Zool. vol. 28.

Gonin, J. ('94). "Recherches sur la métamorphose des Lepidoptères." Bulletin de la Société Vaudoise des Sciences Naturelles. Vol. 3I (I 894), pp. 89-I39, with five plates.

Grote, A. R. ('96a). "System der nordamerikanischen Schmetterlinge." Mitt. aus dem Roemer-Museum, Hildesheim No. 7, I 896.

Grote, A. R. ('96b). "Die Saturniiden." Mitt. aus dem Roemer-Museum, Hildesheim, No. 6, I 886.

Grote, A. R. ('97). "The British Day Butterflies, and the Changes in the Wings of Butterflies." Proc. South Lond. Entom. and Nat. Hist. Soc. (I 897 ).

HAASE, ERICH. ('9r). "Zur Entwicklung der Flügelrippen der Schmetterlinge." Zool. Anz. Vol. 14 (1891), pp. I 16-1 I7.

HaAse, E. ('93). "Untersuchungen über die Mimicry." Stuttgart, I893.

HAGEN, Dr. ('7o). "Ueber rationelle Benennung des Geäders in den Flügeln der Insekten." Stett. Ent. Zeitung, Vol. 31, pp. 316-320, with one plate.

Hancock, J. L. ('o2). "The Tettigidæ of North America." Chicago, 1902. Published by special grant of Mrs. Frank G. Logan.

Handlirsch, Anton ('o6). "Revision of American Paleozoic Insects." Proc. U. S. Nat. Mus. Vol. 29, pp. 66I-820.

Handlirsch, Anton. ('o6-'08). "Die Fossilen Insekten und die Phylogenie der Rezenten Formen." Leipzig I906-1908, I vol. text, pp. IX + VI + +30; I vol. plates, pp. XL and $5 \mathrm{I}$, plates.

Headlee, Thomas J. ('o7). "A study in butterfly wing-venation, with special regard to the radial vein of the front wing." Smithsonian Miscellaneous Collections, Vol. 48 , pp. 284-296, with five plates.

Hinds, W. E. ('o3). "Contribution to a monograph of the insects of the order Thysanoptera inhabiting North America." Proc. U. S. Nat. Museum, Vol. 26, pp. 79-242, with eleven plates.

Holmaren, Nils. ('og). "Termitenstudien. I. Anatomische untersuchungen." Kungl. Svenska Vet.-Ak, Hand. Vol. 44, No. 3 (I909), pp. I-2I 5 .

Holmgren, Nils. ('II). "Termitenstudien, 2. Systematik der Termiten." Kungl. Svenska Vet.-Ak, Handl. Vol. 46, No. 6, pp. I-86, with six plates.

Horvath, G. ('I3). "Étude morphologique sur la construction de l'elytre des Cicadides." Trans. 2d. Int. Cong. Entom. Vol. 2, pp. $422-432$.

Jones, Paul R. ('I2). "Some new California and Georgia Thysanoptera." Bull. U. S. Dept. of Agri. Bureau of Ent. Tech. Series No. 23, Part I, I9I2.

Jurine, L. (I 820$)$. "Observationes sur les ailes des Hymenopteres." Mem. Reale Accad. Sci. Torino, Vol. $2+$ (1820), pp. 177-214, with six plates.

KelloGg, V. L. ('94). "The Taxonomic Value of the Scales of the Lepidoptera." Kans. Univ. Quar. Vol. 3, No. I, (1 894 ). Kellogg, V. L. ('95a). "The Ephemeridæ and Venation Nomenclature." Psyche,
Vol. 7, pp. I $17-126$.

KellogG, V. L. ('95b). "The Affinities of The Lepidopterous Wing." The Amer. Nat. Aug. I895, pp. 709-7 I 7 .

KellogG, V. L. ('o8). "American Insects." New York, Henry Holt and Company, I 908, pp. XIV + 694.

Kempers, K. J. W. ('99-'o9). "Het Adersysteem der Kevervleugels." Tijdschriftvoor Entomologie, Vol. 4r, verslag, p. 3I; Vol. 42, pp. I80-208; Vol. 43, pp. 172- 
I90; Vol. 4t, pp. 13-38; Vol. 45, pp. 53-7I; Vol. 5I, pp. IX-XVI; Vol. 52, pp. $272-283$.

Klapálek, F. ('I2). "Perlodidæ monographische Revision." Coll. Selys Longchamps. Fasc. 4, pp. I-66. Bruxelles.

Kr ̈̈̈Ger, Edgar. ('98). "Ueber die Entwicklung der Flügel der Insekten mit besonderer Berücksichtigung der Deckflügel der Käfer." Inang.-Diss. Gôttingen, I 899; Biol. Ctrbl. $\mathrm{V}^{r}$, I9, No. 23 u 24, pp. 797-783.

Kuhne, Otтo. ('I5). "Der Tracheenverlauf im Flugel der Koleopterennymphe." Zeit fur wiss. Zool. Vol. I12, pp. 691-718, with two plates.

Lameere, A. ('o8). "La paléontologie et les métamorphoses des insectes." Ann. Soc. Ent. Belg. Vol. 52, pp. 127-r 49 .

LANDoIS, H. ('7I). "Beiträge zur Entwicklungsgeschichte der Schmetterlingsflugel in der Raupe and Puppe." Zeit. f. wiss. Zool. Vol. 2I, pp. 305-315.

Leovard, M. D. ('I6). "The immature stages of two Hemiptera-Empoasca oblusa Walsh (Typhlocybidæ) and Lopidea robinia Uhler (Capsidæ)." Ent. News, Vol . 27 , pp. 49-54, with two plates.

LoEw, H. ('62). "Monographs of the Diptera of North America." Part I, Smithsonian Misc. Coll. (1862).

LOWve, B. T. ('92). "The anatomy, physiology, morphology, and development of the blow-fly." 2 Vols., London, I $890-1895$.

Micllendon, J. F. ('o6). "Notes on the True Neuroptera." Ent. News, 1906, pp. II 6 -I 2 I.

MacGillivray, Alexander Dyar. ('06). "A Study of the Wings of the Tenthredinoidea, a Superfamily of Hymenoptera." Proc. U. S. Nat. Mus. Vol. 39, pp. 569-654, with twenty-four plates.

MacGillivray, A. D. ('i2). "The Pupal Wings of Hepialus Thule." Ann. Ent. Soc. Am. Vol. 5, pp. 239-245.

M'Lachlan, R. ('77). "On Notiothauma Reedi, a remarkable new genus and species. of Neuroptera from Chili, pertaining to the family Panorpidæ." Trans. Ent. Soc. Lond. 1877, p. 427.

Marshall, WM. S. ('I5). "The development of the hairs upon the wings of Platyphylax designatus Walk." Ann. Ent. Soc. Am. Vol. 8 (I9I5), pp. 153-160.

Marei, M. ('69). "Reproduction mecanique du vol des Insectes." C. R. Ac. Sci. Vol. 68, pp. 667-669.

MAYER, A. G. ('96). "The development of the wing scales and their pigment in butterflies and moths." Bull. Mus. Comp. Zool. Vol. 29, pp. 209-236, with seven plates.

Meinert, F. ('so). "Sur 1' homologie des Elytres des Coléoptères." Entomologist Tidskrift, I880, p. 168 .

Melander, A. L. ('o2a). "Two new Embiidæ." Biol. Bull. Vol. 3, pp. i6-26.

Melander, A. L. ('o2b). "Notes on the structure and development of Embia texana." Biol. Bull. Vol. 4, pp. 99-II8.

Mercer, W. F. ('oo). "The development of the wings in the Lepidoptera." Jour. N. Y. Ent. Soc. Vol. 8, pp. I-20, with five plates.

Metcalf, Z. P. ('Iza). "The Wing Venation of the Jassidæ." Ann. Ent. Soc. Am. Vol. 6, pp. I03-I I5, with eight plates.

Metcalf, Z. P. ('izb). "The Wing Venation of the Fulgoridæ." Ann. Ent. Soc. Am. Vol. 6, pp. $34 \mathrm{I}^{-}-35^{2}$, with six plates.

Metcalf, Z. P. ('I 7 ). "The wing venation of the Cercopidæ." Ann. Ent. Soc. Am. Vol. I0, pp. 27-34, with two plates.

MEYRICK, E. (12). "Lepidoptera Heterocera Fam. Micropterygidæ." Genera Insectorum, Fascicule, $\mathbf{I}_{32}$. 
Mryaké. T. ('I3). "Studies on the Mecoptera of Japan." Jour. College of Agriculture, Imperial University of Tokyo, Vol. 4, pp. 265-400, with ten plates.

Morgan, A. H. ('12). "Homologies in the Wing-Veins of May-Flies." Ann. Ent. Soc. Am. Vol. 5, pp. 89-106, with five plates.

Moulton, Dudley. ('7I). "Synopsis, Catalogue, and Bibliography of North American Thysanoptera." Bull. U. S. Dept. of Agri. Bureau of Ent. Tech. Series No. 2 I, I9II.

Nakahara, Waro. ('15). " "On the Hemerobiinæ of Japan." Annotationes Zoologicæ Japonenses, Vol. 9, I915, pp. I I-48.

Navás, Longinos S. J. ('I2). "Neuroptera Fam. Nemopteridæ." Genera Insectorum, Fas. 136.

Needham, J. G. ('oo). "Some general features of the metamorphosis of the FlagWeavil, Mononychus vulpeculus Fabr." Biol. Bull., Vol. 1, pp. I79-191.

Needham, J. G. ('o3). "A Geneologic Study of Dragon-fly Wing-Venation." Proc. U. S. National Museum, Vol. 26, pp. 703-764, with twenty-four plates.

Nuttall, G. H. F. and Shipley, A. E. ('or). "The Structure and Biology of Anopheles." Jour. of Hygiene, Vol. I, p. 475.

Osten-Sacken, R. ('69). "Mlonographs of the Diptera of North America." Smithsonian Miscellaneous Collections 219, I869.

PACKARD, A. S. ('95). "On a rational nomenclature of the veins of insects, especially those of the Lepidoptera." Psyche, Vol. 7, I895, pp. 235-2+1.

Pancritics, P. ('84). "Beiträge zur Kenntniss der Flügelentwickelung bei den Insecten." Inagural-Dissertation, Königsberg (I 884).

Ратсн, Едiтh M. ('o9). "Homologies of the Wing Veins of the Aphididæ, Psyllidæ, Aleurodidæ, and Coccidæ." Ann. Ent. Soc. Am. Vol. 2, pp. IoI-129, with six plates.

Pierce, W. Dwight. ('o9). "A monographic revision of the twisted winged insects comprising the order Strepsiptera Kirby." Bulletin of the United States National Museum, No. 66.

Powell, P. B. ('04-'05). "The development of wings of certain beetles and some studies of the origin of the wings of insects." Jour. N. Y. Ent. Soc. Vol. 12 (1904), pp. 237-243; Vol. 13, (1905), pp. 5-22, with seven plates.

Redtenbacher, Josef. ('86). "Vergleichende Studien über das Flügelgeäder der Insecten." Ann. des k. k. nat. Hofmuseums, Bd. I, Heft 3, I 886, pp. I53-232, with twelve plates.

Rohwer, S. A. and Gahan, A. B. ('16). "Hormismology of the Hymenopterous wing." Proc. Ent. Soc. of Wash. Vol. 1 8, pp. 20-76.

Ris, F. ('96). "Die schweizer-Arten, der Perlidengattung Dictyopteryx." MIt. Schweiz ent. Ges. Vol. 9, pp. 333-313.

Rosen, Kurt von. ('13). "Die fossile termiten: eine kurze zusammemfassung der bis jetzt bekannten funde." Trans. 2nd. Intern. Congress of Entomology, I913.

SchatfFer, C. ('89). "Beiträge zur Histologie der Insekten. I. Die Bauchdrusen des Raupen. II. Ueber Blutbildungsherde bei Insektenlarven." Zool. Jahrb. von Prof. Spengel. Abth. f. Anat. u. Ontogenie. Vol. 3, pp. 6 I I-652.

Sccdder, S. H. ('8o). "The Devonian Insects of New Brunswick." Anniv. Mem. Boston Soc. Nat. Hist. (I 880 ), pp. I-+1, with one plate.

Scudder, S. H. ('9o). "The fossil insects of North America, with notes on some European species." New York, I89o, 2 v. I. The pretertiary insects.-II. The tertiary insects.

Scudper, S. H. ('93). "The Songs of our Grasshoppers and Crickets." Ent. Soc. Ont. 23d Ann. Report (for 1892), pp. 62-78. 
Sellards, E. H. ('O4). "A Study of the Structure of Paleozoic Cockroaches, with Descriptions of New Forms from the Coal Measures." Am. Jour. Sci. th ser. Vol. I 8, (I904), pP. II $3-227$.

Sellards, E. H. (06, 'o 7 . 'og). "Types of Permian Insects." Am. Jour. Sci. Vol. 22 , p. 249-258; Vol. 23, pp. 345-355; Vol. 27 , pp. 151-173.

Semper, C. ('5i). "Ueber die Bildung der Flügel, Schuppen und Haare bei den Lepidopteren." Zeit. f. wiss. Zool. Vol. 8, pp. 326-339, with one plate.

Sharp, D. ('99). "Insects." The Cambridge Natural History, Vol. 6, London, I 899.

SHELFORD, V. E. (' 13 ). "Noteworthy variations in the elytral tracheation of Cicindela (Coleop.)." Entomological Nerrs, Vol. 24 (I9I3) pp. I24-I 25.

Shelford, V. E. ('15). "Elytral tracheation of the tiger beetles (Cicindelidæ)." Trans. Am. Micro. Society, October, 1915.

Silvestri, F. ('o9). "Die Fauna Südwest-Australiens, Isoptera." Bd. II, Lieferung I 7 , 1909. Ergebnisse der Hamburger Sudwest-australischen Forschungreise I 905 (Nichaelsen und Hartmeyer).

Sмiтt, R. G. "Evolution of the Venation in the anal area of the wings of Insects." A thesis presented to the Faculty of the Graduate School of Cornell University, I9I4. (not published).

Srodgrass, R. E. ("og). "The Thorax of Insects and the Articulation of the Wings." Proc. U. S. Nat. MIus. Vol. 36, pp. 5 I I-595, with thirty plates.

Sxodgrass, R. E. ('ioa). "The Thorax of the Hymenoptera." Proc. U. S. Nat. Mus. Vol. 39, pp. 3i-9I, with sixteen plates.

Sxodgrass, R. E. ('rob). "The Anatomy of the Honey Bee." U. S. Dept. of Agri. Bureau of Entomology, Tech. Series, No. I8.

Spexer, A. ('zo). "Zur Genealogie der Schmetterlinge." Stettin. Entom. Zeit. I 870 , pp. 202-223.

Spuler, A. ('92). "Zur Phỳlogenie und Ontogenie des Flügelgeäders der Schmetterlinge." Zeit. fur wissen. Zoologie, Vol. 53, pp. 597-649, with two plates.

Sptler, A. ('95). "Beitrag zur Kentniss des feiner Baues und der Phylogenie der Flügelbedeckung der Schmetterlinge." Zool. Jahrb. Vol. 8, pp. 520-5+3, with one plate.

Strats-Derckheim, H. 'I $\measuredangle 2 ১)$. “Considerationes générales surl'anatomie comparée des animaux articules." Royal Institute of France.

StRICKLAND, H. E. ('40). "On the occurrence of a Fossil Dragon-fly in the Lias of Warwickshire." Nag. Nat. Hist. Vol, 4, N. S. (1 840), pp. $301-303$.

Sulc, K. ('12). "Ueber Respiration, Tracheensystem und Schaumproduktion der Schaumcikadentareen 'Aphrophorinæ-Homoptera)." Zeit. f. wiss. Zoologie, Vol. 99 (I912, pp. I $47-188$ ).

Trllyard, R. J. ('I 4 ). "On some problems concerning the derelopment of the wingvenation of Odonata." Proc. Linn. Soc. New South Trales Vo1. 39, pp. I63-2I6.

Tillyard, R. J. ('I6). "Studies in Australian Neuroptera." "No. I.-The wingvenation of the Myrmeleonidæ." Proc. Linn. Soc. New South Wales, Vol. to (I9I6), pp. 73+-75I. with tro plates. "No. 2-Descriptions of new genera and species of the Families Osmy-lidæ, Myrmeleontidæ, and Ascalaphidæ." l. c., Vol. f1, pp. fI-jo, with six plates. "No. 3-The wing-renation of the Chrysopidæ." l. $c$. Vol. + I, pp. 22 I- 248 , with tro plates.

TILlyard, R. J. ('I 7 a). "Further researches upon the problems of the radial and zygopterid sectors in the wings of Odonata, and upon the formation of bridges." Proc. Linn. Soc. New South Wales, Vol. fI (1916), pp. 8; I-887.

Tillyard, R. J. ('I $;$ b). "The wing-venation of Lepidoptera (Preliminary report.)" Proc. Linn. Soc. New South Wales, Vol. +2 (I9I 7 , pp. 16 $7-17+$. 
TILlyard, R. J. ('I7c). “Mlesozoic Insects of Queensland." “No. I.-Planipennia, Trichoptera, and the new Order Protomecoptera." Proc. Linn. Soc. New South Wales, Vol. 42 (1917), pp. 175-200, with three plates.

Tower, W. L. ('oza). "The Origin and Development of the Wings of Coleoptera." Zool. Jahrb. Abth. fur Anat. und Ontogenie. Vol. I7, pp. 517-572, Pl. I4-20.

Tower, W. L. ('o3b). "Colors and Color-patterns of Coleoptera." Decennial Pubs. of Univ. of Chicago, 1903, Vol. Io, pp. 33-70.

Uluer, George. ('o7). " "Trichoptera." Genera Insectorum, Fascicule 60.

Verson, A. ('goa). "La formazione delle ali nella larva del Bombyx mori." Publ. R. Staz. Bacol. Padova.

Verson, A. ('9ob). "Der Schmetterlingsflugel und die sogen. Imaginalscheiben desselben." Zool. Anzeiger, Vol. I 3.

Voss, F. ('05). "Ueber den Thorax von Gryllus domesticus, mit besonderer Berücksechtigung des Flügelgelenks und dessen Bewegung." Zeit. f. Wiss. Zool. Vol. 78, I905.

Weele, H. W. van der. ('o8). "Ascalaphiden, Monographisch Bearbeitet." Coll. Zool. Selys Longchamps, Bruxelles, I 908.

Weele, H. W. van der. ('io). "Megaloptera Monographic Revision." Coll. Zool. du Baron Edm. de Selys Longchamps. Fasc. V, Bruxelles, I9Io.

Weismann, A. ('64). "Die nachembryonale Entwicklung der Musciden nach Beobachtungen an Musca vomitoria und Sarcophaga carnaria." Zeit. f. wiss. Zool. Vol. I4.

Weismann, A. ('66). "Die Metamorphose von Corethra plumicornis." Zeit. f. wiss. Zool. Vol. I6.

Williston, S. W. ('o8). "Manual of North American Diptera." New Haven, James T. Hathaway, I908.

Wood-Mason, J. ('83). "A contribution to our knowledge of the Embiidæ, a family of Orthopterous Insects." Proc. Zool. Soc. Lond. I883., pp. 628-634, with one plate."

Woom worth, C. W. ('o6). "The Wing Veins of Insects." Univ. Cal. Pub. Agri. Exp. Station, Tech. Bull. Ent. Vol. I, I 906. 



\section{INDEX}

Figures in bold-faced type refer to pages bearing illustrations.

Acanthaclisis, 205

Acanthiidæ, 292

Acanthinerania princips, 379

Accessory cells, 342

Accessory vein of Enderlein, 248

Accessory veins, 7 I, 99, I 46, 402

Acridid nymph, 17, 128

Acroneuria, 243

Acroschismus hubbardi, 301

Actias lman, 33

Aculeatæ, 324

Aculei, 323

Acutalis, 278

Adolph, G. Ernst, 4

Adoneta, 338

Adventitious veins, 76

Aelothrips nasturtii, 267

Aenigmatodes danielsi, 77

Agallia 4-punctata, 281, 282

Albarda, H., 173

Albardia furcata, 207

Aleurodes, 289

Aleurodidæ, 289

Aleuropteryx, 213

Alula, 55

ambient vein, 8 I

A mblychila, 299

Anal area, 58, I 44

Anal crossing, 237

Anal furrow, 58, 131, 340, 394

Anal loop, 239

Anal triangle, 239

Anal vein, the, 67

Anal veins, 237, $39^{\circ}$

Anastomosis of veins, 76,342

Anax junius, 13, 43, 44, 47, 113, 234

Androconia, 322, 323

Angles of wings, 54, 394

Anisoptera, 24

Anisota virginiensis, 331

Annandalia, $\mathbf{1} 79$

Anosia p'exippus, 337, 342, 344, 401

Antenodal cross-veins, 235

Anterior arculus, 392

Anterior notal wing process, 55

Anterior tuberosity, 57

Antherca pernyi, 18

Antherca roylei, 33

Anthony, Necdham and, 47

Aphid, wings of an, 269

A phidicla, 285, 29 I

Aphis, 286

1 pis mellifica, 23, 40, 362, 369, 375, 377

1phrophora suticis, 28

1 pochrysa crocsus, 210,211

A pochrysa matsumura, 2 I I

Apochrysicte, 210

Appendiculate cell, 8 I
Apterygogenea, 52

A rchasia belfragei, 279

Arculus, 20, 78, 236, 358, 292

Argynnis, 5

Articulation of the wings, 55

A scalaphus italicus, 207

Aspidothorax, 94

Atrophy, Reduction by, 37 I

A ulacinus fusiger, 379

A ustrolestes, 47

Axillaris, 65,263

Axillary cord, 54

Axillary excision, 60

Axillary furrow, 59, 394

Axillary membrane, 55

Axillary sclerites, $\mathbf{5 6}$

Axillary vein, 248

Balaga micans, 200

Banks, Mr. Nathan, I 83

Basal anal area, 239

Basal anal cell, 247

Bathytaptus falcipennis, 97, 98, 103

Becauselia Grehanti, 107

Berotha insolita, 186

Berothidæ, 186

Betten, Dr. Cornelius, 310,31 I

Bittacomorpha, 36,37

Blastophaga, 52

Blattidæ, I 23

Bleaching wings, method of, 399

Bombyx mori, 58, I I 6, 332

Boveria irene, 234, 235

Brachynemurus longipalpus, 201

Braconid, Wing of a, 373, +14

Bradley, J. C., 364, 37 I

Brauer, Fr., 52, 193

Bridge, ormation of the, 230

British system, 346

Brongniart, C., I 85, 305

Bullæ, 8I

Busck, 1., 323

Cabbage butterfly, development of wings of, 115

Cacrecia, 34I, 342

Caddice-fly, 22, 308

Canis, 214

Calypteres 55

Cumpteroneura reticulata, 97, 98, 102

Cantharis, 300

Capnia, 252

Capniidxe, 244, 251

Castnia, $3+3$

Colithemis elisa, 112

Cells of a typical hymenopterous wing, 364

Cerambycid pupa, 298

Ceresa, 278 
Ceresa borealis, 275

Ceresa diceros, 280

Chaitophorus populicola, 286, 287

Chalcopteryx rutilans, 80, 233

Chapman, R. N., 26, 27

Chapman, T. A., 3I3, 3I 7

Chauliodes, 21, 22, 32, 73, 405

Chuuliodes pecticornis, 149,170

Cicada, 60, 270, 271, 272, 29I

Citheronia regalis, 336

Chermes abietis, 287, 288

Chermes pinifolice, 287,288

Chermesinæ, 287

Chief branches of the wing-veins, 65

Chief cubito-anal cross-vein, 239

Chirotonetes, 40

Chirotonetes albomanicatus, 222, 223

Chloroperla, 251

Chloroperla cydippe, 255

Chrysopa nigricornis, 190, I9I

Chrysopa plorabunda, 189

Chrysopa signata, 189

Chrysopidæ, I 80

Clavus, 292

Climaciella brunnea, 174

Clisiocampa americana, 87, 116, 340

Clothing of the wings, 64

Clothoda nobilis, 262, 265

Coccidæ, 54, 290

Cockroach, 73,403

Coleoptera, I 2 I, 297

Comparison of terminologies of the wingveins of the Odonata, 228; Aphididæ, 289; Lepidoptera, 345; Diptera, 358

Concave veins, $8 \mathrm{I}, 405$

Coniocomposa, 213

Coniopterygidæ, 2 I 2

Coniopteryx, 213

Conocephalus, 128,129

Conops, 61, 354

Convex veins, 81, to 5

Conwentzia, 213

Cordulegaster diustatops, 232

Cordulegaster sayi, 227, 236, 2 40

Corium, 292

Corodentia, I 2 I , 258

Corrugations of the wings, $5 \overline{7}, 393$

Corydalinæ, 170

Corydaloides, 94

Corydalus cornutus, I2, 72, 153, 154, 157 , $171,403,405$

Corydulus primitious, 155

Costa, 65, 390

Costal cross-veins, 78

Costal hinge, 59

Costal sclerite, 57

Costal trachea of Orthoptera, $12+$

Costo-radial group of tracheae, 17, 2 I 6

Croce filipennis, 208, 209

Cross-veins, $76,77,79,131,235,389,391$

Cryptoleon nebulosum, 205

Cubital area, 239

Cubital fork, primary, I65; secondary, I 65
Cubitalstamm, 263

Cubital supplement, 240

Cubito-anal excision, $8 \mathrm{I}$

Cubito-anal fold, 57

Cubito-anal group of tracheæ, 17, 216

Cubito-anal loop, 240

Cubito-anal sulcus, 57

Cubitus, 65, 390

Cuneus, 292

Dactylopius 290

Damsel-fly, 224

Definitive accessory reins, 72, 146,403

Dermaptera, I 2 I, 295, 296

Desmocerus palliatus, 297

Desneux J., 135, 136

Development, of wing-veins, 12; of the wings of larvæ, I 15 ; of the wings of nymphs, IIO

Diamphipnoa, 252

Diaphanoptera Munieri 94, 95

Diastatomma liasina, 228, 229, 238, 242

Dictyoneura libelluloides, 100, Io.4

Dictyoneuridæ, 93

Dictyopteryx, 248

Diedrocephala coccinea 281

Dilar americanus, 185

Dilar nohire, 185

Dilarturcius, 185

Dilaridæ, I 84

Diptera, 22, 1 22, 347, 395

Directions for the study of wings, 395

Discal cell, 82

Discal vein, 82

Dixa, 352

Dolichopus coquilletti, 355,356

Donaconethis abyssinica, 264

Doubleday, Edward, 5

Draeculacephala mollipes, 281

Dragon-fly, 224

Earwig, 295, 296

Elytra, 54

Embia, 265

Embia sabulosa, 263, 264

Embia texana, 263

Embiidina, I 2 I, 262

Embolium, 292

Enderlein, Dr. Günther, I8, 33, 65, I 57 , 2 I $3,244,248,260$

Epeorus, tracheæ of, 39, 40, 45; wings of, $74,216,217$

Ephemerida, I 21, 2I 4, 220, 405

Erax, 357

Eristalis, 357

Erythrothrips urizona, 268

Enibleptus danielsi, 89

Euclea cippus, 320

Entlonchus, 363, 366

Eurythomopteryx antiqua, 19, 77, 98, 103, 106,107

Eustheniz spectabilis, 247, $25 \mathrm{I}$

Eiania appendigaster, 379, 381

Evaniellus, 381 
Evolution, of the costa, 92; subcosta, 92; radius 95; media, 99; cubitus, IO4; anal veins, 107

Evolution and Taxonomy, 8

Expanded humeral angle, 63

Faltentheil, 7

Fan-like wings, 53

Fibula, 61; of Corydalus, 63; of Mnemonica, 315 of Rhyacophila, 63, 312

First Anal Vein, 65

First radio-medial cross-vein, 167

Fitch, Dr Asa, 30.4

Fixed fan-like type, $\mathbf{5 3}$

Fixed hairs, 323

Flügelrippen, 4

Folding fan-like type, 53

Forbes, Dr W. T. M., 315

Fossil insects, 85

Frenatæ, 8, 326

Frenulum, 61, 330; loss of, 331

Frenulum hook, 6I, 330

Froggatt, Walter $\mathrm{WT}^{\top}$., I 36

Fungus gnats, 350

Funkhouser, W. D., 27 I, $27+$

Furrows of the wing, 58, 39t

Gall-gnat, 351

Genesis of the Uniform Terminology, I

Geologic Time and Formations, Chart of, 84

German system of terminology, 346

Glossonotus, 278

Gera, 313

Gomphus descriptus, 2ł, 225, 226, 227, 237 . 240

Gonin, J., IIt

Graber, Dr. V., 2

Gradate veins, I66, 204

Gripopterygidæ, 24t, 250

Gripopieryx tessellata, 250

Gypona 8-lineata, 281, 282

Haase, Dr. Erich, 6

Hadentomum americanum, 94

IIadroneura bohemica, 101

Haftfeld, 323

Hagen, Dr. H. A., 2, 5, 224; Plate by, 3

Halteres, 54

Hampson, Sir G. F., $3+6$

Hamuli, 60, 61

Handlirsch, A., 52, 88, 89, 185, 238, 293

Harmostes reflexulus, 59,294

Heinemann, H. von, 8

Helicoris, 213

Heliocharis, 241

Ifeliria, 278

Hemelytra, 5t, 292

Hemerobiid group of families, $1+5$

Hemerobiidæ, 180

IIemerobius humuli, 158, 159, I64, I77, 181,182

Hepialidx, 3 I 8

Ile Dialus, 9, 82
Hepialus sylvinus 323

Hepialus thule, 327, 328

Heptagenia interpunctata, 218

Herrich-Schäffer, 345

Hetaerina, 241

Heteroptera, 12 I, 292

Hexagenia, 219

II ippodamia I3-punctata, 297

Holmgren, Nils, 135, I 37,140

Holognatha, $2+4$

IIomaloneura punctata, 104

Homoptera, I 2 1, 269

Homothetus fossilis, 86

Honey-bee, 367

Humeral cross-vein, 78, 39I

Humeral suture, $1+3$

Humeral veins, $8 \mathbf{I}, 3+3$

IIydromanicus, 312,313

Hymenoptera, 1 22, 362, 406

Hypostigmatic space, 83

Hypothetical primitive type, I5, 16, 64, 388

Iyptia, 380

Ichneumon-fly, 69, 373

Increase of the number of wing-reins, 70

Inocellia longicornis, I7I, 172

Intercalary veins, $71,74,232,405,406$

Interpolated sectors, 233

Interradial nexus, 206

Isogenus sp., 245

Isoptera, I 2 I , I 32

Isolated front branch type of media, 100

Italian loop, 2 to

Ithone fulva, I 76,182

Ithone fusca, 175,176

Ithonidæ, I75

Janus abbreviatus, 377, 378, +1 3

Janus cy'nosbuti, 377

Jassidæe, 280, 282, 29 I

Jones, P. R., 267

Jugatæ, 8, 325

Jugum, 61, 63, 327

Kellogg, T. L., 32 I, 323

Kempers, K. J. 11 ., 300

Klapalek, Fr., 246

Kruger, E., 299

Kühne, O., 300

Labidarge dibapha, 82

Lameere, A., 88

Landois, H., $4,5,320$

Lanthus pariulus, 2.37

Leonard, M. 1)., I I 2

Lepidoptera, 25, 122, 319, 398

Leptis, 352

Leptocerus, 313

Leptophlebia, 219

Lestes, $+3,+4,+5,+7$

Lestes rectangularis, 23!, 2.32

Lethocerus, 3.5 
Leucotermes, I $3+$, I 35

Leucotermes flavipes, 141, 142, I 43

Lencolermes, unknown species of, 142

Limnophilida, 38

Lithomantis carbonaria, 90

Loew, H., 359

Lomamyia, 187

Longitudinal veins, 389

Lopidea robinia, 111 , I 12

Lycocercus Goldenbergi, 91

Lycomorpha constans, 320

Lydida, 362

McClendon, J. F., I 89

MacGillivray, Dr. A. D., 78, 327, 328, 364, $368,370,376,377$

McLachlan, R., I 85, 305, 3 I 3

Macrocephus satyrus, 377

Macroryela, 363, 372, 408

Manoxyela, 374

Mantichora, 299

Mantispidæ, I74

Narginal accessory veins, $72,1+7,403$

Marginal dots or dashes, 167

Margins of wings, 54,394

Marshall, ITm. S., 324

Mastotermes darwiniensis, 132, 133, 134, $135,137,1+3$

Maver, A. G., 320

Maver, Paul, s's

IIay-fly, 406

Necoptera, I2 I, 302

Media, 65.390

Medial cross-rein, $78,39 \mathrm{I}$

Median furrow, 59,394

Median nexus, 206

Median plates, $\mathbf{5} 6$

Medio-cubital cross- - ein, 78,392

Medius, 65

Megalomus mostus, I64, 183

Melanoplus, $+2,+9$

Membracidæe, $27+, 291$

Membranule, 239

Mercer, II. F., IIt

Merope fuber, 302, 30.3, 304, 305

Mesonemura Maaki, 249

Metcalf, Z. P., 27I, 280, 282, 283

Metropator pussillus, 96, 97, 101

Meyrick, E., 313

Micropterygidæ, 3 I 3, 3I T

Micropterygina, 3 I 3

Microptery unimaculella, 323

Micrutalis, 278

Mixotermes lugauensis, 94

Mnemonica, 3 I3, 314, 316

Monarch butterfly, 401

Monohammus, 36

Moth-like fly, 351

Ioultori, D., 268

Musca domestica, 356

I usical organs, tracheation of, I 3 I

My-iodactylidæ, 193

Miodact ylus osmvloides, 193

Myiodactylus pubescens, 194
Myrmecia, 82

Myrmeleon, 197

Myrmeleonid group of families, I 45

Myrmeleonid. Tracheation, 198, 199

Myrmeleonidæ, 196

Nakahara, Waro, I 85

Named cross-reins, I9

Needham, J. G., quoted, 9, 76, 225, 23I, $235,237,242,299,304$; on Myrmeleonid Venation, 203

Venoptera sinuata, 208, 210

Nemopteridæ, 208

Nemoura, I3, 20, I08, 244, 250, 252, 253

Nemourida, 24t, 249, $25 \mathrm{I}$

Neosticta canescens, 23 I

Neuroptera, I 2 I, I +5, fOI

Teuroptynx appendiculatus, I49, 151

Newman, E., 175

Nodal furrow, 59, 273, 394

Nodus, 230

Votiabiella, $\mathbf{7}-9$

Notiothauma Reedi, 302, 305, 306

Nymphes myrmeleonides, 195, 196

Nymphidæ, 195

Oblique rein, 197,230

Odonata, 22, 2t, I 21, 224,228

Odontaulacus editus, $377,378,+13$

Oecanthus, 130

Ogcogaster tesselata, 206, 207

Oligoneuria, 2 It

Oligotoma saundersi, 262, 265

Oliverina extensa, 208, 209

Oncometopia undata, 281

Origin of $1 \mathrm{Tings}, 8 \mathrm{~T}$

Orthemis ferruginea, 240

Orthoptera, I 20, I 23

Oryssus abiełinus, 377

Osmylidæe, I92

Osmylus hyalinatus, ; I, I 5 I , 152, 153, I 54, 192

Osmylus tessella:us, I $5 \mathrm{I}$

Osten-Sacken, R., 359

Outline of Laboratory ITork 38;

Packard, A. S., 7

Packardia, 3.38

Palpares aeschnoides, 164, 204

Paleontological data, 85,88

Pamphilius, 363, 372, 407, 409

Panorpa, 302, 303

Pantarbes, 354,365

Paolia Gurleyi, 97, 102

Paolia retusta, 97, I01, 102, 105, I07

Papilio Marhaon, 6

Papilio polyxenes, 339

Papilionida, 3+I

Paraxenos eberi, 301

Parnassius smin!heus, 321

Patch, E. 11., 27I 285, 289, 290

Pelopous cemen!arius, 377

Pentatomidx, 293

Perissoneura, 3 I I 
Perla, 249

Perlidæ, $24425 \mathrm{I}$

Petalura gigantea, 232

Phanostoma, 3 I 3

Philaenus lineatus, 28, 27 I

Phryganeina, 307

Phylodromia germanica, 3I, 126

Pielus Labyrinthecus, 326, 327, 399400

Pieris rapa, I I $4,324,333$

Pieridæ, $34 \mathbf{I}$

Planates, 205

Platephemera antiqua, 86

Plathemis lydia, 43

Plecoptera, I 2 I, 243

Polioptenus, 96

Polioptenus elegans, 108, 109

Polystochotes punctatus, 150, I87, 188, 402

Polystocchotidæe, 187

Pontia protodice, 333

Postanalfield, I 37

Posterior arculus, 392

Posterior lobe, 60

Posterior notal wing process, 55

Posterior tuberosity, 57

Postnodal cross-veins, 236

Powell, P. B., 87, 299

Preanal area, 58

Preparation of specimens, 4 I 5

Principal wing-veins, 64

Prionoxystus robinice, $75,335,400$

Protentomon, 88

Protohermes davidi, 155, 156

Protoplasa fitchii, 349, 395

Protosialis, 168

Psectra, I 79

Pseudofouquea cambrensis, 99, 103, 106

Pseudo-cubitus, I9o

Pseudo-halteres, 54

Pseudo-media, 190

Psilopodius sipho, 355,356

Psocus, I 3, 14, 258, 259

Psychopsid, 189

Psychopsidæ, 188

Psychopsis, 188

Psylla floccosa 284, 285

Psyllidæ, 283, 29 I

Pteronarcella badia, 252

Pleronarcys, $32,45,246$

Pteronarcys dorsata, 243, 256

Pteronarcidæ 244252

Pteronidea ribesii, 383, 412

Pterostigma, 81, 247, 408

Pterygogenea, 52

Puer, 206

Pupal tracheoles of the wing, 116

Quadrangle of the Zygoptera, 240

Radial cross-vein, 78, 39I

Radial cuneate area, 162

Radial planate, 206

Radial sector, 66, 390; in butterflies, 343 ; division of the stem of, 180 ; numbering of the branches of, 156 ; pectinate type of, 404; suppression of the dichotomy of, 147, 148; suppression of the stem of, I 80 ; switching of the base of, 376,413 ; two types of, 95

Radio-medial cross-vein, 78, $39 \mathrm{I}$

Radius, 65, 390; Diagrams of several types of, I 48,404 ; Diagrams of the typical and of the hymenopterous, 367 , tI I

Raphidia adnixa, 172, 173

Raphidiidæ, I 7 I

Rapisma viridipennis, 176, 177

Reaumur, 320

Recurrent vein, 166

Redtenbacher, Josef, $2,4,5,6$, I 1, 65, 85

Reduction of the number of wing-veins, 67

Rexavius japonicus, I 86

Rhamphomyia, 355, 366

Rhogas parasiticus, 414

Rhyacophila, 37, 38, 311

Rhyacophila fuscula, 308, 309, 3 I I

Rhynchocephalus, 347

Rhyphus, 68, 79, 347, 388

Ris, F., 248

Rosen, Kurt von, 135

Sabatinca, $3 \mathrm{I} 4$

Saltatorial Orthoptera, 127

Samia cecropaea, 33

Saussure, H. F. de, 5

Scales, 319

Scenapinus, 354

Schäffer, 320

Schizoneura americana, 287

Schizoneura rileyi, 285, 286

Scott, G. G., 43

Scudderia, 129, I 3 I

Second Anal Vein, 65

Secondary anal vein, 238

Secondary longitudinal veins, 7 I

Sectoral cross-vein, 78, 391

Selys-Longchamps, Baron de, 5, 224

Semidalis aleurodiformis, 212, 2 I 3

Semcodogaster barticensis, 380

Semper, Car1, 4, 320

Serial veins, $69,376,413$

Sharp, David, 2, 313, 346

Shelford, V. E., 299

Sialis, 13

Sialis infumata, I68, 169

Sialidæ, 168

Sialinæ, 168

Silvestri, F., I35, I 36

Siphlurus, 220

Sirex, 383, 413

Siricid, +13

Sisyra, 405

Sisyra flavicornis, 149, 158, I 77, 178

Sisyridx, I 77

Smilia camelus, 279

Smith, Miss Lucy W., 244, 256

Smith, Mr. R. C., 189

Spangbergiella, 283 
Spaniodera ambulans, 91

Specialization by addition, 70

Specialization by reduction, 6 -

Spermophorella, i 87

Sphecius speciosus, 362

Spreitentheil, 7

Spuler, Dr. Arnold, 6, 7

Spurious vein, 358

Squamæ, 55

Stacheln, 323

Staudinger and Schatz, 345

Stenobiella, I87

Stenodictya, 96

Stenodictya lobata, 18, 90, 93, I00, 108

Stenophylax, 39

Stenopsocus, 260

Steps in the Specialization of Wings, I 8

Sihenopis, 328, 329

Stigma, 8I, 229, 408

Strationyia, 358

Strationys, 359

Strepsiptera, 54, I 2 I , 30 I

Strickland, H. E., 238

Stygne Remeri, 98, 99, 104, I 05, I06, 107

Subcosta, 65, 39; three types of the, 93

Subcostal area, 79

Subcostal fold, 57

Subnodus, 230

Subquadrangle of the Zygoptera, $2+$ I

Subtriangle, 239

Sulc, Karel, 28, 27 I

Supertriangle, 237

Supplements, 234, 235

Supplemental anal loop, 240

Symmathetes contrarins, 202

Sympherobiidæ, $\mathbf{I} 78$

Sympherobius amiculus, 179

Synthemis, 235

Systellognatha, $24+$

Tabanus, 68, 359

Teaching of the Uniform Terminology, 382

Tegmina, 5 t

Tegula, 54

Telamonanthe pulchella, 279

Telmona, 278

Teratembia geniculata, 265

Terminology of the cells of the wing, 79

Termopsis, $135,1+3$

Termopsis angusticollis, 132, 138, 139, 140,141

Terrestrial Trichoptera, 313

Thelia bimaculata, 270, 275, 276, 277, 278

Theria, 353

Third Anal Vein, 65

Thoracic supports of the wings, 55

Thryidoptery e phemerceformis, 62,330

Thysanoptera, I 21,267

Tillyard, R. J., $43,47,48,49,83$, I57, 175 , $182,189,225,231,237,240$

Tiphia, $36+$

Tipula, 357

Tomatares clavicornis, 200

Tower, IV. L., 8-, 299, 322
Trachea, transverse basal, 2 I 6

Tracher, basal connections of, 25,27 ; typical condition, 29; in a cockroach, 31; Pteronarcys, 32; Chauliodes, 32; Antherca, 33; notonectid nymph, 34; corisid nymph, 34; Lethocerus, 35; Monahamus, 36; Bittacomorpha, 37; Rhyacophila, 38; Limnophilidæ, 38; Stenophylax, 39; Epeorus, 40; Chirotonetes, 40; Apis, 41; Melanoplus, 42; Anax, 44; Lestes, 44; Blattilæ, 124; Saltatorial Orthoptera, I27; Membracidæ, $27 t$

Tracher, Limitations to the value of, 24

Tracheation of the IVings, 12, 19, +14; eccentric, 23; increased, 2I; simpler type of, $2 \mathbf{I}$; variations in, 20

Tracheen, geknäuelten, 4

Tracheoles, distinction between tracheæ and, I I3; larval tracheoles of the wing, I 16

Transverse basal trachea, I7

Transverse cord, 82,247

Tremex, 23, 369

Triangle of the Anisoptera, 236

Trichoma, I 87

Trichoptera, 22, 1 22, 307

Trigonal fork, 206

Trigonal planate, 206

Truss cell, 203

Tuberosities of the base of the wing, 57

Ululodes hyalina, I 50, 206

Fanduzea, 278

Vanduzea arquata, 278, 279

I'anessa, 4

Veins of the anal area, 66

Veins of a typical hymenopterous wing, 364

Teins $\mathrm{Cu}_{2}$ and the second anal vein, coalescence of, 355

$V$ eins $\mathrm{M}_{3}$ and $\mathrm{Cu}_{1}$, coalescence of, 353

Vein $\mathrm{MI}_{4}$, loss of, 348

Vena media, 65

Verson, A., 87

WValsh, B. D., 224

IVeele, Dr. H. WT, van der, I 55

Westwood, J. O., 239, 304

Williston, S. WV., 359

Wing-buds, IIt

Wing process of the pleurum, 55

IVings, different types of, 53; fundamental structure of, 53; presence or absence of, 52

Wood-\lason, J., 262

Xantholobus trilineatus, 279

Xenoneura antiquarum, 85

Xiphidium, 127

Xyelidæ, 362

Zygoptera, $2+$ 




Date Due

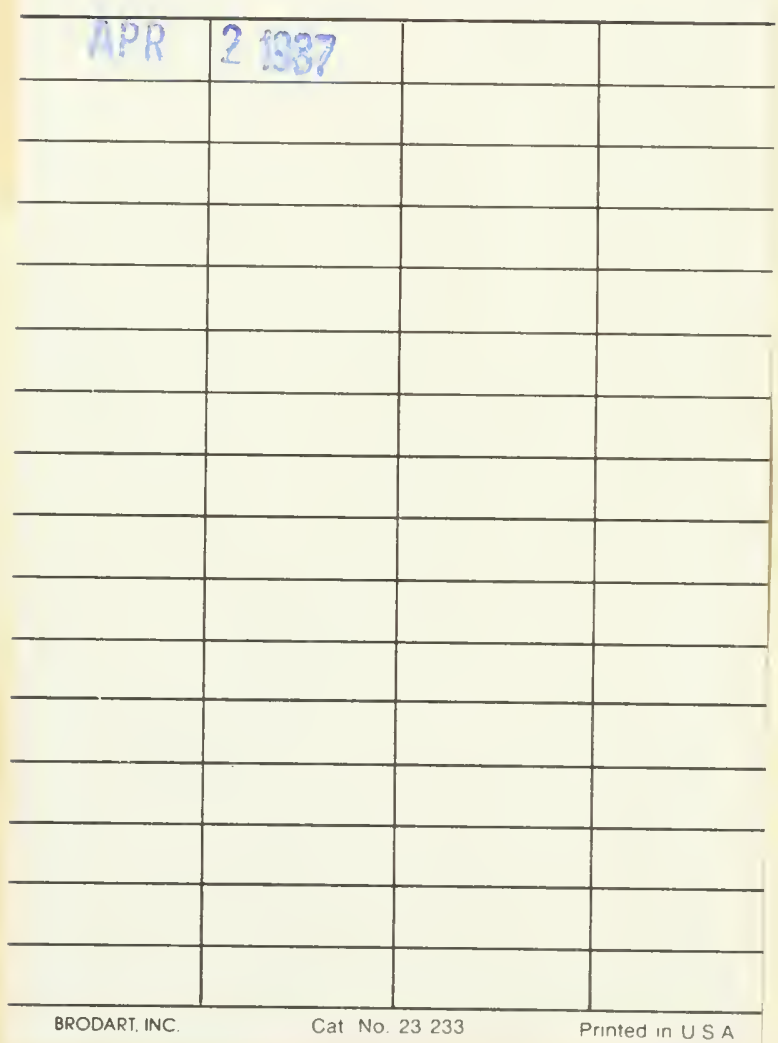


Rebound guly' 39. 


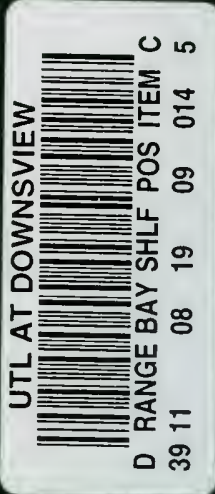

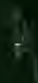

